Transforming Shape: A simultaneous approach to the body, cloth and print for textile and garment design (synthesising CAD with manual methods)

\author{
Katherine Townsend
}

A thesis submitted in partial fulfilment of the requirements of The Nottingham Trent University for the degree of Doctor of Philosophy

JULY 2003 


\section{Acknowledgements}

I would like to thank the following people for their help during the development of this thesis. My director of studies Dr Gillian Bunce and supervisors Dr Amanda BriggsGoode and Peter Phillips; Professer Winifred Aldrich and Rosemarie Goulding for their generous advice; the members of the Textile Design and Textile Research Departments for their positive encouragement; Graham Cope and Sue Keen for their contribution to the project Transforming Shape; Professor Richard Woodfield, Jean Williamson and the School of Art and Design for supporting the exhibition; Lectra Systems for their sponsorship and Dr Hilary Carlisle for creating a beautiful CD for the thesis.

I would particularly like to thank my friends and family, my partner lan Cutmore and our children Alex, Ella and Celeste for their constant support throughout.

- This thesis is dedicated to the memory of my brother Leo Alexander Townsend (19641998) and my mother Daphne Katherine Townsend (1936-2000). 
Transforming Shape: A simultaneous approach to the body, cloth and print for textile and garment design (synthesising CAD with manual methods)

\title{
Katherine Townsend
}

\begin{abstract}
A thesis submitted in part fulfilment of the requirements of The Nottingham Trent University for the degree of Doctor of Philosophy
\end{abstract}

Printed textile and garment design are generally taught and practised as separate disciplines. Integrated CAD software enables textile and clothing designers to envisage printed garments by assimilating graphic imagery with 2D garment shapes, and $3 D$ visualisations. Digital printing can be enlisted to transpose print-filled garment shapes directly onto cloth. This research challenges existing $2 \mathrm{D}$ practice by synthesising manual and CAD technologies, to explore the integration of print design and garment shape from a simultaneous, 3D perspective.

This research has identified three fundamental archetypes of printed garment styles from Twentieth Century fashion: 'sculptural', 'architectural' and 'crossover'. The contrasting spatial characteristics and surface patterning inherent in these models provided the theoretical and practical framework for the research. Design approaches such as 'textile-led', 'garment-led' and 'the garment as canvas' highlighted the originality of the simultaneous design method, which embraces all of these concepts.

This research recognises the body form as a positive influence within the printed textile and printed garment designing process, whereby modelled fabric shapes can be enlisted to determine mark making. The aim of the practice, to create printed garment designs from a 3D perspective, was facilitated by an original method of image capture, resulting in blueprinted toiles, or cyanoforms, that formed the basis of engineer-printed garments and textiles. Integrated CAD software provided the interface between manual modelling, design development and realisation, where draping software was employed to digitally craft 3D textiles. The practical and aesthetic characteristics of digital printing were tested through the printing of photographic-style, integrated garment prototypes.

The design outcomes demonstrate that a simultaneous approach to the body, cloth and print can result in innovative textile vocabulary, that plays a proactive role within the design equation, through its aesthetic integration with garment and form. The integration of print directly with the garment contour can result in a 3D orientated approach to printed garment design that is empathetic with the natural body shape. 


\section{Contents}

\section{Chapter 1. Introduction: The Nature of the Research}

1.1. BACKGROUND TO THE PROPOSAL................................................ 1-2

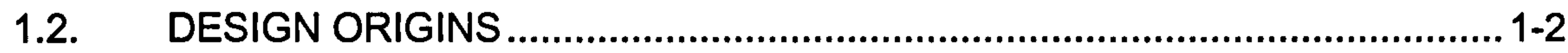

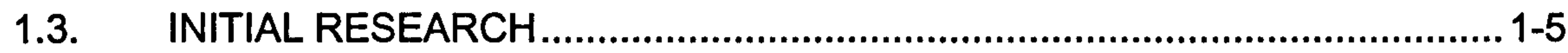

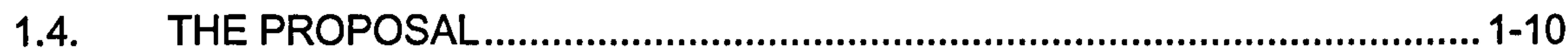

1.5. TECHNOLOGICAL RELEVANCE ..................................................1-11

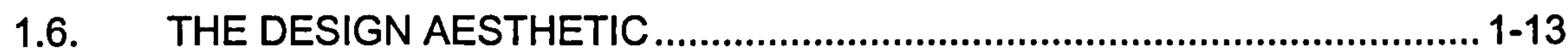

1.7. AESTHETIC INSPIRATION ............................................................. 1-14

1.7.1. Not Made By Hand ..................................................................... 1-20

1.7.2. The Notion of Wear ................................................................. 1-23

1.7.3. Wrapping the Form ............................................................... 1-23

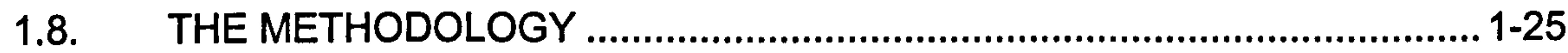

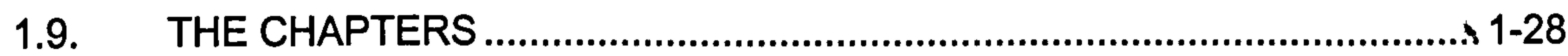

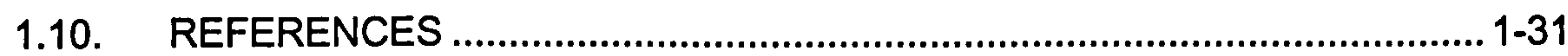

\section{Chapter 2. On the Dress She Wears a Body}

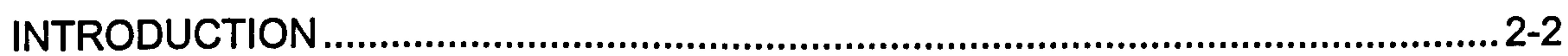

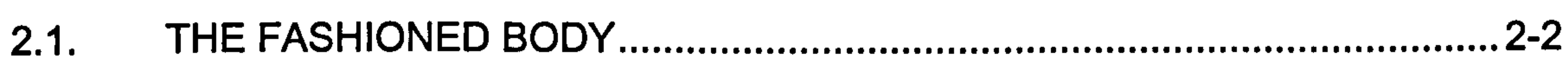

2.1.1. Fashion and Cubism .................................................................... 2-4

2.1.2. Ready to Wear Design Issues ....................................................... 2-7

2.1.3. The Changing Silhouette in the 20th Century ................................2-9

2.2. CONSIDERATION OF THE BODY ........................................................ 2-17

2.2.1. The Mass Clothed Body ............................................................2-17

2.2.2. The Haute Couture Body........................................................ 2-19

2.2.3. The Designer Body .................................................................2-20

2.2.4. The Role of the Mannequin ......................................................2-20

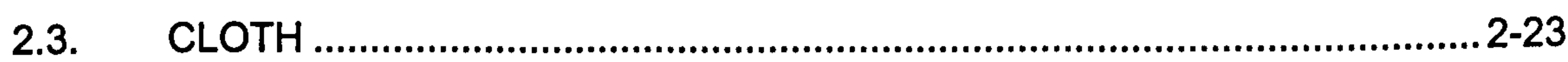

2.3.1. Fabric Determines Form...........................................................2-26

2.3.2. The Influence of Lycra on Garment Shaping ...............................2-28

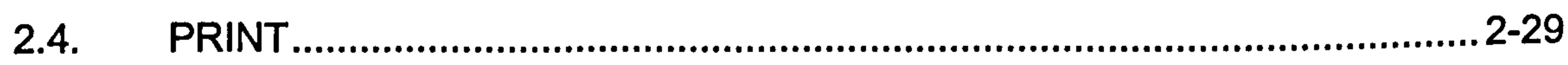

2.4.1. Printed Dress Fabrics.................................................................. 2-31

2.4.2. Print Design Structures ........................................................... 2-33

2.4.3. Print and Body Image.............................................................. 2-34

2.4.4. The Case for Fashioning the Form in Print................................... 2-36

2.5. CONCLUSION OF CHAPTER ............................................................... 2-37

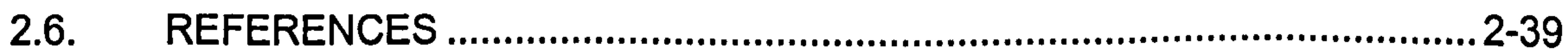


Chapter 3. The Spatial Garment: Sculptural, Architectural and Crossover Forms

INTRODUCTION.

3.1. POPOVA'S SPATIAL GARMENT CONCEPTIONS ................................... 3-2

3.2. THE SCULPTURAL GARMENT ...........................................................

3.3. THE ARCHITECTURAL GARMENT .................................................... 3-11

3.4. THE CROSSOVER GARMENT ............................................................

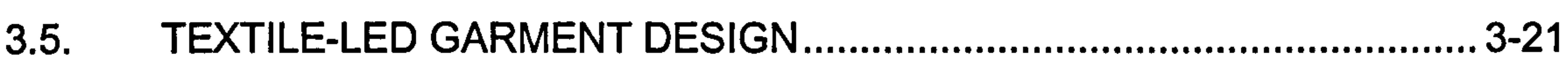

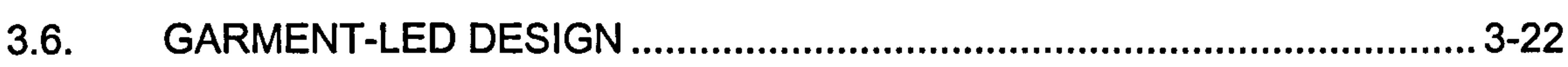

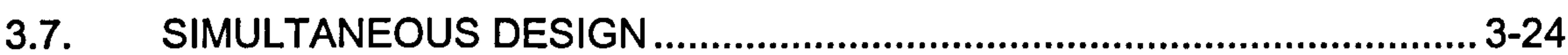

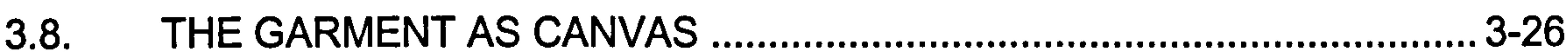

3.8.1. The Tear Dress ........................................................................

3.9. CONCLUSION OF CHAPTER …………….......................................

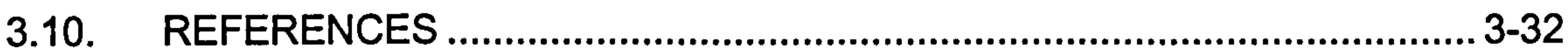

Chapter 4. The Limited Exploitation of CAD by Printed Garment Designers

INTRODUCTION................................................................................................. 4-2

4.1. COMPUTER AIDED TEXTILE DESIGN.............................................. 4-3

4.1.1. Repeat and Colour Management ................................................. 4-6

4.1.2. Textile Draping Software ........................................................... 4-8

4.1.3. Graphic Software ................................................................... 4-10

4.1.4. CAD: A New Visual Aesthetic................................................... 4-13

4.2. GARMENT PATTERN DESIGN SYSTEMS ........................................... 4-18

4.2.1. 3D Pattern Design Systems ....................................................... 4-19

4.2.2. Made to Measure Pattern Cutting................................................. 4-19

4.2.3. Body Scanning...................................................................... 4-20

4.2.4 3D Computer Draping Systems................................................... 4-22

4.2.5 Cloth Animation/Dynamic Drape .............................................. 4-25

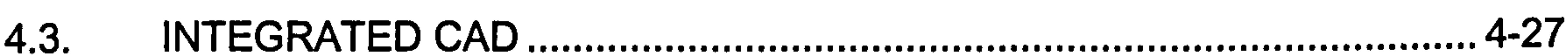

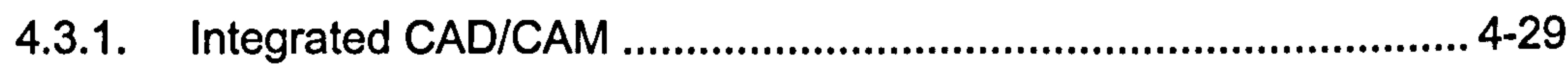

4.3.2. Mass Customisation.................................................................... 4-30

4.3.3. Print Customisation ................................................................... 4-31

4.4. DIGITAL FABRIC PRINTING ............................................................. 4-33

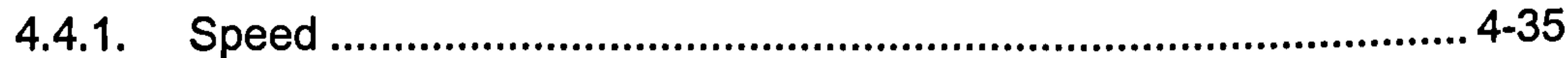

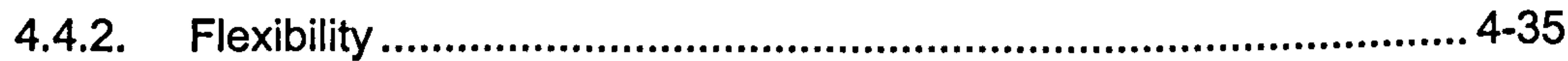

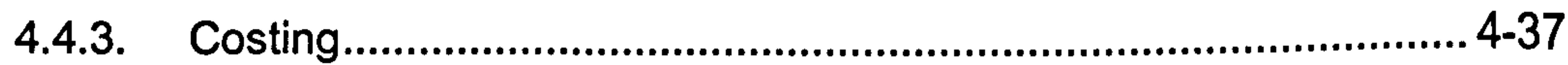

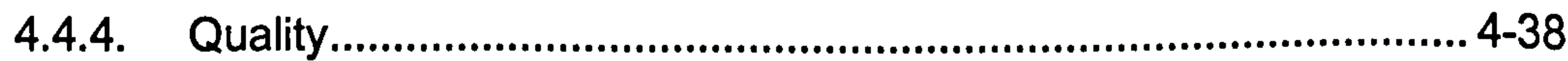

4.4.5. Sustainable Design Issues ......................................................... 4-39

4.4.6. Summary................................................................................... 4-39

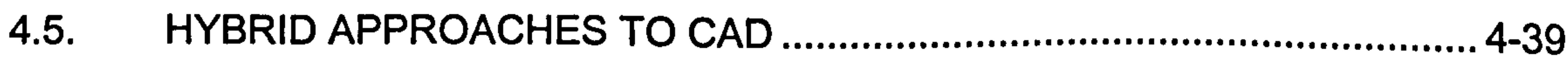


4.5.1. Laura Rotger Buadas ........................................................ 4-40

4.5.2. Hilary Carlisle..................................................................... 4-40

4.5.3. Helena Rosen .................................................................. 4-42

4.6 CONCLUSION OF CHAPTER ........................................................ 4-44

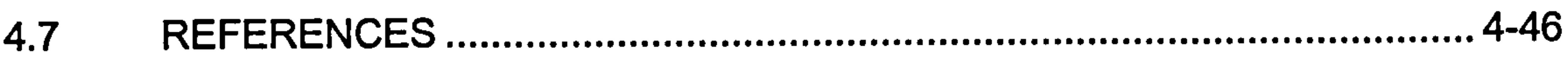

Chapter 5. A Holistic Approach to Print and Cut

INTRODUCTION

5.1. A HOLISTIC APPROACH TO PRINT AND CUT .................................... 5-2

5.2. INITIAL PRINT/GARMENT INTEGRATION ........................................5-3

5.2.1. Digitising ........................................................................ 5-4

5.2.1.1. Reflections ................................................................ 5-5

5.2.2. Paper Dresses ................................................................... 5-5

5.2.2.1. Reflections .............................................................. 5-8

5.2.3. Manual Mark Making: Print Fluidity.............................................. 5-8

5.2.3.1. Reflections ............................................................... 5-11

5.2.4. Digital Mark Making................................................................ 5-11

5.2.4.1. Reflections ........................................................... 5-13

5.2.5. Synthesising Manual and Digital Techniques ........................... 5-13

5.2.5.1. Reflections ........................................................... 5-13

5.2.6. Initial Print/Garment Integration using CAD .............................. 5-15

5.2.7. Reflections: The printed toile ................................................5-20

5.3. DESIGNING WITH LIGHT .......................................................... 5-21

5.3.1. The Cyanotype Process ..................................................... 5-23

5.3.1.1. 2D Image Capture .................................................... 5-23

5.3.1.2. Reflections ............................................................ 5-24

5.4. MODELLING PRINT: THE RIBBON TUNIC...................................... 5-24

5.4.1. Ribbon Tunic: Intentions...................................................... 5-24

5.4.2. Ribbon Tunic: Process ........................................................ 5-26

5.4.3. Ribbon Tunic: Reflections .................................................... 5-26

5.4.4. CAD Design Development: Realignment................................... 5-29

5.4.5. Digital Manipulation: Water Pleat ............................................. 5-31

5.5. DIGITAL FABRIC PRINTING: TEST 1 ............................................. 5-34

5.5.1. Colour Translation................................................................ 5-34

5.5.2. Visual Qualities .................................................................. 5-34

5.6. CONCLUSION OF CHAPTER ....................................................... 5-37

5.7. REFERENCES ............................................................................... 5-40

Chapter 6. Design Synthesis: The Simultaneous Design Method

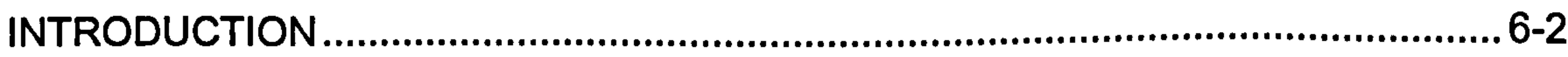

6.1. SYNTHESISING PHYSICAL AND COMPUTERISED DESIGN METHODS. 6-2 
6.2. THE SIMULTANEOUS DESIGN METHOD.......................................... 6.5

6.2.1. Aims of the Continued Investigation ..........................................6-6

6.2.2. The Design Collections ............................................................6-7

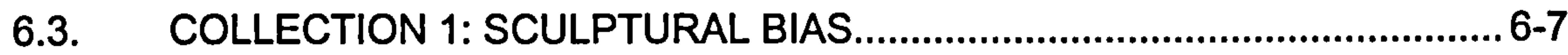

6.3.1. Design Intentions ...................................................................6-8

6.3.1.1. Cord Tunics: Process ...................................................6-9

6.3.2. Re-shaping the garment in accordance with the print imagery ..... 6-11

6.3.2.1. Reflections .................................................................6-11

6.3.3. Vine Tunics: Intentions ....................................................... 6-11

6.3.3.1. Process ..................................................................6-13

6.3.3.2. Stretching and re-colouring.........................................6-13

6.3.3.3. Printed outcomes ...................................................... 6-16

6.3.3.4. Reflections .......................................................... 6-16

6.3.4. Shadow Tunic: Intentions .................................................. 6-18

6.3.4.1. Process: Capturing the effect of light on cloth................ 6-18

6.3.4.2. Transposing Trompe L'oeil Pleats ............................... 6-18

6.3.4.3. Printed outcome ...................................................... 6-20

6.3.4.4. Reflections ..............................................................6 6-20

6.4. COLLECTION 2: ARCHITECTURAL BIAS ....................................... 6-23

6.4.1. Pin Wraps: Intentions .......................................................... 6-23

6.4.1.1. Pin Wraps: Process....................................................6-24

6.4.1.2. Pleat Simulation ...................................................... 6-24

6.4.1.3. Printed Outcome ........................................................ 6-27

6.4.1.4. Pin Wrap Skirts: Reflections ........................................ 6-32

6.4.2. Win Dress: Intentions and Process ........................................6-32

6.4.2.1. Digital Patchwork......................................................... 6-35

6.4.2.2. Printed Outcome .......................................................6-35

6.4.2.3. Reflections ...............................................................6-39

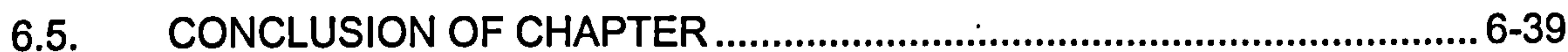

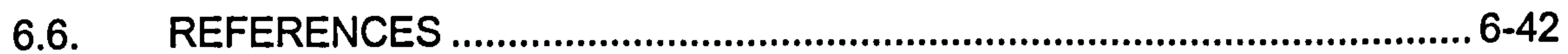

Chapter 7. Transforming Shape

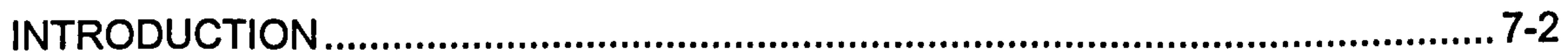

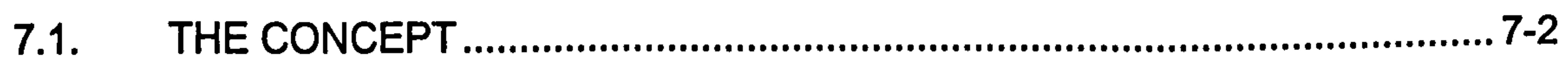

7.1.1. Group Objectives ................................................................ 7-3

7.1.2. Context .............................................................................. 7-4

7.1.3. Envisaged Outcomes ........................................................... 7-5

7.1.4. Circle, Square, Rectangle .................................................. 7-6

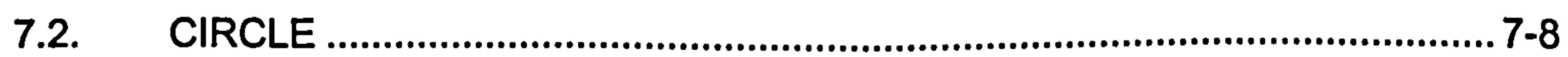

7.2.1. Circle Pleats 1-3: Contouring the boundary ................................ 7-8 
7.2.2. Circle Pleats 4-6: Multi-mapping ............................................... 7-10

7.2.2.1. Evaluation of Effects.......................................................7-14

7.2.3. Circle Skirt: Intentions...............................................................7-14

7.2.3.1. Circle Skirt: Process .........................................................7-14

7.2.3.2. Evaluation .........................................................................7-16

7.2.4. Nautilus: Intentions .................................................................18

7.2.4.1. Process: Mapping the surface .........................................7-18

7.2.4.2. Analysis of Outcome .......................................................7-20

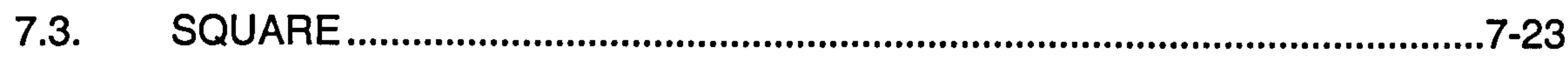

7.3.1. Initial Experimentation ...............................................................23

7.3.2. Dress Square: Intentions ............................................................7-25

7.3.2.1. Process: Directional contouring .......................................7-25

7.3.2.2. Integrating the Concept of 'Flow' ......................................7-25

7.3.3. Contrasting Approaches ..............................................................7-26

7.3.4. Consideration of Colour............................................................7-30

7.3.4.1. Contour Colour ..........................................................7-30

7.3.5. Tide: Analysis of Outcome ........................................................7-31

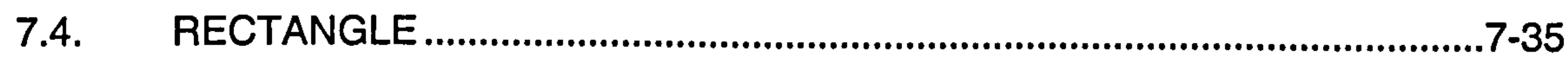

7.4.1. Initial Experimentation .............................................................7-35

7.4.2. Rectangle Wrap: Process.............................................................7-35

7.4.3. Wrap: Extending Mark Making beyond the Form ...........................7-37

7.4.4. Wrap: Analysis of Outcome.........................................................7-38

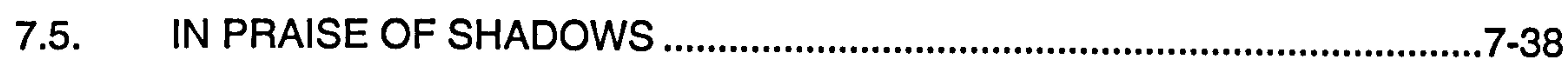

7.5.1. Personal Design Outcomes..........................................................7-42

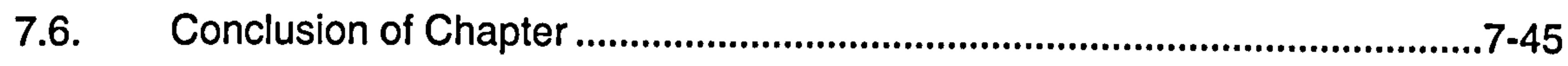

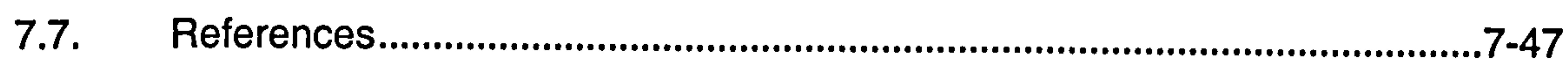

Chapter 8. Contributions to New Knowledge

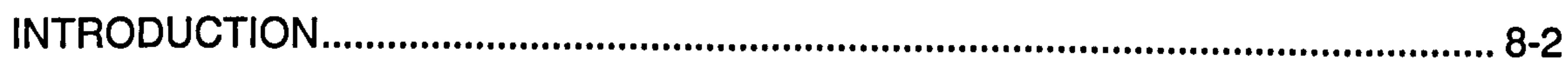

8.1. OVERALL CONCLUSIONS................................................................. 8-2

8.2. CONTRIBUTIONS TO NEW KNOWLEDGE............................................ 8.5

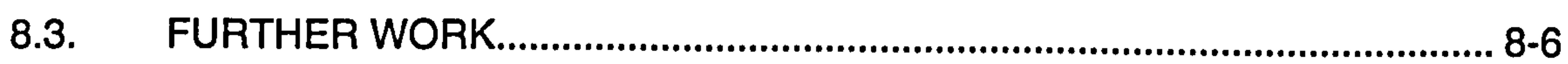

\section{Appendix 1 Past Practice}

Appendix 2 Related Studies

Appendix 3 Poem for Madame Delaunay

Appendix 4 First Hand Observations of Schiaparelli's Tear Dress

Appendix 5 Published Papers

Bibliography 


\section{Figures}

\section{Chapter 1}

1-A Cocky's Shed 1997: Pleated dress with printed bodice (Fashion Weekly 1989).. 1-4 1-B Cocky's Shed: Metallic printed dress (Clothes Show Magazine 1990).................. 1-4

1-C Cocky's Shed 1990: Op Art Bodysuit (Company 1990) ........................................ 1-6

1-D Cocky's Shed 1991: Ring Dress (Another Magazine 2003)................................. 1-6

1-E Sonia Delaunay 1925: Tissus Simultané (Biennale di Firenze 1996).................... 1-9

1-F Apollodaurus of Phocaea second century B.C. (Hollander 1978) ....................... 1-15

1-G Running Niobid early 3rd century B.C. (Hollander 1978)................................... 1-15

1-H John Galliano 1986: Fallen Angels (Biennale di Firenze 1996) .......................... 1-17

1-I Vionnet: Dress for Winter 1933/4 (Dormonex 1991) ........................................... 1-17

1-J Ruffo Research 2003: Pleated leather dress (Harpers and Queen 2003) ........... 1-19

1-K Issey Myake 1991: Heat Molded Dress (Braddock and O'Mahony 1994).......... 1-21

1-L Man Ray 1934: Black Dress (Vanci-Perahim 1999) ........................................... 1-21

1-M Sean Ellis 2002: Dreamweaver (Surface 2002) ............................................... 1-22

1-N Michelangelo de Battista 2002: Grace (managementartists.com 2003).............. 1-22

1-O Hussein Chalayan 1995: Buried Dress (Braddock and O'Mahoney 2001) ........ 1-24

1-P Martin Margiela 1997: Mould garment, '9/4/1615' exhibition (De Givry 1998).... 1-24

1-Q Caroline Broadhead 1989: Web (Colchester 1991) ........................................... 1-26

\section{Chapter 2}

2-A Pablo Picasso 1907: Les Demoiselles d' Avignon (Martin 1998).......................... 2-5

2-B Delaunay 1913: Bookbinding, collage of fabrics (Damase 1991).......................... 2-8

2-C Sonia Delaunay 1913: Simultaneous dress (Damase 1991) ................................. 2-8

2-D Charles Frederick Worth 1889/1892: Belle epoque-style evening dresses (Martin

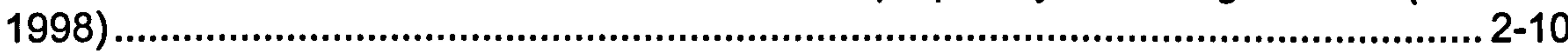

2-E Callot Soeurs 1910-14: The softening of the dress shape (Martin 1998) ............ 2-10

2-F Callot Soeurs 1926: The flattened, collaged, dress shape (Martin 1998)............ 2-10

2-G Alix Grés 1938: Sculptural jersey dress (Milbank 1985) ...................................... 2-12

2-H Christian Dior 1955: Garden Party, architectural printed dress (Giroud 1989) ... 2-12

2-I Rudi Gernreich 1967: 'Mrs. Square' (Moffit and Claxton 1991)........................... 2-14

2-J Rudi Gernreich 1967: 'Miss Hip' (Moffit and Claxton 1991).................................. 2-14

2-K Harry Borden 1968: Paper Poster Dress (Eye) (Hayward Gallery 1998) ............ 2-14

2-L Emilio Pucci 1968: Moonlight Dress in silk crepe (Casadio 1997)....................... 2-14

2-M Cocky's Shed 1991: Octobriana range for S/S 1991/2..................................... 2-16

2-N Chanel 2003: Printed chiffon dress (The Independent 2003) ............................. 2-18

2-O Maison Martin Margiela: Customised original tailors mannequin USA. C. 1930s.

S/S 2001: Check jacket enlarged $157 \%$ and white rectangular Tent dress 2-22 
2-P Masataka Kuroyanagi 2000: Circles 1 (47 x 136 cm) mezzotint (North 2000).... 2-25

2-Q Tina Modotti 1924: Cloth Folds (Barnett 1999)...........................................2-25

2-R Owen Gaster S/S 1996: Layered transparent vest (Braddock and O'Mahoney 1998)

2-S Issey Miyake 1999: Printed APOC (Guardian Weekend 2000).

2-T Jean Paul Gaultier 1995/6: Catsuit from Horsewomen and Amazons of Modern

Times (McDowell 2000).

2-U John Galliano 1997/98: Egyptian-inspired, printed bodysuit (McDowell 1997)... 2-30

2-V Sonia Delaunay 1933: 'Op Art' scarf and fabric design (Damase 1991). 2-35

2-W Unichi Arai 1989/90: 'Melting Off', polyester yarns coated in a metal devoré pattern (Colchester 1991). 2-35

2-X Cocky's Shed 1991: 'Brigit', optical print on cotton Lycra $2-35$

2-Y Gillian Bunce 2001: Optical engineered print for Transforming Shape (supplied by the designer)

\section{Chapter 3}

3-A Luibov Popova 1923/4 Dress designs (Adaskina \& Sarabianov 1991). 3-4

3-B Léon Bakst: architectural costume for Anna Pavlova in Swan Lake (1908) and sculptural design for the Nymph in Narcisse (1911) (Schouvaloff 1991) ................... 3-6 3-C Mariano Fortuny 1907: Delphos (Hayward Gallery 1998)................................. 3-8

3-D Madeleine Vionnet 1930 Embroidered Wedding dress (Martin 1998).................. 3-8 3-E Ossie Clark 1974: Printed crepe dresses featuring prints by Celia Birtwell (Watson 1999)

3-F Azzedine Alaia Winter 1986: Mermaid dress (Steele 1997) 3-9

3-G Rick Owens Asymmetric Vest (1) and Sophia Kokoslakis Nude Dress (Guardian Weekend 2003)

3-H Alexander McQueen and Hussein Chalayan S/S 2003 (Frankel 2003)

3-I Yinka Shonibare 1995: 'How does a girl like you, get to be a girl like you'? (Rosenthal et al 1997).

3-J Gianni Versace S/S 1988: Printed evening dress with panniers (Martin 1997)... 3-14 3-K Roberto Capucci 1985: Blades (Hayward Gallery 1998)................................... 3-15

3-L Hussein Chalayan S/S 2001: Poppy Dress, Ventriloquy (Wilcox 2001).............. 3-15

3-M Emilio Pucci 1996 Jersey silk printed tunic (Casadio 1998) .............................. 3-18

3-N Halston 1970 Tie-dyed silk chiffon evening pyjamas (Steele 1997).................... 3-18

3-O Junya Watanabe 1998: Metallic printed dress (Vogue 1998) ........................... 3-20

3-P Rei Kawakubo AW 1997/98 Purple Punk (Grand 1998) .................................. 3-20

3-Q Marcus Lupfer and Martine Sitbon 2000 textile-led garment designs (Guardian Weekend 2000)

3-R Sonia Delaunay Simultaneous Contrasts 1914; Dress designs 1925 (Damase 1991) 


\section{Chapter 4}

4-A Rebecca Sexty 2003: Simple repeats created in Colour Matters

4-B Rebecca Sexty 2003: Engineered-print idea

4-C Katherine Townsend 1999: Print visualisation using textile draping grid.

4-D Nahed Seleman-Baba 2001: Nubian palm tree (supplied by the designer).

4-E Nahed Seleman-Baba 2001: Variations of Nubian palm tree (supp by the designer)

4-F Vibeke Riisberg 1992: Curtain 'Impression' (supplied by the designer).

4-G Vibeke Riisberg 2002 (supplied by the designer).

4-H Amanda Briggs 2001: Image for Transforming Shape (supp. by the designer).. 4-16

4-I Hussein Chalayan 1998: Cocoon Dress (Frank 1998).

4-J Laura Rotger Buadas 1998: Print for Hussein Chalayan (supplied by the designer)

4-K Flattened pattern from a CDI-3D System (Chen 1998).

4-L CDI-3D System showing second skin pattern (Chen 1998)

4-M Katherine Townsend 2000: 3D garment visualisations created on PAD 3D System

4-N Lectra System's 2000: Virtual Mannequin (VM) visualisation by Laura Mylius... 4-23 4-O Jane Harris 2000: Digital textile from the Portrayal Series (Williams 2002) 4-25

4-P Katherine Townsend: Drip print integrated with $2 D$ and $3 D$ visualisations 4-27

4-Q TC2 Engineered printed garment and pattern pieces ( tc2.com/RD/RDPrinting.htm 2003) 4-31

4-R John Galliano: Union Jacket (SHOWstudio 2003). 4-33

4-S Stork Amethyst and Amber digital fabric printers (Townsend 2001) 4-35

4-T Hilary Carlisle 2000: Non-repeating patterns (supplied by the designer). 4-40 4-U Helena Rosen: 2002 MA Degree Show (supplied by the designer). 4-42

\section{Chapter 5}

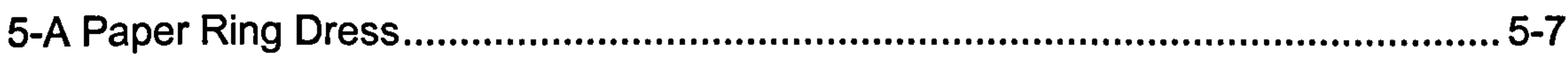

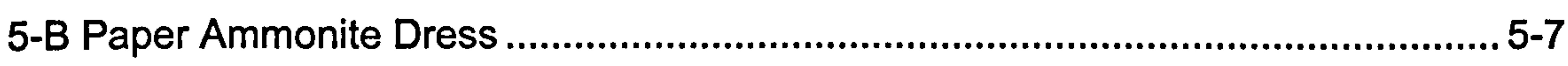

5-C Ink stain and cup rings on tissue paper ......................................................... 5-10

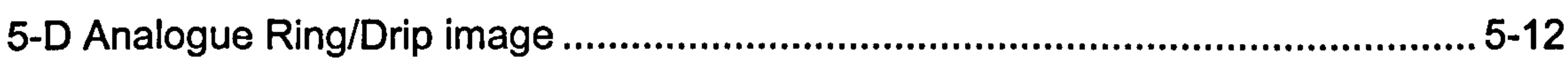

5-E Digital 'oil' drips combined with analogue cup ring.......................................... 5-14

5-F Experimental print/garment integration ..........................................................16

5-G Marrying Ring/Drip print across seams .......................................................16

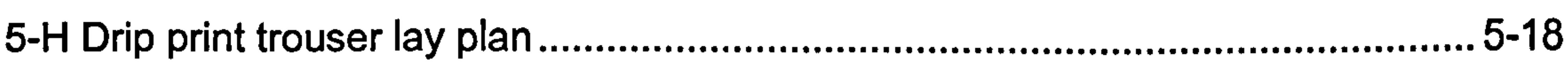

5-I A-line and re-shaped Stain shift dresses ..................................................... 5-18

5-J Printed T-shirt visualisation in PAD's 3D system........................................... 5-19

5-K Robert Rauschenberg \& Susan Weil 1950: Cyanotype (Weitemeier 1995) ....... 5-22

5-L 2D cyanotype exposed using artificial ultraviolet light source.............................. 5-25 
5-M Test strip of cord showing attached shadow effect.

5-N Muslin, drape neck and pattern contours

5-O Wrapped Toile during process of image capture

5-P Ribbon Tunic cyanoform on the stand

5-Q Ribbon Tunic, front and back pieces 5-30

5-R Contour with curved mapping grid. 5-32

5-S Ribbon Tunic front modelled in CAD with attached shadow 5-32

5-T Water Pleat 5-33

5-U Digital printing Test Files 1-3. 5-35

5-V Samples showing colour variation 5-36

5-W Samples showing pixelation and 3D effect 5-36

\section{Chapter 6}

6-A Cord Tunic 3 front 6-10

6-B Cord Tunic 3 back 6-10

6-C Re-cutting paper toile and resulting new pattern shapes $6-12$

6-D Process of image capture for Vine Tunics 6-14

6-E Vine Tunic 5

6-F Rendered versions of Vine Tunic 4.

6-G Shadow Tunic 6 .

6-H Bara Dress: 2D print integration with Shadow T5 ...................................... 6-21

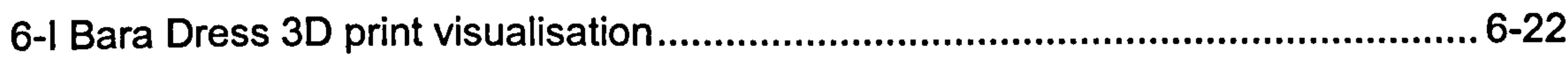

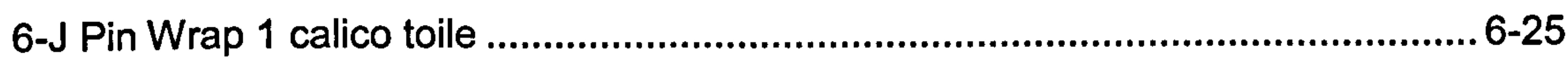

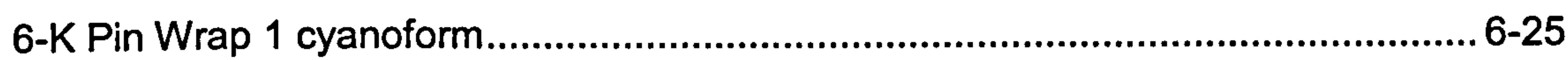

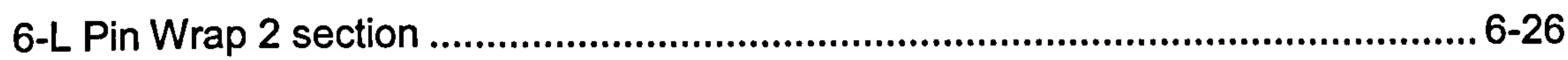

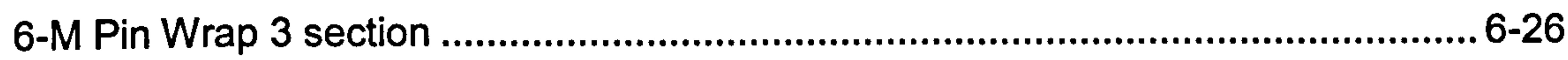

6-N Pin Wrap 1 aligned with rectangular contour ..............................................6-28

6-O Pleated skirt, design stages .................................................................6-29

6-P Pin Wrap 4, design development in PAD 3D System .....................................6-30

6-Q Wrap Skirt: digitally printed sample on viscose ........................................... 6-31

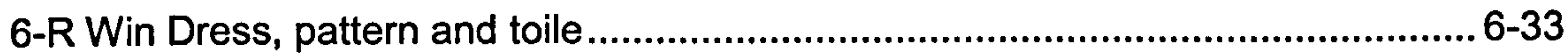

6-S Win Dress, wrapped, sensitized toile......................................................... 6-34

6-T Win Dress patterned shoulder area ....................................................... 6-34

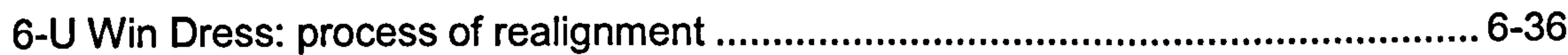

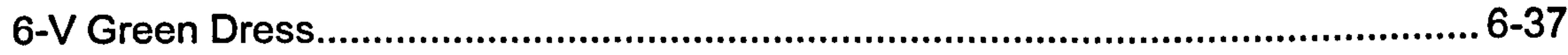

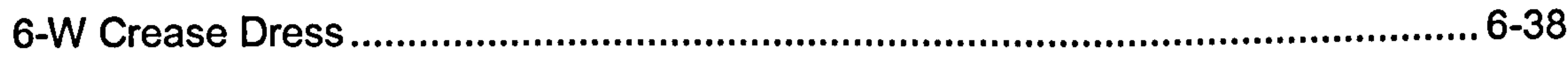

\section{Chapter 7}

7-A Ruched Circle toile by Rosemarie Goulding integrated with Circle Pleats 6........ 7-9 


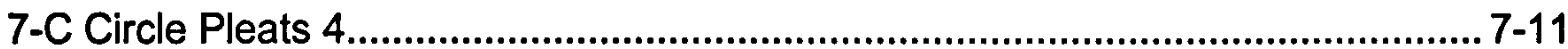

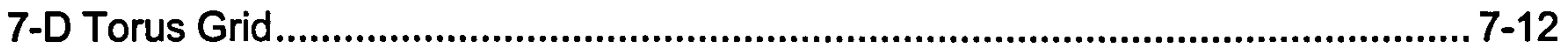

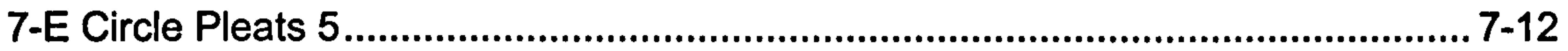

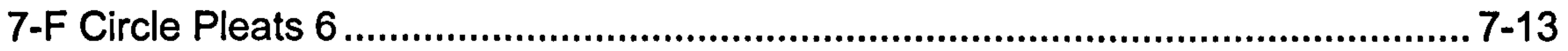

7-G Circle Skirt toile on the form ................................................................... 7-15

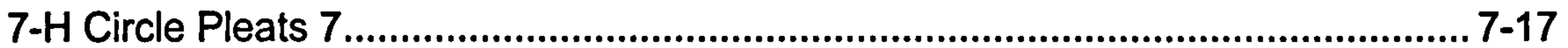

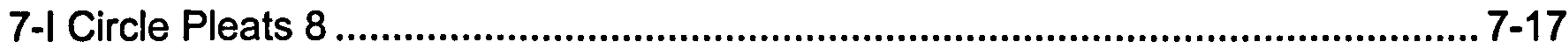

7-J Circle Pleat 8 on cotton drill and silk georgette, on stand ................................ 7-19

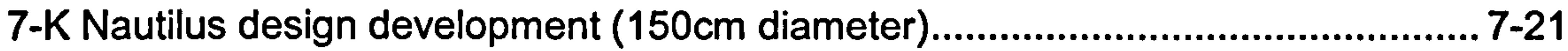

7-L Nautilus on the mannequin in Transforming Shape ...................................... 7-22

7-M Dress Square toile by Sue Keen.......................................................... 7-24

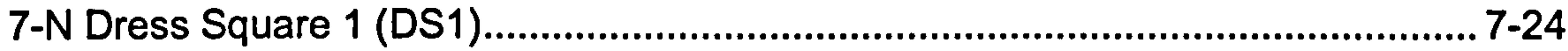

7-O Diamond draping grid ......................................................................... 7-27

7-P Dress Square 2 (DS2) and Dress Square 6 (DS6) ..................................... 7-28

7-Q Dress Square designs by Katherine Townsend, Rosemarie Goulding, Gillian Bunce and Amanda Briggs-Goode ............................................................. 7-29

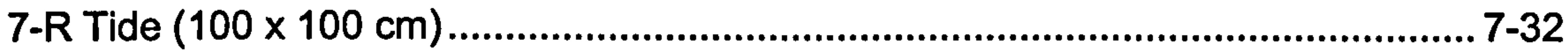

7-S Tide on the model, four views in movement ............................................. 7-33

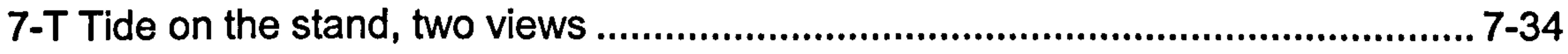

7-U Rectangle Wrap toile by Sue Keen ........................................................ 7-36

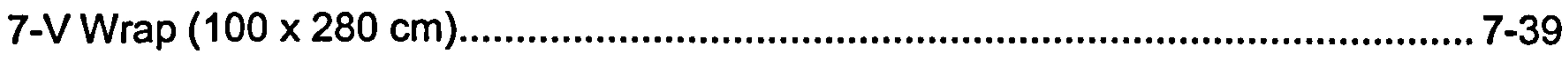

7-W Wrap on model, four views ........................................................................... 7-40

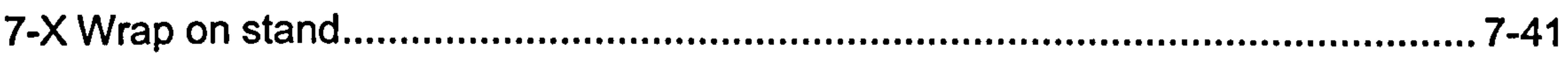

7-Y Transforming Shape December 2001.......................................................... 7-43 


\section{Chapter 1. Introduction: The Nature of the Research}

1.1. BACKGROUND TO THE PROPOSAL .............................................. 1-2

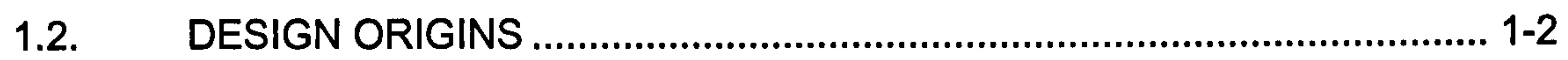

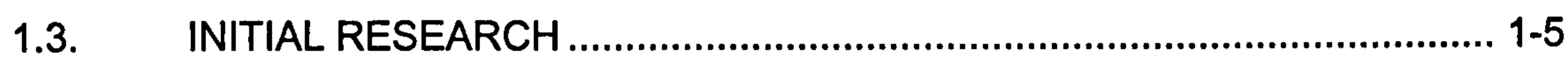

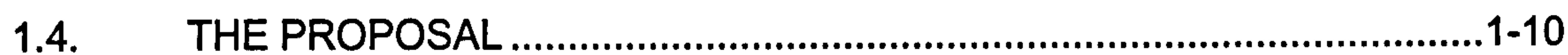

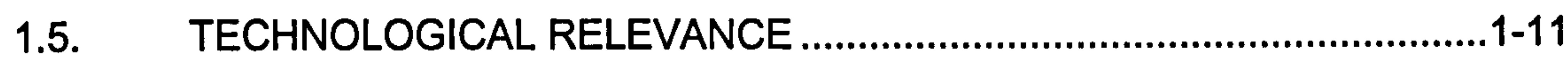

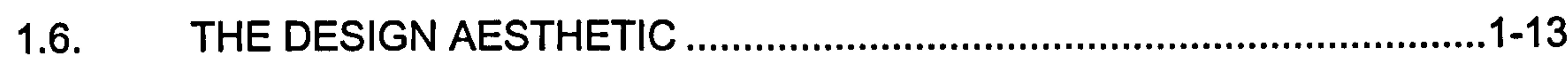

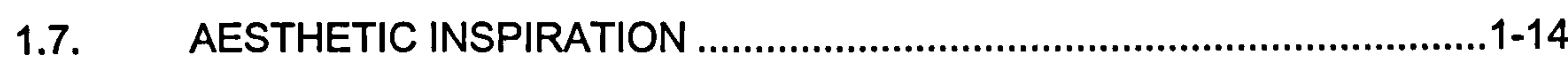

1.7.1. Not Made By Hand ..............................................................

1.7.2. The Notion of Wear ..............................................................

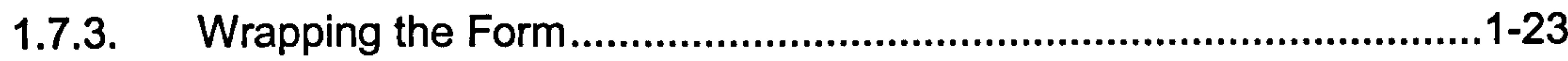

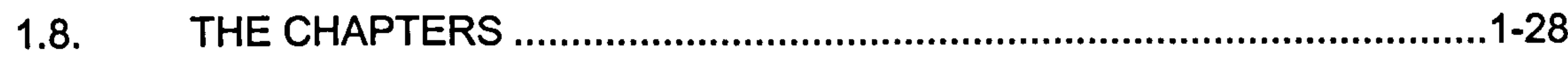

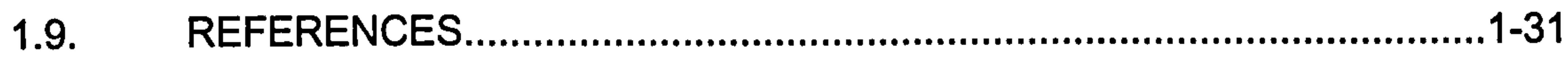




\subsection{BACKGROUND TO THE PROPOSAL}

In 1998 a group of fashion and textile practitioners at the Nottingham Trent University, formed a research group, Impact, to investigate the impact of new technologies on design processes. Impact ${ }^{1}$ included fashion and textile design practitioners who combined theoretical and practical research to investigate the impact of new technologies on design processes. The group's outcomes included research degrees investigating the effect of CAD on: clothing design (Aldrich 1990); repeat pattern (Bunce 1993)3; textile design (Briggs 1997); colour (Leak 1998) and 3D pattern cutting (Chen 1998). Each thesis included a practical element, resulting in the design of new software, ${ }^{4}$ new designing strategies, and a perception of CAD as not only a tool, but as an 'independent media' in its own right (Briggs 1997: 174). This research is situated within this group and is concerned with an investigation into the relationships between printed textiles and garment shapes using CAD.

A common finding of the research at Impact, was that most recent technological developments had been 'reactive', and were 'based on analyses of how designers had worked during the development of CAD', rather than how they might work 'if they were allowed to use CAD as a design medium' (Briggs and Bunce 1995: 187). By 1997, there was a growing realisation that to compete successfully in the global market, the British Clothing and Textile Industries needed to place greater emphasis on design, in order to 'add value' to garments (Fearon 1997: 46). It was recognised that in couture an integrated design approach was taken to the design of printed garments. Integrated CAD software offered the mass clothing industry the opportunity to work from a similar perspective, but its use as a creative design tool remained largely 'unexploited' (Bunce 1996: 32). Based on these key factors Impact sought to create a project linking CAD with textile and clothing design, resulting in the funding by NTU of this practice-led research investigation into 'the integration of print design and garment shape using CAD.'

\subsection{DESIGN ORIGINS}

My past practice as a printed garment designer (1981-1993) and freelance textile designer between (1993-1998) provided valuable insights into the specific design and production considerations of integrating printed imagery with garment shapes. Areas of

\footnotetext{
${ }^{1}$ In 1998 Impact formed an integral part of Fashion and Textile Research at Nottingham Trent University, other groups included Computer Clothing Research (CCR) and Work and Technology.

${ }^{2}$ See also: Aldrich, W. Ed (1996) CAD in Clothing and Textiles, Oxford, Blackwell Science

${ }^{3}$ See also: Phillips, P. and Bunce, G. (1993) Repeat Patterns, London: Thames and Hudson

${ }^{4}$ Aldrich designed Ormus-Fashion (1987), an early teaching software package for fashion and textile colleges, Ormus-Industrial (1988) and Ormus Hi-Res (1990).
} 
- The design and application of a considerable range of printing techniques 5

- Knowledge of printed fabric performance in relation to garment and form

- The combining of innovative prints with a complementary cut

- The ability to streamline small-scale production.

The combining of different printing processes to achieve new fabric qualities has been a continuing theme within my practice. For example, I found that the application of reactive and pigment dyes, together on silk resulted in both sheen and opacity, which significantly altered both the appearance and the fabric hand. ${ }^{6}$ The use of pigment, puff and metallic dyes on wool and cotton Lycra was 'inadvisable' according to commercial printers, but resulted in novel, textured fabrics (Fig.1-A). The design and manufacture of stretch garments incorporating Lycra, called for a considered application of printing inks in order for the base fabric to retain its inherent elasticity. The innovative print styles created by my company often required a simple, straightforward cut, that allowed the cloth and body shape to govern the outcome (Fig.1-B). Small-scale production requires greater organisation and dependency on manual methods than mass production. As well as designing and hand printing textiles, I gained experience in garment design and production through toiling, hand cutting, sewing and finishing sample ranges

Both of the companies I was involved in, Katsu ${ }^{7}$ and Cocky's Shed, ${ }^{8}$ worked from a 'textile-led' (3.5) perspective, with the imagery and quality of the textile, providing the dominant inspiration for the garment collections. The screen-printing techniques adopted by my first company were a continuation of the skill-base I had acquired as an undergraduate. Hand printed woven qualities such as; silk, chiffon and viscose were printed using cellulose reactive, discharge and devorè techniques. In keeping with other textile-led designers working in the early 1980s, such as Artwork, Body Map and the English Eccentrics, the print was the selling feature, providing the catalyst for the garment shapes, which were cut to emphasise the characteristics of the cloth. This design tendency was further cultivated within my second company, Cocky's Shed, which specialised in printed jersey fabrics containing Lycra. Working with stretch fabrics required a restrained approach to cutting, and for the integration of surface print

\footnotetext{
${ }^{5}$ Printing techniques included hand and rotary screen methods.

'The term fabric 'hand' is used to define the particular textural and draping qualities of a cloth (Aldrich 1996).

7 The partnership Katsu (1981-1985) was formed with the printed textile designer, Sue Watton.

${ }^{8}$ For a synopsis of the work undertaken by these two companies see Appendix 1.
} 

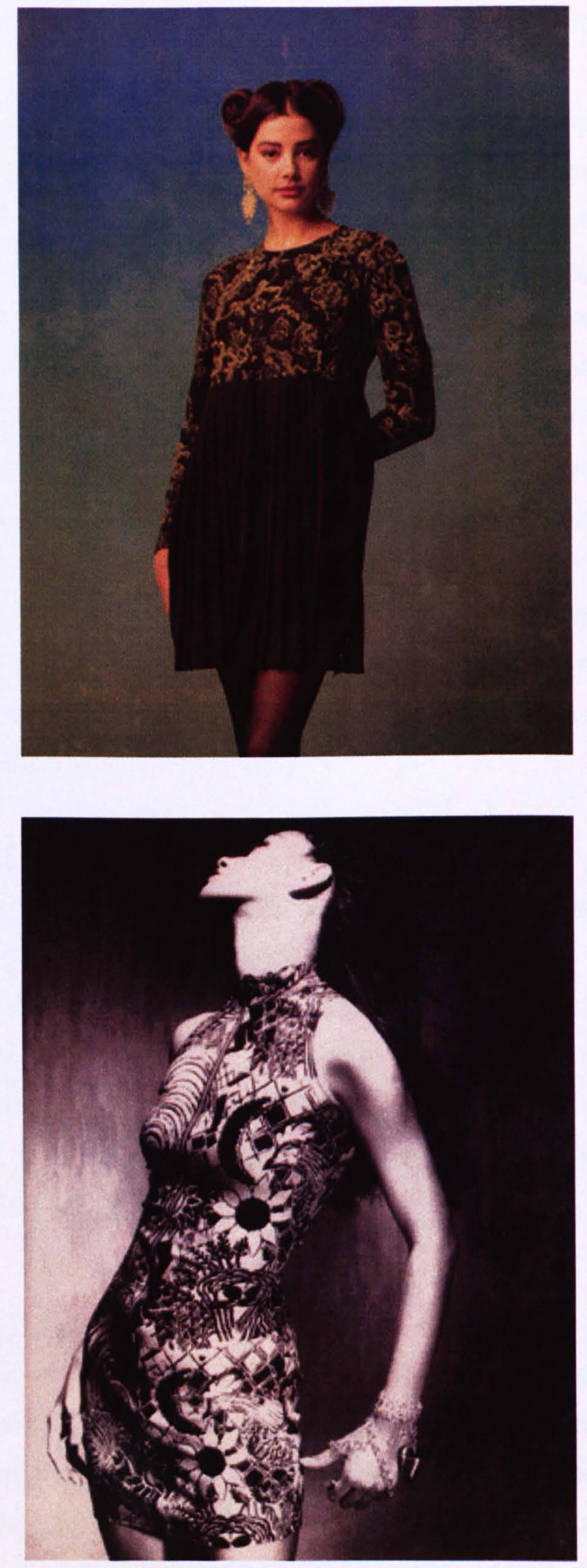

Figure 1-A Cocky's Shed 1997: Pleated wool dress with textured printed bodice (Fashion Weekly 1989)

Figure 1-B Cocky's Shed: Metallic printed dress (Clothes Show Magazine 1990). 
During the mid-1980s until the early 1990s, when my second company was formed, ${ }^{9}$ the revival in the use of Lycra had a revolutionary impact on printed garment design (2.3.2). Lycra's stretch-to-fit properties enabled garments to be cut to fit the contours of the body without the aid of tailoring or specially constructed undergarments, allowing printed imagery to interface more closely with the form. Lycra determined a garment silhouette that was cut close to the body, but could be produced easily by employing simple shapes based on rectangular shaping (2.1.2). Graphical prints were employed to enliven basic shapes that drew on Pop and Op Art and comic book heroines (p.215). However, not all the shapes were simple, as indicated in Figure 1-C, which illustrates the interesting contoured effects that could be created in stretch fabric. The plain shapes worked with the general rhythm of the form, while the printed wave-like sections introduced complex optical effects into the design. Even non-printed models incorporated complex panels that contoured the body in a striking manner and drew attention to the shape of the form (Fig.1-D). ${ }^{10}$

Working with stretch fabrics significantly altered my perception of garment design. Instead of viewing the body as a malleable frame that could be visibly altered by the shape of a (woven) garment, I now considered it as an interactive force within the design equation. I developed a new way of working that was intuitively centered on the form, so that when designing a printed garment in 2D, I was able to envisage the outcome in 3D. This way of working, based on tacit knowledge of designing and making of garments, was a major influence on the simultaneous design approach advocated through this research.

\subsection{INITIAL RESEARCH}

At the outset of the research I was provided with pattern cutting, lay planning and computer graphic software and peripherals. ${ }^{11}$ Using Prostyle (Lectra), an integrated CAD package, enabled me to combine garment shapes (vector) and textile patterns (raster) within a single interface, I soon found that a major advantage of using integrated $C A D$ was the ability to visualise a prospective design style as both a $2 D$ pattern and a 3D garment simulation, prior to production. The combined use of CAD

\footnotetext{
${ }^{9}$ Cocky's Shed (1985-1992) was formed with Sue Watton and the fashion knitwear designer Dawn Foxall. ${ }^{10}$ The Ring Dress pictured in Figure 1-D was designed by Cocky's Shed in 1991 and attributed to the vintage clothing outlet Snoopers Paradise in Another Magazine in 2003.

${ }^{11}$ Modaris pattern cutting, Dianimo lay-planning, Prostyle integrated fashion and textile software, digitiser and plotter were supplied in August 1998, and were operational by January 1999. An A3 scanner was added in September 1999. The specifications of the hardware and software are discussed in Chapter 6.
} 

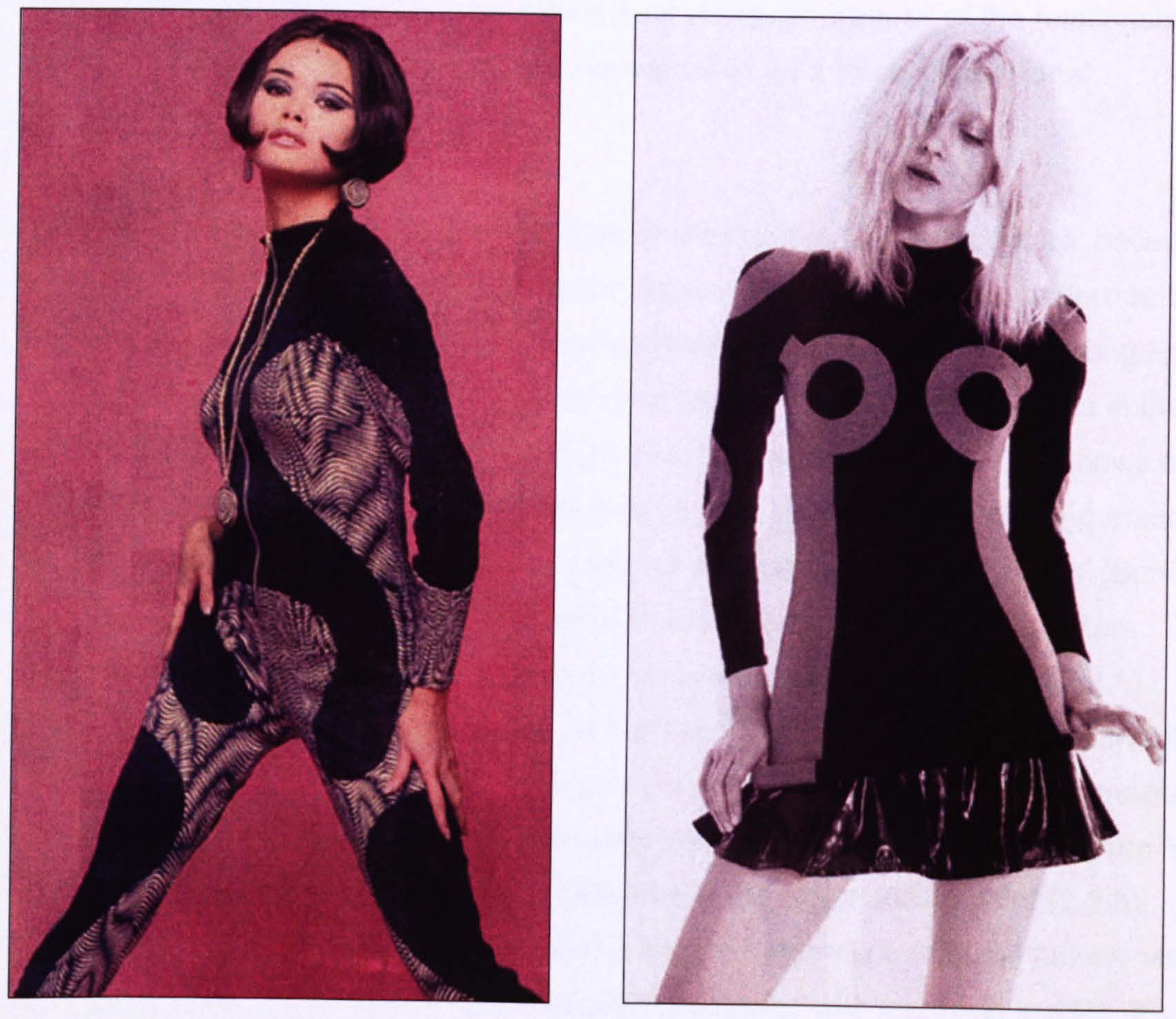

Figure 1-C Cocky's Shed 1990: Op Art Bodysuit (Company 1990)

Figure 1-D Cocky's Shed 1991: Ring Dress (Another Magazine 2003) 
with inkjet fabric printing technology facilitated the translation of the pattern-filled garment shapes directly onto fabric, a method used primarily for sample garment production. During my past practice as a designer of printed garments I had worked in a comparable way using manual methods. ${ }^{12}$ As most of the garments I had designed during my past practice were created in Lycra, I had learned to anticipate the interaction between printed imagery, garment shape and the human form, accurately. This resulted in my practice being governed by a strong awareness of the relationship between two-dimensional design and it's manifestation as a three-dimensional, patterned form.

I began the theoretical research by investigating the practice of haute couture, because it offered a practical example of the aesthetic relationship between textile pattern and garment shape that had existed prior to the introduction of CAD. In couture strong links have always existed between these two areas of design. The art of couture lies in the aesthetic manipulation of print, cloth and form to create a garment style that shows off the materials and the body to their best advantage (2.2.2). In the mass clothing market economic constraints have led to a more 'negative approach to printed pattern' (Bunce 1993: 143). Here, the relating of print with cut is a far more pragmatic affair, often undertaken with the intention of decorating an otherwise, non-descript style (2.2.1). Conversely, mass-produced clothing can be both economically viable and attractive if the textile and garment are designed with consideration of the aesthetic requirements of the customer. ${ }^{13}$ The designer clothing market represents the most exciting forum for print/garment integration, as originality of outcome is the major selling point (2.2.3). This is particularly true of some independent designers who mix traditional fabrics with cutting edge technologies, and established craft processes with technical textiles, to create innovative fashion fabrics, as explored in the 'Fabric of Fashion' exhibition (Braddock and O'Mahoney 2001). Ironically, I found that this group sometimes had limited exposure to the latest CAD systems, and their success was often based on hybrid designing methods that combined manual and digital technologies (4.5).

My past practice, as a designer and manufacturer had made me aware of the considerable influence that fabric quality had on the design of garment shapes, and the subsequent application of surface print. The idea that different spatial garment forms existed and could determine general styles of surface print was developed, following research into the work of Luibov Popova (3.1). This resulted in the conception of 'sculptural', 'architectural' and 'crossover' archetypes, which provided a way of

\footnotetext{
${ }^{12}$ Single colour, print-filled garment shapes were designed on paper, then a transparency was created and exposed onto a silkscreen and finally printed onto cloth.

${ }^{13}$ As exemplified by the success of the Top Shop brand through commissioning designer ranges.
} 
categorising the relationship between print style, garment shape and the role of the body (Townsend, K: 2000). Further research into print/garment integration revealed a range of different design methods that encompassed 'textile-led', 'garment-led' and 'simultaneous' approaches (lbid.). Highly integrated and body-centred examples of surface and structural integration were found in the work of Sonia Delaunay and Madeleine Vionnet, whose practices were focused respectively on a simultaneous (3.7), and three-dimensional, modelled design approach (3.2).

Sonia Delaunay designed and produced her garments of the 1920s in a manner that pre-empted CAD/CAM production, by printing her 'fabric patterns' ${ }^{14}$ directly onto cloth (Damase 1991: 58). Delaunay's novel designing strategy was facilitated by the geometric, 'Cubist' shaping of the time, which in turn fueled the production of ready-towear garments (2.1.2). She had an innate understanding of the relationship between pattern and form, as Cunningham (1998) states: 'the fusion of the female body with her clothing was a goal set early in the design of her simultaneous dresses' (Fig.1-E). Delaunay approached textile and garment design from a unique simultaneous perspective, whereby:

...the cut of the dress is conceived by its creator simultaneously with its decoration. Then the cut and the decoration suitable to the shape are both printed on the same fabric' (Delaunay in Damase 1991: 58).

Both Delaunay's and my own (pre-CAD) method of directly printing garments onto cloth involved the use of screens ${ }^{15}$ containing the hand drawn contours/images of a printed garment design. The use of integrated $C A D$ enables designers to incorporate images at photographic resolution, manipulate them in accordance with a garment contour, visualise in $2 \mathrm{D}$ and $3 \mathrm{D}$, and adjust, prior to printing. Digital printing enables designers to print a single garment, in order to assess aesthetic design issues. It occurred to me that such technology offered designers the opportunity to apply an advanced, simultaneous design approach, facilitated by the ability to envision a 2D garment surface in relation its 3D garment shape, prior to production. By using 'draping' or 'texture mapping' software (4.1.2), CAD also allowed the designer to assess where a print would fall in relation to the garment shape and the form (5.3.1).

The project became focused on the creative integration of engineered printed textile designs and garment shapes. Engineered print structures (2.6.2) were chosen over repeating patterns, as through the use of CAD they can be integrated and manipulated

\footnotetext{
${ }^{14}$ Garment shapes filled with prints.

${ }^{15} \mathrm{Screens}$ require that imagery is converted into separate layers of flat or half-tone colour. A separate screen is required for each different colour.
} 


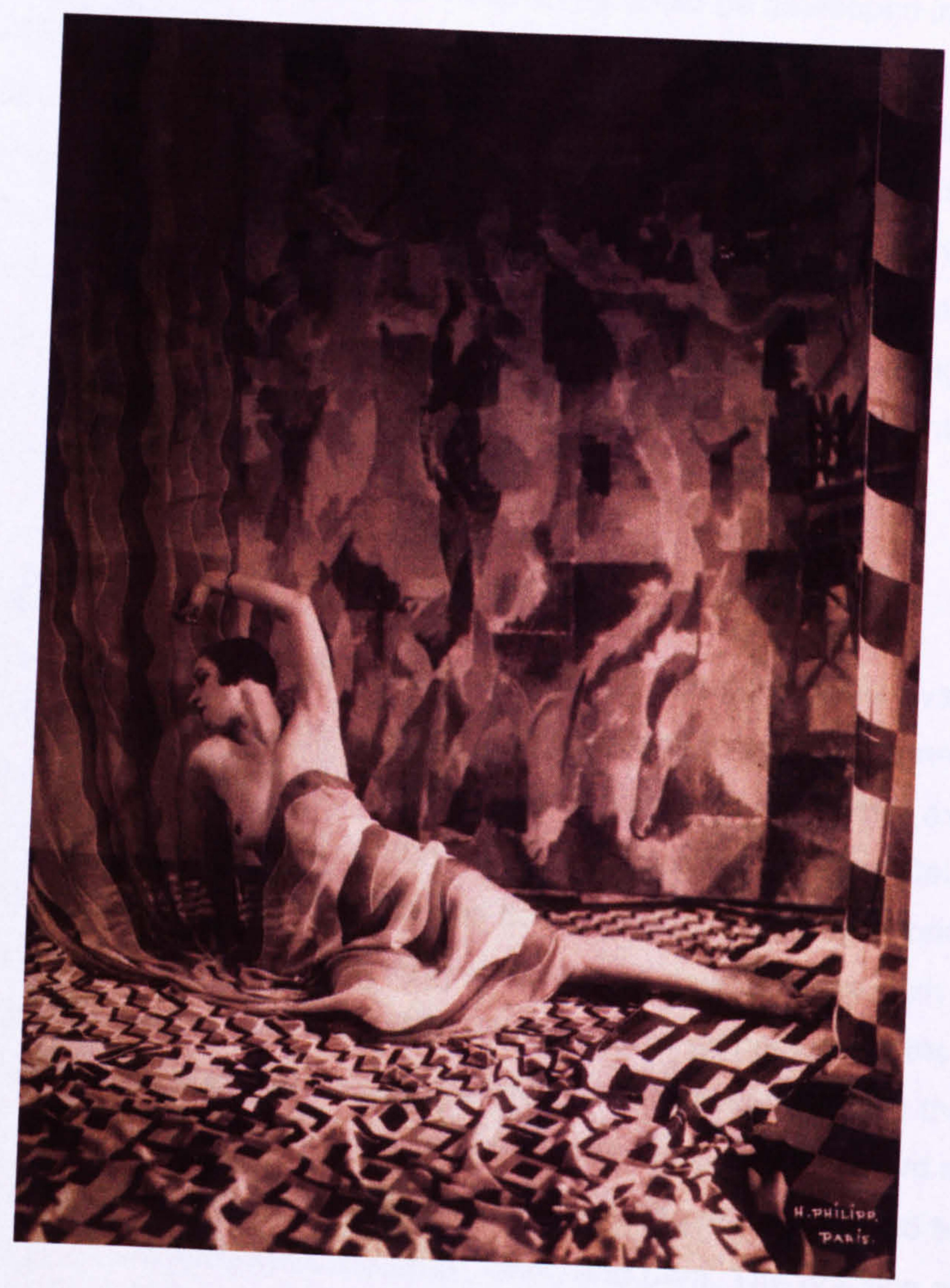

Figure 1-E Sonia Delaunay 1925: Tissus Simultané (Biennale di Firenze 1996) 
with any contour, without disrupting the flow of the image (2.4.2). Engineered prints also have considerable unexploited potential for being integrated with the underlying contours of the form, which represents a new area of textile research. Within the early stages of the practice, prints were incorporated as simple placements comprised of isolated images. It was envisaged that these ideas could be developed into complex designs, in which garment shapes were printed with patterns that linked across individual pieces to enhance their shapes. ${ }^{16}$ Although this approach has largely been confined to haute couture, technological developments now provide the opportunity to apply such signifiers of exclusivity to designs for the mass market. However, despite the further integration of CAD/CAM, I found that the design of garments and fashion textiles for the mass market are still often originated separately, with designers in industry rarely having the time or flexibility to experiment with CAD or to master its design possibilities (Jerrard and Bell 1998: 93).

\subsection{THE PROPOSAL}

The proposal of this research is that the most effective design process available to practitioners wishing to undertake an integrated approach to printed garment design is to adopt a simultaneous approach. This proposal is based on the further exploration of the simultaneous design approach, which was first advocated by Sonia Delaunay in the 1920s. Her interpretation of this concept was based on the designing of prints and garment shapes 'simultaneously', resulting in integrated designs were both aesthetically pleasing and effectively utilised the available technology of the time. This research recognises the capacity for current CAD/CAM technology to aid the designer in taking a simultaneous design approach that not only encompasses print and cut, but also anticipates the influence of the form. The process I have investigated has been informed by three principle factors: the body, cloth, and print. The practice advocates that a holistic approach to body, cloth and print can lead to the creation of innovative print vocabulary and new design styles. The research proposes that such outcomes demonstrate that a more creative use of $C A D$ can result in aesthetic value being added to designer garments through the creation and application of new design vocabulary.

CAD offers designers the opportunity for integrating prints and garment shapes. Digital fabric printing offers the possibility for producing such styles. This research proposes that a simultaneous approach can be taken towards printed garment design and towards CAD/CAM and existing manual design techniques. These include the combining of analogue and digital mark making, garment/pattern design methods and garment modelling methods. By examining emerging processes such as integrated

\footnotetext{
${ }^{16}$ This design concept is explored in Chapters 5 and 6.
} 
$C A D$ and digital fabric printing, this research will provide practical guidelines for the effective use of such technologies and propose new related working practices applicable to the designer clothing and textiles with ramifications for the art textile market. The design-orientated approach will demonstrate the effectiveness of combining the accepted quick response and cost saving benefits of CAD with its unexploited potential to aid design innovation.

This research is focused on the area of printed textile design, but is strongly influenced by fashion. The nature of this practice-led research can be described as singular in its approach, due to the specific context in which it has been undertaken. This context has largely been governed by the use of particular CAD hardware and software, provided by NTU, together with associated CAM technology, which has been accessed through sponsorship by Lectra Systems. The combined CAD/CAM technology has been approached in a creative and experimental manner with the ultimate objective of discovering new ways in which digitally printed textiles and printed garments can be designed and integrated.

\subsection{TECHNOLOGICAL RELEVANCE}

Integrated CAD/CAM systems have established technological links between fashion and textile design, and production processes (Abernathy et al 2002) ${ }^{17}$ Until fairly recently 'innovative' design outcomes were centered on the computer-aided-design of motifs on 'white styles' (blank, digitised garment pieces), which were screen printed with solvent based inks onto pre-cut garment pieces (Briggs and Bunce 1995: 187). The widespread compatibility of raster and vector-based software and the integration of CAD with digital fabric printing has revolutionised printed textile and garment design (Watkins 1999: 18). As Wentzel (2002) states: 'It is now possible to design a fabric, design a garment, cut a pattern, generate a sample layplan, print the fabric and makeup the sample all in-house and in one day.'

While the linking of CAD and digital printing offers designers the opportunity to experiment with new shapes and print styles, it has generally been used to 'speed-up the processes between design and industrial production' (Pötz 2002: 80). Mass clothing production continues to be governed by the 'rectangular' approach that developed in fashion in the 1920s (2.1.2). This has resulted in print/garment integration being restricted to the filling of simple garment shapes with repeat or placement prints, with little creative exploration of these combined elements. In response to this situation, 
this research examines the possibilities of designing and printing fabric and garments, from a new simultaneous perspective.

The benefits of integrated, or pipeline systems, include reductions in sample costs, cloth storage, and lead times as well as suitability for short runs. Since 1997 Companies such as [TC]2 have emphasised the option to address the made-tomeasure market, a concept that is currently high on the British Clothing Industry's (BCl) agenda (Crawford 2003). Large software providers, such as Lectra Systems, stress advantages of 'integrated clothing solutions' to allow users to create multiple 'looks' from a single construction, to cut and customize patterns using 'intelligent' software, preview prospective styles using virtual modelling (VM), digitally print, cut and manufacture garments, using streamlined systems (Lectra 2003). However, because most fashion and textile designers continue to work in separate spheres, which are linked but not integrated, the design potential of integrated CAD technology on printed garment design has still not been fully exploited (Bunce 1996: 33).

Most commercial fashion fabrics are still designed as two-way or non-directional patterns to reduce fabric wastage and there has been limited exploitation of the CAD's ability to create complex repeating print structures (Ibid. p.32). Others, such as border designs or directional patterns, incur high costs in fabric wastage, lay planning time, and rejects. While CAD has resulted in an increased use of such designs at a high designer level, they are still generally configured in a fairly rudimentary fashion. Some of the most exciting uses of CAD for textiles tend to configured by approaching 'the garment as a canvas' (3.8), whereby the garment shape acts as the frame for the 'action' of the surface pattern. In the designer market this approach facilitates the application of cutting edge imagery, while in the mass clothing sector the garment may be treated as a sophisticated form of T-shirt, with the key focus on the front of the garment. We have had the technology ${ }^{18}$ to transpose a print wherever we please onto a garment, for some years, but often the process of integration is conducted with minimal consideration of the aesthetic interaction between a textile image, a garment shape, and the underlying contours of the form.

One reason for the dearth of creative examples of print/garment integration is the limited access that independent designers have to the latest CAD technology. This situation is changing, as CAD/CAM becomes increasingly accessible to more users through local and international bureaus, such as TUKAtech (Davies and Tilley 2003). It

\footnotetext{
18 'We Have The Technology', Drapers Record (1997), discussed the work of designers at CV Apparel, who were the first company in the UK to offer the combined use of CAD and digital printing.
} 
is also only fairly recently that fashion and textile students have been able to access digital printing technology through bureaus, ${ }^{19}$ so although exploration of the medium is growing, the outcomes tend to be limited to the production of sample pieces, rather than as integrated garment designs. ${ }^{20}$ This research pre-empts the growing availability of integrated CAD and digital printing, as with $40-50 \%$ of the cost of a garment being incurred in the development of the fabric, I consider these to be the key 'creative designing' elements within current printed textile/garment designing technology.

As the profitability ceiling for short production runs increases, digital printing presents a viable prospect for smaller design companies. Its improved environmental features also offer designers the opportunity to adopt a more positive, local approach to printing (Pötz 2002: 80). The combined use of integrated CAD and digital printing technology, presents designer-makers with the opportunity to create new design styles using manual and digital crafting techniques. As Bunce (1999) states:

The ability to sample designs using the same process could mean that the designer's role in industry may develop to encompass the exploration of printing effects. This proposed use of CAD/CAM can be considered as a continuation of the craft tradition.

This design-centered research seeks to resolve many of the practical problems associated with 'uneconomic' textile patterns and also to produce innovative styles in which textile patterns are integral to a design concept that is centered on the enhancement of both garment and form.

\subsection{THE DESIGN AESTHETIC}

The design aesthetic of this thesis is derived from three different areas, which I have analysed as the body, cloth and print. The aesthetic governing the body is concerned with the appearance of the clothed female form. Cloth is a device that clothes and amplifies the form of the human body in action and at rest. Print is an embellishment of cloth that allows the form to be iterated through surface pattern.

For this research I have approached the designing of printed clothing for the female form from the perspective of creating a three-dimensional canvas. Printed textiles are generally created in two-dimensions but as soon as fabric is modelled it takes on a three-dimensional aspect. Consequently my design aesthetic has been governed by

\footnotetext{
${ }^{19}$ Such as the Centre for Advanced Textiles (CAT) at Glasgow School of Art and Belford Prints.

${ }^{20}$ The Centre for Advanced Textiles (CAT) provides textile students at Glasgow School of Art access to a Stork Zircon printer. In 2002 Hewlett Packard ran a competition at the London College of Fashion to test its newly developed fabrics and inks on its large format printers. Most students access digital printing via bureaus, which they have to pay upwards of $£ 35$ per meter, leaving little room for experimentation.
} 
the notion of creating a 2D surface that will perform in 3D. The design concept investigated through this research builds on my past practice in the field of printed garment design (1.2). Working with fabric and form provided me with tacit knowledge of how surface pattern can be transformed when it is converted into a 3D garment shape and articulated on the form. A printed garment can also have a considerable influence on the way that a body is articulated through particular clothing styles. This research proposes that the influence of this $2 D$ to $3 D$ conversion process can be anticipated within the designing process, through the engineering of imagery in three dimensions. This radical design concept challenges existing textile practice by consciously addressing the notion of form as a prerequisite of the designing process.

I have chosen to focus on the female form and its relationship to cloth and print. The form represents a set of contoured surfaces that act as an armature for the designing and modelling process. Cloth is the central catalyst; used to originate design ideas and generate design outcomes. Cloth is used to iterate the female form in order to create textile designs based on the notion of manipulating cloth to enhance, describe and/or transform the female shape. Print is conceived as a surface rendering for cloth, created and engineered in such a way that it strategically enhances fabric in both two and three dimensions.

\subsection{AESTHETIC INSPIRATION}

My perception of the form as an articulator of cloth and image has been strongly influenced by photographic images of the female body swathed in drapery. These images stem from antique notions of beauty as exemplified through classical Greek sculptures of draped female figures (Figs.1-F \& 1-G). In Seeing through Clothes, Anne Hollander (1978: 11) discusses the fact that sculptures of male subjects were often depicted completely naked, whilst female figures were usually dressed:

The hidden archaic female body, on the other hand, a more static and simplified shape, was inseparable from its formal garments, somehow incapable of energy without drapery. It is this female body, by custom requiring a concealing dress that made drapery a sculptural necessity for the Greeks.

Stylistic links can be made between the 'sculptural' model, defined through this research and classical drapery (3.2). Early Greek dress was based on the chiton, a rectangle of cloth fastened at the shoulders, which the Greeks draped to express their 'individuality, nobility, virtue, morality, sexual allure', and because the cloth was arranged anew every day, the ways in which all the conventions could be broken and made personal were never ending (Westwood in King 1996). The complexity of the 

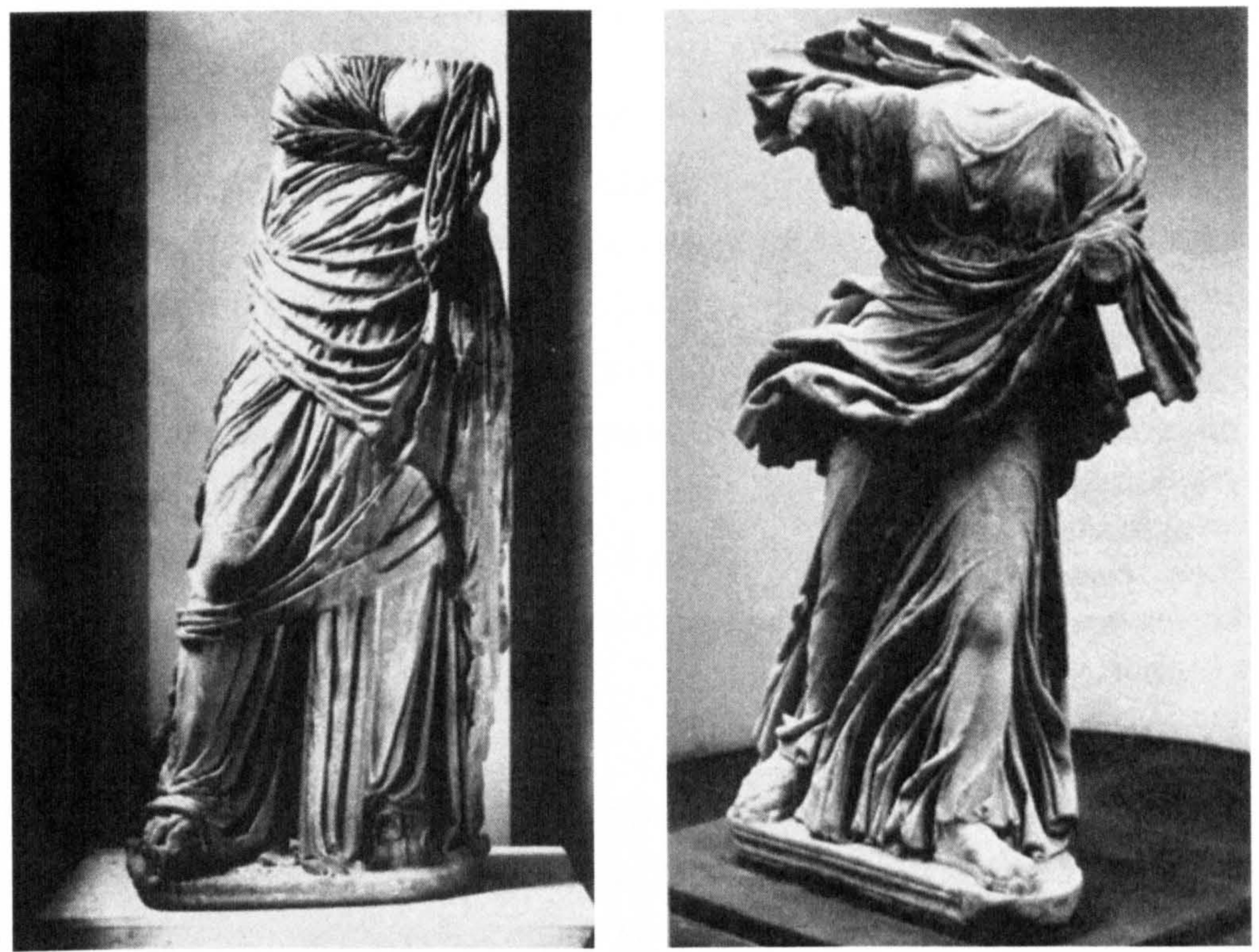

Figure 1-F Apollodaurus of Phocaea second century B.C. (Hollander 1978)

Figure 1-G Running Niobid early 3rd century B.C. (Hollander 1978) 
patterning achieved through the manipulation of the chiton is analogous to the deep psychological permutations of Greek mythology, where the Gods provided a pattern for everything that could happen in life. ${ }^{21}$ The fascination with Greek dress has continued to be evidenced through the history of fashion, as Hollander states:

The first drapery that Western civilisation fell in love with was the Greek drapery that was made to look as if it behaved the way that cloth naturally does. Some ideal of naturalness was invented for the drapery by these Greek sculptors and it starts with fairly decorous folds, folding in ways that fabric folds (Quoted in King 1996).

Hollander's observation highlights the Greeks strategic use of the chiton to heighten the illusion of draped cloth on the form. Historians of Art and Fashion assume that a 'film of moisture' was actually applied to the chitons of models posing for the Greek sculptors, as the cloth describes the contours of the wearer so accurately. In 1996 Vivienne Westwood investigated this concept by wetting the draped chiton on the body, to prove that this was the only way such drapery could have been achieved. John Galliano employed the device in his Fallen Angels (1985/6) collection, when he dampened semi-transparent, white muslin dresses fashioned in the Directoire style (Fig. 1-H), his objective being to appreciate the beauty of flesh moving behind 'a film of gauze' (Evans and Thornton 1989: 70).

The fluid characteristics of particular fabric qualities ${ }^{22}$ are often compared to the flow of water, as defined in phrases such as 'liquid drapery' and 'flowing robes' (3.2). Artistic associations between water, cloth and the female form stem also from Ancient Greece, when the personification of flowing water was the river goddess Isis:

...her garment seemed made of a film of moisture issuing from her body. In other words, if the great leaning river gods represented, symbolically, the force and horizontal flow of the river, the open vase of the water nymph and the robe of Isis represented the fertile copiousness of the Source (Schama 1996: 370).

The idea of the female shape being defined through drapery has been employed by artists to imbue subjects with drama and invoke the style of antiquity (Ribiero 1999). The Baroque period was suffused with swathing draperies and fantastic curves; 'an art of dynamic movement, emotional display, swooning saints ${ }^{23}$ in spiritual and somatic rapture, all expressed through the agency of the fold' (Barnett 1998: 27).

\footnotetext{
${ }^{21}$ According to Vivienne Westwood, 'the Greeks felt superior to barbarians because they were always in touch with their bodies through the cloth that caressed it.'

${ }^{22}$ Such as; silk crepe, satin and jersey.

${ }^{23}$ Bernini's St Teresa incorporates dramatic drapery that has a life beyond the body.
} 

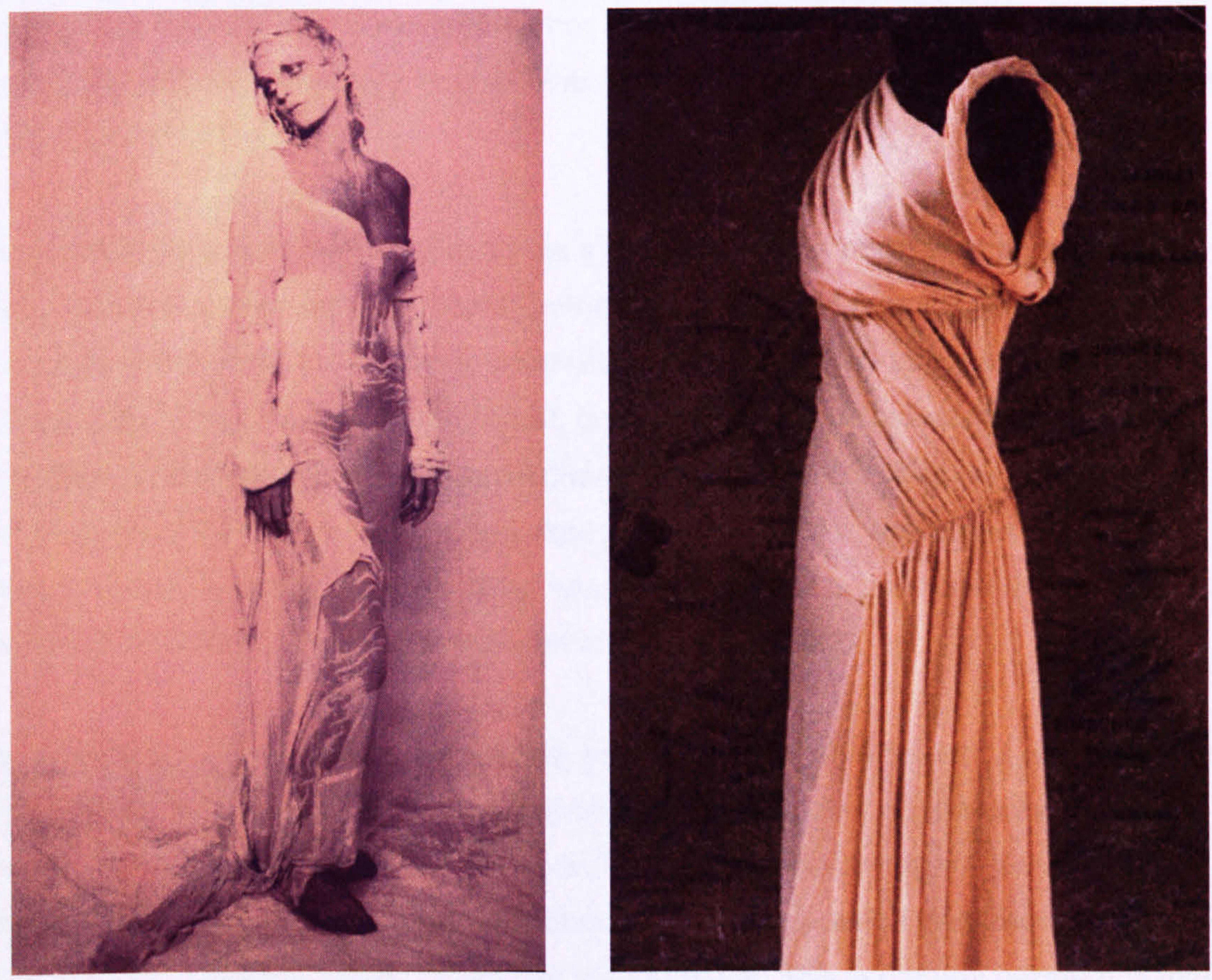

Figure 1-H John Galliano 1986: Fallen Angels (Biennale di Firenze 1996)

Figure 1-I Vionnet: Dress for Winter 1933/4 (Dormonex 1991) 
In painting fashion, drapery has been employed similarly, to create sensual, often sensational visual interpretations of the form, and to explore the elusive boundary between dress and undress. The French couturier Madeleine Vionnet created some of the most fluid garments of the last century; her modern interpretations of classical drapery from the 1920s and 30s have provided artistic inspiration for this research (Fig.1-I). Other, more recent interpretations can be identified in the practice Romeo Gigli, Gianni Versace and the Greek-born designer, Sophia Kokoslaki (3.2), who lists Vionnet, St. Laurent and Kawakubo as her heroes (British Elle 2001). As well as producing her own classically inspired line, she designs for the directional Italian label, Ruffo Research (Fig.1-J).

The interpretation of classical drapery as a modern fashion phenomenon began in 1907, when the artist/designer Mario Fortuny introduced his famous Delphos. The garment was inspired by the Doric sculpture of the Delphi Charioteer and was constructed along the lines of the chiton, consisting of two pieces of cloth joined at the shoulders and sides. The most revolutionary aspect of the Delphos was the way in which Fortuny translated the sculpted drapery into a series of tiny pleats to form the body of the silk garment. The resulting tubular structure was permanently pleated, requiring no further manual manipulation of the drapery (3.2).

Issey Miyake's Pleats Please collections, produced from 1990 onwards, are fashioned along similar lines to the chiton and Delphos, in micro-pleated polyester, which interacts differently with the form than silk. ${ }^{24}$ Another piece by Miyake, Heat Molded Dress (1991) illustrates how synthetic fabric can be manipulated and treated to articulate the underlying form. As shown in Figure 1-K: 'this sculptural garment is made of iridescent nylon, which has been molded by heat, the shape is achieved without cutting or sewing' (Braddock and O'Mahony 1994: 19). The use of dramatic light and shade, known as 'photographic chiaroscuro', heightens the sculptural appearance of the piece. This style of fashion imaging developed out of photographic surrealism, which was first used extensively in the 1920s to aesthetically render architecture and sculpture. By the 1930s photography had virtually replaced fashion illustration to become the new form of fashion art (Hollander 1994: 155).

The Surrealist artist and photographer Man Ray produced some of the most striking fashion images of the period using a variety of lighting and processing techniques to produce arresting images of the female form dressed in light, fabric and couture

${ }^{24}$ A Pleats Please garment does not cling to the body in movement, but forms concertina-style shapes away from it. 


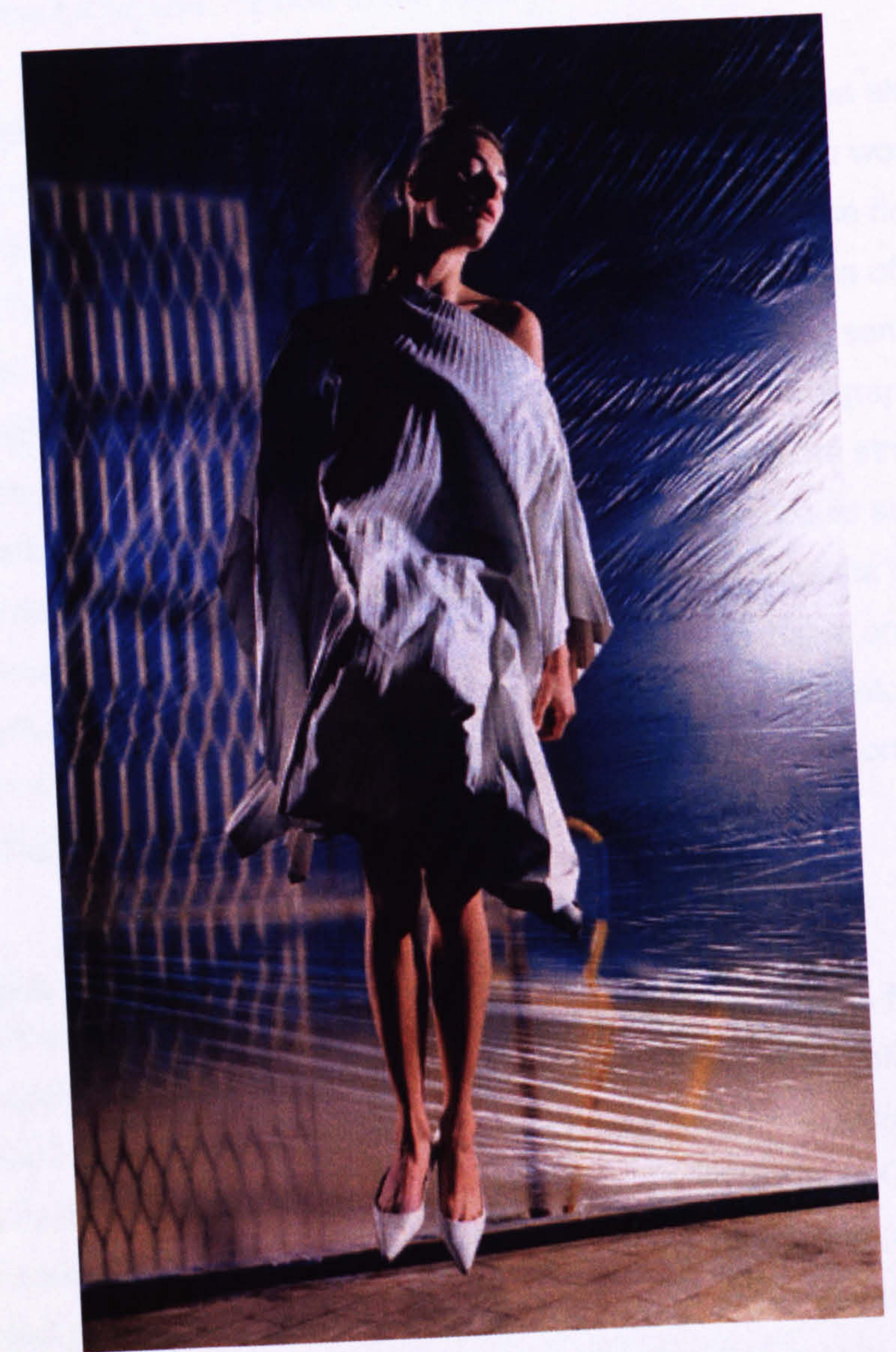

Figure 1-J Ruffo Research 2003: Pleated leather dress (Harpers and Queen 2003) 
garments. ${ }^{25}$ Man Ray recognised the potential of light to render the form in new ways which he expressed in 1928 by saying; 'we need to use light now... it is light that I create' (Brandon 1999: 188). 'Black Dress' (1934), also referred to as the 'Cellophane Dress' (Fig.1-L) illustrates how the artist sculpted the body in light to create the impression that the fabric was melded to the form.

The complex, draped styles of designers such as Vionnet and Alix Grès also provided perfect subject matter for Man Ray, Horst and Honygen Heune, whose work represents a 'high moment in modern feminine fashion' (Hollander 1994: 159). The dramatic manipulation of light on 1920s and 30s costume resulted in new visions of the clothed female form that combined Greek goddess with Hollywood siren. The sense of mystery conveyed through these images is still sought by contemporary photographers, such as Patrick Demarchelier and Michealangelo de Battista who both explore strong contrasts of light and shadow in their work, and Sean Ellis (Fig.1-M) who creates surreal effects by digitally rendering the garment on the model (Surface 2002). Battista captures images of women that emphasises the idea that they are untouchable and achieves supernatural effects by combining analogue photography with digital retouching methods (Fig.1-N). In 'And birds do sing' ${ }^{26}$ he explored the notion of women as fragile light, 'like the flight of a bird back-lit by a sun filled sky' (Kim 2002).

\subsubsection{Not Made By Hand}

The notion of the body's ability to leave its mark on another material is fundamental to the human experience. Two of the most well known examples of this phenomenon are the Turin Shroud and Veronica's Cloth. Known in Greek as archeiropoietos, meaning 'not made by hand', these historical textiles (are believed to) testify to Christ's actual presence on earth through his interaction with specific pieces of cloth (Kuryluk 1991:

1). The inverted graphic image of a man's head and body, presented by the Turin Shroud is particularly interesting from a 'print' perspective. The creation of imagery based on impressions of the body has been explored through many examples of fine art practice, including Yves Klein's 'human brush' paintings of the 1960s featuring prints of the female form. The Cuban artist Ana Mendieta's created concave sculptures based on impressions of her own body in mud (Chicago and Lucie Smith 1999: 22). The growing use of DNA sampling in forensic science provides evidence of the body's physical presence in a material context, an idea explored through a printed 'art textile' context by the fashion designer Helen Storey, in the exhibition Primitive Streak (1997).

\footnotetext{
${ }^{25}$ Man Ray's career as a fashion photographer began in the early 1920 s following an introduction to Paul Poiret by Frances Picabia, when he was given carte blanche to take whatever photographs he wanted. Whilst developing the images he accidentally came across his 'rayograph' technique (Brandon 1999: 188). ${ }^{26}$ 'And birds do sing' was an 18 page feature in Rebel Magazine AW 2002.
} 

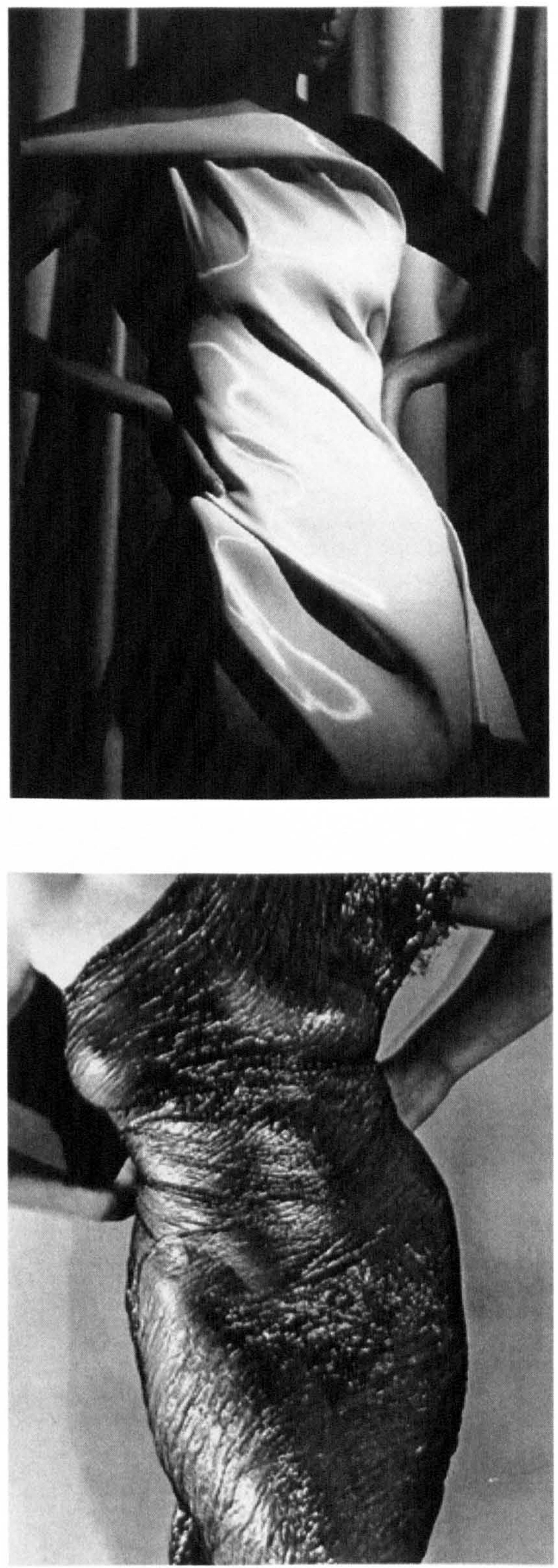

Figure 1-K Issey Myake 1991: Heat Molded Dress (Braddock and O’Mahony 1994)

Figure 1-L Man Ray 1934: Black Dress (Vanci-Perahim 1999) 

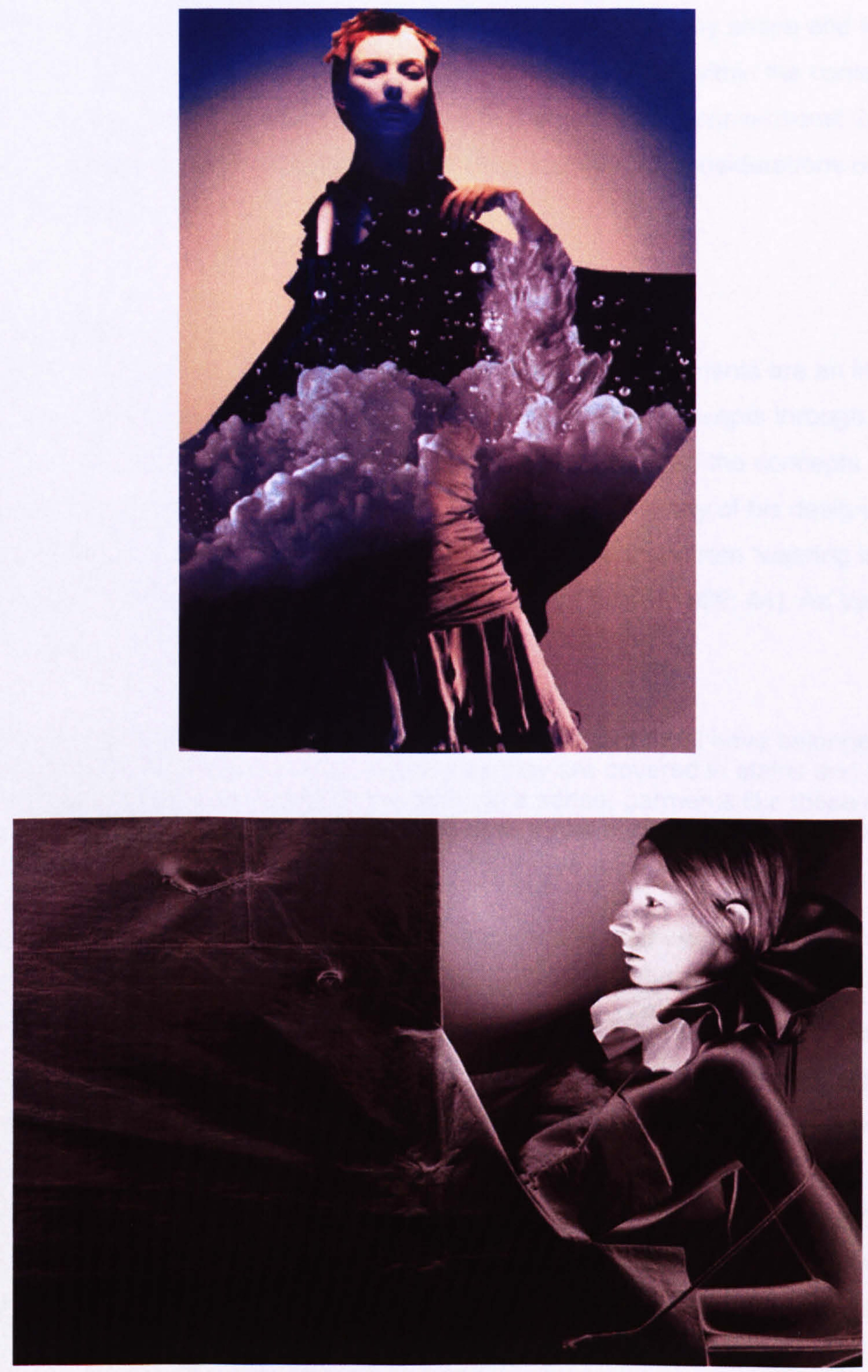

Figure 1-M Sean Ellis 2002: Dreamweaver, jersey top by Hugo Boss, layered skirt by Raphael Lopez (Surface 2002)

Figure 1-N Michelangelo de Battista 2002: Grace (www.managementartists.com 2003) 
The idea of creating patterns based on the unique association of the body with cloth presented an intriguing design possibility for the research, whereby shape and form, as well as body measurements, could be implemented as catalysts within the context of contemporary textile design. The idea represented a shift from a conventional $2 D$ design emphasis, based on body or garment 'size' towards 3D considerations of body and garment 'shape'.

\subsubsection{The Notion of Wear}

The markings associated with the physical 'wear and tear' of garments are an integral aspect of material culture and have been pursued as creative concepts through 'deconstructed' design. For the fashion designer Dries Van Noten the concepts of age and aging are as important as borrowing from history. While many of his designs reference styles from the past, it is the patina of age that comes from 'wearing in' a garment that is integral to the designer's artistic vision (Tucker 1999: 44). As Van Noten states:

One of my favourite things is a pair of old work pants that must have belonged to someone working in the chemical industry as they are covered in stains and so worn that they follow the shape of the body. In a sense, garments like these are more precious than anything else, as they have a real personal history (Quoted in Tucker).

Other designers who have explored the notion of wear in their work are Hussein Chalayan and Martin Margiela. Chalayan's infamous Buried collection explored the concept of erosion, by burying garments with iron fillings (Fig 1-O). The exhumed items evidenced their treatment through beautiful rusted patterns that permeated the pieces (3.8). During the 1990s, Margiela's collections regularly featured items of second-hand clothing, transformed with a print or re-made through a unique process of 'deconstruction and reproduction' (Evans 1998: 75). In 1997 he collaborated with a microbiologist to create the installation '9/4/1615', where conceptual garments were treated with mould spores, which were cultivated on the garments and became their embellishment (Fig 1-P).

\subsubsection{Wrapping the Form}

The process of wrapping and un-wrapping the form in cloth can be perceived as symbolic in various ways. The aesthetic articulation of the female form through cloth is central to this creative enquiry. In the practice the female form has been replicated by a dressmaker's mannequin comprised of a 'torso' on a stand (2.2.4). As Edward LucieSmith observes, 'the torso, deprived of head and limbs - that is, of the power of either 

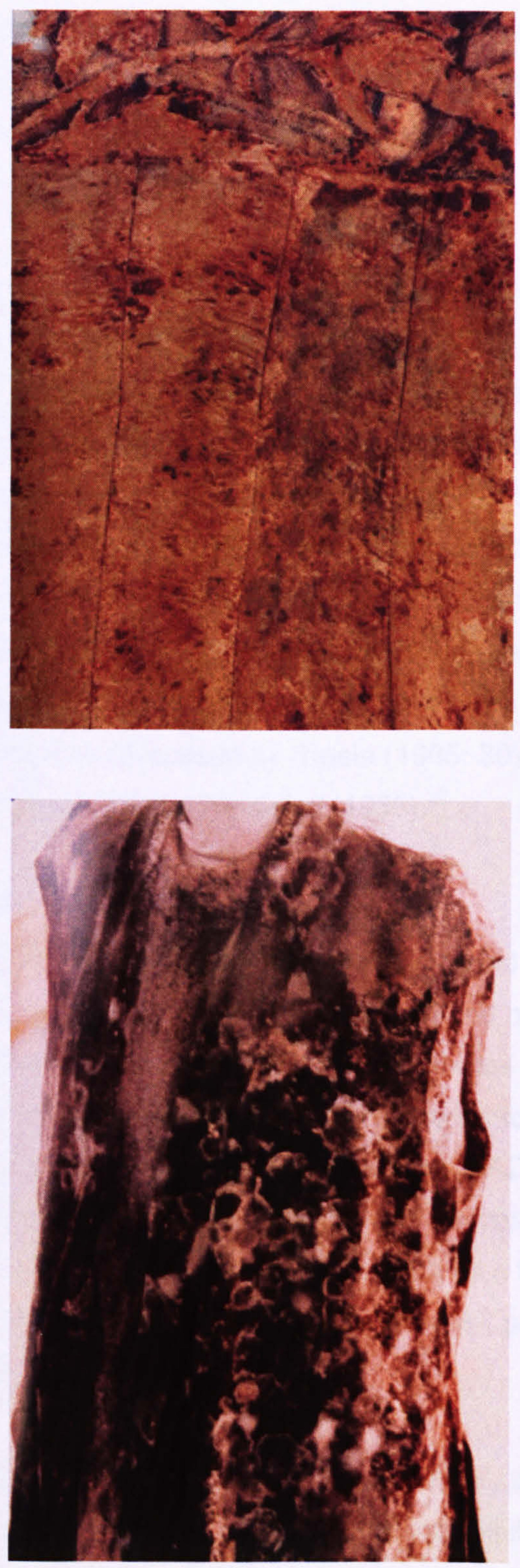

Figure 1-O Hussein Chalayan 1995: Section of Buried Dress (Braddock and O'Mahoney 2001)

Figure 1-P Martin Margiela 1997: Garment embellished with mould from the '9/4/1615' exhibition (De Givry 1998) 
thinking or acting - has played a prominent role in the way women have been represented in art' (Chicago and Lucie-Smith 1999: 140). However, I wish to clarify that my use of the torso is related to aesthetic and practical design issues, as I wanted to work directly with the form but was unable to do so, due to the method of 3D image capture employed in the research (5.4).

The wrapping of cloth and materials around the form, to create sculptural textiles (6.3) raises parallels with some of Caroline Broadheads work. In the exhibition Bodyscape, Pamela Johnson (1998: 21) described the development of Broadhead's work as a process of 'circling and orbiting of the body'. This concept is particularly evident in one piece, Web (1989) where the presence of the form is signified by a wire armature covered in strips of fabric (Fig.1-Q). Like Broadhead, my use of a wrapping action celebrates the shape of the female form both physically and symbolically, through fabric. The wrapping action employed within this practice is essentially decorative in function, representing a gesture of visual description that is not to be confused with the theme of feminine restriction as discussed by Steele (1985: 30). and explored photographically by Man Ray in Venus Restored (1936). ${ }^{27}$

\subsection{THE METHODOLOGY}

The interdisciplinary nature of this practice-led investigation led to a research approach that encompassed historical, contextual, interview, action and practice-based research methods. ${ }^{28}$ The approach was underpinned by current debates and outcomes in the fields of CAD for fashion and textiles. Conferences dedicated to art and design research such as Computers in Art and Design Education (CADE) and the European Academy of Design (EAD) provided valuable insights into recent developments in practice-led research. The model that I found most useful as a framework for the research was based on Le Grice's theory of 'critical, general, parallel and generative' methods (Le Grice ${ }^{29}$ in Briggs 1997: 15).

The literature search focused on the aspect of 'critical theory', by contextualising printed garment design through past and existing practice. While I found many publications related to 'costume' and 'textiles', there were few dedicated to the specific area of 'printed fashion'. It was therefore necessary to research this subject area through historical and contemporary texts related to art, design and manufacture.

\footnotetext{
${ }^{27}$ In Venus Restored (1936), Man Ray used rope to 'imprison the feminine image.' Swartz, A. Man Ray: The Rigour of Imagination, London: Thames \& Hudson, 1977, p. 171.

${ }^{28}$ See Appendix 2 for a list of Related Studies that were undertaken for this research.

${ }^{29}$ See Le Grice, M. (1988) The place of theory in practical art and design, in Bougourd, J. and Gronberg,

T. (1988) The Matrix of Research in Art and Design Education, London: CNAA and the London Institute.
} 


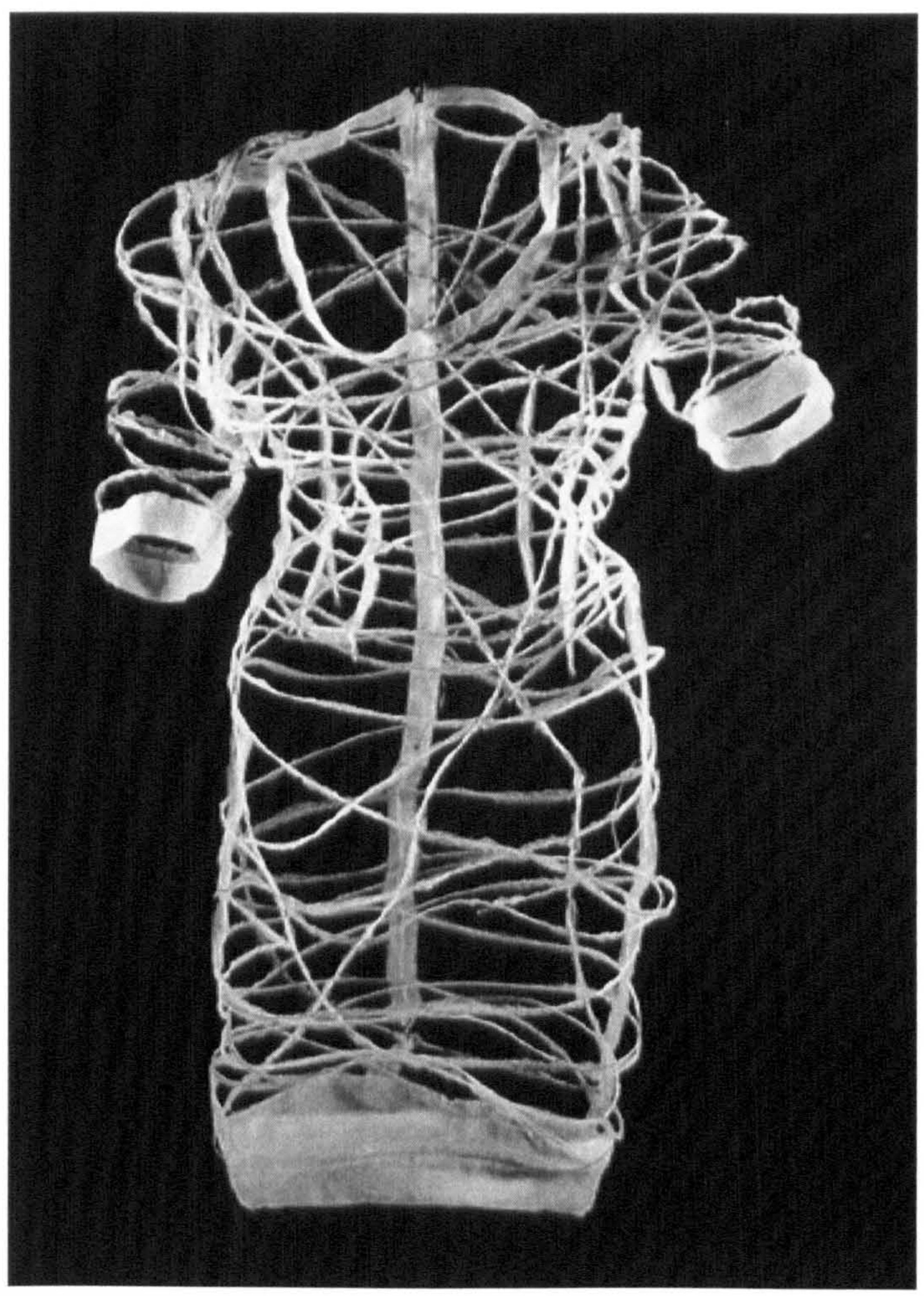

Figure 1-Q Caroline Broadhead 1989: 'Web’ (Colchester 1991) 
The historical enquiry concentrated on practice and artefacts dating from the late $1880 \mathrm{~s}$ to the early 2000s that demonstrated an 'integrated' or 'simultaneous' approach towards fashion and textile design through the aesthetic combining of cloth, print and the body. The contemporary enquiry concentrated on research into the way in which designers created printed garments using CAD. However, detailed information was fairly limited and in order to compile a general theory, or overview of the influence of $C A D$ on printed garment design, l interviewed a series of expert practitioners working in the fields of fashion, textiles, and CAD/CAM technology. Consequently, designers working for high street, independent, and ready to wear clothing labels answered questions relating to integrated methods of practice. Design consultants working with $C A D$ and digital printing technology provided case studies that evidenced of the influence of these new technologies on the design and production of printed textiles and garments. Overall the interviews highlighted the limited exploitation of CAD by textile and garment designers, which informed Chapter 4.

During the PhD process (1998-2003) there was an increase in practical research outputs, which enabled me to carry out 'parallel' investigations into the 'hybrid practices' of other design researchers. Contact with other users of CAD technology working in fashion, textiles, art, graphics and industrial design provided examples of innovative practice through the use of 'appropriate digital technologies' (Beardon 2000). The 'generative' aspect of the research was based on my practice, which was focused on the study of a 'singularity', defined by Bassey (1995: 111) as:

...a set of anecdotes about particular events occurring within a stated boundary, which are subjected to a systematic and critical search for some truth. The search for truth will seek answers to some research questions, maybe a research hypothesis that is being tested, or a research problem that is being probed, or a research issue that is being explored.

The particular circumstances of the singularity were to utilise integrated software and digital printing technology provided for the fashion and textile design industry (1.5), alongside manual methods of working, to explore new ways of integrating printed textiles with garment shapes (1.4). The research sought to make a contribution to new knowledge in the area of printed textile and printed garment design through creative, experimental research, based on the principle of 'design as reflection in action' 30 (Schon 1983). Manual and CAD methods were combined through the development and testing of a simultaneous, 3D method of printed garment origination that synthesised

\footnotetext{
${ }^{30}$ Generally referred to as 'reflective practice', discussed in the forthcoming paper by Glanville, $R$. and Schiak, L. (2003) Designing reflections: Reflections on Design, in Durling, D. and Sugiyama, K. Proceedings of the Third Conference of Doctorial Education in Design, 14-17 October 2003, Japan: University of Tsurkuba
} 
'analogue and digital practices. ${ }^{31}$ Although the theoretical research, dealt with in Chapters $1-4$ and the practice detailed in Chapters 5-7 could possibly work as independent studies, within this thesis they are viewed as integral components of a single study (Newbury 1996, Briggs 1997).

\subsection{THE CHAPTERS}

The thesis is arranged in eight chapters. Chapters 1-3 cover the theoretical, historical, contextual and practical background of the thesis. Chapters 5-7 are dedicated to the practical aspect of the research. Chapter 4, which deals with CAD technology for textiles and clothing, acts as a bridge between the theoretical and practical areas of focus. Chapter 8 deals with the Conclusions drawn from the project.

In Chapter 2, which is entitled 'On the Dress She Wears a Body', I consider the three areas that inform printed garment design: the body, cloth and print. I begin by discussing the role of the body as a fashioned form. In Western societies the form is fashioned according to many social codes and practices, and debates around this theme are acknowledged (2.1). The chapter takes an historical approach towards modern shaping, which is considered by this research to have evolved from the rectangular shaping strategies of the 1920s that embraced the principles of Cubism and facilitated mass-production (2.1.1). The ways in which the form has been articulated through key silhouettes are discussed (2.1.3). The varying approaches taken by the couture, mass clothing and independent design sectors of the fashion industry towards the body are considered in 2.2. The role of the mannequin as both a purveyor of the fashionable ideal and as a focus for the practical element of the research is clarified at the end of the section (2.2.4).

The poetic and practical dimensions of cloth are explored in 2.3. The capacity for 'fabric to determine form' is discussed in 2.3.1, from the perspective of both garment and wearer. The influence of stretch fabrics on modern shaping is recognised as a pivotal event in the emergence of the form as the articulator of contemporary fashion. The relationship of print, to body and cloth is considered; traditionally as an embellishment, and currently, as a positive contributor to body image. Ultimately, Chapter 2 places the form as central to the practical focus of the research.

Chapter 3 focuses on the theoretical and contextual basis of the research, which is where the initial enquiry was focused. The concept of garment spatiality as an informer

${ }^{31}$ For an in-depth account of the development of digital design practice, see McCulloch, M. (1997) Abstracting Craft: The Practiced Digital Hand, London: MIT Press 
of surface print is considered, as raised through the practice of the Constructivist artist Luibov Popover (3.1). The chapter proposes the existence of three archetypes: 'sculptural' (3.2), 'architectural' (3.3) and 'crossover' (3.4) garments, and the association of surface embellishment that is aesthetically appropriate to these forms. The research also identifies and discusses historical and contemporary approaches such as: 'textile-led' (3.5), 'garment-led' (3.6) and 'simultaneous' (3.7) design, which present a range of aesthetic considerations. The 'simultaneous design' approach, which is rooted in the practice of Sonia Delaunay, is regarded by the research as the most relevant method for approaching contemporary printed garment design.

Chapter 4, 'The Limited Exploitation of CAD by Printed Garment Designers' seeks to uncover why printed garments have continued to be designed from a 'separate sphere perspective', despite advances in integrated CAD/CAM. The chapter discusses the characteristics of CAD textile and computer graphic software and how the creative use of such design technology is generally dictated by the requirements of the clothing industry and/or the parameters of the available software (4.1). The use of similar CAD software by independent designers has resulted in three-dimensional visual qualities that have yet to be explored fully within the context of printed garment design. Pattern design systems (4.2) are becoming more pre-disposed towards a couture approach, as body scanned data is integrated into garment design. The research recognises that a greater consideration of 'shaping over sizing' issues could have ramifications for integrated print.

Section 4.3 assesses the potential for combining textile designs with pattern shapes using integrated CAD. The use of integrated software in association with digital printing (4.4) technology presents considerable advantages for designers to visualise, sample and produce printed garments on a short-run basis. The section makes a comparison between the potential of this technology and its limited realisation throughout the industry. The chapter ends by discussing hybrid approaches to CAD, which explore computer software from different garment-led, textile-led, and customer-led perspectives (4.6). The discussion of different CAD technologies and approaches sets the scene for the practical element of the research, which commences in the following chapter.

Chapter 5 documents the initial, experimental stage of the practical research. The first section elucidates on the intention to take a 'holistic approach to print and cut' (5.1) through the combining of manual and CAD technology. An experimental approach is adopted towards a range of methods of print/garment integration including $2 D$ digitising 
(5.2) and the 3D modelling of paper dresses (5.3), the latter becoming a key informer of the future practice. Manual (5.4) and digital (5.5) mark making strategies are explored and compared, leading to the synthesisng of both mediums to undertake the task of print/garment integration (5.6). In Modelling With Light (5.7) elucidates upon the adaptation of the cyanotype process into a method of 3D image-capture. The creation of the first cyanoform, Ribbon Tunic is the turning point in the practice. The use of CAD and digital fabric printing to translate the manually modelled blueprint into a garment prototype is documented in 5.9 .

Chapter 6 begins by discussing The Synthesising of CAD and Manual Design Methods; the concept of digital craft is explored as a relevant approach towards combining existing and new CAD technologies. In 6.2, The Simultaneous Design Method, as devised by this research, is documented. The ensuing sections describe, analyse and reflect upon the taking a simultaneous approach towards two collections of crossover garment shapes, one with a sculptural (6.3) and the other with an architectural bias (6.4). The pieces are evaluated to assess how contrasting manipulations can render similar cloth shapes as different textiles.

The exhibition Transforming Shape is the subject of Chapter 7. This group project explores the concept (7.1), raised through this research, of taking a form-centred approach to the design of fashion textiles. The pieces were created in a context of reflective research and are sited as relevant examples of contemporary design practice that embrace the creative principles of art/fashion textiles (7.1.2). The choice of fundamental geometric shapes such as the circle, square and rectangle as pieces that can be mediated with the form through surface pattern is clarified (7.1.4). The exploration of the Circle (7.2) involves the integration of pattern and movement, resulting in a final piece Nautilus, which illustrates the possibility for enlisting print to define the form sculpturally. The Square (7.3) is rotated and integrated with imagery that accentuates both the fluidity of the garment and the underlying contours. Finally, the Rectangle (7.4) explores the parameters of CAD in association with digital printing, beyond those of the accepted scale of 'dress'. The outcomes are discussed as pieces that challenge existing notions of textile design, by demonstrating the aesthetic potential of print to, transform shape. Chapter 8 deals with the Contributions to New Knowledge arising out of the research and details the Further Work expected to be undertaken in the future. 


\subsection{REFERENCES}

Abernathy, F., Dunlop, J., Hammond, J., and Weil, D. (2002) A Stitch in Time: Lean retailing and the transformation of manufacturing lessons from the apparel and textile industries, Harvard Centre for Textile and Apparel

Aldrich, W. Ed (1996) CAD in Clothing and Textiles, Oxford, Blackwell Science Aldrich, W. (1990) New Technology and Clothing Design, PhD thesis, Nottingham Trent University

Another Magazine (2003) Blow, Spring/Summer 2003, p.323

Barnett, P. (1999) 'Folds, fragments, surfaces: towards a poetics of cloth', Essay in Textures of Memory The Poetics of Cloth, Nottingham: Angel Row Gallery

Bassey, M. (1995) Creating Education Through Research, Newark: Kirklington Moor Press

Beardon, C. (2000) Seminar hosted by Colin Beardon, editor of Digital Creativity, at CADE: Post-Graduate Forum, Falmouth College, Cornwall, July 2000

Biennale di Firenze (1996) Looking at Fashion, Florence: Biennale di Firenze Braddock, S. and O'Mahony, M. (2001) Fabric of Fashion, London: Crafts Council Braddock, S. and O'Mahony, M. (1994) Textiles 2010, London: Crafts Council Brandon, R. (1999) Surreal Lives, London: Macmillan

Briggs, A. (1997) A Study of Photographic Images, Processes and Computer Aided Textile Design, PhD thesis, The Nottingham Trent University

Briggs, A. and Bunce, G. (1995) Breaking the Rules: Innovatory Uses of CAD in Printed Textiles, Ars Textrina, Vol. 24, p.187

British Elle (2001) Sophia Kokoslaki: My Inspiration, London: Hatchette-EMAP Magazines Ltd., June, p. 191

Bunce, G. (1999) CAD and the role of the printed textile designer, CADE99, 7-9 April, University of Teeside, published in conference proceedings, pp. 59-65

Bunce, G. (1996) The Unexploited Potential of New Technology for Repeat Pattern Innovation in Printed Textile Design, Point, No. 2, pp. 32-36

Bunce, G. (1993) An Investigation into the CAD/CAM Possibilities in the Printing of Textiles, PhD thesis, Nottingham Trent University

Chen, J. (1998) An Investigation into 3-Dimensional Garment Pattern Design, PhD thesis, Nottingham Trent University

Chicago, J. \& Lucie-Smith, E. (1999) Women and Art: Contested Territory, London: Weidenfeld \& Nicolson

Clothes Show Magazine (1990) Watertight, April/May issue, p.89

Colchester, C. (1993) The New Textiles: Trends and Traditions, London: Thames and Hudson

Company Magazine (1990) Shake it up Baby, November 1990, p. 50 
Crawford, A. (2003) Satisfying Consumer Demand, Seminar, Seminar held by The Textile Institute, Leicester, 6/3/03

Cunningham, R. (1998) The Russian Women Artist/Designers of the Avant-Garde, TD \&T, Spring

Dormonex, J. (1991) Madeleine Vionnet, London: Thames and Hudson

Fearon, F. (1997) Cutting Edge Exhibition, World Clothing Manufacturer, May, pp. 4647

Fer, B. (1998) The Pleasure of Cloth, Essay in Liz Rideal: New Work, Exhibition catalogue, Angel Row Gallery, Nottingham, 30/5/98 - 4/7/98

Damase, J. (1991) Sonia Delaunay: Fashions and Fabrics, London: Thames and Hudson

Davies, J. and Tilley, E. (2003) The Design Café: A new approach in the textile industry, Journal of the Institute of Management Services, March

De Givry (1998) Art and Mode: I'inspiration artistique des creators de mode, Paris:

Editions du Regard

Evans, C. (1998) Martin Margiela: The Golden Dustman, Fashion Theory, Vol 2, Issue 1, pp. 73-94

Evans, C. and Thornton, M. (1989) Women and Fashion: A New Look, London: Quartet Books

Fashion Weekly (1989) One to Watch, 16 Feburary, p. 26

Gerrard, B. and Bell, S. (1998) The Fashion Designer in the Technological Workplace, Digital Creativity, Vol 9, No. 2, pp. 91-100

Harpers and Queen (2003) Birdsong, styled by Alison Edmond, photographed by Ralph Mecke, pp. 100-108, June issue

Hollander, A. (1998) Sex and Suits: The Evolution of Modern Dress, Brinkworth:

Claridge Press

Hollander, A. (1978) Seeing Through Clothes, New York: The Viking Press

Johnson, P. (1998) Bodyscape: Caroline Broadhead, Exhibition catalogue, Nottingham: Angel Row Gallery

Kim, Y.A. (2002) An Interview with Michelangelo Di Battista, Fashion Photographer, Apogee Photo Magazine, September 2002

King, C. prod. (1996) Painted Ladies: Nobility, Virtue and Morality, presented by Vivienne Westwood, Channel 4, Diverse

Kuryluk, E. (1991) Veronica and Her Cloth: History, Symbolism, and Structure of a "True" Image, Oxford: Blackwell

Leak, A. (1998) A Practical Investigation of Colour and CAD in Printed Textile Design, PhD thesis, Nottingham Trent University 
Le Grice, M. (1988) The place of theory in practical art and design, in Bougourd, J. and Gronberg, T. (1988) The Matrix of Research in Art and Design Education, London: CNAA and the London Institute

McCulloch, M. (1997) Abstracting Craft: The Practiced Digital Hand, London: MIT Press

Mendes, V. and De La Haye, A. (1999) $20^{\text {TH }}$ Century Fashion, London: Thames and Hudson

Newbury, D. (1996) Knowledge and Research in Art and Design, Design Studies, Vol.7, no.2

Phillips, P. and Bunce, G. (1993) Repeat Patterns, London: Thames and Hudson Pötz, T. (2002) Inkjet Printing: Present situation and prospects, International Textile Bulletin, No.5, October

Primitive Streak (1997) Catalogue for international 1997-99 touring exhibition, designed by Helen and Kate Storey, sponsored by Phzer, New York and London Ribeiro, A. (1999) Muses and Mythology: classical dress in British eighteenth-century portraiture in Wilson and De La Haye (1999) Defining Dress Schama, S. (1996) Landscape and Memory, London: Fontana Press Steele, V. (1985) Fashion and Eroticism, New York: Oxford University Press Surface (2002) Dreamweavers, photographed by Sean Ellis, Issue No. 39 Swartz, A. (1977) Man Ray: The Rigour of Imagination, London: Thames \& Hudson Townsend, K. (2000) Integrated Design: From Delaunay to Digital, Tucker, A. (1999) Dries Van Noten: Shape, Print and Fabric, London: Thames and Hudson

Watkins, P. (1999) The Appliance of Science, International Textiles, No. 806, Aug/Sept, pp. 17-20

Wentzel, B. (2002) Sampling the benefits of digital printing, Fashion Business International, 5/12/02

Vanci-Perahim, M. (1999) Man Ray, New York: Harry N Abrams

\section{Websites}

http://www.belfordprints.co.uk

http://www.cat@gsa.ac.uk

http://www.lectra.com

http/l:www.managementartists.com

http://www.tc2.com

http://www.tukatech.com 


\section{Chapter 2. On The Dress She Wears a Body}

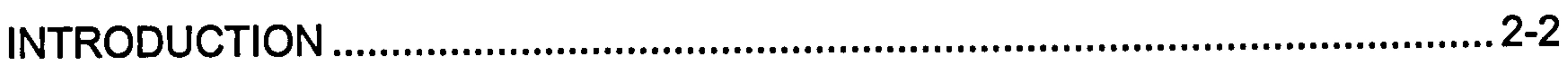

2.1. THE FASHIONED BODY ............................................................. 2-2

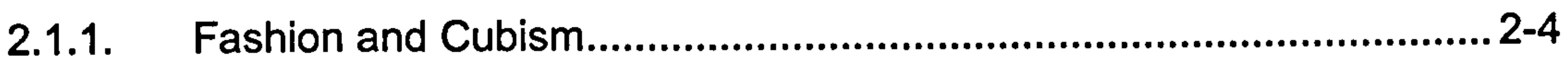

2.1.2. Ready to Wear Design Issues ........................................................... 2-7

2.1.3. The Changing Silhouette in the $20^{\text {th }}$ Century ......................................2-9

2.2. CONSIDERATION OF THE BODY .................................................... 2-17

2.2.1. The Mass Clothed Body ................................................................... 2-17

2.2.2. The Haute Couture Body .................................................................. 2-19

2.2.3. The Designer Body..................................................................... 2-20

2.2.4. The Role of the Mannequin .......................................................... 2-20

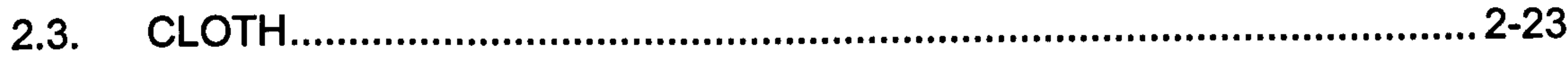

2.3.1. Fabric Determines Form ............................................................. 2-26

2.3.2. The Influence of Lycra on Garment Shaping..................................... 2-28

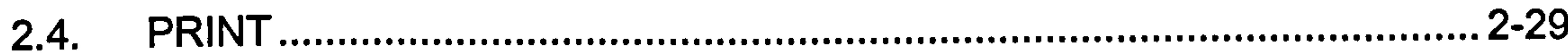

2.4.1. Printed Dress Fabrics .................................................................. 2-31

2.4.2. Print Design Structures.................................................................. 2-33

2.4.3. Print and Body Image .................................................................... 2-34

2.4.4. The Case for Fashioning the Form in Print ....................................... 2-36

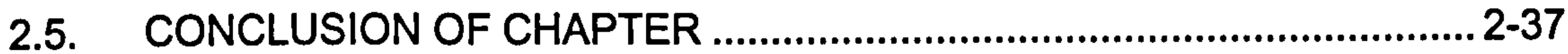

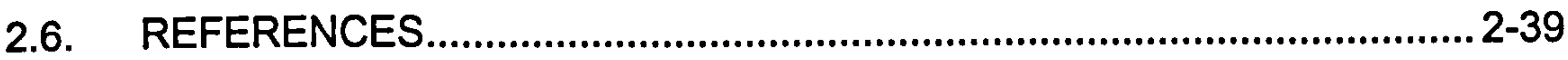




\section{INTRODUCTION}

Blaise Cendrar's poem for 'Mme Delaunay" of 1914 begins with the line: 'On the dress she wears a body' (Damase 1991: 8). For me, this encapsulates the role that printed garments play within this research. Delaunay recognised early on that surface print could be employed to iterate both garment and form. Computer aided design can integrate the once separated practices of textile and garment design, enabling practitioners to adopt a simultaneous approach, that anticipates the effect of print on garment, and printed cloth on form, prior to the production process. In sympathy with Delaunay's approach, this research considers surface print as an aesthetic device that can enhance, define and re-define the female form that wears it.

The chapter begins by exploring some of the critiques that have been made with regard to the fashioning of the female form, as a way of introducing the aesthetic relationship between clothing and body that is sought through this research. The chapter continues by tracing the beginning of modern fashion to the early part of the twentieth century, when Cubism influenced the way that pictorial space was represented in art, fashion and textiles. The shift from $3 D$ to $2 D$ conceptions of pattern and form resulted in the flattening of the garment silhouette and streamlining of the female form, which became articulated by a soft cylinder of cloth based on a rectangle. Designers like Sonia Delaunay combined the simplified shaping with new surfacing strategies, which fueled the start of ready-to-wear. The body is considered within the different forums of massclothing, couture and designer fashion. The role of the mannequin is considered to provide on the one hand a body double for the fashion system to work with, and on the other, an aesthetic ideal that is challenged by the more astute practitioners.

Cloth is considered for its ability to be transformed into a myriad of shapes and its potential to sculpt and amplify the form. The notion that fabric quality is the key determining factor of garment shape, and the influential role that Lycra has played in this area is explored. The final section of the chapter is devoted to print, where traditional and contemporary subject matter is discussed. The use of repeating, placement and engineered print structures are defined. The chapter ends by discussing the dynamic influence of print on the visual articulation and perception of the body and body image.

\subsection{THE FASHIONED BODY}

Within this research the female body is viewed essentially as a 'fashioned body', an

${ }^{1}$ See Appendix 3. 
armature on which design ideas can be attached. The body can be fashioned in so many different ways, that it is important to define the type of fashionable garment that concerns this thesis. In The Psychology of Clothes (1930: 129) Flugel identified the two main forms of clothing as 'fixed' and 'modish' (or fashionable) costume. To summarise, fixed costume 'changes slowly in time ... but varies greatly in space' and modish costume 'changes very rapidly in time... but varies comparatively little in space'. Fixed costume is generally located within independent communities, outside the sphere of Western influence, whereas fashionable clothing predominates Western society (Barnard 1996: 12). ${ }^{2}$ Whilst this study is located within the category of fashionable Western clothing, it acknowledges the draping of the form as an enduring, universal expression of dress.

As Entwistle (2000:1) states 'fashion is about bodies'. It is a craft and a social practice centered on the articulation of the form. Whilst this study is primarily concerned with the crafting aspects of fashion design, I feel that it is important to discuss the fashioning of the body within its wider social context. To begin with the terms 'dress' and 'fashion' have many different meanings, not least to the individuals that engage with them. Flügel (1930: 129) saw clothing as a means of preserving our modesty while simultaneously exhibiting ourselves as sexual beings. While Bell (1976: 20) recognizes the power of dress to signal status, class and group affiliation, he also ultimately considers it as 'an aid to beauty' that can be used to intensify emotion.

Much has been written about the relationship between the body and dress. Entwistle and Wilson (1998: 107) note that the body is rarely viewed in unadorned nakedness, but rather as 'Art', where it can be governed by social conventions. As Hollander Hollander states (1978: 237):

Dress is so crucial to our understanding of the body, and our way of seeing the body is so determined by the fashions of the day, that representations of the naked body reproduce the shapes of those fashions and the conventions of dress in any given period.

Since the nineteenth century 'fashion and decoration' have been associated with women, leading to an investigation of the relationship between the notion of the trivial and the feminine (Carlisle 2002: 1-8). Associations between women and their desire to make themselves more attractive to the opposite sex through wearing beautiful clothing

\footnotetext{
${ }^{2}$ Recent research challenges the perception of 'fixed costume' by suggesting that non-Western dress is also influenced by changing fashions in different ways (Jackson in Wilson and De la Haye 1999).
} 
can be traced to the Bible ${ }^{3}$ and through stories of mythical characters such as Eve and Pandora (Entwistle 2000). James Laver (Quoted in Entwistle 2000) further explored this theme by suggesting that the female propensity for fashion was based on the principle of 'seduction.' This view is typical of early psychoanalytical studies into the wearing of clothes, which took a rather moralistic view, by focusing on women's somewhat irrational passion for the 'vagaries of fashion' (De La Haye and Wilson 1999: 5).

In The Language of Clothes (1981), Alison Lurie analysed clothing as a series of grammatical statements that are consciously or subconsciously made by the wearer. This view was challenged by Davis (1993) who saw clothing's role as similar to that of music: an 'undercoded' [sic] form of communication expressive of mood and personality (De La Haye and Wilson 1999: 5). Lemione-Luccioni (1983) suggests that: 'clothing draws the body so that it can be culturally visible, and articulates it as a meaningful form' (Ibid.p.6). Entwistle (2000) suggests that we use clothing as protection, which explains the choice of smart but anonymous city clothing. Crane (2000: 207) observes that: 'Postmodern fashion, does not offer women a specific identity'. Instead the 'heterogeneity of contemporary styles allows women to assume a variety of possibly contradictory identities' (Partington 1996: 205).

My concern with fashion is its ability to articulate the individual form by enhancing its physical characteristics. I consider surface print as a device that can positively contribute to this process of iteration. This study focuses on the aesthetic relationship between the female body, cloth and imagery and the possibility of creating new dialogues between these elements, "because it is the body that gives form to clothes, and it is clothes that articulate the body' (Evans and Thornton 1989: 156). ${ }^{4}$

\subsubsection{Fashion and Cubism}

At the beginning of the twentieth century a fundamental change in perception occurred within the Avant Garde. The moment of change is often pinpointed as 1907, when Picasso unveiled Les Demoiselles d'Avignon, heralding the beginning of Cubism (Fig.2-A). The naked and partially draped women ${ }^{5}$ in the picture are not treated classically at all, as both the figures and drapery are reduced to the twodimensional plane of the canvas. The new art style broke with five hundred years of

\footnotetext{
${ }^{3}$ Bell (1976: 21) uses a passage from the book of Isaiah iii, which describes the intricately detailed dress of the daughters of Zion, to illustrate this point.

${ }^{4}$ Quote based on observations of Rei Kawakubo's practice.

5 The closest prototype for this type of composition is to be found in the work of Cézanne, who had reduced forms to cones and cylinders in his earlier work. Other influences include Gauguin, El Greco, Greek vase painting, and Iberian and African sculpture (Golding 1997: 51).
} 


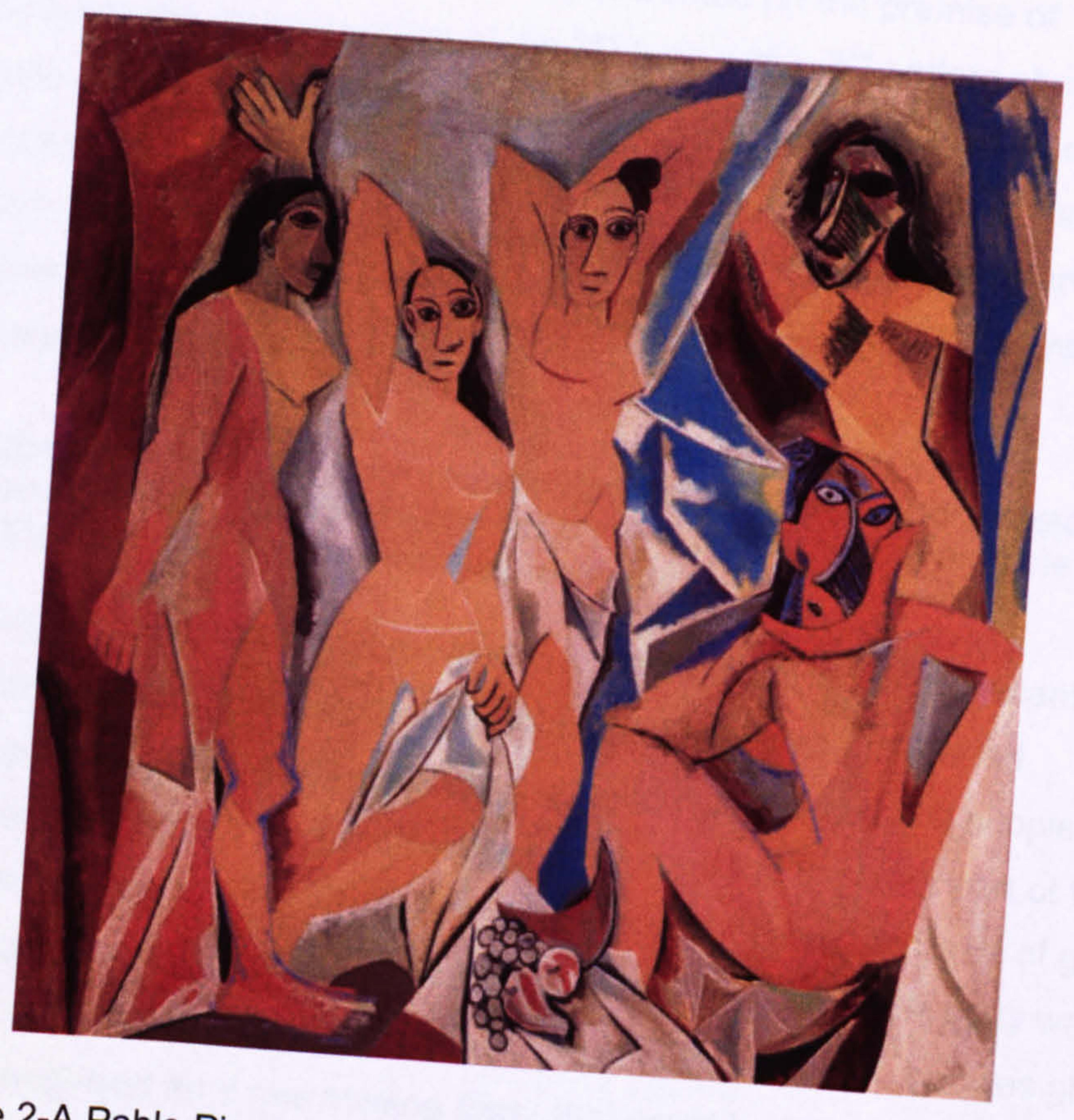

Figure 2-A Pablo Picasso 1907: Les Demoiselles d' Avignon (Martin 1998) vignon (Martin 1998) 
mathematical and scientific perspective, that had begun with the Italian Renaissance, whereby the artist viewed his subject from a single, stationary viewpoint.

It is as if Picasso had walked 180 degrees around his subject and had sythesised his impressions into a single image. The break with the traditional perspective was to result in what contemporary critics called 'simultaneous' vision - the fusion of various views of a figure or object into a single image (Golding 1997: 54).

From a conceptual perspective the simultaneous vision of Cubism was analogous with garment design and construction, which worked on the premise of accommodating the characteristics of the 3D form within 2D pattern shapes. Significantly, the reduction of illusionistic space within the picture plane coincided with the collapsing of the fashionable female silhouette through the streamlining of the corset by Poiret in $1906 .^{6}$ Such parallels of approach led to what Martin (1998: 7) describes as 'an unnamed revolution' in fashion between the critical years of 1908 and the late 1920s, which saw:

Three-dimensional forms, once of Belle Epoque amplitutde and corseted and buttressed fortification, dissolve into flat planes, cylinders, and mutable forms suggesting abstraction rather than representation.

The flattening of the dress shape more closely to the form led to significant changes in the appearance and perception of the female body and its associated embellishment. Fashion's move from the 'statuesque to the soft and supple' resulted in a 'soft cylinder' shape that revolutionized fashion during the early part of the twentieth-century (Ibid.). The new tubular forms soon became the basis of garment design, bringing garments physically closer to the form. The female body was no longer viewed as an invisible chassis that supported the garment, but was gradually becoming recognised as a real moving form, that could be glimpsed in action beneath the vertical drapery. In this sense, simplified shaping was instrumental in liberating women from the role of 'designed object'?

The cylinder shape that came to dominate fashion by the 1920 s was founded on a rectangle that could easily be interpreted into a 'myriad of patterns' (Aldrich 2002). Collage, an art form central to the Cubist aesthetic, became the new paradigm for garment decoration with 'sheer, collapsed, transparent forms taking the place of the bulky, space assuming, representation-seeking forms of the earlier threedimensional silhouette' (Martin 1998: 17). Sonia Delaunay's collaged Simultaneous

\footnotetext{
${ }^{6}$ In 1906 Paul Poiret softened the formal silhouette by extending the corset to the hips and later by removing it altogether.

7 Hollander (1998: 142) refers to this phenomenon as 'the clothed woman as designed object'.
} 
Dress of 1913 (Figs.2-B \& 2-C) provides a unique early example of the translation of the Cubist painting aesthetic into a patch-worked costume, which was in 'perfect harmony' with the art of the time (Damase 1991: 71). The move towards a twodimensional, collaged, approach can be identified in fashion at this time through the work of the couturiers Lucile and Callot Soeurs (2.3.1).

\subsubsection{Ready to Wear Design Issues}

The cylinder shape of the 1920s led directly to mass clothing manufacture with rectangular pattern shapes forming the basis of commercial pattern cutting. The geometric approach to clothing the body was echoed by an empathetic surface design strategy; printed textiles changed from organic natural forms into geometric repeats that could be fitted easily into the width and length of lengths of cloth and garments. The rectangular designing system fuelled ready to wear clothing production as it allowed garments and textiles to be mechanically produced in large quantities for the first time.

Mass clothing production coincided with the 'triumph of the new order' for women in the late 1920s, by offering them greater choice of style, colour and design (Steele 1994: 141). However, the choice was at a price, as they had to relinquish a great deal of control over the specific sizing of their garments (Gamber 1997:231). The move towards simpler garment shapes is often presumed by historians to have been more liberating for the female wearer, but as Steele (1985: 122) argues, the concealing style of Victorian clothing had enabled the average woman to adhere more easily to contemporary standards of beauty than subsequent more revealing styles. The liberation of the body shape from hourglass to gamine still involved the taming of the natural body shape, albeit in a less severe form (2.3.1). The most significant ramification of ready-made clothing on women was that it could only be manufactured by adopting standardised sizes, which 'gave legitimacy to the idea of a normative size range' (Brumberg in Gamber 1997: 231). Consequently, the average woman's shape was now dressed in garments constructed from average statistics. As Daves (1967: 52) asserts the use of 'standard proportions' was really the birth of 'fashionable proportions', into which a woman now had to shape herself.

The move towards simplified shaping was positive in the sense that it empowered the natural body shape in movement and at rest (Aldrich 2001). But primarily, it was practical and economical to produce, in keeping with the principles of 'standardisation' 

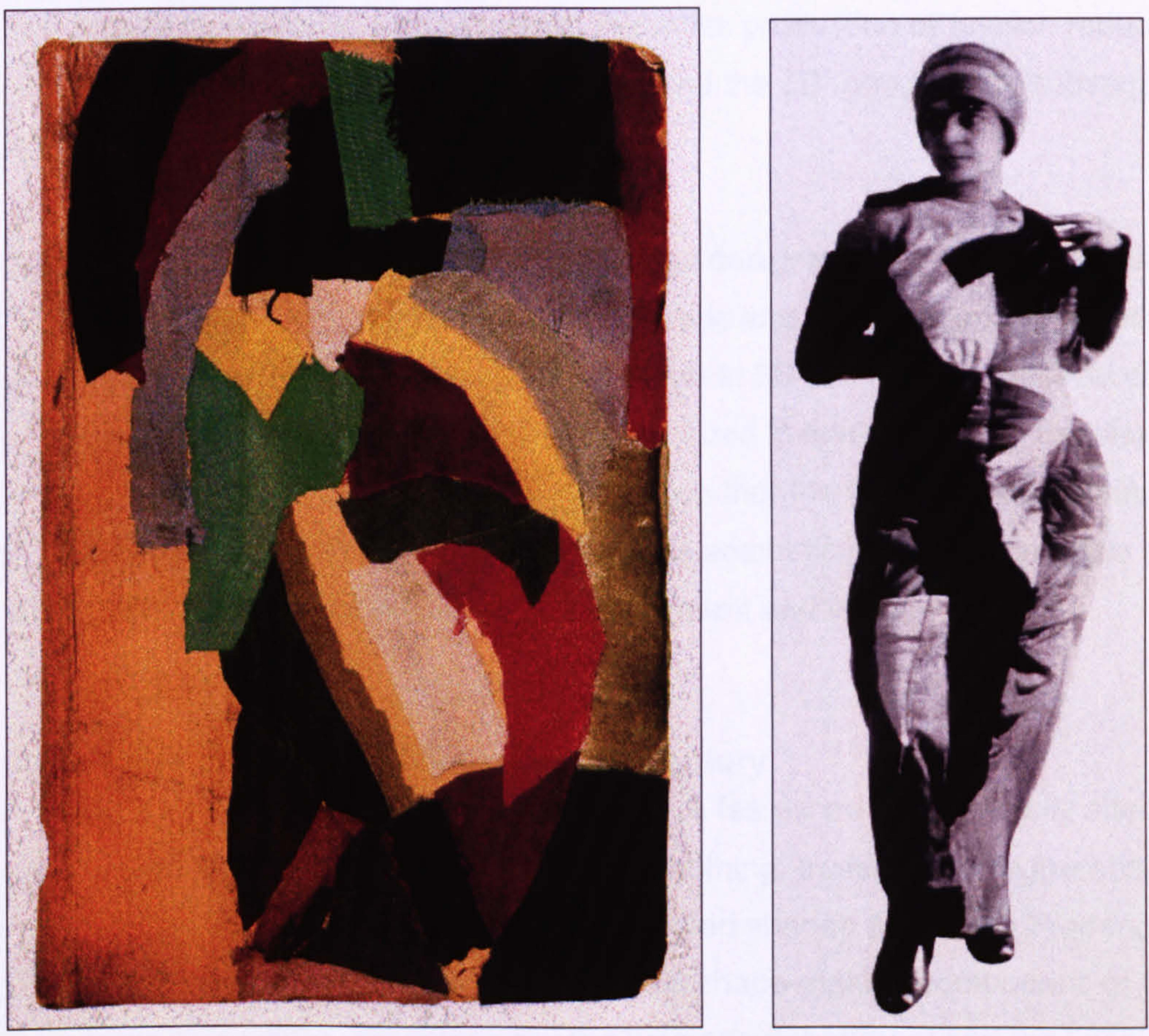

Figure 2-B Delaunay 1913: Bookbinding, collage of fabrics (Damase 1991)

Figure 2-C Sonia Delaunay 1913: Simultaneous dress (Damase 1991) 
that derived its commercial success from Henry Ford's approach to manufacturing (Thompson 2003). Rectangular shaping shifted the emphasis of fashion away from the fashioning of the body, towards the production of fashion. The rectangular design approach continues to dominate the ready-to-wear market resulting in the body being required to fit into a series of pre-determined pattern shapes and sizes. Many of these garments are created from on a two-dimensional, rather than a three-dimensional, consideration of the form. Consequently, the mass production of fashion reduces the emotional intensity that exists between fabric and the 3D form, and its subsequent meaning to the wearer.

Integrated CAD for fashion and textiles presents designers with possibilities for deviating from a 2D rectangular approach to fabric and form by working directly within the garment contour and visualising the outcome in 3D (4.3). In the practical chapters trompe l'oeil and fluid styles of imagery are explored in relation to both the shape of the garment and the underlying form. It is my opinion that the strategic engineering of printed pattern could be employed to extend the aesthetic potential normative sizing, by visually influencing the appearance of both garment and form.

\subsubsection{The Changing Silhouette in the $20^{\text {th }}$ Century}

Until the early 1900s most formal garments were fashioned to structurally alter the appearance of the body, achieved through smoothing, trussing or exaggerating the physical proportions of the wearer. The convoluted shapes of Charles Frederick Worth ${ }^{8}$ are typical of the Belle Epoque era. The 'critical shape-making component' of this style of dress was the corset, which dictated the wearer's deportment and the lines of her outer clothes (Mendes and De la Haye 1999:12). Surface decoration tended to be integrated in accordance with the structure of the garment, which in keeping with the role of the corset alluded to a 'fantasy femininity' (Rule 2001: 9). As shown in Figure 2$D$, the side view of the Worth dress (1892) indicates the ' $S$ ' shape that was achieved with a corset and bustle. Embroidery is applied to the different areas of the garment, but bears little relationship to the natural shape of the underlying form, from which it is distanced via the architectonic volumes of cloth. Figures 2-E and 2-F show two pieces by Callot Soeurs, who were instrumental in the re-interpretation of women's fashion in the early 1900s (Martin 1999: 17).

By 1910, the fashion ideal of tight-fitting, complicated garments that encased women in whalebone and steel was replaced by the revolutionary soft cylinder. This change in

\footnotetext{
${ }^{8}$ Worth redefined the female shape in 1864 when he abolished the crinoline and replaced it with a train, and later raised the waistline and created a bustle behind (O'Hara Callan 1998: 261).
} 

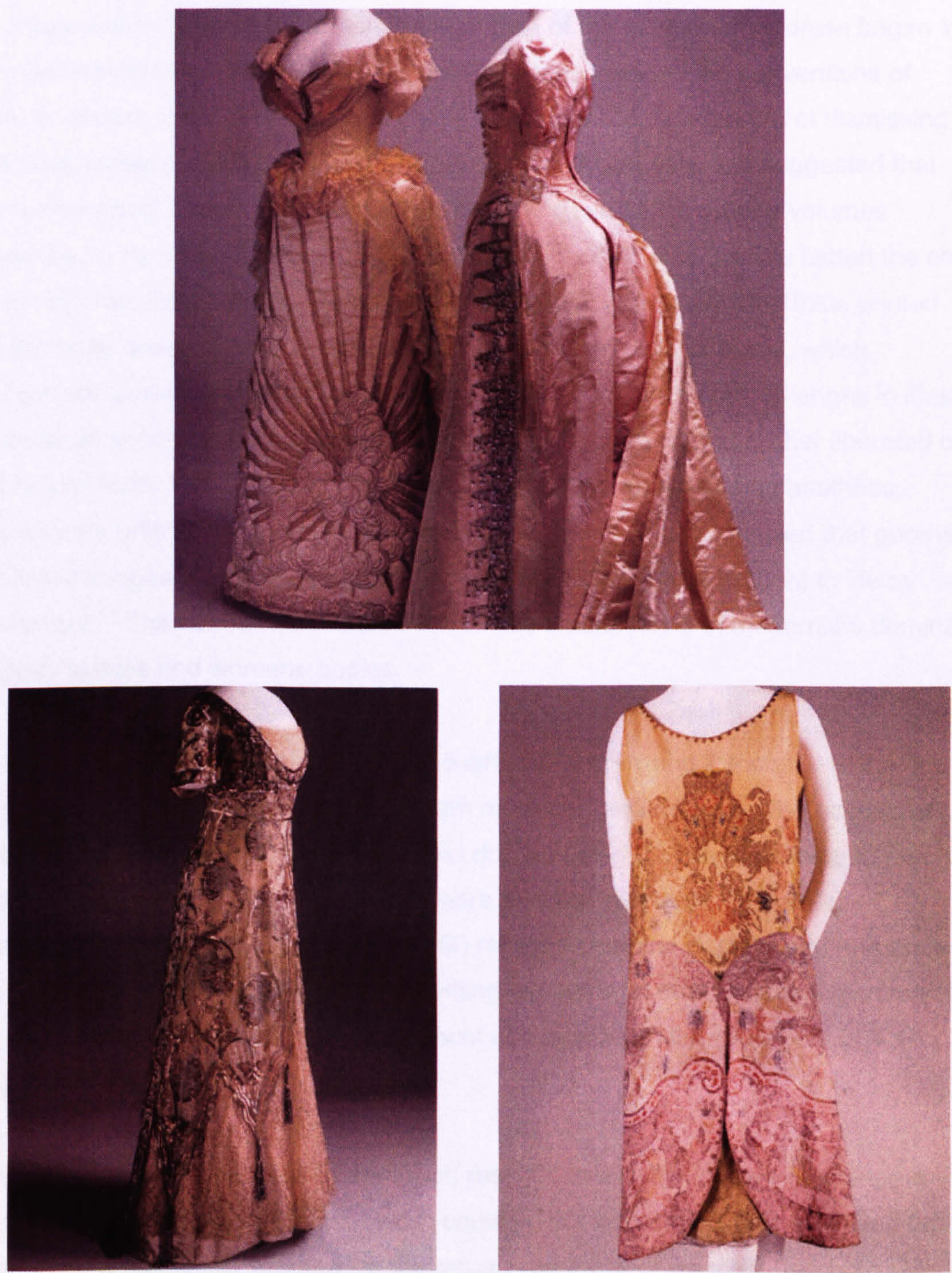

Figure 2-D Charles Frederick Worth 1889/1892: Belle epoque-style evening dresses (Martin 1998)

Figure 2-E Callot Soeurs 1910-14: The softening of the dress shape (Martin 1998)

Figure 2-F Callot Soeurs 1926: The flattened, collaged, dress shape (Martin 1998) 
shaping represents a fundamental shift from what this research has identified as 'architectural' (3.3) shapes which are centered on the female body's achievement of an artificial silhouette, towards 'sculptural' (3.2) shaping, which enables the natural form to be articulated through cloth. Although the origins of the new vision of dress began in the Aesthetic Movement in Britain, ${ }^{9}$ it was Paris that changed the conventions of fashion (Aldrich 2001: 17). The new shape was achieved by 'Paul Poiret dismissing the distorting corset in 1908 and Coco Chanel designing clothes which suggested that women's natural bodies were beautiful from 1913' (Ibid.). The tubular volumes demanded a new kind of shaping device, the bra, ${ }^{10}$ which was used to flatten the chest to achieve the characteristic, garçonne silhouette of the time. By the 1920s printed textiles were being created in Cubist, Futurist and Constuctivist styles, which harmonised perfectly with the rectangular contour of the garments. Changes in lifestyle made sport accessible to women, which impacted on fashion and further liberated of the female form. The dynamism of modern life was recognised as an aesthetic influence by artists/designers, like Delaunay and others who recognised that geometric patterned shapes harmonised perfectly with the body and were brought to life by movement. ${ }^{11}$ The 1920 s was a decade when the smooth lines of modernism dominated fashion, textiles and womens bodies.

By the 1930s the bra was employed quite differently to extend the profile of the bust, helping women define themselves beneath more complex drapery. The basic tube shape of the previous era was twisted and draped using the newly developed rayons and fine-gauge silk jerseys, to create a more sensual silhouette. The styles of Madeleine Vionnet and Alix Grés (Fig.2-G) recalled classical drapery and referenced the growing influence of Hollywood, providing women with new visions of glamour to aspire to. The greater emphasis on the bust combined with floral imagery (2.4.1) heightened the new feminine silhouette.

During World War II a utilitarian approach resulted in slimline shapes combined with small repeats and textured prints, which could be cut with a minimum of wasted fabric an approach that is still adopted for the mass production of inexpensive styles (Mendes

\footnotetext{
${ }^{9}$ The word aesthetic was defined as 'the science of the beautiful and the philosophy of taste'. By 1880 the Aesthetic Movement was well-established fact with a profound influence on the decorative arts. It was members of William Morris's Arts and Crafts movement associating with Pre-Raphaelite painters who introduced visions of the natural body form of 'aesthetic dress' (Aldrich 2003: 17).

${ }^{10}$ The bra was first patented in 1914 in the USA by Mary Phelps Jacob (O' Hara Callan 1998: 43).

$"$ At the Exposition International des Arts Decoratifs in Paris in 1925, Delaunay exhibited textile designs based on her orphic cubist paintings that explored the illusion of movement created by the juxtaposition of colours and shapes (Mendes and De La Haye 1999: 66).
} 

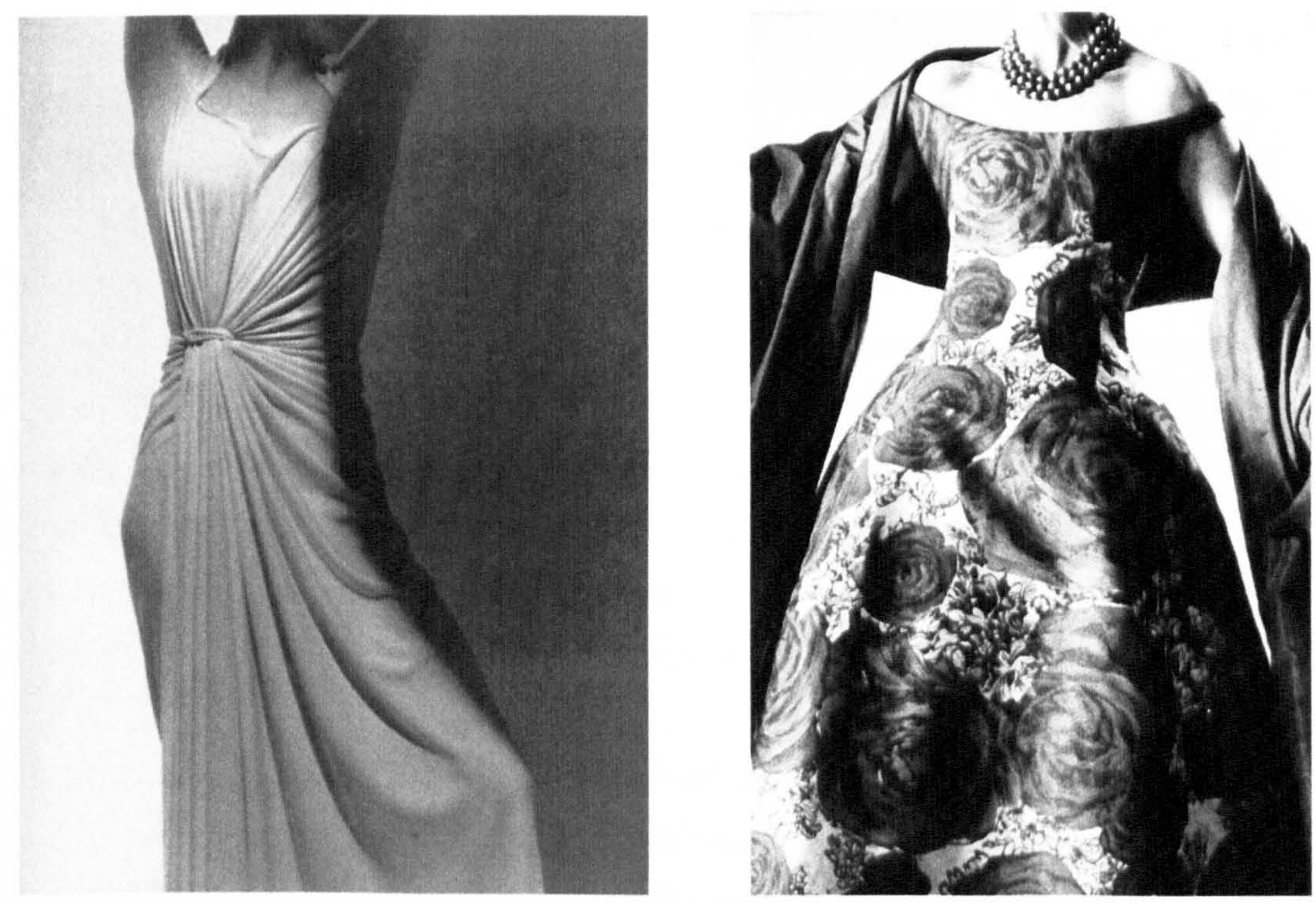

Figure 2-G Alix Grés 1938: Sculptural jersey dress (Milbank 1985)

Figure 2-H Christian Dior 1955: Garden Party, architectural printed dress (Giroud 1989) 
and Hinchcliffe 1987). Following World War II $^{12}$ Christian Dior's New Look injected glamour back into fashion in the 1940s and 50s (Fig.2-H). Once again the hourglass silhouette was artificially defined with the aid of the corset, so in this sense the shaping was regressive. Flowers were Dior's favourite textile motif, which he employed to decorate garment shapes conceived as: 'women flowers, (with) flowing busts, soft shoulders, fine waists like liana and wide skirts like corolla'13 (Dior in Steele 1997: 1).

The widespread introduction of synthetic fabrics in the 1960s had a major influence on printed garments, with the subsequent use of new fabrics and associated printing techniques ${ }^{14}$ resulting in a plethora of printed styles. The work of designers Emilio Pucci, Rudi Gernreich (2-I \& 2-J), Foale and Tuffin, and Mary Quant is typical of this period. Knitted, woven and even paper substrates were cut into short geometric shapes integrated with geometric and optical prints that compensated for the garments lack of complexity and drew attention to the form through pattern (2-K \& 2-L). The A-line silhouette is the most memorable shape of the era, reflecting women's newly acquired 'sexual liberty' (Rabanne in Huckbody 2003). Yves St. Laurent's Body Dresses (1966), created in collaboration with the artist Andrew Westleman, epitomise the period with their synthesising of Pop Art-inspired imagery of the female body, with the form itself.

The late 1960s and early 70s silhouette moved from short structured shapes to more complex cutting in ethereal fabrics. Key innovators, such as Ossie Clark and Zandra Rhodes (3.5) designed theatrical shapes that were strongly influenced by the work of Leon Bakst (3.1). Dresses were often 'set on the bias, handkerchief points rippled becomingly around the body, permitting glimpses of the legs in this period of transition from thigh-high to ankle-length fashion' (Mendes and De La Haye 1999: 214). ${ }^{.15}$

In the 1980s Vivienne Westwood and John Galliano teamed fitted bodices and bras with circular skirts over leggings. At this time 'many of the London collections were textiles-led (3.2.1) with print and knitwear especially strong' (Ibid. p. 226) Body Map's ruffled tubular jersey garments in monochromatic prints offer a key example of the combined use of pattern and volume that signified the shaping of the early 1980s. The work of the Japanese designers Issey Miyake, Rei Kawakebo and Yohji Yammamoto was incredibly influential at this time, leading to hybrid shapes that

\footnotetext{
${ }^{12} \mathrm{~A}$ memorable shape of the war years was the 'Rosie the Riveter' look, which represented the overallclad women of the munitions factories in the USA.

13 'Corolla' is a botanical term describing open petals, which referred to his ideal of women as femmesfleurs (Steele 1997: 11).

${ }^{14}$ Such as disperse printing, which encouraged the use of photographic imagery and rainbow techniques.

15 During the time of style transition in the early 70 s two contrasting silhouettes co-existed, the geometric shift championed by Courreges, and the ethereal drapery of Biba, with consumers gravitating towards one style or the other (Aldrich 2002).
} 

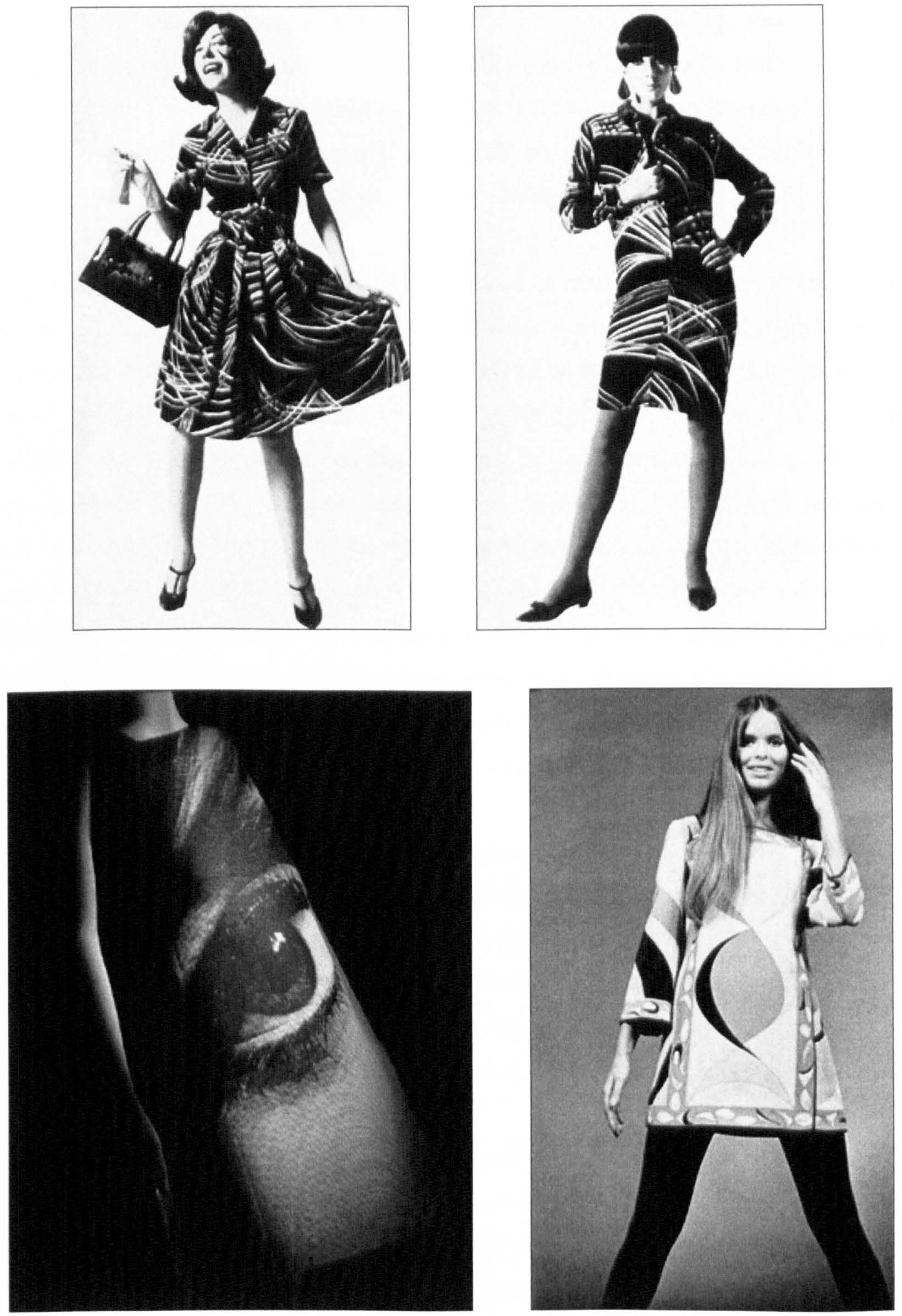

Figure 2-I Rudi Gernreich 1967: 'Mrs. Square’ (Moffit and Claxton 1991)

Figure 2-J Rudi Gernreich 1967: 'Miss Hip’ (Moffit and Claxton 1991)

Figure 2-K Harry Borden 1968: Paper Poster Dress (Eye) (Hayward Gallery 1998)

Figure 2-L Emilio Pucci 1968: Moonlight Dress in silk crepe (Casadio 1997) 
challenged Western tailoring ${ }^{16}$ and associated notions of femininity. For her Spring/Summer 1983 collection for Commes des Garçons, Kawakebo (3.4) sent warrior women down the catwalk in 'ink-black coat dresses, cut big, square, away from the body with no line, form or recognisable silhouette' (Steele 1997: 128). Gaultier's famous corset and girdle dresses of 1984 were the antithesis of the Japanese look with their 'aggressive' 'fetishistic' shaping achieved through the strategic manipulation of fabric to emphasise the female form (Ibid.p.138).

The reintroduction of Lycra and the development of new ranges of technical textiles inspired the 'cyber fashions' of the early 90s, when garment styling became inspired by 'Punk, science fiction, virtual reality, films such as Mad Max and new genre adult comic characters' (Mendes and De La Haye 1999: 258). The outfit shown in Figure 2-M illustrates all these influences and was part of Cocky's Shed's 'Octobriana'17 collection for AW 1991. This conception of the form was the direct result the use of Lycra, which determined a close fitting silhouette that defined the contours of the body precisely. This, in turn, influenced the styling of print designs that were required to interface directly with the form. In my own practice, graphical imagery was often integrated with Lycra garments, which distracted the eye from the contours to the graphic. A similar approach can be identified in the work of Lisa Bruce and Red or Dead, who also used print to underpin a strong silhouette.

Versace's 'supermodel' silhouette was a dominant influence on mid-90s fashion (3.2), before shape became much more diffused through a range of looks that included the androgynous, 'heroin chic'. Dries Van Noten's combined use of Western tailoring and Eastern-style saris and salwar khamiz presented an eclectic mix of 'urban ethnic' influences (3.2.1). Here the sensuality of printed drapery juxtaposed with the solidity of the tailored jacket, present a global fashion statement.

Since $\mathbf{2 0 0 0}$ designers of couture, such as Alexander McQueen and Hussein Chalayan have presented the industry with some theatrical silhouettes (3.3). On a more wearable garment level there is a strong indication that 'the body beautiful' is back and is 'begging to be revealed' (Quick 2003: 329). Today, the modern form is expected to be lithe, toned and fit, as Steele (2001) states: 'the corset has become internalised in a transformation of disciplinary regimes'. The recent revival of Lycra clothing recognises this (Fig.1-D p.1-6) but is being interpreted by design houses

\footnotetext{
${ }^{16}$ Western tailoring made a comeback in 1986 in the form of the padded-shouldered, women's 'power' suit. The inverted triangular shapes presented a new take on the traditionally masculine silhouette that could not be clouded by embellishment, traditionally 'pathologised as feminine' (Fer 1998: 11).

${ }_{17}$ Octobriana was based on a Russian underground comic book heroine. The range incorporated graffiti style prints, Lycra, PVC and eyelets.
} 


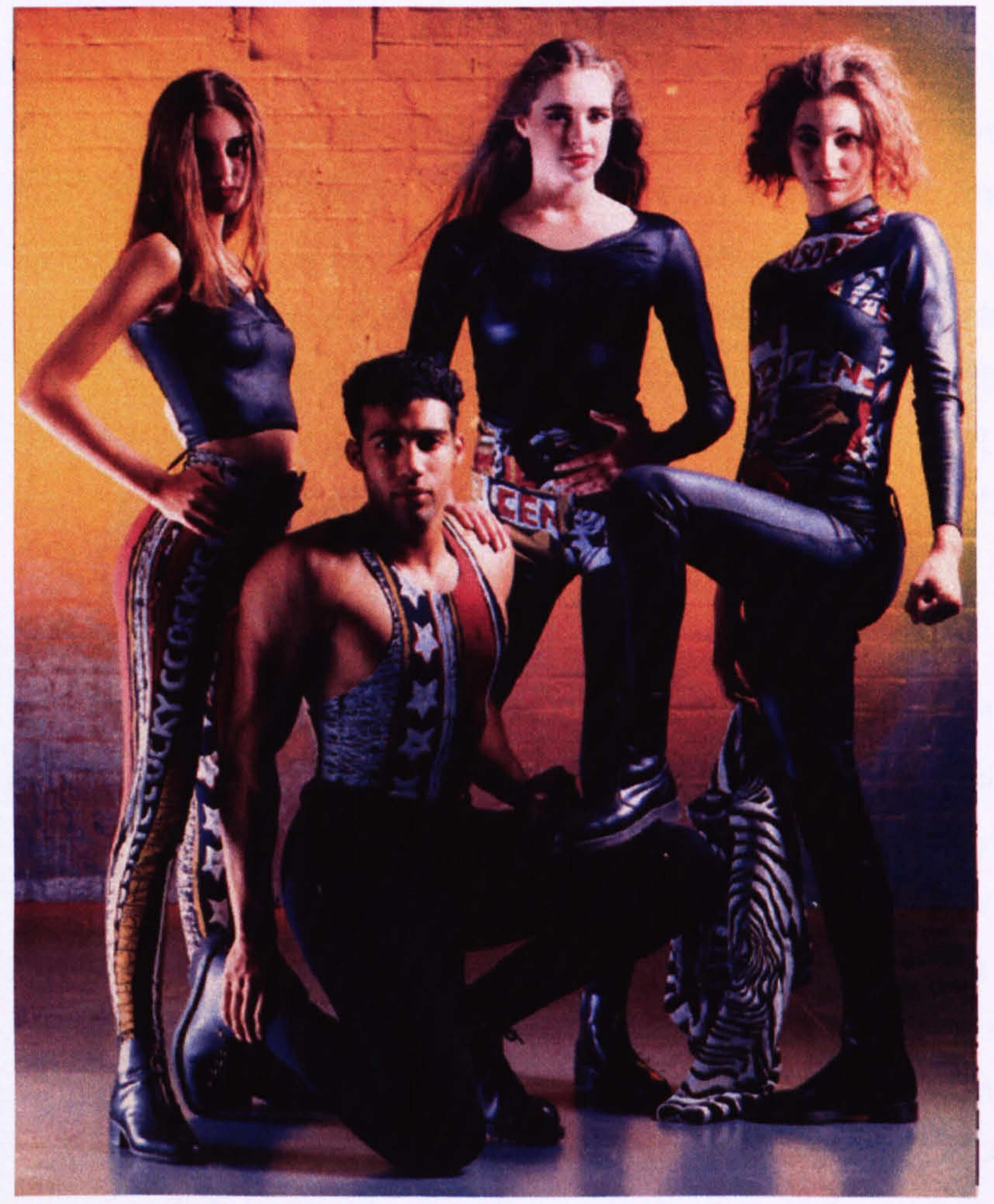

Figure 2-M Cocky's Shed 1991: Octobriana range for S/S 1991/2 
such as Chanel, to describe the form in a new complex double silhouette, comprised of different layers (Fig.2-N). Helmut Lang has adopted a similar approach, as described by Frankel (2003: 11):

His models were urban angels, their layered and pleated attire suspended from reflective silver harnessing and worn over layers of stretch clothing, so that despite an ultra sexy silhouette barely an inch of flesh was exposed.

Lang is recognised as one of contemporary fashion's visionary shapers. The essence of his Autumn/Winter 2003/4 collection relied on the synthesising of drapery with a strong feminine silhouette; which are qualities that I seek to capture in my own practice through a single layer of printed cloth (7.4). Fabric quality is now more important than ever, with smart and performance textiles increasingly used by the industry to articulate the body through 'functional fashions' (Braddock 2000). It is my opinion that by approaching surface imagery from a three-dimensional perspective, print can be employed to iterate the form in a manner that is both functional and aesthetic.

\subsection{CONSIDERATION OF THE BODY}

It is difficult to discuss clothing without addressing the body. As Wilson (1992: 15) states: 'without the living body clothing cannot be said to fully exist.' Within this study the body, or form, plays two significant roles; firstly, as a catalyst for the designing process, and secondly, as an articulator of the final printed textile/garment. As discussed earlier, the consideration of the form throughout the designing process can be the norm for garment designers. This is less usual for textile designers who tend to engage with the form as a concept rather than a physical presence. However, within this research the form is utilised as a positive informer of the design process, which represents a unique departure for textile designers. In view of the pivotal role that the form plays within this research, I feel it is important to explain my perception of the body within the garment design equation by discussing the contrasting approaches taken by different sections of the fashion industry.

\subsubsection{The Mass Clothed Body}

While it is no longer appropriate to consider the body as a 'biological given', in order to fashion garments, designers must be equipped with data that relates to the physical size and shape of bodies (Wilson 1999: 3). The body is perceived in different ways by different sections of the market. Bodymetrics and E-Tailor are two strands of the recent SizeUK ${ }^{18}$ survey, which is representative of the mass clothing industry's current major

\footnotetext{
${ }^{18}$ SizeUK is the first national sizing survey to be carried out since 1953 , and is currently analysing bodydata and market research information from 5,000 women and 5,000 men.
} 


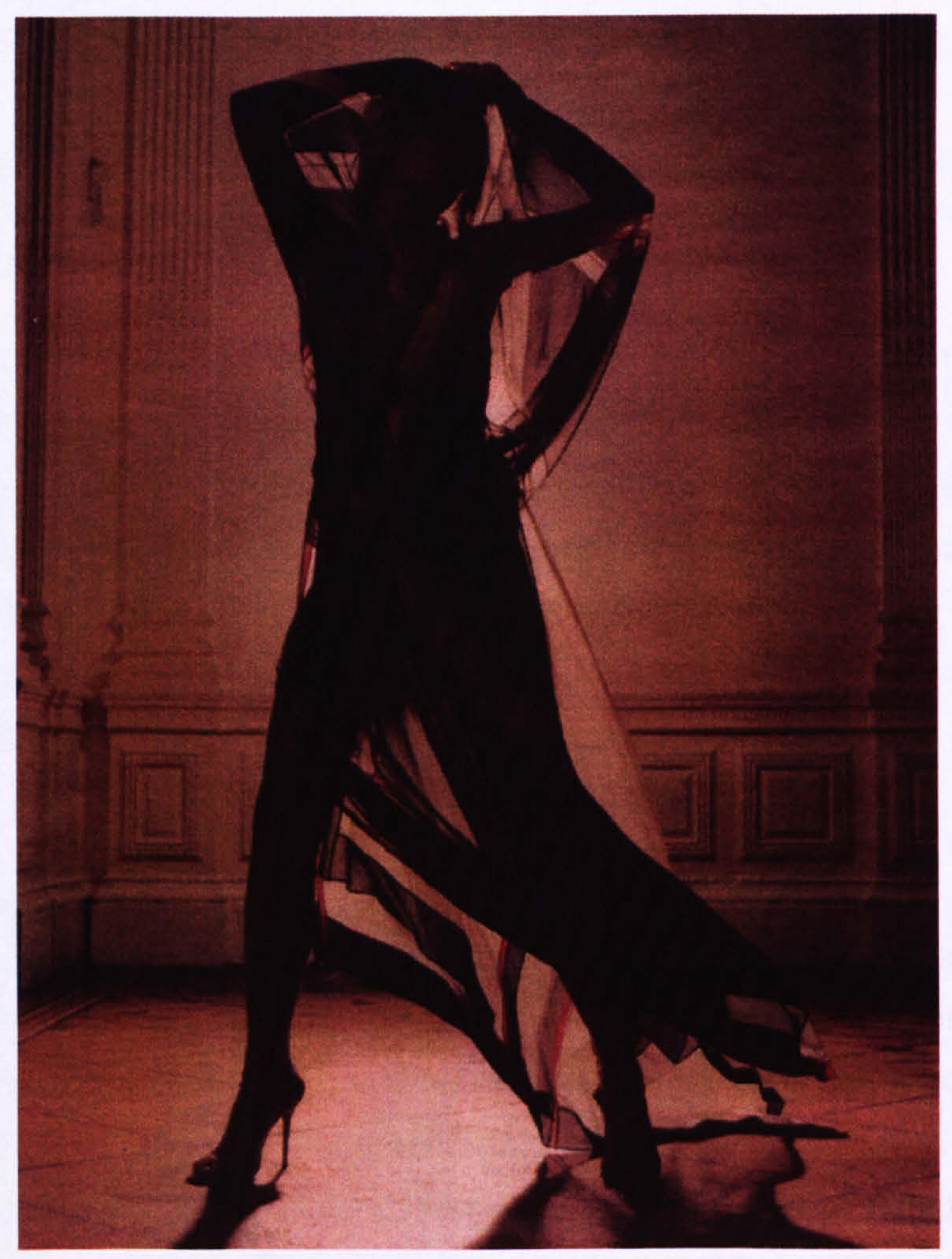

Figure 2-N Chanel 2003: Printed chiffon dress (The Independent 2003) 
concern with the body. The survey is the largest in the world, and the first to use body scanners (4.2.1), which theoretically make it possible to 'analyse shape as well as measurements' (Crawford 2003). According to Crawford: 'the body is the last piece of personal information to have gone digital'. ${ }^{19}$ One of the most interesting findings of SizeUK is evidence of how the physical size, shape and posture of the population has altered as a result of changes in lifestyle that have occurred over the last 50 years. The SizeUK data has a variety of possible applications such as: virtual shopping and the possibility for 3D-shape analysis, as Crawford states:

Many retailers work from size ranges based on the measurement of the hip girth. By taking an average banding of Size 12 data analysis it transpired that many different shapes occurred within this banding.

Although such an observation seems fairly obvious to anyone involved in garment design, it is the first time that the mass clothing industry has had access to such detailed information about potential clients. If applied by individual companies such information could potentially lead to the alteration of size charts, better fitting garments and 'no more frock horror' (Fernand 2002: 37). However, for the present the mass clothed body continues to be fashioned according to issues of 'fit' based on standardised sizing. ${ }^{20}$

\subsubsection{The Haute Couture Body}

While body scanning facilitates the collection of highly accurate measurements, it is interesting to assess how such data compares with traditional hand measuring techniques as practised in tailoring and haute couture. Although haute couture garments account for only a small percentage of total clothing sales, the ready-to-wear collections produced by these design houses are the most influential factor on garment styling trends in the mass clothing market (Entwistle and Wilson 1998: 107). The differences between the genuine article and the 'more flash than cash' replicas on the high street are in the cut, fabric and finish. The cut of a couture garment is carefully devised through creating patterns based on meticulous hand measuring, modelling on the stand and countless fittings on live models followed by adjustments using manual and CAD pattern cutting techniques (Durandaud 1998). Such garments are created with exclusive fabrics, which are sourced through specialist suppliers or commissioned from textile designers, with no expense spared to bring the couturier's idea to fruition. ${ }^{21}$

\footnotetext{
${ }^{19}$ Quote attributed to Phillip Trevelian, one of the founders of Bodymetrics.

${ }^{20}$ Mass produced garments tend to be made in sizes $8,10,12$, and 14 , and upwards depending on the customer profile. These sizes are based on average measurements and are designed to accommodate as many average body shapes as possible. Companies such as Next now supplement their Standard ranges with Tall and Petite, which reflects the requirements of their broad customer profile.

${ }^{21}$ See McDowell, C. (1997) Galliano, London: Weidenfeld and Nicholson.
} 
The focus of the painstaking, couture process is to articulate the body, but not just any body. In many ways the body dressed by the couturier is that of a fantasy female, an archetypal form of perfect shape and proportions, that satisfies the 'cultural imaginary' of the time (Gatens 1996: 41).

The imaginary body is not simply a subjective phenomenon of imagination or fantasy; rather, it is a social product, culturally specific, constructed from those images, symbols, metaphors and representations which help construct various forms of subjectivity (Ibid.).

Ironically, although the ideal haute couture customer is a model or celebrity, some of the customers wealthy enough to afford such garments, rely on the made-to-measure service that will accommodate and aesthetically improve upon their individual body shape.

\subsubsection{The Designer Body}

Designer clothing interfaces between mass and couture approaches. Designer labels consist of both diffusion ranges marketed by couture houses to make a profit from the loss leader couture collections, and independent companies vying for a stake in the cutting edge fashion market. Here the body is expected to be, if not young, then youthful. The designer body belongs to an individual who is aware of their shape and knows how to dress it. In contrast with mass clothing and haute couture, designer garments are not constructed on a made-to-measure basis, nor to standardized measurements, but for a size range that reflects their individual, yet relatively small customer profile. While ranges are more limited than those offered by the multiples, a more creative approach towards pattern, or 'style cutting', can result in a creative fit that, unlike couture garments, may accommodate more than a single body shape (Aldrich 2002).

\subsubsection{The Role of the Mannequin}

In the past, tailors and couturiers often had life-scale dress mannequins constructed to the exact statistics of their customers. Madeleine Vionnet famously used a half-scale mannequin to experiment with her bias cut styles on a manageable scale. Quarterscale mannequins were often used in the past in higher fashion education, to experiment with pattern shapes. However designers working at a reduced scale must be aware of the inconsistent performance of some fabrics when translated to full scale (Aldrich 1996: 20). Garment design companies generally enlist standardised mannequins, purchased from suppliers to the clothing manufacturing industry, to aid them in their craft. Fashion students continue to have access to standard sized mannequins on which they can model, toile and fit prospective styles. Independent and home dressmakers often use a tailor's dummy to assess the fit of their garments. 
In women's fashion the dress mannequin is the female body double, but there are important differences. Unlike a lot of British women who are deemed pear-shaped, the female dress stand can be almost androgynous in shape from the bust down, with a flat stomach and virtually no bottom, its rigid proportions in keeping with an upright, static posture. Although mannequins have an almost timeless ambience, they do change in relation to the prevailing silhouette, and as such are relied upon as an approximation of the fashionable proportions of the time.

The first layer of meaning encountered in the mannequin is her close (in Freudian terminology 'uncanny') resemblance to the human body. She represents the perfect simulacrum - a copy without original - since the idealization of the showroom or shop window figurine rarely reflects a sculpted truthfulness, but rather an imagined perfection (Lehmann 1998: 89).

In theory, there is a marked distinction between the role of the fashion mannequin, as described by Lehmann, and the tailor's mannequin; one is promoted as a technically correct, while the other exists 'primarily to make people dream' (Ibid.). In practice both versions promote an aesthetic ideal that women aspire to, but few physically resemble. Martin Margiela has explored the aesthetic implications of the dress and fashion mannequin within his practice. In the 1997 exhibition '9/4/1615' he used a group of female dress stands as the basis for experiments using mould cultures as surface embellishment (1.7.2). He also appropriated the idiosyncratic markings of the mannequins as surface detailing; a surreal take on the body wearing the mannequin (Fig.2-O). In 1998 Margiela commissioned ten life-size wooden puppets to animate his Autumn/Winter collection. The use of marionettes to present a collection was ultimately linked to the 'displaced' nature of the garment's construction (O'Neill 2001: 39). In 2000 he explored the idea of unfashionable proportions by employing a large made-tomeasure tailor's mannequin as its starting point The resulting pieces included oversized jeans, created at $200 \%$ and separates at $157 \%$, which had to be wrapped around the models (Fig.2-R). The collection jarred within the context of contemporary fashion and highlighted the issue of how Western society views style in relation to preconceived notions of size and shape.

The dress mannequin plays an important role within my own practice. As described in Chapter 6, the female form was substituted early on with a full and half-scale dress stand. On a practical level the mannequin that I used closely represented the physical attributes of my own form. It was not a standard 'size 12 mannequin' but one that had been custom-built to the specifications of a real size 12 woman by researchers at the University of Loughborough. This provided me with a more shapely form to work with 

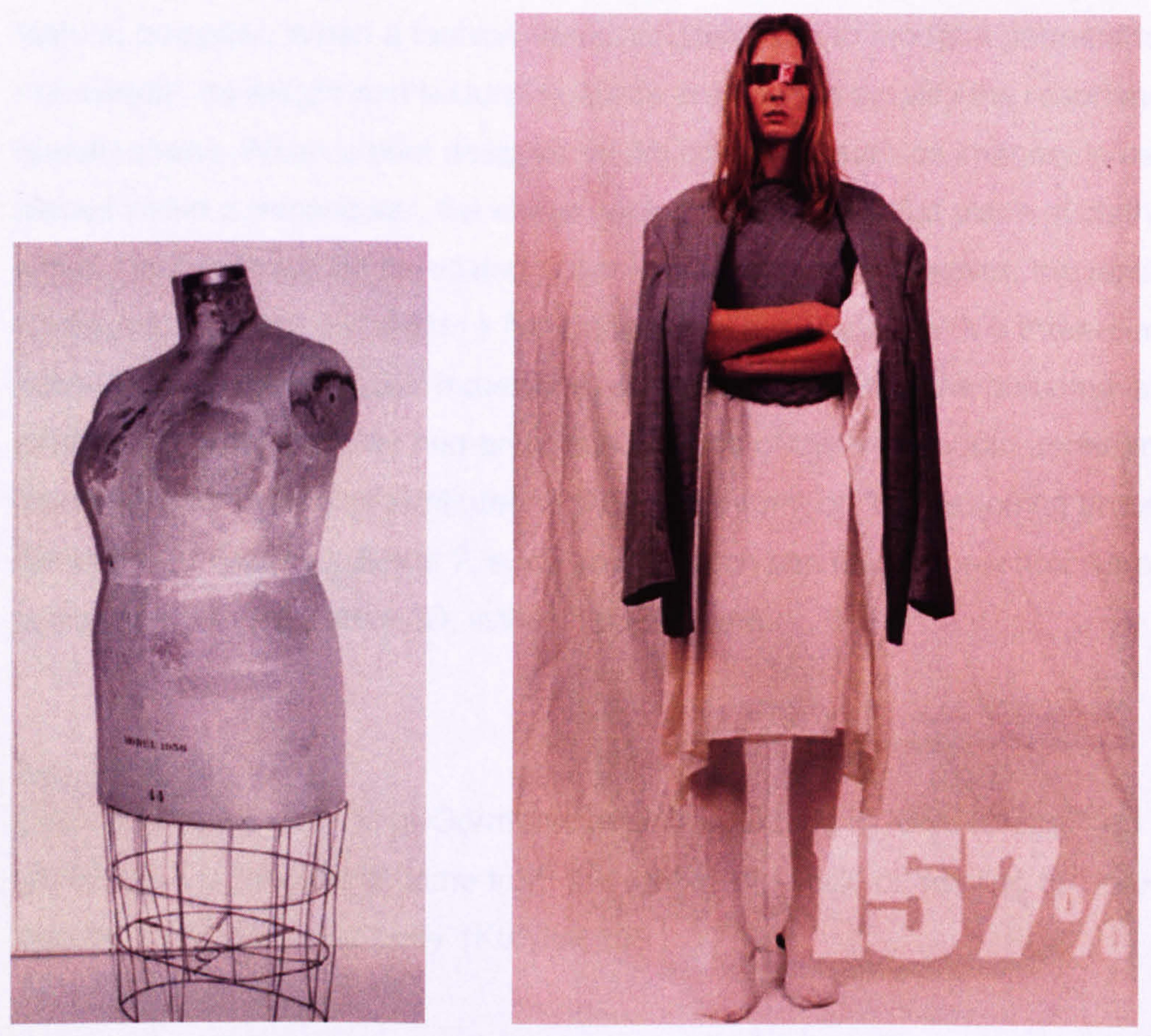

Figure 2-O Maison Martin Margiela: Customised original tailors mannequin USA. C. 1930s(left). Maison Martin Margiela S/S 2001: Check jacket enlarged 157 per cent and white rectangular Tent dress with appliquéd suiting (right) 
that was more representative of the natural body shape. ${ }^{22}$ The static nature of the mannequin enabled me to create a dialogue between it and my own similarly shaped, moving body. From the outset $I$ found it more challenging to originate textile patterns in direct association with cloth and this form, than creating marks on a flat surface.

By employing a mannequin I used the same series of surfaces as those employed by a fashion designer. When a fashion designer uses cloth to model a garment toile on a mannequin, its weight and textural qualities are used to amplify the resonance of the human shape. When a print designer works on paper, surface imagery is usually placed within a rectangular, flat shape, which represents a flat piece of cloth, onto which the design will be translated at some later stage. If, however, the textile designer configures imagery, not within a flat plane but in association with a three-dimensional notion of cloth (as a draped material or garment shape) then the outcome is created in greater sympathy with the human shape. My use of the mannequin underpins the influence of the physical attributes of the female form on the designing process. As discussed in Chapters 6 and 7, such an approach can lead to new notions of textile design that are created in 3D, rather than 2D form.

\subsection{CLOTH}

Cloth: The word 'cloth' is of Germanic origin, appearing in Kleid (dress) and Kleidung (clothing). It is thought to come from the root kli- 'to stick' or 'to cling to', making 'cloth', 'that which clings to the body' (Kuryluk 1991: 179).

From birth to death, through swaddling, clothing, sleeping ${ }^{23}$ and shrouding, our bodies have a unique association with cloth. Textile artists are continue to investigate the aesthetic, semiotic and physical relationships that individuals experience through cloth. Barnett (1999: 28) describes the synthesis of cloth and form as: 'the texture of the intimate... a space of close-vision: the curl of a hair, the twist of a thread, the crease of a cloth. A place to lose oneself in the intimacy of the fold, as satin reshapes and velvet vibrates.'

Cloth has been part of the fabric of our lives for as long as bread (Hollander 1975:1). In its early use, the term 'whole cloth' was used synonymously with 'broad cloth', meaning the full width of the loom (Constantine and Reuter 1997: 7). Originally garments were created from a full length of cloth, which was woven in natural materials in accordance to the height of an individual. The creative potential of a length of cloth is infinite, as

\footnotetext{
${ }^{22}$ Standardised mannequins have a flat barrel-shaped abdomen and behind, whereas the model I used was curved in these areas.

${ }^{23}$ Elinor Carucci (2002) has recorded the sleep marks left by cloth on the body in her book Closer.
} 
John Ruskin observed: 'It can be shaped beyond the boundaries of origin: it shifts from the potential to an actuality that has a myriad of shapes and a myriad of ways of moving, responding to the action of the individual who manipulates it' (Quoted in Constantine and Reuter 1997: 9).

Within this thesis, cloth is located in both these intimate and practical context; it has a poetic language of its own, but is also 'the physical stuff' from which garments are made (Barnett 1999: 28). The print 'Circles 1 ' by Masataka Kuroyanagi (Fig.2-P) and the photograph 'Cloth Folds' by Tina Modotti (2-Q) illustrate both these qualities. Modotti's black and white image documents the static physical properties of a piece of cloth suspended in time and space, but also implies movement and an existence beyond the frame: 'fabric caught in motion, creased like the cratered surface of the moon, or the flux and flow of matter' (Ibid. p.29). The philosopher Gilles Deleuze ${ }^{24}$ imagined matter as a sheet of paper 'divided into infinite folds...unfolding its pleats at great length, some smaller, some larger, endlessly dividing' (Quoted in Barnett). The artist Liz Rideal has explored the aesthetic potential of folds in her series of fabric portraits (1996-98), where the flow of cloth is arrested by the mechanistic click of the photo-booth (Fer 1998). The textile designer Jane Harris's research into the aesthetic potential of CG animation of cloth has resulted in some breathtaking images of the virtual life of textiles (4.2.3).

Representational art has consistently focused on the capacity of cloth to "bunch, stretch, hang, or flutter, to be smooth or unsmooth', while fashion makes use of its possibilities of reinvention (Hollander 1975: 2). Although the work of some fashion and textile designers is considered as Art, their approach to cloth and clothing is more pragmatic than that of the artist. They must strike a balance between an aesthetic ideal and reality. While garments may be hung in galleries, ostensibly they are created as a means of clothing and articulating the human form, and as such are often diminished without it (Wilson 1992: 15). The characteristics of cloth that interest me as a designer, are centered on its aesthetic potential as media for iterating the form; the synthesis of drapery and the human body being far more evocative than the separate elements.

Just as drapery covers and conceals the body, so it serves to reveal it, to echo its crevices, to draw attention to its erotic points. It excels as a fetish object, displaying erotic focus onto the textures and touch of fabric, or onto undulations and folds of something which is not flesh, but which may stand as a substitute for it (Fer 1998: 11).

Within the practical element of the research cloth is considered in relation to the form,

${ }^{24}$ See The Fold in Deleuze, G. (1983) Liebniz and the Baroque, London: Athlone. 

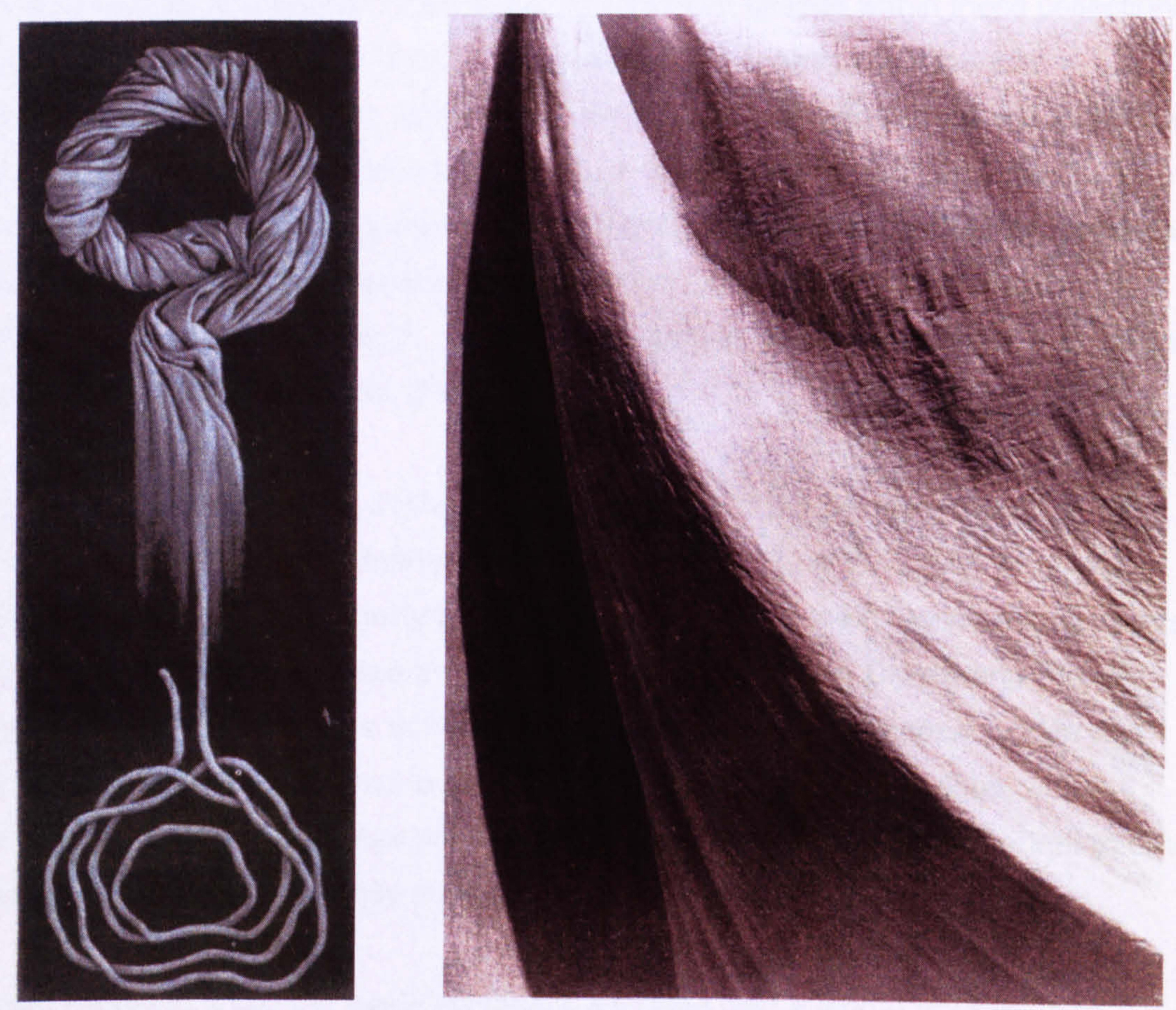

Figure 2-P Masataka Kuroyanagi 2000: Circles $1(47 \times 136 \mathrm{~cm})$ mezzotint (North 2000) Figure 2-Q Tina Modotti 1924: Cloth Folds (Barnett 1999) 
which provides the central point of reference for the material to cleave to, and/or be supported by. The resulting plastic shapes provide the catalyst for mark making to occur, as explored in chapters 5-7.

\subsubsection{Fabric Determines Form}

Contemporary garment styling is primarily dictated to the industry by the ready-to-wear collections of haute couture designers, and by the 'fashion system' ${ }^{25}$ that promotes them (Entwistle and Wilson 1998: 107). The garment shapes within these collections are primarily determined by new fabric qualities and/or methods of surface embellishment. In the 1990s momentous advances in technology provided fashion with a new range of futuristic fabrics to interpret. In 1998 Braddock and O'Mahoney (p. 100) identified that the increasing complexity of 'techno textiles' had resulted in designers adopting pared down functional shaping with 'the intricate tailoring previously necessary to shape a garment ...giving way to simple, classic silhouettes that display these sophisticated materials.'(Fig.2-R)

According to Aldrich (1996: 2) the principle concerns of the garment designer in the creation of a style are: 'the fabric's aesthetic appearance, its fitness for purpose, its structure and the elusive quality fabric hand'. She lists the main fabric characteristics that determine garment shape as: 'Weight, Thickness, Shear, Drape, and Stretch' (Ibid.). Different qualities are suited to the creation of different shapes: woven and composite dress weights tend to be used to create semi-tailored shapes, whilst lightweight shears and jerseys are often fashioned more fluidly. It is important to note that fabric performs differently through varying scales (Ibid. p.20).

When choosing a fashion fabric designers will often hold a length of cloth up to themselves. This intuitive response to cloth allows them to estimate the hand and shape-making potential of the material. Miyake's (1983: 103) practice of 'wrapping a piece of cloth around himself' prior to designing with his 'hands and body' is a key example. His revolutionary garment the APOC, ${ }^{26}$ enables the wearer to be involved in the designing/making process, by choosing from a range of pieces integrated into a length of cloth (Fig.2-S). Rei Kawakebo professes to 'start from zero' sometimes designing the cloth before the garments, as exemplified by her Wrapped Collection $(1983)^{27}$ (Evans and Thornton 1989: 156). The work of these and other Japanese designers illustrates the 'fabric determines form' ethos that has influenced fashion since the early 1980s. Instead of cutting cloth to fit existing pattern shapes, a more

\footnotetext{
${ }^{25}$ For a philosophical overview see Barthes (1983) The Fashion System, New York: Hill and Wang.

${ }^{26}$ APOC is an abbreviation for 'a piece of cloth'.

27 Designed for Commes des Garçonnes.
} 

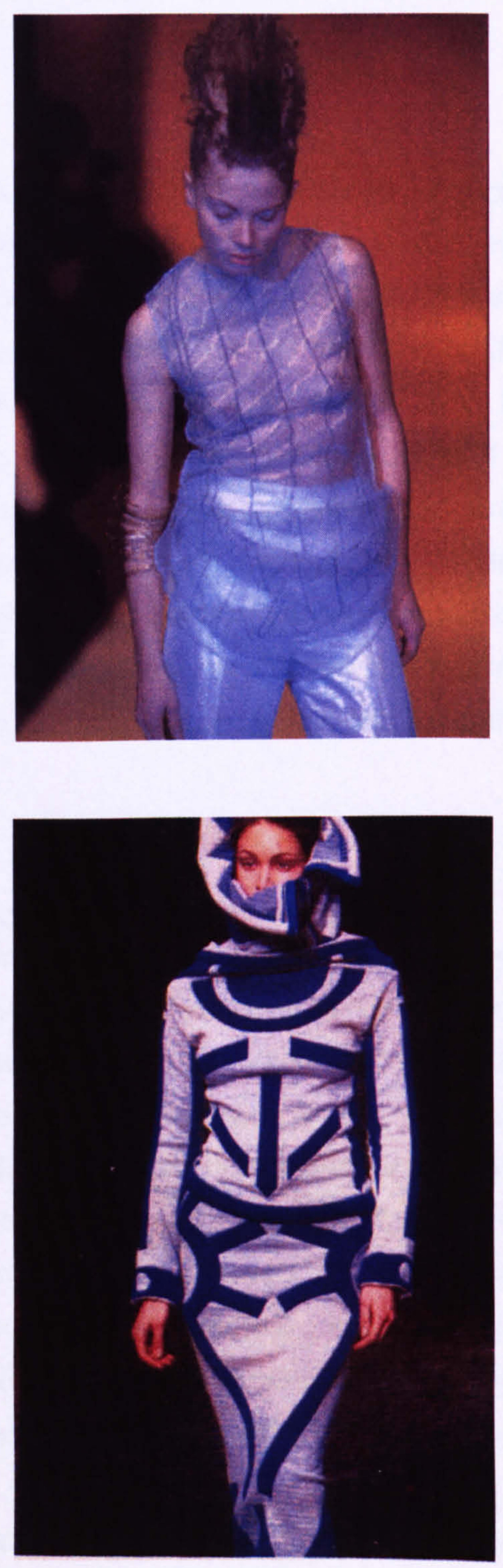

Figure 2-R Owen Gaster S/S 1996: Layered transparent vest (Braddock and O'Mahoney 1998)

Figure 2-S Issey Miyake 1999: Printed APOC (Guardian Weekend 2000) 
organic approach is taken, allowing the garment to 'change the parameters of the wearer's body, the sense of where the edges of the body are, where it meets the space around it' (Ibid.) (3.4).

The move towards computerised methods of garment production, have resulted in automated systems of measuring fabric hand such as KES and FAST (De Boos et al 1991) and KAWABATA (Kawabata and Niwa 1989). Such systems are becoming more sophisticated and are a useful addition to CAD. However, Aldrich (1999: 2) believes that there is no substitute for the 'human estimation' of fabric hand, which she sees as a 'personal, sense-driven, experience.' My own experience of CAD methods has led me to the similar conclusion, 'that clothing designers need an intuitive sense of different fabric qualities and their relationship with garment form.' While haptic systems may offer designers more sophisticated levels of sensory perception in the future, currently, computers cannot replicate the sensory perception experienced between designer and material, or the physical interaction between cloth and form, that is so vital to the creative process.

\subsubsection{The Influence of Lycra on Garment Shaping}

Following the revolution initiated by the soft cylinder, this research considers the next major influence on twentieth-century fashion to be Lycra, which combined the fluid characteristics of jersey with 'stretch and recovery'. In 1965 Kirk and Abrahim identified the advantages of stretch fabrics as: 'comfort, fit, reduced pucker, improved wrinkle resistance, the need for fewer sizes and alterations, and greater design flexibility'. True fitting to the body shape can only be achieved with stretch fabrics, which can expand and contract to accommodate body movement. Stretch fabrics responded to the practical requirements for modern garments to 'conform more or less to body shape'28 (Denton 1972: 14). Stretch garments were created in three main types: 'comfort stretch', 'stretch-to-fit' and 'power-stretch' (Ibid. p.15).

As well revolutionising garment shape, resulting in what Steele (1997: 121) refers to as: 'the most unforgiving silhouette in fashion history', Lycra also had a significant effect on printed textile design. Printed embellishment could now be related much more closely to the human form, without the aid of tailoring or specially constructed undergarments. Lycra production peaked between 1987 and 1992, having been reintroduced in 1985 as a performance fabric (Ibid.). Independent designers soon identified the modelling potential of the fabric. Azzedine Alaia (3.2) incorporated spiral seams, curves, and

\footnotetext{
${ }^{28}$ The introduction of revealing styles coincided with the mood of liberation that prevailed from the mid-60s to early 70 s.
} 
darts with Lycra during the 1980s, to create an 'ultra-feminine silhouette' (lbid.). The new fitted qualities called for alternative printing approaches that would not hinder the elastic content in the cloth (2.3.1). Subsequently placement prints were popularly employed using existing methods together with new techniques developed specifically for stretch fabric. Print had now truly become a second skin (2.3.1).

\subsection{PRINT}

The body and cloth can be defined in many different ways. Printed textiles also exist in a broad variety of contexts. Some of the earliest 'direct patterning'29 techniques date back to the Neolithic Era (2,000 B.C.), when pintaderas were used to apply prints directly to the body (Wells 1998: 1). The quest for adornment through decoration continued with the printing and dyeing of animal skins and simple woven fabrics that were wrapped around the human form. The general supposition is that a mechanistic form of textile printing 'probably originated with the Chinese, who were letterpress printing onto paper by wood-block two thousand years ago' (Clark 1985: 3). Today textile design and production are an important part of the global economy, encompassing a plethora of traditional and CAD/CAM methods.

Despite the ever-increasing choice of design method available, the basic principle of enlisting pattern as a means of enhancing the body has continued within haute couture. In the early 1990s ancient styles of physical adornment appeared to have come fullcircle as tattoo-style prints appeared on stretch and shear fabrics in the collections of Jean Paul Gaultier and John Galliano (Figs.2-T \& 2-U). This research also seeks to directly address the form, by investigating it as a method of aesthetically enhancing the contour of garment and the underlying contours, simultaneously.

Printed fashion textiles are created in many different ways and applied to cloth through a range of diverse processes that include screen, rotary, transfer, and inkjet methods. ${ }^{30}$ The ways in which print imagery is translated onto cloth, the types of inks or dyes used, can influence the appearance, hand and overall quality of a textile. It is therefore vital that garment designers are aware of the potential changes that different printing processes ${ }^{31}$ can incur on a base cloth, and final garment. Digital or inkjet fabric printing (4.4) currently offers designers a direct link between the textile design and printing process, eliminating the need for colour reduction, separation and screen production.

\footnotetext{
${ }^{29}$ Direct patterning/printing: the production of an image by the application of colourants directly to the surface of the cloth (Wells 1998: 1).

${ }^{30}$ See Appendix 3: Textile Printing Processes

31 For an overview of textile printing techniques see Chapter 5 in Bunce, G. (1993).
} 

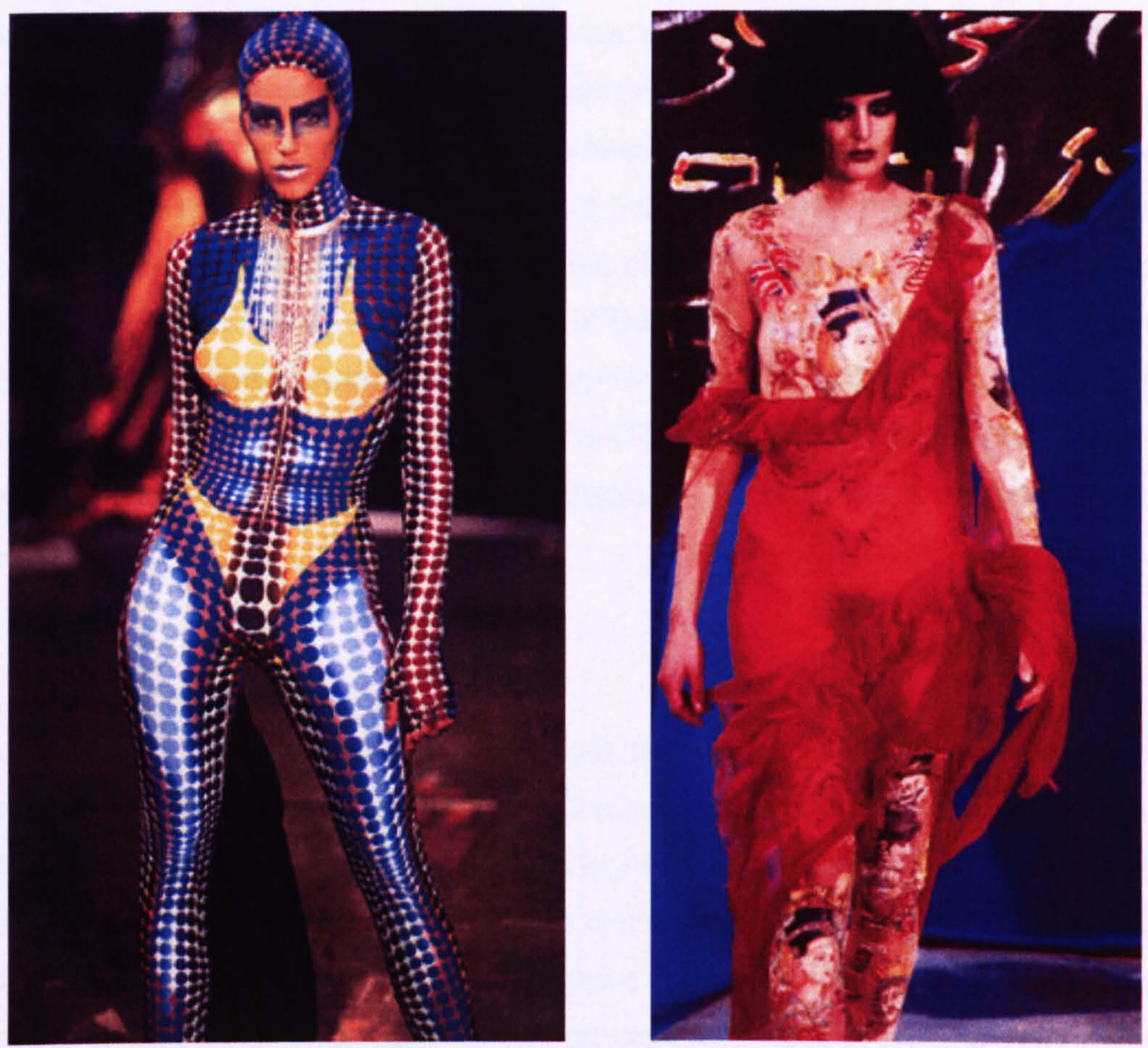

Figure 2-T Jean Paul Gaultier 1995/6: Catsuit from Horsewomen and Amazones of Modern Times (McDowell 2000)

Figure 2-U John Galliano 1997/98: Egyptian-inspired, printed bodysuit (McDowell 1997) 
This enables designers to be more adventurous with their use of colour and imagery, but as discussed in Chapter 4, there is little evidence to suggest that such advances have altered the ways in which designers approach printed garment design. One reason for this is the strong tradition of textile and garment design being taught and practised as separate disciplines, with the textile designer rarely credited for what they do (Braddock and O'Mahony 1998: 105). In the mass clothing market prints continue to be created in economical, multi-directional repeats. Print is considered within the context of 'adding value' to inexpensive fabrics, carried out by designers who often have little or no knowledge of the garment shapes that they are designing for (4.1.1). This is not the case for couture and independent labels, where closer links have been forged between fashion and textile designers over the last two decades (Ibid.) The exhibition Fabric of Fashion demonstrated the creative potential of such strategic print/ garment design partnerships through work of Boudicca and Savithri Bartlett, Hussein Chalayan and Eley Kishimoto, and that of printed garment designers Rebecca Early, Shelley Fox, and I.E. Uniform (Braddock and O'Mahony 2000). The work of these designers illustrates how imagery can be integrated aesthetically to enhance a garment shape.

\subsubsection{Printed Dress Fabrics}

At the beginning of the twentieth century most commercial fabrics were roller printed ${ }^{32}$ by passing ink through an engraved cylindrical screen. Limited edition 'art prints' were produced using woodblocks, whereby each layer of colour and shape was hand-cut onto a separate tablet, inked and applied to cloth to create the pattern. By the end of the century it was possible to digitally transpose full colour, photographic-style images onto cloth using a single, computer-driven process. Changes in printing technology have had a major influence on the styling and level of detail inherent in textile prints. Other major factors include the prevailing silhouette as well as art movements, or styles, which continue to act as catalysts for innovative print styles. In addition to these factors there are enduring trends in print imagery for dress fabrics such as flowers, which are traditionally linked with female fashion and continue to feature strongly in designs (Carlisle 2002). Some print studios still expect their designers to be able to create 'beautiful drawings of flowers' as part of their skill base (Bannister 2003). ${ }^{33}$

According to Fletcher (1937: 23) to successfully design dress fabrics, the designer must have:

\footnotetext{
${ }^{32}$ Roller, or rotary screen, still accounts for most fabric printing production worldwide.

${ }^{33}$ A view expressed by Jane Bannister, director of Palm Studio, London (2003).
} 
...knowledge of the subject, and patterns both past and present, know how to make a good working drawing, and last but not any less important, he must study the prevailing fashions and the needs of the manufacturer in this connexion.

Fletcher (p.11) also provides an extensive list of motifs that are 'suitable decoration for fabric in which to drape the human form', which include: leaf forms, flower forms, vegetables and roots, fruit, animals, birds, reptiles, fish, insects and marine animals. Interestingly, she advises potential designers that the 'human figure' must be avoided as a motif for pattern, unless it is used in an antique context. ${ }^{34}$ In the 1930 s prints tended to be composed of floral elements, in multi-directional, repeats which were practical for the bias cut styling of the day (Hinchcliffe 1988). The versatility and economical aspects of this style of repeat, has led to its continued use within the mass clothing industry ever since (4.1.1).

In the 1950s the use of one-way prints and borders reflected the popularity of gathered dresses and skirts, as produced by the company Horrockses. Pat Albeck (1969: 21) was the chief textile designer for the company at this time and reflects that: 'occasionally, a print design was influenced by the garment shape, but the stylisation of imagery was largely governed by the printing process...a screen print could be much looser as the colour went on dry on dry. In roller printing all the colours went on together and the line-work could be much finer.' Another significant influence on textile design in the twentieth century was art and artists, with companies such as Horrockses, Ascher and Edinburgh Weavers' interest in well-designed prints resulting in their commissioning of numerous painters and sculptors (3.8). Such liaisons led to the creation of innovative print styles featuring sketches and painterly studies of sculptures, barbed-wire, landscapes, figures and abstract forms, that would not otherwise have found themselves on cloth (Mendes and Hinchcliffe 1987: 52). Parallels can also be drawn between influential painting styles such as Cubism, Futurism, Surrealism, Abstract Expressionism, Pop Art, Op Art etc. and the appearance of corresponding, textile prints.

The notion of creating a surface with drips was famously explored by Jackson Pollock, a leading member of the Abstract Expressionists. Pollock's work continues to inspire textile designers. ${ }^{35}$ The painter Robert Motherwell described his work as: 'a dialectic between conscious (straight lines, designed shapes, weighted colours, abstract language) and the unconscious (soft lines, obscured shapes, automatism)...'(Stangos 2001:171). Images such as Morris Lewis's Veils (Ibid.), Yves Klein's Drip paintings (Weitemeier 1995), Andy Goldworthy's (1996) Snowball and Damien Hirst's (1997)

${ }^{34}$ Egyptian pattern experienced a revival following the discovery of Tutankamen's tomb.

${ }^{35}$ As illustrated by Boyd's S/S 2000 collection which featured an abstract print called 'Pollock'. 
series of Circle Paintings demonstrate how paint can be manipulated to create fluid patterning (5.2.3). Optical Art, as practiced by the painter Brigit Riley has been an enduring influence on printed textiles. The repetition of controlled, monochrome linear or geometric elements can be used to create optical illusions on fabric and the form. Sonia Delaunay believed that her work in painting and fashion in the 1920s inspired the Op Art movement of the 1960s, and clear comparisons between her work and this style of mark making can be drawn (Figs.2-V - 2-Y).

Since the mid-1990s one of the strongest influences on printed textile imagery has been computer aided design (CAD), which has led to an increase in the use of photographic-style prints (Watkins 1999: 17). The use of digital cameras and peripherals has broadened the types of subject matter now employed as prints, as discussed in 4.1.4. Flowers are still the most popular embellishment of womenswear, but now often appear as 'hyper real' placements, as well as in repeating formats (4.1.4). Ultimately CAD has enabled prints to be rendered more realistically, or threedimensionally, which has affected the appearance of garments and in some cases the form in fabric. CAD has also opened up the possibilities for integrating imagery in new ways that challenge existing garment structuring methods, based on cut, make and trim (CMT). Although there is some evidence that CAD has influenced the styling of print imagery, the integration of printed textiles with garment shapes has only been explored on a fairly rudimentary level.

\subsubsection{Print Design Structures}

Fashion prints are generally created as 'croquis', ${ }^{36}$ which are reproduced in different repeating structures. In Repeating Patterns, Phillips and Bunce (1993) provide examples of some of the most popular repeating structures employed by the fashion (and furnishing) industry. On most textile courses, students are introduced to the notion of 'repeat' early on in the programme. ${ }^{37}$ The way that an image or design element is repeated can have a significant effect on the overall patterning of a piece of cloth, which in turn affects the appearance of a garment and the way that the form is iterated.

'Placement' prints are non-repeating structures that are popular within the fashion industry, as they can be placed on the front, back, hem or sleeve to add surface interest to a garment. Placement prints are sometimes referred to as 'engineered' prints:

\footnotetext{
${ }_{37}^{36}$ Printed textile design showing an arrangement of motifs, which can be repeated.

${ }^{37}$ At NTU first year students are introduced to a range of structures that include: half-drop, brick, mirror and composite repeats, which they annotate using CAD and manual techniques.
} 
An engineered print is a design printed directly onto a fashion garment, usually for catwalk designs, by a textile designer. It can be placed with exactness, avoiding seams and darts. A successful design that goes into production is (often) re-worked and printed on a continuous length of fabric (Braddock and O'Mahoney 1998: 176).

The strategic placement of an engineered print requires consideration of the garment shape, and how the imagery will equate with the overall structure. In the mass clothing market this technique is used in a manner redolent of T-shirt design, by placing an image on the front of a garment. At designer level, images are often integrated more strategically within the garment shape to attract attention to areas of the garment, and form. The growing use of CAD in association with digital printing techniques has led to recent growth in the application of this approach. In this research 'engineered prints' are explored in direct association with the garment structure.

\subsubsection{Print and Body Image}

According to Schilder our 'body-image ${ }^{, 38}$ can 'shrink or expand' depending on the clothing we wear.

... whatever comes into connection with the surface of the body is more or less incorporated into the body... Whatever article of clothing we put on immediately becomes a part of the body-image and is filled with narcissistic libido...since clothes are a part of the body schema, they gain a the same significance as part of the body (Quoted in Bergler 1953: 202).

In the wearing of plain garments the visual dynamic between body and clothes centres on the cut and quality of the fabric and its interplay with the form. The wearing of printed garments involves a similar dynamic, but with the added element of surface pattern, which can significantly alter the overall visual impression. A well-designed fashion print has to perform on three fundamental levels: to enhance cloth, garment and wearer. Different styles of print can have diverse effects on the appearance of the underlying form. This can be either an intentional or serendipitious outcome depending upon the tacit knowledge of the fashion or textile designer or through interaction between the two.

The exhibition, Pattern Crazy, recently proclaimed that 'pattern is back in vogue', a statement reinforced by contemporary fashion's revisiting of the 1970s (Taylor 2002). The reappearance of printed pattern on clothing (and furnishings) in recent years is in stark contrast with the 'understated minimalism' of the early 1990s (Jackson 2002: 31). Printed garments tend to send out more powerful visual signals than plain garments

${ }^{38}$ Body image: the picture of our own body which we form in our mind (Bergler 19xx: 202) 

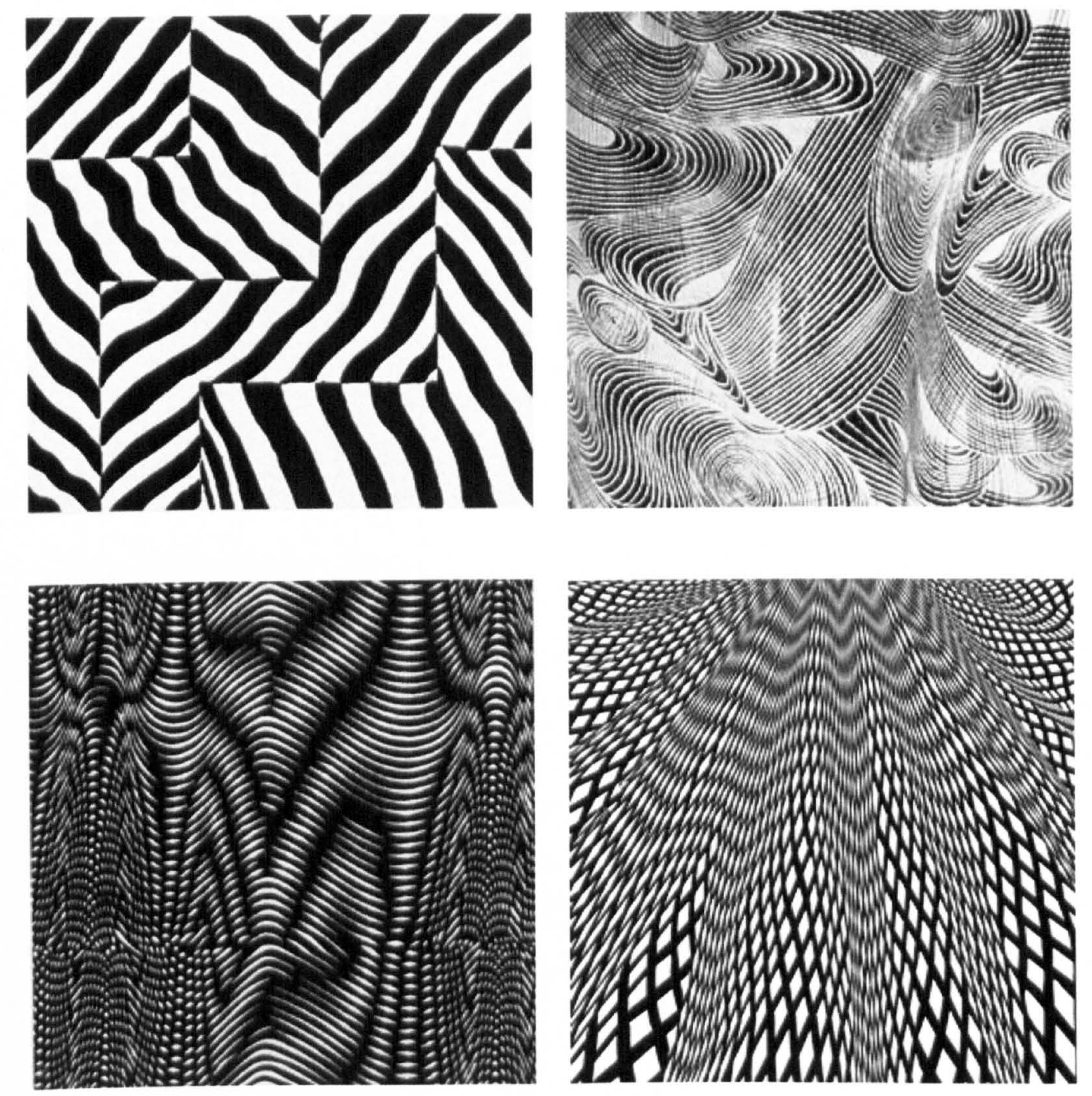

Figure 2-V Sonia Delaunay 1933: ‘Op Art' scarf and fabric design (Damase 1991)

Figure 2-W Unichi Arai 1989/90: 'Melting Off', polyester yarns coated in a metal devoré pattern (Colchester 1991)

Figure 2-X Cocky's Shed 1991: 'Brigit', optical print on cotton Lycra

Figure 2-Y Gillian Bunce 2001: Optical engineered print for Transforming Shape (supplied by the designer) 
because pattern attracts the eye and 'stimulates the senses by triggering activity in otherwise somnolent areas of the brain' (lbid.)

Pattern, colour and texture are employed both intuitively and deliberately by individuals to enhance their physical appearance, to convey gender, status, mood, and above all, 'image'. Within the rules of fashion people need to appear be 'social and individual' ' $^{39}$ at the same time, and printed clothing enables us to 'dress like our friends but not be clones' (Barnard 1996: 11). Print is just one of the many considerations faced by the postmodernist consumer who is expected to be a sophisticated interpreter of codes so as to be able 'to discriminate between alternatives, while at the same time identifying with chosen commodities, in order to articulate a particular persona' (Partington 1996: 212). Clearly, many issues inform the daily decision making process of what to wear, and I would suggest that the wearing of a printed garment can require greater consideration than that of a plain one.

While the exclusivity of couture offers customers a sense of individuality, interest in the use of print to customise garments is growing within the mass and independent sectors of the market. As discussed in 4.4.1, [TC]2 and Levi's have researched this area with some success. However, the most innovative ideas in this area can be found in the work of independent designers, who take a more 'hybrid design' approach to the relationship between the body, cloth and print (4.6). In my opinion this trend will continue with CAD/CAM being implemented by designers to create more individual products that tailor both shaping and patterning needs more closely to the aesthetic and physical requirements of the wearer.

\subsubsection{The Case for Fashioning the Form in Print}

The term 'fashion' is used as a noun to describe fashionable clothing, a way of doing something, or as a verb to describe the act of forming or making. Originally tailored garments were fashioned, by being designed, cut and sewn to accommodate an individual's body shape, which is where the term and the act became merged. Although most garments are no longer created on a bespoke basis, it is still widely accepted that garments are fashioned to fit and enhance the body. In contrast, prints tend to be conceived of, firstly; to enhance the surface of cloth, secondly; to enhance garments and thirdly to enhance the body. This observation is based on my tacit knowledge of the fashion industry where I learnt of the accepted hierarchy that exists within garment design, which places the form first, fashion or clothing design second and surface designers, third. This hierarchy was derived from the couture houses where the

${ }^{39}$ Quote attributed to Wilson, E (1992) Fashion and the meaning of life, The Guardian, 18 May, p. 34. 
couturier employed surface designers to complete his vision. There have been exceptions to this 'garment-led' (3.6) approach, determined by 'textile-led' designers and others, such as Delaunay who have combined cloth, print and form, from a simultaneous perspective (3.7).

I believe that within printed garment design, the body, or form, should be the key source of design inspiration, as this is the shape to be articulated through cloth. This thesis argues the case for rethinking the order of garment shaping and surface designing, by placing both disciplines on the same footing within the designing hierarchy. This thesis proposes that it is desirable for both fashion and textile designers to consider the form at the outset of the designing process. Observations of the way cloth performs on the form can influence decisions regarding the manifestation of surface print as well as the creation of garment shapes. The re-situating of textile design more closely to the form, also challenges the notion that surface designers have little influence on fashion, or the fashioning of the human body.

\subsection{CONCLUSION OF CHAPTER}

The influence of Cubism on fashion in the 1920s, led to the collapsing of garment shapes into soft cylinders and a move towards rectangular shaping strategies that fuelled the production of ready-to-wear. Rectangular shaping continues to dominate the mass clothing market, and be cut in a variety of basic repeating printed patterns. These are generally designed in a separate design environment from the garment, where practical and economic considerations dominate the way in which print imagery is configured.

The contemporary silhouette has evolved throughout the last century to be more streamlined. Fashionable garments are increasingly cut to articulate the natural body shape. The relating of stretch and fluid garment shapes close to the body requires a textile design approach that enhances both fabric and the underlying form. The body is considered and articulated differently by the couture, designer and the mass clothing sectors of the industry. Approaches vary between the extremes of an imaginary or fantasy female to the measurement-based, standardised body. Few individuals fit into either category, but the industry's interest in returning to made-to-measure principles, as practised in couture, could lead to better fitting styles that call for a more shape orientated application of print.

When a print designer works on paper, surface imagery is usually placed within a rectangular, flat shape, which represents a section of a length of cloth. However, if the 
textile designer configures imagery, not within a flat plane, but in association with a three-dimensional notion of cloth, as a draped material or garment shape, then the outcome is created in greater sympathy with the human shape.

Following the creation of the soft cylinder, which simplified garment shaping and fuelled ready-to-wear from the late 1920 s, the second significant influence on modern fashion is considered to be the widespread use of Lycra from the 1960 s onwards. Stretch fabrics have enabled imagery to interface with the contours of the body, leading to a reconsideration of the role of print and the development of new processes. 


\subsection{REFERENCES}

Albeck, P. (1969) Printed Textiles, London: Oxford University Press

Aldrich, W. (2002) Private interview with Professor Winifred Aldrich, Nottingham Trent University, 23/8/03

Aldrich, W. (2001) The Impact of Fashion on the Cutting Practices for the Woman's Tailored Jacket, University of Reading Conference: A History of Clothing: the business of Fashion or the Fashion of Business, 14 December 2001

Aldrich, W. (1996) Fabric, Form and Flat Pattern Cutting, Oxford: Blackwell Science Bannister, J. (2003) Private interview with Jane Bannister, director of Palm Studios, printed and woven textile designers, London, 14 April 2003

Barnard, M. (1996) Fashion as Communication, London and New York: Routledge Barnett, P. (1999) Folds, fragments, surfaces: towards a poetics of cloth in Textures of Memory the Poetics of Cloth, Nottingham: Angel Row Gallery

Barthes, R. (1983) The Fashion System, translated by M. Ward and R. Howard, New York: Hill and Wang

Bergler, E. (1953) Fashion and the Unconscious, New York: Robert Brunner Braddock and O'Mahoney (2002) check

Braddock, S. (2000) Textiles and Function within Fashion, Point, 9, 2000, pp.7-17 Braddock, S. and O'Mahony, M. (2000) Fabric of Fashion, London: Crafts Council Braddock, S. and O'Mahony, M. (1998) Techno Textiles, London: Thames and Hudson

Bell, Q. (1974) On Human Finery, London: Hogarth Press

Carlisle, H. (2002) Towards a New Design Strategy: A visual and cultural analysis of small-scale pattern on clothing, PhD Thesis, The Nottingham Trent University

Casadio, M. (1997) Emilio Pucci, London: Thames and Hudson

Carrucci, E. (2002) Closer, London: Chronicle Books

Colchester, C. (1993) The New Textiles: Trends and Traditions, London: Thames and Hudson

Constantine, M and Reuter, L. (1997) The Whole Cloth, New York:The Monacelli Press

Crane, D. (2000) Fashion and Its Social Agendas: Class, Gender, and Identity in Clothing, Chicago: University of Chicago Press

Crawford, A. (2003) Satisfying Consumer Demand, Seminar, The Textile Institute, Leicester, 6/3/03

Damase, J. (1991) Sonia Delaunay: Fashions and Fabrics, London: Thames and Hudson

Daves, J. (1967) Ready-made Miracle, New York: Putnam \& Sons

Denton, M.J. (1972) Fit, Stretch and Comfort, Textiles, Vol. 1, The Shirley Institute 
De Boos, A., Wemyss, A. and Rocznoik, A. (1991) The Fast and Kes-F Systems, A special report prepared for the FAST Management Committee, Keighley, International Wool Secretariat

De La Haye, A. and Wilson, E. eds. (1999) Defining Dress: dress as object, meaning and identity, Manchester; Manchester University Press

Deleuze, G. The Fold: Leibniz and the Baroque, translated by T. Conley, London: Athlone

Durandaud, C. (1996) The Luxury Goods Industry in a High Tech Era, Lectra Magazine, September

Entwistle, J. (2000) The Fashioned Body: Fashion, Dress and Modern Social Theory, Cambridge, USA: Polity Press

Entwistle, J. and Wilson, E. (1998) The Body Clothed, in Addressing the Century: 100 Years of Art and Fashion, London: Hayward Gallery

Evans, C. (1998) Martin Margiela: The Golden Dustman, Fashion Theory, Vol 2, Issue 1, pp. 73-94

Evans, C. and Thornton, M. (1989) Women and Fashion: A New Look, London: Quartet Books

Fer, B. (1998) The Pleasure of Cloth, in Liz Rideal: New Work, Exhibition catalogue, Angel Row Gallery, Nottingham, 30/5/98 - 4/7/98

Fernand, D. (2002) No More Frock Horror, The Sunday Times Magazine, 31/3/02, pp. 32-37

Flügel, J. C. (1930) The Psychology of Clothes, London: Hogarth Press, Rep. in 1971 Goldsworthy, A. (1996) Wood, Middlesex, UK: Viking

Hollander, A. (1998) Sex and Suits: The Evolution of Modern Dress, Brinkworth: Claridge Press

Gamber, W. (1997) The Millinery and Dressmaking Trades, Illinois, Chicago: University of Illinois Press

Giroud, F. (1997) Dior: Christian Dior 1905 -1957, London: Thames and Hudson Golding, J. (1997) Cubism in Stangos, N. Ed (2001) Concepts of Modern Art: From Fauvism to Postmodernism, London: Thames and Hudson

Hinchcliffe, F. (1988) Thirties Floral Fabrics, London: The Victoria and Albert Museum Hirst, D. (1997) I want to spend the rest of my life everywhere, with everyone, one to one, always, forever, now, designed by Jonathan Barnbrook, London: Booth-Clibborn Hollander, A. (1998) Sex and Suits: The Evolution of Modern Dress, Brinkworth: Claridge Press

Hollander, A. (1978) Seeing Through Clothes, New York: The Viking Press Kawabata, S. and Niwa, M. (1989) Fabric Performance in Clothing and Clothing Manufacture, Journal of the Textile Institute, 80 , No. 1, 1989, pp. 19-50 
Jackson, L. (2002) Who's Afraid of Pattern Design, Crafts, No. 177, July/August, pp. 28-31

Kirk, W. and Ibrahim, S. M. (1965) Fundamental Relationships of Fabric Extensibility to Anthropometric Requirements and Garment Performance, Orlon Lycra Technical Division, Textile Research Laboratory, E.I du Pont de Nemours \& Co., Delaware Kuryluk, E. (1991) Veronica and Her Cloth: History, Symbolism, and Structure of a "True" Image, Oxford: Blackwell

Lurie, A. (1981) The Language of Clothes, London: Heinemann

Lemoine-Luccioni, E. (1983) La Robe, Paris: Seuil

Lehmann, U. (1998) Stripping Her Bare: The Mannequin in Surrealism in Hayward Gallery (1998) Addressing the Century: 100 Years of Art and Fashion, pp. 88-95

Martin, R. (1998) Cubism and Fashion, New York: Metropolitan Museum of Modern Art Martin, R. (1988) Fashion and Surrealism, London: Thames and Hudson

McDowell, C. (2000) Jean Paul Gaultier, London: Cassell

McDowell, C. (1997) Galliano, London: Weidenfeld and Nicolson

Mendes, V. and De La Haye, A. (1999) 20th Century Fashion, London: Thames and Hudson

Mendes, V. and Hinchcliffe, F. (1987) Zika and Lida Ascher: Fabric-Art-Fashion, London: Victoria and Albert Museum

Milbank, C. (1985) Couture: The Great Fashion Designers, London: Thames and Hudson

Miyake, I. (1983) Issey Miyake Bodyworks, Edited by Shozo Tsurumoto, Tokyo: Shogakukan Publishing

Moffit, P. and Claxton, W. (1991) The Rudi Gernreich Book, Koln and London: Taschen

North, M. Ed. (2000) Relativities: The $4^{\text {th }}$ British International Miniature Print Exhibition, Leicester: Loughborough University School of Art and Design

O'Hara Callan, G. (1998) Dictionary of Fashion and Fashion Designers, London:

Thames and Hudson

O'Neill, A. (2001) Imagining Fashion: Helmut Lang and Martin Margiela, in Wilcox, C. Ed. (2001) Radical Fashion, London: The Victoria and Albert Museum Osma, G. de (1980) Fortuny: His Life and Work, London: Aurum Press Partington, A. (1996) Perfume, Pleasure, Packaging and Postmodernity, pp. 204-218 in Kirkham, P. Ed. (1998) The Gendered Object, Manchester: Manchester Univ. Press Phillips, P. and Bunce, G. (1993) Repeat Patterns, London: Thames and Hudson Rule, V. (2001) Strictures of the Fainter Sex, Review of The Corset: A cultural History by Valerie Steele, The Guardian, 10/11/01, p.9

Stangos, N. Ed (2001) Concepts of Modern Art, London: Thames \& Hudson 
Steele, V. (2001) The Corset: A cultural history, London \& New Haven: Yale University Press

Steele, V. (1997) Fifty Years of Fashion: New Look to Now, New Haven \& London: Yale University Press

Steele, V. (1985) Fashion and Eroticism, New York: Oxford University Press Taylor, L. (2002) Pattern Crazy, Exhibition catalogue, London: The Crafts Council The Independent (2003) Tales of the Unexpected, Living Review: Fashion, photographed by Jean Francois Carly, The Independent on Sunday, 2/3/2003, p. 38 Thompson, F. (2003) Fordism, Post-Fordism and the Flexible System of Production, www.williamette.edu

Vanci-Perahim, M. (1999) Great Modern Masters: Man Ray, New York: Harry N. Abrams

Watkins, P. (1999) The Appliance of Science, International Textiles, No. 806, Aug/Sept, pp.17-20

Weitemeier, H. (1995) Yves Klein (1928-1962) International Klein Blue, Koln: Taschen Wells, K. (1997) Fabric Dyeing and Printing, London: Conran Octopus Wilcox, C. Ed (2001) Radical Fashion, London: V\&A Publications Wilson, E (1992) Fashion and the meaning of life, The Guardian, 18 May, p. 34 
Chapter 3. The Spatial Garment: Sculptural, Architectural and Crossover Forms

INTRODUCTION

3.1. POPOVA'S SPATIAL GARMENT CONCEPTIONS.................................. 3-2

3.2. THE SCULPTURAL GARMENT ........................................................... 3-5

3.3. THE ARCHITECTURAL GARMENT ..................................................

3.4. THE CROSSOVER GARMENT …..................................................... 3-16

3.5. TEXTILE-LED GARMENT DESIGN ................................................... 3-21

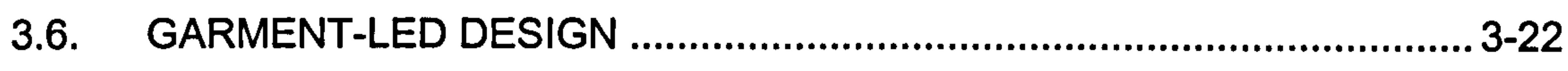

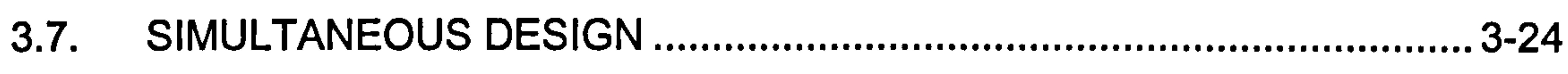

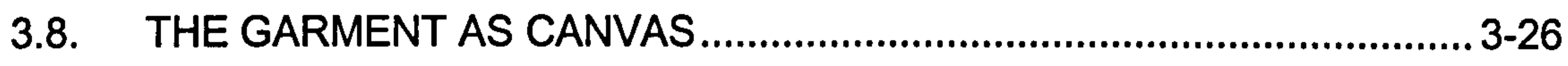

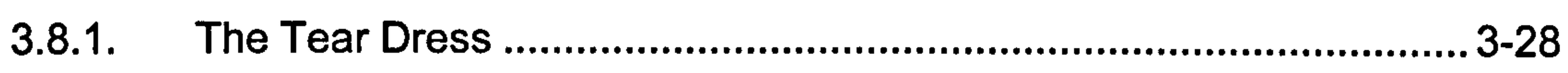

3.9. CONCLUSION OF CHAPTER ……...................................................

3.10. REFERENCES .............................................................................. $3-32$ 


\section{INTRODUCTION}

In Chapter 2, I established that it is primarily the fashionable silhouette that determines the way the female form is conveyed, and that print can play an influential role in the process of iteration. In this chapter I consider garment shapes as spatial forms that conduct print around the body in different ways. This idea stems from research into the work of the Constructivist artist Luibov Popova, who like Sonia Delaunay, approached textile and garment design and with an innate sense of its 3D application. The chapter describes three archetypal shapes: 'sculptural' and 'architectural', identified through analysis of Popova's work, and 'crossover', a category created by this research. The three models have provided a practical framework for categorising garment styles from the Twentieth Century and the aesthetic association of surface embellishment that is appropriate to those forms.

In addition to identifying these spatial archetypes, the research has identified four different design approaches that have been applied to printed garment design; 'textileled', 'garment-led', 'simultaneous' and 'the garment as canvas'. Each approach places a contrasting emphasis on the role that the printed textile plays within the design equation. For example a textile-led design may be configured around the style or decorative detail of a print, a garment-led piece places greater emphasis on structural detail, a simultaneous garment illustrates an equal consideration of print and cut, and when treated as a canvas, a garment provides a surface for graphic or conceptual imagery.

\subsection{POPOVA'S SPATIAL GARMENT CONCEPTIONS}

As a designer of printed garments, I am able to envisage a print design as a threedimensional form. Although some textile designers work in this way the ability to conceptualise a 2D pattern as 3D shape is more prevalent within garment design, which is inherently focused on the form. Traditionally, artists have a strong affinity with the form, having often learnt their craft by painting and sculpting the nude. The practice of depicting three-dimensional space and form on a two-dimensional canvas enables painters to readily diversify into the area of surface design. The switch from fine to applied art can lead to new approaches, as demonstrated by both Popova (1889-1924) and her Russian contemporary Delaunay ${ }^{1}$ (1885-1975) who were creating innovative printed garment designs in Russia and France in the early 1920s. My interest in Popova's work is focused on her design approach, rather than the specific design outcomes.

\footnotetext{
${ }^{1}$ Delaunay emigrated from St. Petersburg to Paris in 1905.
} 
Liubov Popova was a protagonist of Constructivism, ${ }^{2}$ which stands alongside Cubism and Futurism as one of the defining movements of Avant Garde art at the beginning of the twentieth century. By the early 1920s, Popova, along with her colleagues Vivara Stepanova and Alexandra Exter, had applied the theory of Productivism ${ }^{3}$ to her practice in Soviet Russia, emerging as 'a master of textile design' (Adaskina 1999: 188). Popova's textiles derived much from their links with her painting style, which synthesised a number of artistic movements. In his essay, Liubov Popova and Artistic Synthesis, Sarabianov (1999: 191) describes the distinctive characteristics of her painting as, 'a precise sense of up and down, a frontality in the construction of form, and a strong awareness of foreground and surface.' Such aesthetic considerations are implicit in the design of printed textiles and garments.

Popova's relief paintings from 1915 onwards had anticipated the interaction between forms and space, the tension between the static and dynamic, and centrifugal and centripetal forces (Ibid). She translated these concepts through surface pattern on to clothing, to create new dialogues between abstract patterning and its animation by the human form. Consequently, Popova's works express an 'anthropomorphic spirit', not because the forms recall the human figure, but because the creative principles themselves are 'human, natural and simple' (Ibid.). Like Delaunay, Popova took the canvas and wrapped it around the figure, with the intent of exploring 'the highest correspondence between pattern, body, and fabric' (Adaskina 1990:303). She integrated geometric prints with great attention to the structure of her garments, integrating contrasting aspects of the design with different garment pieces, to create an interesting visual composition (Fig.3-A). Popova's printed garment designs reflected her artistic conception of 'clothing as spatial form', as understood by Adaskina:

Her clothing was a spatial-architectural rather than a sculptural-architectonic phenomenon. The human figure was conceived as a constructive carcass bracing, supporting the clothing at precise, designated points. Otherwise the outfits had a life of their own - the construction of the human body and a spatial envelope of fabric.

In contrast, with a spatial-architectural shape, Adaskina (Ibid.) alludes to a 'sculpturalarchitectonic' garment as being 'constructed on the motif of soft, draping, figure

\footnotetext{
${ }^{2}$ Constructivism was based on the elimination of easel painting. It applied a three-dimensional Cubist vision, inspired by the sculptor Alexander Archipenko and by Picasso's reliefs of 1912-14, first to wholly abstract non-objective 'constructions' with a kinetic element (1914-20) and thereafter to the new social demands and industrial tasks of the time. The Fontana Dictionary of Modern Thought, 1979, p. 133.

${ }^{3}$ After the October Revolution of 1917 many Russian artists diversified into new, more practical fields of expression. As well as textiles, Popova investigated stage, costume, book and poster design.
} 

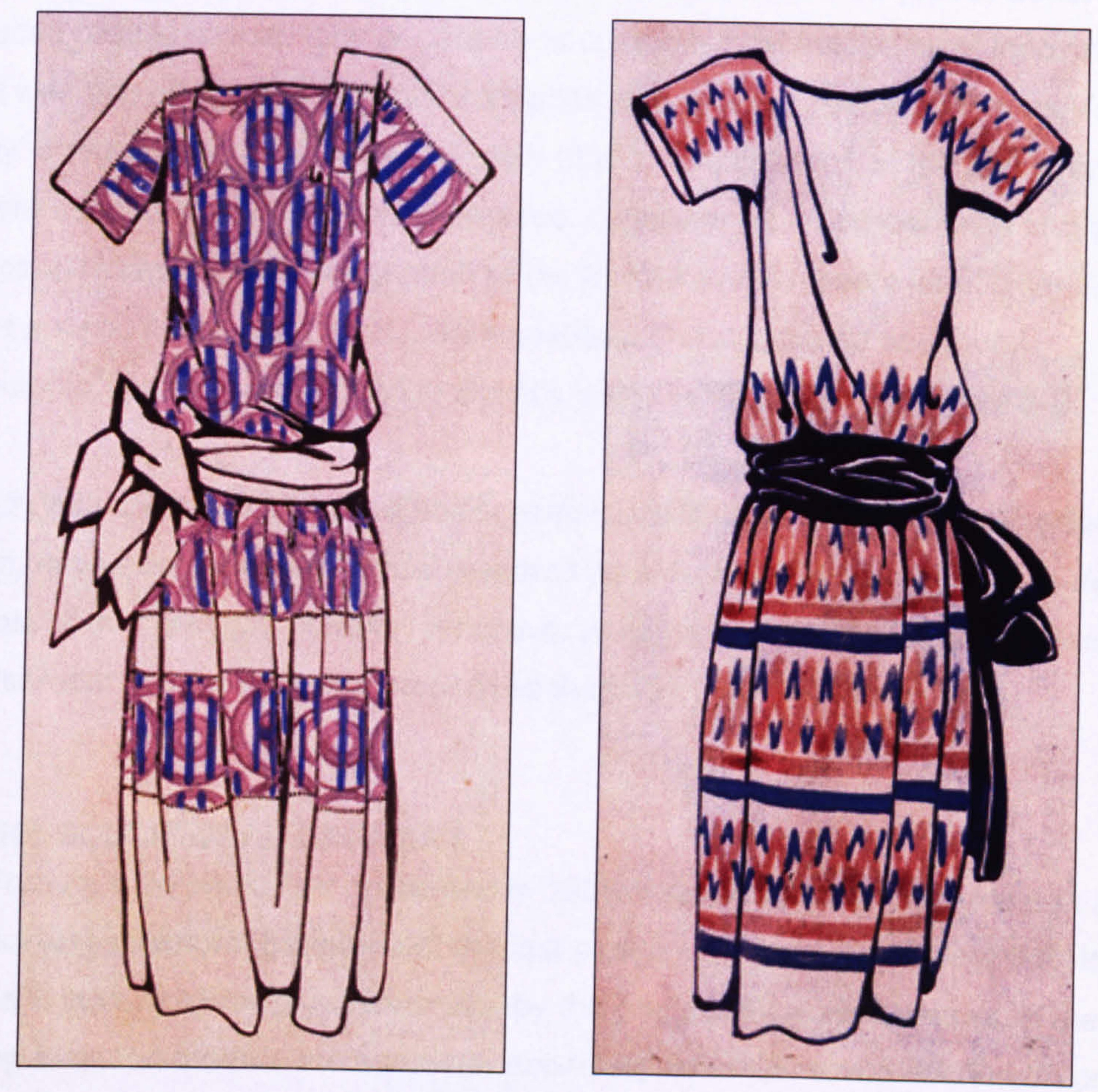

Figure 3-A Luibov Popova 1923/4 Dress designs (Adaskina \& Sarabianov 1991) 
enveloping fabric,' implying that this style necessarily relies more closely upon the body for its expression.

The art historian John Bowlt (1976: 16) suggests that Popova's novel, spatial conception of clothing was inspired by Leon Bakst's costumes for Sergei Diaghilev's Ballet Russes (1910-14). In Scheherazade and L'Oiseau du Feu (1910) Bakst introduced radical conceptions of décor and costume in which the most innovative aspect was the 'underlying method of emphasizing and exaggerating the body's mobility' through different volumes of cloth (Ibid.). The absence of the corset and brassiere combined with long loose dresses, consisting of 'cadential folds and a halfmoon base maintained his conception of the female anatomy as a kinetic generator and not a static figure eight' (lbid). Both spatial-architectural and sculpturalarchitectonic ${ }^{4}$ forms can be found in Bakst's work, as illustrated by Figure 3-B.

The architectural and sculptural spatial garment definitions, elicited from Popova's practice, have been adopted by this research as a method for categorising fashionable garments of the twentieth century. Wherever possible, styles of print and surface embellishment have also been categorised in relation to these forms.

\subsection{THE SCULPTURAL GARMENT}

Mario Fortuny's Delphos, first presented in 1908 is considered by this research as one of the earliest sculptural garments of the last century. As shown in Figure 3-C, the tubular silk structure was given its shape by the body; the creased texture of the cloth adjusting to accommodate the contours, especially when in movement. When printed, the Delphos was decorated at the hem with a simple stencil which enhanced the natural, kinetic patterning created by the interaction between pleats and form. The pleating acted as both structural and surface detail, in common with the classical drapery that inspired it (1.7). The Delphos described the body shape, while from a distance appeared to be composed of linear patterns that visually contoured the form. ${ }^{5}$ Some of Issey Miyake's Pleats Please collections ${ }^{6}$ embody the characteristics of the sculptural model. The micro-pleated structure of the garments can expand and contract to fit a range of shapes, and like the Delphos they have a timeless, universal quality leading them to be worn by women of all ages. ${ }^{7}$ Some of Miyake's early designs were based on the idea of a 'second skin'; that a garment gains meaning from the body that it is draped around, a concept inspired by Vionnet (Falkman 2002: 58).

\footnotetext{
${ }_{5}^{4}$ From this point in the thesis these forms will be referred to as 'sculptural' and 'architectural'.

5 The notion of trompe l'oiel printed pleats is investigated in Square (7.3).

6 Such as the Pleats Please Scarf, which like a chiton, can be worn in a variety of different ways.

7 See Benaim, L. (1997) Issey Miyake, London: Thames and Hudson
} 

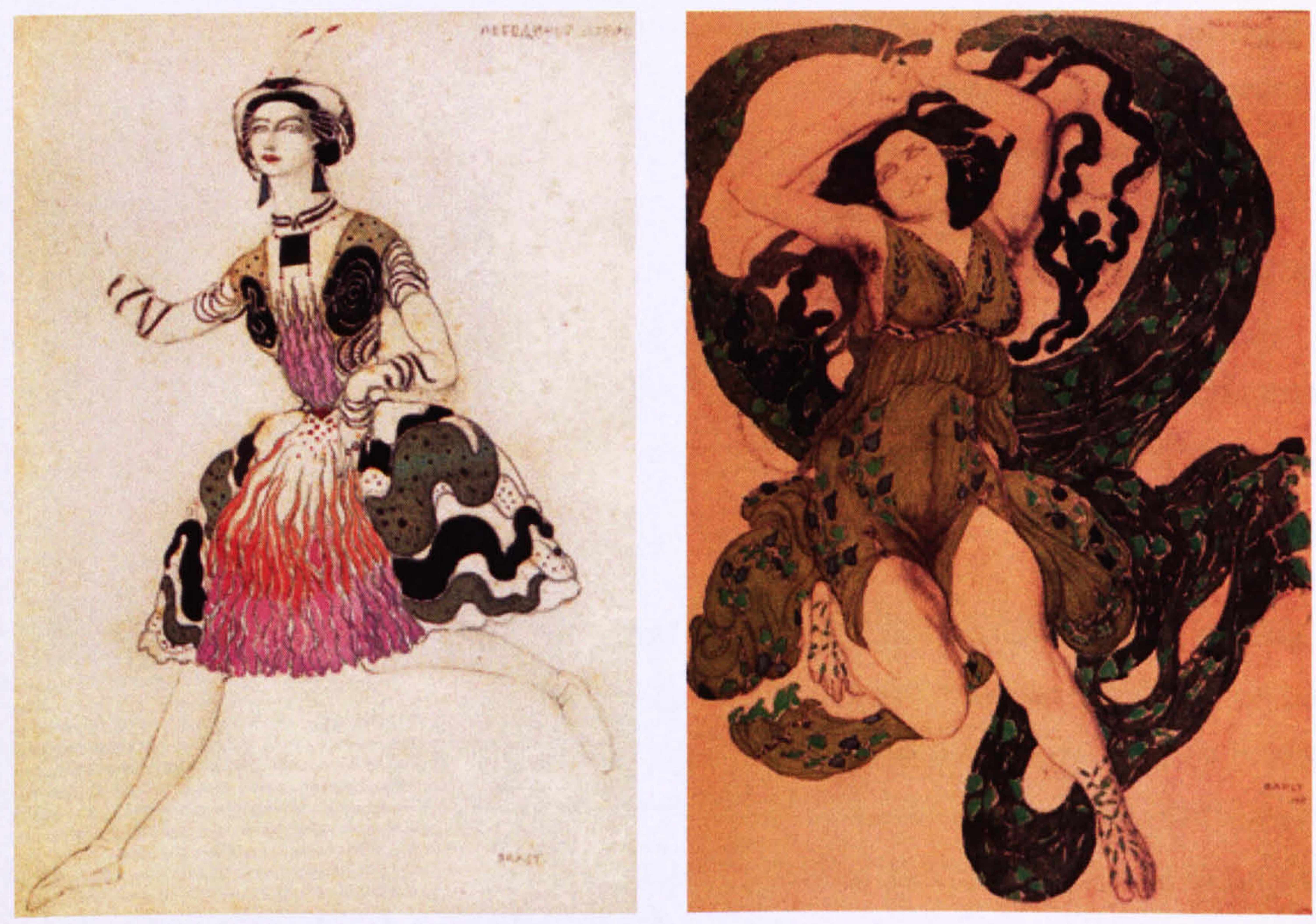

Figure 3-B Léon Bakst: architectural costume for Anna Pavlova in Swan Lake (1908) and sculptural design for the Nymph in Narcisse (1911) (Schouvaloff 1991) 
The garment designs of the French couturiere, Madeleine Vionnet are legendary for their complexity and their ability to mould to the body contours. Vionnet has often been described as a sculptress, who used fabric as her sculpting medium and her bias cut garments of the 1920s and 30s epitomize the sculptural model. Milbank (1985: 160) suggests that Vionnet was the first designer to approach fabric in a modern way; 'working with the natural body of the twentieth century- she moulded the dress to the woman, rather than the woman to the dress.' Vionnet's 'bias cut ${ }^{8}$ transformed the smooth cylinders of the 1920 s into garments that interacted with the form. Although she rarely used print, but her embroidered garments provide important examples of the restrained, highly considered style of embellishment that I consider to be most appropriate for sculptural garment styles. Vionnet's three-dimensional, modelled approach ensured that the strategic manipulation of the fabric often provided sufficient surface interest, and where it did not, she incorporated surfacing techniques that followed the line of the piece so closely that it appeared to be 'welded into the material' (Latour in Bryant 1991: 74). Figure 3-D shows a wedding dress with embroidered detail integrated with the structure of the sculptural shape.

The work of Alix Grès ${ }^{9}$ is often compared with that of Vionnet. Grès's early training as a sculptor is obvious from the Grecian draping and the use of the female figure as both inspiration and anchor (Milbank 1985: 154). When they first appeared Grès's dresses were described as 'Gothic statuary', an effect she achieved by directing the flow of her pleats with her hands then stitching them into place so that they appeared to be woven into each other (Ibid.) As Grès stated:

I have always respected the structure of the body and the natural movement of a given material. I limit the number of seams to give a better impression of freedom of suppleness, of silhouette. I like to make a body look beautiful to enhance its its qualities, to make the waist look thinner, a bust higher; I want people to guess about the body underneath.

The designs of Ossie Clark resonate with the work of Vionnet and Grès, and his bias cut dresses of the 1970 s perfectly illustrate the printed sculptural garment. Clark integrated Celia Birtwell's feminine, floral prints in a manner that always flattered the underlying form, sometimes cutting on the straight of grain and the bias to align the print with the contours most effectively. Clark used 'crepe and gauze in a way it had never been used before... his cut and Celia's prints were indivisible' (Boler in Clark 1998: 26) (Fig. 3-E). As Watson (1999: 2) states: 'what made him totally unique was his

\footnotetext{
${ }^{8}$ The cutting of all or parts of the garment on the diagonal, or bias, rather than the lengthwise gain allows the fabric to be shaped over the body contours (Bryant 1991: 73). See Figure 1-I.

${ }^{9}$ See Figure 2-G.
} 

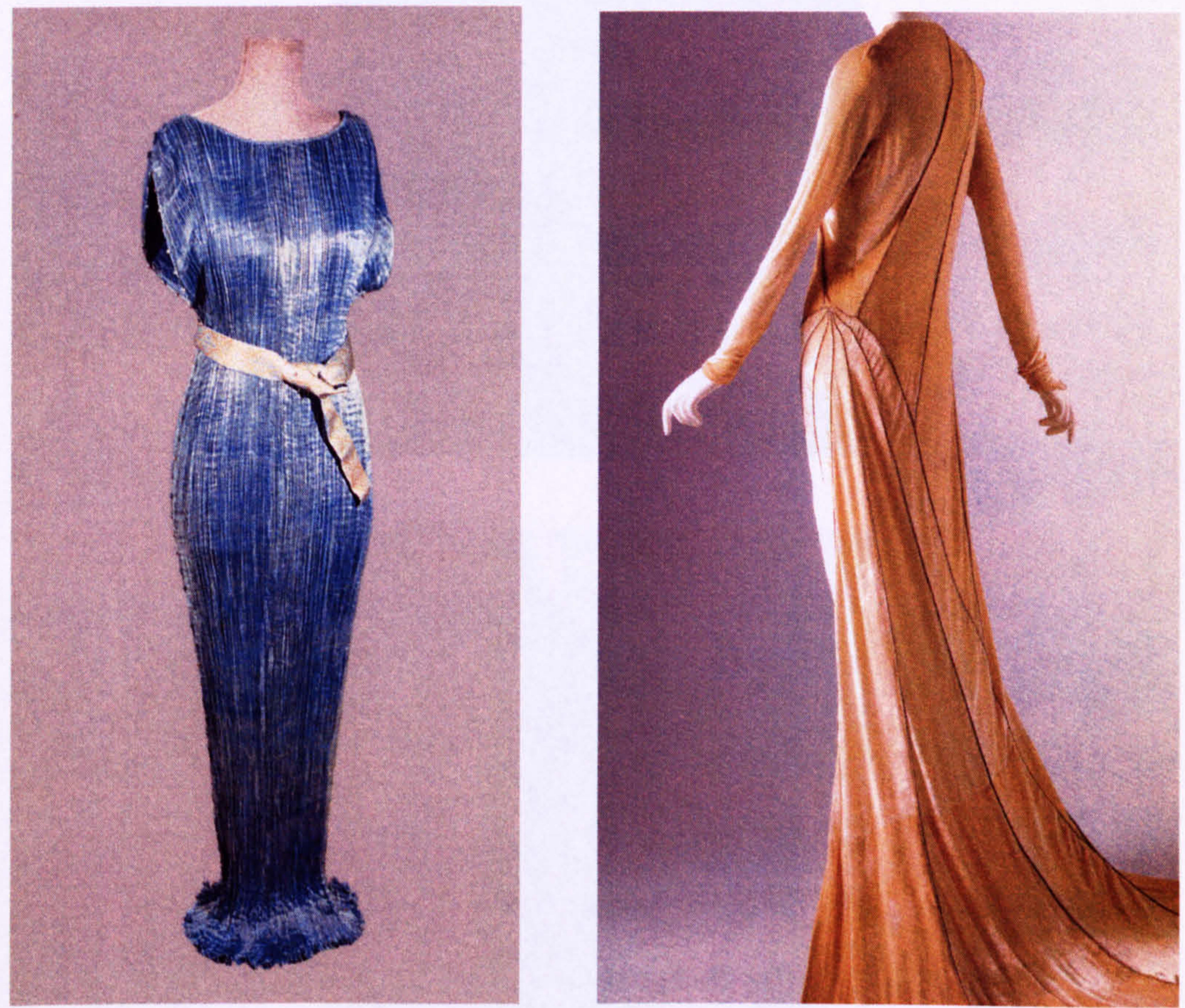

Figure 3-C Mariano Fortuny 1907: Delphos (Hayward Gallery 1998)

Figure 3-D Madeleine Vionnet 1930 Embroidered Wedding dress (Martin 1998) 

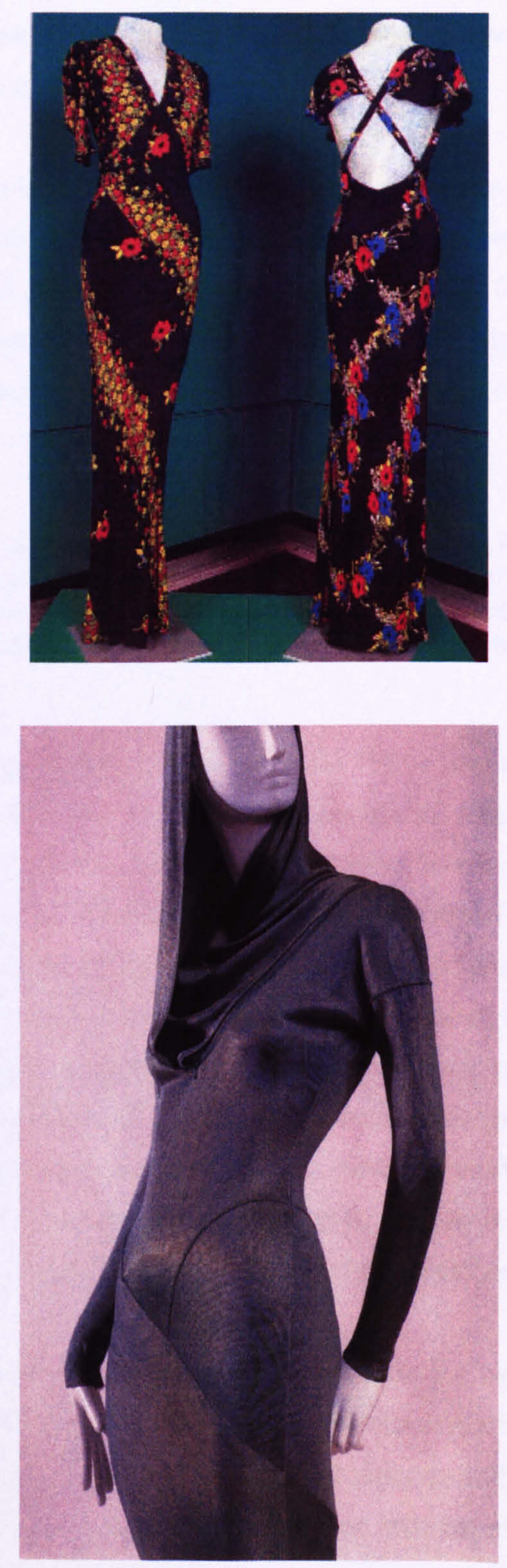

Figure 3-E Ossie Clark 1974: Printed crepe dresses featuring prints by Celia Birtwell (Watson 1999)

Figure 3-F Azzedine Alaia Winter 1986: Mermaid dress (Steele 1997) 
absolute understanding of the female anatomy: ${ }^{10}$ how it worked, moved and responded. Sexuality was always part of the package, but it was comfort, which Ossie regularly cited as the most important thing.

The revival in the use of Lycra in the late 1980 s and early 90 s, discussed in 2.3.2, resulted in garment shaping that was wholly dependent on the contours of the form. Fine gage knitted fabrics provided new levels of comfort and fit, enabling garments to mould to the form as a second skin. Shapes created with a high elastic content, by designers such as Azzedine Alaia, literally sculpted the body into shape (Fig.3-F), as White (Quoted in Steele 1997: 124) states:

The strong, abstract seams were the secret of the perfect Alaia fit, those pathways laid down on the bias across the body, lines as magical as the tailor's dummy stitching in the metaphysical paintings of de Chirico or the mysterious flow charts of the acupuncturist - lines that lovingly cup breasts, whittle the waist, lift legs, mold legs.

Gianni Versace's rippling sculptured gowns of the 1980s and 90s were some of the most opulent of recent decades. The form was central to Versace's garment styling, reinforced by the 'supermodels' ${ }^{\prime 11}$ that wore his clothes. Printed and embroidered embellishment was featured heavily on his dresses 'that often appeared moulded to the body $^{\prime 12}$ (Buckley and Gundle 2000: 339). A famous printed piece, the Warhol Dress (1991) features a repeat of Marylin Monroe and James Dean and although the print does not particularly follow the contours, further emphasis is placed on the breasts through the application of beading. Donatella Versace's designs continue to explore the sensual relationship between garment and form, which she often achieves with the use of abstracted, fluid prints. She recently explained her highly feminine as styling to be the result of the fact that she understands women's bodies because she is a woman. ${ }^{13}$

Current sculptural approaches can be identified include the work of the American designer Rick Owens and UK - based Sophia Kokoslaki. With both these designers we return to the body-centred designing principles of Vionnet and Grès with the dialogue between the drapery and form, creating the surface interest of the garment. Owen's dresses are often fabricated from deconstructed garments, which he melds into alternative body defining creations. Kokosalaki combines pleated leather and draped

\footnotetext{
${ }^{10}$ A talent expanded upon by Birtwell in The Ossie Clark Diaries, The South Bank Show, LWT 1998.

${ }^{11}$ Versace is credited with creating the cult of 'supermodel' by turning top photographic models into celebrity clothes-horses to attract attention to his garments (Buckley and Gundle 2000: 340).

${ }_{12}$ Quote attributed to Alexandra Schulman.

${ }^{13}$ Donatella Versace in Fame and Fashion: Inside Versace (2002), Channel Four, Diverse.
} 
jersey to create contemporary configurations based on Greek drapery, which she describes as: 'feminine, confident and realistic' (British Elle 2001: 191) (Fig.3-G).

I consider that the most appropriate decoration for a sculptural garment to be composed of fluid elements that follow the rhythm of the drapery and/or the contours of the underlying form. Alternatively, the fabric of the garment can be manipulated in such a way, that sufficient surface interest is manifest through the drapery. Although every garment is dependent on the body for its realisation, a sculptural model is often entirely reliant on the shape of the contours for its aesthetic expression. The fluid fabric qualities often used to create sculptural styles, can result in garments that appear as unstructured lengths, or, in the case of the Delphos or Pleats Please Scarf, twisted pieces of cloth, that are brought to life by the body of the wearer. It follows that any imagery that comes into contact with the surface of a sculptural garment, also tends to interface directly with the underlying form, and therefore has a greater capacity to affect the visualisation of that form. Consequently, fluid print styles, as discussed in 2.4.3, harmonise well with sculptural forms, as illustrated by the work of Donna Karan for the Venice Biennale (3.8). Hussein Chalayan's S/S 2003 combines a complex distressed cut in stretch fabric, with camouflaged-style stripes that underpin the sculptural shaping, while McQueen's use of prints featuring layers of feathers, flow with the volumes of the garment and form (Fig. $3-\mathrm{H})$.

\subsection{THE ARCHITECTURAL GARMENT}

Having identified architectural styles in Bakst's (3.1), additional architectural examples have been selected from twentieth century fashion. The architectural model provides a strong contrast with the sculptural form; often appearing as a structure that is supported by, yet autonomous of the body. The strong silhouettes promoted through the architectural model can be integrated with a greater variety of surface pattern, as observed by Adaskina (1991: 303):

This spatial element, so 'emancipated' from the human figure, made possible the vivid decorativeness of the large geometric patterns, the colour expression, the clearly articulated inner logic of ornament that does not quite fit the proportions of the body.

The first architectural pieces of the twentieth century can be attributed to the exaggerated shaping of the Belle Epoque, still in evidence in the early 1990s (2.3.1). Although embroidery was very fashionable for the embellishment of evening gowns at this time, prints were becoming more popular for day dresses. Plant forms and flowers 

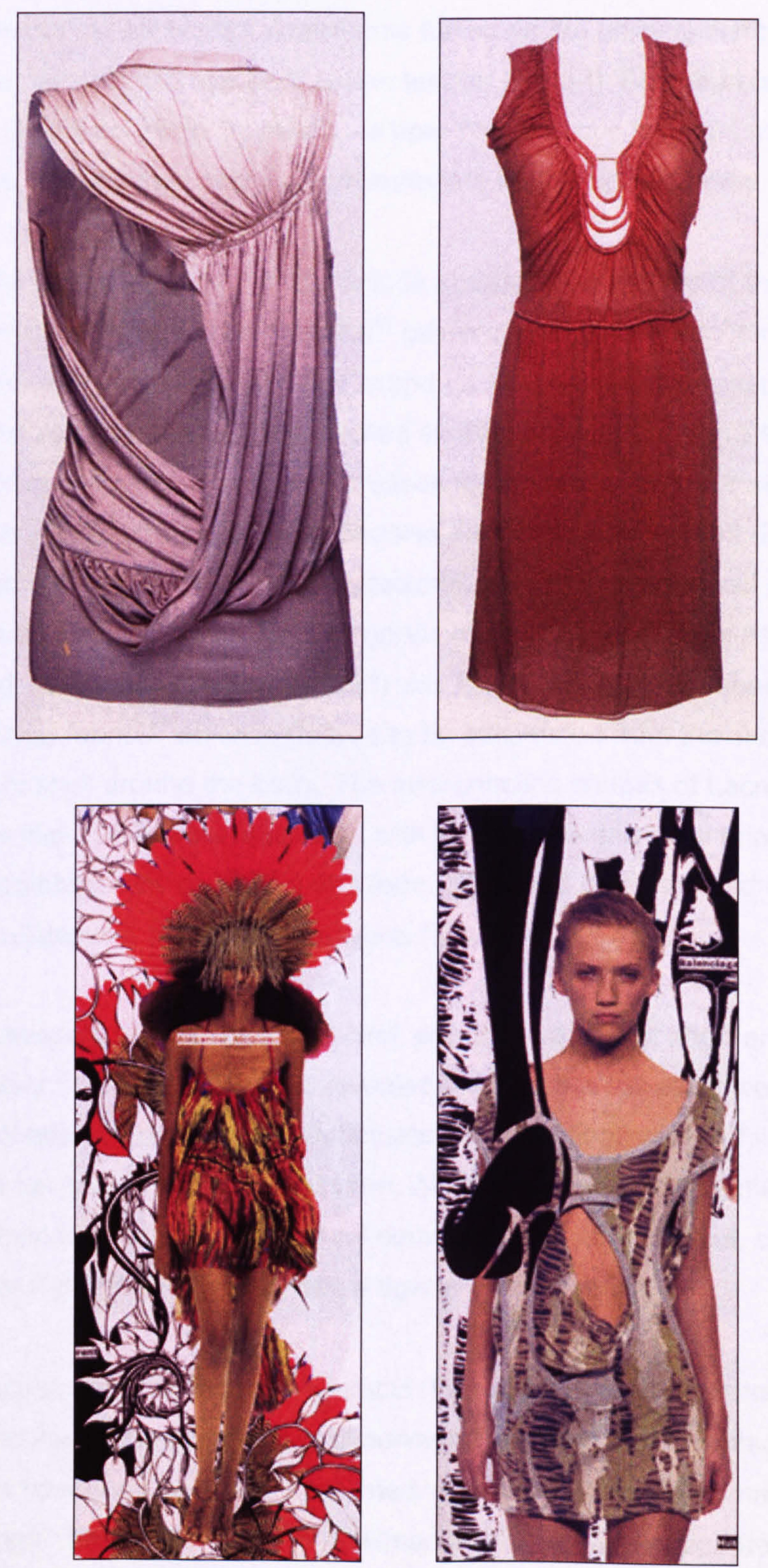

Figure 3-G Rick Owens Asymmetric Vest (1) and Sophia Kokoslakis Nude Dress (Guardian Weekend 2003)

Figure 3-H Alexander McQueen and Hussein Chalayan S/S 2003 (Frankel 2003) 
in all-over and striped structures were integrated with the still-generous volumes of the period. In the widely acclaimed Sensation exhibition (1997) the artist Yinka Shonibare ${ }^{14}$ created a collection of architectural garments based on the unlikely combining of Victorian dress with African wax print cotton textiles (Fig.3-I). Shonibare's exuberant use of pattern and form perfectly illustrates how the generous volumes of the architectural model can successfully accommodate bold, colourful prints.

Christian Dior's garments of the 1950s include archetypal examples of the architectural model. The large volumes of skirt material ${ }^{15}$ gathered into the re-corseted waists of the New Look silhouette provided enormous scope for the use of large bold prints. ${ }^{16}$ In couture Balençiaga and Jaques Fath created simililar styles around this time, while Horrockses produced ranges of printed dresses for the mass market that employed large florals and directional prints to emphasise full skirts (Albeck 1969: 21). While fullskirted garments are most obviously architectural, geometric shapes cut closer to the body can also be emancipated from it, depending upon the fabric they are constructed in. Pierre Cardin's Egg Carton dress (1968) was fashioned in a permanently molded, three-dimensional fabric, ${ }^{17}$ which appeared to be suspended from the shoulders to form an independent shell around the body. The mini-crinoline shapes of Lacroix and Versace in the mid-1980s were integrated with bold stripes and floral prints that created strong visual combinations of pattern and form. Versace's bell-shaped dress is composed of a jigsaw of floral printed shapes (Fig. 3-J).

Vivienne Westwood's rose printed 'mini-crini' presented a similar short architectural shape that unlike the original crinoline revealed the legs but still eschewed the natural body shape. Westwood continues to punctuate her collections with architectural pieces that reference her love of historical costume. At the Radical Fashion exhibition Westwood provided a further architectural combination of print and cut, by juxtaposing a romantic dress shape from 1890 s with a tiger print from 1990 s.

The Italian fashion designer Roberto Capucci (Fig. 3K) has designed architectural shapes that incorporate a strong three-dimensional element that is rooted in the Renaissance's horizontal lines and articulated shapes: clothes that demand big rooms and high ceilings' (Falkman 2002: 58). Falkman (Ibid.) likens the appearance of Cappucci's garments to 'static Murano vases' and describes them as: 'not art in the

\footnotetext{
${ }^{14}$ Shonibare's work raises issues of identity, culture and memory. His work was also featured in Secret Victorians (1998), Ikon Gallery, Birmingham and Personal Effects (1999), Angel Row Gallery, Nottingham. ${ }_{15}$ Up to 12 yards of fabric were used in Dior's skirts (Ref).

${ }^{16}$ See Figure 2-H.

17 The dress was constructed from Cardine Dynel (Steele 1997: 68).
} 

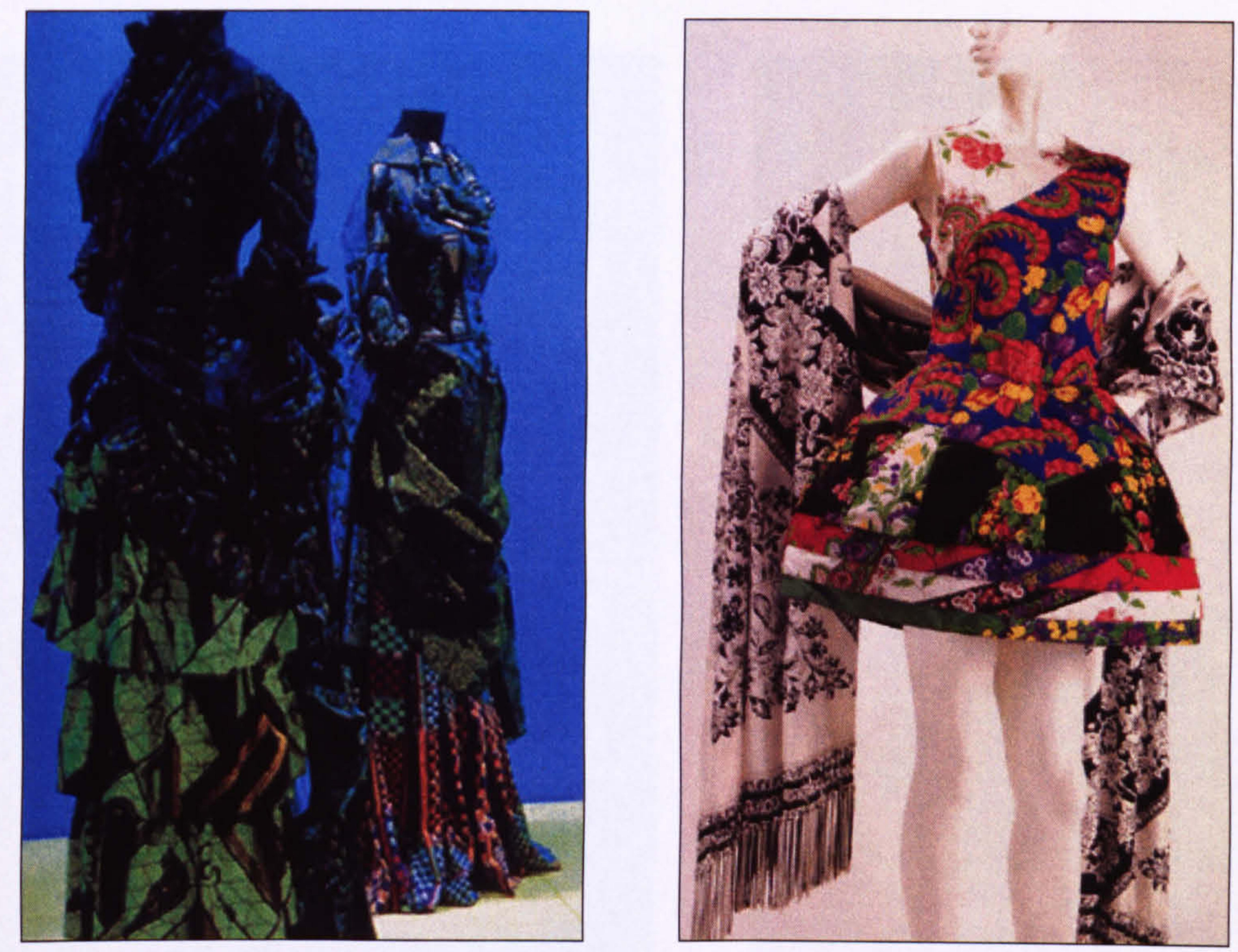

Figure 3-I Yinka Shonibare 1995: 'How does a girl like you, get to be a girl like you'? (Rosenthal et al 1997)

Figure 3-J Gianni Versace S/S 1988: Printed evening dress with panniers (Martin 1997) 

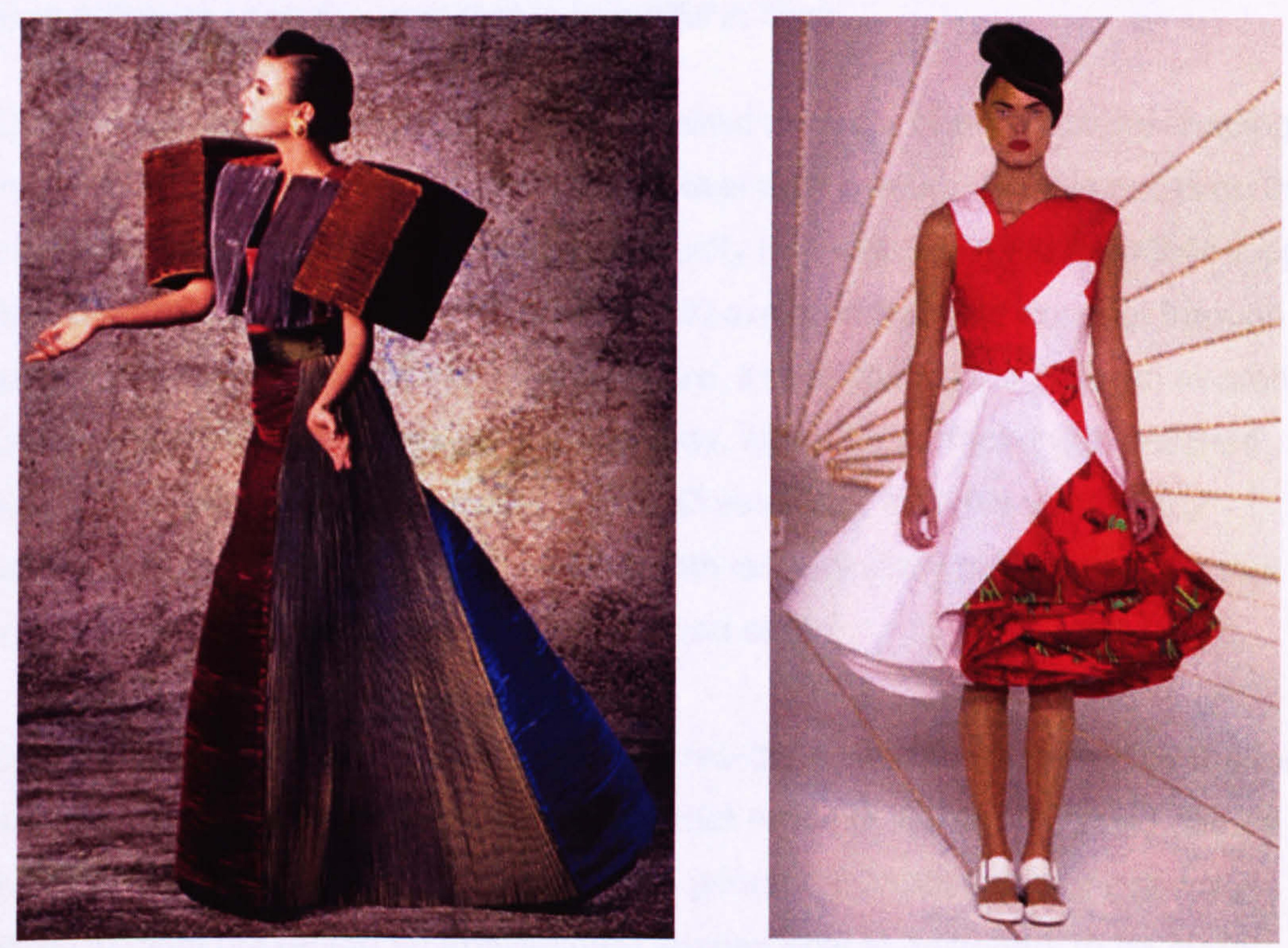

Figure 3-K Roberto Capucci 1985: Blades (Hayward Gallery 1998)

Figure 3-L Hussein Chalayan S/S 2001: Poppy Dress, Ventriloquy (Wilcox 2001) 
sense of sculptures, but rather fanciful adaptations of past fashions with the addition of a modern idiom. It is therefore more apt in Capucci's case to talk about architectural shapes. $^{18}$

As everyone knows it is only possible to hang clothes around the neck and on the shoulders, waist and hips. The eternally recurring question is whether the garment should be allowed to limit the body's movements in order to achieve a form à l'haute couture - one that is beautiful in itself.

McQueen's Lampshade skirt (1999) is an inspired example of architectural shaping that borrows from Poiret's creation from the early twentieth century. On this occasion the shape is rendered in metal, having no opportunity to interact with the form that supports it. Hussein Chalayan's After Words (AW 2000) explored a similar concept through garments that converted into pieces of furniture. In this collection Chalayan treated space as an architectural zone around the body, which he surfaced with polished panels of wood veneer. A later piece, Poppy Dress (3-L), from his Ventriloquy collection (S/S 2001) combines minimalism with large digitally printed poppies that echo the three-dimensional shape of the layered skirt.

To summarise, the architectural garment is three-dimensional, supported by the form, yet independent of its contours. It is a shape that exists in its own right and can be surfaced with pattern accordingly. The strong geometric shapes and/or generous volumes of cloth presented by architectural shapes enable designers to be more experimental with surface pattern than sculptural garments, presenting the opportunity to adopt a 'garment as canvas' approach (3.8). The architectural garment often presents an artificial shape, that if required could 'stand by itself' and whose structure generally remains unaltered by the introduction of the form. The garment's autonomy from the body facilitates the integration of a wide variety of print styles that can interact with the surface volumes of the garment, with a minimum of disruption to the form.

\subsection{THE CROSSOVER GARMENT}

While it still is possible to identify architectural and sculptural archetypes within haute couture, it has become increasingly difficult to do so in the mass clothing market after the mid-1960s. The main reason for this change can be pinpointed to the increased use of manmade fibres, resulting in new fabric qualities and new shapes that incorporate elements from both archetypes; structured/tailored (architectural) and unstructured/draped styles (sculptural). In order to recognise this change, I have

\footnotetext{
${ }^{18}$ The static nature of his creations was striking, and they looked as if they needed attendants in order to be moved forwards.
} 
devised a third 'crossover' category. The crossover shape evolved out of the style explosion of the 1960s and 70 s that embraced the stark shaping of Courrèges and the ethereal styling of Biba. Despite the contrasts in fabric quality and volume, neither of these shapes stood emancipated from the form, nor cleaved to it in a sculptural manner.

One of the first designers to create crossover shapes was Emilio Pucci, who cut shift dresses in stretch silk ${ }^{19}$ that 'skimmed' the body (Kennedy 1991: 47). The combination of a geometric shape integrated with a brightly coloured, optical print was revolutionary (2.4.3). The prints were often executed on a large scale that would have suited the proportions of an architectural shape, but by cutting them close to the form, he created a new dialogue between print, cut and the body. Pucci's prints were multi-directional, alluding to pattern itself, as opposed to the body (sculptural) or the garment (architectural). Pucci manufactured his own stretch silk jersey, which has sculptural, body-defining characteristics. However, the simple geometric shaping and lack of drapery resulted in crossover shapes. Figure 3-M shows pieces by Pucci and Halston; in both cases the fluid print style provides the focus of the garment.

Jean Muir's shapes fit into a crossover category. Muir's extensive use of jersey informed her cut, which was relaxed, but not clinging, comfortable, 'classic'. As Muir states:

The first thing to remember when thinking of clothes is that you are covering a body that already exists; that is the reason for the craft. Secondly, to remember that the body comes in different shapes and sizes and thirdly, that the body moves (Leeds Art Galleries 1980: 11).

Muir's consideration of the form raises parallels with Vionnet's practice, but the shaping is different. Although Vionnet used jersey fabrics in the 1930s, her shapes were based on classic drapery, while Muir exploited the relatively new concept of fabric 'ease'. This quality was heightened through the use of Lycra, which allowed the body to move slightly beyond the boundary of the cloth, and garment.

In the early 1980s the Japanese designers introduced the fashion world to a nonWestern idea of clothing based on the belief that cloth comes first and that shape follows. The Japanese viewed the figure as a landscape: horizontally, asymmetrically and in the round resulting in new shapes and spaces that concentrated on scale and proportion (the challenges of cutting) and texture and colour (the challenges of fabric

${ }^{19}$ Pucci's early sporting career as an Olympic ski champion, made him aware of the potential of stretch fabrics, leading to the development of his own stretch shantung silk, Emilioform, in 1961. 

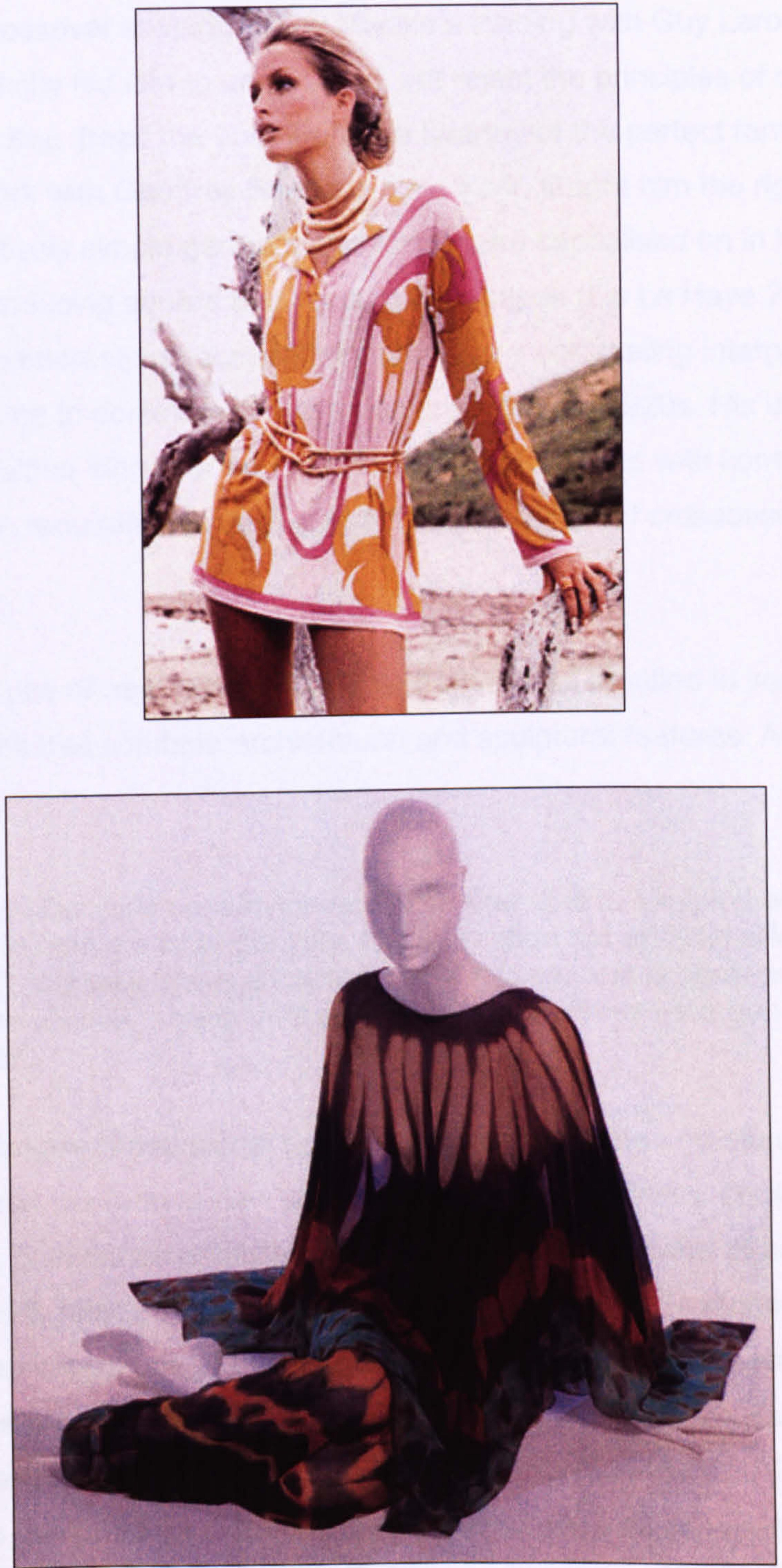

Figure 3-M Emilio Pucci 1996 Jersey silk printed tunic (Casadio 1998)

Figure 3-N Halston 1970 Tie-dyed silk chiffon evening pyjamas (Steele 1997) 
design) (Constantine and Lehman 1997: 197). The concept of fabric determining form (2.3.1), which underpins the Japanese design aesthetic, has been a major influence on contemporary, crossover shaping. Issey Miyake's training with Guy Laroche and his assisting of Givenchy led him to understand, yet reject the principles of couture for a mode of shaping that 'freed the body from the tyranny of the perfect form' (Falkman 2002: 58). His work with Geoffrey Beene in New York, taught him the rigours of massproducing deceptively simple garments, which Miyake capitalised on in his own early collections, by producing square and rectangular shapes (De La Haye 2001: 30). These pieces are interesting because they provided a contrasting interpretation of the rectangle that came to dominate Western fashion from the 1920s. His desire to 'design dress that was neither elitist nor ephemeral, but simply in tune with contemporary function and style requirements' presents a fitting definition of crossover styling (Ibid.p.29).

Rei Kawakubo's use of new materials and processes has resulted in some novel shaping strategies that combine architectural and sculptural features. As Grand (1998: 8) states:

If Commes des Garçons uses nylon and polyester, it is to exploit their intrinsic qualities, not to mimic a false gentility. Nylon is nylon not artificial silk, a true synthetic that folds well, stays uncreased and drapes, and is possessed of its own distinctive volume, sound, feel and look. A new Venus emerges from the polymer waves.

Kawakubo challenges conventional notions of feminine shape and beauty, by creating garments that orbit the form in new ways. The Body Meets Dress, Dress Meets Body pieces (1997/8), questioned established fashion thinking and were evocative of the aesthetic sensibility raised by Blaise Cendrars 'Poem for Mme Delaunay' (1913). On the surface, Kawakubo's use of print appears fairly uniform; checks, stripes, spots, dogtooth, but the way that they are manipulated within the Commes des Garçons system of shapes invests such patterns with a fresh significance (Ibid.). Junya Watanabe's has designed for Commes Des Garcons since 1992, creating all manner of shapes. He describes his product as 'techno couture', which he produces by synthesising established and cutting edge design methods. Figures 3-0 and 3-P show crossover pieces by Junya Watanabe and Rei Kawakubo for Commes des Garçons.

Since the early 1990 s reductions in the Lycra content in knits, and the combining of Lycra with wovens, has resulted in more subtle fabric qualities that can be cut into a greater variety of shapes and worn by a larger percentage of the population. The Lycra revolution has continued in a new direction, articulating the body through soft tailored 

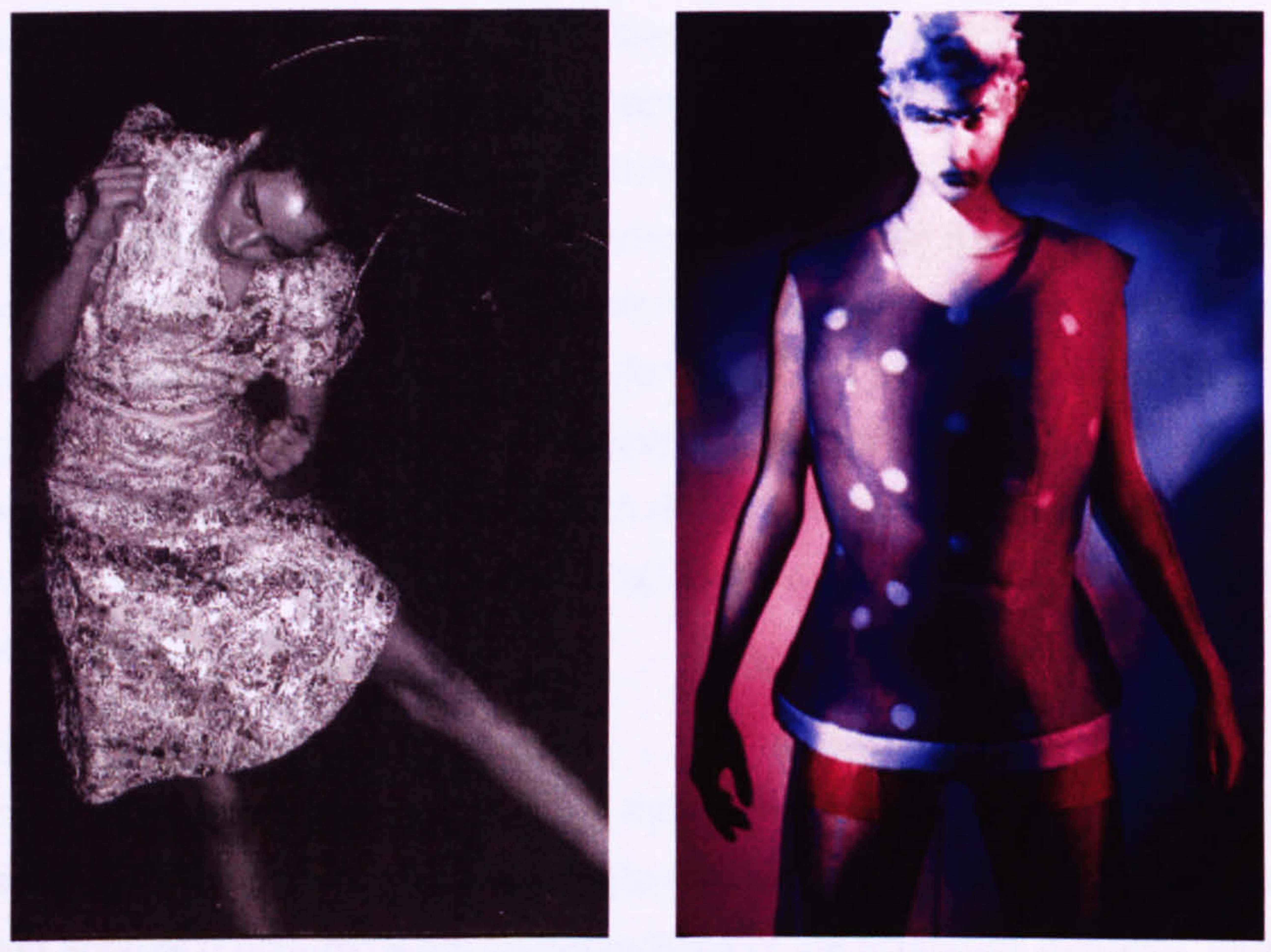

Figure 3-O Junya Watanabe 1998: Metallic printed dress (Vogue 1998)

Figure 3-P Rei Kawakubo A/W 1997/98 Purple Punk (Grand 1998) 
shapes. In many ways, although sophisticated crossover shapes are produced in couture, at a ready-to-wear level contemporary shapes tend to be configured on a rectangular basis (2.1.2). When shaping remains fairly similar, surface embellishment becomes more important, providing the all-important 'added value' and an illusion of complexity that is absent in the garment structure.

In 1969 the textile designer, Pat Albeck (p.63) cited the shift dress as a static shape that could be interpreted through print with great variation. The shift dress continues to be a classic crossover template, its semi-fitted structure interfacing between the extremes of architectural and sculptural shaping, allowing a plethora of print styles to be integrated easily. CAD has made the process of integration much more straightforward, enabling the flat filling of simple shapes with repeat pattern. However, little use has been made of the creative potential of CAD to integrate prints in new ways with garment shapes. The practical element of this creative research has investigated potential strategies for designing and integrating prints in association with a series of crossover shapes. The research demonstrates the possibilities for transforming even the simplest garment shape into something that can appear much more complex.

\subsection{TEXTILE-LED GARMENT DESIGN}

The term 'textile-led' is used generically in the fashion industry to describe garments that are designed to accommodate the patterning of a particular textile. In this sense a textile-led approach underpins the characteristics of the sculptural garment, through its elicitation of a shaping strategy that is sympathetic to the characteristics of the cloth. $A$ textile-led garment is cut with prior knowledge of the appearance, hand and texture of the textile in which the garment will be fashioned. This can lead the fashion designer to shape a garment in accordance with the placement, direction or repeat structure of a print design. Working with the textile as catalyst can dictate issues such as length, width, fullness, grain and overall style considerations. Early examples of a textile-led approach can be identified in the work of members of the Wiener Werkstätte group. Designs from 1911 by Hoffman (Völker 1994:15), Wimmer-Wisgrill (p. 41), and Peche (p. 61) demonstrate a strategic shaping approach to garments that displayed the features of the print.

Mario Fortuny was one of the most inspiring textile-led designers of the early twentiethcentury. His printed Knossos Scarves (1906) were semi- transparent lengths, embellished with Cycladic-inspired borders that wrapped sari-style around the body. Fortuny designed his textiles directly onto the cloth by printing metallic inks with blocks and screens, often cutting one-piece garments from the resulting richly embellished 
pieces (Osma 1980). Fortuny worked very much within the rectangular formats of cloth lengths, which could easily be translated into mantles, togas and tunics. Originally a painter, he treated cloth as a broad canvas to be related to the form. During the 1970 s Zandra Rhodes' method of building up her garment shapes with textile printing screens echoed Fortuny's organic approach (Knight 1984). The collections of established design houses Kenzo, Emanuel Ungaro and Yves St Laurent continue to demonstrate an idiosyncratic or 'brave' use of print (Eley 2000).

The Belgian designer Dries Van Noten's collections have often featured textiles incorporating up to five printing techniques in a single design. Fabric provides the underpinning for each season's direction; prints, weaves and colourways are developed and sampled before a single garment is designed. Van Noten keeps shaping to a minimum in order to retain the visual integrity of the cloth; 'when the fabrics arrive they are so beautiful that it seems a great shame to cut them up. Perhaps that's why we've always had so many wraparound skirts (Van Noten in Tucker 1999: 13).

Textile-led design is more prevalent among fashion designers who have either studied textiles or have a strong affinity with the discipline. Georgina Von Ertzdorf and English Eccentrics both began their careers as printers and have both diversified into fashion. Like Rhodes, the shaping of their garments has been strongly related to the geometric structures of their print designs. Current examples of garments cut with great consideration of the print can be defined in the work of Marcus Lupfer, Martine Sitbon (Fig.3-Q), Custo (Barcelona) and Eley Kishimoto.

\subsection{GARMENT-LED DESIGN}

In her book, Couture: The Great Fashion Designers, Milbank refers to Balançiaga, Charles James, Roberto Capucci, Piere Cardin and Courrèges as 'architects', who I consider as 'garment-led' designers. Unlike Vionnet and Grès, they did not look at the individual nature of women's bodies, but focused on them as a starting point for their own designs. As Milbank (1986: 318) states:

...the clothes themselves have an actual shape, and are more like pieces designed by an engineer than sculptural dresses with no inherent shape of their own. These clothes never look as if they happened naturally, but show what went into them. They celebrate the shape without actually mirroring it.

Clear parallels can be drawn between architectural and garment-led approaches, as in both cases it is the construction, rather than the fabric of the garment that is the key focus. Within this research the term 'garment led' describes designs in which the 

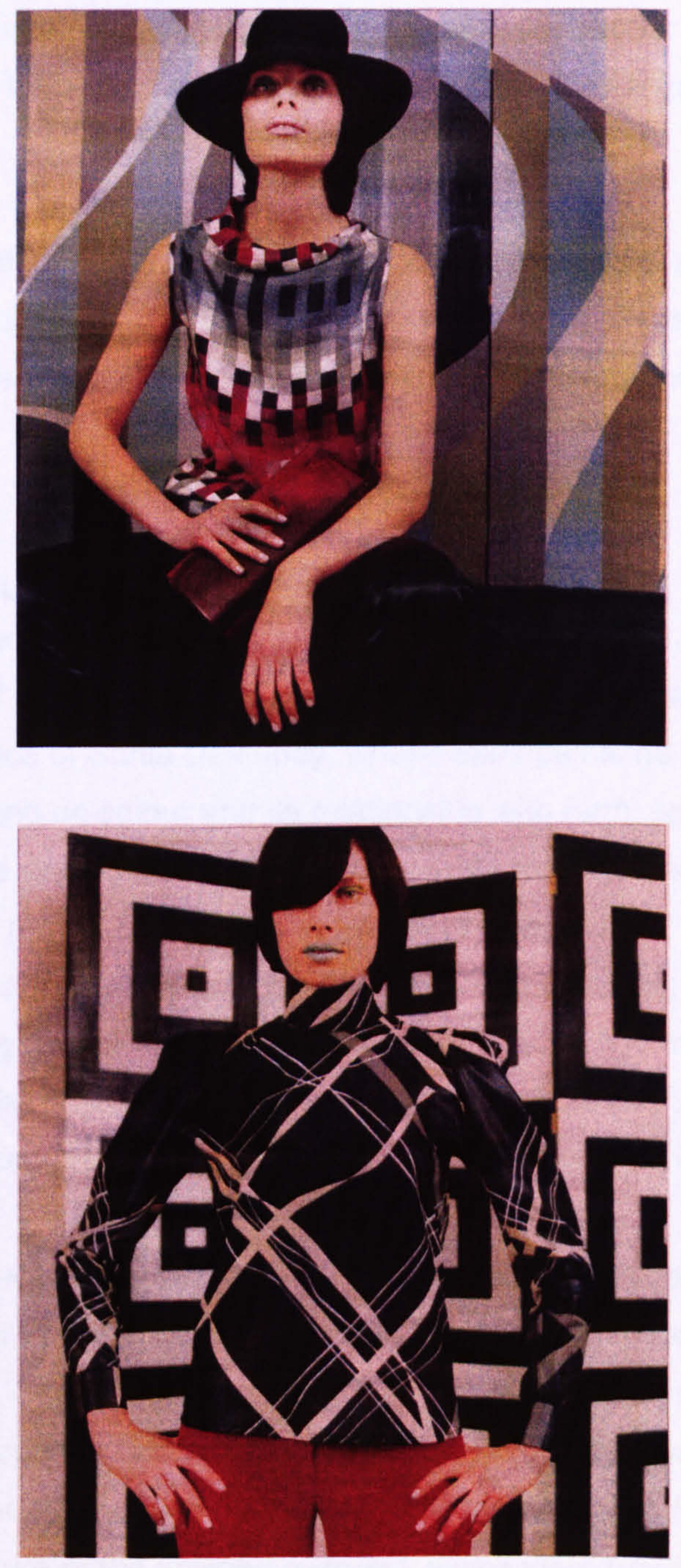

Figure 3-Q Marcus Lupfer and Martine Sitbon 2000 textile-led garment designs (Guardian Weekend 2000) 
garment shapes are conceived of prior to the surface embellishment, which is originated, or selected (from existing designs) to compliment these shapes. This approach dates back to the rise of the couture houses that grew up in Paris in the late nineteenth century, where the couturiers were revered but the artisans who brought their creations to life were usually anonymous. As Jackson (2002: 31) states: 'pattern is still characterised as trivial by many, whereas shape design is regarded as serious and heavy weight.'

The use of a print within a garment-led design can be innovative and striking, but ultimately it is chosen to enhance the cut, which is the focus of the design equation. A garment-led design is focused on the shape and volume of a piece, rather than the surface detail.

\subsection{SIMULTANEOUS DESIGN}

The simultaneous design approach advocated by this research (1.4) presents an innovative method of designing crossover printed garments. The approach was inspired by the practice of Sonia Delaunay, whose early paintings of Simultaneous Contrasts concentrated on colour and its relationship with form, space and movement. She developed these studies into textiles and by 1913 had designed her first 'simultaneous dress' (Fig. 2-C, p.2-8). The patch-worked garment was constructed from curved shapes of fabric that echoed the various proportions, curves and gestures of the body. Further garment designs led to Delaunay being commissioned by Diaghilev to design the costumes for the Ballet Russes production of Cleopatra in 1917, which was followed by her successful launch into Paris fashion.

Delaunay was fairly unique in designing both the fabric and the garment; her design ethos stemming from the belief that the print and garment shape should be originated simultaneously (1.3). Seeking greater control over the production of her 'fabric patterns', Delaunay opened her own printing workshop, Atelier Simultané in 1924, which guaranteed her autonomy over the translation of colour and the placement of the print within the structure of the finished garment, which were fundamentally rectangular. As Morano (1986) states:

The garçonne-style clothing of the mid-1920's was perfectly suited to Delaunay's fabrics as it had little structural detail or complicated seaming, no waistline and a straight neckline. The effect, aided by bust and hip flatteners, produced a twodimensional dress and image. 

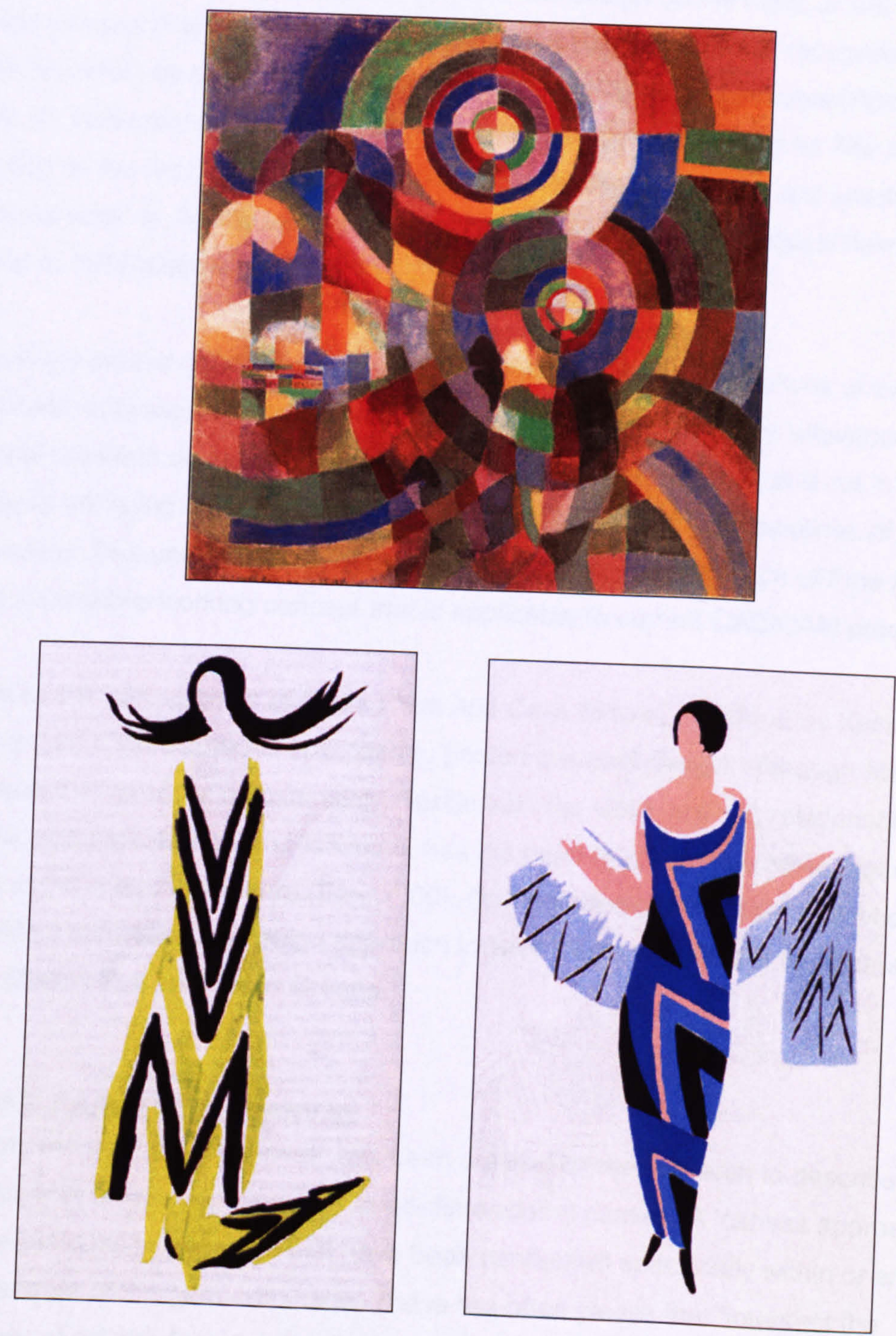
Figure 3-R Sonia Delaunay Simultaneous Contrasts 1914. Dress designs 1925
(Damase 1991) 
The geometric shaping enabled Delaunay to focus on the pattern and colour of her garments. She created numerous variations on a similar theme, often changing the colours around to create different visual effects. She designed her printed garments in relation to the form, pre-empting the effect of the design on the body, at the start of the design process (Fig. 3-R). Throughout the 1920s Delaunay gained recognition as 'the artist couturier', by promoting her work through collections and lectures (Buckburrough 1980: 8). Delaunay gave lectures on her combined specialism such as The Influence of Painting on the Art of Clothes, presented at the Sorbonne in 1927, and predicted 'ready-to-wear' in Artists and the Future of Fashion published in Jaques Heim's house journal in 1932 (Damase 1991: 171).

Delaunay's printed garment designs pre-empted the potential objectives of integrated CAD/CAM software. Her simultaneous design ethos holds particular relevance to the practical research documented in this thesis; the symbiosis of print and cut in her garments providing unique examples of integration between the disciplines of fashion and textiles. Delaunay's shifting of the Applied Arts into the paradigm of Fine Art, yielded a creative working concept that is applicable to current CAD/CAM practice.

Pieces by the partnerships of Ossie Clark and Celia Birtwell and the Eley Kishimoto, demonstrate a simultaneous approach to printed garment design. Although Mark Eley describes their practice as ostensibly, 'textile-led', the close working relationship with his wife, and partner Wakiko Kishimoto, has led them to create outcomes that consider print and cut in equal measure (Eley 2000). Other contemporary designers whose work illustrates a simultaneous design approach include the fashion/textile designers Emma Cook, Shelley Fox and Robin Greene.

\subsection{THE GARMENT AS CANVAS}

The term 'the garment as canvas' has been created by the research to describe printed garments that employ clothing as a three-dimensional canvas. A 'canvas approach' describes images or concepts that have been configured specifically within or around the parameter of the garment shape. These are often pieces that 'intersect the disciplines of art and fashion' (Wollen 1999: 7). Artists including Robert Rauschenberg and Andy Warhol have explored the potential of clothing as a vehicle for photographic imagery (Biennale di Firenze 1996). The textile artists Caroline Broadhead (Johnson1998), Shelly Goldsmith (Millar 2002), and Diedre Nelson (Schoeser 2003) have interpreted dress to convey layers of meaning that transcend the ephemera of fashion. In fashion, garment shapes have been transformed with the application of graphic, trompe l'oeil and conceptual prints, as illustrated by Paul Gaultier's Cyberbaba 
collection 1996, when he transposed photographic prints of male torsos onto women's garments (McDowell 2000: 75).

Couture has endured a 'complex two-way relationship with painting' throughout the twentieth century (Wollen 1998: 9). The commissioning of artists to design 'visual tableaux' for dress began with Poiret and Dufy, whose partnership (1909-1929), imbued printed garment design with some of the prestige associated with painting (Ibid.p.8). In the 1930s Schiaparelli commissioned artists to design prints for her collections, using the dress as a frame for an illustrated narrative. The Tear Illusion Dress (1938) featuring a print designed by Salvador Dali represents an early use of trompe l'oeil, conceptual imagery (3.8.1). During the 1940s and 50s Zika and Lida Ascher encouraged celebrated artists including Moore, Matisse, Beaton, Topolski, Sutherland, Hepworth and Freud to design prints in order to raise the profile of their collections (Mendes and Hinchcliffe 1987: 94). The practice was highlighted at the Festival of Britain in 1953, which saw artists actively designing fashion textiles and accessories. Although many of the designs were composed as single images for scarves, some of the repeating dress fabrics featured highly original subject matter that challenged existing textile imagery.

The printing of tee shirts in the 1960s marked the invention of fashion's most enduring canvas; the synthesising of image with text resulting in a new articulation of the form as a walking advertisement. The artist/designer Sarah Caplan recently reinvented the 'paper poster dress' of the 1960s by digitally printing photographs of New York onto simple A-line dresses constructed in Tyvek ${ }^{20}$ (Ings-Chambers 2000). Caplan's dresses represent a contemporary version of Harry Borden's Eye Dress (Fig.2-K, p.2-14), where the simple dress shape allows the photographic-style imagery to dominate the composition. Since 1993, Issey Miyake's Guest Artist Series has enabled artists and photographers to explore the artistic potential of his Pleats Please collections, through a range of image-making processes (Benaim 1997). Hussein's Chalayan's ethereal Buried Dress touched on issues of mortality, the patina of age and erosion (Fig.1-0, p.1-24), while in 1999, Alexander McQueen's used a garment literally as a canvas, by spraying it through 360 degrees on the model (Wilcox 2001: 101).

Integrated CAD/CAM technology enables designers to approach a garment as a canvas. Firstly, the use of computer graphic software encourages a compositional approach to be adopted towards textile/garment design, enabling designers to combine a range of concepts and perspectives within a single form (4.1.4). Secondly, the use of

${ }^{20}$ Tyvek is the revolutionary paper composite developed by Dupont. 
integrated $C A D$ enables textile and garment designers to visualise and design a garment contour and in relation to the form (4.3). To date, the ability to design in this manner has largely been exploited from a two-dimensional perspective, through the integration of placement and repeat prints that pay little attention to the garment contour, silhouette or form. Within the practical element of this research it has been my intention to explore integrated CAD from a new perspective, by addressing the printed garment as a three-dimensional canvas for the form.

\subsubsection{The Tear Dress}

While Cubism can be said to have influenced the re-structuring of fashion, the effect of Surrealism has led to the some of this century's most intriguing garments (Martin 1988). Elsa Schiaparelli was one of the first couturiers to incorporate the Surrealist imagery into her collections, using a black woolen sweater with a white trompe l'oeil ${ }^{21}$ bow at the neck to launch her fashion career in 1927.

In an anti-decorative era there is wit in the discovery of illusory decoration and the use of trompe l'oeil is her hallmark, a symptom of her sensitivity to the relation between dress and illusion (Mendes and De La Haye 1999).

Schiaparelli's work sparked a 'crisis in textile vocabulary'22 through her work with various artists, such as Jean Cocteau and Christian Bérard and her most famous collaboration with Salvadore Dali. The Lobster (1937) and Tear (1938) dresses are the most notable printed examples of this artistic liason. Both dresses consist of a fairly straightforward cut that ultimately work as vehicles for the exuberant print imagery, and as such represent a 'garment as canvas' approach. As Mendes and de la Haye (1999: 99) state: 'Surrealism influenced the surface decoration of Schiaparelli's clothes rather than the cut, which conformed to general 1930s trends.'

The Tear Dress (Fig. 3-S) was inspired by a figure in Dali's painting Three Young Surrealist Women Holding in Their Arms the Skins of an Orchestra (1936), in which one of the figures wears a skin-like dress covered with tears, which reveal the body (Ibid.). The dress has been credited with inspiring Zandra Rhodes, Vivienne Westwood, and Rei Kawakubo's ripped styles of the late 80 s and early 90s (Steele 1991:42). The dress has been discussed at length by numerous fashion historians who have associated various meanings to the piece:

\footnotetext{
${ }^{21}$ Trompe l'oiel or 'deception of the eye' is a painting or effect that gives a convincing illusion of reality (Bullock \& Stally brass 1979).

22 Quotation is a reference to contemporary press headline, 'Schiaparelli collection is enough to cause crisis in vocabulary' (Schiaparelli, 1954, p.72).
} 


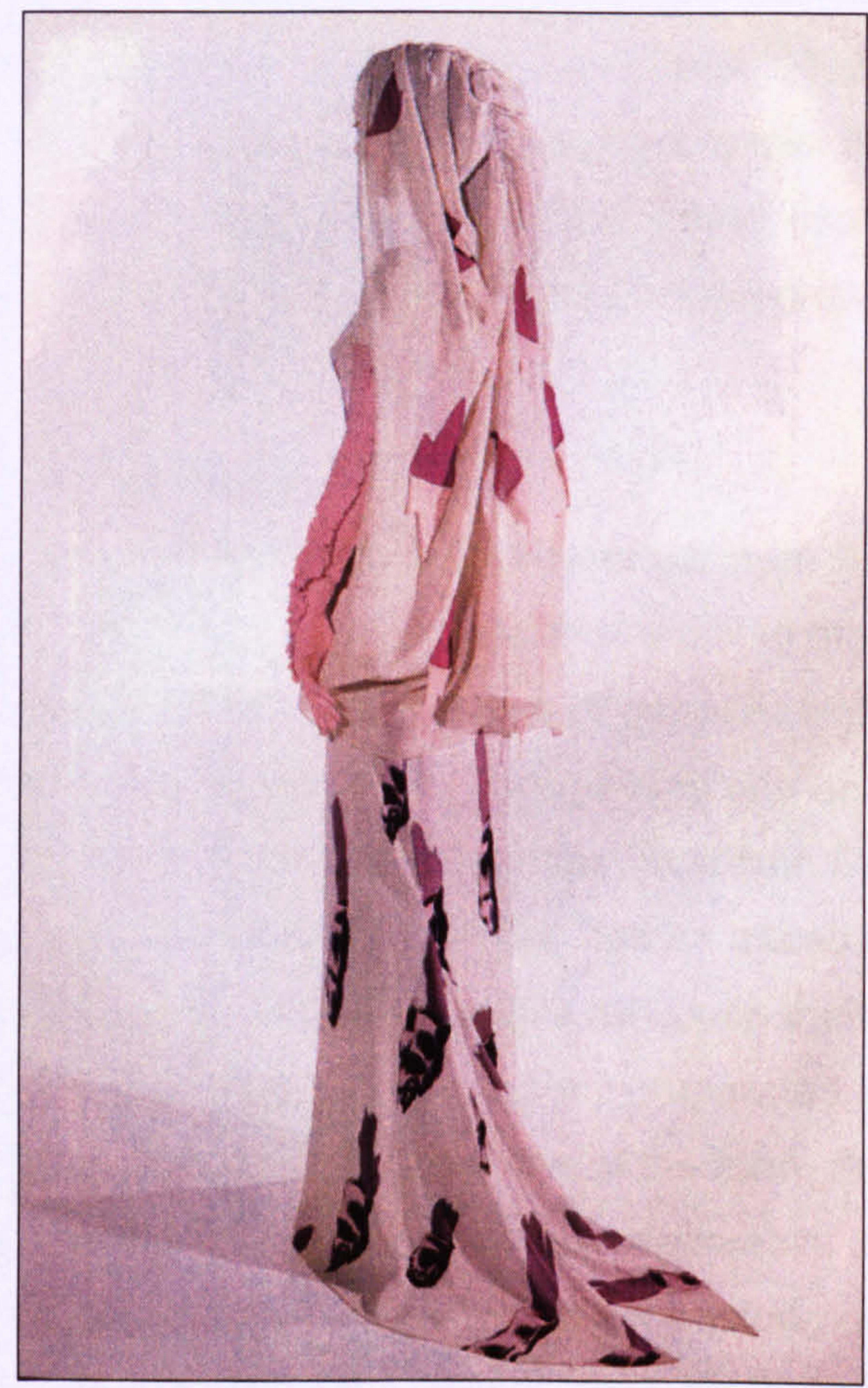

Figure 3-S Elsa Schiaparelli 1938/9 Tear Illusion Dress (White 1986) 
The imagery of the violence is counter posed by the elegance of the dress, its existence as sophisticated fashion, and the fact that it is not rags, not torn. The way in which the dress acts to displace sexual meanings from the body is brilliantly exploited. It is a piece suggestive of fantasy that is both acknowledged and denied. Violence and eroticism are simultaneously displayed and made to disappear; beauty is brought to bear on rupture (Evans and Thornton 1989: 139).

The significance of the Tear Dress within this research is related to its illusory qualities as a print, and garment form. The printed tears have been variously described as: 'peeled bark', 'torn flesh' and 'rags' (Ibid.). The Tear Dress ${ }^{23}$ (Fig.3-S) provides a unique, early example of the use trompe l'oeil images to depict the physical characteristics of fabric, as printed textile vocabulary. I have explored a similar concept in the practical research through the manipulation of scanned textile constructs in CAD.

\subsection{CONCLUSION OF CHAPTER}

The notions of sculptural, architectural and crossover garment spatiality discussed early on in the chapter were developed as ideas that enabled me to articulate and explore the relationships between different styles of garment and surface print. The models provided a theoretical framework for categorising and analysing the aesthetic qualities of selected printed garment styles from the Twentieth Century. The correlation between a sculptural garment and fluid patterning can be traced through modern interpretations of classical dress. Sculptural styles rely upon the interaction of draped and manipulated cloth with the form. When print is incorporated into this dialogue it has to flow with, rather than detract from, the contours of the form. Sometimes the textural patterning created by the drapery provides sufficient decorative detail in itself. The dramatic silhouettes of architectural garments present a strong contrast with the sculptural model. Architectural garments present large, more artificial spatial volumes that are supported by the form. These shapes provide more scope for integrating bold decorative printed patterns, as the focus of the design equation is between print and garment, rather than print and form.

It is more difficult to generalise about the aesthetic appropriateness of print styles in relation to crossover shapes, as the cleaner lines of this model can accommodate a wide variety of decorative concepts. The crossover shape has evolved since the 1960s, when synthetic fabrics became more widely used, leading to shapes that could be worn comfortably without the aid of complex structuring or fastenings. The crossover shape is therefore most closely allied with contemporary shaping, particularly within the mass clothing industry, where simple geometric cuts can be manufactured most effectively.

\footnotetext{
${ }^{23}$ See Appendix 4 for a first hand account of the garment based on observations of the piece in the costume archive at the Victoria and Albert Museum.
} 
Textile-led garments are designed by considering the configuration of print imagery prior to the cutting of the style. A textile-led approach often results in the creation of simple shapes, including those that wrap around the form, which retain the visual cohesion of the imagery. Textile-led garments place greater emphasis on the surface qualities, as opposed to than the structural composition of a garment. A garment-led design represents a reversal of a textile-led approach, with the shaping or structural detail providing the focal interest. In couture, garments are often created with a painstaking attention to the detail of all the materials involved but, in some cases, issues of shape and volume take precedence over surface pattern. Most massproduced clothing is designed from a garment-led perspective, with shapes dictated by trends and print often configured as 'wallpaper' to add value to a range. This can lead to a monotonous use of similar repeating structures, incorporating average or small scale elements.

The simultaneous design approach investigated through this research is rooted the design practice of the artist couturier, Sonia Delaunay. A simultaneous design approach merges textile and garment-led approaches by considering both the textile design and garment shape at the outset of the design process. The designing of the fabric and garment pattern simultaneously, allows alterations to be made to the scale or organisation of the print, or the styling of the cut. A simultaneous approach can be identified in the work of key fashion and textile designers. Delaunay took her abstract paintings and wrapped them around the form. The simplified shaping of the 1920s provided an ideal vehicle through which to translate her paintings into textiles. Similarly, while a 'garment as canvas' approach can be adopted towards sculptural or architectural styles it is most effective when allied with a more straightforward crossover shape, where the graphic or conceptual imagery can dominate the equation. 


\subsection{REFERENCES}

Adaskina, N, and Sarabianov, D. (1990) Liubov Popova, London: Thames \& Hudson

Albeck, P. (1969) Printed Textiles, London: Oxford University Press

Baudot, F. (1997) Yohii Yamamoto, London: Thames \& Hudson

Benaim, L. (1997) Issey Miyake, London: Thames and Hudson

Biennale di Firenze (1996) Looking at Fashion, Florence: Biennale di Firenze

Bowlt, J. (1976) Russian Art of the Avant Garde: Theory and Criticism 1902-1934,

New York: Viking Press

Bryant, N. (1991) The Interrelationship between Decorative and Structural Design in Madeleine Vionnet's Work, Costume, No. 25

Buckburrough, S. (1980) Sonia Delaunay: A Retrospective, Buffalo: Albright-Knox Gallery

Buckley, R. and Gundle, S. (2000) Flash Trash: Gianni Versace and the theory and practice of glamour in Bruzzi, S. and Church Gibson, P. Eds. (2000) Fashion Cultures, London: Routeledge

Bullock, A. and Stallybrass, O. Eds, (1979) The Fontana Dictionary of Modern Thought, London: Fontana Books

British Elle (2001) Sophia Kokoslaki: My Inspiration, London: Hatchette-EMAP Magazines Ltd., June, p.191

Casadio, M. (1998) Emilio Pucci, London: Thames \& Hudson

Clark, O. (1998) The Ossie Clark Diaries, London: Bloomsbury

Constantine, M and Reuter, L. (1997) The Whole Cloth, New York:The Monacelli Press

Damase, J. (1991) Sonia Delaunay: Fashions and Fabrics, London: Thames and Hudson

De La Haye, A. (2001) A Dress is No Longer a Little Flat Closed Thing: Issey Miyake, Rei Kawakubo, Yohii Yamamoto and Junya Watanabe in Wilcox, C. (2001)

Eley, M. (2000) Private telephone conversation with Mark Eley, Co-director of Eley Kishimoto $16 / 1 / 00$

Evans, C. \& Thornton, M. (1989) Women and Fashion: A New Look, London: Quartet Books

Fame and Fashion: Inside Versace (2002), presented by David Furnish, Channel Four, Diverse

Falkman, S. (2002) A Second Skin, Form, 1/02, pp.52-59, 83-84

Frankel, S. (2003)

Gan, S. (2000) Visionnaire's Fashion 2001: Designers of the New Avant Garde London: Laurence King

Grand, F. (1998) Commes des Garçons, London: Thames and Hudson 
Guardian Weekend (2003) Shopping Life by Patricia Kwateng, 26/6/06, p.51

Hayward Gallery (1998) Addressing the Century: 100 Years of Art and Fashion,

London: The Hayward Gallery

Ings-Chambers, E. (2000) Over a Paper Moon, Financial Times Weekend, 5/2/2000

Jackson, L. (2002) Who's Afraid of Pattern Design, Crafts, No. 177, July/August, pp. 28-31

Kennedy, S. (1991) Pucci: A Renaissance in Fashion, New York: Abbeyville Press

King, C. (prod.) (1996) Painted Ladies: Nobility, Virtue and Morality, presented by

Vivienne Westwood, Channel Four, Diverse

Guardian Weekend (2003) Shopping Life by Patricia Kwateng, photographed by lan Nolan, 26/6/06, p.51

Knight, A. (1984) The Art of Zandra Rhodes, London: Jonathan Cape

Leeds Art Galleries (1980) Jean Muir, Leeds: Leeds Art Galleries

Martin, R. (1998) Cubism and Fashion, New York: Metropolitan Museum of Modern Art Martin, R. (1997) Gianni Versace, New York: The Mueum of Modern Art

McDowell, C. (2000) Jean Paul Gaultier,

McDowell, C. (1997) Galliano: Romanti, realist, revolutionary, London: Weidenfeld \& Nicolson

McDowell, C. (1987) Mc Dowell's Directory of $20^{\text {th }}$ Century Fashion, Great Britain:

Frederick Muller

Mendes, V. and De La Haye, A. (1999) 20TH Century Fashion, London: Thames and Hudson

Mendes, V. and Hinchcliffe, F. (1987) Zika and Lida Ascher: Fabric-Art-Fashion, London: Victoria and Albert Museum

Milbank, C. (1985) Couture: The Great Fashion Designers, London: Thames and Hudson

Millar, L. (2002) Jerwood Applied Arts Prize 2002: Textiles, Catalogue essay, London: Crafts Council

Morano, E. (1986) Sonia Delaunay: Art Into Fashion, New York: George Braziller Inc.

Osma, G. de (1980) Fortuny, His Life and Work, London: Aurum Press

Rosenthal et al (1997) Sensation: Young British Artists from the Saatchi Collection, London: Royal Academy

Sarabianov, D. (1999) Liubov Popova and Artistic Synthesis, in Bowlt, J and Drutt, M. Eds. (1999) Amazons of the Avant-Garde, London: Royal Academy of Arts Schiaparelli, E. (1954) This Shocking Life, London: Dent

Schoeser, M. (2003) Distilling History, Crafts, No. 182, May/June, pp 40-43

Schouvaloff, A. (1991) Léon Bakst: The theatre art, London: Sotheby's Publications Steele, V. (2001) Style in Revolt: Hussein Chalayan, Alexander Mc Queen and 
Vivienne Westwood in Wilcox, C. (2001)

Steele, V. (1997) Fifty Years of Fashion: New Look to Now, New Haven \& London:

Yale University Press

Steele, V. (1991) Women of Fashion, New York: Rizzoli

The South Bank Show (1999) Ossie Clark, parts 1 and 2, LWT and ITV

Völker, A. (1990) Textiles of the Wiener Werkstatte 1910-1932, London: Thames and Hudson

Watson, L. (1999) Ossie Clark Fashion Designer 1942-1996: A Retrospective,

Catalogue essay, Warrington Museum and Art Gallery

Wilcox, C. Ed (2001) Radical Fashion, London: V\&A Publications

Wollen, P. (1998) Addressing the Century, essay in Hayward Gallery (1998)

White, P. (1986) Elsa Schiaparelli: Empress of Paris Fashion, London: Aurum Press, 1986 
INTRODUCTION

4.1. COMPUTER AIDED TEXTILE DESIGN .............................................. 4-3

4.1.1. Repeat and Colour Management.................................................... 4-6

4.1.2. Textile Draping Software .................................................................. 4-8

4.1.3. Graphic Software......................................................................... 4-10

4.1.4. CAD: A New Visual Aesthetic ......................................................... 4-13

4.2. GARMENT PATTERN DESIGN SYSTEMS …..................................... 4-18

4.2.1. 3D Pattern Design Systems........................................................... 4-19

4.2.2. Made to Measure Pattern Cutting ..................................................... 4-19

4.2.3. Body Scanning .................................................................................... 4-20

4.2.4 3D Computer Draping Systems.......................................................... 4-22

4.2.5 Cloth Animation/Dynamic Drape.................................................... 4-24

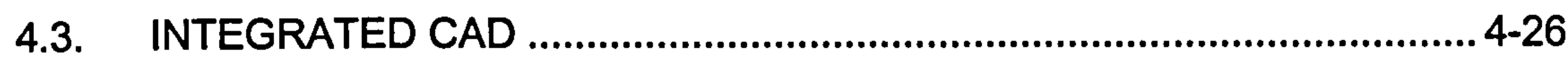

4.3.1. Integrated CAD/CAM................................................................... 4-28

4.3.2. Mass Customisation ...................................................................... 4-29

4.3.3. Print Customisation ........................................................................ 4-30

4.4. DIGITAL FABRIC PRINTING ...................................................... 4-32

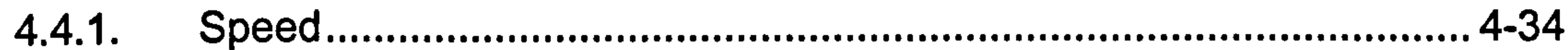

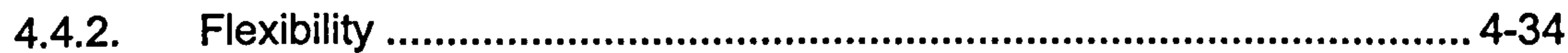

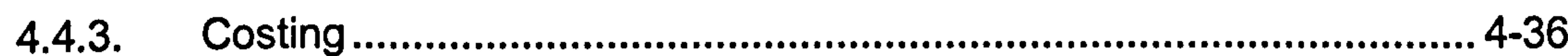

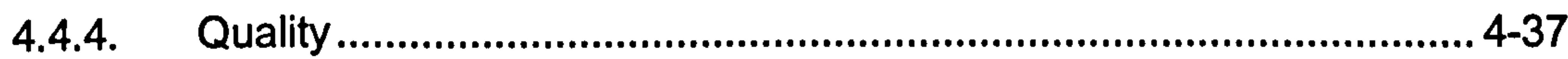

4.4.5. Sustainable Design Issues ............................................................ 4-38

4.4.6. Summary .......................................................................................... 4-38

4.5. HYBRID APPROACHES TO CAD...................................................... 4-38

4.5.1. Laura Rotger Buadas .................................................................... 4-39

4.5.2. Hilary Carlisle ............................................................................ 4-39

4.5.3. Helena Rosen..............................................................................4 4-41

4.6 CONCLUSION OF CHAPTER ................................................................ 4-43

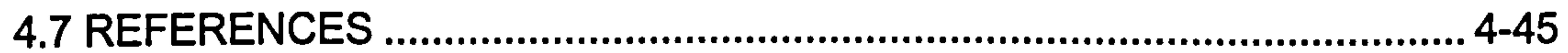




\section{INTRODUCTION}

Following a considerable period of development, Computer Aided Design (CAD) is now an integral part of all aspects of the Fashion and Textile industry. Reductions in the cost of hardware and software, the availability of more powerful systems and the compatibility of different file formats have led to a growth in the use of CAD. This has made CAD more accessible to a host of new independent users who have contributed to its development as both a tool and a medium. While textile software allows designers to explore the 2D surface through a wide variety of repeat patterning structures, draping software has extended this process by facilitating the visualisation of surface designs through a myriad of 3D forms. The use of digital cameras and computer graphic (CG) software has led to an increase in the use of photographic imagery and has contributed to a new sense of three-dimensional space in textile design.

In the mass clothing industry garment design continues to be executed using pattern design systems (PDS) which are predominantly based on flat cutting. This way of working underpins an architectural/crossover approach to the form, whereby surface print can be related easily to garment shapes, with minimal consideration of the body shape. The move towards mass customisation is influencing garment designing and cutting strategies to incorporate individual measurement data, accrued through body scanning. A return to the principles of made-to-measure garment design could have important ramifications for fashion and textile designers in the future, who may need to consider their craft from a more three-dimensional perspective.

Integrated $\mathrm{CAD}$ enables designers to combine (raster) textile designs with (vector) garment contours. The assimilation of surface imagery with 2D and 3D garment shapes has opened up new opportunities for designing printed garments from a simultaneous perspective. While the mass clothing industry has had access to integrated CAD for some time it has been slow to explore the creative design potential of such software.

As predicted by Jerrard (1986: 74) the widespread use of CAD/CAM has resulted in 'new working patterns, new machinery and new products.' Currently, most of the larger CAD/CAM providers offer the Industry 'integrated design solutions' that streamline hardware and software applications, within a single package. The main users of such technology have neither the time nor the inclination to investigate the aesthetic design potential of key areas of CAD/CAM. The impact of 'fast' fashion has led to a slight shift away from offshore manufacturing to more local production. This is encouraging growth in niche merchandising, which could stimulate interest in craft-based production 
methods. For the independent printed garment designer the most relevant area of new $\mathrm{CAD/CAM}$ technology is the further integration of computer graphic software with digital fabric printing, which has initiated a more direct link between textile design and fabric/garment production. The ability to print and manufacture to order, allied with emarketing strategies is opening up new possibilities for print customisation.

While mass clothing producers have the greatest access to all the technology discussed in the chapter, their use of CAD has tended to be limited to mechanistic, mass production objectives which are driven by the demands of garment costings. In contrast, the work of some independent designers and artists demonstrates a hybrid approach to digital designing and making systems. Such practice has resulted in innovative outcomes that stretch the medium and present alternative strategies for negotiating new and appropriate technologies. This chapter forms a bridge between the theoretical and practical design areas of research. It focuses on key aspects of CAD for clothing and textiles that are relevant to the area of practice, and how this technology is generally applied within the industry.

\subsection{COMPUTER AIDED TEXTILE DESIGN}

Computer Aided Textile Design (CATD) ${ }^{1}$ has existed in many forms since the early 1960s, when it was first enlisted in the jacquard knitting and weaving industries (Ref). During its early development, CAD software was primarily designed to replicate 'existing design and pre-production processes' such as repeat, colour way and colour separation (Briggs and Bunce 1995: 187). As Watkins (1991: 4) noted the use of CAD to mechanically interpret designs often led to 'banal results', leaving textiles behind other industries ${ }^{2}$ in the creative development of the medium. Hearle (1994: 37) analysed this situation as 'the problem of three (divided) cultures', which he saw as, 'engineering, design and commercial reality.'

Originally, CAD for textiles was provided in the form of 'proprietary'3 software, which was relatively expensive, limiting its use to larger design companies. While CAD was used successfully to speed-up the technical aspects of print production, systems were often under-used, which hindered its creative development as a designing medium (Ashby 1994: 21). ${ }^{4}$ During the 1990s the increase in the speed and power of hardware and improvements in the compatibility between textile and graphic platforms, such as IBM and Apple Macintosh, led to a growth in the use of CAD (Gray 1998: 17). As a

\footnotetext{
${ }^{1}$ Usually referred to as CAD in the UK.

2 Such as graphics, publishing, architecture and industrial design

3 Proprietary software refers to industry-specific programmes, not available outside of the textile industry.

${ }^{4}$ Ashby found that in some cases as little as $10 \%$ of a CAD system's potential was utilized.
} 
result, textile companies were able to replace 'dedicated'5 systems with 'modular' 6 software applications and off-the-shelf packages. The prevailing trend towards more flexible systems led to an increase in competition and a decrease in price (Ibid.). The key issues that finally influenced the creative development of CAD in recent years were the switch to off-the-shelf packages, which increased the number of users, and a greater consideration of "user-led requirements" by software designers (Dickinson 1999: 38, Dewar 2003). A case in point is Lectra Systems' U4ia software, which was originally developed by $\mathrm{CDI}$ in 1981 and has subsequently been updated by incorporating changes based on advice from textile designers using the programme (Mylius 2002). The constant modification of U4ia has resulted in it being recognised as one of the leading-edge textile software packages on the market place.

Today, modular textile packages typically include Print, Weave and Knit designing software that can be purchased either individually or collectively and used to create original designs or interpret existing artwork. Most printed textile modules incorporate colour-reduction, colour way and repeat management functions as well as image rendering, positioning and scaling tools. One of the most effective components of printed textile software continues to be its ability to manipulate repeats and colour ways rapidly and with considerable variation; designs can be transformed from a simple tile to a half-drop, while individual motifs can be moved as required (Figure 1-A).

The emphasis of proprietary Print software ${ }^{8}$ is on preparing prints for production, acknowledges the fact that the artwork is often created outside of the system, using a variety of traditional and CAD media. While repeats are still favored by the mass clothing industry, CAD's facility to create complex repeating patterns has remained largely unexploited (Bunce 1996: 35). CAD textile patterns have evolved compositionally, with 'composite' prints often consisting of superimposed layers of disparate images, as opposed to a mathematical arrangement of similar motifs that work horizontally and vertically across a width and length of cloth. While the new style of 'layered' imagery can be sufficiently interesting when repeated in the most basic formats, CAD has resulted in an increase in the use of placement and engineered prints.

\footnotetext{
${ }^{5}$ An alternative term used to describe 'proprietary' systems.

${ }^{6}$ Software packages focused on specific aspects of CAD for textiles.

7 In 1994 (p. 21) Ashby predicted the creative development of CAD was dependent on an improved dialogue between engineers and users.

${ }^{8}$ Such as Lectra System's Prima Vision Repeat, U4ia Prints Simulation and Quick Tex.

${ }^{9}$ Within the context of repeat patterns composite overlays are created when one repeat system is superimposed by another. Various combinations of structure can be used. The interaction of these structures produces unexpected and exciting pattem variations (Phillips and Bunce 1993: 147).
} 

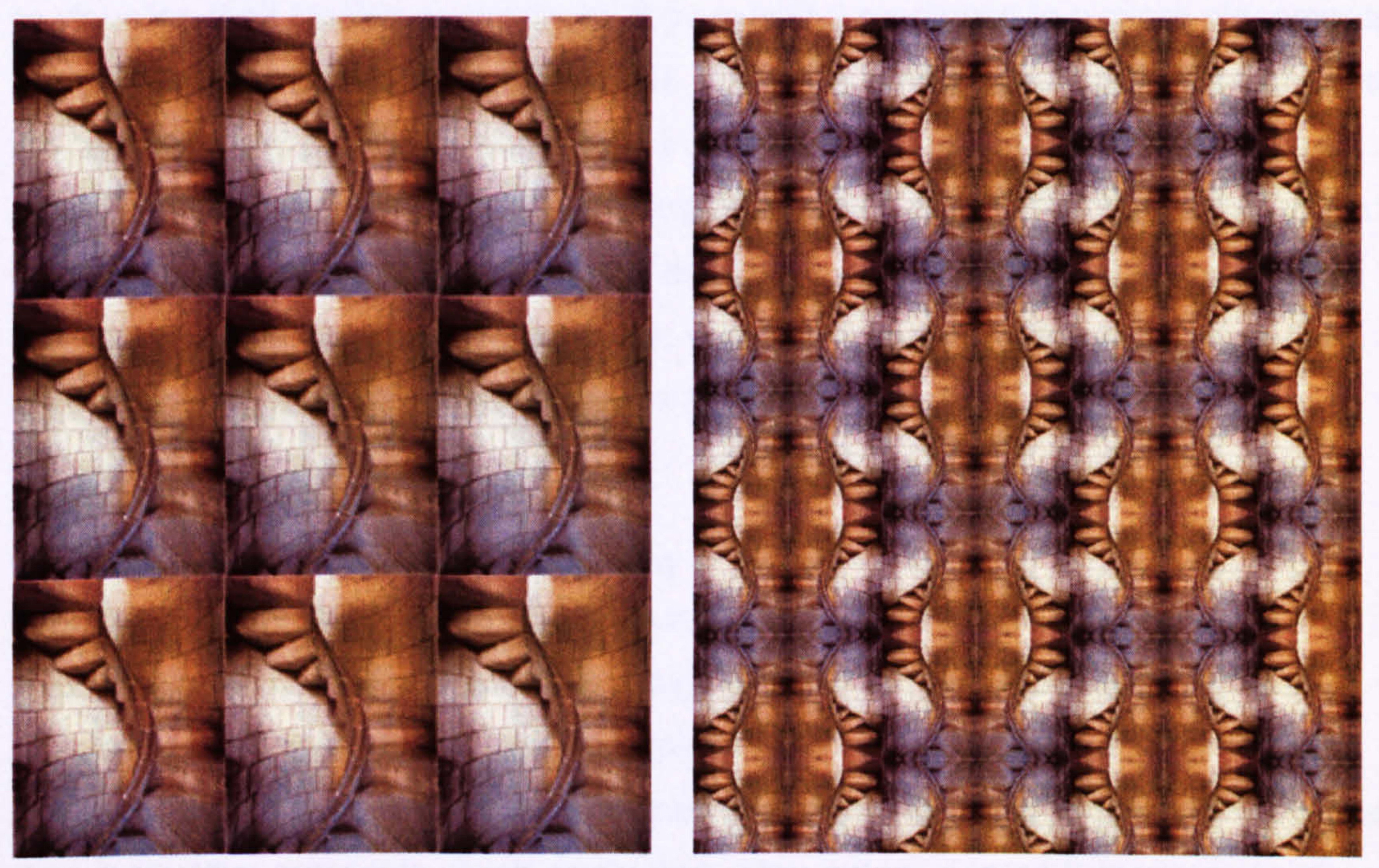

Figure 4-A Rebecca Sexty 2003: Simple repeats created in Colour Matters (Options Systems) by first year BA Textile Design student at the Nottingham Trent University 
Early in the development of any new medium there is a tendency for it to be used to imitate older media. It is not until a medium reaches a sort of maturity that it begins to take on a life of its own and displays characteristics that belong to it and no other (Lansdown 2002: 53).

I consider the current trend in engineered prints to be both an intuitive and aesthetic response to designing textiles on computer because CAD facilitates the novel placement and artistic rendering of motifs within a textile or a garment shape. My work with undergraduate students at NTU supports this opinion, as when using CAD to visualise their textiles as products, they exhibit a readiness to explore placements over repeats, as illustrated in Figure 4-B. The increasingly novel application of prints on garments has helped to reinforce the conception of the 'garment as a canvas' within contemporary fashion (3.8). Having employed CAD to reconfigure the notion of patterning, I think it is time for designers to reconsider the crucial role that the form plays within the designing process, which could further influence the way that prints are integrated with fashion fabrics and garments.

\subsubsection{Repeat and Colour Management}

Within the middle market in the UK, Laura Ashley, River Island and Monsoon and Accessorize all use U4ia (Lectra) to design printed garments. Despite the creative possibilities of this software, these companies are bound by their product, which is governed by offshore production, and their customers to produce commercial rather than innovative garments. Such production often entails a large turnover but with a fairly limited use of leading edge technology. A good example is Monsoon, who produce four collections a year featuring prints with up to 25 colours. The company employs one textile designer, Joanne Collins (2000), who purchases designs from agents and uses U4ia for repeat and colour management. ${ }^{10}$ The company has a number of fashion designers who develop print swatches ${ }^{11}$ into garment visualisations and mood boards for design development and selection purposes. Monsoon's success is founded on their use of offshore production and imported craft textiles.

Jenna Williams is a textile designer for Low Profile, a company who design textiles and garments for high street outlets, such as Next. Like Monsoon, many of their designs are purchased from agents, adapted in CAD and printed by hand or rotary methods offshore. The company use U4ia software for creating repeats, which tend to be limited

\footnotetext{
${ }^{10}$ Collins (2000) confirmed that this task was previously completed manually by matching individual swatches of coloured cloth to correspond with shades of a design, to accurately convey the palette to their screen-printers in India.

${ }_{11}$ These are created using digital printing in anticipation of hand printed strike-offs from India which take six weeks to prepare.
} 

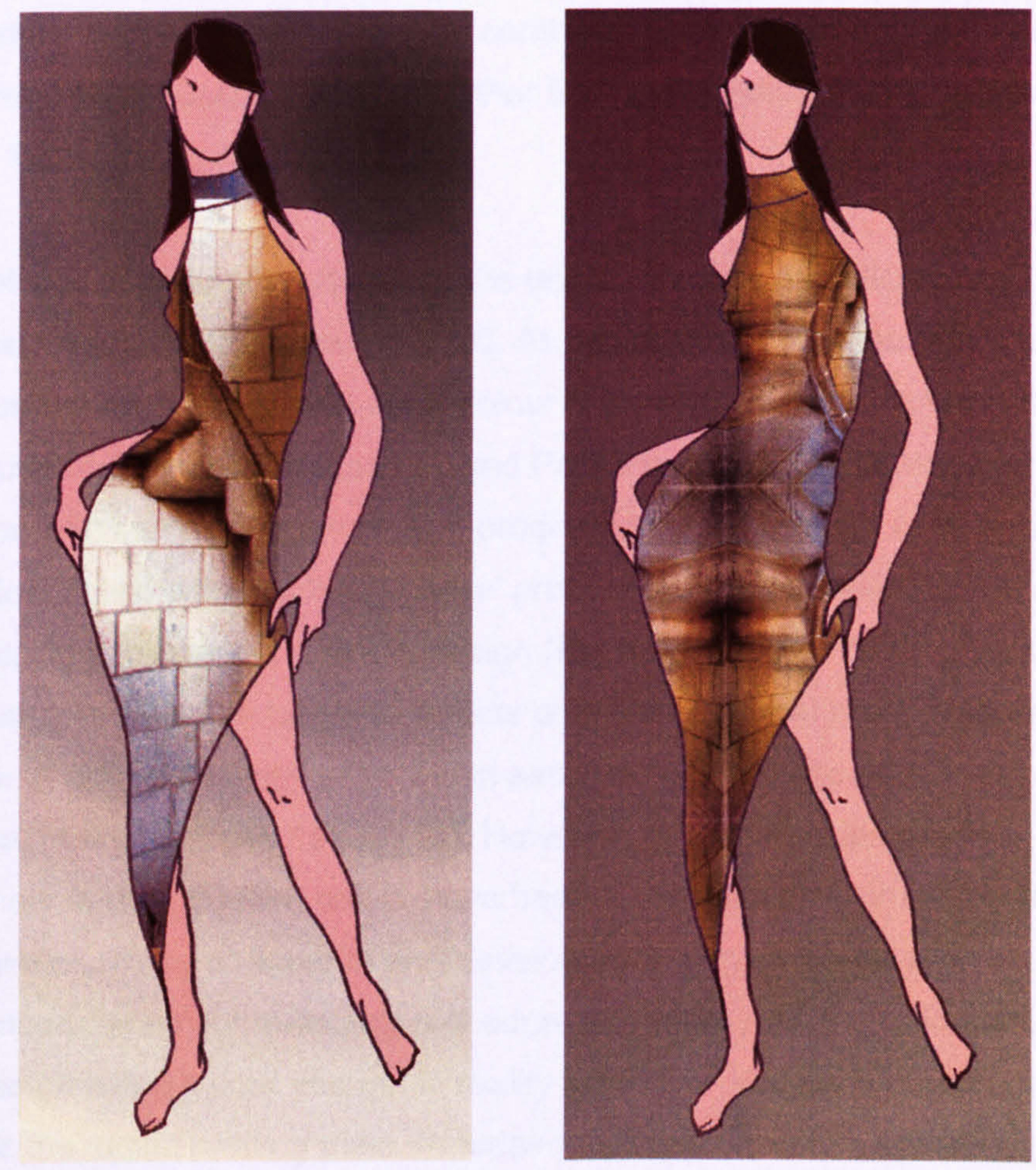

Figure 4-B Rebecca Sexty 2003: Engineered-print idea 
in colour 'to keep the cost down' and configured in 'half-drop' or 'multi-directional' repeats 'for maximum usage when constructing garments' (Williams 2003). At Low Profile the colourway of a design is considered as important as the print imagery, 'if not more so', and customers expect to see prints tailored to their own palettes, containing up to 10 stories per season (lbid.). This scenario is typical of design practice in the middle market, where the emphasis has continued to be placed on the use of CAD for the 'interpretation of supplied artwork' rather than the creation of original design ideas (Shenfield 1994: 107).

Colour fidelity is of major importance in the textile industry, as indicated by Lectra's strategic partnering of Datacolour in 2000. As discussed above, the prime utilisation of CAD for many design companies is for colour matching, achieved through the combined use of spectrophotometers ${ }^{12}$ and Pantone charts, the latter generally being incorporated within textile modules. The production of colour ways is an established CAD function, in line with 'quick-response' production, where textile buyers expect ever-increasing variations of a single design (Davies and Tilley 2003). The capability of the technology to visualise 'complex effects containing a great many colours, such as watercolour in different colour ways within seconds' has provided CAD with an edge over manual methods (Leak 1998: 116). However, inconsistencies between screen and fabric, sample and production colour have been a constant problem in the fashion and textile industries. Recent research and development by companies such as Datacolour have advanced the colour matching procedure to ensure that 'the colour you choose and you design is the colour you get in reality when the product is manufactured'. ${ }^{13}$ Throughout the digital printing trials undertaken for this research, I found a considerable difference existed between the appearance of colour on screen and its translation onto paper and fabric, where it varied dramatically between substrates (5.5). The experimentation underpinned the importance of sampling and why colour fidelity has become such an important aspect of CAD/CAM.

\subsubsection{Textile Draping Software}

Computer Design Inc. (CDI) ${ }^{14}$ is generally acknowledged as the first garment software company to have introduced 'contour' or 'texture mapping' techniques into CAD (Chen 1998: 3-8). Over the last five years the use of textile draping software has become a significant aspect of CAD, enabling designers to 'drape' their designs on a photograph or illustration of a garment. The draping procedure is conducted by building a '3D'15

\footnotetext{
12 Instrument for automatically recording colour.

${ }^{13}$ www.datacolour.com

${ }^{14} \mathrm{CDI}$ was purchased by Lectra in 2000.

${ }^{15}$ The square grid actually simulates in $2.5 \mathrm{D}$, but is referred to as ' $3 D$ '.
} 

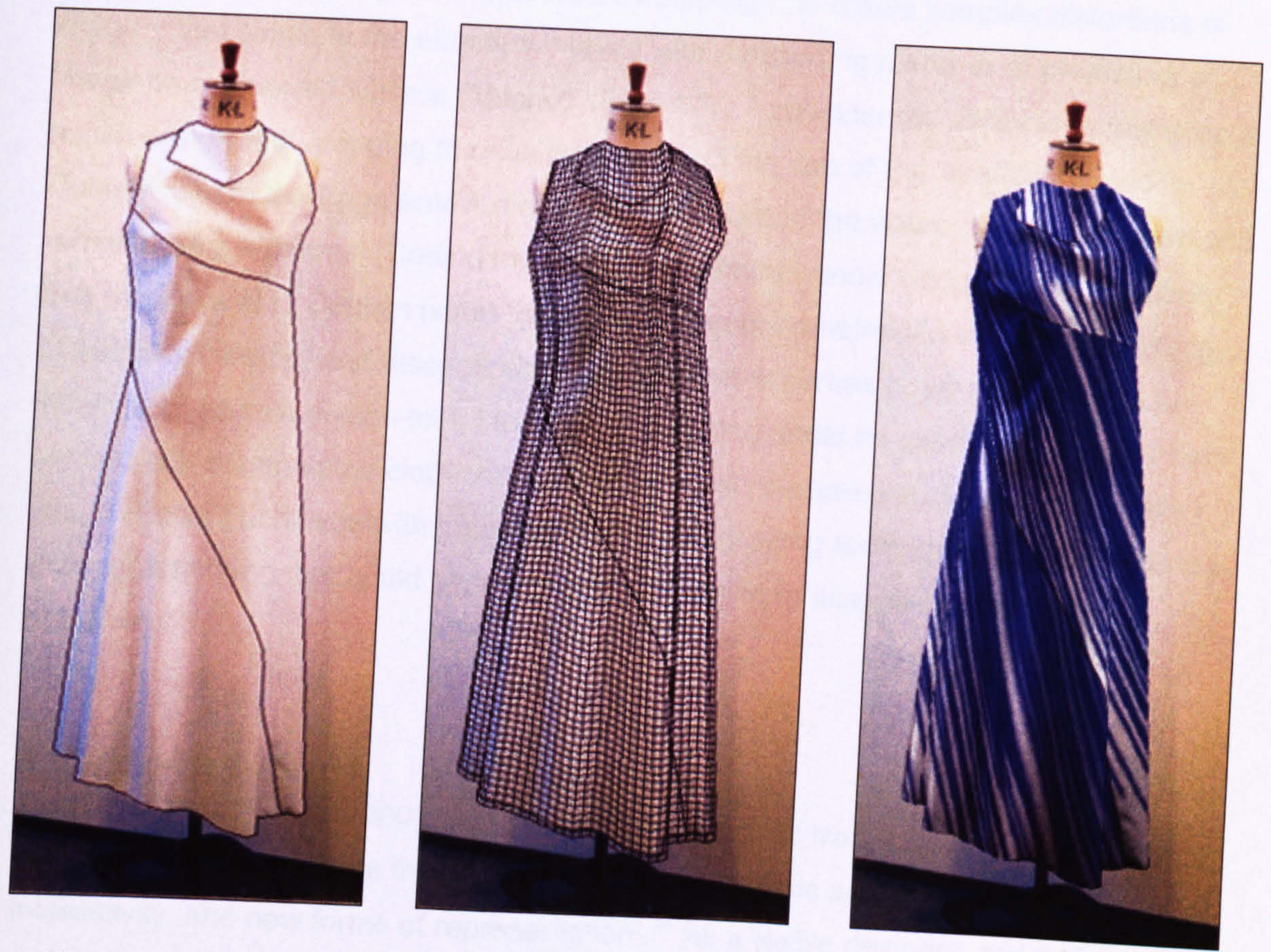

Figure 4-C Katherine Townsend 1999: Print visualisation using textile draping grid 
wire-fram $\mathrm{e}^{16}$ based on the contours of a garment (Fig. 4-C). The corresponding grid can be used to mediate concept driven ideas such as prints, textures, or flat colour to create garment visualisations. Light and shade ${ }^{17}$ can also be incorporated to create a more convincing illusion of the fall of fabric within a garment, which has led draping software to be used primarily for the creation of 'point of sale' graphics.

As well as being employed to emphasise specific (garment) forms, textile draping can be used in a similar way to 'displacement mapping' ${ }^{18}$ to create complex distortions of imagery that simulate the effects achieved with a distorting mirror or of projecting an image onto a curved surface (Mitchell 1992: 177). I consider the ability to reconfigure a textile design with mapping to raise parallels with the use of the 'scaffolding grid' in Cubism, where the fragmentation of an image afforded the viewer a fusion of 'seen and remembered elements' (Cottington 1998: 52). 'Another understanding of simultaneity that was central to Cubism (was) the juxtaposition or combination in a single painting, of radically different and discontinuous perspective schemas or viewpoints' (Ibid.). When applied as a design tool, I found that mapping could be used to synthesise both smooth and manipulated cloth characteristics within the same surface. The distorted visual effects I achieved with mapping and multi-mapping techniques presented a new style of patterning that could be integrated with garment shapes to create novel outcomes (7.2).

\subsubsection{Graphic Software}

According to Lansdown (2002:53) the three main artistic trends in the development of computer graphic software in recent years are 'algorithmic and mathematical art, interactivity, and new forms of representation'. ${ }^{19}$ As a textile designer, my main concern is with the CAD's ability to assist me in the creation of new design vocabulary. The further integration of graphic software with the stylus and design tablet 'has transformed the 2D world' (Johnson 2002). ${ }^{20}$ The increasing sophistication and versatility of CG software often leads it to be favoured over textile applications for image creation, as demonstrated by designers at Paul Smith who employ Photoshop off the shelf textile software for repeat management (Britain 2002).

Arguably, the most popular application used by textile designers is 'the ubiquitous Adobe Photoshop' (Harrod 2002). Unlike proprietary software Photoshop does not

\footnotetext{
${ }^{16}$ Sometimes referred to as a 'bump map' in graphics.

${ }^{17}$ Called 'mapping with shadow' in Prostyle, Lectra.

${ }^{18}$ A technique popularly applied in graphics and animation.

${ }^{19}$ Lansdown cites 'networking' as the fourth and most recent trend, which describes collaborative art work undertaken through the internet.

${ }^{20}$ Comment made in relation to Adobe Photoshop, Fractal Painter and Quantel graphic systems.
} 
promote specific textile tasks due to its origins in graphic design. However, if required, repeats, colour ways and colour separations ${ }^{21}$ can be produced through a lateral use of the software and/or by integrating 'plug-ins'. ${ }^{22}$ While many CAD applications can be used to collage and manipulate ideas, Photoshop's layered method of image building has proved particularly useful for creating innovative composite effects (Fig.4-D). This has led some practitioners to consider their designs as 'images' to be viewed more in the 'context of a painting' rather than 'designs' (Briggs 1997:181). Adobe Illustrator ${ }^{23}$ Corel Draw, Micrographics and Painter are other popular graphic packages.

3D computer graphic (CG) modelling software has been used extensively by architects, graphic and product designers and is increasingly being used by textile designers to incorporate innovative three-dimensional patterning effects into their work. '3D-CG modelling' works in a similar way to textile draping by using a notional wire frame, which the sculptor Bruce Gernand (2002: 29) refers to as an 'exoskeleton'. However, in contrast with draping software, which uses a square grid structure to create a '2.5D' visualisation, CG modelling builds a '3D' wire frame based on a triangulated structure, affording the maker a 360-degree perspective of an object. As Gernand (p.30) observes: 'this can be confusing in that the back of the object's structure interferes with the front, as one sees 'through' the object'. Consequently functions such as 'hidden line' and 'quick paint' and other of rendering techniques provide additional ways of representing the object to confirm and test its volumetric conditions.

In my research practice 3D modelling presented new possibilities for visualising different combinations of print and cut, to provide an indication of how these might work in real space. In September 2000 I investigated 3D Studio Max as a method of shaping my textiles into simple garment forms. I found that shapes could be simulated, surfaced and flattened out. However, the outcomes were of a solid nature, more evocative of a molded piece of carpet than a fluid fabric form. The results did not support my working process, which was centred on the nuances of draped cloth, and told me "less rather than more' about the prospective garment design (Ibid). I chose not to pursue the use of 3D CG software within the research for a number of reasons. The main issue was that it worked in a similar manner to $3 D$ garment visualisation software (4.2.3) which requires that the textile 'skin' that is applied to the surface of the 3D model is configured prior to its integration with the model. As my design method was centred on the origination of prints in three dimensions, I felt that this type of software would not

\footnotetext{
21 Term used to describe the individual positives that represent the different areas of colour within a print.

${ }_{22}^{2}$ For example: the Clicdesign Photoshop Suite at http/www.agetechnologies.com.

23 Adobe lllustrator is often used in conjunction with Photoshop as it offers more accurate drawing tools (King 2001).
} 

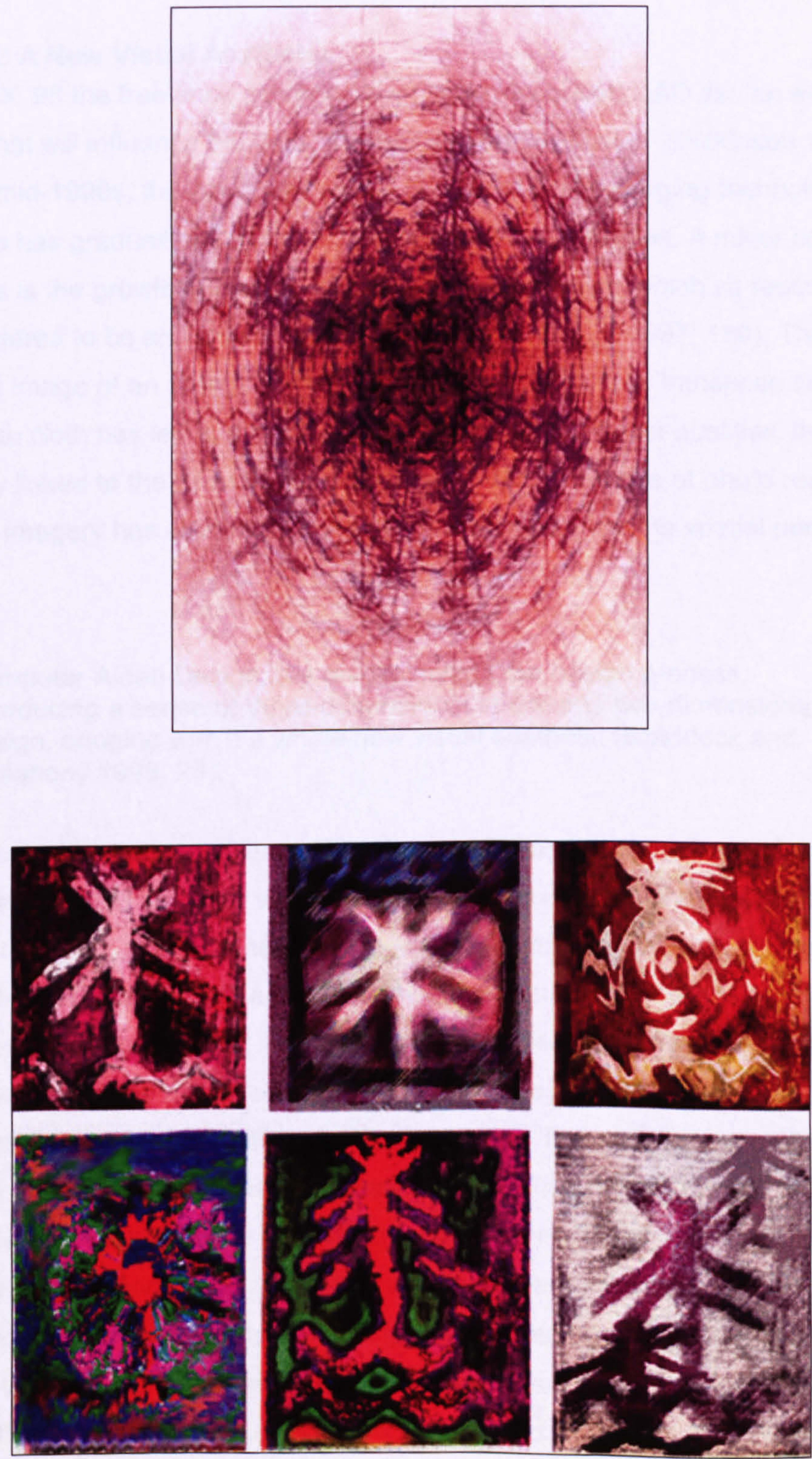

Figure 4-D Nahed Seleman-Baba 2001: Image of Nubian palm tree manipulated in Adobe Photoshop (supplied by the designer)

Figure 4-E Nahed Seleman-Baba 2001: Further variations of Nubian palm tree manipulated in Adobe Photoshop (supplied by the designer) 
necessarily enhance that process. I was also concerned that the inconsistencies between a virtual model of a printed garment and its manifestation in 'the real world of design as a reality' may further complicate my approach (Johnson 2002).

\subsubsection{CAD: A New Visual Aesthetic}

At SURTEX '98 the freelance designer, Ceri Isaac described CAD as: 'an evolutionary tool, one that will influence the user, the culture and the design' (Dickinson 1999: 38). Since the mid-1990s, the combined use of CAD with digital imaging technology and peripherals has gradually transformed the appearance of textiles. A major contributor to the change is the growth in the use of photographic imagery, which as recently as 1997 was considered to be an 'under-used' design source (Briggs 1997: 180). The ability to capture an image of an object, scene or event, manipulate and transpose the outcome directly onto cloth has led to the creation of 'completely different qualities' that are intrinsically linked to the use of CAD as a media (Ibid.). The use of photo realistic and hyper-real imagery has altered both the graphic qualities and the spatial perception of textiles.

Computer Aided Design has revolutionized the design process, introducing a sense of three-dimensional space into two-dimensional design, bringing with it a whole new visual aesthetic (Braddock and O'Mahony 1998: 28).

The Danish textile designer Vibeke Riisberg (2003) has explored the three-dimensional characteristics of CG software since the late 1980s, through her combined use of the 'strict geometry and gradient tools' provided by the systems. Riisberg designs fashion and furnishing fabrics, as well as exhibition pieces that rely on contrasting colour and tone to provide 'various optical effects' (Fig.4-F) (O'Mahoney 1998: 30). Prior to digital printing, the translation of screen images onto positive films enabled designers like Riisberg, to explore 3D print effects without having to 'flatten' ${ }^{24}$ the image for print production (4-G). Although it was technically possible to print photographs onto cloth from 1839 onwards, interest in such imagery was minimal until the 1970s, when improvements in printing techniques ${ }^{25}$ made the process more feasible (Briggs 1997: 63). $C A D$ in association with digital printing has opened up new possibilities for textile designers to employ photographic and complex imagery, with no limit to the number of different effects, colours or perspectives that can be combined within a print.

\footnotetext{
24 Textile designers have traditionally 'flattened' an image into separate colours during the design process, both for visual effect and to avoid the cost of producing expensive CMYK colour separations.

${ }^{25}$ Processes such as photo-gravure, transfer (or sublimation), and four-colour separation enabled designers to transpose highly detailed graphic and photographic imagery onto cloth automatically.
} 

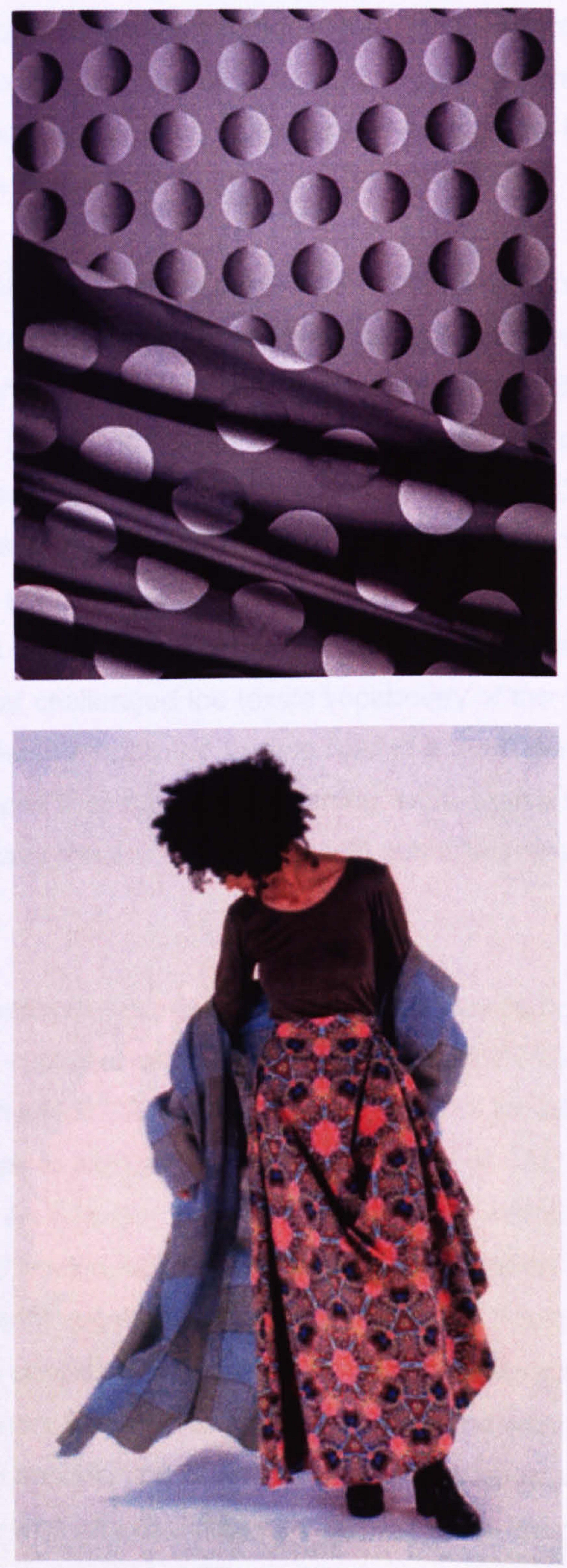

Figure 4-F Vibeke Riisberg 1992: Curtain 'Impression'. Printed cotton satin designed on a Mac 11 (supplied by the designer)

Figure 4-G Vibeke Riisberg 2002 (supplied by the designer) 
The impact of CAD on printed textiles has been evidenced via the high street and designer collections through a plethora of photographic designs. Other designers have explored the new textile spatiality in a more conceptual manner through cloth and garment forms. An aspect of Amanda Briggs (1997) PhD research into the use of CAD for textiles involved the manipulation of scanned and photographic images of flowers that explored movement. Briggs used Photoshop to develop the layered, ethereal qualities of her images (Fig.4-H). ${ }^{26}$

Since 1995 Brigit Appleyard's fashion prints have incorporated the use of objects and simple pattern structures such as stripes, which she scans and alters using Stork printing software to achieve 'solarized' or 'trompe l'oiel effects (Braddock and O'Mahony (1998: 84). Despite the ability to work in full-colour, Appleyard has often employed a limited tonal palette, such as deep indigo blues. CAD's facility to transpose photographs of objects onto cloth was exploited quite literally in 1999, when images of costume jewelry were applied to garments by designers such as Seraph and Eley Kishimoto. The pieces recalled the earlier work of Elsa Schiaparelli and her utilisation of surreal elements that challenged the textile vocabulary of the $1920 \mathrm{~s}$ and $30 \mathrm{~s}$ (3.8.1). In 1999 Dries Van Noten incorporated trompe l'oeil in a more considered graphic context by printing stripes that suggested seaming, while Martin Margiela's S/S 2000 collection included a wraparound skirt printed with oversized pins that appeared to perforate the cloth.

During the practical research I explored both literal and conceptual translations of photographic images, captured using the cyanotype method (5.3.1), which made me aware of the ease with which CAD could be used as a tool for editing images. The chief aim of the research was to explore the creative potential of $C A D$ for integrating prints with garment shapes. As a textile designer I was naturally interested in exploring CAD for image creation and manipulation. Following experimentation I found CAD a flexible way of extending my print vocabulary, creating effects that could be combined with specific garment/cloth shapes that would have been unachievable using only manual methods. Other designers who I consider to have engaged with CAD in similar way include Marcus Lupfer and Martine Sitbon who have incorporated optical gradient effects, Robin Greene who has explored montaged graphic imagery and Laura Rotger Buadas (4.5), who has incorporated 3D modelled imagery into her designs for Hussein Chalayan and TSE (Fig. 4-I \&4-J).

\footnotetext{
${ }^{26}$ Other textile designers exploring the three-dimensional possibilities of CAD in the late 1990s included Susan Thrower, Heather Lindsay, Hazel Fernandez RCA and Steve Bryan RCA (Watkins 1999).
} 


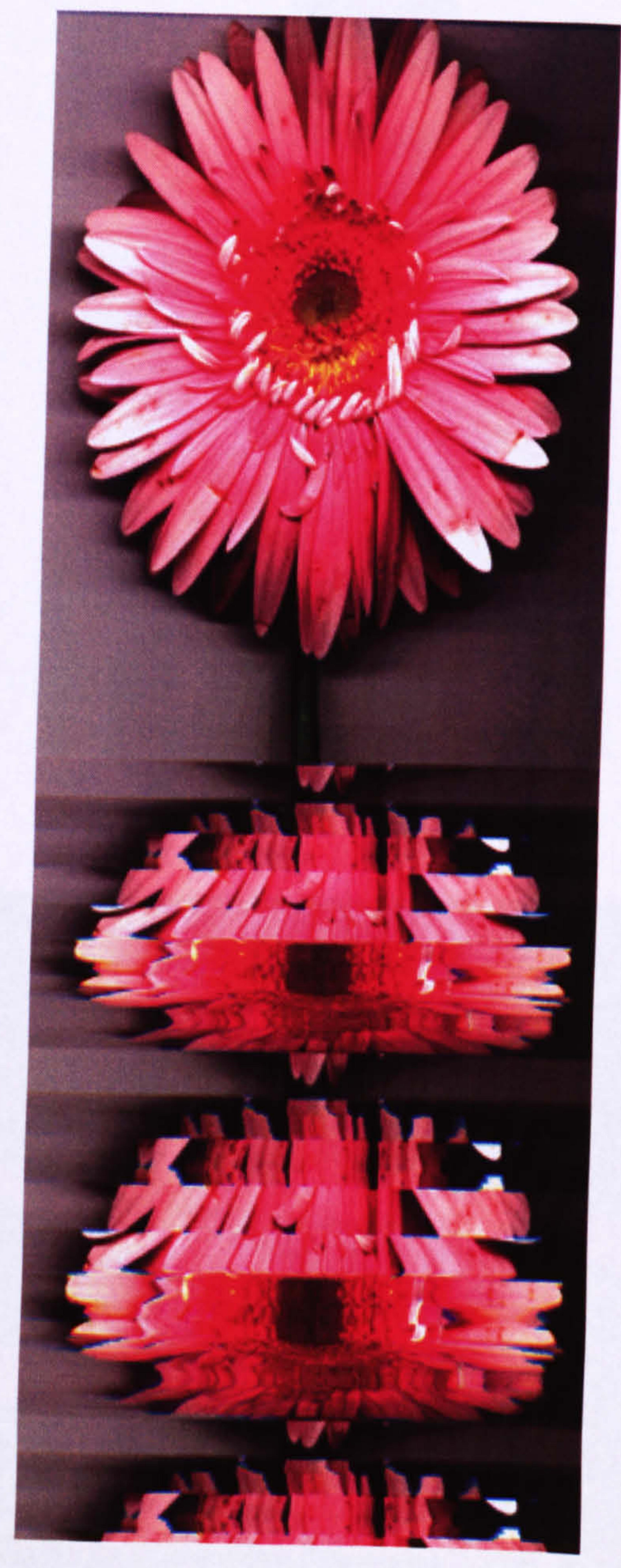

Figure 4-H Amanda Briggs 2001: Engineered image created in Adobe Photoshop for Transforming Shape (supplied by the designer) 

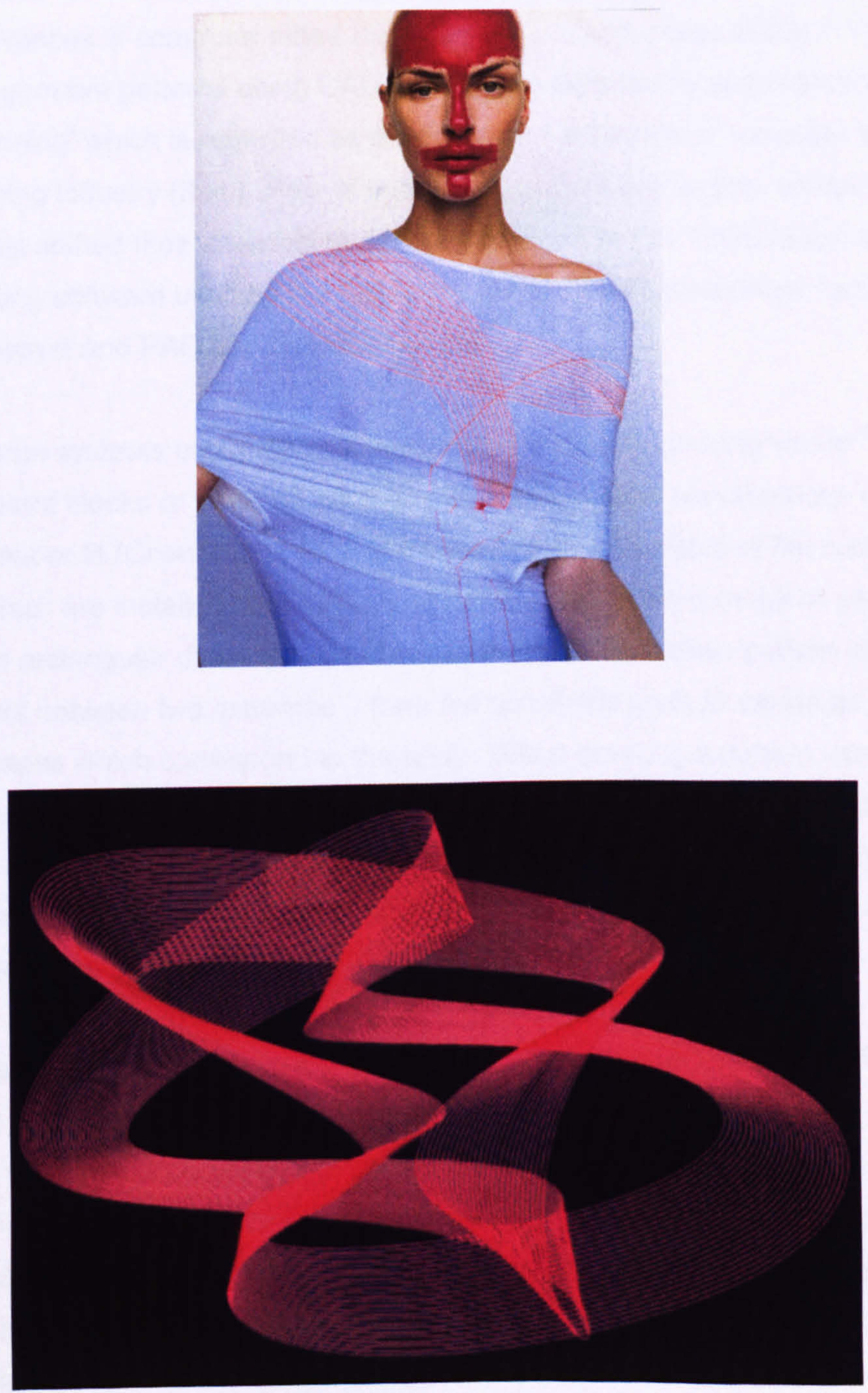

Figure 4-I Hussein Chalayan 1998: Cocoon Dress (Frank 1998).

Figure 4-J Laura Rotger Buadas 1998: Design incorporating 3D graphic modelling effects, for Hussein Chalayan (supplied by the designer) 


\subsection{GARMENT PATTERN DESIGN SYSTEMS}

CAD technology has been applied to 2D pattern shapes since the 1970s (Chen 1998: 3-1). Like CAD for textiles, pattern design systems (PDS) have developed as a direct result of advances in computer aided manufacturing (CAM) (Knox 2003). ${ }^{27}$ The creation of garment patterns using CAD was quickly followed by automated 'grading and lay planning' which is regarded as the first major influence of computer technology on the clothing industry (Ibid.). Having automated pattern production, computer technologists shifted their attention to garment design. Gerber Technology is the main pattern cutting software used by the fashion industry, while Investronica, Lectra Systems, Assyst and PAD are also widely used.

Pattern design systems cover the drafting of construction lines using vector ${ }^{28}$ tools to create garment blocks or patterns according to mathematical specifications of size, measurement or fit (Chen 1998). PDS are based on the principles of flat cutting from blocks, ${ }^{29}$ which are installed on a system, or can be built using a range of square, circular and rectangular drawing tools. As Aldrich (1996: 5) states: 'pattern making from blocks works between two extremes - from flat geometric grids to create an envelope, to curvy shapes which correspond to the body'. When creating a pattern using computerised methods, a pattern can be digitised into the system or created on screen using a series of geometric-shaped vector tools. It is easier to construct geometric pattern contours, than curved shapes, which has influenced modern crossover garment shaping strategies (3.4).

Pattern design systems facilitate the convenient storing of company blocks ${ }^{30}$ and associated patterns on computer, enabling new styles to be created quickly or alterations to be made accurately, in line with the current garment silhouette. In theory PDS allow the designer greater creative potential for the origination of new shapes. In practice this occurs more readily at couture level where patterns cut on a system are originated as toiles on a mannequin and constantly evaluated on the form, as practised by the designers at Yves St Laurent (Durandaud 1996). ${ }^{31}$ This approach can lead to

\footnotetext{
${ }^{27}$ According to Knox the initial impetus for PDS was to create pattern control data for automatic fabric cutting machines, which required pattern shapes and arrangements in digital electronic format.

28 'Vector' images are produced with line segments based on $X$ and $Y$ co-ordinates. The outline shapes, which are made up of a number of control points, can be easily manipulated to alter the image. The technology is mathematics based.

${ }_{29}$ Clothing companies generally construct their own blocks in accordance with the size profile of their customers.

${ }^{30}$ Pattern blocks based on the size of a companies customer profile.

${ }^{31}$ Pattern makers at Yves St. Laurent create a mould and flat pattern from sketches, using Modaris pattern cutting software, from which a prototype is created and tried out on a live model. Any changes deemed necessary are entered directly on the screen.
} 
the creation of complex sculptural (3.2) or architectural shapes (3.3), which are featured on the catwalks but rarely found on the high street.

Most designers working in the mass clothing industry have had the difficult task of transposing 3D mental images of garments onto 2D pattern shapes (Aldrich 1996: 5). Experienced designers can work creatively in 2D exploiting 'the tension between precision and the speculative cut of new fabrics' (Ibid.). But a lack of understanding of fabric performance can lead to designers taking an editorial approach to garments cutting, by altering existing garment shapes in line with trends (Jerrard and Bell 1998: 93). Aldrich (1996: 5) suggests that the lack of opportunity for some designers to engage with fabric and form is also symptomatic of design education, where modular structures in colleges and universities make 'an increasing separation between fabric appreciation and pattern cutting.' While PDS present an efficient method for generating garment shapes, I believe that they are used most effectively by designers with tacit knowledge of the relationship between fabric and form.

\subsubsection{D Pattern Design Systems}

There are an increasing number of 3D pattern design systems (3D-PDS) on the market that allow designers to engage with fabric in a virtual context. At the time of writing her thesis in 1998, Chen concluded that further development was needed in the area of converting patterns originated using 3D Pattern Design Systems (3D-PDS) into accurate 2D patterns. ${ }^{32}$ The complex nature of garment modelling has proved much more difficult to automate than flat cutting, which could help explain the dearth of draped styles in recent years. ${ }^{33}$ However, recent advances in 3D-PDS have finally enabled accurate 2D patterns to be converted from 'cyberpatterns' (Kalman in Chen1997). This could open up the possibilities for designing patterns in CAD in three dimensions and encourage designers to employ more complex cutting strategies that work more closely with the body (Figs. 4K \& 4-L). The creation of more sophisticated shapes could lead to a more 3D-orientated approach to printed pattern that harmonized with such styles.

\subsubsection{Made to Measure Pattern Cutting}

In contrast with CAD for textiles, which is finally developing away from a pure replication of manual methods, PDS are currently revisiting the concepts of manual

\footnotetext{
32 In contrast with 2D-PDS which rely on $X$ and $Y$ co-ordinates, 3D patterns are built using $X, Y$ and $Z$ points which are also the basis of $3 D$ graphic modelling (4.1.3) draping (4.2.3) and animation (4.2.4). ${ }_{33}$ Companies with computerised pattern cutting systems will naturally veer towards styles that are either already on the system or easy to cut from blocks.
} 
garment design as practised in couture. The two current major influences on PDS are 'made-to-measure' and 3D pattern cutting and visualisation software (4.2.4).

Programmes such as Fitnet (Lectra) enable garment patterns to be adjusted in accordance to an individual's measurements, which are obtained using both manual and electronic methods such as body scanning (4.2.3). It is envisaged, by some members of the $\mathrm{BCl}$, that links between the body scanned data and 'intelligent' pattern cutting will lead to a situation whereby high-street shoppers can purchase made-tomeasure garments off the peg (Fernaud 2002: 37). The prospect of integrating personal garment profiles into mass clothing manufacture has important ramifications for printed textiles which, in the future, could also be tailored to individual design requirements.

\subsubsection{Body Scanning}

The recent research carried out by SizeUK was the largest sizing survey in the world, and the first to use 3D body scanners. The SizeUK survey was conducted at six venues around the country and involved the taking of 141 electronic and manual measurements of each individual. ${ }^{34}$ The body scanner works as an electronic tape measure and raises a 200,000-point cloud based on key body landmarks. A 3D-wire frame of the body is generated from the data, which can be used to 'analyse shape as well as measurements' (Crawford 2003). In 2002 Lectra Systems and Human Solutions (Tecmath) entered into an: 'exclusive worldwide strategic partnership' to provide 'leading edge body measurement solutions for mass customization'. ${ }^{35}$ The LectraTecmath partnership indicates the future role for body scanning will be at the centre of the fashion industry's move towards made-to-measure production.

In September 2002, I became involved with SizeUK, through the Size, Shape, Fit research group, ${ }^{36}$ which gave me access to a Wickes and Wilson body scanner. Following discussions with the group regarding the translation of measurement data with garment patterns, I became interested in the potential of the technology to act as a mediator for mapping surface print onto garment shapes. With the help of body scanning technician Claire Cox I was electronically measured in various states of dress, including printed and plain draped cloth shapes relating to my research practice. The scans revealed the limitation of the technology to capture drapery, as the cameras

\footnotetext{
${ }_{35}^{34}$ Head girth, height and weight were measured manually.

${ }^{35}$ www.lectra.com

${ }^{36}$ Size, Shape, Fit, was formed by ex-members of Computer Clothing Research (CCR) at NTU, who were one of the leading research and development bodies exploring 3D measuring and 3D CG fabric drape in the 1990s.
} 

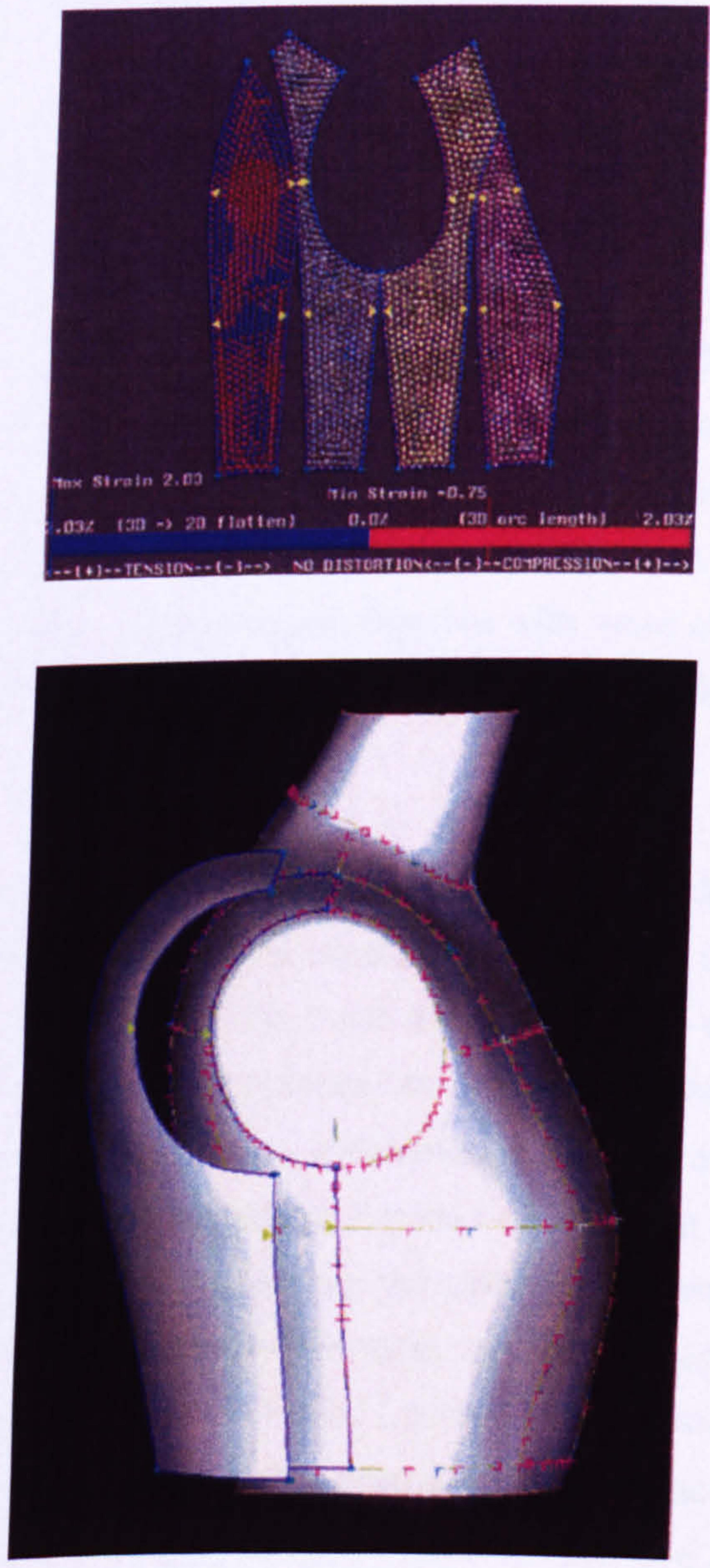

Figure 4-K Flattened pattern from a CDI-3D System (Chen 1998)

Figure 4-L CDI-3D System showing second skin pattern (Chen 1998) 
cannot read around corners, ${ }^{37}$ but presented possibilities for creating surface design solutions based on an analysis of size and shape. It is my opinion that the integration of bespoke printed textiles with made-to-measure garment shapes will become a significant area of future design research and practice.

\subsubsection{D Computer Draping Systems}

In common with 3D CG modelling (4.1.2) 3D computer draping systems (3D-CDS) use triangulated grid structures to simulate the draping behaviour of cloth. 3D-CDS ${ }^{38}$ enable designers to visualise patterns originated in 2D and 3D as virtual garments on a virtual mannequin, constructed to the designer's specifications and aligned with a corresponding pattern. 3D CDS require a large amount of memory, and can be prohibitively expensive (Dewar 2003). ${ }^{39}$ However, increases in the capacity of graphic cards to handle complex, moving images together with more affordable software, provided by companies such as Optitex (USA) is making this technology more accessible (lbid.).

During the research I used PAD's 3D System to simulate simple garment shapes integrated with print. While the system allowed me to repeat a motif, I was unable to engineer the print around the garment. I was also unable to re-cut the garment around the print to create alternative pattern pieces, as the software works purely as a visualisation tool, and is not interactive, which means that any adjustments must be made to the 2D pattern prior to modelling. Figure 4-M, shows a modelled, printed skirt. Although I found the 3D images interesting, the software required a linear working method that did not enhance the 'make-remodel' approach adopted in the practice (Ch. 5-7). I had a similar experience when I used Lectra's Virtual Mannequin (VM) software, ${ }^{40}$ which allowed me to move the print around as a placement (Fig. 4-N). It is not yet possible to originate imagery directly on the surface of a 3D virtually modelled garment, which is why I synthesised manual and CAD methods within the practice.

While the facility to manipulate graphics within a 3D garment visualisation remains limited, 3D-CDS offer the fashion industry the opportunity to assess the design potential of printed garments by taking accurate 2D patterns, filled with prints and wrapping them around the body. The increasing sophistication and accessibility of 3DCDS software is finally influencing some of the larger clothing suppliers to think more

\footnotetext{
${ }^{37}$ This is an inherent problem that poses difficulties for measuring key areas of the body such as breasts, underarm, crotch etc.

${ }^{38}$ The Kawabata Evaluation System is used to translate the characteristics of cloth into the computer.

${ }^{39}$ Software costs can be $£ 9,000$ with training sessions of up to $£ 500$ per day, from the larger suppliers.

40 I had the opportunity to try this software out while it was still being developed, during a visit to Lectra's Research and Development centre at Cestas, Bordeaux in October 2000.
} 

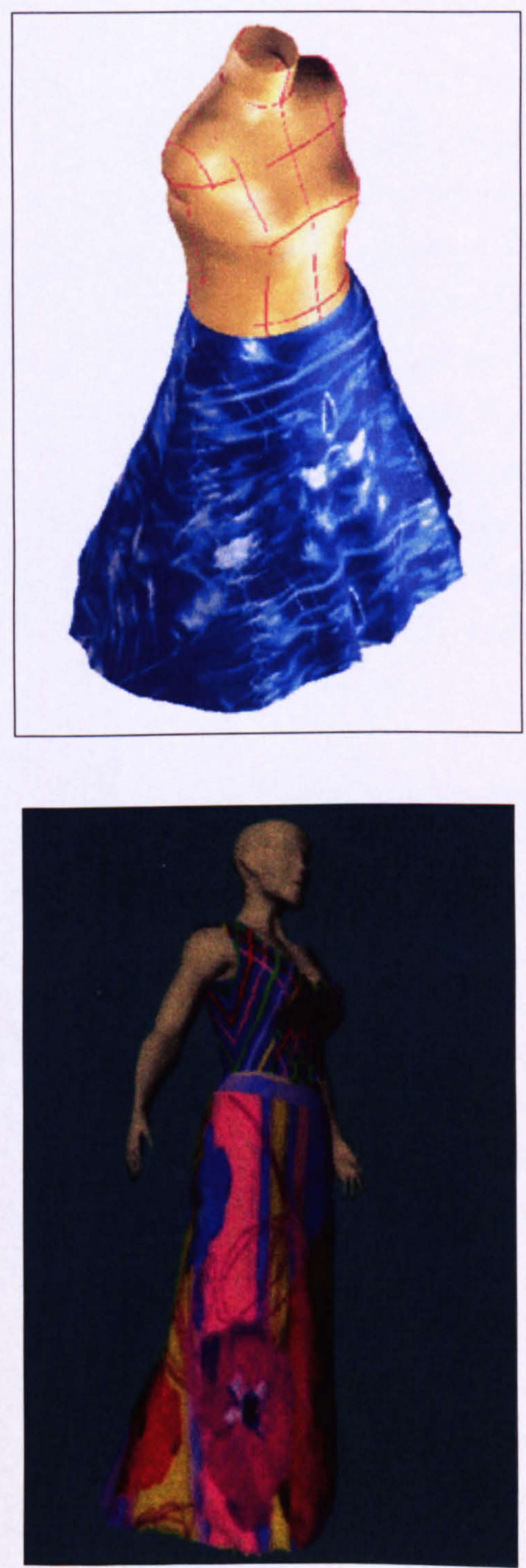

Figure 4-M Katherine Townsend 2000: 3D garment visualisations created on PAD 3D System

Figure 4-N Lectra System's 2000: Virtual Mannequin (VM) visualisation created by Laura Mylius 
three-dimensionally. While many companies have still failed to grasp the potential of $2 \mathrm{D}$ software, it is recognised that ' $3 \mathrm{D}$ is the route that designers should now follow' as a route for innovation (Dewar 2003).

\subsubsection{Cloth Animation/Dynamic Drape}

Fabric animation drape has been investigated since the 1960s, but was not adopted by the fashion and textile industry until fairly recently because of distortions arising from pattern conversion and the fairly rigid translation of the dynamic drape of cloth (Stylios et al 1996: 112). Some of the most innovative research into cloth animation has been carried out by Nadia and Daniel Thalman, in Switzerland, ${ }^{41}$ whose work has been applied to the fashion, textile and CG film industry (Thalman and Volino 1996). Brendan Hinds is the most prominent researcher working in the UK. ${ }^{42}$ His recent research into the issues of 'real time' CG garment and textile simulation is one of the only projects to be directly supported by the fashion industry. The objective of real time $3 \mathrm{D}$ computer draping systems is to replace the 'physical ${ }^{43} \mathrm{cloth} /$ garment prototyping process in order that the manufacturer may respond more efficiently to the demands of the buyer and distributor. As Harris (2000: 41) states:

Manufacturers need to be able to design in 3D offering greater variables, make alterations to designs more rapidly, provide more choice to buyers, and cut down on materials and wastage in the process. A successful 3D CG and CAM system will dramatically alter the production process and increase levels of efficiency.

The textile artist/designer Jane Harris is one of the few independent designers to have researched the 'unexplored aesthetic potential' of CG animation through an extensive use of software including Alias Wavefront's Maya ${ }^{44}$ (Harris 2002). Her resulting digital textiles are a breathtaking fusion of a dancer's movement with a disembodied garment, colliding and floating in an ethereally in virtual space (Fig.4-0). Although Harris's pieces have been created primarily as digital art, she sees the 3D CG animation of cloth as a tool that is set to 'revolutionise the creative and commercial future of the fashion and textile industries' (Harris 2000: 33). There is already some evidence of this as the use of virtual mannequins in 'catwalk' scenarios are experimented with by designers as a method for promoting collections. The collaboration between Infographica and Thierry Mugler (1999) is an early example that illustrates the potential of $C G$ animation to showcase printed garments. It is envisaged that it will soon it be possible for individuals to view garments in a similar manner on their own moving body

\footnotetext{
${ }^{41}$ For an overview of the Thalman's research profile see: www.miralab.com.

42 Dr. Hinds research group is based in the engineering department at the University of Belfast.

${ }^{43}$ Each cloth has its own data, which is measurable by the Kawabata Measuring System.

44 Alias Wavefront is considered one of the most versatile products on the market and one of the only interfaces to have attempted to incorporate 'the sketching side of things at a fundamental level' (Johnson 2002).
} 


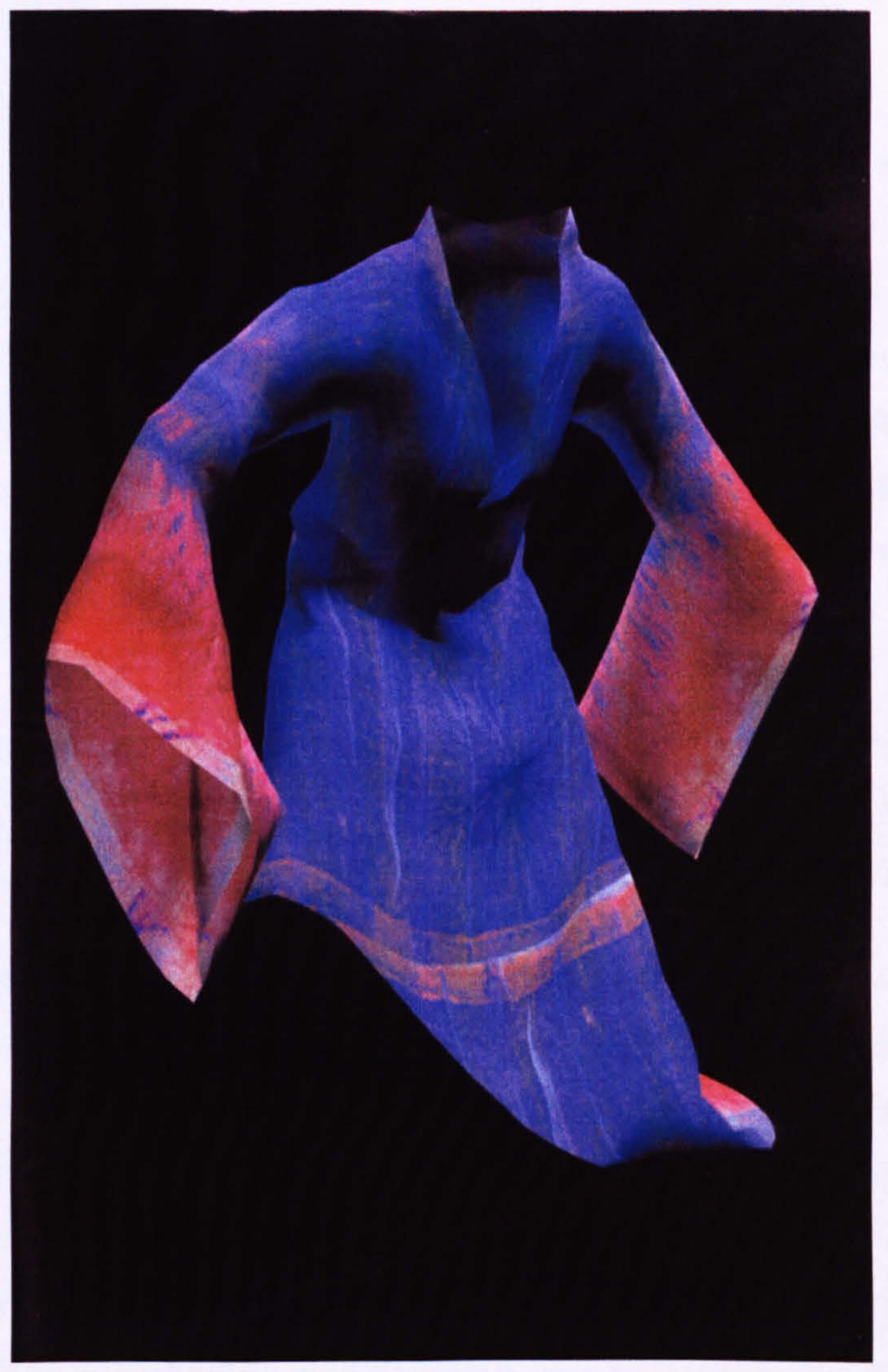

Figure 4-O Jane Harris 2000: Computer animated digital textile from the Portrayal Series (Williams 2002) 
double, where the dialogue between garment and form can be assessed more stylistically. This could prove to be a much more positive selling point than the static or rotating virtual mannequins currently featured by some internet catalogue sites (4.3.2).

\subsection{INTEGRATED CAD}

Chen (1998) identifies the two areas of CAD for clothing as: 'concept', raster-based design (4.1) and 'pattern' vectors (4.2). The practical element of this research is concerned specifically with exploring the design potential of these two integrated technologies. One of the earliest integrated software applications was Lectra Systems' Prostyle version 1.0, which was launched in 1994 after three years development (Mylius 2002). However, it was also possible to work with raster and vectors simultaneously using the 1992 version of U4ia (CDI) (Ibid). Prior to this, smaller companies such as Concept II facilitated the combining of raster and vector formats as early as $1987,{ }^{45}$ as described by Aldrich (1990: 215):

Colours could be transferred to the vector system, line images from the vector system could be transferred to the paint system. It was the first stage of the connections that I saw as vital if any CAD design system was to be used in any way comparable to the methods available to the designer working manually.

The availability of more powerful CAD systems and interchangeable file formats has fueled the climate of integration currently permeating the fashion and textile industry, enabling designers 'to seek solutions that cross the software boundaries' (Ibid: p. 218). Despite the availability of integrated formats, there is little documentation of its creative use within the design community. As illustrated in Fig.4-P, integrated CAD software enables designers to combine printed textiles with 2D and 3D garment shapes. Integrated CAD also incorporates textile draping software (generally sold separately) which allows garment designers to switch spontaneously between $2 \mathrm{D}$ pattern shapes and 3D garment visualisations. The ability to envisage 2D pattern ideas in 3D also has important ramifications for printed textile designers, allowing them to explore surface design in a new spatial context.

To date the use of integrated CAD has mainly been evidenced in the graphical context of 'product line development', for visualising and promoting printed garments, its use as a designing method has been limited as clothing design companies continue to follow a traditional 'critical path"46 (Gordon 2003). Integrated CAD technology offers new

\footnotetext{
${ }^{45}$ Ormus-Fashion was designed by Winifred Aldrich in association with Concept II 'specially for Fashion/Textile patterns and graphic sketches.' In this early version of integrated CAD raster and vector graphics had to be incorporated as ready-made images and could not be worked on simultaneously, as in the case of U4ia and Prostyle.

${ }^{46}$ Term used to define strategy for design and production of garments.
} 

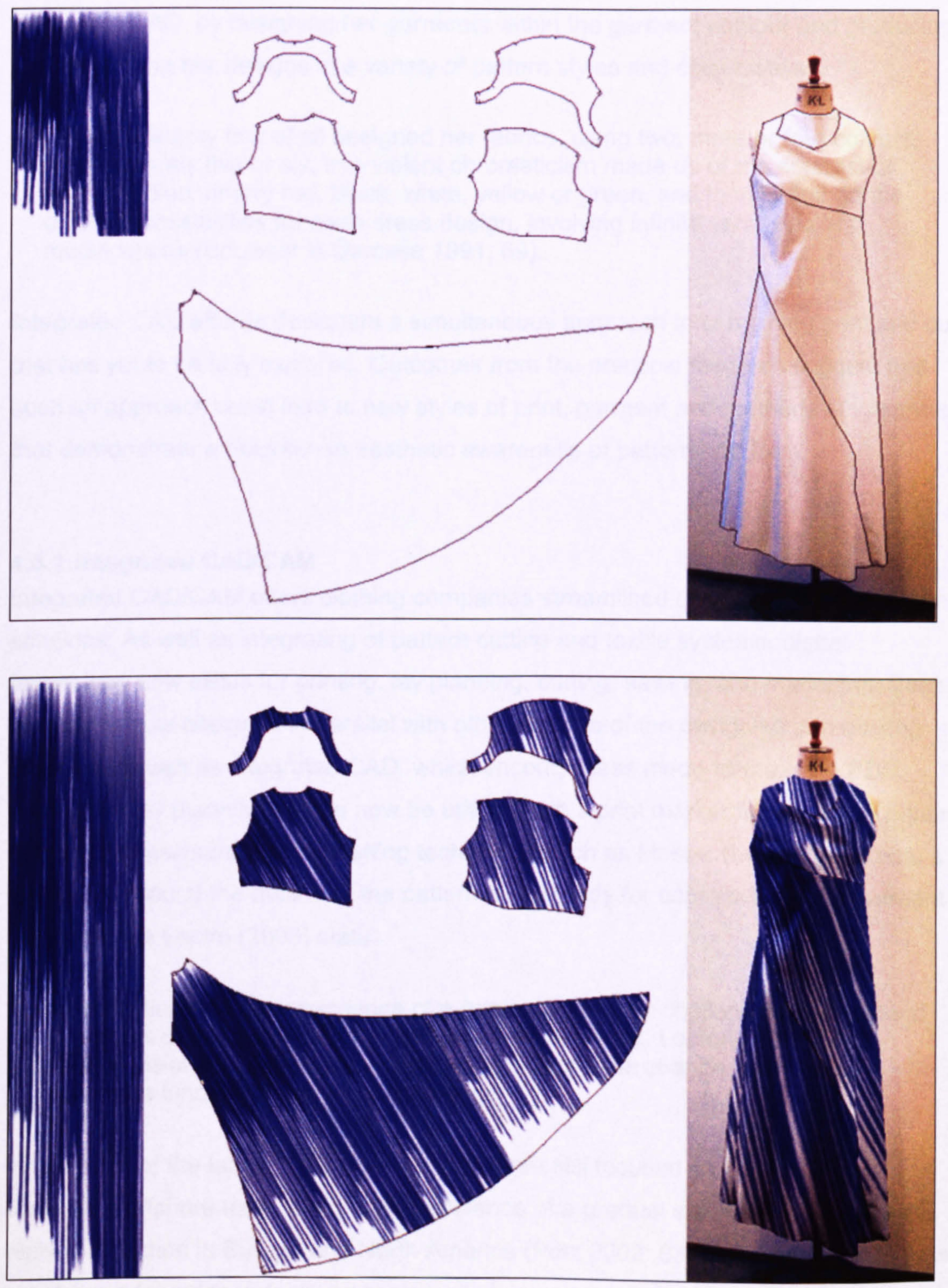

Figure 4-P Katherine Townsend: Drip print integrated with 2D garment contour and 3D visualisation 
approaches to the critical path, presenting designers with the opportunity to explore infinite design possibilities that could only be imagined in the past. Sonia Delaunay's strong design aesthetic enabled her to work in manner that pre-empted the use of integrated $C A D$, by designing her garments within the garment contour and producing and visualising her designs in a variety of pattern styles and colour ways.

Sonia Delaunay first of all designed her fabrics, using two, three or four colours, or more rarely five or six, in a violent chromaticism made up of the contrast of midnight blue, cherry red, black, white, yellow or green, and then imagined the different possibilities for each dress design, involving infinite variations and modifications (Bouisset in Damase 1991: 69).

Integrated CAD affords designers a simultaneous approach to combining print and cut that has yet to be fully explored. Outcomes from the practical research suggest that such an approach could lead to new styles of print, garment and methods of integration that demonstrate a heightened aesthetic awareness of pattern and form.

\subsubsection{Integrated CAD/CAM}

Integrated CAD/CAM offers clothing companies streamlined design and manufacturing solutions. As well as integrating of pattern cutting and textile systems, digital technology now exists for printing, lay planning, cutting, sewing, and marketing. Each element is now designed in parallel with other aspects of the designing and making process. As well as integrated CAD, which encompasses made-to-measure PDS, automated lay planning can be now be utilised with a print marker for the digital printing of individual garment pieces. Cutting technology such as Mosaic (Lectra) laser cuts a single ply, around the outline of the pattern piece ready for construction as a garment prototype. As Lectra (2003) state:

Globalization and the emergence of e-business are new challenges that demand new levels of performance from technological solutions. Lectra's policy is to develop visionary partnerships that give our clients the change to offer their customers innovative integrated solutions.

While most of the larger CAD/CAM providers are still focused on capturing and facilitating offshore trade there is also evidence of a gradual shift towards more local, niche production in Europe and North America (Pötz 2002: 83, Metchek 2003). This is good news for independent companies which have been edged out of manufacturing by larger producers or prevented from accessing cutting edge manufacturing methods by their relatively low output. At present, I consider the key area of CAD/CAM that is of benefit to the printed textile/garment designer to be the combined use of CAD with 
digital fabric printing, which allows the designer to exercise greater 'autonomy' over the designing and printing process.

The integration of washing and fixation units with digital printing technology, will soon include sewing and other making-up machines. It is envisaged that this style of CAD/CAM could lead to a reduction in the proportion of global production and an increase in local involvement (Potz 2002: 83). According to the American marketing analyst, Ilsa Melchek (2003) 'licensing and merchandising' will gain more significance in the future, in both design and manufacturing contexts. Instead of recruiting or retraining staff to produce new styles, increasingly, specialist units will be sourced to design and manufacture specific clothing lines, which could present new opportunities for local designer-makers, leading to a reduction in offshore investment (lbid).

\subsubsection{Mass Customisation}

Increasingly, sophisticated technology is being used to 'micromarket' clothing to consumers through techniques known as 'mass customization', 'one-to-one' marketing and 'relationship marketing' (Berry 2000: 49). The consumer analyst Morris Holbrook (1999: 23) refers to such marketing strategies as: 'McCustomization', which in the clothing industry has tended to focus on issues of size, shape and fit. Lands' End and Levi's Original Spin custom clothing services are prime examples of this merchandising approach.

The e-catalogue company Lands' End, were the first clothing web site to use a virtual 'Personal Model'47 to boost sales of womenswear. At present the service excludes the modelling of printed apparel, which can be ordered on a more conventional catalogue basis in up to two colour-ways, subject to availability. ${ }^{48}$ Levi Strauss \& Co. have offered a custom-fit jeans service since 1995 when it introduced its 'Personal Pair' service. The system has evolved from using measurements provided by customers to those based on their biometric data. ${ }^{49}$ Customers can choose jeans to be made in a range of denim weights and finishes, enabling them to consider surfacing as well as styling issues. Until recently, bleached and worn effects have been integrated with Levi's by manually sandpapering the garment. This process is now performed by lasers, which can

\footnotetext{
${ }^{47}$ A visitor to the www.landsend.com site can create a virtual model of themselves based on their statistics, which can be used to 'try-on', a limited range garments that can be ordered online.

${ }_{48}$ At the time of writing the company could offer me only 'a few blouses in stripes and plaids, a paisley skirt and a range of swimwear' in two sizes, as generally 'prints don't' seem to sell as well as solids' (Jan W 2002).

${ }_{49}$ The electronic body scanning system used by Levi's since 1999 was developed by the Tailored Clothing Technology Corporation, an industry R \& D consortium known as [TC]2, who have also undertaken research into print customisation (4.5.1).
} 
achieve greater consistency of mark making, but still appear to be authentic (Kerrigan 2003).

In 2001 Levi's Engineered Jeans range featured printed ${ }^{50}$ separates accompanied with written instructions on how to 'customise' the item. ${ }^{51}$. The printed tee shirt featured imagery consisting of cutting lines, tiny scissors and threaded needles that both decorated and directed the customer to a series of shaping possibilities. ${ }^{52}$ The selfcustomisation of a garment offers further choice but an additional cost for the consumer, which presents an important consideration for designers.

\subsubsection{Print Customisation}

As well as promoting the advantages of improved garment fit [TC]2 are internationally acclaimed for their research into the customisation of printed garments using digital printing:

The integration of digital printing into the apparel supply chain is instrumental to the ability to provide mass customized printed apparel...No longer limited by the inherent nature of the screen printing process, it is possible to engineer a print design according to the shape of garment pieces. It is also possible to customize design elements and colorways according to individual consumer preferences. ${ }^{53}$

So far [TC]2's investigation into print/garment integration has centred on issues of motif placement and print matching across seams. Figure 4-R shows consideration of both aspects, as both a 2D (print-filled) pattern and a 3D, garment visualisation. The mathematical placing of the diamond shaped motifs ensures that the design can be joined across most of the seams and the button stand when the pieces are married together. The repeat has been engineered within the pattern shapes, and a similar effect would not be achieved with a conventional style of repeating design.

[TC]2's research into printed apparel has recently been supplemented by The Ink Drop Boutique, ${ }^{54}$ which sells digitally printed accessories via the internet. Most of the print designs are fairly conventional and exemplify a combined use of scanning, CAD and digital printing to create regular repeating prints, with the exception of the Abstract and

\footnotetext{
${ }^{50}$ As yet, Levi's do not use digital fabric printing because of it's 'prohibitive' costs (Kerrigan 2003).

51 The development of the Engineered collection was the focus of BBC2's Coolhunters: Jeans (2001), which charted the progress of Levi's designers Christinr Detlefson and Frederik Willems.

52 The top could be cut in two lengths with three different sleeves and could shaped more closely into the waist by sewing.

${ }^{53}$ www.tc2.com/RD/RDPrinting.htm

54 At www.inkdropboutique.com, scarves retail for between $\$ 43.95$ for a 21 inch, and $\$ 69.95$ for a 36 inch square. Oblong scarves are $\$ 49.95$ for no specified measurement. (Convert to $\ell^{\prime} s$ to indicate profit margin).
} 

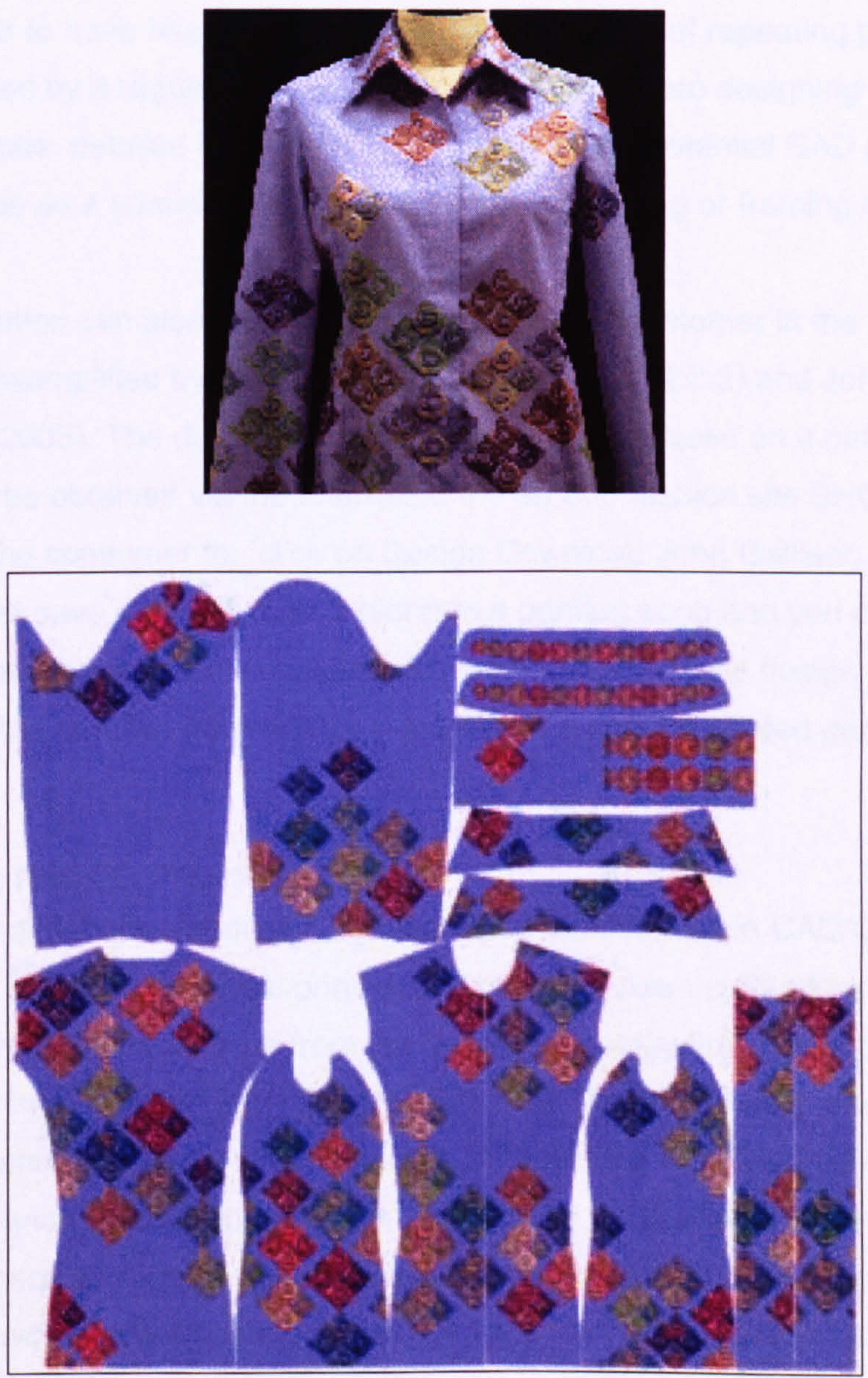

Figure 4-Q TC2 Engineered printed garment and pattern pieces (http//:www. tc2.com/RD/RDPrinting.htm 2003) 
Textural collections, which illustrate a less formulaic use of CAD. Customers are encouraged to order online from a collection of 'square' or 'oblong' scarf designs in up to three different colourways. From an integrated design perspective neither shape seems to have influenced the way that the imagery has been incorporated; most of the oblongs appear to have been cut from a continuous length of repeating print and each square is framed by a regular border. My own exploration into designing prints within geometric shapes, detailed in Chapter 7, investigates the potential CAD provides for treating a shape as a spatial entity as opposed to a cropping or framing device.

Print customisation can also be employed to involve the customer in the 'style cutting' procedure as exemplified by the Levi's Engineered range (4.3.2) and John Galliano's Union Jacket (2003). The design, shown in Figure 4-S, is based on a patchwork of flags, and can be obtained via the Internet at the art and fashion site SHOWstudio.com, which directs the consumer to: 'click on Design Download John Galliano on the homepage. Just save it to disc, take it along to a printing shop and you can have the full-size template ready to customise in any way you see fit.' The design concept demonstrates the creative potential for e-marketing exclusive printed garments.

\subsection{DIGITAL FABRIC PRINTING}

Digital printing direct onto fabric is a consequence of advances in CAD/CAM and the integrated use of CAD with digital printing is a natural follow on (Watkins 1999: 18). Digital fabric printing has evolved from the inkjet technology first introduced to the paper industry by Canon in 1979 (Gregory 2000: 39). Milliken ${ }^{55}$ were the first company to patent a machine for jet printing textiles in 1978 (Bunce 1993: 121). Following a considerable period of development, the turning point for the fabric technology came at ITMA 1999, where a range of systems provided an indication of the future direction that textile printing would take (Xudong \& Yenmai 2002: 64, Wilson 2001: 18). Following its application at all levels of the clothing market it is evident that digital printing has impacted on conventional printing methods and is influencing emerging fashion. As Ujiie (2002) states:

Mechanical production methods influence both design aesthetics and styles. In the fields of printed textile design, the latest digital printing technology has influenced the style and definition of printed textile design.

${ }^{55}$ The Millitron was used for printing carpets which was acceptable as the pile disguised the crude application of dye. 


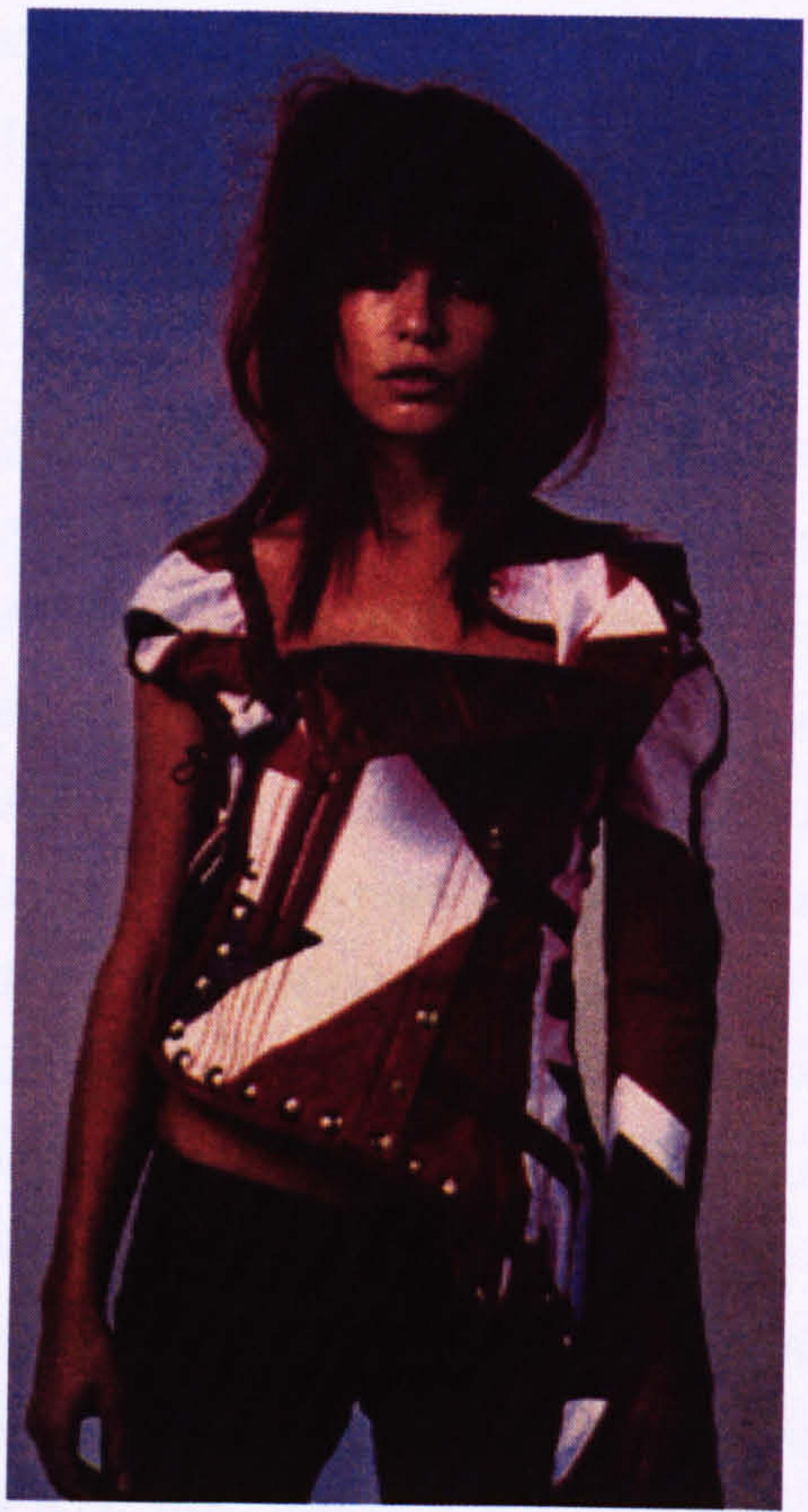

Figure 4-R John Galliano: Union Jacket (SHOWstudio 2003) 
Patterning techniques and materials are subject to constant change. The development of printing over the past three hundred years has evolved from contact printing procedures such as woodblocks, flat and rotary screen where ink is pushed through a stencil, to non-contact, inkjet methods where the ink is sprayed onto the cloth. The reason for all these advances has been to make the printing process 'faster, more flexible, more economical and of higher quality' (Böhringer et al. 2001: 8). This research is concerned with how these improvements can influence the way that that printed textiles and garments are designed and the new aesthetic qualities that such technological change offers.

\subsubsection{Speed}

The main advantage of digital printing over existing techniques is the speed at which fabric samples can be created. The ability to transpose a design directly from CAD to cloth removes the need for colour separation and screen production, reducing the turnaround period from weeks to hours (Pötz 2002: 80). For production printing the speed is less attractive, but the larger machines are faster, for example the Stork Amethyst (Fig.4-T) continuous printer for natural fibres is claimed to be capable of printing 350 metres of cloth per day, with designs up to $3.2 \mathrm{M}$ in length and $1.6 \mathrm{M}$ wide (Xudong \& Yenmai 2002: 64). This translates into $17 \mathrm{M}^{2}$ per hour, and compares favourably with rotary printing, which continues to be the industry's leading printing method. The Amber sample printer is Stork's smallest model and can print approximately $1 \mathrm{M}$ per hour, depending on the required precision of the print, to a width of $160 \mathrm{~cm}$ (Fig.4-Y). The Amber prints onto Stork PFP ${ }^{56}$ fabric, and can be used in conjunction with customers own 'grey goods' ${ }^{57}$ if required. The main advantage for designers is the ability to sample ideas quickly, which can be a useful way of verifying or gaining orders in a selling situation. In my experience, buyers prefer to handle a sample of cloth or view a prospective garment style as a material object. Digital printing can aid this process of realisation.

\subsubsection{Flexibility}

The development of digital fabric printing has been 'retail driven', fuelled by the shift in the retail clothing market from mass-production towards niche marketing and production strategies (Watkins 1999: 17). In Europe fashion manufacturers now tend to produce more, smaller collections on a rapid response basis. In printing terms this

${ }^{56}$ Fabric which has been 'prepared for printing'.

${ }^{57}$ Customers can treat their own cloth with a finishing chemical supplied by Stork. 

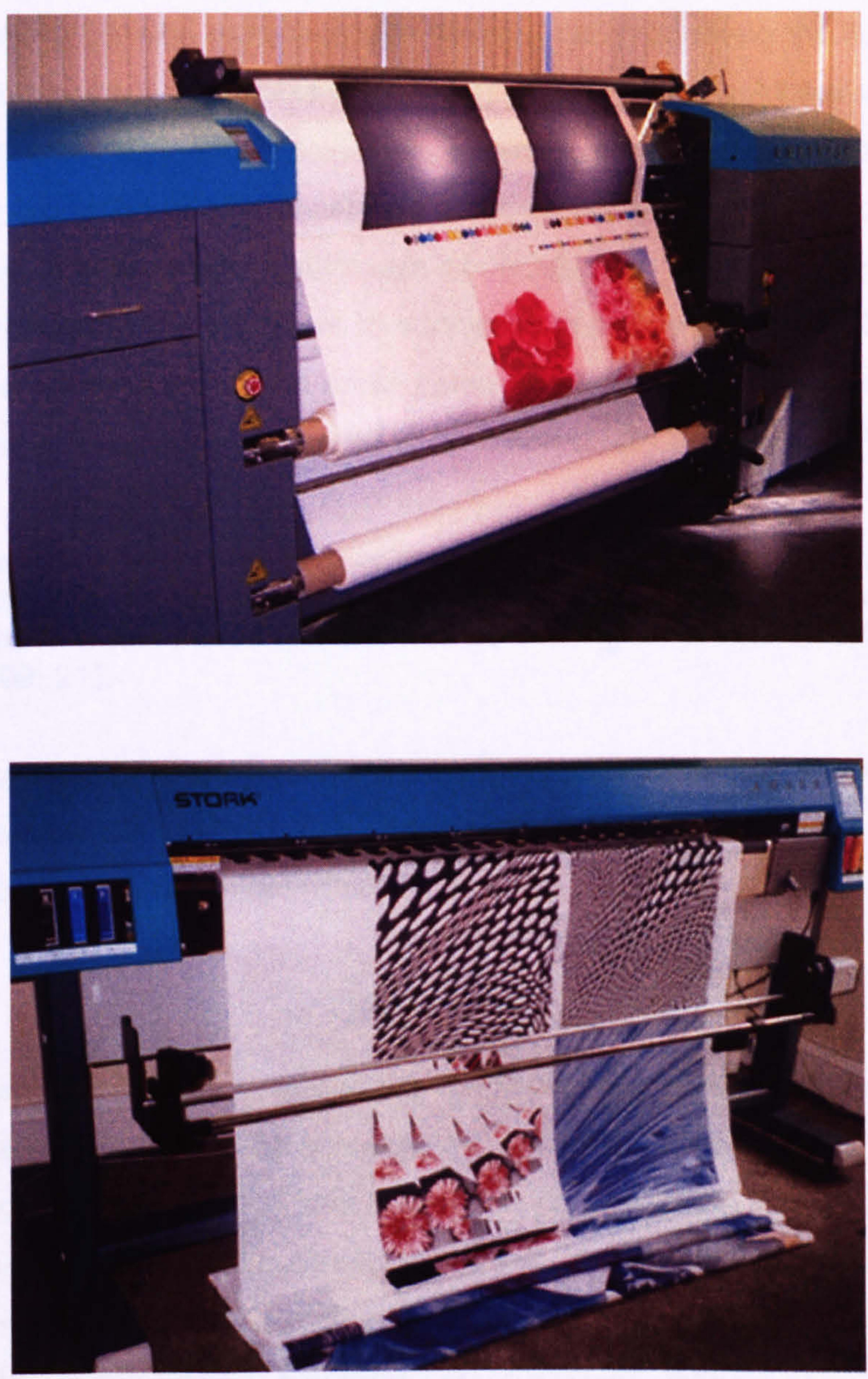

Figure 4-S Stork Amethyst and Amber digital fabric printers (Townsend 2001) 
means more designs and fewer metres. As digital printing often runs on a 'no fixed minimum ${ }^{158}$ basis this makes it an increasingly viable option (Shaw 2003).

The Amber was first launched at ITMA 1999 for use with reactive colours on cotton viscose and silk. Following Stork's strategic partnership with Lectra in 2000, their digital printing technology became more geared towards accommodating the fluctuating needs of the fashion industry (Wilson 2001: 19). As a result, the Amber was relaunched in 2001 to function with acid dyes, pigment colour and disperse transfer for 'the effortless production of high quality digital prints on nearly any type of polyester substrate' (Stork in Wilson 2001). Although it is possible to use a single machine for all four printing processes, it is advisable to specialise in one type of dye. This means that for customers seeking to transpose prints using disparate methods, access to more than one machine is required, as predicted by Mitch Wade of Encad in 1999:

I believe service bureaux and smaller manufacturers will become the printers of tomorrow because they are more adaptable. I can see a 'printing loom'59 scenario where you have whole banks of machines all running for production (Quoted in Watkins 1999: 21).

The flexibility of printing onto natural and manmade substrates has made digital printing more accessible to designers. Pigment printing especially offers creative and economic advantages as it is cost-effective and can be printed on most substrates.

\subsubsection{Costing}

For the independent designer accurate costing is crucial for survival in a highly competitive market. However, the conveyance of a visual 'concept' will often be financed to secure the success of a collection. Since graduating from St Martins in 2000, the fashion designer Robin Green has creatively explored digital printing techniques through his collections. He has used both Stork's Amethyst and Amber technology to transpose all-over figurative and placement designs onto natural substrates. Due to the high printing costs of working with reactive dyes, ${ }^{60} \mathrm{Green}$ has become very strategic in his print usage. Digital printing is charged per square metre of coverage, so when printing a garment shape, in theory the customer pays only for the area that is printed. This reduction in waste raises parallels with Delaunay who printed her designs as garment shapes directly onto silk, to save inks (3.7).

\footnotetext{
58 The Printworks regularly produce as little as $10 \mathrm{~cm}$ colour strike-offs in lieu of a larger order (Yarwood 2001).

${ }_{59}$ The 'printing loom' refers to printing machines set up in series, in a similar manner to weaving looms.

${ }^{60}$ Reactive printed fabric is always fairly expensive to produce because of the nature of the process, which involves printing, drying, steaming and washing. In the future washing and fixation units will be integrated into the printing process so that they are no longer stand-alone solutions (Pötz 2002: 83).
} 
Digital printing has been functioning on a 'bespoke' basis for some years and will continue to offer textile and other design companies ${ }^{61}$ a convenient method for sampling or producing one-off design solutions. The costs for producing sample pieces vary from between $£ 30$ - $£ 100$ per meter depending on the type of printer, method of printing, fabric quality and level of design service. Until recently, larger design companies have followed-up digital sampling with rotary or flatbed methods production methods, which are still more economical for high meterage (Bannister 2003, Collins 2000). ${ }^{62}$ However, with the reduction in the cost of printing inks and the advances in the hardware, costs are falling, leading to digital printing gradually being incorporated into designer clothing through bureaus, such as The Print Works, the Centre for Advanced Textiles (CAT) and the Quantum Design Group (Frogson 2000, Shaw 2003). ${ }^{63}$ The combining of digital; with traditional printing methods is a new area of textile development, as facilitated by R.A. Smart and its sister company Belford Prints. ${ }^{64}$

\subsubsection{Quality}

The Stork Amber is considered to be; 'the most complete and affordable basic inkjet model - especially suitable for companies wishing to start up in digital printing without making any concessions to quality' (Wilson 2001: 19). As a designer, I consider the most impressive aspect of digital printing to be the quality of image that can be achieved. The clarity of image is dependent on using the appropriate resolution, or DPI, for a given design. While $300 \mathrm{DPI}$ is acceptable for most printing on textiles, transposing an image at photographic resolution can require $400 \mathrm{DPI}$ or higher. Although it has been possible to print photographic subject matter onto cloth since the $1960 \mathrm{~s}^{65}$ inkjet printing has enhanced this process, enabling high quality imagery to be transposed onto natural and manmade substrates. This development has provided textile and garment designers with the possibility to create new surface design vocabulary. Digital printing enables the new sense of three-dimensional space, alluded to in contemporary textile design (4.1.3) to be translated directly into garment shapes.

\footnotetext{
${ }^{61}$ I have been approached by the web design company www.redsnapper.net, to advise them about providing their customers with a 'bespoke printing service.'

${ }_{62}$ Palm Studios use an Encad printer to digitally print swatches and sample garments then have bulk rotary printing undertaken in Portugal. Monsoon use an Iris printer to sample and commission flatbed production printing in India.

63 In 2000 Andy Frogson of CV Apparel was instrumental in printing a range of digitally printed separates using the Stork Amethyst for Marks and Spencer's S/S 2000 range and pieces for Robin Greene's designer collections. His new company the Quantum Design Group regularly produces short-run production for designers. See quantumclothing.com.

${ }^{64}$ Belford Prints produce fabrics for the designer and couture market. See www.belfordprints.co.uk. ${ }^{65}$ Techniques such as the Star process and other sublimation techniques relied on four-colour separation printing onto synthetic fabrics (Briggs 1997).
} 


\subsubsection{Sustainable Design Issues}

Digital fabric printing has been hailed as 'more environmentally friendly' than other methods (Xudong and Yenmai 2002). While digital printing with reactive dyes produces less effluent than traditional processes such as rotary screen, metal-based dyestuffs are still used to achieve key colours, which are not totally biodegradable. Reactive dyes are generally printed onto natural substrates, the most popular being cotton which requires enormous amounts of water to be grown and manufactured. Water is an increasingly precious resource, which makes natural fibres like cotton expensive to produce. One of the most sustainable aspects of digital printing is the transfer or sublimation process, which prints dispersal dyes onto manmade fibres, such as polyester. This fabric is economical to produce, can be recycled easily and according to Riisberg $(2003)^{66}$ represents 'the future for printed fashion'.

\subsubsection{Summary}

With digital printing designers can integrate prints directly with the garment contour, and concentrate on the surface area within this boundary. Garment shapes, in keeping with the body, are rarely comprised of straight lines. The designing of prints within garment shapes requires a new mindset that considers the relationship between a printed piece of cloth and the body shape, more carefully. Digitally printing also requires a new approach that utilises its potential to create innovative textiles, as opposed to replicating rotary screen printed fabric (Yarwood 2003). In general, textile design still tends to be introduced and practiced within a rectangular format, based on a length of cloth or an approximate garment shape. Digital printing facilitates the 'breaking of the rectangle' by enabling designers to relate surface print more directly to both garment and form (Briggs and Bunce 2001).

\subsection{HYBRID APPROACHES TO CAD}

As discussed in 4.1.3, the widespread use of CAD has resulted in new 'hybrid' styles of imagery. However, less is known about how designers negotiate and integrate new and existing technologies to create such outcomes. Independent designers tend to approach CAD technology in a more organic way than those employed in the mass clothing sector, for economic, practical and creative reasons. The following section discusses creative design work that challenges the modular approach adopted by the industry. 


\subsubsection{Laura Rotger Buadas}

In 2001, the print designer Laura Buadas contacted me having accessed one of my papers. ${ }^{67}$ She was interested in the same designers as I was and intrigued to know what software I used to integrate prints with garment shapes. Buadas work includes some memorable prints for Hussein Chalayan, including the vapour trail design featured on the Cocoon Dress, which I had collated as a key printed sculptural piece (Fig.4-I, p.4-17). She described her design method, which involved the creation and manipulation of spontaneous images in Photoshop. Following this stage she combined the basic format of her print with the proposed garment design by drawing directly onto paper patterns, ${ }^{68}$ which allowed her to assess the scale, positioning and overall effect of the imagery on the final piece (Buadas 2001). She was then able to alter the design on screen based on the observations and measurements of the decorated pattern. By pre-empting the interaction of her print with the garment shape, working between digital and manual technologies, Buadas was able to create a visual statement that was unique to that form. I had worked in a similar way at the beginning of the practical research, as I found this the most direct way of evaluating the visual relationship between the print and garment, and the potential impact on the form.

\subsubsection{Hilary Carlisle}

In 2002 Hilary Carlisle has completed a practice-led PhD at the Nottingham Trent University in printed textiles entitled: Towards a new design strategy: a visual and cultural analysis of small-scale pattern on clothing. The practice involved the creation of imagery in Photoshop, which she manipulated using computer randomising techniques. ${ }^{69}$ Carlisle's designs featured both figurative and abstract motifs in arrangements based on the opposition of order versus chaos. The non-repeating pattern structures were developed using automated procedures such as 'a random number function within Microsoft's spreadsheet package Excel and the computer programming language, Visual C ++' (Carlisle 2002). Carlisle's harnessing of imagebased and mathematical packages represents a subversion of the intended use of the software.

Introducing elements of chance or randomness into their work is a concept that has excited many artists, from the unpredictable splash of paint in Jackson Pollock's work, to the more contrived use of chance in which dice throws and coin tosses are used to determine elements of the work.

\footnotetext{
67 Integrated Design: From Delaunay to Digital, Exchange online (Feb 2001). See Appendix 5.

68 Designed and supplied by Chalayan.

69 John Maeda and Paul Brown have also used computer technology to enable them to create randomstyle images in which some parameters are determined by the computer program.
} 

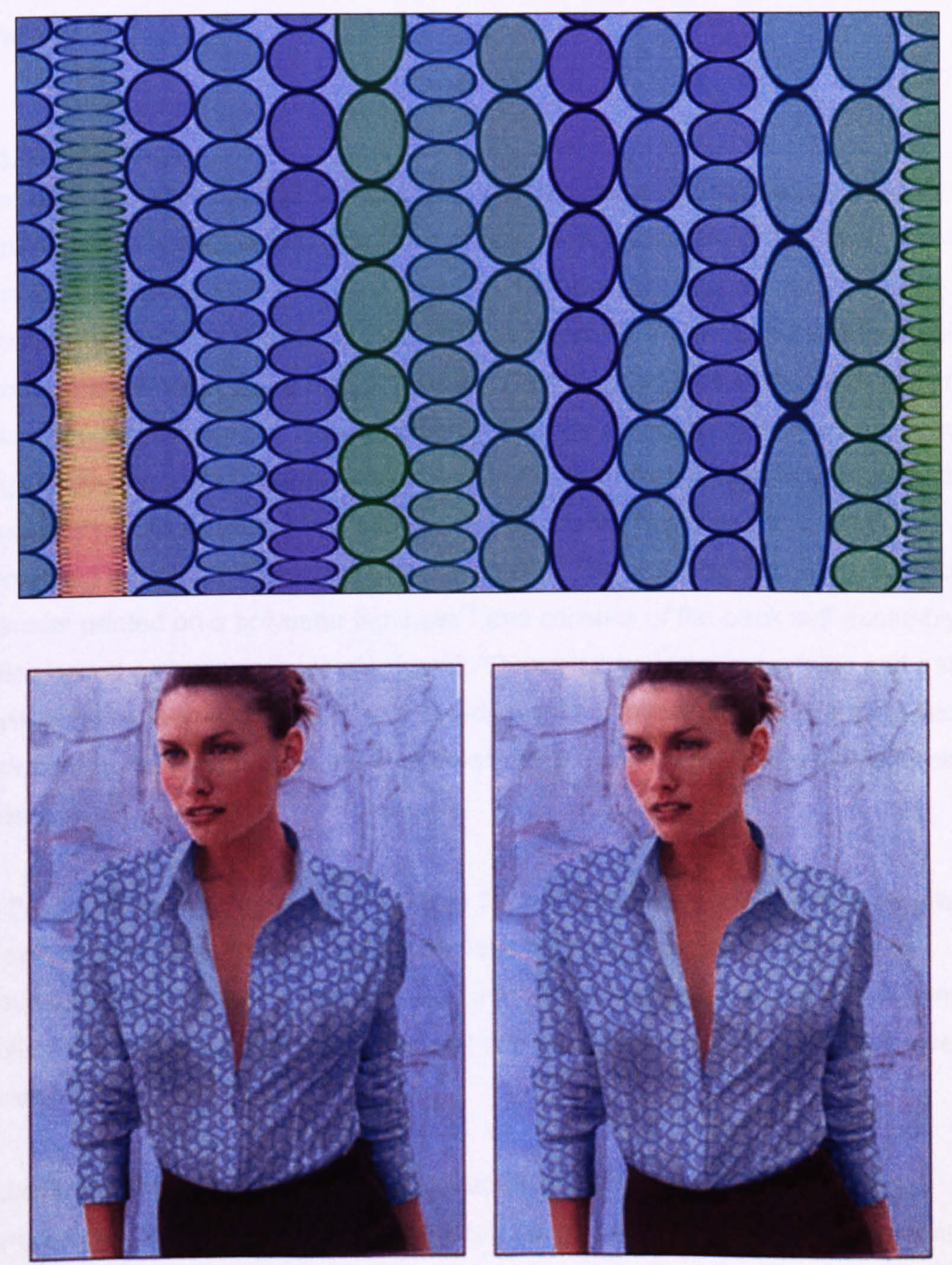

Figure 4-T Hilary Carlisle 2000: Experiments in non-repeating pattern (supplied by the designer) 
Despite the random nature of the patterns, at first glance Carlisle's designs appear to repeat in a traditional manner. However, as illustrated in Figure 4-T, when compared to a basic repeating structure (pictured bottom right) it is clear that the novel arranging of the motifs contributes to the aesthetic appearance of the garment, which appears more interesting. $^{70}$

\subsubsection{Helena Rosen}

Helen Rosen's summer 2002 collection $^{71}$ (Fig.4-U) was commissioned by Intel Computers in association with The Design Lab $^{72}$ to publicise the impact that technological advances, such as the Pentium 4 processor, have on society. The starting point for the project was to look at how people are 'interacting with technology in more creative ways, using Audio, Visual and gaming facilities to create their own personalised digital worlds.' Rosen designed a range of garments and accessories using Photoshop, using imagery based on the Pentium 4 microchip to symbolise these effects and create a product that allowed the consumer 'the power to create' by customising the design themselves (Rosen 2002). The resulting 'Anywhere' collection is transfer printed on a polyester laminate ${ }^{73}$ and consists of flat-pack self-assembly fashion based on the principles of origami: 'Through a series of cuts, folds and gathers a layer of fabric is transformed from a two-dimensional piece into a three-dimensional garment or accessory. It turns the consumer into a designer by responding to their needs (lbid).'

The flat pack kits were intended to be sold through vending machines in public places of travel to reflect the freedom that technology now offers us. The needs of the consumer are now dictating that they play a more interactive ${ }^{74}$ role in the designing process. Rosen's work illustrates how print can be used to embellish and empower the wearer.

I found it interesting that Buadas, Carlisle and Rosen all used Photoshop in very different ways, and that none used dedicated textile software developed specifically for textile design. This demonstrates the accessibility of Photoshop as a versatile designing package, and illustrates that independent designers are unlikely to invest in dedicated modules that can be creatively limiting.

\footnotetext{
${ }^{70}$ Some of my own trompe l'oeil-style prints work in a similar way, such as Tide (7.3.5), which appears as a repeating stripe from a distance, but is composed of a single manipulated image.

${ }_{71}$ Rosen produced the collection for her MA show for Design Futures at Central St. Martins.

${ }_{72}$ A creative design consultancy based at St Martins College of Art and Design, London.

${ }^{73}$ This substrate can be cut without fraying.

${ }^{74}$ Other designers such as Lucy Orta and Urban Outfitters have also explored the area of interactive clothing (Ref $\vee \&$ A publication).
} 


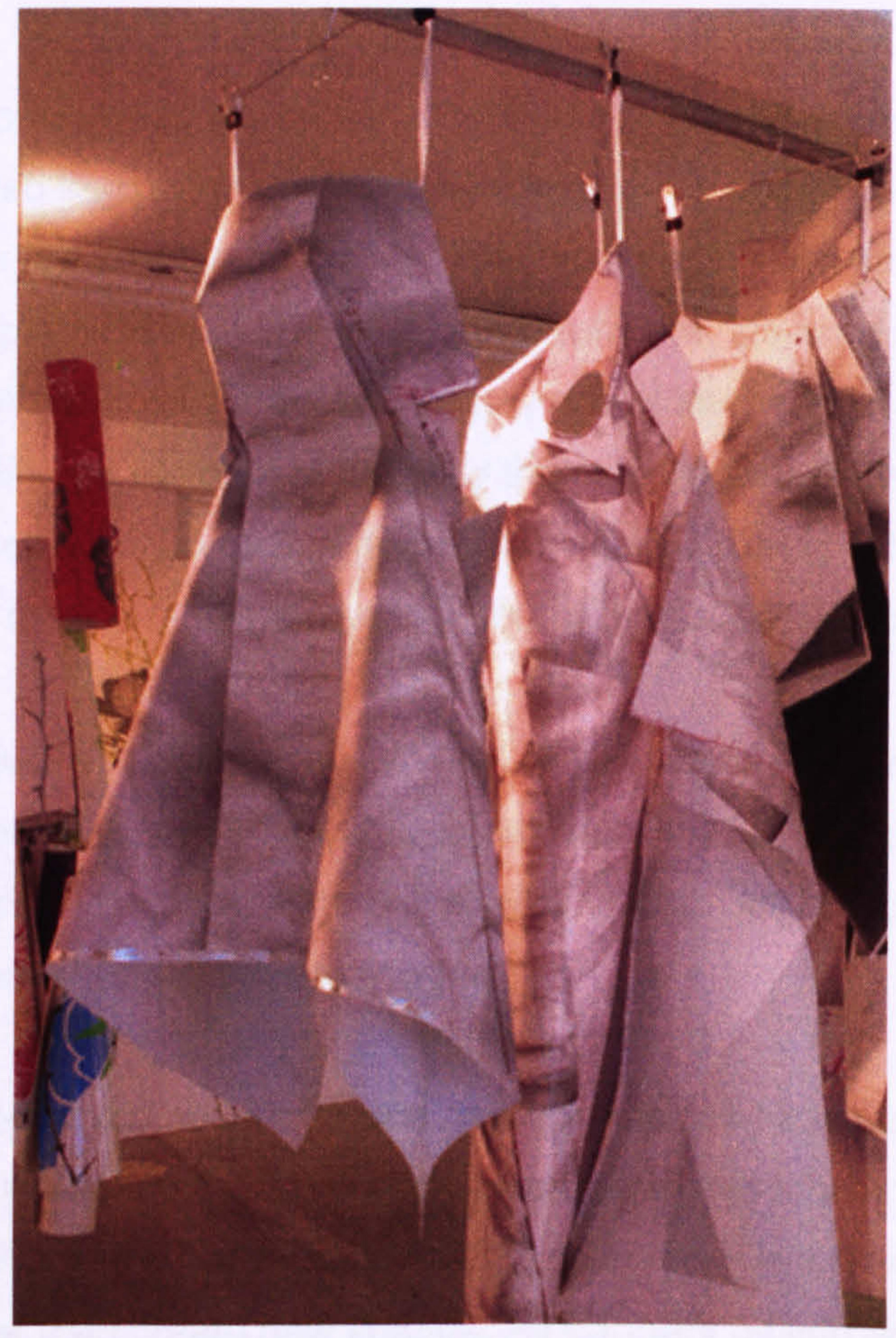

Figure 4-U Helena Rosen: 2002 MA Degree Show (supplied by the designer) 


\subsection{CONCLUSION OF CHAPTER}

Modular software provision enables textile designers to adopt a creative design approach by assimilating textile and graphic packages, as required. CAD has transformed the process of textile design, by facilitating the manipulation of imagery into new styles, repeats and colour ways. Although this has freed designers from the 2D limitations of designing on paper, these have been replaced by the different parameters of the screen.

Within the mass clothing industry colour often takes precedence over imagery. In couture colour is also important, but innovative imagery is a high priority. Independent designers are often responsible for creating the most cutting edge ideas, and it is within this forum that the practical exploration of textile software, discussed in the following chapters, is cited. While colour attracts, imagery draws attention to a collection of garments by providing an element of diversity that cannot always be afforded through the cut. In the challenging economic environment of the clothing industry I consider the role of print design to be a relevant way of incorporating aesthetic value to garments.

Textile draping software enables textile designers to envisage prints as 2.5D garment forms, affording them a simultaneous design perspective. 3D garment modelling software is becoming more accessible and enables designers to explore a variety of integrated design possibilities, prior to sampling.

Pattern design systems are used to create garment shapes based on draped or flat-cut styles. When used in couture PDS are used creatively in association with manual toiling and fitting, whereas in the mass clothing sector there is a tendency to adjust existing styles rather than create new shapes. As garment design and manufacture moves towards made-to-measure systems, a greater consideration of 'shape' over 'fit' could lead to a more 3D orientated approach to print. Body scanning, 3D pattern design systems and the CG animation of cloth are all impacting on the way that garments are designed and marketed. This technology could also have considerable influence on the way that prints are engineered within garment shapes.

Synthesising pattern cutting and graphic software within integrated packages presents new opportunities for adopting a simultaneous design ethos that challenges the 'separate sphere' mentality of the clothing and textile industry. The further integration of CAD/CAM continues to service the production of 'flash fashion'. Increasingly, independent designers are accessing such technology through bureaus, which could lead to a growth in niche design production. Digital fabric printing is still going through a 
period of acceptance, with the uptake far less than expected. This is primarily due to its use to replicate and pre-empt rotary screen production. A new approach is required towards digital printing that stretches this new printing technology.

New technologies require new design approaches. The hybrid design approaches discussed at the end of Chapter 4, merge manual, digital and mathematical approaches to create innovative outcomes. The consideration of the final product and how designs can empower the wearer in different ways resonates with my own aesthetic design objectives. This research takes a creative, experimental approach towards printed garment/textile design by synthesising leading edge CAD software with manual designing methods. The following three chapters map the creative journey, from its experimental origins in Chapter 5, through design synthesis and the testing of the Simultaneous Design Method in Chapter 6, and the final realisation of the designs through the public exhibition Transforming Shape in Chapter 7. 


\subsection{REFERENCES}

Aldrich, W. (1996) Fabric, Form and Flat Pattern Cutting, Oxford: Blackwell Science Aldrich, W. (1990) New Technology and Clothing Design, PhD thesis, Nottingham Trent University

Ashby, C. (1994) Software by Design in Aldrich, W. Ed (1994) CAD in Clothing and Textiles, Second Edition, Oxford: Blackwell Science

Bannister, J. (2003) Private interview with Jane Bannister, director of Palm Studios, printed and woven textile designers, London, 14 April 2003

Berry, S. (2000) Be Our Brand: Fashion and personalization on the web, in S. Bruzzi, and P. Church Gibson (Eds) Fashion Cultures: Theories, explorations, and analysis, London: Routledge, pp. 49-60

Bohringer, A., Hilden, J., Yonenaga, A., and McClain, A. (2001) Printing: New Ways to Achieve Higher Quality and Efficiency, International Textile Bulletin, 4/2001, pp. 8-26 Bouisset, M. (1969) Sonia Delaunay: Simultaneous Art and Fabrics, in Damase, J. (1991) Sonia Delaunay: Fashion and Fabrics, London: Thames and Hudson Braddock, S. and O'Mahony, M. (1998) Techno Textiles, London: Thames and Hudson

Briggs, A. (1997) A Study of Photographic Images, Processes and Computer Aided Textile Design, PhD thesis, The Nottingham Trent University

Briggs, A. and Bunce, G. (1995) Breaking the Rules: Innovatory Uses of CAD in Printed Textiles, Ars Textrina, Vol. 24, p.187

Britain, M. (2002) Private interview with Monarch Britain Textile studio manager, Paul Smith, Nottingham, date

Buadas, L. (2001) Private email correspondence, 19/11/01, 12/12/01

Bunce, G. (1996) The Unexploited Potential of New Technology for Repeat Pattern Innovation in Printed Textile Design, Point, No. 2, pp. 32-36

Bunce, G. (1993) An Investigation into the CAD/CAM Possibilities in the Printing of Textiles, PhD thesis, Nottingham Trent University

Chen, J. (1998) An Investigation into 3-Dimensional Garment Pattern Design, PhD thesis, Nottingham Trent University

Collins, J. (2000) Private Interview with Joanne Collins, Textile Designer, Monsoon Head Office, London date

Cottington, D. (1998) Movements in Modern Art: Cubism, London: Tate Gallery Crawford, A. (2003) Satisfying Consumer Demand, Seminar, The Textile Institute, Leicester, 6/3/03

Davies, M. (2003) A Retailer's Perception of the Changing World, Cyril Hurd Memorial Lecture, The Textile Institute and De Montfort University, Leicester, 15/5/03 
Davies, J. and Tilley, E. (2003) The Design Café: A new approach in the textile industry, Journal of the Institute of Management Services, March

Dewar, I. (2003) Private interview with lan Dewar, co-director of CAD for CAD, London, 9/5/03

Dickinson, J. (1999) CAD: A Still Evolving Tool, Surface Design Journal, Vol. 23, no.

2, pp. 38-9

Durandaud, C. (1996) The Luxury Goods Market in a High Tech Era, Lectra Magazine, September Issue

Frank (1998) Mixed Metaphors, photographed by Steven Klein, Feburary issue, p.112

Fernaud, D. (2001) No More Frock Horror, The Sunday Times Magazine, March 31

Frogson, A. (2000) Private Interview with Andrew Frogson digital fabric printing consultant at CV Apparel 10/12/00

Gernand, B. (2002) Serpents and Snails: Virtual Modelling and Material Process, Hertogenbosch, The Netherlands: European Ceramics Work Centre (EKWC)

Gordon, J. (2003) Private email correspondence with Jackie Gordon, software consultant at Lectra Systems

Gregory, P. (2000) Colouring the Jet Set, Chemistry in Britain, August 2000, pp. 42 Gray, S. (1998) CAD/CAM in Clothing and Textiles, Design Council, Aldershot: Gower Harris, J. (2002) Beauty in the CG Beast, Presentation at Pixel Raiders, Applied artists and digital technologies, The Victoria and Albert Museum, London March 2002 Harris, J. (2000) Surface Tension: The Aesthetic Fabrication of Digital Textiles (The design and construction of $3 D$ computer graphic animation), PhD Thesis, The Royal College of Art

Harrod, T. (2002) 'Otherwise Unobtainable: the applied arts and the politics and poetics of digital technology', Pixel Raiders: Applied artists and digital technologies, The Victoria and Albert Museum 19/3/02

Hearle, J.W.S. (1994) computer-Aided Textile Design: The Problem of Three Cultures, World Review of Textile Design, XXXVII

Holbrook, M. B. (1999) Higher Than The Bottom Line: Reflections on some recent macromarketing literature, Journal of Macromarketing, 19 (1): 4-74

Jerrard, R. and Bell, S. (1998) The Fashion Designer in the Technological Workplace, Digital Creativity, Vol. 9, No. 2, pp.91-100

Jerrard, R. (1986) An Examination of Adaptive Behaviour in the Relationship Between Users and Computer Aided Design (CAD) Systems with Specific Reference to The Textile Industry, PhD Thesis, City of Birmingham Polytechnic Johnson, G. (2002) PHD@JISCMAIL.AC.UK, 10/4/02 Kerrigan, J. (2003) Private interview with Dr. Judith Kerrigan, technical textile consultant at Levi's, the Nottigham Trent University, 12/6/03 
King, J. (2001) Private Interview with Jane King RCA, Textile Designer/Printer, Lectra Systems, London

Knox, A. (2003) Private Interview, Nottingham Trent University, date 14/2/03

Lansdown, J. (2002) Some Trends in Computer Graphic Art, in Mealing, S., Ed (2002)

Computers in Art, Second Edition, Bristol: Intellect

Leak, A. (1998) A Practical Investigation of Colour and CAD in Printed Textile Design,

PhD thesis, Nottingham Trent University

Lectra (1998) Jobs and Peolple, The Lectra Systems Magazine, Vol. 1, p.6

Metchek, I. (2003) How the California Clothing and Textile Cluster has Transformed, EMCAT (East Midlands Clothing and Textiles) Festival, Nottingham, 15/5/03

Mitchell, W. J. (1992) The Reconfigured Eye: The Truth in Post-Photographic Era, London and Cambridge, Massachusettes: The MIT Press

Mylius, L. (2002) Private email correspondence with Laura Mylius, Textile Designer, Lectra Systems, Research and Development, Cestas, Bourdeaux, France, 21/11/00 Phillips, P. and Bunce, G. (1993) Repeat Patterns: A Manual for Designers, Artists and Architects, London and New York: Thames and Hudson

Pötz, T. (2002) Inkjet Printing: Present situation and prospects, International Textile Bulletin, No.5, October, pp. 80-83

Riisberg, V. (2003) Private Interview with Vibeke Riisberg textile designer, Nottingham Trent University, 21/5/03

Robson, L. (2002) Private interview with Linda Robson, software consultant at Options Systems, Leicester, 8/3/02

Shaw, A. (2003) Private telephone conversation with Alan Shaw, digital printing consultant at the Centre for Advanced Textiles (CAT), Glasgow School of Art Shenfield, C. (1994) in Aldrich, W., CAD in Clothing and Textiles, Oxford, Blackwell Science, 1994, p.107

Stylios, G. K., Wan, T. R., and Powell, N. J. (1996) Modelling The Dynamic Drape of Garments on Synthetic Humans in a Virtual Fashion Show, International Journal of Clothiong Science and Technology, Vol. 8, No. 3, pp. 95-112

Thalman Mangenat, $\mathbf{N}$ and Volino, P. (1996) Sculpting, Clothing and Hairdressing our Virtual Humans, in Interactive Computer Animation, Europe: Prentice Hall Ujiie, H. (2001) The Effect if Digital Textile Printing Technology on Textile Design Styles, Centre for Excellence of Ink Jet for Textiles, Philadelphia Univesity, August 2001, accessed via Techexchange.com Watkins, P. (1999) The Appliance of Science, International Textiles, no. 806, Aug/Sept, pp. 17-21

Watkins, P. (1991) Innovation in Print, World Review of Textile Design, IV 
Williams, J. (2003) Private email correspondence with Jenna Williams, textile designer for Low Profile Design, London

Williams, H. (2002) Pixel Raiders, [a-n] Magazine for Artists, May, pp. 22-23

Wilson, A. (2001)

Xudong and Yenmai (2002)

Yarwood, A. (2003) Private Interview with Alan Yarwood, UK Stork Representative, Samuel Bradleys Ltd. Stockport, 6/6/03

Jan W, Webline Chat: Lands' End Live at www.landsend.com, 6/8/02

\section{Websites}

http://www.agetechnologies.com

http://www.belfordprints.co.uk

http://www.datacolour.com

http://www.inkdropboutique.com

http://www.landsend.com

http://www.lectra.com

http://uww.miralab.com

http://www.quantumclothing.com

http://www.SHOWstudio.com

http://www.stork-digital-imaging.com

http://www.techexchange.com

http://www.tc2.com/RD/RDPrinting.htm 


\section{Chapter 5. A Holistic Approach to Print and Cut}

5.1. A HOLISTIC APPROACH TO PRINT AND CUT ….............................5-2

5.2. INITIAL PRINT/GARMENT INTEGRATION ..........................................5-3

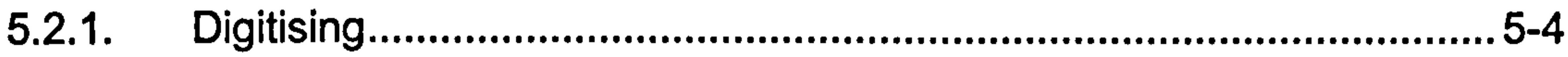

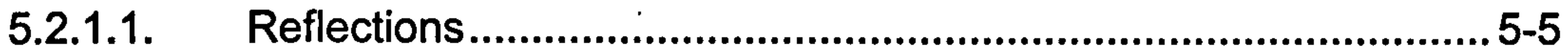

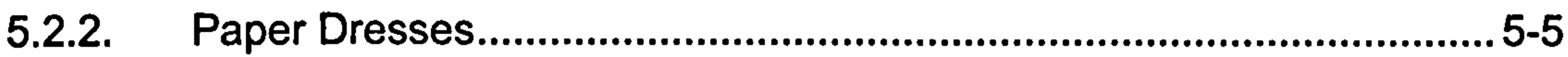

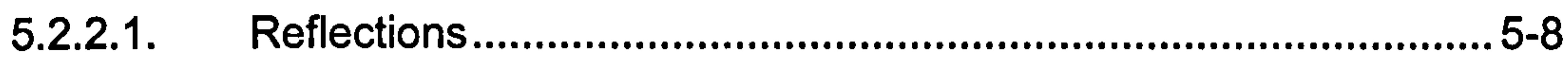

5.2.3. Manual Mark Making: Print Fluidity .................................................... 5-8

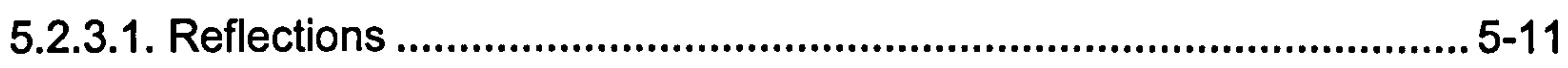

5.2.4. Digital Mark Making ....................................................................... 5-11

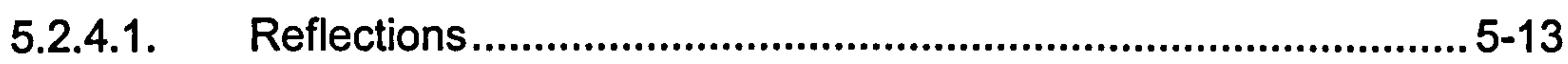

5.2.5. Synthesising Manual and Digital Techniques.................................... 5-13

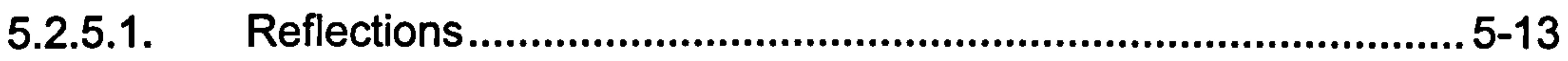

5.2.6. Initial Print/Garment Integration using CAD ..................................... 5-15

5.2.7. Reflections: The printed toile ........................................................ 5-20

5.3. DESIGNING WITH LIGHT ..............................................................5-21

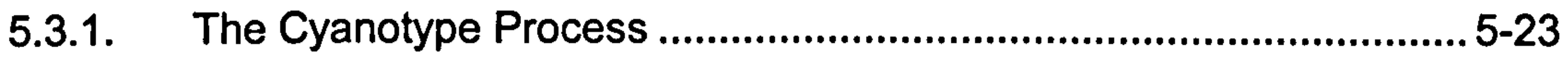

5.3.1.1. 2D Image Capture .................................................................23

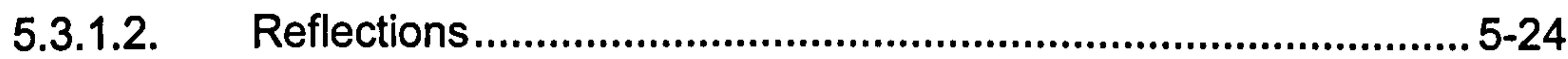

5.4. MODELLING PRINT: THE RIBBON TUNIC …..................................5-24

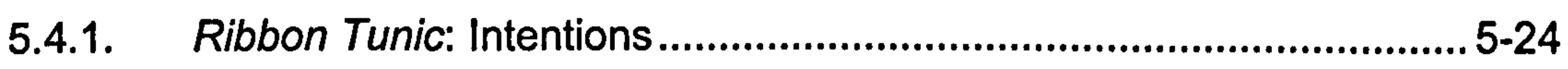

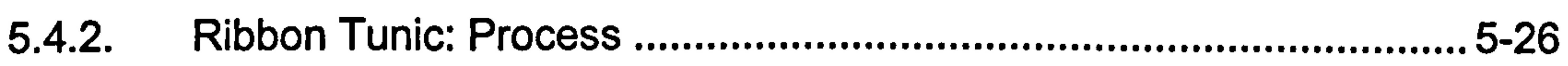

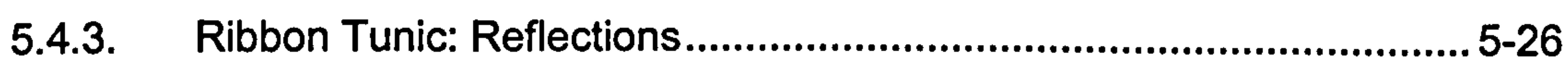

5.4.4. CAD Design Development: Realignment........................................5-29

5.4.5. Digital Manipulation: Water Pleat....................................................5-31

5.5. DIGITAL FABRIC PRINTING: TEST 1 ….......................................... 5-34

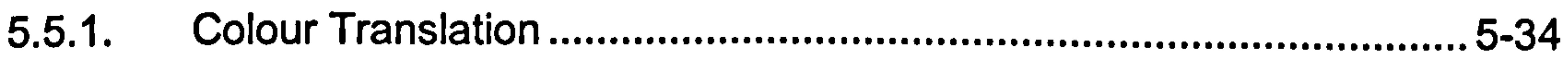

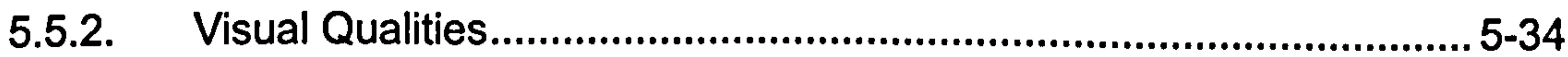

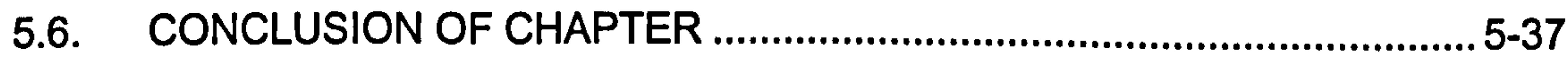

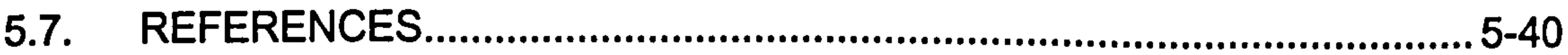




\section{INTRODUCTION}

This chapter details the journey from the start of the practical research in January 1999 , which began in a traditional $2 D$ textile context, through to the creation of a 3D printed garment toile in September 1999, which represented a significant turning point in the practice. From the outset of the practice I had attempted to tackle the equating of print and cut holistically, through various modes of integration that included and eventually combined $2 D$ and $3 D$, manual and computerised design methods. I have used the term "holistic"1 to describe my personal design philosophy, which considers the creation of print imagery and garment shape within the context of their relationship with the underlying (female) form. 'Holistic' can also be used to reinforce the manner in which appropriate manual and digital technologies are combined within the practice to create a 'simultaneous' method (6.2) for designing printed garments that synthesises established craft with integrated CAD technology.

\subsection{A HOLISTIC APPROACH TO PRINT AND CUT}

As discussed in Chapter 1.2 the articulation of the form through printed stretch fabric was a key informer of my early practice as a designer-maker. Throughout the research the form continued to be the central catalyst, but with a shift of focus away from achieving the stretch-to-fit definition afforded by Lycra, towards the creation of woven, draped, more sculptural-style printed garments that worked with the natural body shape (3.2). My past practice had provided me with a strong understanding of the relationship between printed cloth and the female form. Integrated CAD presented me with an interface where it was possible to design and visualise printed garments in 2D and simulate them in 3D, prior to production. Equipped with this tacit and new knowledge I reconsidered the objectives of the practice.

There are few creative luxuries in life greater than non-commercial projects. The freedom to experiment responsibly within a completely irresponsible envelope of expression is by no means easy. The intellectual challenges of solving a client's problems are indeed formidable and should not be belittled. But when the world's greatest problem solver runs out of other peoples problems to solve, she realizes that her own problems are not only the most difficult to solve, but the most difficult to articulate (Maeda 2000: 143).

Freed from the constraints of commercial practice, it became my intention to combine print, cloth and the form from a new, holistic perspective, in-line with a couture approach towards the fashioned body (2.2.2). The core aim of the practical research was to integrate printed textiles and garment shapes in new ways. I was interested in using CAD/CAM tools to reverse the 'garment-led' approach adopted by the mass

\footnotetext{
${ }^{1}$ Holistic: Theory that certain wholes are greater than the sum of their parts.
} 
clothing industry (2.2.1). I wanted to reverse the traditional advantage that 'shape' has over 'surface' design', by creating printed styles where the textile and garment were considered more equally. The realisation of this aim would be achieved by designing a range of interrelated prints and garment shapes, through the combined use of established (analogue) and CAD/CAM (digital) technologies.

The holistic approach adopted by the research was influenced by the work of key practitioners such as: Sonia Delaunay (3.7), who envisioned print decoration in direct association with the contour of the garment; Ossie Clark $(3.2,3.7)$ who strategically cut Celia Birtwell's prints to work with the garment shape and flatter the underlying form, and Martin Margiella (3.8), for his referencing of the process of construction as surface embellishment. Madeleine Vionnet (3.2) provided the ultimate model of holistic practice for the research, on both a practical and aesthetic level: through her practice of modeling on the half-stand and her intuitive sculptural approach to fabric and form.

An investigation into contemporary printed textile/garment design found that the most innovative outcomes were often the result of designers tailoring manual and computerised technology to suit their individual requirements (4.5). It also became apparent that integrated design solutions were the outcome of either tacit knowledge or theoretical awareness of printed textile and garment design, or the ability to collaborate with other specialists. The background research indicated that while there were creative advantages to using integrated CAD/CAM (4.3.1), these were rarely exploited by independent designers for economic reasons. Based on these findings, an important objective of the practical research was to adopt a broad-based attitude towards both existing and new garment and textile technology by demonstrating how such a holistic approach could lead to hybrid practice and original design outcomes.

\subsection{INITIAL PRINT/GARMENT INTEGRATION}

When I began my PhD in June 1998, I was provided with a Lectra workstation and textile (Prostyle), pattern cutting (Modaris), and lay planning (Diamino) software to be used in conjunction with a digitiser (garment pattern input) and a plotter (pattern output). ${ }^{2}$ While I was aware of what this technology was capable of, this was unfamiliar territory and a period of familiarisation ensued. Due to technical problems ${ }^{3}$ I was unable to use the system effectively for the first year of my research. This situation encouraged me to concentrate on the theoretical/historical investigation and to

\footnotetext{
2 The workstation and software was set up as a Beta testing research site by Lectra Systems, which included sponsorship for future licensing of software and a service contract.

${ }^{3}$ The different components did not function in an integrated manner until January 1999, due to a fault in the system.
} 
approach the practice of integration in a variety of ways. In retrospect this was an advantage, as it led to a period of experimentation whereby manual methods and different aspects of CAD were explored on an individual basis. Each experiment directed the practice in a new direction, so that by the time the CAD system was fully operational, I had a much clearer idea of what I wanted to achieve with the technology. The following sections describe the initial experimentation that was undertaken using manual and computerised methods of print/garment integration.

\subsubsection{Digitising}

Following basic training in graphic, pattern cutting and digitising software ${ }^{4} \mathrm{I}$ began by considering some of the technical possibilities that CAD offered for integrating print and garment ideas using vectors. The first experiments concentrated on the possibilities of orientating regular and irregular shaped motifs within a garment contour, using a digitiser. A simple 3-piece 'shift' dress pattern was cut from basic blocks, incorporating bust darts for shaping and measuring $100 \mathrm{~cm}$ in length. Shift Dress 1 was a classic shape designed in medium-weight cotton, with a back-zip fastening. Traditionally this versatile style of dress can be cut from a repeating print or used as a vehicle for a placement, but it was my intention to engineer a design in relation to the external contour. My design response to the symmetry of the shape was to introduce a pattern based on evenly spaced circular, motifs measuring $8 \mathrm{~cm}$ in diameter. Following the digitising of the shape, a series of circles were orientated within the pieces. The process of integration raised questions, which became the key design issues driving the future experiments, which were:

- How to integrate print imagery aesthetically within pattern pieces

- How to integrate print imagery to avoid darts and seams

- How to align print imagery across darts and seams

A paper model of Shift Dress 1 indicated that circles placed in the darted and seamed areas would clearly be distorted when the garment was assembled. The distortion of the shapes in these areas was visually incompatible with the geometric styling of both motif and garment. The anomalies between the shape of the motif and garment prompted me to re-cut the dress as a new one-piece pattern, Shift Dress 2, in stretch jersey, without darts or side seams. The motifs could now be placed with greater visual cohesion within the boundary of the single, external contour. The simplified shaping

\footnotetext{
${ }^{4}$ Lectra Systems provided preliminary training for Prostyle in November 1998, when it was discovered that the problems I had been experiencing were due to a bug. Training for Modaris/Diamino was provided in January 1999, when the system was functioning correctly.
} 
increased the possibilities for motif placement, particularly in the traditionally difficult area of the bust, and improved print continuity within the garment shape. The experiment resulted in the concept of re-designing the garment to accommodate the placement of print imagery.

The integration of irregular-shaped motifs with garment shapes was also explored. By working directly on the pattern piece (placed on the digitiser) it is possible to assess the placement and coverage of a motif in relation to a garment piece at life-scale, which can be difficult to assess on screen. Digitising can also be used to incorporate additional contours into a pattern shape, either by eye or by following drawn lines. These can be configured as additional pattern pieces (using pattern-cutting software) or as contour lines to fill with print or texture map, $^{5}$ using graphic software.

\subsubsection{Reflections}

The Ring Dress experiments clarified how digitising could aid in the process of integrating prints with garment shapes, both as a 'placement' and 'grading' tool. Digitising allows the designer to strategically place a regular or irregular shaped outline of a motif or printed area, strategically within a garment contour. ${ }^{6}$ Motifs can be introduced to pattern pieces by importing the model (MDL) into an integrated $C A D$ programme, where print imagery can be synthesised with the internal contour provided.

\subsubsection{Paper Dresses}

Although the digitising experiments demonstrated the considerable design potential for strategically placing motifs, the research was primarily concerned with seeking solutions for all-over, engineered style imagery. As a textile designer, I am naturally concerned with mark making and continued with the practice by considering the style of imagery I required and how it might be produced. The regularity of the digitising experiments encouraged me to take a less structured approach to a similar dress shape. I began by using watercolour paint as it could be applied quickly and fluidly, facilitating the application of spontaneous brush strokes, resulting in controlled and more organic water-based marks similar to those found in nature (5.2.3). Rather than designing printed garments as scaled down fashion drawings, I decided to use the Shift Dress paper patterns as the starting point for the designs by responding to them as irregular shaped canvases (3.8). I proceeded by manually painting and printing marks

\footnotetext{
${ }^{5}$ When filling a vector-based contour with raster-based imagery it is often necessary to break the shape down into smaller sections, as discussed in 6.4.

${ }^{6}$ The shape of the motif can also be graded in accordance with a specific grade-rule, to provide an indication of how it would be configured on different sized garments.
} 
directly onto the dress as a $2 \mathrm{D}$ shape and a 3D model.

The first painted toile, Ring Dress was created by hand-printing 'rings' onto a flat paper pattern, joining the seams with tape and placing the piece on the stand, where additional marks were applied directly to the 3D paper structure. ${ }^{7}$ The joining of the pattern pieces to create a paper dress rendered the normally inaccessible construction points, as an accessible surface for patterning. This enabled textural mark making to be applied across the side and shoulder seams more densely to suggest shading (Fig. 5-A). The concept of integrating trompe l'oeil shading, by building up the layers of tonal colour/imagery in key areas made the print and garment appear more interesting.

The second paper dress investigated larger, more irregular print imagery. Using the pattern for Shift Dress 1, a freehand, painted design, based on the curvilinear structure of an ammonite, was integrated directly with the 3D paper model..$^{8}$ The Ammonite Dress was cut from the stand along one of the side seams to form a single, flat, decorated piece, which in theory could have formed the basis of a printed garment prototype (Fig.5-B). In contrast with the initial pieces where imagery was configured to avoid seaming, the Ammonite Dress positively investigated the concept of printcontinuity across garment shaping devices. The use of curvilinear ${ }^{9}$ imagery built on earlier research into print/garment integration by organisations such as TC[2] which has tended to concentrate on vertical or horizontal placements of simple geometric shapes which are easier to align (4.3.3).

A lengthened, two-piece version of Shift Dress 1 was used to create the Willow Dress. The $140 \mathrm{~cm}$ length facilitated vertical brush strokes of up to $100 \mathrm{~cm}$, to be applied; opaquely at the hem, becoming more translucent at the shoulders. The image was concentrated mainly on the front of the dress and continued across the side seams. The Willow Dress explored the possibility of originating a print in direct response to the surface area of the garment, avoiding difficult areas such as the bust and shoulders. Following its placement on the stand, the front and back-neck of the dress were torn into ' $V$ ' shapes, in sympathy with the orientation of the print. This adjustment inspired the notion of re-cutting a piece to accommodate mark making, as opposed to treating a garment shape as a predetermined surface area that could not be altered.

\footnotetext{
${ }^{7}$ The rim of a mug was dipped in watercolour paint and applied to the paper pattern and additional textural marks were added with a brush.

${ }^{8}$ The paper pattern pieces were cut without seam allowances, joined together with masking tape and the paper toile was placed on the dress stand to be painted 'in-the-round'.

9 Curvilinear imagery is difficult to match across seams, requiring absolute accuracy with cutting and realignment to achieve an aesthetically pleasing outcome. This style of patterning is explored in greater depth in the Nautilus Skirt (7.4).
} 

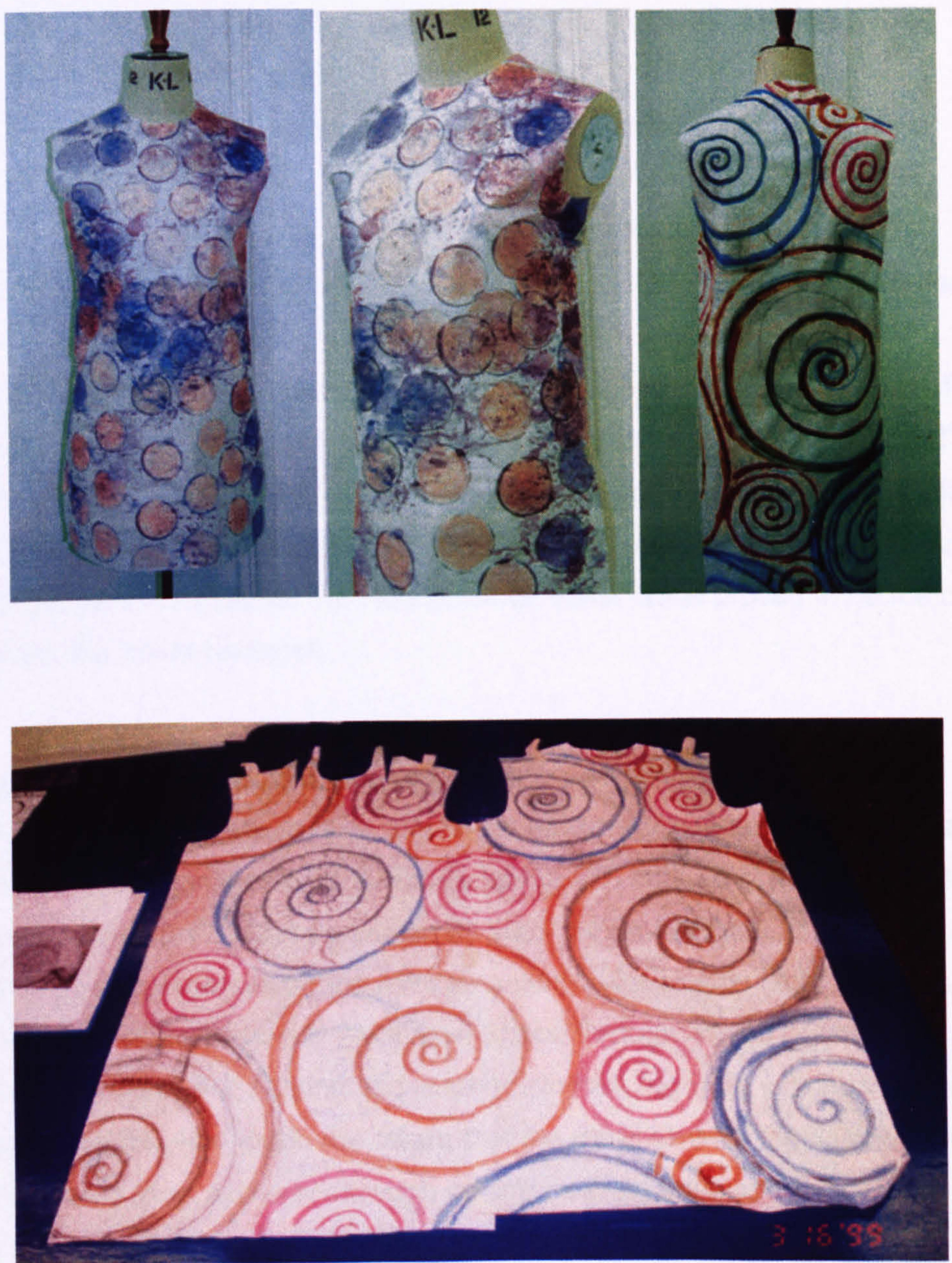

Figure 5-A Paper Ring Dress

Figure 5-B Paper Ammonite Dress 


\subsubsection{Reflections}

Despite the highly experimental nature of the paper dresses, the practical outcomes raised a series of relevant integrated design issues, such as:

- The importance of equating the scale and style of mark making with a prospective garment shape

- The concept of re-shaping a garment in accordance with the style and orientation of the print

- The introduction of trompe l'oeil 'shadow' as printed textile vocabulary

- The potential for approaching printed garment design from a 3D perspective

Ultimately the experiments presented a (possible) three-dimensional method of designing that embodied the holistic design ethos underpinning the research. The approach also referenced some of the key influences on the practice. The envisioning of a flat pattern shape as a spatial form presented the idea of integrating $2 D$ surface print with 3D garment shapes. This fundamental observation proved to be the defining influence on the future research.

\subsubsection{Manual Mark Making: Print Fluidity}

Following the painterly experiments with paper patterns, I concentrated on creating more sophisticated mark making. As discussed in 1.7, images of 'the form in cloth' had strongly influenced my design aesthetic. By 1999, when I embarked on the practical research, I no longer perceived the form as a vehicle for stretch fabric, but was more interested in the amplification of the female shape through woven drapery. My experiential knowledge of making and wearing clothes, together with historical research into sculptural dress had made me aware that the most sensual fashioning of the female form had been achieved through cutting cloth on the bias.

The fall of drapery in bias cut garments has often been compared to the flow of liquid. Images of Vionnet's and Alix Grès's garments triggered the idea of creating fluid prints that would enhance and/or visually express the drama of such shapes. In order to create prints that flowed with or were evocative of this style of drapery, I would require non-repeating imagery that did not necessarily have a beginning or ending, but permeated a cloth shape as if it had been poured or splashed in the manner of an accidental stain. I searched for a definition to describe such imagery and found it within Chinese philosophy where it is referred to as 'Li' and is described by Watts (1976: 46) as: 
...the asymmetrical non-repetitive, and unregimented order which we find in the patterns of moving water, the forms of trees and clouds, of frost crystals on the window, or the scattering of pebbles on beach sand.

Having defined the type of imagery that I required I began to manually experiment with wet media. Spontaneous mark making based on staged 'accidents' was originated through the manipulation of a range of viscous substances, ${ }^{10}$ building on techniques that I had employed for my last commercial print collection. ${ }^{11}$ The first designs were produced using black ink, as from the outset the concept and tonal quality of the mark was of greater importance than the colour. The Ring prints were created with imprints of an inked cup base, which further explored the patterning concept investigated through the paper Ring Dress. The use of this image directly referenced the familiar, 'accidental' impression left by liquid that has dripped from the rim to the base of a cup. ${ }^{12}$ Although the image had a strong geometric quality, I was more interested in the imperfect-circular shape of the imprint, which evidenced the flow or natural behaviour of the ink.

The following set of images were based on the random effect of 'staining' and were configured as all-over print ideas. Stain 1 is typical of the series and was the result of ink and water being mixed and dropped onto tissue paper. ${ }^{13}$ / was attracted to the idea of liquid staining a cloth shape randomly, in keeping with dip dyeing which can results in an uneven distribution of dye. The Ring and Stain elements were later combined to create composite images. The images were evocative of the liquid evidence left on tables in bars- a similar concept to that explored by Vivienne Westwood in her Spring/Summer 2000 collection. ${ }^{14}$ Figure 5-C shows Stain 1 and a composite image incorporating six rings.

The Rings were further developed as isolated figurative elements in association with a third series of images based on the effect of vertically dripped, watercolour paint. The Drip prints provided a visual record of paints' undulating journey down a tilted (paper) surface. The Drip designs were created as an intuitive response to the medium of (watercolour) paint and provided a suitable visual metaphor for the fluid patterning of

\footnotetext{
${ }^{10}$ Using ink, paint, and dripped candle wax on paper and various dyes on cloth, images based on the effects of liquid running down a surface, were created. Controlled 'accidents' were also staged, to achieve spontaneous marks.

${ }^{11}$ My last freelance collection of fashion prints was produced for Suzsie Corio, London in 1997 and featured resist waxed and bleached, abstract prints in watercolour paint and inks.

12 My experimentation with this image in early 1998 preceded the Audi advertising campaign in 2000 which featured the translation of their brand as five cup rings, and the use of the element as the key graphic in the Workspheres exhibition at MOMA, New York in 2001.

${ }_{13}$ The use of ink in association with the absorbance of the tissue produced a diffused, ethereal effect.

${ }^{14}$ Westwood incorporated a print featuring a pattern of red wine spills and stains.
} 

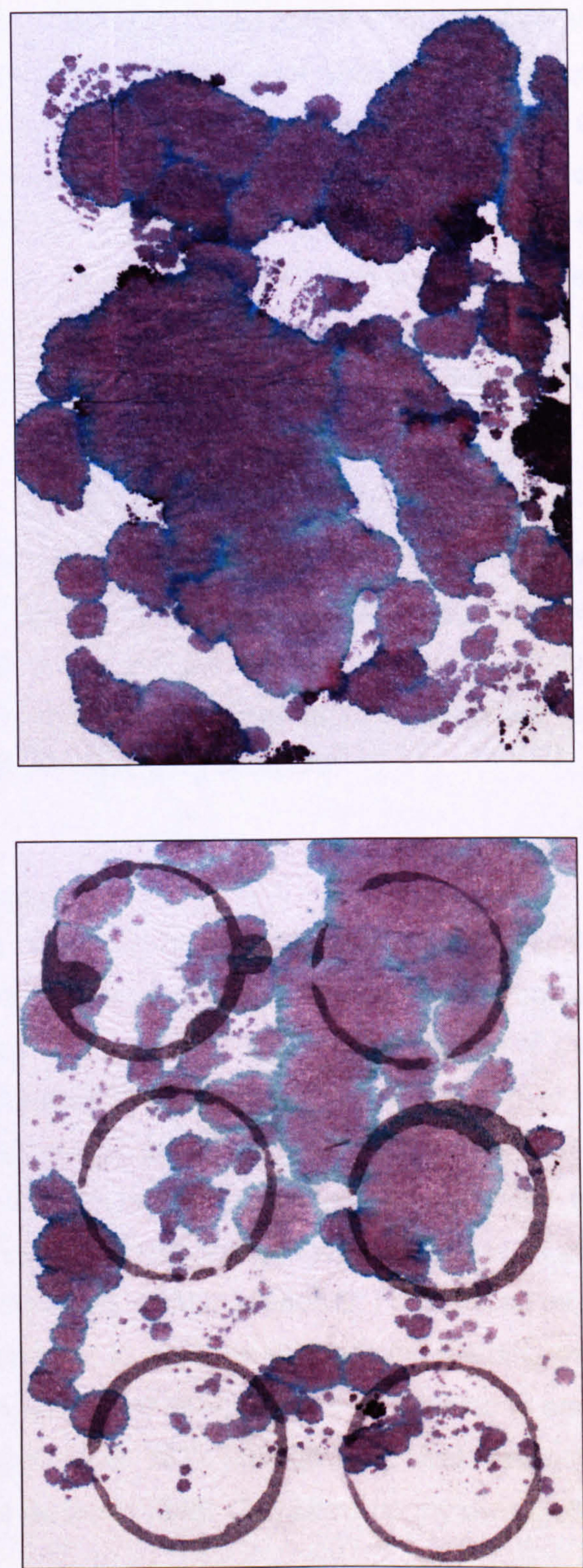

Figure 5-C Ink stain and cup rings on tissue paper 
water and bias cut drapery.

Originally, the paint was applied to create single-coloured statements, which were later layered-up using masking fluid to achieve tonal and multi-coloured abstract effects. The Ring/Drip designs combined both 'conscious' (printed cup rings) and 'unconscious' (dripped lines) image-making strategies, resulting in contrasting composite images (Fig.5-D). The Drip designs inspired the idea of dripping paint directly onto cloth toiles placed on the half-stand, then deconstructing and scanning pieces to create 'printed' components for garment prototypes. The concept was explored, but the absorbent nature of cloth resulted in stained patterning that lacked directional interest.

\subsubsection{Reflections}

It was envisaged at this stage of the practice, that the strong downward pull of gravity evidenced in the Drip designs, could be utilised to exaggerate the directional flow of vertically draped cloth, as found in a full-length garment. The experiments suggested the possibility for employing fluid mark making to emphasise a sculptural style by echoing the rhythm of the underlying contours.

\subsubsection{Digital Mark Making}

Following the manual experimentation, I attempted to create similar, Drip designs using a range of graphic software applications, including Adobe Photoshop 5, Fractal Painter 4 and Lectra Prostyle 5. The use of CAD to create 'accidental' marks proved challenging. ${ }^{15}$ For example it was impossible to actually 'drip' or tilt the 'canvas' to manipulate the media or to put too much 'paint' on the brush due to the regulated, preprogrammed nature of virtual paint. ${ }^{16}$ I soon realised that within the limitations of my experience and those of the software itself I was unlikely to be able to produce the subtle, irregularities that I had created manually. I proceeded by adopting an, 'anthropocentric' ${ }^{\text {'17 }}$ approach to CAD, by investigating the different creative effects I could achieve with particular software, rather than seeking to emulate my earlier physical practice (Briggs 1997: 163). The following observation by the ceramic designer-maker Katie Bunnell (1998: 152) sums up my own feelings at this time:

\footnotetext{
${ }^{15}$ I did not find Photoshop very useful for creating direct marks, but used it for specific rendering tasks later on in the practice. Prostyle had a limited selection of art tools and also came to be used strategically rather than spontaneously.

${ }^{16}$ When using water-based paint in an analogous context it is often difficult to achieve a flat or smooth effect as the pigment accumulates and dries unevenly. When 'painting' in CAD, the different paint menus tend to exhibit the overall characteristic of a particular quality, which all tend to dry uniformly.

${ }^{17}$ Briggs discusses the difference between 'anthropocentric' and 'technocentric' approaches to CAD, which are discussed in 4.3 .
} 


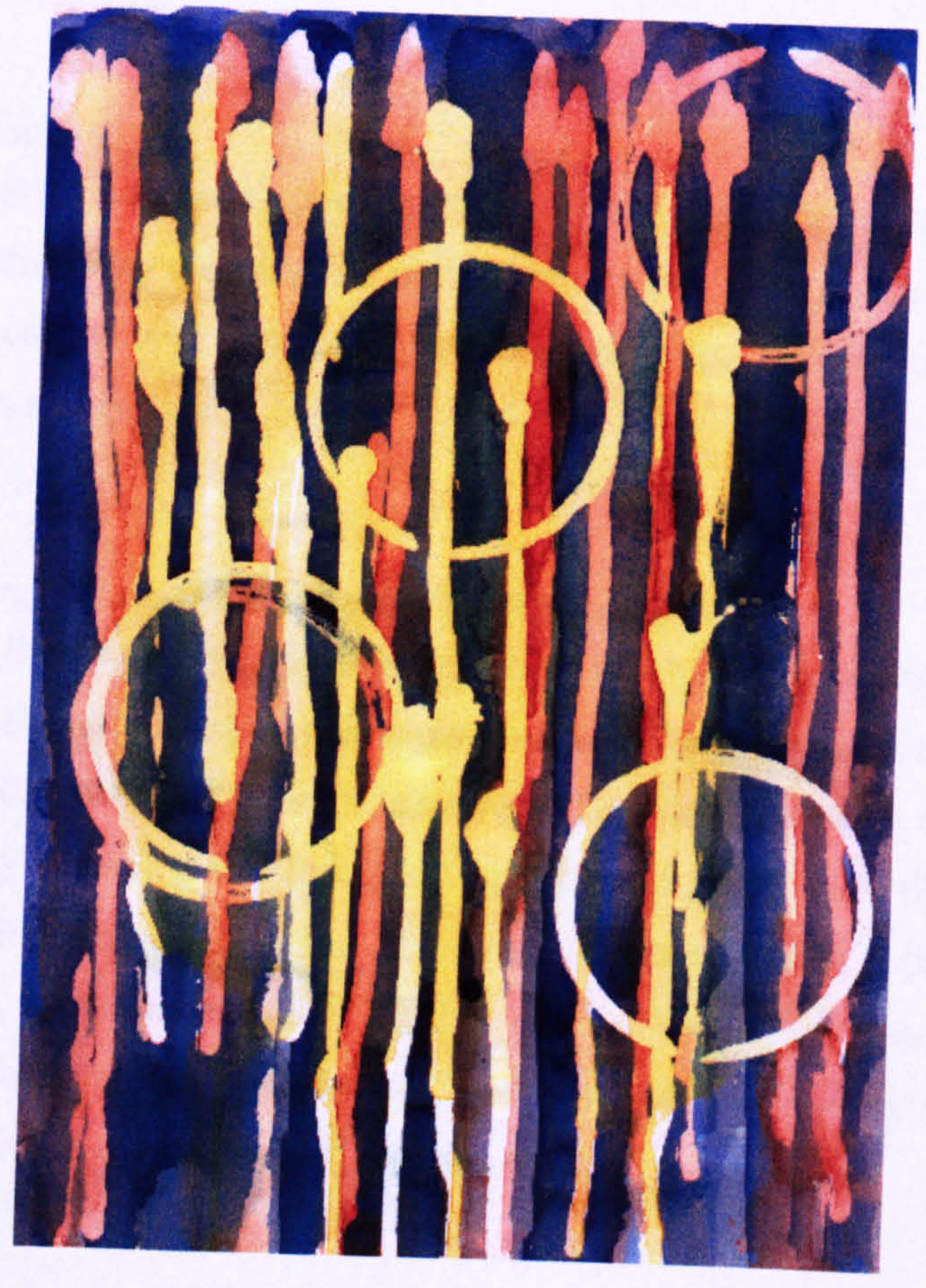

Figure 5-D Analogue Ring/Drip image 
To some extent the researcher allowed specific personal conceptual developments to be superseded by the exploration of techniques: instead of "having an idea" and then working out how it might be done, the situation was reversed into having a piece of equipment, finding out what it might do and deciding how to use it.

Figure 5-E shows a selection of the digitally dripped outcomes, created using 'oil paint' in Painter. ${ }^{18}$ For further examples see the Ring/Drip section on the enclosed CD.

\subsubsection{Reflections}

The digital Drip series was less spontaneous than the analogue outcomes, but the images were aesthetically pleasing as pattern structures. The ability to layer levels of colour to create designs with different levels of complexity, without having to start anew each time was advantageous.

\subsubsection{Synthesising Manual and Digital Techniques}

The next stage of the experimental image making involved the use of CAD as a method for synthesising analogue and digital mark making strategies. By using a combination of Photoshop and Painter, new Ring/Drip designs were created through; isolating, repeating, re-sizing and re-colouring imported (analogue) Rings and combining them with digital Drips. The combined use of scanned, individual impressions of cup rings, overlaid with digital, 'watercolour' drips resulted in some ethereal, translucent, images. The smooth, semi-transparent, quality of the watercolour stripes was reminiscent of the work of Morris Lewis ${ }^{19}$.

\subsubsection{Reflections}

The digital Drips were not comparable with the analogous designs but presented an alternative version of the same concept. The exercise demonstrated that although it was possible to create 'conscious'-style marks, such as shapes, lines and uniform effects using the wide range of art tools, it was much more difficult to create the textural depth of 'unconscious'-style marks, such as 'spills' and 'splashes'. It had become apparent that designing an illusory 3D surface using 2D software was creatively limiting without the use of original source material (Harris 2000: 32). I decided that if I planned to incorporate spontaneous mark making into my designs, I would create such images outside of the system, and import them using scanning.

\footnotetext{
${ }^{18}$ For further examples see the Ring/Drip section on the enclosed Transforming Shape CD.

${ }^{19}$ Lewis further explored Jackson Pollock's 'dripped painting' technique through his Veils, Unfurled and Stripe series (Britt 1999: 264).
} 


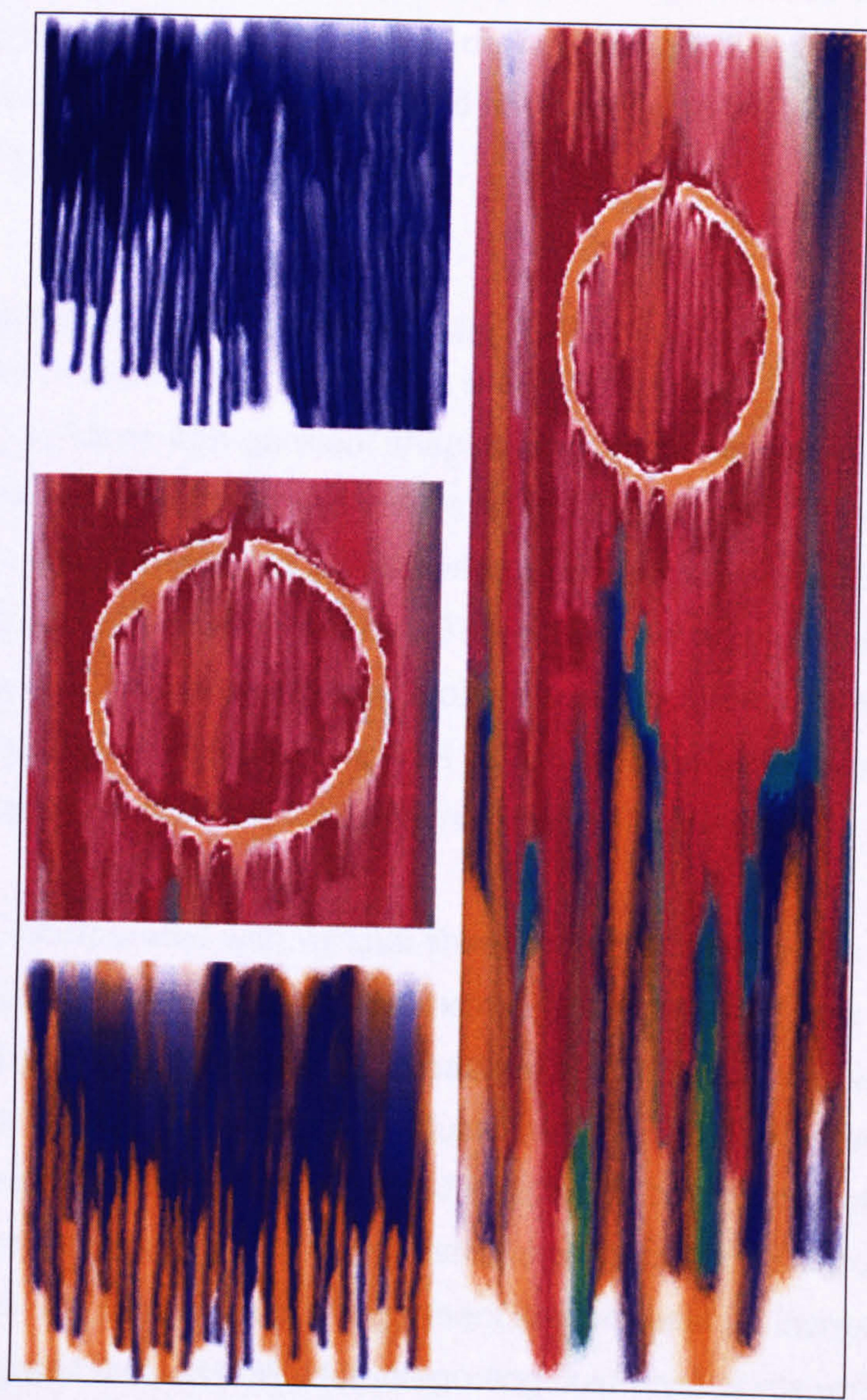

Figure 5-E Digital 'oil' drips combined with analogue cup ring 
At this stage of the practice I was slightly frustrated with CAD as a medium, as despite creating some interesting outcomes, I had not been able to create effects that were as visually exciting as the manual marks. However, I was impressed with CAD's potential as a tool for rendering and synthesising analogue and digital based concepts to form a single, innovative design statement. I could now appreciate the debate regarding whether CAD was a 'tool' or a 'medium', and envisaged it to be of value within both contexts (Lansdown 2000).

\subsubsection{Initial Print/Garment Integration using CAD}

Following my first in-depth training in Lectra software ${ }^{20} \mathrm{I}$ began to experiment with integrating my print ideas with garment shapes. Specific prints were chosen from the manual (analogue), CAD (digital) and combined (analogue/digital) design experimentation, and incorporated with a series of simple sculptural (3.2), architectural (3.3), and 'crossover' (3.4) garment styles. This was achieved by drawing the outline of simple garments onto an (imported) image of a dress stand (on screen) using integrated CAD software, Prostyle. Garment pattern shapes were also created using pattern cutting software, Modaris, and integrated with similar prints.

Print ideas were incorporated with various shapes in order to visualise print placement on prospective (3D) garment shapes. The exercise demonstrated how the strategic placement of the print could suggest the presence of structural detail within the garment that was not actually present. As illustrated in Fig. 5-F, the flaring effect around the ring motif provided a trompe l'oeil impression of gathered cloth in the bust and lower torso areas, and the strong directional illusion of the background drips seemed to accentuate the length of the garment and suggest an increased volume of cloth. This highlighted the possibility for integrating fluid-style prints with simple (crossover) shapes to insinuate the sculptural characteristics of a draped garment style. The Ring Panel design was also integrated with an alternative (2D) garment (pattern) shape to assess the feasibility of marrying engineered prints across seams (Fig.5-G). Drip 1 was integrated with a trouser pattern and converted into a lay plan, using Diamino software (Fig.5-H). Other variations in the placement, scale and colour of the prints were explored, in relation to different garment contours.

Textile draping grids were employed to introduce greater surface interest and a sense of three-dimensional form to the garment visualisations. The most notable effects were

${ }^{20}$ Training in Prostyle, Modaris and Diamino was undertaken at Lectra Systems, Shipley, Yorkshire, 5-10 July 1999. 

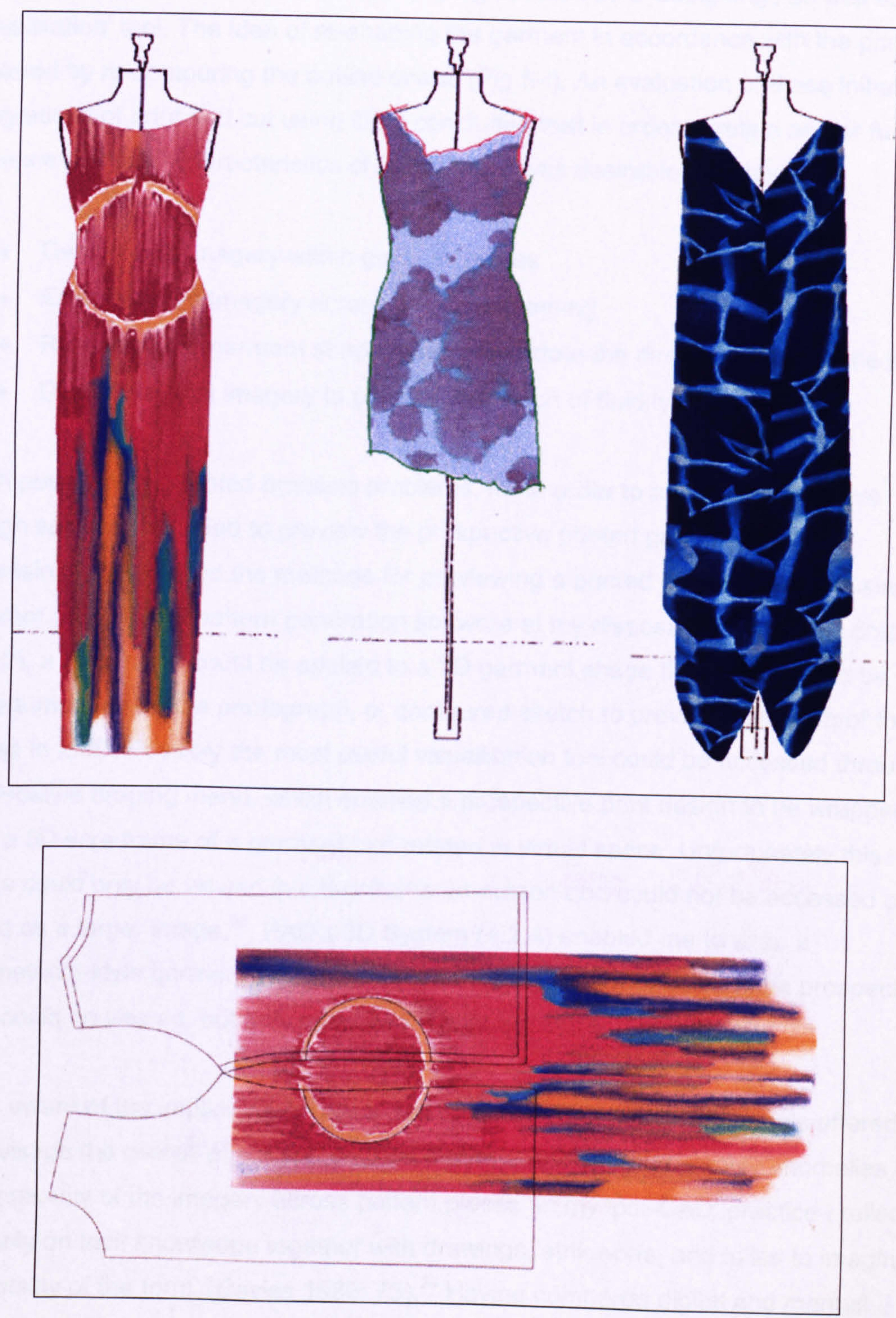

Figure 5-F Experimental print/garment integration

Figure 5-G Marrying Ring/Drip print across seams 
achieved by applying the grids 'out of sequence', which introduced an illusion of 'autokinetic' ${ }^{21}$ movement to the prints (Davies 1980: 28). The Stain Dress designs further explored the subversion of the draping function as a 'designing', as well as a 'visualisation' tool. The idea of re-shaping the garment in accordance with the print was explored by re-contouring the outline shape (Fig 5-I). An evaluation of these initial integrations of print and cut using CAD concluded that in order to retain and/or further enhance the 'fluid' characteristics of the prints, it was desirable to either:

- Design print imagery within garment pieces

- Engineer print imagery across garment seaming

- Re-design the garment shape to accommodate the directional flow of the print

- Distort the print imagery to provide an illusion of fluidity

Each possibility presented practical problems, for in order to achieve an effective design solution, I needed to preview the prospective printed garment in three dimensions. I evaluated the methods for previewing a printed garment design using the different graphic and pattern generation software at my disposal. Using textile draping (4.1.2), a wire frame could be applied to a $2 \mathrm{D}$ garment shape then prints could be texture-mapped onto a photograph, or contoured sketch to provide an illusion of the pieces in 2.5D. Possibly the most useful visualisation tool could be accessed through the Prostyle draping menu, which enabled a prospective print design to be wrapped onto a 3D-wire frame of a garment and rotated in virtual space. Unfortunately this image could only be viewed in a tiny frame on-screen and could not be accessed or saved as a larger image. ${ }^{22}$. PAD's 3D System (4.2.4) enabled me to wrap a symmetrical-style garment pattern around a wire frame mannequin, and a prospective print could be viewed, but only as a 'tiled'23 print structure (Figure 5-J).

I was aware of the implicit advantages that all these CAD visualisation tools offered me to envisage the overall effect of a print on a garment shape and identify anomalies in the continuity of the imagery across pattern pieces. In my 'pre-CAD' practice I relied primarily on tacit knowledge together with drawings, strike-offs, and toiles to imagine the 'totality of the form' (Davies 1980: 73). ${ }^{24}$ Having compared digital and manual methods of visualisation I concluded that however useful all the aforementioned CAD

\footnotetext{
${ }^{21}$ Davies states that there are two major types of illusions: "static," or not moving, and "autokinetic," or appearing to move. See 2.3.

${ }^{22}$ Lectra are currently developing software that will convert $2 \mathrm{D}$ patterns into accurate $3 \mathrm{D}$ visualisations. PAD's 3D System already facilitates this within the limitations of particular garment styles.

${ }^{23}$ The size of 'tiling' is governed by the power of the PC, so although it may have been possible to exceed the scale of the print with more memory, PAD works on the basis of symmetry, and my designs do not ${ }_{24}$ Amheim notes that we have a "visual concept of solids" that allows us to visualise all around a solid body at the same moment. Davies (1980: 73) relates such perception to extend to garment design.
} 

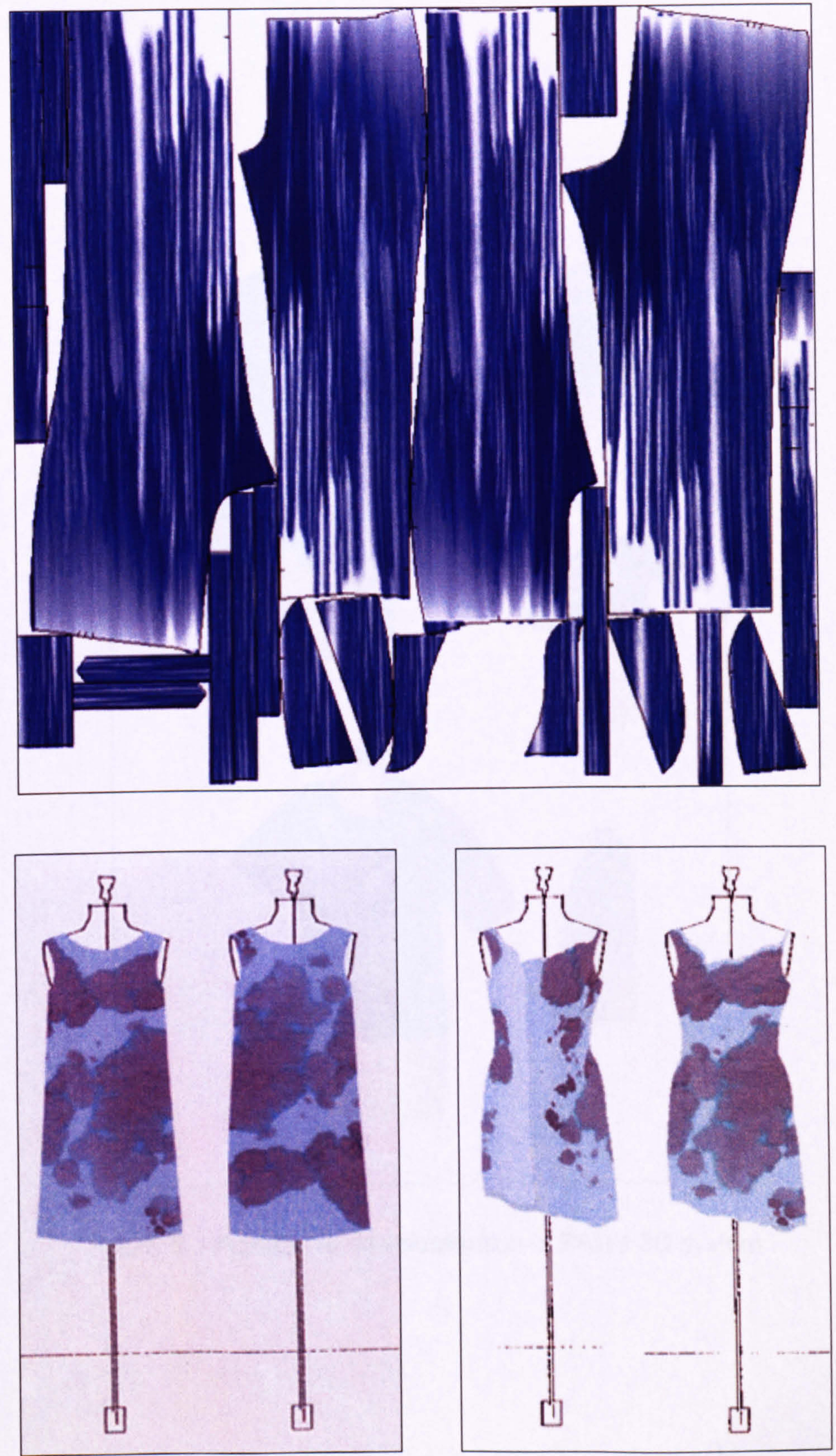

Figure 5-H Drip print trouser lay plan

Figure 5-I A-line and re-shaped Stain shift dresses 


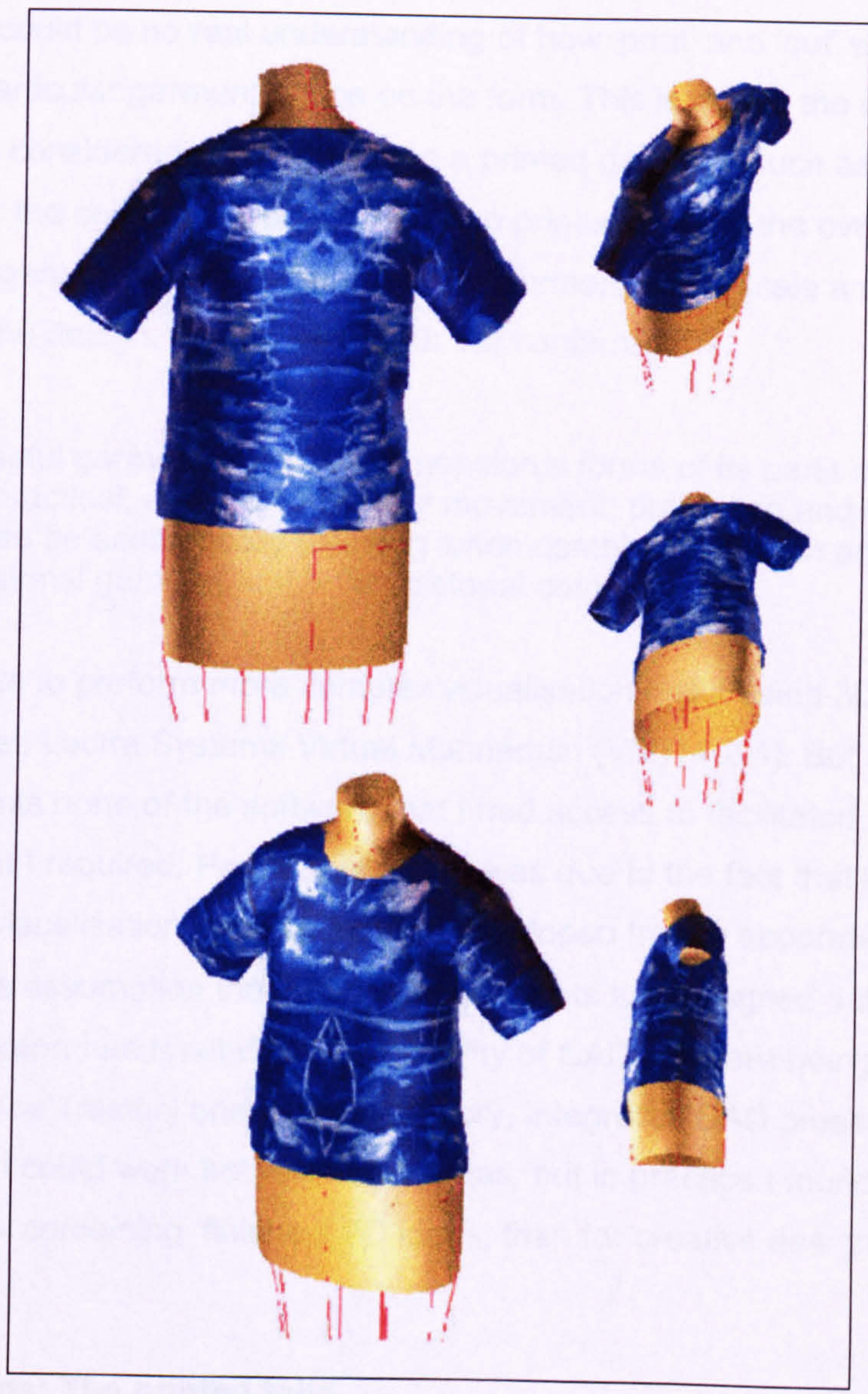

Figure 5-J Printed T-shirt visualisation in PAD's 3D system 
software could be in aiding the designing process, its effectiveness was limited to the parameters of the system and size of printing output device, which resulted in an image of the proposed design, at a fraction of the final life-scale.

I concluded that until a printed garment design was printed onto cloth and sewn together there could be no real understanding of how 'print' and 'cut' would perform together in a particular garment shape on the form. This is due to the many variables that have to be considered when designing a printed garment, such as: final fabric and draping quality; the colour and resolution of the printed design; the overall visual effect of the print imagery in relation to the cut of the garment at full-scale and the effect of movement on the design. As Davies (1980: 73) confirms:

For a successful garment, the three-dimensional forms of its parts must be functionally practical; and must allow for movement, protection and comfort. Yet they must also be aesthetically pleasing when combined, as both an actual, three-dimensional garment and a flat, pictorial composition.

It is now possible to perform more complex visualisation tasks using 3D draping software, such as Lectra Systems Virtual Mannequin (VM) (4.2.4). But at the time of these experiments none of the software that I had access to facilitated the level of visualisation that I required. Part of this failure was due to the fact that like modular software, CAD visualisation tools have been developed from a separate sphere perspective. The assumption that prints and garments are designed autonomously, then combined later, has resulted in the majority of CAD software being either 'shape' (vector) or 'surface' (raster) orientated. In theory, integrated CAD presented me with an interface where I could work between both areas, but in practice I found the software more suitable for combining 'finished' $2 \mathrm{D}$ ideas, than for creative designing.

\subsubsection{Reflections: The printed toile}

I reflected upon how I could practically envision engineer-printed styles, I decided that the most effective way of previewing a prospective design in 3D would be by creating a 'printed' toile. The idea, which drew on garment modelling methods, could be realised through the development of a three-dimensional, method of designing printed garments that considered the form more positively at the start of the design process. Such a fundamental yet radical concept challenged the basic principles of conventional, twodimensional, printed textile design, flat pattern cutting and printed garment design in general, which all tend to reference the form as a flat decorated shape or a set of standardized body measurements, rather than a potential, physical, spatial influence on the designing process. 
I considered how I could incorporate the human form into a 3D design process and was reminded of Vionnet's practice, which relied heavily on the use of a half-scale dress mannequin (3.2). By adopting a similar strategy, I planned to synchronise surface print with garment cut by investigating the origination of print imagery in direct association with the decorative influence of draped cloth on the form (1.7.3) - as opposed to decorating a flat surface of cloth that would finally be united with a body. ${ }^{25}$ As 'draping' naturally leaned towards the sculptural (3.2), it was envisaged that this style of garment shaping would be explored through the practice in greater depth than the architectural (3.3) and crossover (3.4) models.

\subsection{DESIGNING WITH LIGHT}

The novel idea of placing the form central to the initial stages of designing a printed garment required an equally novel approach to print origination. From July 1999, the key objective of the practice was to devise a method of integrating engineered prints with sculptural garment shapes. This objective would be achieved by taking a 'simultaneous approach' (3.7) to the design of print and cut, placing specific emphasis on the influence of the underlying 3D shape of the form on that process. I therefore researched a strategy for originating mark making 'in-the-round'.

Following the initial experiments with the Paper Dresses (5.2.3) I knew that I needed a process that would enable me to create spontaneous imagery (5.2.3). I did not want to create images by physically 'painting' them onto garment toiles, but required a method that produced random pattern effects that alluded to the erratic behaviour of liquid/dye. The Japanese crafting method of Shibori ${ }^{26}$ was explored, as it presented the possibility for originating patterning through the manipulation, binding and dyeing of cloth, but the technique was impractical in conjunction with a dress stand. The dominant use of the colour indigo in Shibori reminded me of the cyanotype process, which I had researched through the work of the Victorian print-maker Anna Atkins. ${ }^{27}$ The ethereal, yet threedimensional quality of Atkins' images of flora and fauna provided key inspiration along with works by Robert Rauschenberg and Susan Weil, who captured an entire clothed figure through the process (Fig. 5-K). I proceeded by practically investigating the process.

\footnotetext{
${ }^{25}$ Textile designers are often only made aware of the final fabric that they are designing for, through handling a small swatch and being provided with the dimensions of the width of the cloth.

${ }^{26}$ Wada, Y, Kellogg Rice, M, and Barton, J. Shibori: The Inventive Art of Japanese Shaped Resist Dyeing, Japan: Kodansha International Ltd., 1983.

27 See Atkins, A. (1985) Sun Gardens, New York: Aperture.
} 


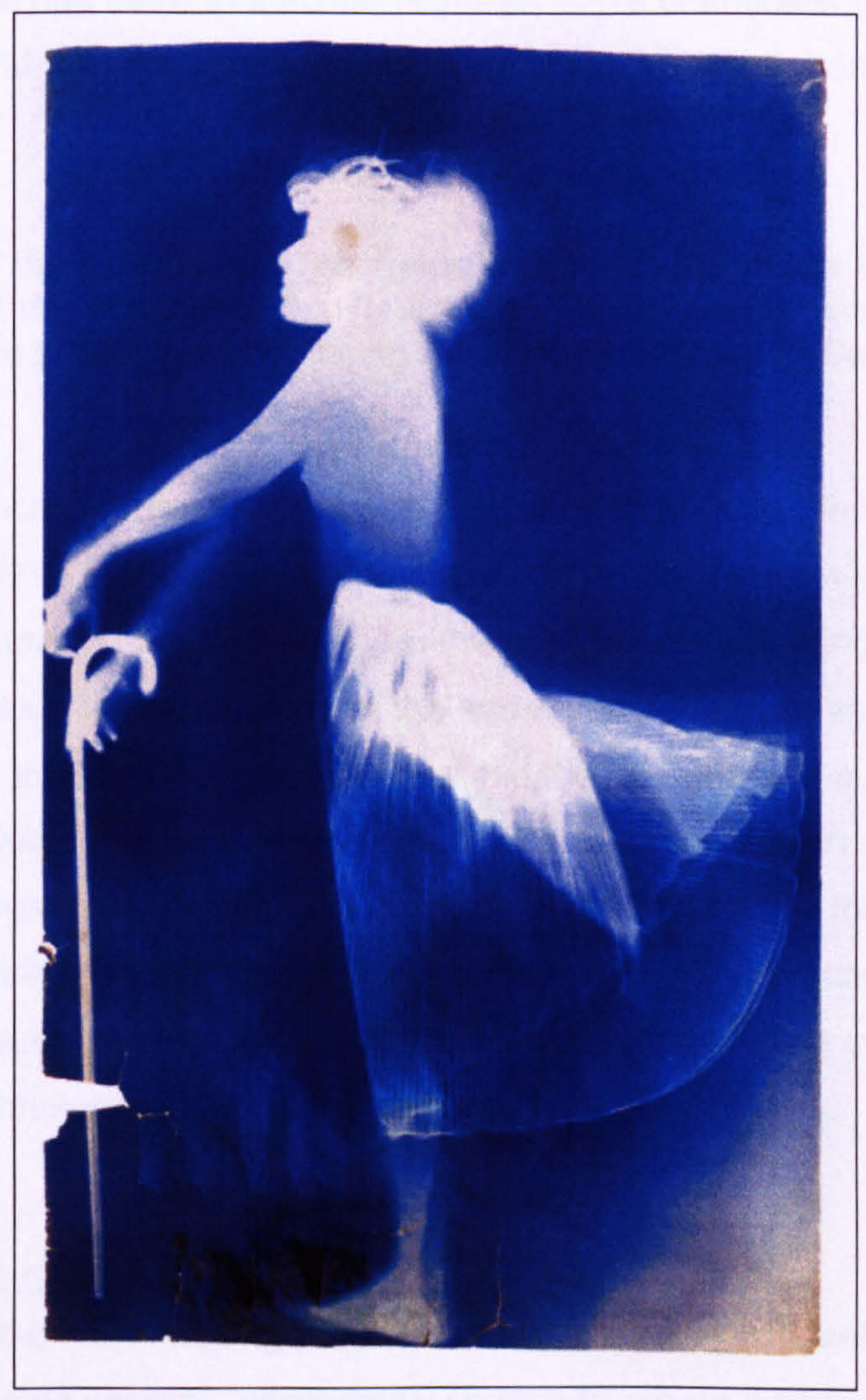

Figure 5-K Robert Rauschenberg \& Susan Weil 1950: 'Female Figure' cyanotype (Weitemeier 1995) 


\subsubsection{The Cyanotype Process}

The cyanotype, or blueprinting was invented in 1842 by Sir John Herschel and is the oldest non-silver photographic process in existence. A 'direct printing' method, the process allows the user to make an imprint of an object by placing it on a surface, (usually paper) that has been treated with light-sensitive chemicals. In daylight the chemicals react and turn the exposed area blue, while the space beneath the object remains white.

The intensity of the contrast and the speed with which the image is obtained depend both on the strength of the sunlight, and the exposure time. The process is halted and the image fixed by rinsing the surface with water (Sacilotto: 1982: 177).

The cyanotype process presented a possible solution to both the aesthetic and practical requirements of the project. The chemical solution is normally applied to rag paper, which encouraged me to investigate the possibility of adapting the process for use with cloth (toiles). The processing of the sensitised cyanotype solution material requires exposure to ultraviolet light, so I realised that the effect of sunlight on sensitised cloth could produce a similar outcome. ${ }^{28}$ The use of cyan as the major sampling colour presented a potentially, limited palette, but I knew that I could extend the colour range using $C A D$ as required. From this point in the practice the visual aspect of the research became driven by the concept of originating printed textiles and garments from a three-dimensional perspective.

\subsubsection{2D Image Capture}

In order to gauge the mark making potential of the medium for myself, blueprinting was initially employed in its original, 'photogram' context to create a series of 2D images on paper and cloth, using sunlight and artificial UV exposure lamps. These first prints explored traditional subject matter such as flora and fauna combined with material elements such as torn cloth and manipulated thread and ribbon, which were arranged on sensitised paper to create a 'mask' (Fig. 5-L)

My immediate response to the paper prints was an interest in the attached shadows of the placed objects (Fig.5-M). The 'sun prints' resulted in more shading around the object, which I discovered could be exaggerated according to: the positioning of the object in relation to the sun; the strength of the sunlight (time of day); and the length of

\footnotetext{
${ }^{28}$ In the absence of sunlight, artificial ultra-violet lighting conditions would be used. Although staged lighting would probably lead to a more controlled result, it was recognized that the manipulation of such conditions may increase design potential of the process.
} 
exposure time. As Gombrich (1995: 37) noted:

The effect of what has been called the 'attached shadow' has always belonged to the resources of trompe l'oeil. The shadow cast by an object on the ground on which it rests immediately enhances the impression of its solidity.

\subsubsection{Reflections}

This early experimentation indicated that the blueprinting process had modelling potential and satisfied the aesthetic requirements of spontaneous mark making, as the resulting impression of the object could not be completely determined due to the unpredictability of the natural lighting conditions. The attached shadows created when using sunlight, imbued the resulting images with a three dimensional, illusionistic quality, that I felt could be exploited within the context of a 3D garment.

\subsection{MODELLING PRINT: THE RIBBON TUNIC}

Having identified the cyanotype process as a potential medium for capturing imagery in-the-round, I proceeded to create a method of designing printed garment prototypes that combined traditional/manual fashion and textile skills with digital CAD/CAM technology. The method investigated the possibilities of approaching printed garment design from a three-dimensional perspective, through the creation of a blueprinted toile. The method encompassed Delaunay's notion of simultaneous design, Vionnet's half-scale garment-modelling technique, and my own tacit knowledge of print and garment integration. The following sections document the design of the Ribbon Tunic in terms of: Intentions, Process and Reflection, a system of evaluation created and adopted by Amanda Briggs-Goode (1997: 245) in her practice-led PhD research.

\subsubsection{Ribbon Tunic: Intentions}

It was my intention to combine the old and new technologies represented by the cyanotype process and integrated CAD, to explore a new way of designing printed garments. The first modelled design would explore the 'poetic demands' of the materials and technology at my disposal (Hepworth 1966: 17). The initial objective was to create a half-scale, blueprinted toile that synthesised textile design and garment modelling methods. It was intended that the resulting outcome would translate the aesthetic dialogue that can exist between cloth and form. It was envisaged that the design would explore the tension between surface design and sculptural garment form, through the integration of non-repeating, fluid mark making. 

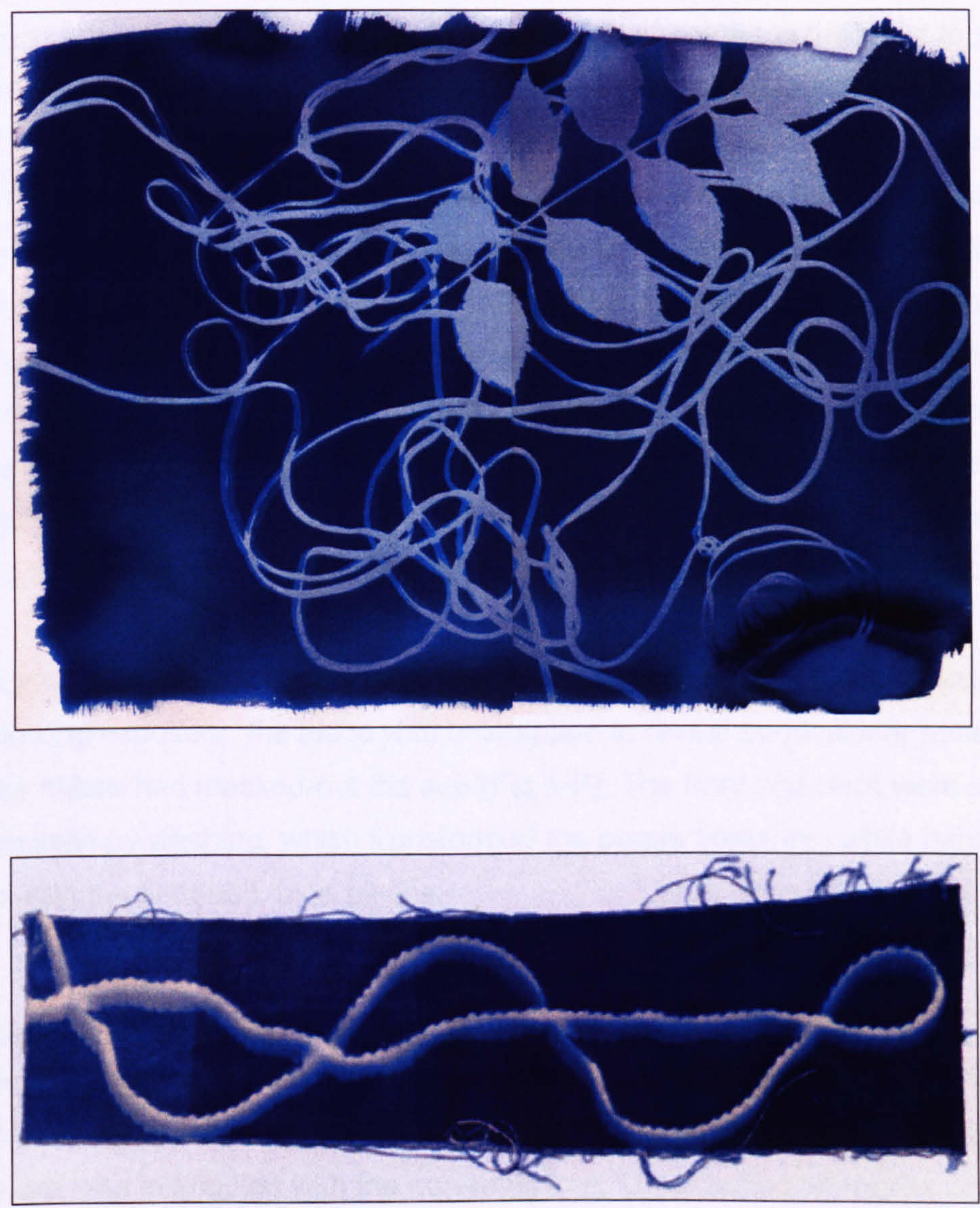

Figure 5-L 2D cyanotype exposed using artificial ultraviolet light source Figure 5-M Test strip of cord showing attached shadow effect 


\subsubsection{Ribbon Tunic: Process}

The initial experiment was carried out using a bias cut, draped-neck tunic designed in muslin, (at full-scale) on the dress stand. Muslin was used, as it is a traditional toiling fabric that interacts well with the form, especially when dampened (1.7). The tunic was modelled to incorporate drapery in the neck area and shaped into the waist to skim the hips. The resulting toile was digitised and adjusted in Modaris (Lectra) to create a pattern, Tunic 1, which was plotted out and re-cut in similar fabric, at half-scale (Fig.5$\mathrm{N})$. The half-scale pattern pieces were coated with light sensitive, blueprinting solution, dried in a darkroom and temporarily joined at the seams using pins. The sensitised toile was placed on the half-stand and mark making was integrated by wrapping the 'dressed stand' with fine ribbon, in a circling-motion. The ribbon acted in the same way as a positive/negative transparency in photography. The wrapping action served the dual purpose of both physically and visually describing the garment shape in relation to the underlying 3D form (of the stand). It was intended that the marks created by the strategic, directional winding would enhance the fluidity of the cloth shape (Fig.5-O).

The wrapped toile was exposed to sunlight, ${ }^{29}$ with the left side of the piece facing the sun. Following exposure, the piece was unwrapped to reveal purple linear patterning where the ribbon had masked-out the sun (Fig.5-P). The front and back were unpinned and processed by washing, which transformed the purple areas into white bands that criss-crossed the flattened, blue pieces.

\subsubsection{Ribbon Tunic: Reflections}

The Ribbon Tunic was imbued with 'negative' linear configurations that traversed the usual boundaries of seaming. The wrapping technique had resulted in fluid-style print imagery that was in keeping with the non-repeating, Li patterning concepts, sought through the practice (5.2.3). However, I was most intrigued by the evidence of the 3D method of origination that had resulted in a subtle shaded effect within the pieces. The pieces did not display the flat blue backgrounds or white markings of a typical cyanotype, but presented more visually arresting variegated imagery. The right side of the Ribbon Tunic was slightly darker than the front, due to the shadow cast by sun on the 3D model. This outcome indicated the necessity for a toile to be rotated at regular intervals if an even exposure was to be achieved in the future.

The use of semi-transparent, muslin contributed to the ethereal, faded qualities

\footnotetext{
29 The sensitised toile was exposed at mid-day for 15 minutes. This length of exposure was chosen following the creation of test strips, exposed for 5 minute intervals up to 30 minutes.
} 

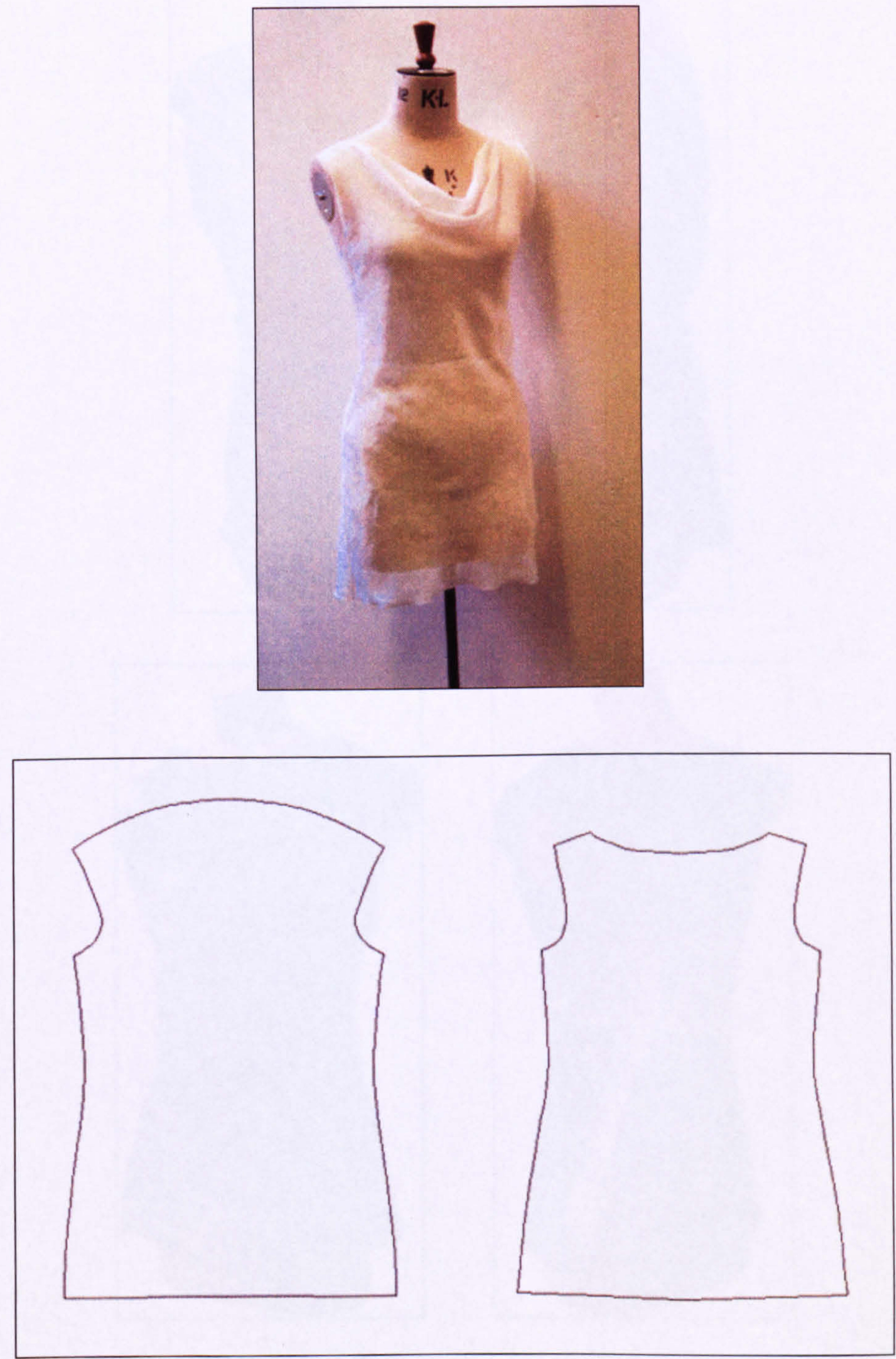

Figure 5-N Muslin, drape neck and pattern contours 

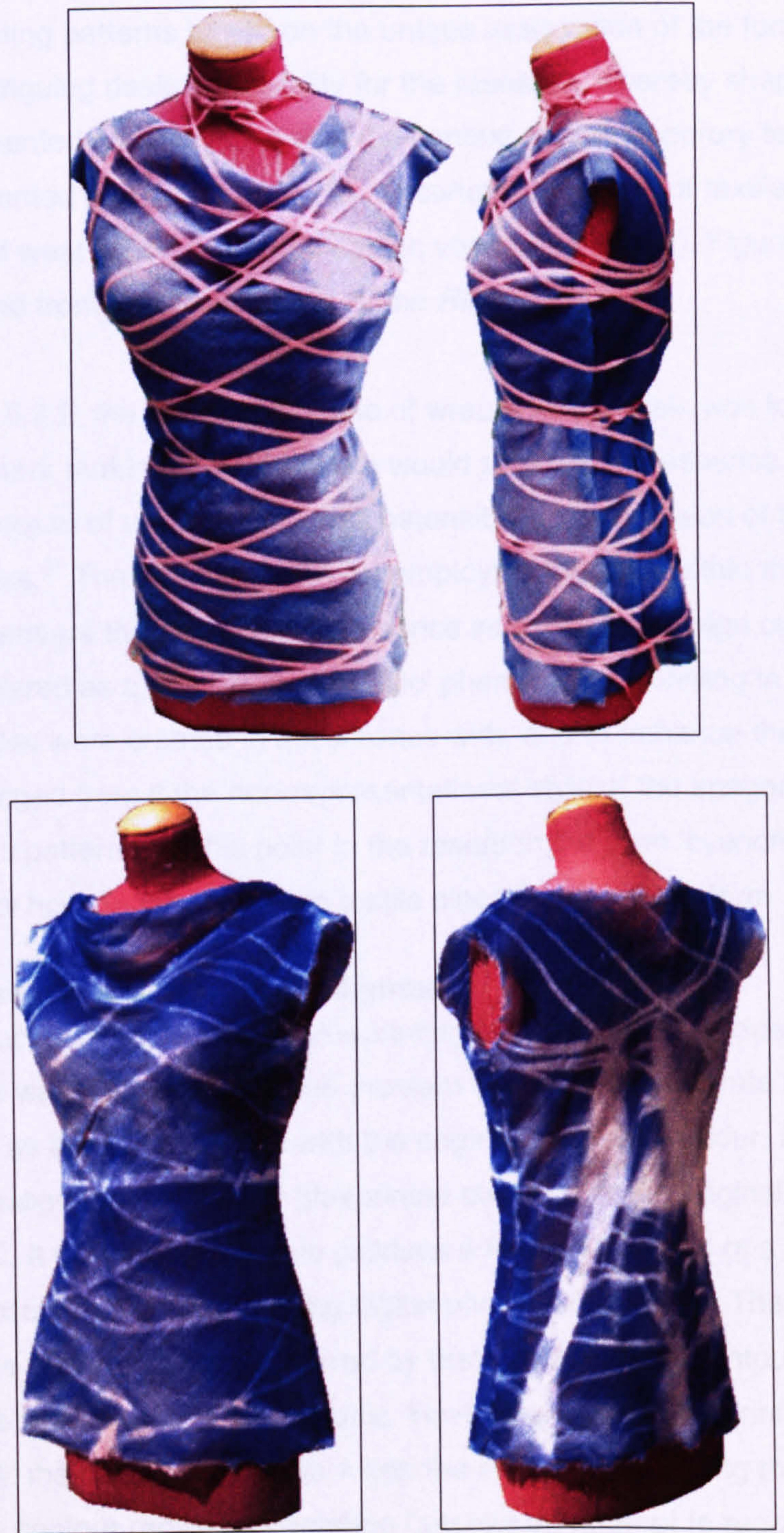

Figure 5-O Wrapped Toile during process of image capture

Figure 5-P Ribbon Tunic cyanoform on the stand 
displayed by the Ribbon Tunic. The antiquated appearance, combined with the subtle evidence of the presence of the underlying 3D form, led to comparisons with antique textiles featuring 'true images', such as Veronica's Cloth and the Turin Shroud (1.7.1). The idea of creating patterns based on the unique association of the form with cloth presented an intriguing design possibility for the research, whereby shape and form, could be implemented as catalysts within the context of contemporary textile design. The idea represented a shift from a 2D to 3D conceptualisation of textile design with the 'the notion of wear' incorporated as design vocabulary (1.7.2). Figure 5-Q shows the deconstructed front and back pieces of the Ribbon Tunic. ${ }^{30}$

As discussed in 5.3.2, the fundamental use of wrapping materials was to create a mask for linear-style mark making to occur which would simulate the essence of 'fluidity'. Similarly, the process of un-wrapping, was ostensibly the conclusion of the print modelling process. ${ }^{31}$ The main intention for employing the form within the designing process was to ensure that its physical presence informed the design outcomes. The form was considered as a positive 'naturalistic' phenomenon (Shilling in Entwistle 2000). The textiles were created in accordance with, and to enhance the female form, and when estranged from it the non-representational style of the imagery rendered them as abstract patterns. At this point in the research the term 'cyanoforms' was created to reflect how dependent these textile pieces were on the form.

\subsubsection{CAD Design Development: Realignment}

Following the successful adoption of blueprinting as a method for modelling textile imagery in 3D, I was presented with the problem of how to re-integrate physical design outcomes such as the Ribbon Tunic with the original garment contour. I began by attempting to realign the scanned, ${ }^{32}$ blueprinted pieces with the original Tunic 1 contour, in CAD. It was my intention to produce a full-scale design of a printed garment prototype that could be fabricated using digital printing technology. The task of realigning shape and image was achieved by first, importing the contours and blueprints of the front and back of the tunic. Having saved the blueprints as motifs, I attempted to 'fill' the contours of Tunic 1 with the images. Realigning the printed pieces with the pattern contour proved challenging (despite an attempt to regulate the shapes by placing them in transparent leaves during scanning) as the muslin had shrunk and become distorted. This led to a re-consideration of the suitability of unstable qualities such as muslin for blueprinting garment shapes. The shaping incorporated into Tunic 1

\footnotetext{
${ }^{30}$ For a more detailed impression see images 1 and 2 of the Ribbon Tunic on the enclosed CD.

${ }^{31}$ When I showed these pieces at CADE 2001, the wrapping/unwrapping action was perceived to symbolise the 'liberation of the female form', while the 'negative' patterning was construed as a graphic equivalent of 'woman as the negative other' (Stickley 2001).

32 The first scans of the Ribbon Tunic were carried out at $100 \mathrm{DPI}$.
} 


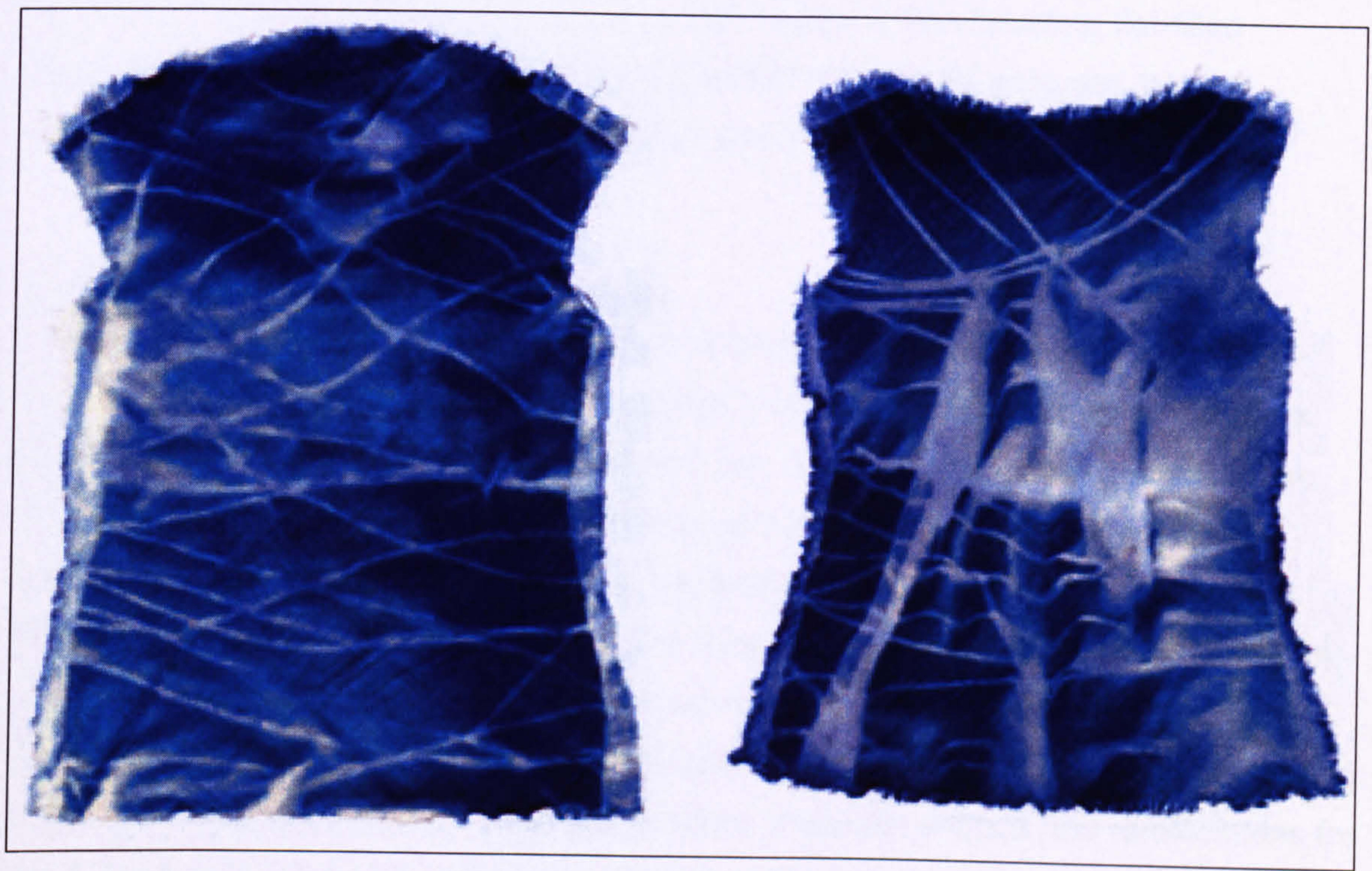

Figure 5-Q Ribbon Tunic, front and back pieces 
also made aligning the 'ribbon' patterns across the side seams difficult, leading to a reconsideration of the shaping of future experimental garments.

The re-alignment of the pattern and print was finally achieved by re-sizing the front and back pieces of the Ribbon Tunic using the scale tool, to alter the blueprints to comply with the proportions of the original pattern pieces. ${ }^{33}$ This process of integration required considerable manipulation and reliance on careful hand-eye co-ordination to place the motif (print) correctly within the contour (pattern shape). The resulting flat-filled contours, Ribbon Front and Ribbon Back (Fig.5-R) were fairly accurate, but the designing process required further research and development.

\subsubsection{Digital Manipulation: Water Pleat}

The placing of the Ribbon Tunic in polythene leaves during scanning resulted in a distortion in the detail and hue of the blueprint, heightening the ethereal effect of the design. Unfortunately the tonal qualities had also been eroded, which presented the idea of replacing the lost analogue markings with a virtual equivalent. I devised a method of applying virtual shadow using the drape 'mapping with shadow' function (4.1.2). The use of virtual shadow to model integrated printed shapes represented an entirely original use of the software. ${ }^{34}$ The device presented new possibilities for introducing trompe l'oeil shading to printed garments, which built on the use of shading in the Ring Dress (5.2.2). The strategic shading of pattern shapes had ramifications for both the appearance of the garment, and that of the underlying contours (Fig.5-S).

A desire to somehow 'get into the computer'35 and manipulate my designs physically, encouraged me to further explore the modelling potential of textile draping/mapping. Consequently, mapping was employed to virtually 'pleat' a length of virtual printed cloth, created from the Ribbon Tunic. The length consisted of three Front and two Back sections of the tunic, pasted together alternately then stretched as a composite image. A Pleated Grid was created and the Ribbon Montage was mediated as a motif into a rectangular contour, which rendered the design similar in appearance to a pleated Fortuny Delphos (Fig.3-C, p.3-8). The shaded areas of Water Pleat denote where the five sections were pasted and camouflaged together (Fig. 5-T). ${ }^{36}$ The use of virtual pleating represented an innovative application of integrated software.

\footnotetext{
${ }^{33}$ The Front and Back pieces of the Ribbon Tunic were increased by $2 \%$ the $X$ (width) and $8 \%$ in the $Y$ (length).

34 This was confirmed by the Lectra software consultant, Jackie Gordon, at the time.

${ }^{35}$ Vibeke Riisberg (2003) described a similar feeling of frustration as wanting to 'attack the surface of her textiles through the monitor.

${ }^{36} \mathrm{CAD}$ drawing and painting tools were used to disguise the joining of the five pieces.
} 

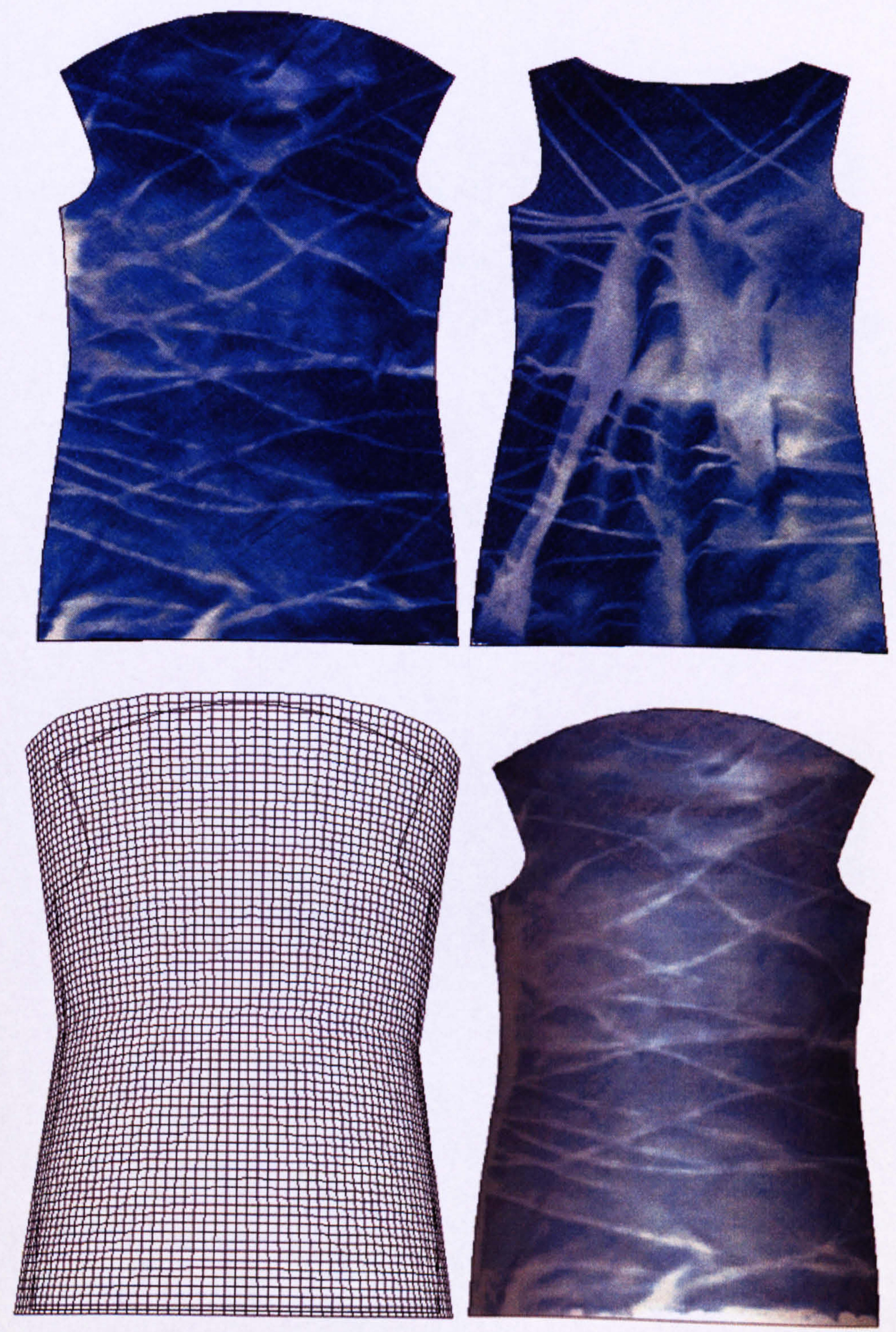

Figure 5-R Contour with curved mapping grid

Figure 5-S Ribbon Tunic front modelled in CAD with attached shadow 


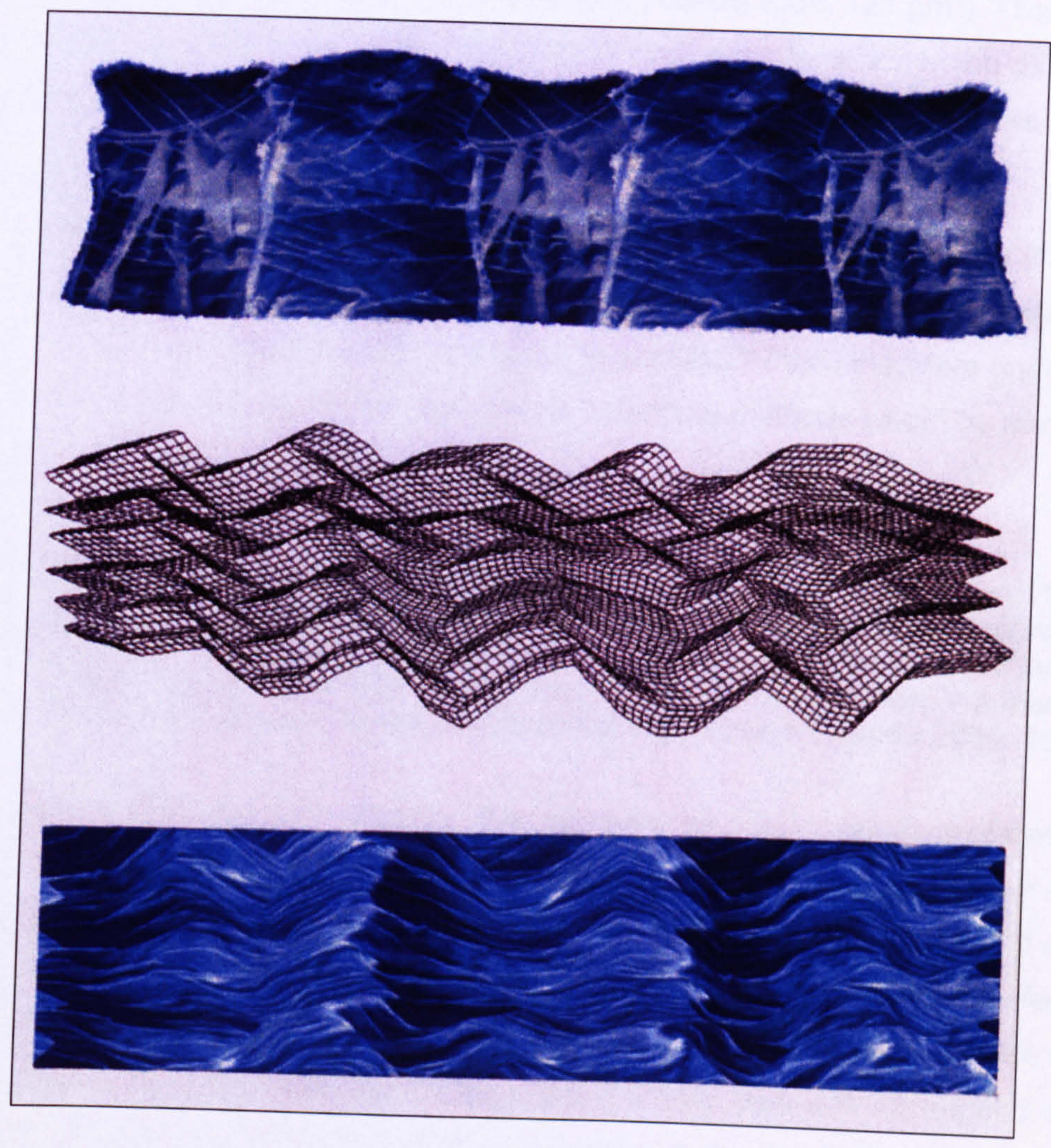

Figure 5-T Water Pleat 


\subsection{DIGITAL FABRIC PRINTING: TEST 1}

In October 2000, sections of the Ribbon Tunic, and Water Pleat designs were digitally printed at Lectra Systems ${ }^{37}$ using a Stork Amber system (4.4). The images were saved in Tiff file formats and formed part of Test File 1 (one of three) that were printed onto Stork, 'prepared for printing' (PFP), cotton poplin (154cm wide, $121 \mathrm{gm}^{2}$ ). The files were the first of a series of experimental printed cloth outputs, which acted as qualitative data that informed the future practice. Figure $5-U$ shows Test Files 1-3.

\subsubsection{Colour Translation}

I was aware that there were likely to be anomalies between the appearance of the designs on-screen and the digitally printed versions on cloth, as differences always arise during the translation from one medium to another. ${ }^{38} \mathrm{I}$ was therefore interested to see how my combining of physical and virtual modelling methods would be realised as a 'digital print' in spite of Maeda's warning:

It seems odd when people describe a piece as a "digital print." By nature of their construction, digitally originated images cannot be so trivially realized in print; an analogy would be to call a photograph or illustration of a building an "architectural print."...A digital print by comparison should be thought of as illusory - a mere sliver or minor facet of what really exists in the digital realm (Maeda 2000: 161).

I had pre-empted some of the possible discrepancies by printing sections of designs onto inkjet paper and cotton. ${ }^{39}$ The first difference I noticed was that the colour of the printed cotton appeared stronger compared to that of the original blueprint and screen image, due to the translation from the brightness of the screen to the matt surface of the cloth. The effect of the $\mathrm{CMYK}^{40}$ printing process on the more, subtle palette of Ribbon Tunic 1 was negligible, but had resulted in a 'true' blue and corresponding 'raw' yellow in the translation of the Water Pleat. I decided that in the future Tiff Lab file ${ }^{41}$ formats would be used if possible, to calibrate the screen and printing colour more accurately. Figure $5-\mathrm{V}$ provides an indication of the variations between the original cyanotype and the digitally printed colour.

\subsubsection{Visual Qualities}

Secondly, I noticed the discrepancies between the 'on-screen' and final, printed resolution of the images. Where half-scale printed garment pieces had been scanned-

\footnotetext{
${ }^{37}$ Test 1 was carried out at the Leamington Spa office with the help of CAD specialist, Eleanor Grieve.

38 Throughout my career, I had witnessed the changes that could occur to a design through roller, screen and transfer printing.

${ }^{39}$ Epson Photo Quality inkjet paper and $100 \%$ Cotton Computer Printer Fabric were used.

40 Cyan, magenta, yellow and black.

41 Unfortunately this was not possible as 1) my PC was not equipped to save in this format and 2) neither of the two Printers I used during the research were prepared to calibrate their Ambers to accommodate these files for such short print runs.
} 


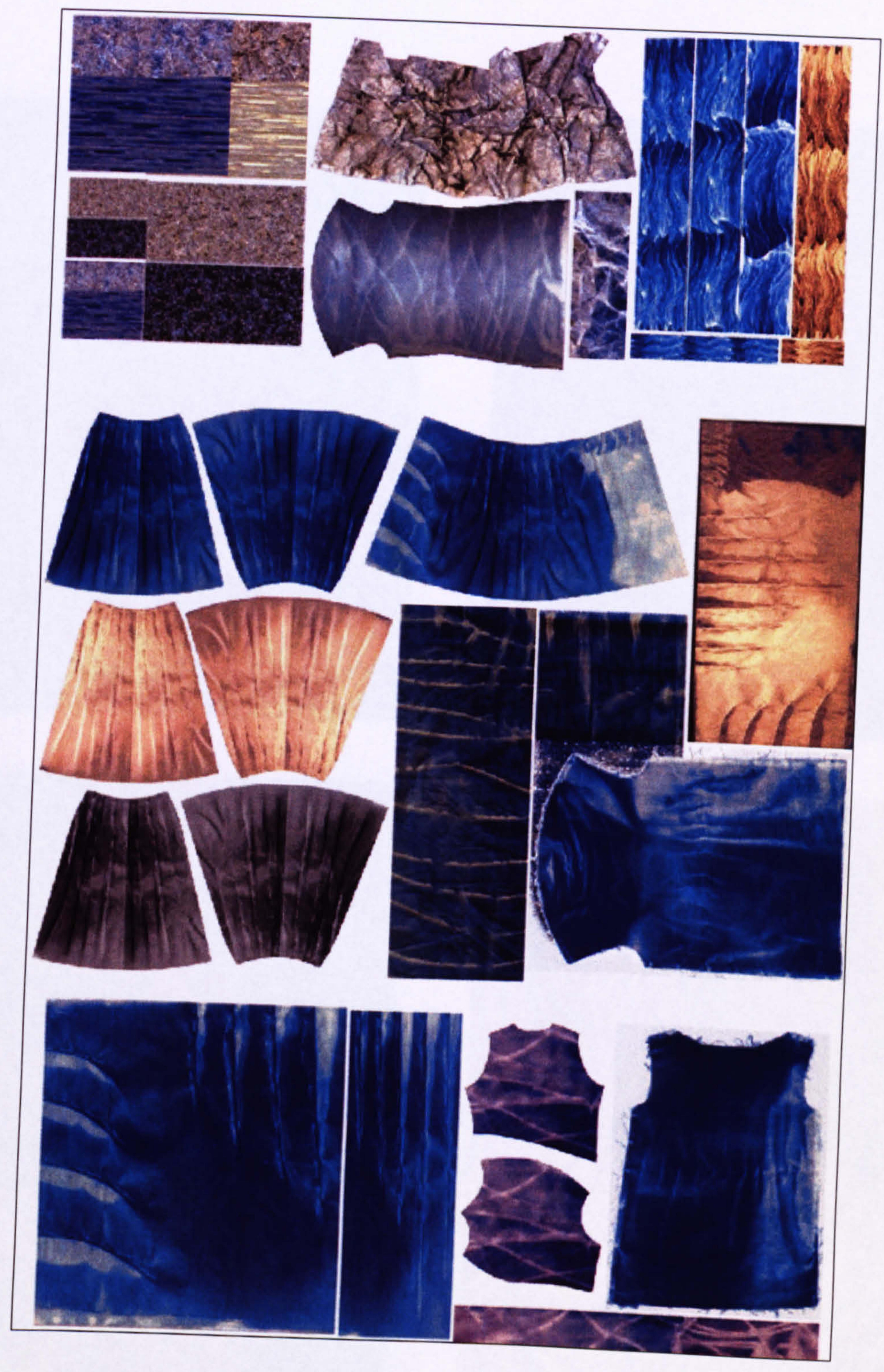

Figure 5-U Digital printing Test Files 1-3 

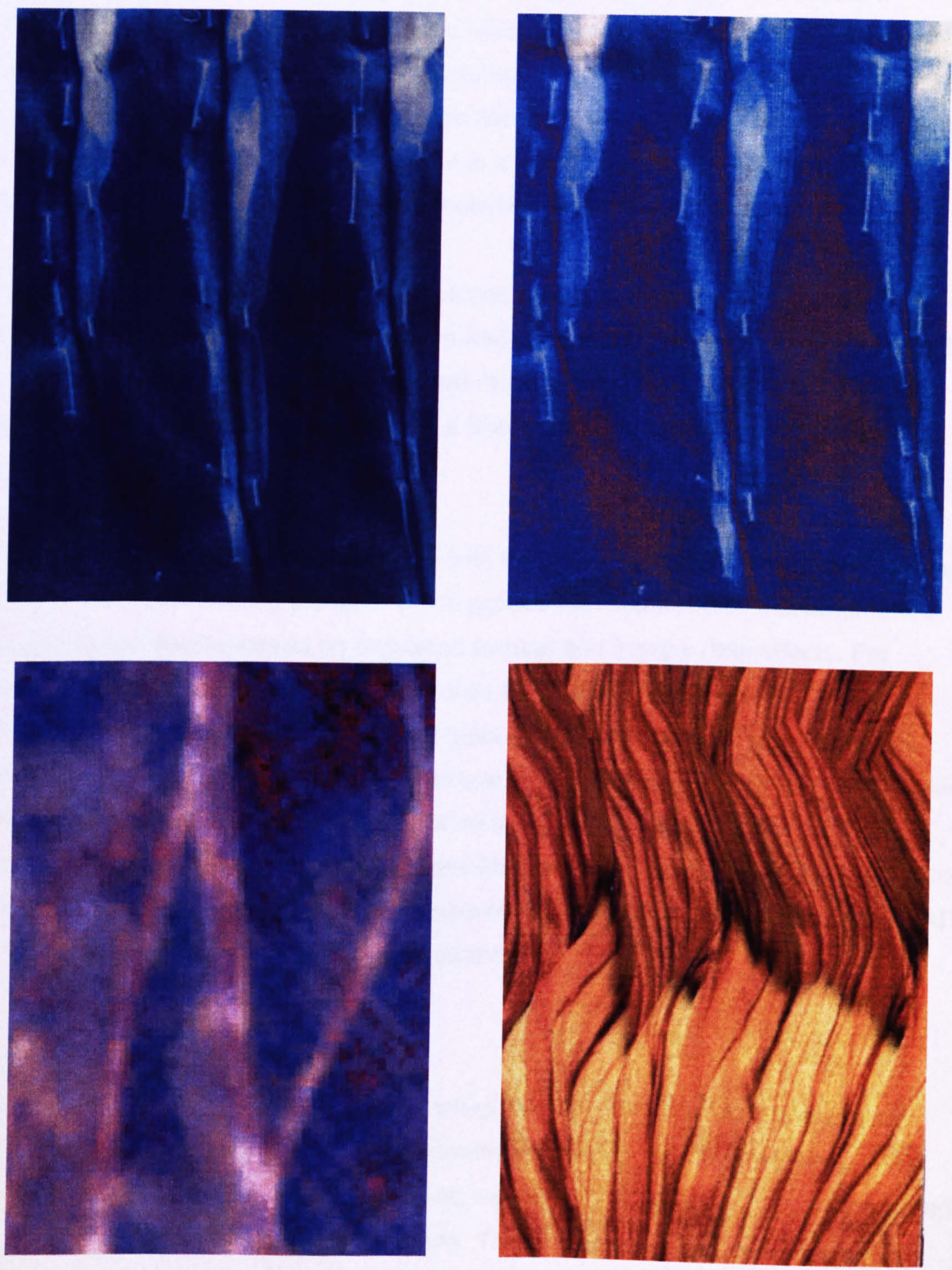

Figure 5-V Samples showing colour variation

Figure 5-W Samples showing pixelation and 3D effect 
at a low resolution, such as $100 \mathrm{DPI}$, the subsequent $200 \%$ conversion to full-scale rendered them as highly pixelated images at $50 \mathrm{DPI}$. The use of enlarged pixels had been explored by Eley Kishimoto for Hussein Chalayan in 1996, which made me avoid pursuing this 'accident' as a design concept. The pixilated surface presented a distraction from the engineered imagery, which led to a series of tests and an increase in scanning resolution to achieve an outcome that accentuated the modelled markings. Throughout the continued practice, it was not always possible to obliterate all evidence of the pixels, but they came to be viewed in a similar manner as 'brushstrokes' in a painting, providing evidence of the computerized crafting process (Fig.5-W).

The third observation of the printed outcomes stemmed from the use of 'cloth' as a design canvas, as the grain of the weave had become an integral part of the print. The use of an open weave such as muslin had resulted in an exaggerated texture and it was decided that to minimise this effect a finer quality, similar to the cotton printing substrate, would be employed in future.

Despite these anomalies, I was pleased with the sharp quality of the imagery achieved through the digital printing process, which provided an important indication of future designing possibilities based on simulated textural and trompe l'oiel effects. For example, Ribbon Tunic 1 retained most of its 3D illusion, despite being slightly 'flattened' through the translation from a 'back-lit' screen to a matt, cloth substrate. Water Pleat still alluded to the surface texture of creased cloth, albeit in a slightly less sophisticated palette. In conclusion, I had to agree with Maeda's (2000: 161) observation that 'digitally motivated images look best on the computer', but for me their translation onto cloth clearly indicated some of the potential advantages of using CAD to create innovative printed textiles and garments.

\subsection{CONCLUSION OF CHAPTER}

A holistic approach to print and cut was taken from the outset of the experimental practice, encompassing the use of experiential knowledge and CAD software made available for the research. Initially digitising was employed as a method for integrating vector-based motifs with garment contours. The exercise highlighted fundamental issues regarding print/garment integration, such as how to avoid disrupting print imagery with the garment structure. This led to the re-cutting of the garment as a onepiece pattern, which provided a simpler shape to work with, and increased the possibilities for print integration. 
mark making with. By approaching the dresses as 3D models it was possible to apply imagery to the normally, inaccessible areas where side, shoulder seams and darts joined. The concept of building up layers of imagery to create deeper tonal effects on the side and shoulder seams as a method of employing print to contour the form was an outcome of these experiments. The idea of integrating engineered imagery across seams was also explored, leading to the basic re-shaping of the garment in sympathy with the configuration of the print. Most crucially, the paper dresses inspired the notion of originating print from a 3D modelled perspective.

My interest in draped garment styles encouraged me to create fluid prints using manual and $C A D$ painting tools. Initially, the analogue marks were more evocative than the digital outcomes, but following a period of adjusting to CAD, comparable effects were created. It was envisaged that the vertically engineered Drips could be integrated to work with the longitudinal flow of a full-length garment. The idea of integrating flowing imagery with woven, crossover styles, to suggest sculptural garment qualities, was also considered at this point.

Manual and digital elements were combined together as composite images and integrated with a range of different garment shapes. The strategic placement of the Ring/Drip prints resulted in trompe l'oeil effects caused by the imagery's visual suggestion of structural detail that was absent from the garment. The strong directional style of the Drip imagery visually accentuated garment length and suggested the effect of draped fabric, in-line with a sculptural style. Print continuity across seams and variations in print placement scale and colour indicated that the concept of fluidity could be enhanced through manipulating designs WITHIN garment shapes.

The decision to use a printed toile as a starting point for the design process established a working method that facilitated a simultaneous approach to garment modelling and mark making. The adaptation of the cyanotype process as a method of 3D image capture resulted in the creation of the Ribbon Tunic. This piece explored the tension between surface design and a sculptural garment form. The term cyanoform was created to describe this and subsequent toiles, which acted as conductors for the creation of photogram-style prints. The use of sunlight as a method of exposure resulted in attached shadows being incorporated into the designs, which enhanced the sense of 3D illusion.

The use of CAD enabled deconstructed 3D cyanoforms to be realigned with $2 D$ pattern contours, and converted into printed garment designs. This use of CAD represented an 
original application of integrated software and presented new ideas regarding the alignment of imagery across seams, the strategic shading of printed garment pieces and the grading of engineered prints. The pieces of the Ribbon Tunic were grafted together and manipulated to create an alternative textile design. Textile draping software was employed to virtually manipulate the design to suggest fine pleats, which raised the idea of introducing trompe l'oeil textural effects into digitally printed textiles/garments.

The first digital printing test raised key issues regarding the translation of designs for production. Anomalies between screen and fabric colour and resolution underpinned the importance of sampling, calibration between systems and the use of the appropriate DPI. The most positive outcome was the potential for reproducing the unique 3D, visual qualities of the cyanoforms as garment prototypes. The combined use of $C A D$ and digital printing presented the possibility for replicating individually crafted pieces as hybrid printed garment designs. This satisfied the initial aim of the practice to synthesise appropriate manual and CAD technologies to create innovative design outcomes. 


\subsection{REFERENCES}

Atkins, A. (1985) Sun Gardens, New York: Aperture

Braddock, S. and O'Mahony, M. (2000) Fabric of Fashion, London: The British Council

Briggs, A. (1997) A Study of Photographic Images, Processes and Computer Aided Textile Design, PhD thesis, The Nottingham Trent University

Bunce, G. (1999) Textile Printing in The Age of CAD/CAM, To See, To Touch, To Feel Symposium, Kuopio Academy of Crafts and Design, Finland Bunnell, K. (1998) Re: Presenting Making, the Integration of New Technology into Ceramic Designer-Maker Practice, PhD Thesis, Grays School of Art, The Robert Gordon University

Britt, D. Ed (1999) Modern Art: Impressionism to Post-Modernism, London: Thames \& Hudson

Davies, M. L. (1980) Visual Design in Dress, London: Prentice-Hall

Entwistle, J. (2000) The Fashioned Body: Fashion, Dress and Modern Social Theory, Cambridge, USA: Polity Press

Gombrich, E. H. (1995) Shadows: The depiction of cast shadows in western art, London: National Gallery Publications

Gordon, J. (1999) Private consultation with Jackie Gordon, Software training consultant at Lectra Systems, NTU, Jan 1999

Harris, J. (2000) Surface Tension: The Aesthetic Fabrication of Digital Textiles (The design and construction of $3 D$ computer graphic animation), PhD Thesis, R.C.A. Harrison, C. (2000) Abstract Expressionism, in Stangos, N. Ed (2001) Concepts of Modern Art, London: Thames \& Hudson

Hepworth, B. (1966) Drawings from a Sculptors Landscape, London: Cory Adams \& Macay

Lansdown, J. (2002) Some Trends in Computer Graphic Art, in Mealing, S., Ed (2002) Computers in Art, Second Edition, Bristol: Intellect

Maeda, J. (2000) Maeda Media, London: Thames and Hudson

Riisberg, V. (2003) Lecture, Department of Textile Design, Nottingham Trent University, 21/5/03

Sacilotto, D. (1982) Photographic Printmaking Techniques, New York: Watson Guptil Publications

Stickley, P. (2001) Private conversation with Dr Paul Stickley, CADE, Glasgow School of Art, 12/4/01

Watts, A. (1976), Tao: The Watercourse Way, Great Britain: Jonathan Cape

Weitemeier, H. (1995) Yves Klein (1928-1962) International Klein Blue, Koln: Taschen 


\section{Chapter 6. Design Synthesis: The Simultaneous Design Method}

INTRODUCTION

6.1. SYNTHESISING PHYSICAL AND COMPUTERISED DESIGN METHODS6-2

6.2. THE SIMULTANEOUS DESIGN METHOD ............................................6-5

6.2.1. Aims of the Continued Investigation .............................................. 6-6

6.2.2. The Design Collections...................................................................6-7

6.3. COLLECTION 1: SCULPTURAL BIAS .................................................... 6-7

6.3.1. Design Intentions............................................................................6-8

6.3.1.1. Cord Tunics: Process...................................................................6-9

6.3.2. Re-shaping the garment in accordance with the print imagery........... 6-11

6.3.2.1. Reflections..............................................................................11

6.3.3. Vine Tunics: Intentions ...................................................................6-11

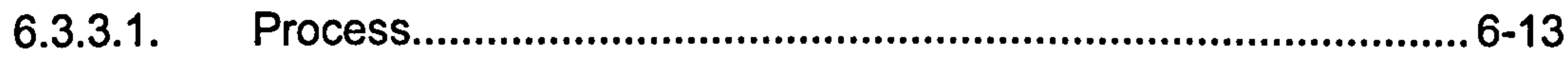

6.3.3.2. Stretching and re-colouring ...................................................... 6-13

6.3.3.3. Printed outcomes.................................................................... 6-16

6.3.3.4. Reflections............................................................................. 6-16

6.3.4. Shadow Tunic: Intentions ................................................................ 6-18

6.3.4.1. Process: Capturing the effect of light on cloth .............................. 6-18

6.3.4.2. Transposing Trompe L'oeil Pleats............................................. 6-18

6.3.4.3. Printed outcome........................................................................6-20

6.3.4.4. Reflections............................................................................. 6-20

6.4. COLLECTION 2: ARCHITECTURAL BIAS.............................................. 6-23

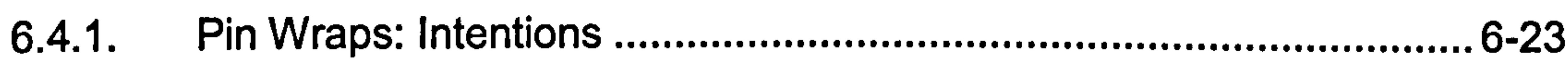

6.4.1.1. Pin Wraps: Process ..............................................................6-24

6.4.1.2. Pleat Simulation......................................................................6-24

6.4.1.3. Printed Outcome..................................................................... 6-27

6.4.1.4. Pin Wrap Skirts: Reflections................................................... 6-32

6.4.2. Win Dress: Intentions and Process................................................ 6-32

6.4.2.1. Digital Patchwork ........................................................................ 6-35

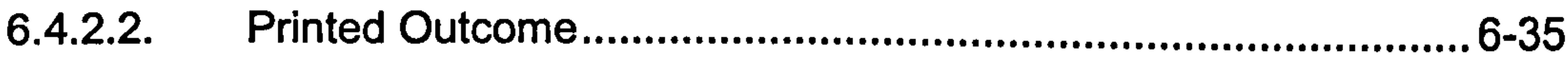

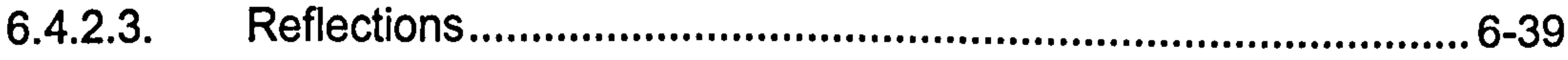

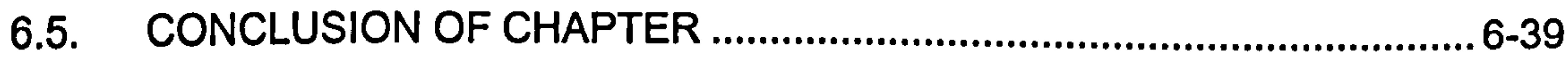

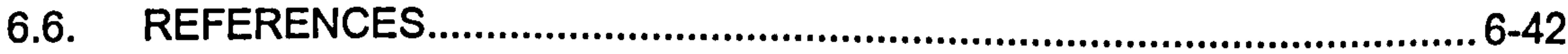




\section{INTRODUCTION}

The design experimentation documented in Chapter 5 led to the formulation of a simultaneous method of designing printed garments. This chapter begins by discussing the philosophy behind this approach to printed garment design and how it evolved from a desire to synthesise 'print' and 'cut' through manual and digital crafting techniques. The idea of approaching CAD/CAM as a method of digitally crafting textiles, in a manner that is empathetic with existing textile practices is discussed. The novel combining of manual and digital technologies enlisted in the Simultaneous Design Method are documented in 6.3. The method builds on Delaunay's practice of creating Tissues Simultané, by not only considering the design of the textile in relation to the shape of the garment, but by also considering the equation of image and cloth in accordance with the 3D form.

The Simultaneous Method is adopted as a way of creating a series of innovative printed pieces that investigate how sculptural and architectural forms can influence the configuration of printed imagery. The Method is also explored as a possible way of approaching the traditional 2D practice of integrating printed textiles with garment shapes, from a new 3D starting point. The potential for CAD/digital printing to be employed to create pioneering textile imagery that articulates the form in an original manner is also practically explored.

The Design Collections describe and illustrate the practical application of the Simultaneous Method in relation to a series of crossover shapes with Sculptural and Architectural bias. The resulting 'cyanoforms' explore the correlation between the spatiality of a garment shape and its corresponding draped or folded patterning. The collections investigate the role of the form as a positive, defining influence within the designing process. Design intentions, process and outcomes are described and illustrated, followed by analysis of the new visual qualities and potential design strategies that arose from applying a radical 3D modelling perspective to printed garment origination. The role of CAD as a tool for integrating and digitally translating manually crafted pieces is discussed. CAD is also used as a medium to aesthetically fabricate innovative designs, presenting new dialogues between print, garment and form.

\subsection{SYNTHESISING PHYSICAL AND COMPUTERISED DESIGN METHODS}

The Simultaneous Design Method, described in 6.3, evolved from an intuitive response to the fundamental aim of the research to "investigate innovative approaches to print/garment integration using CAD' (1.4). In common with other designer-makers who 
received their formative training in a 'pre-CAD' environment, I embarked upon the practical aspect of the research, equipped with 'physical designing and making skills' (Harris 2000). Consequently, tacit knowledge of the hand printing, dyeing, cutting and sewing of cloth formed an integral part of my skill base and designer psyche. It therefore seemed natural for me to combine knowledge of physical crafting methods with CAD/CAM, rather than seek to replace such skills completely.

The tacit nature of designers' knowledge, the indefinable nature of most design problems and the empirical problem solving techniques employed by many designers do suggest that design practice is largely based on experience and experimentation rather than the application of a conscious theory (McCullagh 2000: 47).

During the latter stages of my PhD research, I became aware that the organic approach that I had adopted towards new and existing technology was symptomatic of the 'quiet revolution' going on in the applied arts, as discussed at the Pixel Raiders ${ }^{2}$ symposium in 2002. As the convenor, Mike Press stated 'there has been a shift in practice, with makers raiding new processes and using technology to shape the work they create. This, in turn, extends their making vocabulary.'

My experimentation with both manual and computerised design methods had reinforced a personal preference for the 'hand made' or 'accidental' mark, leading to the adoption of the cyanotype process. This method of image creation combined the mechanical properties of photography with the serendipitous effects of dyeing (5.7). The early work had led to a re-evaluation the role of CAD within the practice, as initially I had imagined it to offer a 'magical' design formula that was somehow superior to existing methods. As Harrod (2002) observed 'there had been a belief that everything not transferable to the language of the computer would be left behind, but this has not proved to be so.' Following investigation into a variety of computer graphic software, I no longer viewed (or feared) CAD as an: 'undefined', 'mechanical' 'it', but rather as a way of extending and developing my existing skill base (Pirsig 1974: 16).

The boundaries between what I had perceived to be 'hand' and 'computerised' techniques were blurring. This had occurred chiefly as a result of the development of the Ribbon Tunic (5.4) which had enabled me to create a bridge between manual and CAD methods, and the digital printing of the final garment (5.5). As I engaged more fully with CAD, by developing new pieces such as Tunic 1 and Water Pleat (5.4.5), I began to comprehend the possibilities for simulating, exaggerating and enhancing

\footnotetext{
${ }^{1}$ McCullagh continues by arguing that the reason why design is generally bereft of theory is 'not a result of its inherent complexity but because it is in the early stages of its historical development'.
} 
physically modelled cloth effects, such as pleating, twisting and pleating through employing draping and other rendering techniques.

I now appreciated that with practice I could experience 'the pleasurable action of making' known as 'flow', ${ }^{3}$ by digitally crafting textile designs using CAD in a manner that was as intuitive, consuming and rewarding as the physical making process. The main difference between 'manually' and 'virtually' crafting designs lay in the loss of 'touch', leading to a strong reliance on tacit knowledge and imagination concerning the behaviour of cloth. According to Shillito (2002) ${ }^{4}$ these material skills could soon be enhanced by 'haptic' systems and multi-sensory applications, but in the meantime I was prepared to rely on my 'eyes instead of my fingertips', to visually 'feel' the fabrics that I was creating (Davison 2002). ${ }^{5}$

Designers in the clothing and textile industry are constantly reinventing existing processes and products by enlisting new technologies; the fusion of the archaic with the cutting edge often leading to the most imaginative outcomes (Karol 2003). ${ }^{6}$ Vibeke Riisberg's design method is rooted within the parameters of graphic software, which she uses to originate and develop geometric patterned textiles. The interpretation of these designs onto cloth sometimes involves what she refers to as 'low tech' methods such as hand screen and discharge printing techniques, resulting in a print with a tactile appearance similar to Shibori (Riisberg 2003). Issey Miyake's design philosophy is based on a strong belief in the value of traditionally 'hand-made' cloth and how 'computer technology and human imagination' can be added to such craft to make clothes that resonate with the contemporary world (Rudge 2001: 22). Since 2000, the $A P O C$ has been the embodiment of this ethos and according to Miyake has 'transported craft into the $20^{\text {th }}$ century' (Ibid).

Printed garment design is generally practised within the commercial constraints of the fashion and textile industry. Having been freed from these particular pressures I was inspired by practitioners such as Riisberg, Miyake and others to employ the traditional and CAD technologies at my disposal to devise an 'intelligent making' design strategy.

\footnotetext{
2 Pixel Raiders: Applied artists and digital technologies, Victoria and Albert Museum, 19 March, 2002.

3 Term attributed to Mihaly Csikszentmihalyi (1991) in Gale and Kaur (2002: 69).

${ }^{4}$ At Pixel Raiders, the jeweller Anne Marie Shillitoe discussed the Tacitus research project into the development of haptic and multi-sensory computer applications for applied arts and design. See http//:www.eca.ac.uk/tacitus.

${ }^{5}$ During her MA study at NTU in 2002 the textile designer Nicola Davison developed innovative software that enables designers/buyers to appreciate different textile qualities through the computer mouse.

${ }^{6}$ Mike Karol of the Blueprint Group made a similar observation when discussing the combined use of origami techniques with technical textiles to create made-to-measure bandages.
} 
A notion of intelligent making emerges from the literature that is a mix of formal knowledge, tacit knowledge, physical and mental skill, contextual awareness, innovation and personal creative autonomy. These are applied to a practice that involves a skilful achievement of relevance in identifying an objectified focus for the craft process, invention of concepts, forms and techniques, an appropriate expression, the exercise of judgement, skills in construction and presentation (Press and Cusworth 1997: 5).

It was my intention to explore a 3D approach to the integration of textile prints with garment shapes by synthesising manual and digital crafting techniques. The following section describes the method that was adopted to achieve this aim.

\subsection{THE SIMULTANEOUS DESIGN METHOD}

Following analysis of the creation of the Ribbon Tunic (5.4.3), I devised a hybrid system for creating printed garment prototypes by enlisting a range of manual and computerised technologies. The Simultaneous Design Method was comprised of three stages:

\section{Stage 1: Garment Shape and Print Origination}

1. Garment manually, modelled on the dress stand in 3D at full-scale.

2. Toile digitised into Modaris (Lectra), adjusted and flat (2D) pattern created.

3. Plotted as a flat pattern at half-scale and cut in suitable toiling fabric.

4. Pieces sensitised and joined at seams. Toile on half stand for 3D print origination.

5. Cyanoform (blueprinted toile) appraised in 3D on stand.

\section{Stage 2: Printed Garment Development using CAD}

6. Half-scale cyanoform deconstructed. 2D pieces scanned into Prostyle.

7. Scanned pieces of the cyanoform re-aligned with original garment contour (imported from Modaris). Or

7a. Pattern pieces re-shaped according to manifstation of blueprinted imagery.

8. Print-filled garment shapes manipulated in CAD.

9. Final design saved at full-scale as Tiff file for digital printing.

\section{Stage 3: Garment Production using CAM}

10. Full-scale garment design digitally printed onto required substrate.

11. Printed garment laser or hand cut.

12. Printed garment constructed using appropriate CAM technology.

\footnotetext{
7 Some of the fabric and printing on a Stork Amber printer, was sponsored by Lectra Systems.
} 
As outlined in the Method, Stage 1 covered the germinal stages of print and garment modelling, synthesised through the creation of the cyanoform.

Stage 2 represented the pivotal design stage of realigning the blueprinted garment shapes with the original pattern contour using integrated CAD software. CAD could also be used to alter the garment shape and/or develop the print imagery to create other innovative design outcomes.

At the time of devising the Simultaneous Method, all aspects of Stage 3 were deemed possible but in the event digital fabric printing was undertaken in association with handcutting and machining, due to issues of accessibility and practicality.

The innovative aspects of the Simultaneous Design Method (SDM) were centred on the combined use of manual and digital design technologies and how these could be applied in parallel to create new strategies for printed garment and printed textile design. In common with much practice-led, PhD research from the past 5 years, the SDM constituted a means of investigating the possible creative benefits of CAD/CAM technology, on an under-researched design specialism. In line with recent findings regarding other practice-led research, the inclusion of physical making skills within the SDM were considered to be 'an essential contribution to the future development of digital imaging processes' (Harris 2002).

\subsubsection{Aims of the Continued Investigation}

Having established a method of print/garment integration that encompassed manual and digital crafting methods, the SDM was applied to a series of crossover/morphic shapes which were treated sculpturally and architecturally, in terms of patterning strategies. The aims of the continued practical investigation were:

1) To create innovative, printed textiles/garments by designing from a 3Dmodelled, perspective.

2) To investigate practically the influence of sculptural and architectural garment spatiality on printed patterning.

3) To highlight the possible advantages of adopting a simultaneous design approach to create integrated printed garments. 
4) To experiment with the possibility for creating illusionistic-style printed textiles using CAD.

5) To explore the creative/translation potential of digital fabric printing.

The issues listed above were believed to be important contributing factors for developing new, more closely integrated design strategies for creating printed garments and printed fashion textiles. The five criteria were considered to varying degrees through the creation of two design collections.

\subsubsection{The Design Collections}

The purpose of the design collections ${ }^{9}$ was to explore the fundamental relationship between cloth, surface pattern and the form. The physical relating of different cloth shapes to the form provided the key inspiration for the designs. The task of creating fashion prints for the designer womenswear market was undertaken with the aesthetic, design requirements of a particular group in mind. ${ }^{10}$ Having explored the potential for modelling imagery in the round I now viewed printed textiles as three-dimensional surfaces that interfaced with and enhanced the form. This novel consideration of the 'end-use' of the designs effectively defined the means of design production.

Subsequently the Sculpturally and Architecturally bias collections were created in direct association with the form, as replicated by the (female) dress stand.

The Sculptural and Architectural collections were originated through the application of the Simultaneous Design Method and as such were designed in a 3D to 2D to $3 D$ context. The following sections document the collections in terms of: Intention, Process and Reflection.

\subsection{COLLECTION 1: SCULPTURAL BIAS}

A similar tunic shape was used for each of the five main Sculptural designs as this allowed comparisons to be made between the varying design treatments and subsequent mark making. Tunic 2 had straight side seams to aid print matching and increase the possibilities of re-shaping the garment easily. Following the problems with

\footnotetext{
- Versalis (Lectra) cutting equipment was sourced but it was not possible to use the equipment for a single ply due to the costs involved in operating the systems (4.5).

The term 'collection' is not used in the strict commercial sense, but rather to describe a 'compilation' of Ideas' that could be considered within a Fashion context.

${ }^{10}$ As a designer and wearer of designer clothing for the 25 upwards age group I felt qualified to make such decisions based on my experiential knowledge, and observations arising out of my research into this aspect of the fashion/textile market.
} 
the instability of muslin as a blueprinting substrate (5.4.3), cotton calico $\left(130 \mathrm{~g} / \mathrm{M}^{2}\right)$ was employed as the main modelling material throughout the practice. It was envisaged that the use of a more closely woven, stable structure would distort less easily than muslin and give rise to a more defined blueprints that could present additional design possibilities for future rendering using CAD. ${ }^{11}$ The use of the same fabric quality for both the Sculptural and Architectural collections represented a compromise in the practice, as at the outset it had been envisaged that each archetype would be constructed in a different fabric. However, by employing a uniform substrate, the emphasis of the practice was shifted from focusing purely on the characteristics of fabric 'drape' to the aesthetic correlation between 'fabric shape' and the 'print'.

\subsubsection{Design Intentions}

The intention of the Sculptural collection was to create integrated printed garment and textile designs that explored the notion of print spatiality, raised by Popova's work (3.1). This would be achieved by blueprinting a series of tunics, modelled on the half-scale dress stand. It was intended that the influence of the underlying contours would contribute to the surface patterning by referencing the physiology of the (female) form. Additional surface detail would be introduced by creating a mask through applying a decorative wrapping procedure (5.4.2). The resulting cyanoforms would be records of the effect of light on three-dimensionally, modelled cloth forms in space. This method of print/garment integration represented a further exploration of Delaunay's twodimensional method of simultaneously, designing geometric prints in accordance with geometric garment shapes (3.7).

It was envisaged that the action of circumventing a garment shape by wrapping it with a variety of materials would result in print imagery that embellished the surface through the act of describing the combination of fabric and form. The idea was a printed interpretation of Vionnet's practice of relating surface decoration in accordance to garment structuring devices, as discussed in Chapter 3.2. It was intended that the 'spiralling' imagery resulting from the wrapping technique would visually express the convergence between the garment shape and the contours the form.

Due to the unpredictable nature of natural lighting conditions, ${ }^{12}$ the resulting cyanoforms would be unique time-based pieces that could never be duplicated. The

\footnotetext{
11 The joining of the ethereal linear markings across the seams of the Ribbon Tunic had proved difficult, so it was envisaged that clearer lines would aid this process. It had also been noted that the clarity and depth of colour of a scanned image was diffused when applied as 'texture mapping'.

${ }_{12}$ Although every effort was made to produce all the cyanoforms in similar, 'midday sun' conditions, this was not always possible.
} 
photographic nature of the cyanotype process to recording the effect of light on manually manipulated materials was expected to provide 'evidence of the hand of the maker', in sympathy with a 'deconstructed' approach (O'Neill 2001: 43). The concept of originality, associated with the creation of the 'one-off' artefact, was central to the research objective to produce original design outcomes.

It was intended that the unique visual qualities inherent in these individually, modelled statements would form the basis of printed garment prototypes by using CAD in conjunction with digital fabric printing. The printed outcomes would serve the dual purpose of concluding the designing process, whilst testing the feasibility of combining manual and CAD/CAM technologies as a method of craft-based production (Bunnel 1998). It was intended that the cyanooforms would also be developed as trompe l'oeilstyle designs, to be viewed as 'sculptural' textiles in their own right, or be integrated with alternative garment shapes, to insinuate the illusion of sculptural form.

\subsubsection{Cord Tunics: Process}

A toile of Tunic 2 was cut at half-scale, sensitised, pinned, placed on the half-stand and wrapped with cotton cord and exposed to sunlight. ${ }^{13}$ The visual qualities of the resulting cyanoform, Cord T2 (Fig.6-A) varied distinctly from the earlier Ribbon Tunic. The change in substrate from muslin to calico had resulted in a more stable template to work with, but at the expense of the mark making, which presented more contrasting, opaque areas of blue and white patterning that were less interesting visually.

A second tunic was cut and treated similarly, but with greater consideration of how the cloth was distributed around the form and how the cord was manipulated. The treatment resulted in slightly more complex mark making, as illustrated in Figure 6-B. Both Cord T2 and T3 lacked the subtle, variegated effect of the Ribbon Tunic, but the clarity of the designs enabled the print imagery to be joined across the side and shoulder seams more easily. Whilst appraising the 3D printed characteristics of the piece it occurred to me that it should be possible to cut the toile into other pattern shapes, dictated by the manifestation of the surface print. This idea built on design issues raised by the Paper Dresses (5.2.2).

\footnotetext{
${ }^{13}$ The toile was exposed for 20 minutes, through a rotation of 360 degrees, to expose the front, right, back and left side of the piece for 5 minutes each.
} 

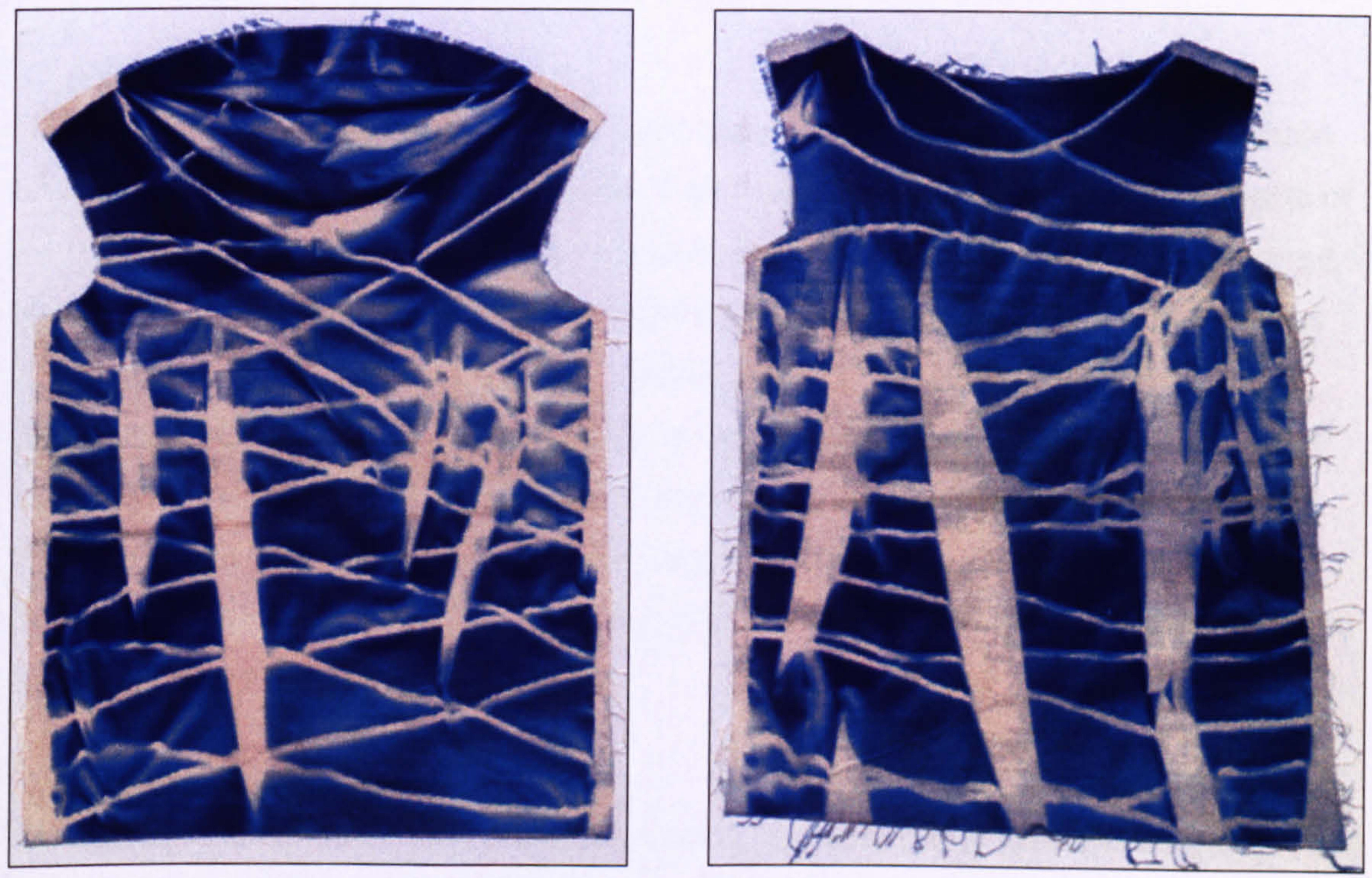

Figure 6-A Cord Tunic 3 front

Figure 6-B Cord Tunic 3 back 


\subsubsection{Re-shaping the garment in accordance with the print imagery}

In order to re-shape Cord T3 without cutting the original, photocopies ${ }^{14}$ were made of the front and back pieces and a paper toile was constructed on the half-stand. The toile was marked and cut along the spiral, linear patterning created by the cord, resulting in a new three-piece (printed paper) pattern (Cord T3a). The experiment was repeated by cutting along other routes that the cord had followed around the toile, to create one and two-piece patterns that resembled long printed strips (Cord T3b \& 3c) (Fig 6-C).

\subsubsection{Reflections}

The spatial influence of the sculptural, tunic shape was evidenced by the blueprinted folds of cloth in the neck and waist areas ${ }^{15}$ and represented the most 'fluid' aspects of the design. The Cord Tunics demonstrated how a printed textile could be engineered to permeate the surface of a garment in three dimensions, by adopting a simultaneous design approach. The continuous, directional flow of the linear markings within the garment shape, enabled the shape to be re-cut to create novel, spiral-seamed forms based on the configuration of the print. The idea represented the ultimate textile-led (3.5) approach, and a reversal of traditional garment-led (3.6) practice, where the design equation is governed by the shape and structure of the garment as opposed to the graphic characteristics of the print.

The re-cutting of Cord T3 was carried out using (printed) paper patterns as guides, but it was envisaged that a similar approach could be adopted using CAD. ${ }^{16}$ Following the realignment of the printed piece with the original garment contour it would be possible to deconstruct and then reconstruct new printed pieces by strategically 'cutting' and 'pasting' on-screen. The reconfigured pieces could conceivably be digitally printed onto cloth as economically as conventional garment shapes, leading to the creation of novel, spiral-seamed, garments. Despite the experimental nature of the procedure, the concept of re-shaping a garment in relation to print placement has considerable potential when originating prints from a 3D perspective.

\subsubsection{Vine Tunics: Intentions}

Following the creation of the clean, linear-style, Cord prints I proceeded to investigate how a more decorative form of wrapping would interact with the tunic shape. Designs

\footnotetext{
${ }^{14}$ Black and white A3 copies were used as issues of 'structure' were the prime focus.

15 The straightening of the seams of Tunic 1 had resulted in extra fabric being introduced to the waist area of the Tunic 2.

${ }_{16}$ As well as performing this task in a dedicated textile package such as Prostyle it was considered that a similar procedure could be carried out using Photoshop, provided the system had enough memory.
} 

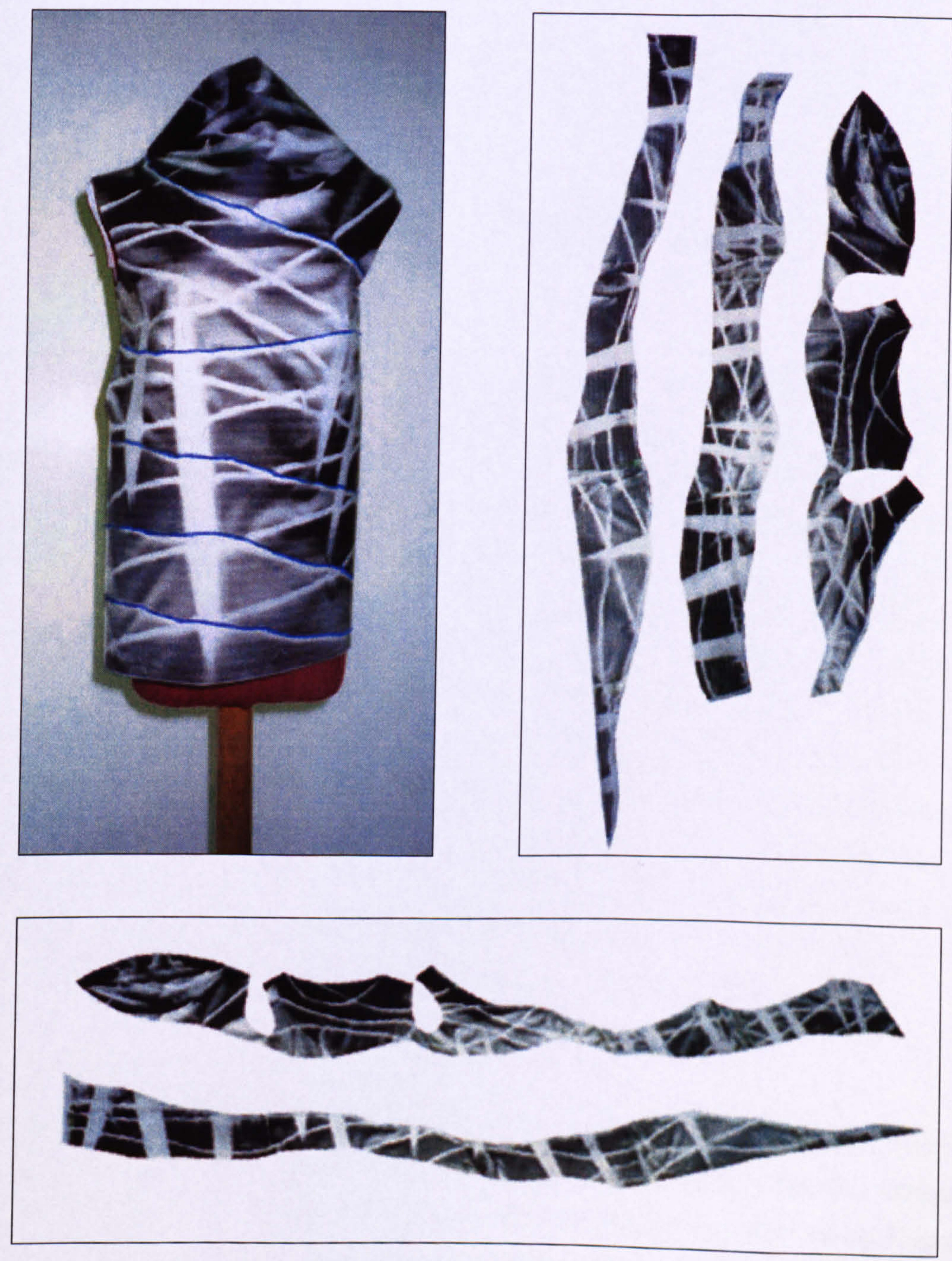

Figure 6-C Re-cutting paper toile and resulting new pattern shapes 
featuring flowers (and leaves) were considered for their strong association with 'feminine' design styles (Carlisle 2002: 1-25). Natural elements are traditional blueprinting subject matter, and while I had employed flowers and leaves during the initial practice, I had generally favoured abstract, rather than figurative subject matter. Having redesigned the cyanotype process to suit my own requirements, I considered it important to document visually how these natural elements would be captured in a new, three-dimensional context. I was also interested in the innovative design possibilities that may be achieved by combining the draped female form and flowers, as together these elements represented classic symbols of femininity.

\subsubsection{Process}

In order to introduce greater textural interest and further define the underlying form, I continued to explore the print modelling procedure by first pinning the sensitised toile more closely to the form, ${ }^{17}$ then combining it with a long length of trailing vine. The vine was secured at the left shoulder then crossed the bust diagonally to the waist where it circled down around the hips, then up again to return to the right shoulder (Fig 6-D). Care was taken not to completely mask the pinned structuring in the waist area. Following the 'wrapping of foliage' the toile was exposed, deconstructed and processed in the usual manner, resulting in Vine T4. The process was repeated for the creation of Vine T5, where more detailed patterning was achieved through taking greater care during the pinning and wrapping procedure. The novel combining of impressions of pinned cloth folds, multi-directional foliage and pendulous blossoms resulted in complex textile imagery (Fig.6-E). Vine Tunic 5 appeared to be composed of different images that had been layered together in CAD, but although the modelling involved two stages, the sophisticated detail had been captured in a single action.

\subsubsection{Stretching and re-colouring}

The successful capturing of the three-dimensional characteristics of foliage and folds in Vine $T 5$ had resulted in a decorative surface that left little need for further manipulation in CAD. I assessed the design from a commercial perspective; while the cyan was an attractive colour it was not a current fashion shade, which led to an investigation of fundamental CATD functions to change the colour and scale of the print. The subsequent changes from cyan to magenta ${ }^{18}$ and an inverted green version slightly 'flattened' the imagery, but this was not detrimental to the overall effect. I used the Scaling tool to stretch ${ }^{19}$ Vine $T 5$, which transformed the elements, particularly the

\footnotetext{
${ }^{17}$ Prior to being wrapped, the excess cloth in waist and neck areas of the tunic was pin-tucked to fit the tunic shape more closely to the waist and chest areas of the stand.

${ }_{18}$ The colour was adjusted from blue to purple using the Colour Balance tools in Adobe Photoshop 5.5.

${ }^{19}$ Sections of Vine Tunic 4 were stretched from a ratio of $1: 2$ to $1: 10$ in length.
} 

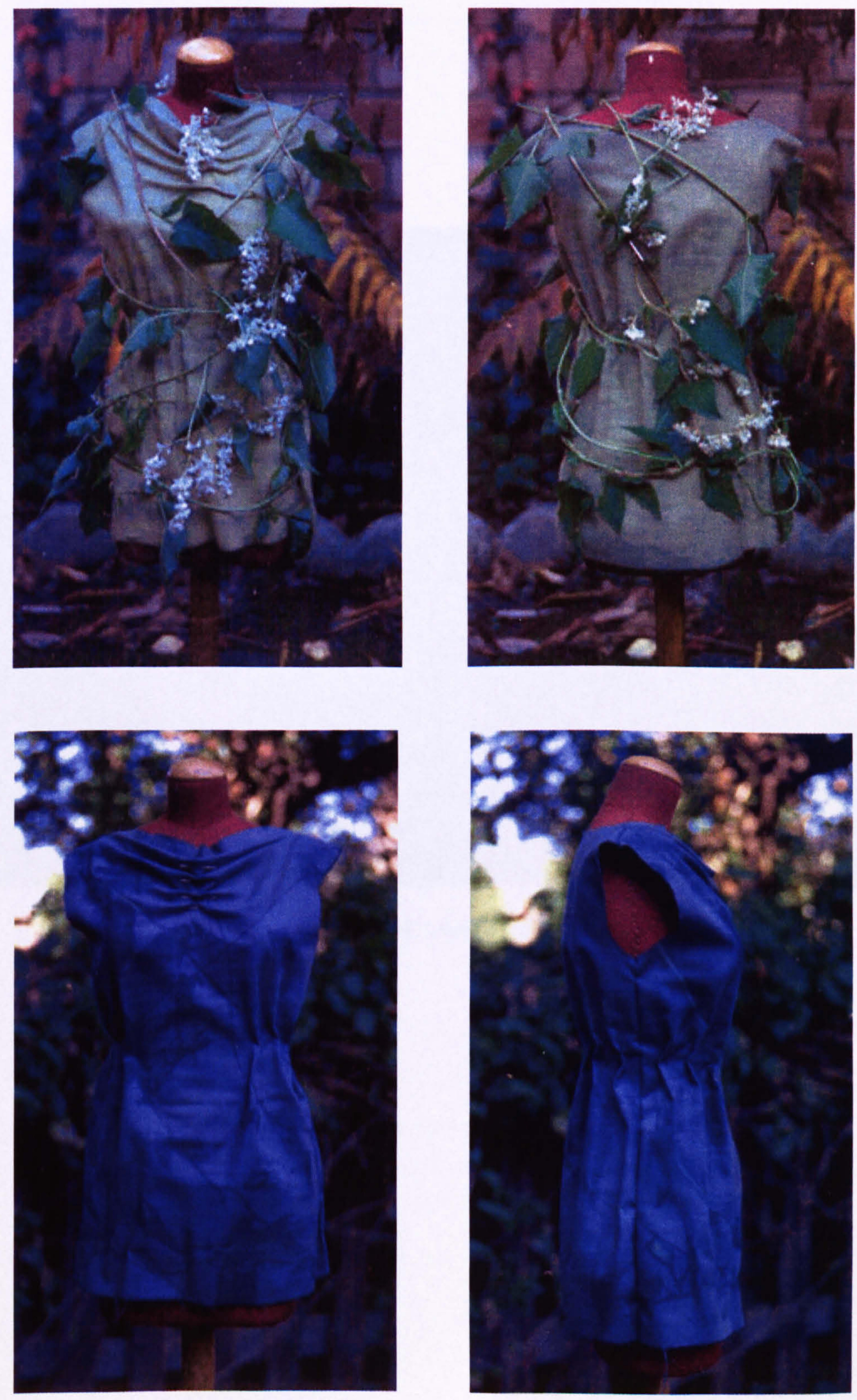

Figure 6-D Process of image capture for Vine Tunics 


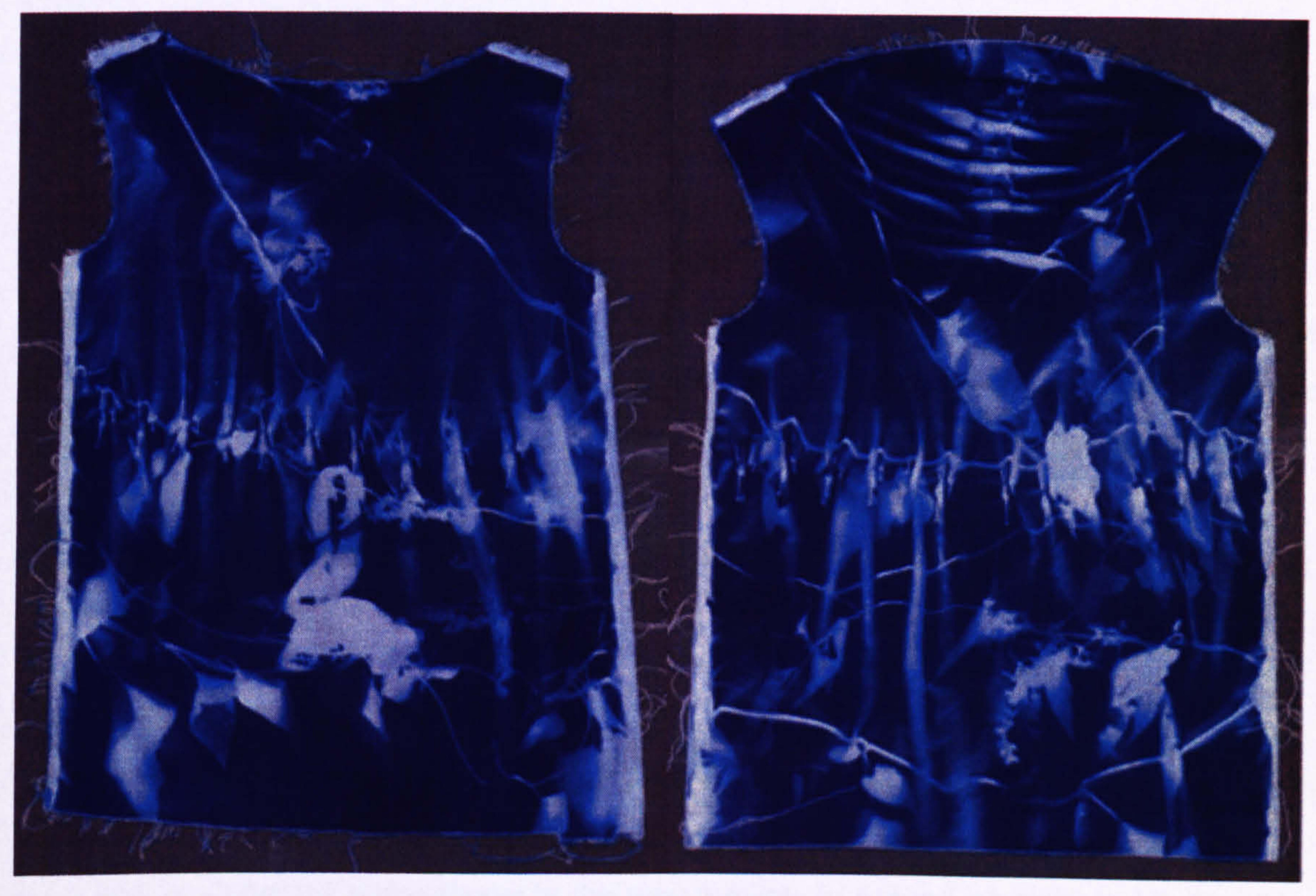

Figure 6-E Vine Tunic 5 
pins, to implausible dimensions and introduced a greater sense of fluidity to the design (Fig.6-F).

\subsubsection{Printed outcomes}

Stretched sections of Vine T5 were printed as part of Test File $8^{20}$ onto cotton jersey and viscose javanaise. The design worked most successfully on the viscose quality, which had a slight sheen that compensated for the loss of iridescence that occurs when translating a backlit screen image onto cloth (5.5.1). The stretching of the design had resulted in a slight reduction of the tonal depth and a diffusion of the quality of the original image. It is widely accepted that the more processes a scanned image is put through, the more visually eroded the image becomes. Digital printing is another stage of erosion, as is the washing process that fixes the printed image to the cloth. Consequently, the digitally printed fabric was much softer in appearance than the digital image. My interest in incorporating the 'notion of wear' (1.7.2) into my designs, made the reduction in clarity interesting rather than disappointing. The printed outcome indicated possibilities for integrating 'faded' and 'worn' effects into garments in a similar to the way that jeans manufacturers incorporate different grades of stonewashing. However, it is important to stress that designers seeking 'clarity' must consider the impact that different stages of rendering and different choices of substrate will have on a design.

\subsubsection{Reflections}

The use of natural elements in a new, 3D context to create Vines T4 and T5 resulted in sophisticated imagery. The multi-layered, structure of the foliage and fauna was captured in a manner more closer to the way it exists in nature, as opposed to being treated as isolated, flattened elements. The prints featured shapes that faded in and out of view as they flowed around the form, intermingling with the pinned folds of the cloth. Evidence of the underlying form was conveyed more 'sculpturally' than in previous examples, through glimpses of the manipulated cloth beneath the leaves in the waist and neck areas. The simultaneous wrapping and modelling procedure had resulted in a unique integration of print and cut that could not have been created by designing in a flat plane. The combining of cloth with natural elements using a 3D method of image-capture raised possibilities for creating personalised, contemporary textiles by draping a stand or individual in fabric and flowers. ${ }^{21}$

\footnotetext{
${ }^{20}$ See Test File 8 on CD.

21 The recording of individuals, particularly women, within 'staged' arrangements was made famous by society photographers such as Madame Yevonde in the 1930's, but a similar approach could inform contemporary, bespoke-style print design.
} 

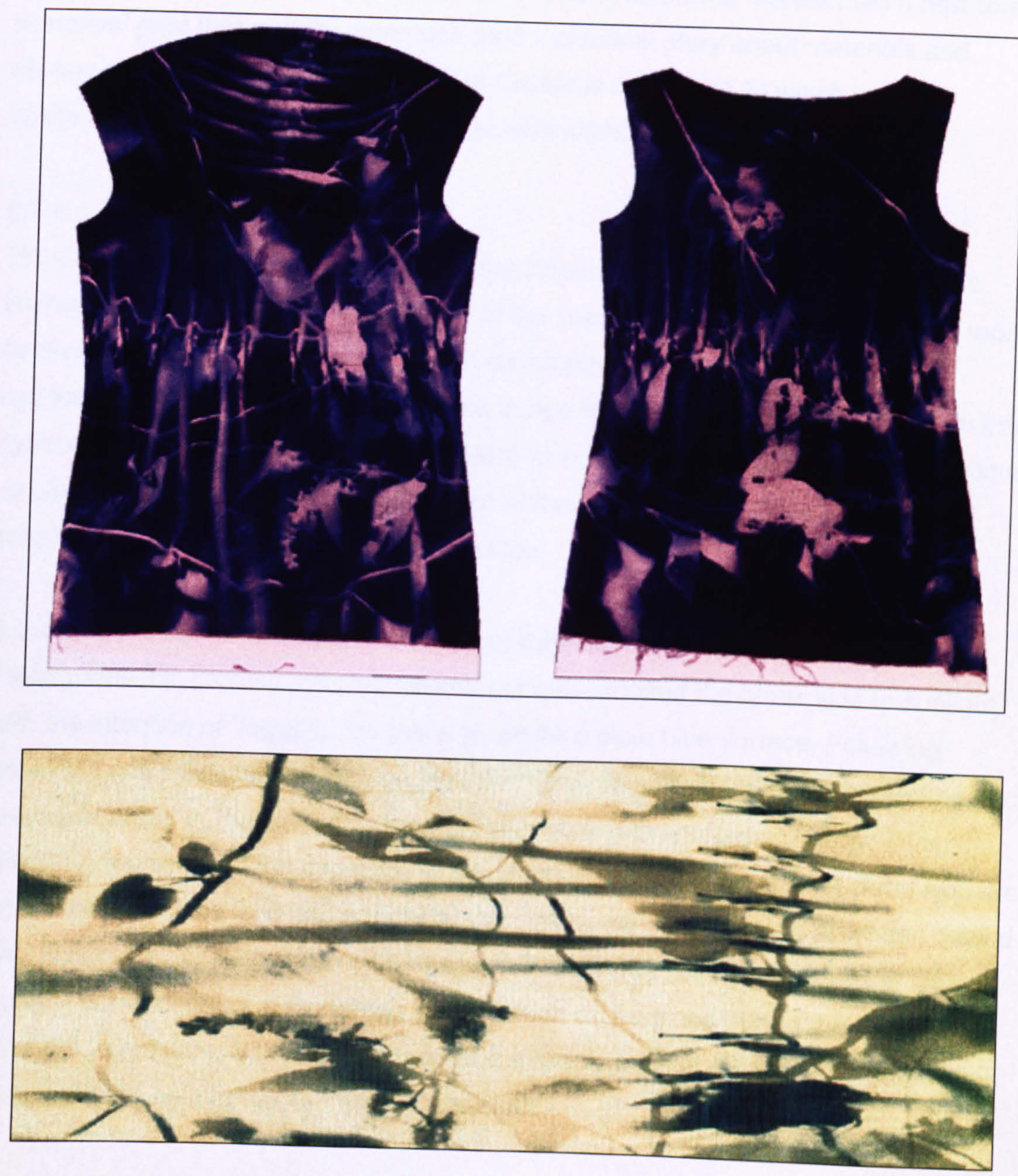

Figure 6-F Rendered versions of Vine Tunic 4 
I was aware at this stage of the research that the emphasis of my textile approach had shifted from a concern with the surface to one that embraced notions of structure. The images of foliage represented 'embellishment' that had been consciously applied to the tunic, whereas the revealing of the pinned folds, creases and seams displayed visual evidence of the creative modelling process. The cyanoforms represented a new form of 'narrative' print that visually communicated a practical story about materials and making, raising parallels with the role of Classical drapery (1.7) which was also designed to fulfil the dual purpose of garment structure and surface detail.

\subsubsection{Shadow Tunic: Intentions}

The Cord and Vine Tunics presented clear blueprints in a mid-tone of cyan. I was interested in increasing the tonal depth of the colour in order to create stronger, more contrasting images. ${ }^{22}$ During the design development of Vine T5, it had been necessary to increase the contrast of the image in CAD. It was my intention to use the cyanoforms as closely to their original state as possible, in order to retain their unique visual qualities. I considered that the face of the cyanoform could be darkened if I sensitised and exposed the inside of the toile.

\subsubsection{Process: Capturing the effect of light on cloth}

Taking Vine T5, I turned the piece inside out and exposed the blank side to sunlight, with the intention of 'fogging' the piece to create a plain blue surface. Following exposure and processing, I was surprised to observe patterns of folds in from the neck and waist areas of the pieces. In theory, the resulting cyanoform, Shadow Tunic 6 (Fig.6-G) represented the capturing of the physicality of light on draped cloth. However on this occasion the toile had not been deliberately manipulated, but had been placed on the stand as a relatively smooth shape. ${ }^{23}$ The trompe l'oeil impressions of folds actually corresponded to the earlier manipulation of the piece during the creation of Vine T5. In practice, Shadow T6 provided visual evidence of this earlier manipulation that had been held in the 'memory' of the cloth.

\subsubsection{Transposing Trompe L'oeil Pleats}

The horizontal and vertical folds of Shadow T6 were a record of the pattern of light on the basic tunic shape. I developed the design in CAD, by investigating whether patterns of drapery, pertaining to specific cloth shapes, could be successfully translated into other garment shapes. Taking a different sculptural garment, Bara Dress, ${ }^{24}$ I proceeded

\footnotetext{
22 I had attempted this earlier by applying two separate coats of the blueprinting chemicals, but this had not 'doubled' the depth of contrast.

${ }^{23}$ Vine Tunic 5 had been exposed, unpinned, developed through washing, dried and ironed.

24 This bias cut dress pattern was kindly provided by Bara Kjartansdottir M.A.
} 


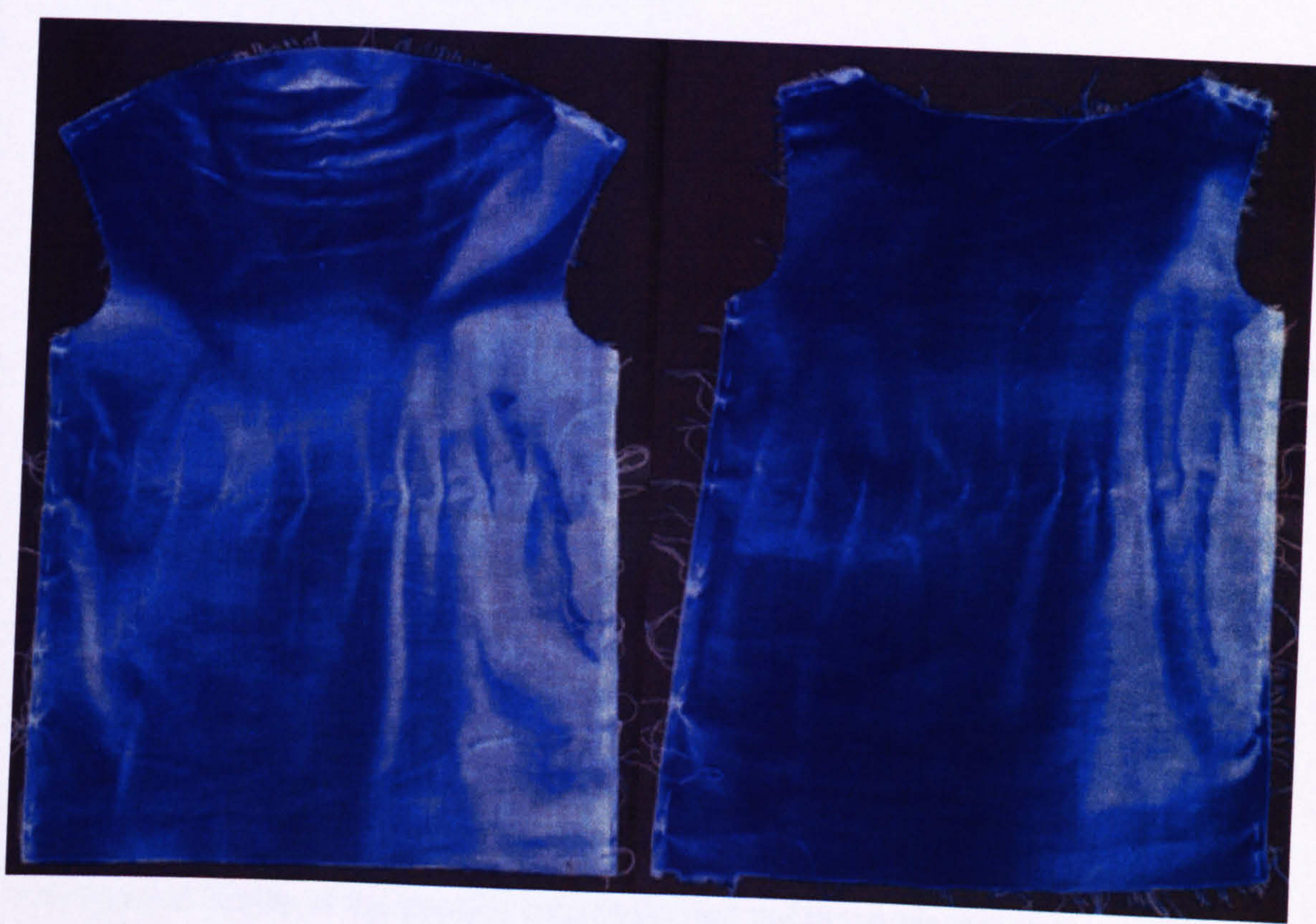

Figure 6-G Shadow Tunic 6 
by integrating visual elements of the Shadow T6 with the new piece. The disparity between the volume of fabric in the proposed garment and the scale of Shadow T6 required that the print be stretched. Additional contours were also incorporated ${ }^{25}$ into the main skirt piece to enable the print to be integrated at an appropriate scale that would be suitable for possible production. ${ }^{26}$ By angling the print at 45 degrees I was able to create $2 D$ and $3 D$ visualisations of the dress that appeared to have been 'printed' on the bias (Fig.6-H).

\subsubsection{Printed outcome}

Shadow T6 formed part of Test Files 2, 3 and 8 and was printed at half and full-scale onto a variety of substrates. ${ }^{27}$ The tests had an important impact on the future research as I was alerted to the pitfalls of creating integrated garment designs at half-scale with a view to printing and fabricating them at full-scale. I discovered that increasing the size of an image by $200 \%$ could not only have drastic effects on the colour and resolution of the image (5.5.2) but on the design concept itself. The ethereal qualities inherent in the half-scale Shadow T 6 were successfully transferred onto cotton poplin at a similar scale. However the translation from a half-scale to a full-scale digitally printed shape was less successful. The main problem lay in the opaque quality of cotton jersey that the design was printed on, which seemed to 'solidify' the draped imagery into a series of large, individual folds, which appeared too large in relation to the human form. Even on the lighter, shinier, viscose, the scale of the imagery appeared out of proportion.

The opaque quality of the printing substrates had not aided the translation process and I decided that a semi-transparent quality with good draping properties, such as viscose organza, could contribute to the illusory style of the design. If impressions of half-scale cyanoforms were to be used as blueprints for full-scale printed garments, it would be necessary to incorporate considerably more of detail into the designs. ${ }^{28}$

\subsubsection{Reflections}

Shadow Tunic 6 was the most innovative design outcome of the Sculptural collection with the trompe l'oeil folds representing a spontaneous impression of the effect of light on cloth. The spatial influence of the tunic and the earlier manipulation of the piece were the sole influences on the mark making. The creation of mark making based on

\footnotetext{
${ }^{25}$ This was undertaken in Prostyle by adding contours to the digitised pattem shape. Digitising could have also been used to indicate the placement of these contours.

${ }^{26}$ It is easy to fill garment contours with prints, which invariably appear effective on-screen or printed out at A4, but by printing swatches of the print design at life-scale, I was able to ascertain what the final the print quality would look like.

${ }^{27}$ Cotton poplin, cotton jersey and viscose javanaise.

${ }^{28}$ I had pre-empted this situation by re-contouring the Bara Dress prior to flood-filling with print.
} 


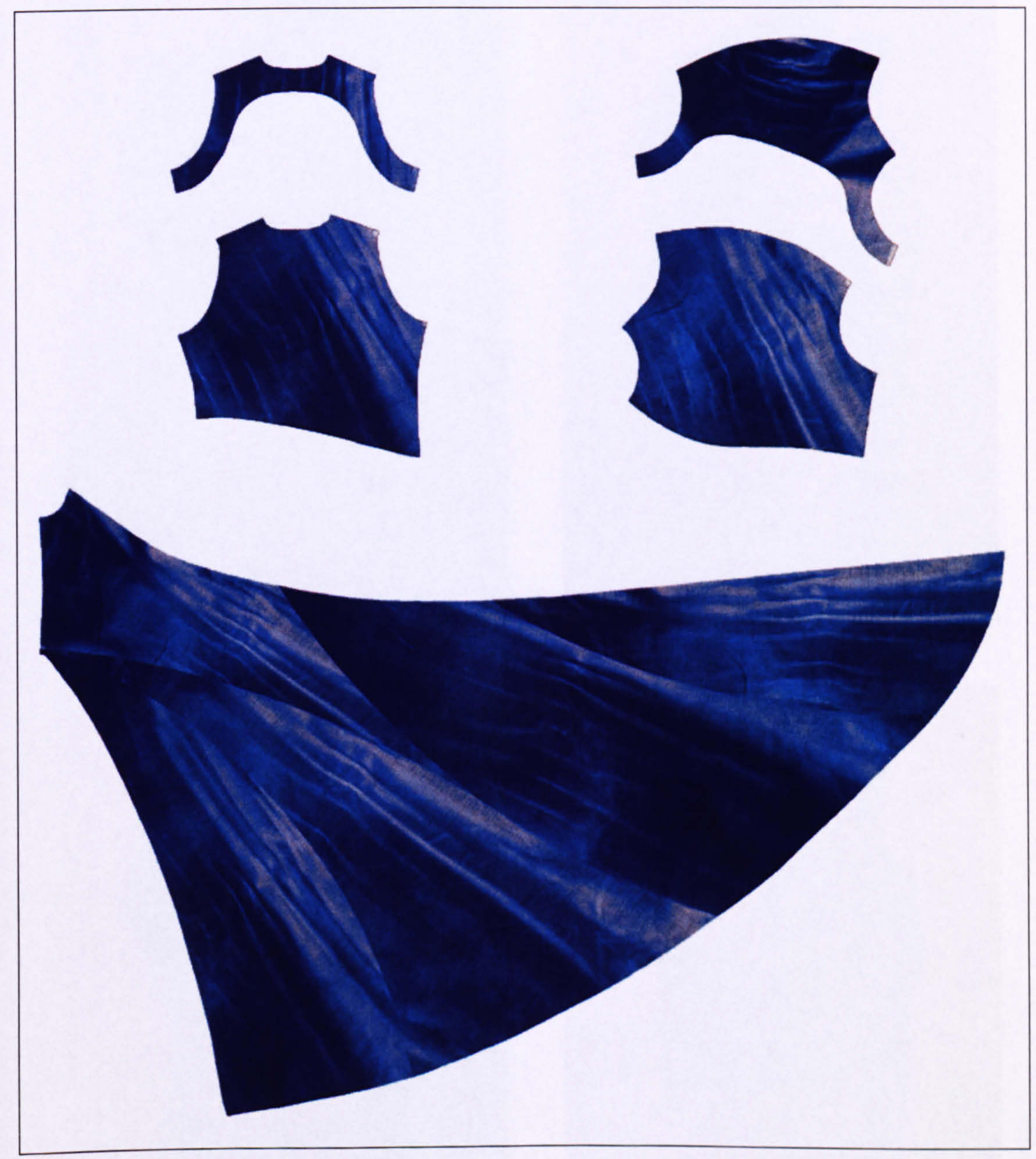

Figure 6-H Bara Dress: 2D print integration with Shadow T5 

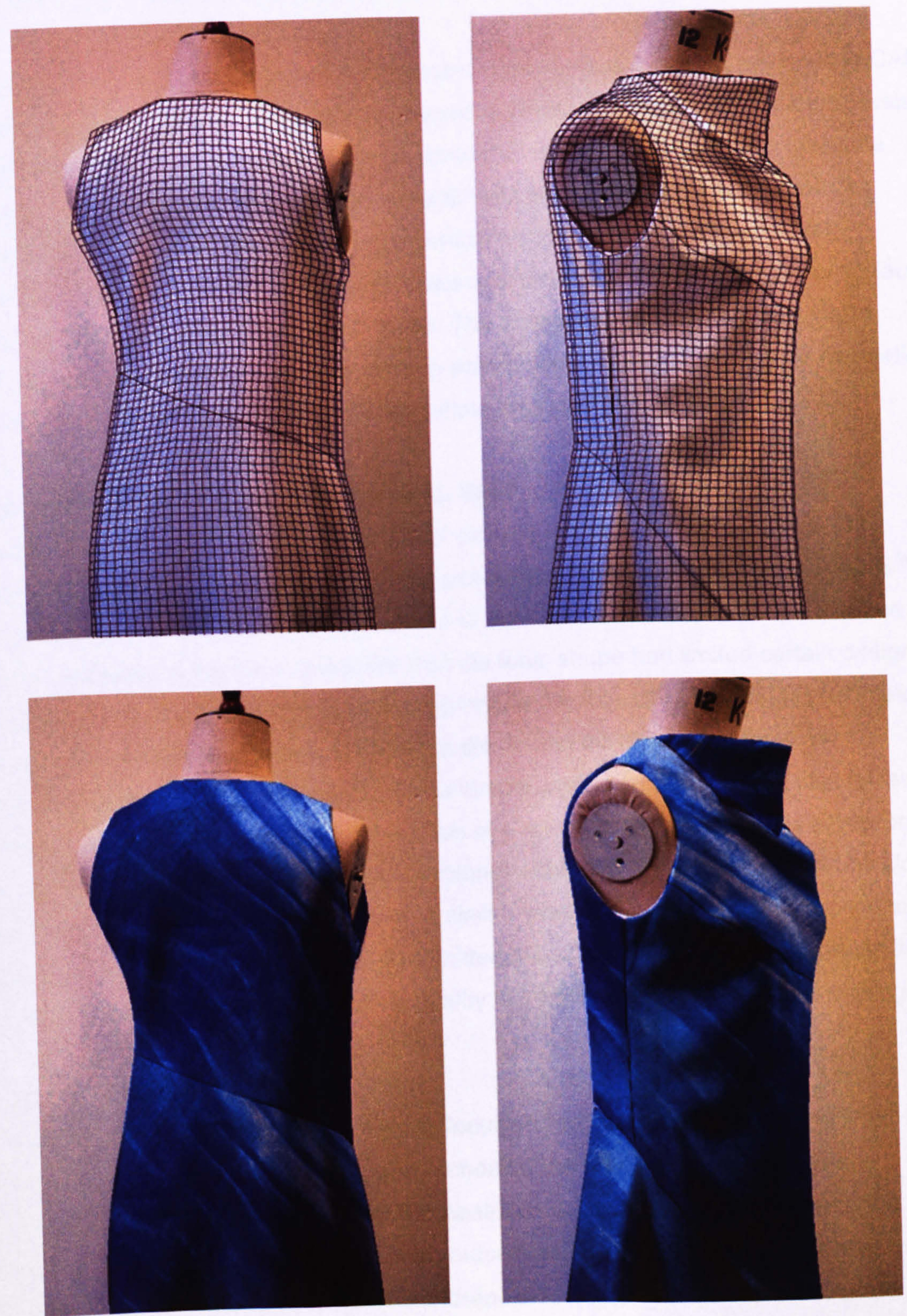

Figure 6-I Bara Dress 3D print visualisation 
the cloths 'memory' of a previous modelling procedure constituted a breakthrough in the practice. As a result Shadow Tunic 6 was a fundamental example of the simultaneous creation of structural and surface embellishment.

The trompe l'oeil folds presented considerable opportunities for being rendered in CAD at improbable angles, to create other illusionistic prints. The digital fabric printing tests established that the design could not be converted directly onto cloth as a full-scale garment, but required further design development prior to conversion and/or more careful choice of printing substrate as a vehicle for translation. Alternatively the outcome could be used deliberately to make a visual statement regarding how surface embellishment is dictated by human scale. The exercise drew parallels with Martin Margiela's experimentation with scaling up dolls clothes, where through their translation to life-scale 'something was lost but something else was gained' (O'Neill 2001).

\subsection{COLLECTION 2: ARCHITECTURAL BIAS}

Designs were created using a rectangle of cloth as opposed to a pre-determined garment shape. The rectangle was more architectural in essence as its dimensions ${ }^{29}$ were based on measurements that related to the form, rather than a shape that had been modelled on the form. It was felt that the tunic shape had limited certain design development procedures that could be explored more fully using a versatile geometric shape. My intuitive design response to the shape and dimensions of the cloth determined the subsequent shaping into a simple wrap-over 'skirt', which was folded and pinned into place and formed the basis of a series of the Architectural cyanoforms. A second shape, Win Dress, was also explored within the collection, to provide a closer comparison with the sculptural Tunics. A similar wrapping procedure was applied to the piece which was cut in both woven and knitted substrates in to further investigate the potential of garment shape and fabric quality to influence subsequent mark making.

\subsubsection{Pin Wraps: Intentions}

The Sculptural collection had evolved to focus on the recording of light on cloth to create textile patterns. The cyanoform embodied the process of surfacing and structuring. The Architectural Collection continued to explore this concept with the intention of providing contrasting design outcomes that practically demonstrated the existence of a correlation between cloth drape and mark making. In the Sculptural pieces the form had been called upon to interact and inform the surface detail of the

\footnotetext{
${ }^{29}$ The original rectangle measured $120 \times 60 \mathrm{~cm}$ at full-scale, $60 \times 30 \mathrm{~cm}$ at half-scale, which enabled the piece to be scanned in two pieces using an A3 input device.
} 
textiles, but within the Architectural collection it would be referenced as a scaffolding structure to support modelled, cloth shapes (3.3).

In order to anchor the rectangle of cloth at the waist (of the stand), it was necessary to pleat the piece around this part of the form. It was decided that a more controlled approach would be adopted, compared with the organic wrapping procedure.

Subsequently, the cloth was folded around the form using pleating and pinning, to simultaneously 'shape' and 'decorate' the cloth. Apart from being supported at the waist, the blueprinted patterning would be a record of the manipulation of a rectangle of cloth in space, as opposed to its interaction with the underlying form. It was envisaged that this style of modelling would lead to more geometric mark making that reflected the design treatment.

\subsubsection{Pin Wraps: Process}

Using a rectangle of calico measuring $120 \times 60 \mathrm{~cm}$, a wrapped skirt was modelled on the dress stand. The shape was fashioned to fit and be supported by the waist with a series of vertically, pinned darts. The front overlap of the skirt was pinned in three horizontal pleats to add surface interest (Fig.6-J). The shaping was copied at half-scale with a $60 \times 30 \mathrm{~cm}$ rectangle of sensitised cloth. The resulting cyanoform, Pin Wrap 1 (Fig.6-K), was imbued with a series impressions of darts, tucks and pin marks that constituted both the surface pattern and provided a visual record of the modelling procedure.

Alternative 'skirts' were created by pleating, pinning and wrapping similar, cloth rectangles in different ways. Pin Wrap 2, was created by shaping the cloth to the waist and hips with a series of vertically pinned pleats that yielded a striped pattern (Fig.6-L). Pin Wrap 3 was pinned both vertically and horizontally to create a chequered effect (Fig.6-M). A square (45x $45 \mathrm{~cm}$ ) formed the basis of Pin Wrap 4 which was pinned to the waist and wrapped with cord in a similar manner to the Cord Tunics. The 'sculptural' treatment resulted in a more fluid result, but the design still lacked the element of flow provided by the volume of the tunic shape. In some senses Pin Wrap 4 represented a 'crossover' print as it combined characteristics of both the sculptural and architectural archetypes.

\subsubsection{Pleat Simulation}

Dealing with a blueprinted, rectangle of cloth during the CAD development stage presented distinct advantages when realigning the print with the pattern contour, as compared with realigning shaped prints/contours. A range of different effects were 

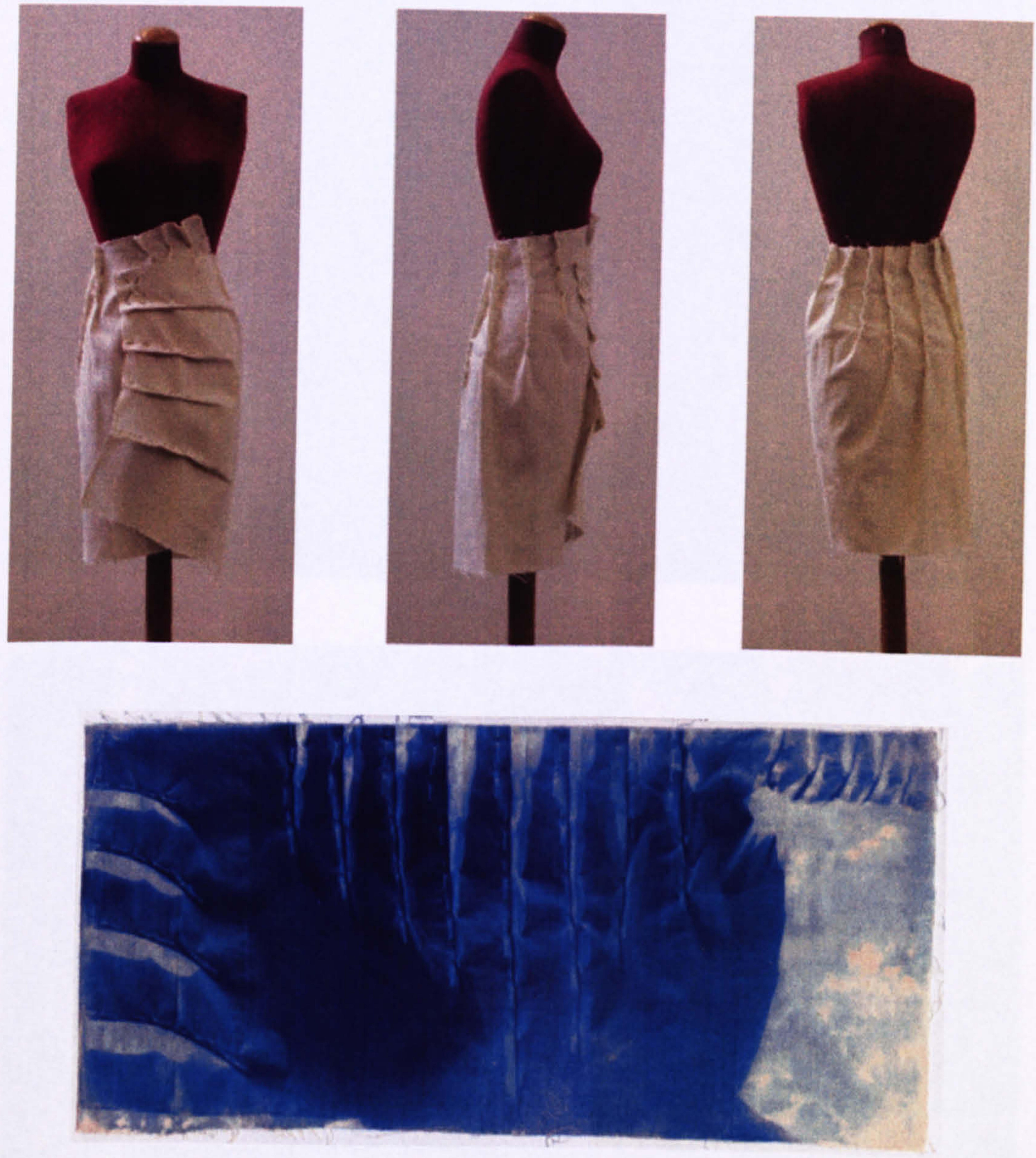

Figure 6-J Pin Wrap 1 calico toile

Figure 6-K Pin Wrap 1 cyanoform 

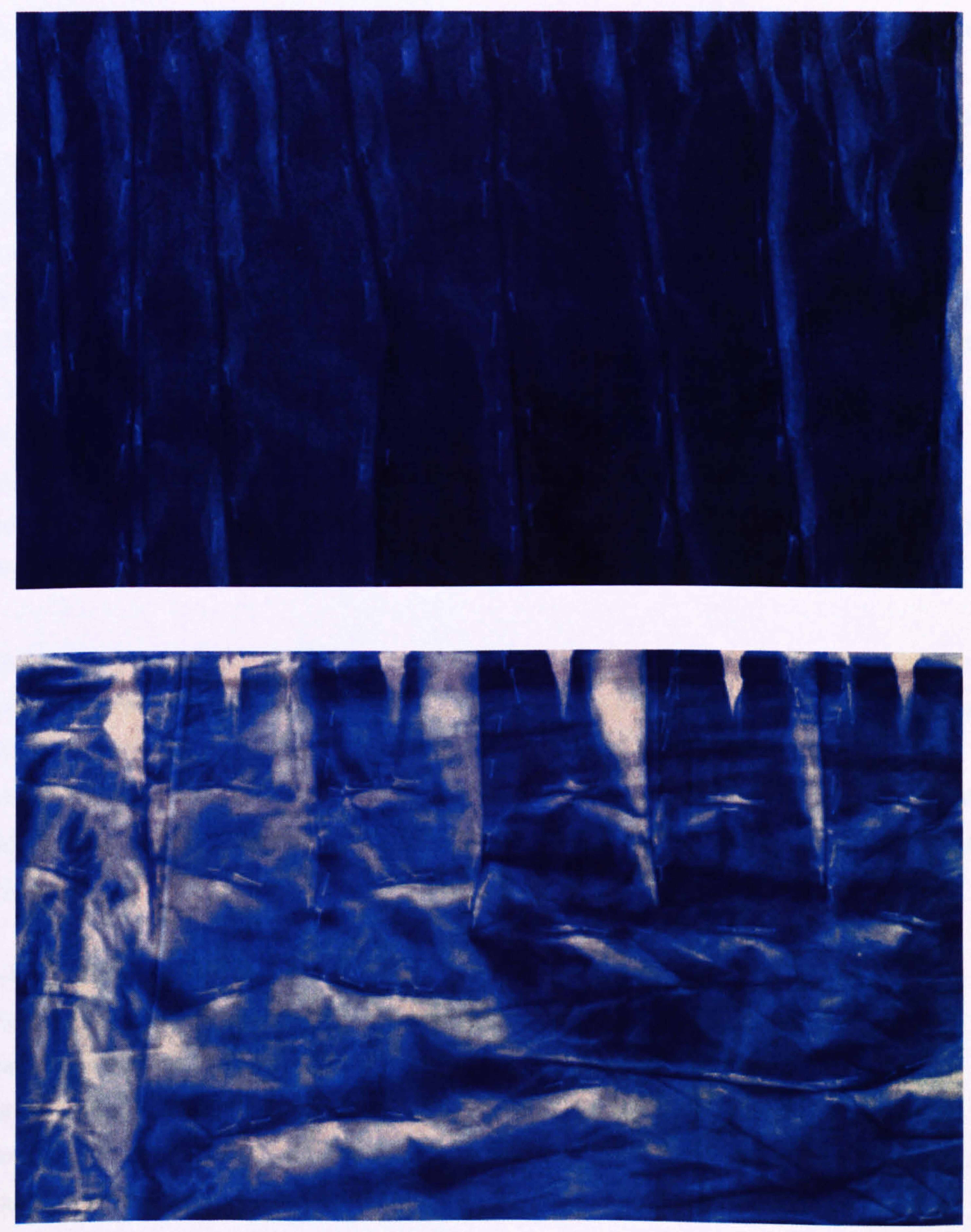

Figure 6-L Pin Wrap 2 section

Figure 6-M Pin Wrap 3 section 
produced through distorting the basic rectangle using the Scale tool to stretch the image. The inversion function was also used to create an alternative, 'negative' image, which interestingly appeared to be more three-dimensional than the original (Fig.6-N).

In order to create an alternative skirt shape, the cyanoform Pin Wrap 1 was re-pinned onto the stand in its original 3D form, with the pins on the inside to create a pleated shape. The piece was digitised as a curved 2D vector into Modaris, to create a simple pattern, Wrap Skirt. The pinned cyanoform was scanned in two halves at $200 \mathrm{DPI}$, then the resulting raster images were joined ${ }^{30}$ and re-aligned with the Wrap Skirt contour. The integrated outcome, Pleated Wrap represented a potential printed garment prototype, which was tested using digital fabric printing (Fig.6-O). ${ }^{31}$ The simulated pleat effect was slightly flattened through the scanning process, but still provided an effective trompe loeil print element. The image was experimented with as a motif through integration at different scales and improbable angles with a series of one-piece garment shapes. The concept of multi-directional, simulated pleats was explored further in association with a circular shape (7.2) for the research project and exhibition Transforming Shape.

The possibilities of re-cutting Pin Wrap 4, in accordance with the manifestation of the print, were investigated using PAD's 3D System. It was possible to visualise the square shape of the skirt, as a tubular, 3D form, but impossible to shape the cloth into the waist and import the engineered print imagery into the shape precisely. However, with help I created a simplified version of the spiral-seamed garment that I imagined (Fig.6P)..$^{32}$

\subsubsection{Printed Outcome}

Pin Wrap 1, Pin Wrap 4 and the Pleated Wrap were printed onto cotton poplin and viscose javanaise, as part of Test Files 2, 3 and 4. The colour and resolution varied between the two substrates; the viscose outputs (Fig.6-Q) were more vibrant and pixelated in appearance than the cotton. These contrasts were related to the chemical reaction of the dyes with the different fabrics, and underpinned the importance of sampling prior to production.

\footnotetext{
${ }^{30}$ The pleated cloth shape exceeded the surface of the A3 scanner, so had to be captured in two halves, then joined in Prostyle.

${ }^{31}$ At half and full-scale in Tests 2 and 4, featured on the CD.

32 Roemarie Goulding helped with this and other visualisations in PAD. The shape was divided more regularly than I envisaged, as it was too difficult to create irregular shaping with the software.
} 

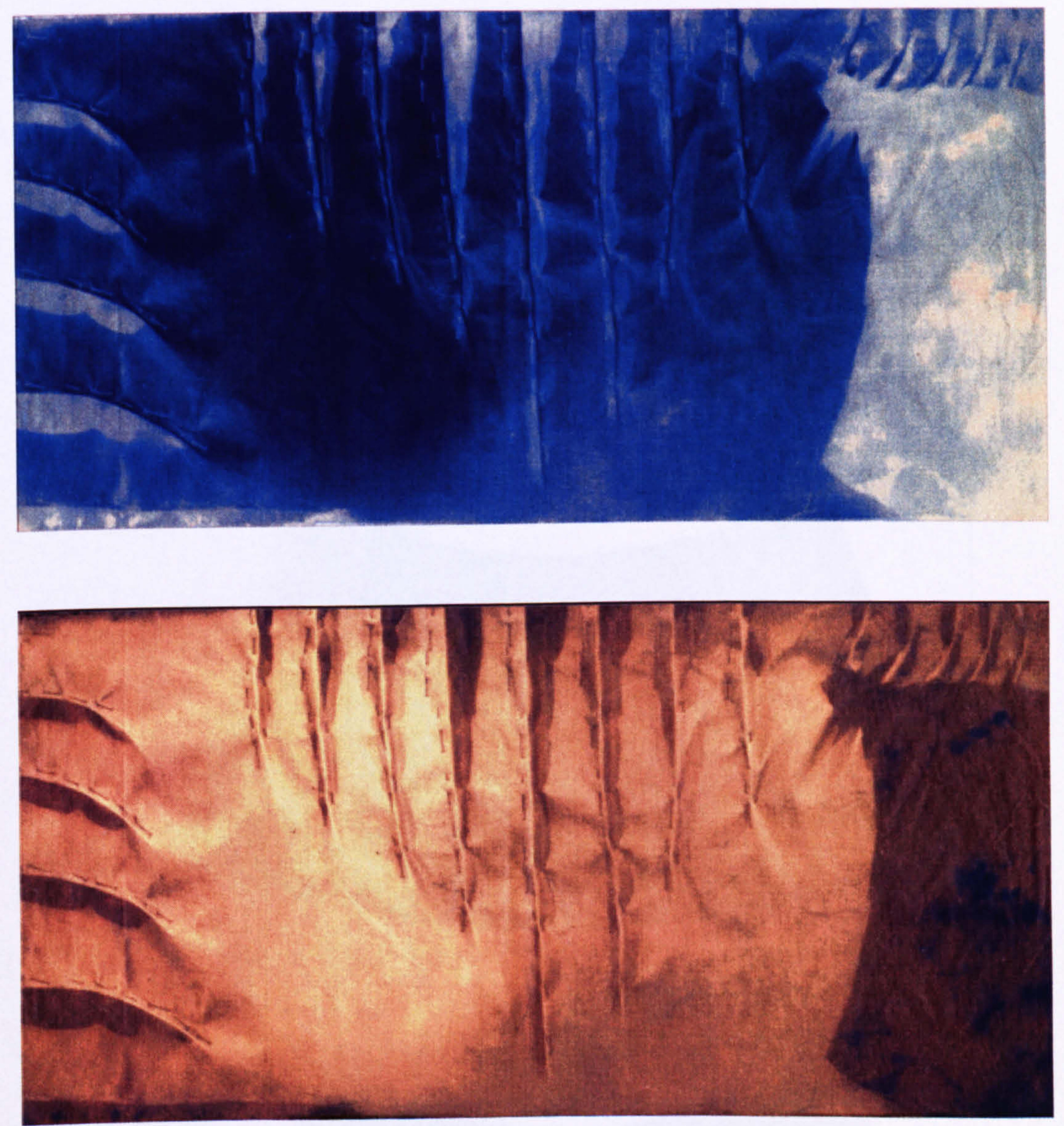

Figure 6-N Pin Wrap 1 aligned with rectangular contour 

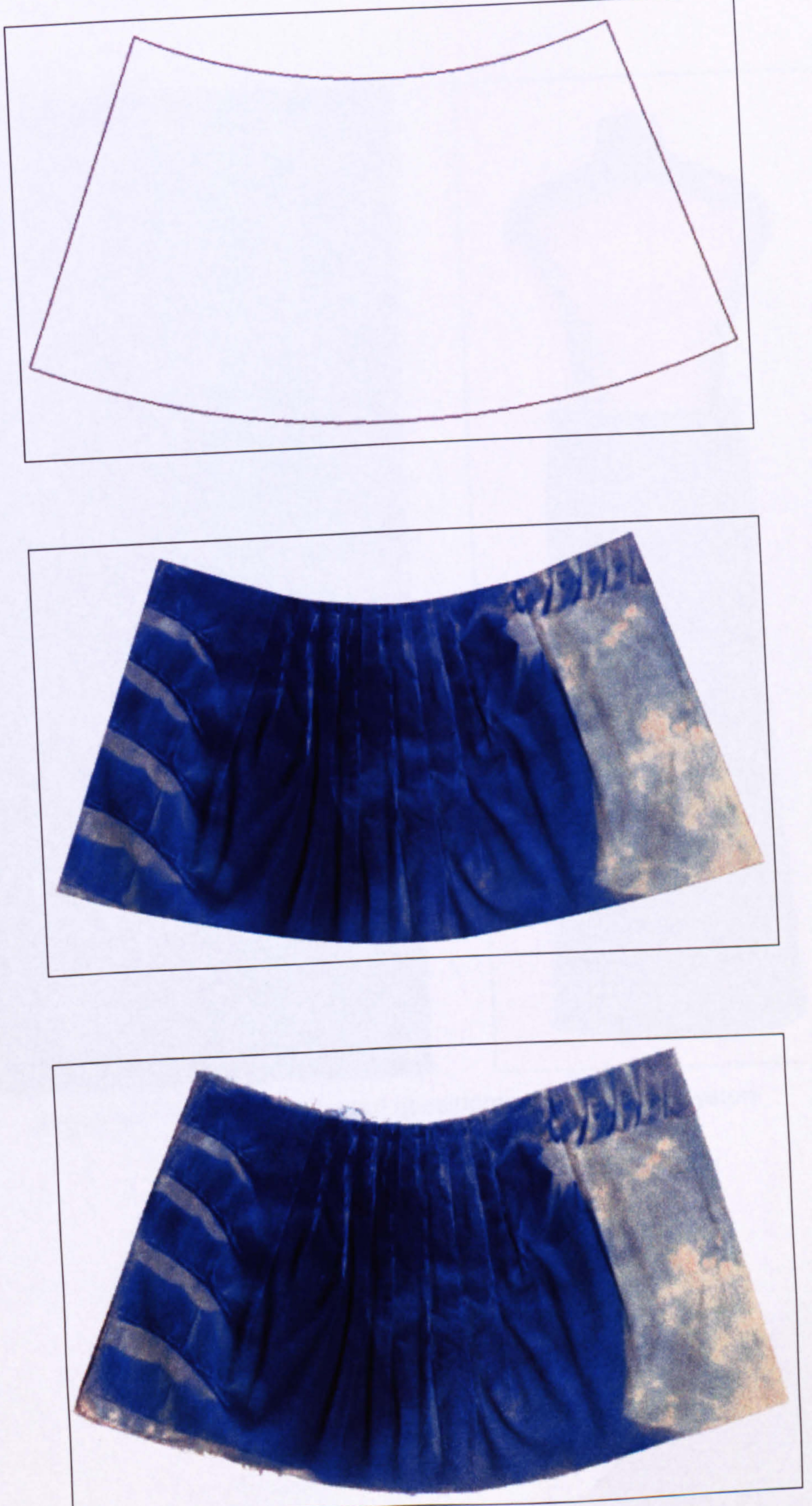

Figure 6-O Pleated skirt, design stages 

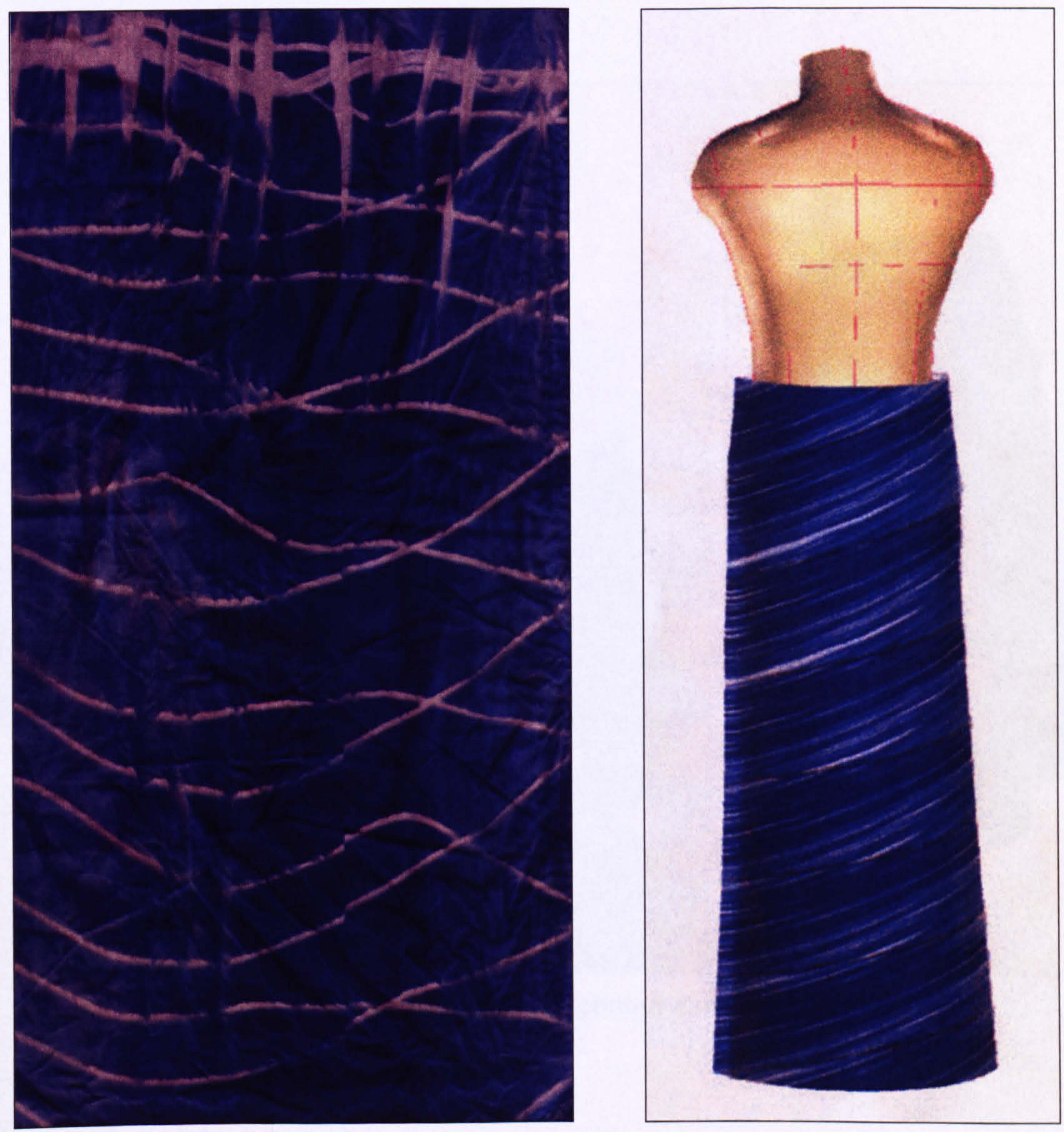

Figure 6-P Pin Wrap 4, design development in PAD 3D System 

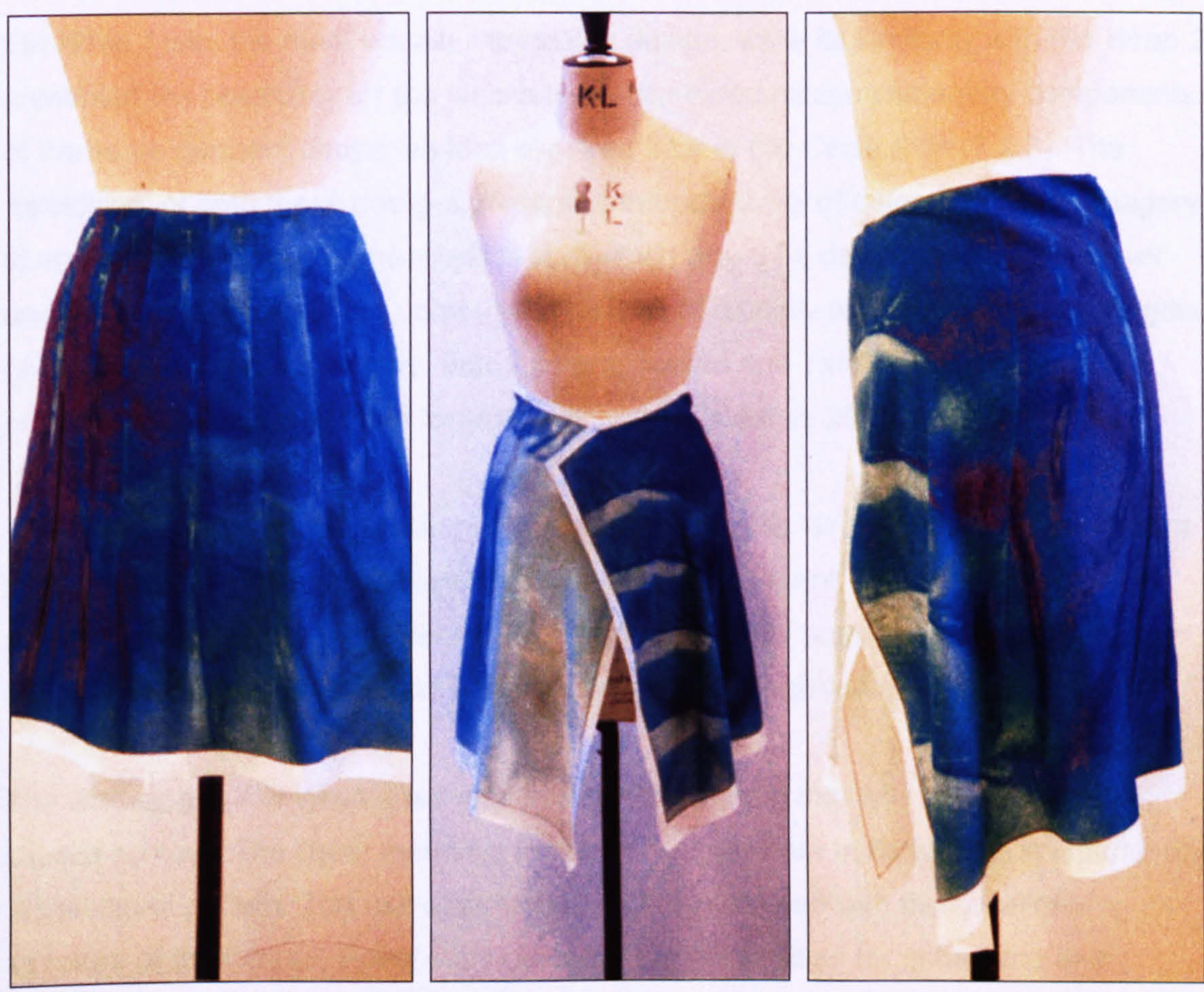

Figure 6-Q Wrap Skirt: digitally printed sample on viscose 


\subsubsection{Pin Wrap Skirts: Reflections}

Pin Wrap Skirts 1, 2, 3 and 4 represented simultaneously designed outcomes. The origination and integration of print and cut had been synthesised into a single modelling action with the surface detail evolving as a direct outcome of the process of structuring the garment.

Pin Wrap 1 was the most visually interesting design, while its similarity with Pin Wrap 2, presented the possibility for the pieces to be combined as complimentary components of the same garment shape, an idea explored later in the Circle Skirt (7.2.3). The 'stretching' of both these designs presented the possibility of extending textile imagery to an extreme length, the measurement of which would be determined by the power and memory capacity of the computer. The idea of digitally printing continuous lengths of non-repeating print imagery, featuring engineered and 'randomised patterns', presents creative possibilities for textile designers (Carlisle 2001: 98).

The use of the 'inversion' function in association with Pin Wrap 1 rendered the design to appear more three-dimensional than the original blueprint. The scanned, pleated effect explored through the Pleated Wrap presented new possibilities for creating and integrating trompe loeil imagery within a contemporary fashion context.

The wrapping of Pin Wrap 4 resulted in a rhythmic result that was curtailed by the square contour. The linear markings interfaced somewhere in between a sculptural and architectural pattern. The use of stretched motifs combined with the curvilinear structure of the (virtual) Spiral Skirt indicated the possibilities for enhancing and exaggerating the inherent rhythm of a print to make garment styles appear more fluid.

\subsubsection{Win Dress: Intentions and Process}

An architectural shape, Win Dress, ${ }^{33}$ was investigated to provide a comparison with the Ribbon and Cord Tunics. As indicated in Figure 6-R, the innovative one-piece pattern had no shoulder seams - enhancing the possibilities of print integration in this area. Win Dress was initially cut in cotton and wrapped in a similar way to the sculptural tunic shapes, to further ascertain the possible influences of garment shaping on mark making. The geometric shape of the garment elicited a geometric-style of wrapping of ribbon and tape, which influenced the design outcome, Win Dress $1 .^{34}$

\footnotetext{
${ }^{33}$ The Win Dress was designed in collaboration with Winifred Aldrich. The shape was originally used for a group research project with Dr Amanda Briggs and Gillian Project which resulted in two separate papers about print/garment integration. See Briggs and Bunce (2001) Breaking the Rectangle and Townsend (2001) Surface, Shape, Structure, CADE2001, 9-12 April Glasgow School of Art

${ }^{34}$ See CD for images of further experimentation with the Win Dress. 

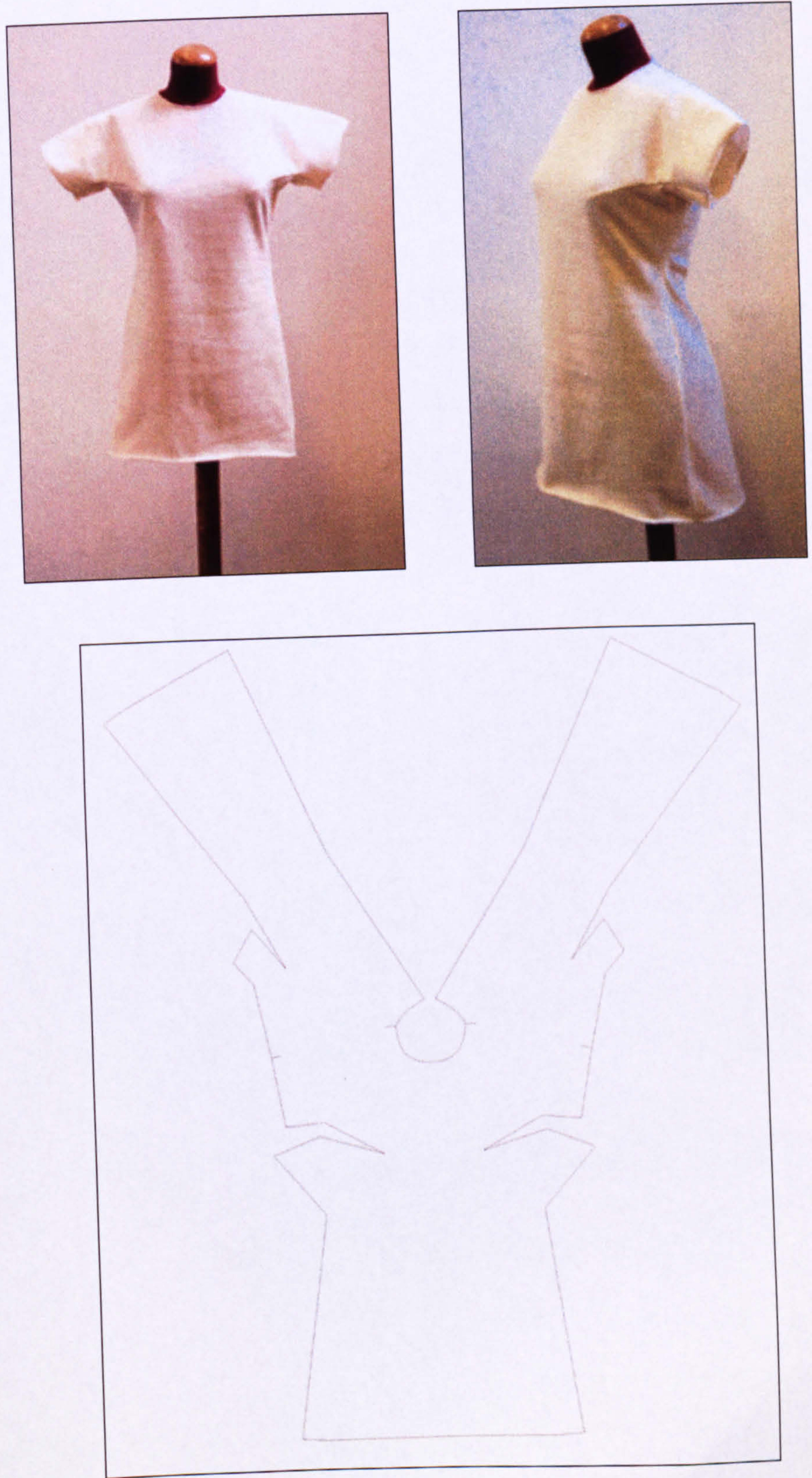

Figure 6-R Win Dress, pattern and toile 

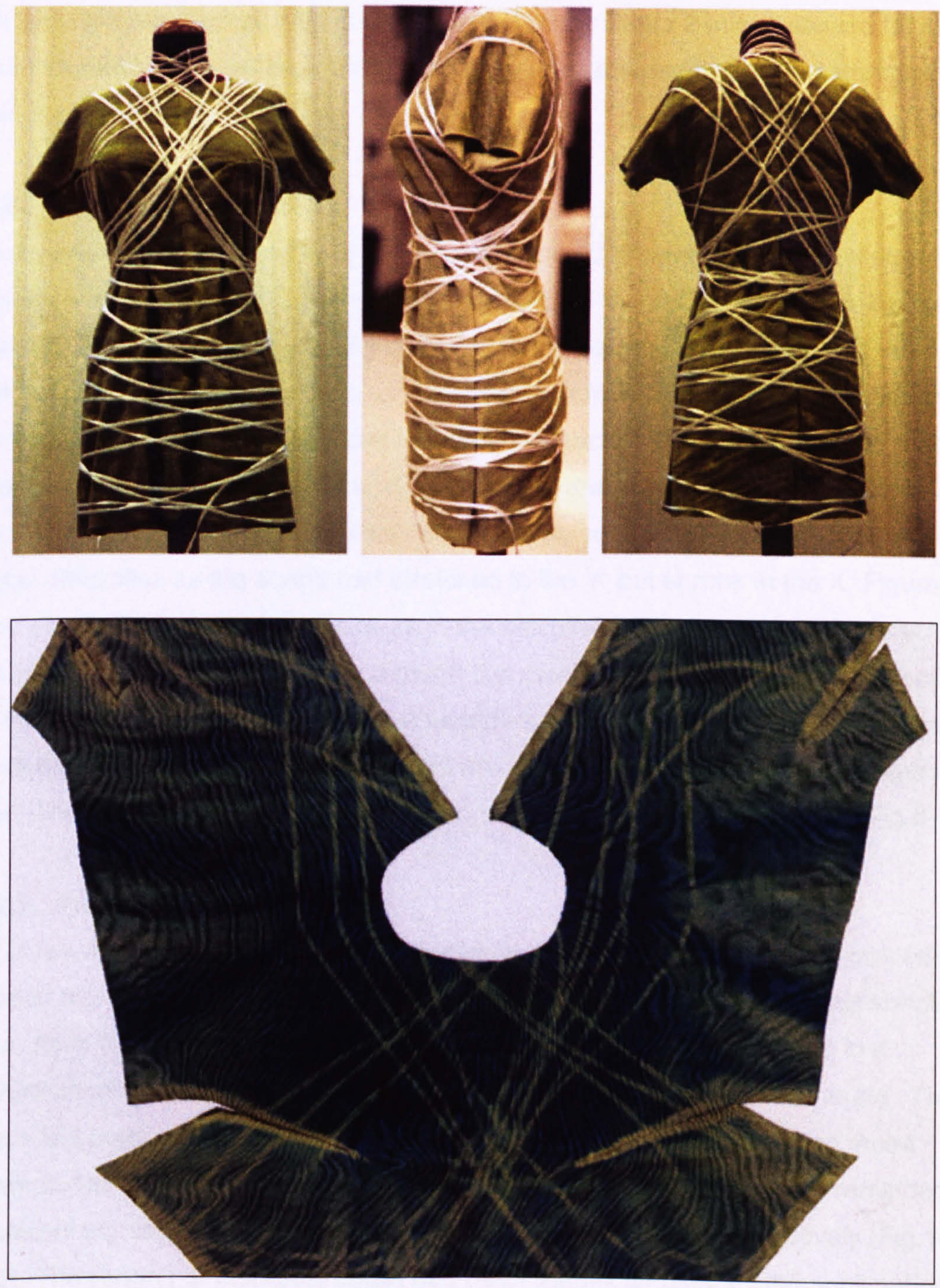

Figure 6-S Win Dress, wrapped, sensitized toile

Figure 6-T Win Dress patterned shoulder area 
To test the influence of fabric quality on the mark making, Win Dress was also cut in cotton jersey and wrapped in ribbon (Fig.6-S). The softening of the substrates resulted in a slightly more fluid design, particularly in the skirt and shoulder areas where the cloth had cleaved more closely to the form (6-T). Win Dress 2 encompassed far more textural detail than the cotton version, due to the capturing of the knitted structure within the cyanoform. ${ }^{35}$

\subsubsection{Digital Patchwork}

The dimensions of the Win Dress far exceeded the A3 scanner, which resulted in the cyanoform being scanned in five separate stages. ${ }^{36}$ This made the realignment stage extremely challenging. The stability of the woven cotton and the regularity of the print on Win Dress 1 aided the process as the linear markings were quite regular and the shrinkage of the cotton had affected the piece uniformly. ${ }^{37}$ The $10 \%$ shrinkage that had occurred in the $Y$ (length) could be re-built into the realigned the pieces. However, the distortion that had occurred in the less stable jersey version, Win Dress 2, led to greater difficulties as the shape had stretched in the $Y$, but shrunk in the X. Figure 6-U which shows the initial attempt to re-align the pieces. The compromised, final realignment was only made possible through the careful manipulation ${ }^{38}$ of each section and the 'cloning' of details to achieve a semblance of continuity throughout the design. The design was rendered in Photoshop to enhance the colour scheme and disguise the 'joins'. The texture of the jersey contributed to the moiréd effect of the print (Fig.6-V).

\subsubsection{Printed Outcome}

Win Dress 2 was digitally printed at half-scale onto viscose javanaise. The procedure provided first hand information of colour reproduction, design resolution and shrinkage ratios. As in the previous cases the colour was reproduced on the viscose in a heightened state, so that 'green' was replaced with a shade closer to 'emerald'. The design had been scanned at 200 DPI, which had resulted in an interesting moiré pattern at half scale that could be very interesting at full-scale. The effect reminded me of some of my earlier optical-style prints ${ }^{39}$ which iterated the form effectively (Fig.1-C, p.1-6). The pasting of individual pixels had been slightly diffused by the sublimation of the dye, but these were still visible in the translation. The greatest discrepancy between

\footnotetext{
${ }^{35}$ On this occasion the cyanotype process yielded a 'green' printed outcome, possibly due to a combination of the age of the solution and quality of substrate.

${ }^{36}$ Win Tunics 1 and 2 had to be scanned in the following sections: Right front, Left front, Neck and shoulder, Right back, and Left back. Ideally the piece would have been scanned on an AO device.

${ }^{37}$ The $10 \%$ shrinkage that had occurred in the $Y$ (length) could be re-built into each section of the printed pattern, in order to realign the pieces with the overall shape of the original pattern contour.

${ }^{38}$ Each of the five sections had to be increased or reduced in scale and rotated at irregular angles before it could be integrated with an adjoining fragment.

${ }^{39}$ For the designer label Cocky's Shed.
} 


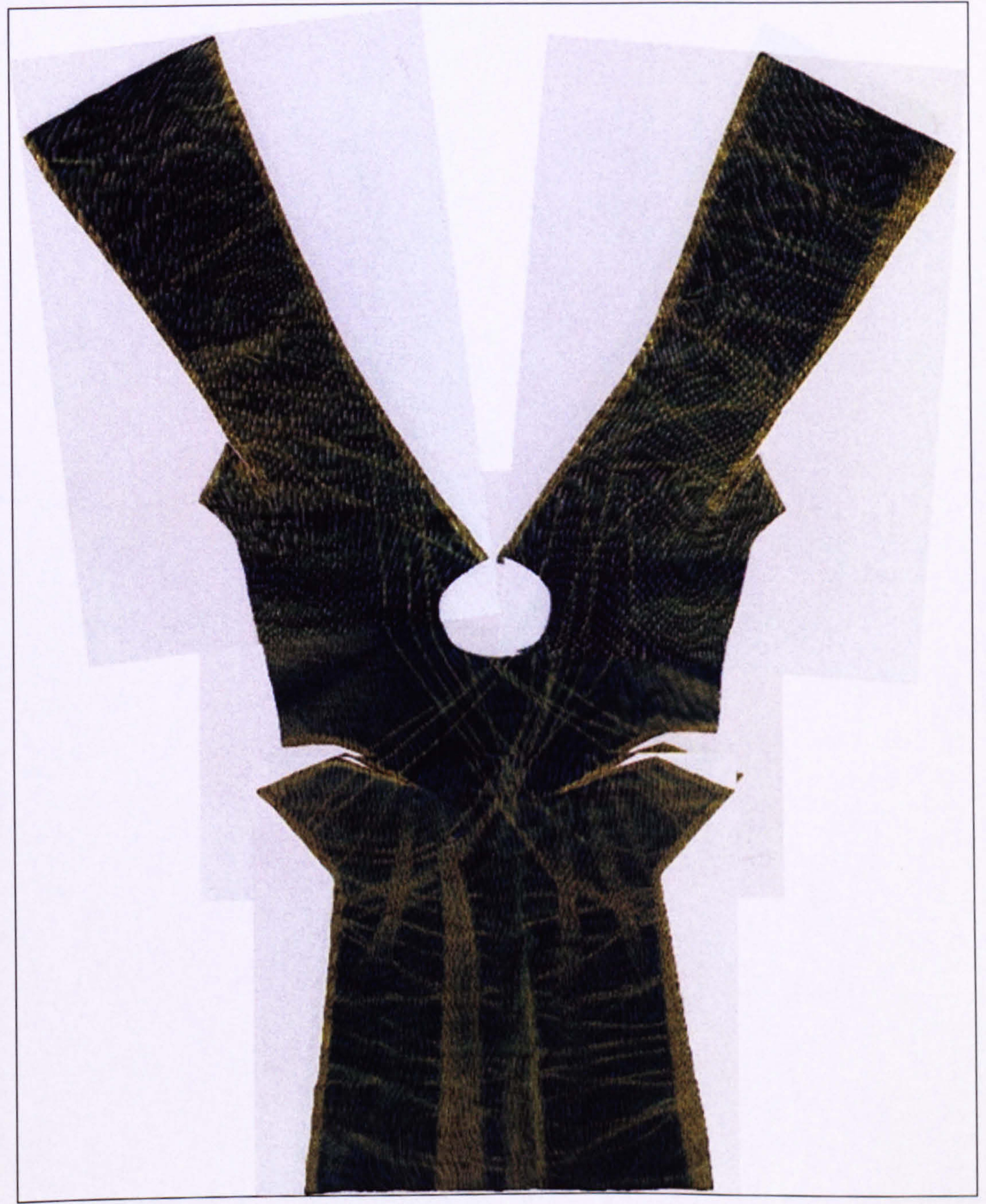

Figure 6-U Win Dress: process of realignment 


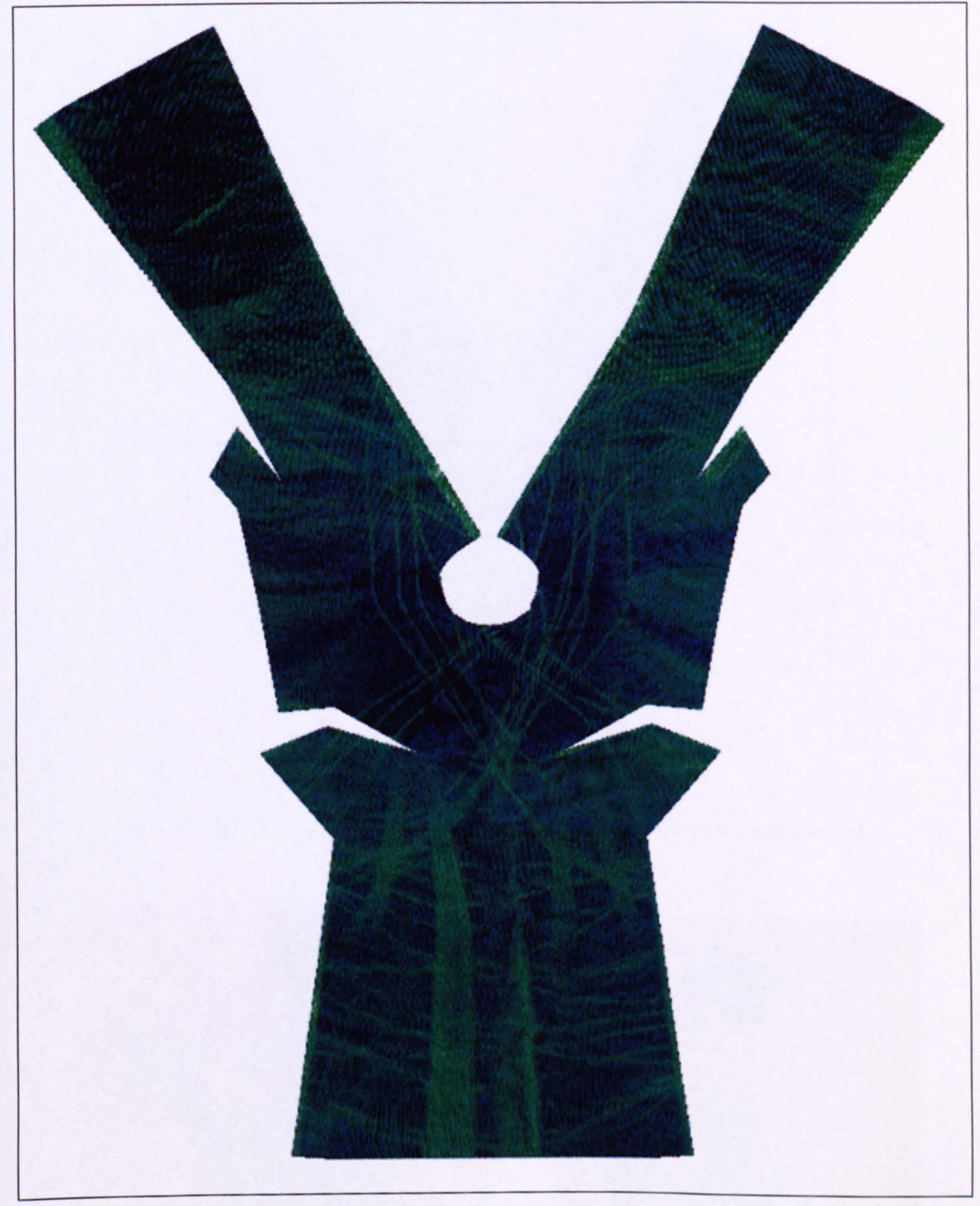

Figure 6-V Green Dress 

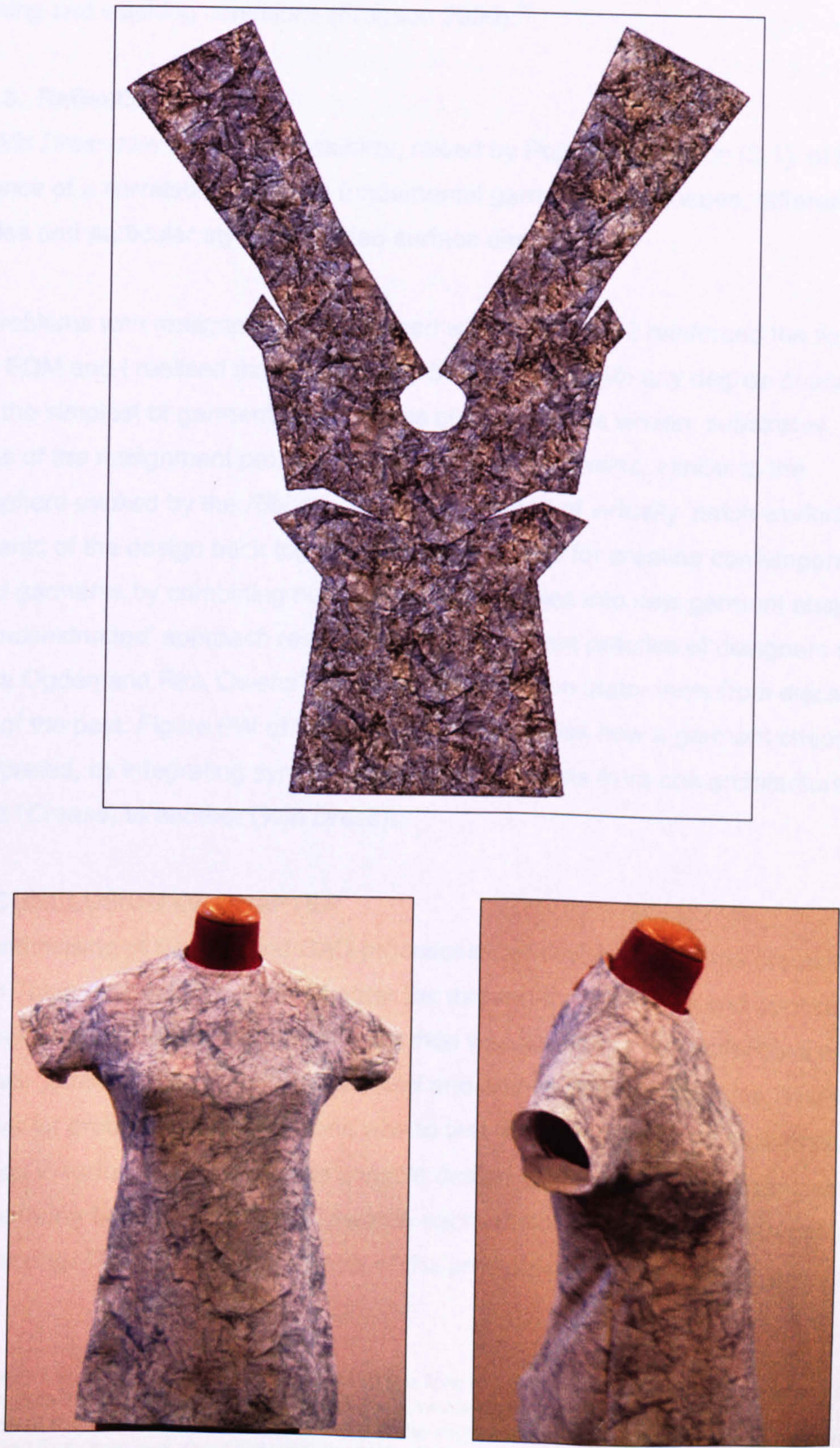

Figure 6-W Crease Dress 
original design and the printed version was the size as the viscose $e^{40}$ had shrunk by $15 \%$ in length. The printing exercise reinforced the importance for designers to "pre-test the shrinkage ratio of fabrics for themselves' because even if such figures are supplied by printing companies, results can still vary slightly depending upon ink coverage, steaming and washing conditions (Frogson 2000). ${ }^{41}$

\subsubsection{Reflections}

The Win Dress reinforced the possibility, raised by Popova's practice (3.1), of the existence of a correlation between fundamental garment/cloth shapes, different fabric qualities and particular styles of printed surface design.

The problems with realignment experienced with Win Tunic 2 reinforced the limitations of the SDM and I realised that it could only be employed with any degree of accuracy using the simplest of garment/cloth shapes cut from stable woven, substrates. The images of the realignment process suggested antique textiles, similar to the atmosphere evoked by the Ribbon Tunic. The method of virtually 'patch working' the fragments of the design back together presented ideas for creating contemporary printed garments by combining new and existing textiles into new garment shapes. This 'reconstructed' approach resonates with the current practice of designers such as Jessica Ogden and Rick Owens ${ }^{42}$ who craft new fashion statements from discarded styles of the past. Figure $6 \mathrm{~W}$ of Crease Dress ${ }^{43}$ illustrates how a garment shape can be reinterpreted, by integrating sympathetic design elements from one architectural context (Crease) to another (Win Dress).

\subsection{CONCLUSION OF CHAPTER}

The synthesising of manual and CAD processes that evolved out of the creation of the Ribbon Tunic were addressed in Chapter Six through the formation and application of the Simultaneous Design Method. The method was applied to two collections of crossover garment shapes with a sculptural and architectural design bias. The main objective for producing the collections was to test the feasibility of a simultaneous approach to form, cloth and print as a viable design method. The contrasting wrapping and anchoring treatments adopted towards each collection resulted in different styles of mark making. The photographic nature of the process resulted in cyanoforms which

\footnotetext{
${ }^{40}$ I was aware that the viscose may shrink, but at the time of printing I was unable to access any accurate shrinkage data from Lectra Systems, so tested for a 'worse-case scenario.'

${ }_{41}$ I discussed this issue with Andy Frogson, one of the most experienced digital sample printers in the UK, who insisted that designers should always pre-test printing substrates themselves by washing 1 square meter of cloth.

${ }_{42}$ See Gan, S. (2000) Visionaire's Fashion 2001, London: Laurence King.

43 The Crease design was developed as a 2D cyanotype on Tyvek, and is included on the CD.
} 
reflected the physical manipulation of cloth and the intervention of a variety of masking materials which contributed additional surface interest.

The re-cutting of the Cord Tunic into three alternative pattern shapes that wrapped around the body, built on an idea raised by the Paper Dresses in Chapter Five. The concept represented a further exploration of a textile-led approach, by re-evaluating the shape of a garment pattern in accordance with the visual configuration of the surface imagery. The Vine Tunics resulted in sophisticated imagery based on the juxtaposing of natural elements with the manual manipulation of a cloth shape. The visual narrative embodied in the cyanoforms represented a new style of textile vocabulary that evidenced the novel 3D method of origination. The Shadow Tunic raised the aesthetic issue of the capacity for cloth to hold the memory of its previous manipulation within its structure. The resulting ethereal folds challenged conventional textile imagery. The use of draped effects as textile constructs was explored by manipulating and integrating the shadow imagery with alternative garment shapes, resulting in complex visual outcomes.

The conversion of designs from half to full-scale raised design issues that led to a reevaluation of the Simultaneous Design Method, as when converted to full-scale the printed folds appeared oversized on certain fabric qualities when related to the human form. The problem was solved by further manipulating the print in CAD through stretching imagery, re-contouring garment shapes to accommodate additional sections of the design, and by transposing the designs onto semi-transparent fabrics, which diffused the graphic effect.

The wrapped and draped treatment of the sculpturally biased, Collection One, generally resulted in fluid print styles. The anchoring method adopted towards the architecturally biased, Collection Two, resulted in geometric patterning that evidenced the folding and pinning treatment. The use of rectangular shapes, as used to create the Pin Wrap cyanoforms, presented increased design opportunities for the future interpretation of the designs into a range of textiles and garments. The Win Tunic highlighted the difficulties of applying the SDM to complex garment shapes, particularly in knitted substrates. The process of realignment proved challenging, but resulted in a patchwork approach that offered design potential for integrating related and disparate printed garment pieces together to create composite styles.

Overall the two collections positively reinforced the aesthetic potential of adopting a simultaneous approach to cloth, print and form using simple woven shapes. The design 
outcomes highlighted the role of CAD as a tool and medium for interpreting innovative mark marking to create original printed textile and printed garment designs. 


\subsection{REFERENCES}

Barnett, P. (1999) 'Folds, fragments, surfaces: towards a poetics of cloth', in Textures of Memory The Poetics of Cloth, Nottingham: Angel Row Gallery

Carlisle, H. (2002) Towards a New Design Strategy: A visual and cultural analysis of small-scale pattern on clothing, PhD Thesis, The Nottingham Trent University

Davison, N. (2002) 'Computers Get Touchy Feely', Press Releases, Nottingham Trent University (www. ntu.ac.uk) 18/12/02

Frogson, A. (2000) Private interview with Andrew Frogson, Digital printing consultant, CV Apparel, Coates Vyella, Huthwaite, Nottinghamshire, 16/1/2000

Gale, C. and Kaur, J. (2002) The Textile Book, Oxford and New York: Berg

Gan, S. (2000) Visionaire's 2001, London: Laurence King

Harrod, T. (2002) 'Otherwise Unobtainable: the applied arts and the politics and poetics of digital technology', keynote speech at Pixel Raiders, Art and Design Symposium, Victoria and Albert Museum, London 19/3/02

Harris, J. (2002) 'Beauty in the CG Beast, Pixel Raiders, Art and Design Symposium, Victoria and Albert Museum, London 19/3/02

Harris, J. (2000) Surface Tension: The Aesthetic Fabrication of Digital Textiles (The design and construction of $3 D$ computer graphic animation), PhD Thesis, The Royal College of Art

Karol, M. (2003) A Patient-Centred View of Designing Medical Textiles, Designing for the Future with Technical Textiles, EMCAT Festival, Pride Park, Derby, 16/5/03 McCullagh, K. (2000) Design Praxis: Towards a Design Context Rooted in Design Practice, in Dudley, E. and Mealing, S. (2000) Becoming Designers: Education and Influence, Wiltshire: Cromwell Press

O'Neill, A. (2001) Imagining Fashion: Helmut Lang and Martin Margiela, in Wilcox, C. Ed. (2001) Radical Fashion, London: The Victoria and Albert Museum

Pirsig, R. M. (1974) Zen and The Art of Motorcycle Maintenance, Great Britain: The Bodley Head

Press, M. (2002) Pixel Raiders, Art and Design Symposium, Victoria and Albert Museum, London 19/3/02

Press, M. and Cusworth, A. (1997) A New Vision in the Making: Exploring the value of craft in the information age, European Academy of Design (EAD) Conference, Stockholm, April 1997

Riisberg, V. (2003) Private interview, the Nottingham Trent University, 21/5/05

Rudge, G. (2001) A Piece of Cloth, Crafts, No. 173, Nov/Dec 2001, pp.22-25

Shillito, A. M. (2002) Tacitus, Pixel Raiders, Art and Design Symposium, Victoria and Albert Museum, London 19/3/02 


\section{Chapter 7. Chapter Seven: Transforming Shape}

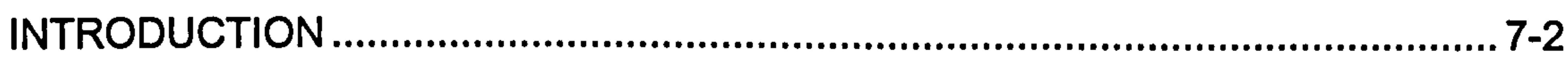

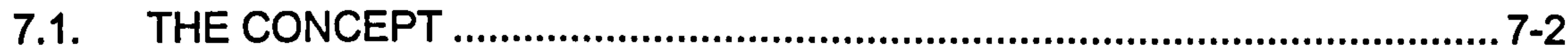

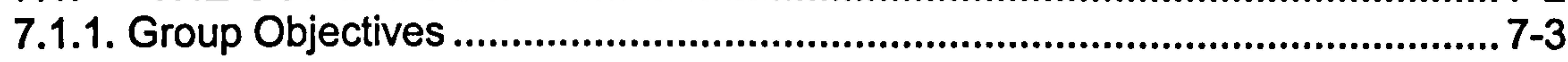

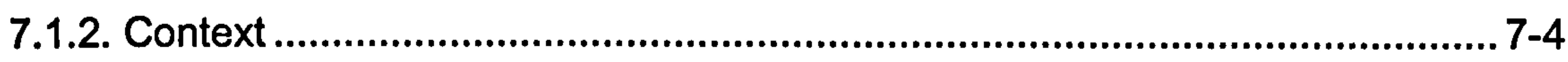

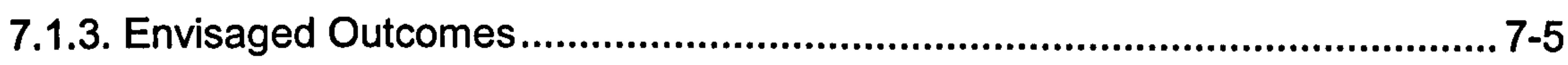

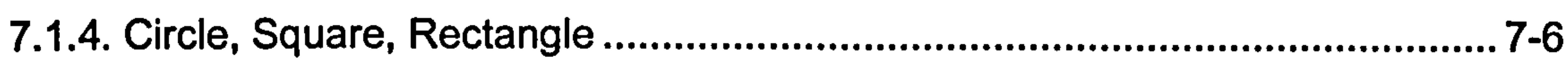

7.1.5 Personal Design Objectives ....................................................................... 7-7

7.2. CIRCLE

7.2.1. Circle Pleats 1-3: Contouring the boundary............................................... 7-8

7.2.2. Circle Pleats 4-6: Multi-mapping …........................................................... 7-10

7.2.2.1 Evaluation of Effects.................................................................... 7-14

7.2.3. Circle Skirt: Intentions ............................................................................. 7-14

7.2.1.1. Circle Skirt: Process.......................................................... 7-14

7.2.1.2. Evaluation .......................................................................16

7.2.4. Nautilus: Intentions ................................................................................. 7-18

7.2.4.1. Process: Mapping the surface ..................................................... 7-18

7.2.4.2. Analysis of Outcome ...................................................................... 7-20

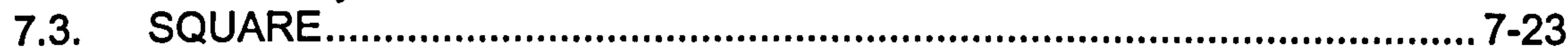

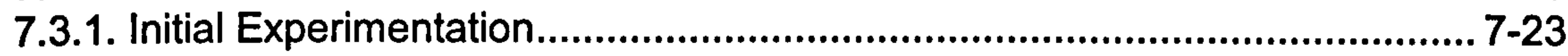

7.3.2. Dress Square: Intentions.......................................................................... 7-25

7.3.2.1. Process: Directional contouring.................................................. 7-25

7.3.2.2. Integrating the Concept of 'Flow' ..................................................... 7-26

7.3.3. Contrasting Approaches ............................................................................ 7-26

7.3.4. Contour Colour ............................................................................................ 7-30

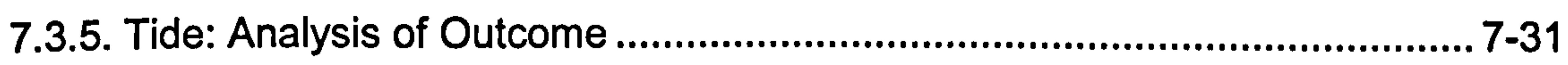

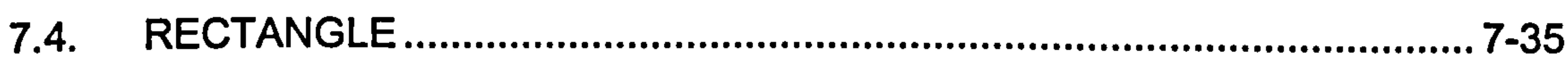

7.4.1. Initial Experimentation............................................................................. 7-35

7.4.2. Rectangle Wrap: Process ..................................................................... 7-35

7.4.3. Wrap: Extending Mark Making beyond the Form ..................................... 7-37

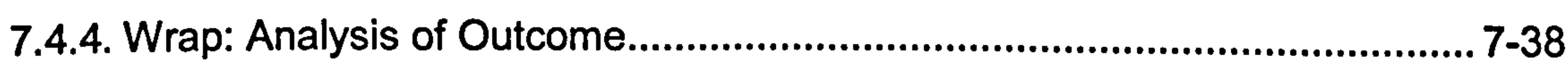

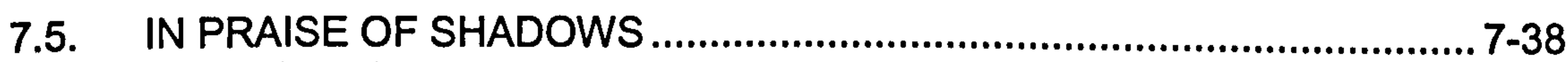

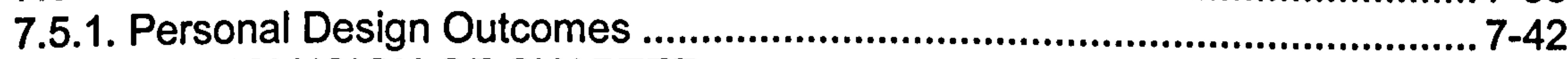

7.6. CONCLUSION OF CHAPTER …..................................................... 7-45

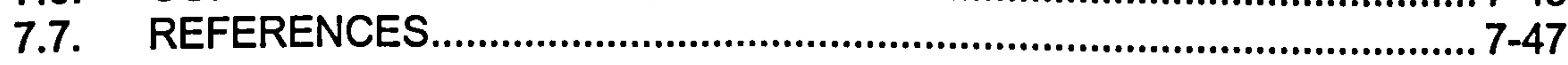




\section{INTRODUCTION}

This chapter documents a group research project and exhibition, Transforming Shape, which was staged at The Bonington Gallery, at Nottingham Trent University, 12-19 December 2001. The exhibition was conceived of as a project for showcasing ongoing practice in the Fashion and Textile Department of the University, which has an international reputation, for its theoretical and practical research into CAD.

\subsection{THE CONCEPT}

The exhibition Transforming Shape was first conceived of in June 2001, as a vehicle for a collaborative Fashion and Textile research project, ${ }^{1}$ investigating the integration of surface design with garment shape. The participants included six designers: $\mathrm{Dr}$ Amanda Briggs-Goode (Print), Dr Gillian Bunce (Print), Katherine Townsend (Shape and Print), Rosemarie Goulding ${ }^{2}$ (Shape and Embroidery), Sue Keen (Shape) Graham Cope (Multimedia) all of whom work as lecturers/researchers within the School of Art and Design. During the project we worked as a group and were collaboratively involved in the decision making process with regards to issues of surface, shape and exhibition design. The choreography and filming (of the video) and the curating of the exhibition, was undertaken by Sue Keen and Graham Cope.

My $\mathrm{PhD}$ research into print/garment integration had resulted in some key findings, leading to the development of the Simultaneous Design Method (SDM) (6.2). As discussed in the previous Chapter 6, I had adopted this method as a means of investigating the relationship between fundamental garment/cloth shapes and the creation of print designs appropriate to those forms. The chief outcome had been the validation of the design method, which had ramifications for printed garment and printed textile design (6.5). The essence of the SDM provided the catalyst for Transforming Shape, prompting the group to consider surface design from a three dimensional, simultaneous perspective. The interrelating of 'cloth, form and mark making', at the outset of the design process, represented a reversal of conventional textile practice and a new way of working. The exhibition presented me with the valuable opportunity to share, test and compare design outcomes with other research practitioners.

\footnotetext{
${ }^{1}$ The idea for an exhibition was put forward by the Head of the Fashion and Textile Department, Jean Williamson, and was subsequently backed by Fashion and Textile Research funding.

2 Gillian Bunce (Director of Studies), Amanda Briggs-Goode (Supervisor) and Rosemarie Goulding (Advisor) were all members of my PhD supervisory team.
} 


\subsubsection{Group Objectives}

The key group aim was to explore the transforming effects of surface design through dialogues between 2 and 3 dimensions: a visual investigation of images, patterns, and 2D and 3D fabric forms. In parallel with my own practice, surface print and embroidery would be considered from a 3D starting point through the relating of geometric cloth shapes to the form. With this visual information in mind, designs would be originated that interacted with, or accommodated the physical draping patterns of the cloth shapes. It was envisaged that the novel consideration of the configuration of the (final) modelled textile at the outset of the designing process would influence each designer in different ways, leading to a collection of contrasting, original outcomes. As stated in the Transforming Shape (2001) press release, composed by the exhibitors, the group aim of the exhibition was to explore the following issues:

The design opportunities created by new technologies, specifically the relationship between innovative imagery and three-dimensional forms. The central inspiration is the premise that textile deigns can be mediated through pattern shapes and that pattern shapes transform the body. The exhibition will demonstrate the integration of imagery with fabric and form through the selected use of computer aided textile design.

It was intended that both the possibilities and limitations of CAD would be investigated. In terms of scale the print ${ }^{3}$ designs were limited to a measurement of $144 \mathrm{~cm}$ in width, whilst the embroidery ${ }^{4}$ was limited to a maximum repeat size of $50 \times 30 \mathrm{~cm}$.

The group chose to focus on the circle, square and rectangle. Within these fabric forms, colour and scale would be manipulated through a variety of different design concepts. Pattern and imagery would be placed, displaced and distorted by the designers in response to the external 3D form. Within the shared objective of demonstrating the possibilities of engineer-printed and embroidered structures, each designer took an idiosyncratic approach with regard to the method by which imagery was chosen and integrated with the shapes. These included Amanda Briggs-Goode's investigation into the digital translation of hyper-real photographic images of flowers; Gillian Bunce's exploration of optical print effects; Rosemarie Goulding's enquiry into the juxtaposing of stitch and form, and my own further research into the reading of the form through illusionistic print. The overall objective was to show innovative approaches to surface pattern that challenged existing notions of textile design.

\footnotetext{
${ }^{3}$ The printers used a Stork, Amber at The Print Works, Samuel Bradleys, Stockport.

${ }^{4}$ The embroidery was undertaken using a Boronden machine at Macphearsons, Nottingham.
} 


\subsubsection{Context}

There is currently considerable research taking place in the textile and clothing world, exploring technologies related to textile design production, which questions the relationship between surface and structure (Gale and Kaur 2000: 25). Sarah Taylor, Janet Stoyel, Janet Emmanuel and Jane Harris's work challenges predetermined views of textiles and is revolutionisiing our perceptions of fabric. The works in the Jerwood Prize for Textiles (2002) exhibition provided positive examples that 'the use of textiles is becoming increasingly sophisticated, both visually and technologically, respecting tradition, craftsmanship and innovation in terms of performance' (Wilson 2000: 35). Many of the pieces illustrated how the fusion of traditional skills with cutting edge technology has led contemporary textile artists/makers to adopt an 'intelligent take on traditional processes' (Johnson ${ }^{5}$ in Millar 2002: 4). This was the second time that the award had been made for textiles and as Binns (2003:87) states: 'we might ask ourselves how a material can be adjudicated with rigour when, as a subject discipline, textiles is so diverse.'

In Britain the established structures of higher education which support the subject area, are broadly based; out of them develops professional engagement that flows across the full breadth of contemporary visual art and design practice (Ibid).

Despite representing a 'continuation of the craft tradition of printed textiles', the use of CAD allied with digital fabric printing is rarely featured within an exhibition context in the UK (1.5). For example, Shelly Goldsmith, the winner of the 2002 Jerwood Prize for Textiles, presented the only digitally printed piece in the exhibition, which utilized a child's garment as a canvas for a photographic print (3.8). ${ }^{6}$ Similarly, the informative publication; The Textile Book (Gale and Kaur 2002) featured 'innovative print' designs by practitioners such as Nigel Atkinson ( $p .22$ ) and Isobel Dodd (p.25), but failed to include a single example of digitally printed fabric. Such an omission is partly due to the industry's focus on 'techno textiles' which has tended to concentrate on investigations into 'moulding, embossing, heat bonding and sculpting' techniques (Ibid.). However, as the work in this thesis demonstrates, while textured inks are not yet a part of the digital printing medium, the technology can be used to simulate a range of sophisticated 3D effects and concepts. While constructed textiles are often created as one-off pieces, prints are not limited to a single interpretation, as Murdoch (2003) confirms: 'print is not just about fabric, but about ideas that can be translated onto many different substrates, within a broad variety of contexts'.

\footnotetext{
${ }^{5}$ Pamela Johnson, chair of the judging panel for the Jerwood Applied Arts Prize 2002.

${ }^{6}$ Her installation, No Escape-reclaimed dresses from the Childrens home of Cincinatti (1999), featured three garments transposed with photographs of a flood disaster.
} 
Within the commercial context of printed garment design, the use of CAD in association with digital fabric printing has generally been limited to the role of sampling and niche production in a replication of existing methods. In an art textile forum few 'digital connections' have been made between 'imagery, cloth and the human form', particularly in the UK (Campbell and Stieglitz 2001). It was in response to this lack of investigation and exposure of what constitutes a new medium for designers, that Transforming Shape was conceived; within the contemporary context of art/fashion textiles:

The spirit that unites artist and dressmaker is the continual creation of original models, but with the former remaining free to move throughout all areas of activity, and the latter constrained to a freedom limited by the particular nature of a product, tied to the dimension of the human body (Tabatabai Asbaghi 1996: 28).

The designs/pieces for the project were initiated within an atmosphere of reflective practice; not as commercial garments, nor as art, but as pieces that fused these two influences by presenting open-ended design solutions that explored the aesthetic implications of a new technology (4.4).

\subsubsection{Envisaged Outcomes}

It was envisaged that a collection of digitally printed textile and embroidered pieces would form the basis of the practical research output. The pieces would present innovative possibilities for integrating surface pattern with rudimentary shapes whilst demonstrating the potential of computer-aided-design. ${ }^{7}$ It was important that a selection of the designs were fabricated as physical, design pieces, to provide evidence of the translation from screen to reality, an issue explored by Miyake in 2000.

The title 'Making Things' can be taken literally to mean the fabrication of physical objects. As electronic information and images proliferate, the boundary between reality and virtual reality is becoming more elusive, and in this computer age people have fewer experiences of coming into direct contact with natural objects or making things with their own hands (Schioda 2000: 6).

The method in which the textiles were presented would determine the format of the exhibition. The adoption of the form as the key point of design reference determined that the final fabrics should be displayed on the female form and mannequins. It was recognised that freestanding, realistic models would not be appropriate vehicles, as a key objective of the project, drawn from my own practice, was to reference the female

\footnotetext{
${ }^{7}$ Photoshop, Prostyle and PAD were the main software used.
} 
form as a 3D spatial entity. Following deliberation, twelve transparent mannequins ${ }^{8}$ (that could be suspended) were chosen as the most effective method of exhibiting the cloth shapes. In view of the submission limit of three pieces for each designer, a video installation featuring the process of CAD development and filmed footage of the final designs on a moving female model, would accompany the textiles.

\subsubsection{Circle, Square, Rectangle}

Following early group discussions about the possible use of a range of simple garment shapes it was decided that the circle, square and rectangle would be appropriate shapes for investigation. The use of these shapes built on an earlier aspect of my practical research ${ }^{9}$ and initial shape development by Rosemarie Goulding. The shapes provided the group with universal templates to explore. The circle, square and particularly the rectangle $e^{10}$ have informed the principles of garment shaping since Antiquity ${ }^{11}$ and continue to inform contemporary pattern cutting methods (4.2).

The geometric shapes were considered as potential one-piece garments; originated in accordance to the shape and proportions the human form. The use of a single pattern piece instead of a series of pattern pieces would allow the print full reign within the contour. A range of circles, squares and rectangles were created on the full-scale ${ }^{12}$ and half-stand, and by modelling on members of the group to assess the draping factor of the shapes in conjunction a real, moving form. Sculptural shapes were modelled in cotton muslin and jersey and architectural shapes were fashioned in calico. The resulting pieces provided the four surface designers with a varied collection of $2 \mathrm{D}$ pattern shapes and 3D cloth forms to explore.

After considerable experimentation on both an individual and collaborative basis, four shapes were developed as final templates. The shapes were Circle Skirt $(144 \mathrm{~cm}$ diameter), Dress Square $(100 \times 100 \mathrm{~cm})$, Rectangle Skirt $(140 \times 100 \mathrm{~cm})$ and Rectangle Twist $(180 \times 90 \mathrm{~cm})$. The practice of integrating surface imagery with these shapes was pursued independently and in pairs, with regular group critiques were to gauge progress. An important aspect of the research was to illustrate how varying design treatments could render similar pieces of cloth to appear as radically different textile forms.

\footnotetext{
${ }^{8}$ The twelve transparent fibreglass mannequins had to be imported from Italy. We were the first to use this product in the UK.

Journal: 21/10/99. 'Square, Circle, Rectangle.' Began researching shapes, with a view to build up a collection of patterns/garments in which I can use prints in as 'elemental' way as possible - i.e. to use the decorated cloth as an element in its own right rather than a length that is 'cut into.

${ }_{10}$ The Greeks used the rectangle to embody the principles of The Golden Section. See 2.3.1.

1 See Tilke, M. (1990) Costume Patterns and Designs, London: Magma Books

12 A standard size 12.
} 


\subsubsection{Personal Design Objectives}

The key issues explored through my designs for Transforming Shape were:

- A 3D approach to printed textile design based on observations and impressions of the form draped in geometric cloth shapes.

- The origination and development of trompe l'oiel engineered prints that related to the shape, contours and movement of the form.

- New design possibilities presented by CAD in association with digital printing technology.

The exploration of the three issues listed above was made possible through the adaptation of the Simultaneous Design Method, involving three separate stages.

Stage 1 entailed 3D-shape development, whereby circles, squares and rectangles were cut, manipulated, observed and recorded ${ }^{13}$ on the stand and life models.

Stage 2 was undertaken in 2D using CAD to integrate print designs with selected shapes. Print imagery would be created from new or existing designs, or from photos of the shapes on the form/stand from Stage 1.

Stage 3 involved the realisation of these virtual designs as physical printed material, which was cut, finished and returned to its original 3D, draped form.

In the Sculptural and Architectural Collections, detailed in Chapter 6, emphasis was placed on capturing the effect of light on static cloth installations (rotated in space). In the creation of the textiles for Transforming Shape, this focus was shifted to encompass the effect of light on both static and moving cloth forms. It was my intention to create print designs that alluded to the physical attributes and dynamic drape of a particular cloth shape in motion. My desire to conceive a mode of dress that integrated the visual sensations of movement would be implemented by exploring the directional possibilities of surface print, using CAD. The designs would be founded on the form and 'the cut of fabric made vibrant by pattern', a notion that resonated with the Futurist's aim to integrate movement into printed clothing designs during the $1920 \mathrm{~s}$ (Tabatabai Asbahgi 1996: 28). I intended to use directional, engineered prints composed of contrasting images to visually sculpt the individual form in cloth. The

${ }^{13}$ Analogue and digital photography, sketches and diagrams were used to record information. 
design issues raised by the final pieces: Nautilus, Tide and Wrap are discussed, and reflected upon, in the following sections.

\subsection{CIRCLE}

Circular (Ring-shaped): This very widespread form of ornamentation draws attention to the round contours of the human body (Flügel 1930: 46). Curves are often used in dress design and the more of a circle that is used the rounder shape appears (Davies 1981: 30).

The circle presented the surface designers with a very different canvas from the more familiar rectangle that governs printed garment design (2.1.2). The Circle Skirt was developed from a series of circular shaping experiments, that included sculptural, architectural and crossover interpretations. The final printed design, Nautilus, was the result of the redevelopment of the original calico shape in the more fluid quality of viscose organza. During the shape development phase importance was placed upon how the different sized circles, cut in contrasting qualities could be related to the form, and how print imagery could be integrated that reflected the visual and physical dynamics created through these dialogues. In the exhibition, Nautilus, explored the aesthetic relationship between printed cloth and the moving form, translated through the application of an expressive, spiralling print. The following sections describe the design development of Nautilus, which illustrates that issues of scale, fabric quality and mark making can significantly influence the way that a circle is perceived on the form.

\subsubsection{Circle Pleats 1-3: Contouring the boundary}

The initial circle designs were based on observations and images of the Ruched Circle. ${ }^{14}$ The draped piece presented a distortion of the original geometric shape into a soft, gathered mass, manipulated through a series of drawn threads. The 3D shape encouraged the exploration of firstly, how a print created as a 2D circle could be visually distorted as a 3D form and secondly, how the textural rhythm of the 3D form could be emulated through a 2D print. Figure 7-A shows the original toile and a visualisation of the piece integrated with a print idea Circle Pleat 6 (Fig.7-F, p.7-13).

I began the process of integration by creating a circular pattern measuring $144 \mathrm{~cm}^{15}$ (diameter) in CAD. The resulting Contour C1, represented a large canvas to fill,

\footnotetext{
${ }^{14}$ The Ruched Circle was modelled by Rosemarie Goulding and consisted of a $150 \mathrm{~cm}$ diameter circle of cotton jersey, with a central $30 \mathrm{~cm}$ slash as an opening for the neck and left shoulder.

${ }^{15}$ The reduction from 150 to $144 \mathrm{~cm}$ was made to account for print production which requires that a margin of at least $2 \mathrm{~cm}$ wide is left either side of the widest point of a design.
} 


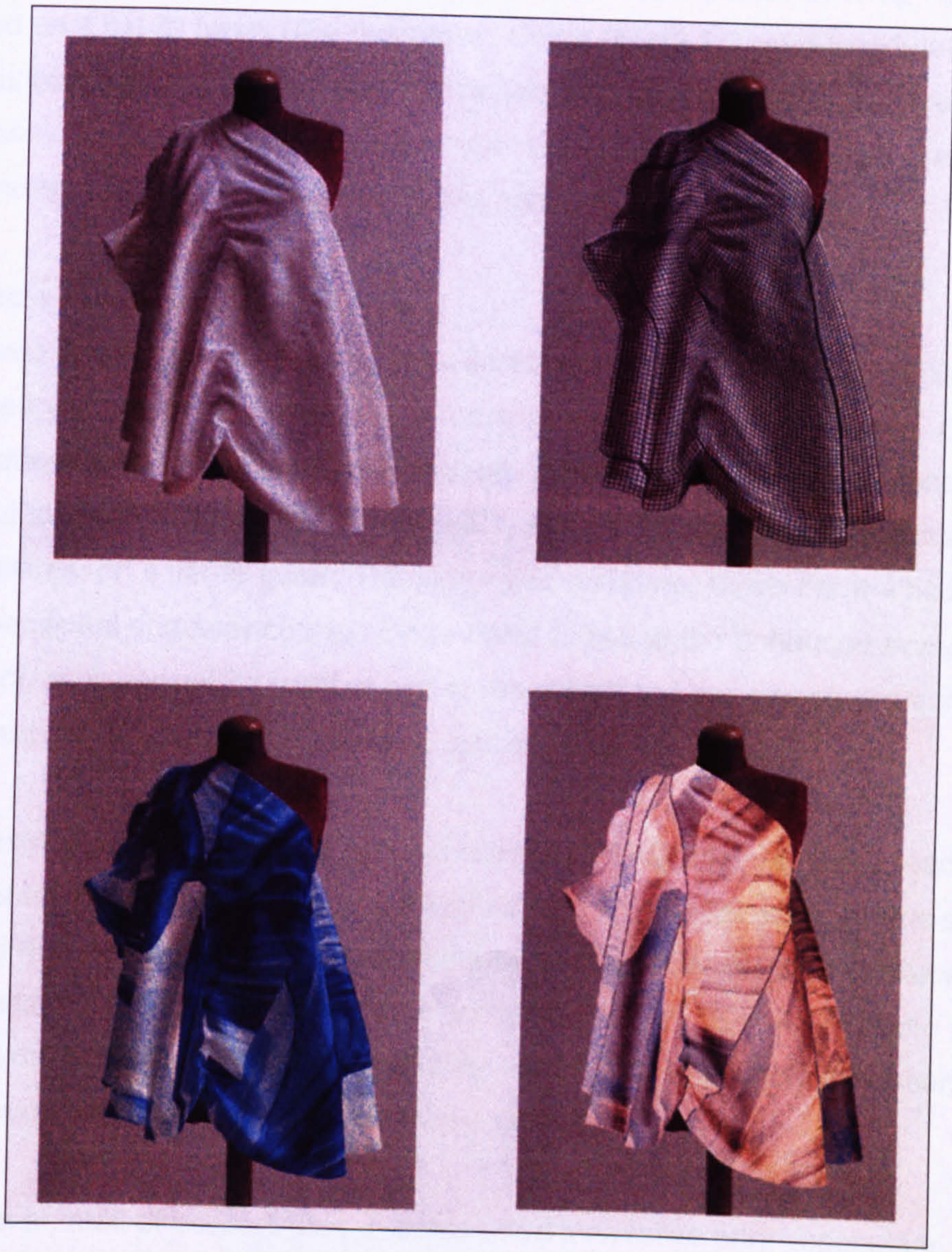

Figure 7-A Ruched Circle toile by Rosemarie Goulding integrated with Circle Pleats 6 
compared to the scale that most print designers work at. ${ }^{16}$ To facilitate the process of print integration the surface was divided into six sections, by three intersecting curves, resulting in Contour C2. Curved contour lines were used to echo the overall shape and suggest sweeping movement. A $30 \mathrm{~cm}$ section of one of the contours would provide an opening for the body. Three different motifs; Darts, Pleat 1, and Pin Wrap ${ }^{17}$ were integrated on a flat-fill basis. The outcomes, Circle Pleats 1-3 were tonally effective but static in appearance, due to the style of imagery and the boundaries enforced by the internal contours. Circle Pleat 3 was the most visually interesting design, due to the three-dimensional illusion suggested by the scanned pleats (Fig.7-B).

\subsubsection{Circle Pleats 4-6: Multi-mapping}

I considered that in order to incorporate a sense of movement into a 2D circle it would be necessary to dissect the surface in a more complex way. A torus shape, Contour C3, was drawn featuring an oval (opening) placed off-centre. Six curved contours were introduced to create Contour C4. A new motif, Pleat $2{ }^{18}$ was incorporated into the seven sections, on a flat-fill basis. The integrated outcome, Circle Pleat 4 had a more three-dimensional appearance than Circle Pleat 2, due to the enhanced trompe l'oiel pleat-effect, achieved with a motif of higher resolution and the new placement of the pleats, which now radiated from the oval opening (Fig.7-C).

In an attempt to introduce greater surface interest that would relate more readily to the qualities of the Ruched Circle, texture mapping was employed, using a torus shaped wire frame (Fig.7-D). The motifs were mediated through the grid to fill Contour C4. Circle Pleats 5 (Fig.7-E) shows the partially filled contour. The most dramatic visual effect was the twisting of the imagery and the suggestion of swirling movement, resulting from the influence of the wire frame on the motif.

The illusion of multi-directional pleats represented innovative print vocabulary. The incorporation of additional contours enabled the motif to be incorporated at a smaller scale. $^{19}$ The re-contoured, re-filled shape, Circle Pleats $6(7-F)$, was much more sympathetic to the soft volume of the original piece. The design was texture-mapped, (for a second time), onto a contoured digital image of the Ruched Circle, in order to visualise the effect of the print on the modelled shape, as shown earlier in Figure 7-A.

\footnotetext{
${ }^{16}$ Designs of: $20 \times 20$ or $30 \times 30$, are usual for dress fabrics although some placement prints exceed these measurements (2.4.1).

17 The motifs were created by selecting different visual aspects of Pin Wrap1 (Fig.6-J, p.6-25).

${ }^{18}$ Pleat 2 was created by scanning the centre section of Pin Wrap 1 at $200 \mathrm{DPI}$.

19 Disparities between the size of the curved, internal shapes of Contour C4 and the rectangular motifs made it difficult to fill the segments of the circle without the image beginning to deteriorate (6.4.4.2).
} 

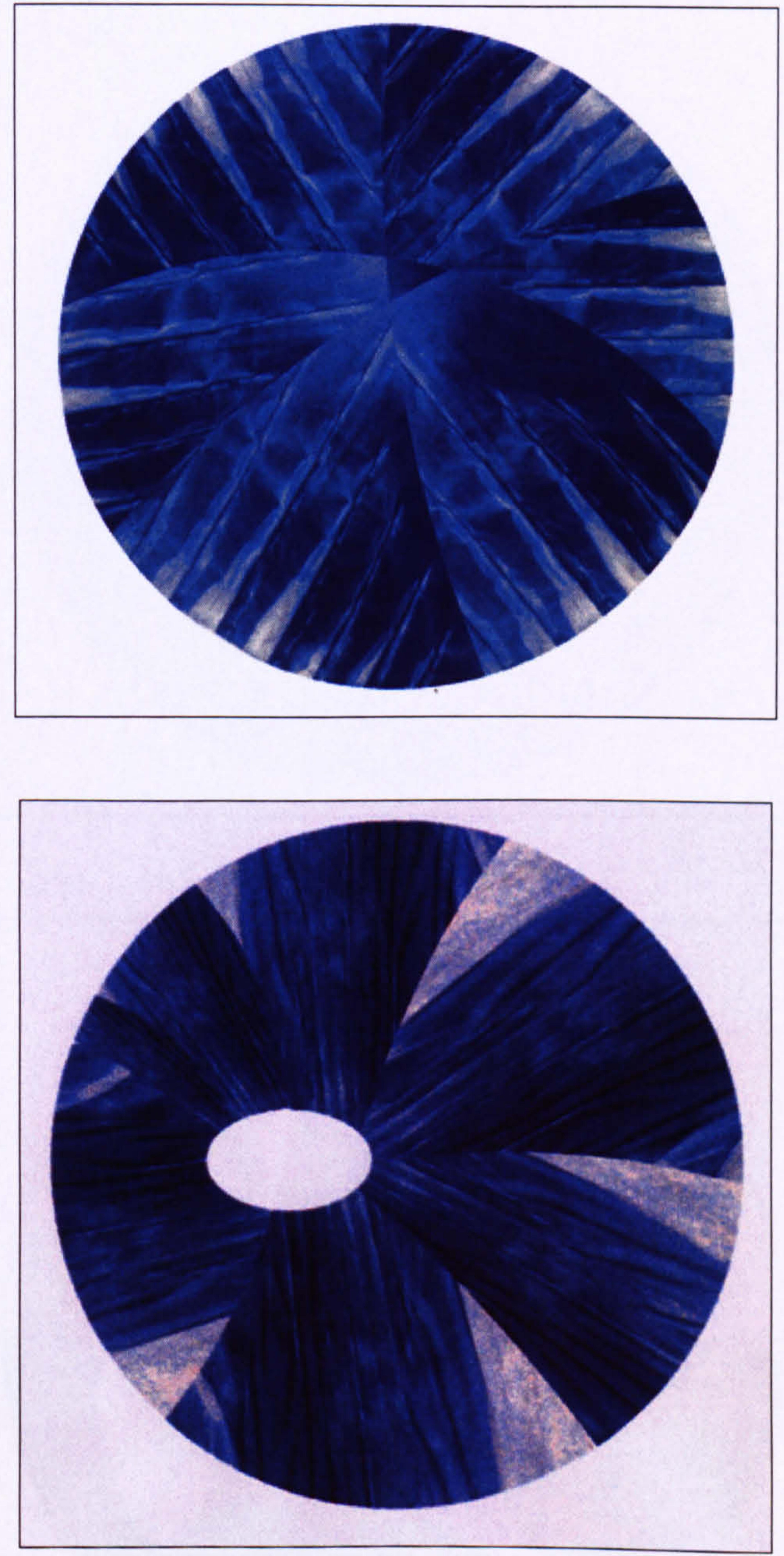

Figure 7-B Circle Pleats 1

Figure 7-C Circle Pleats 4 

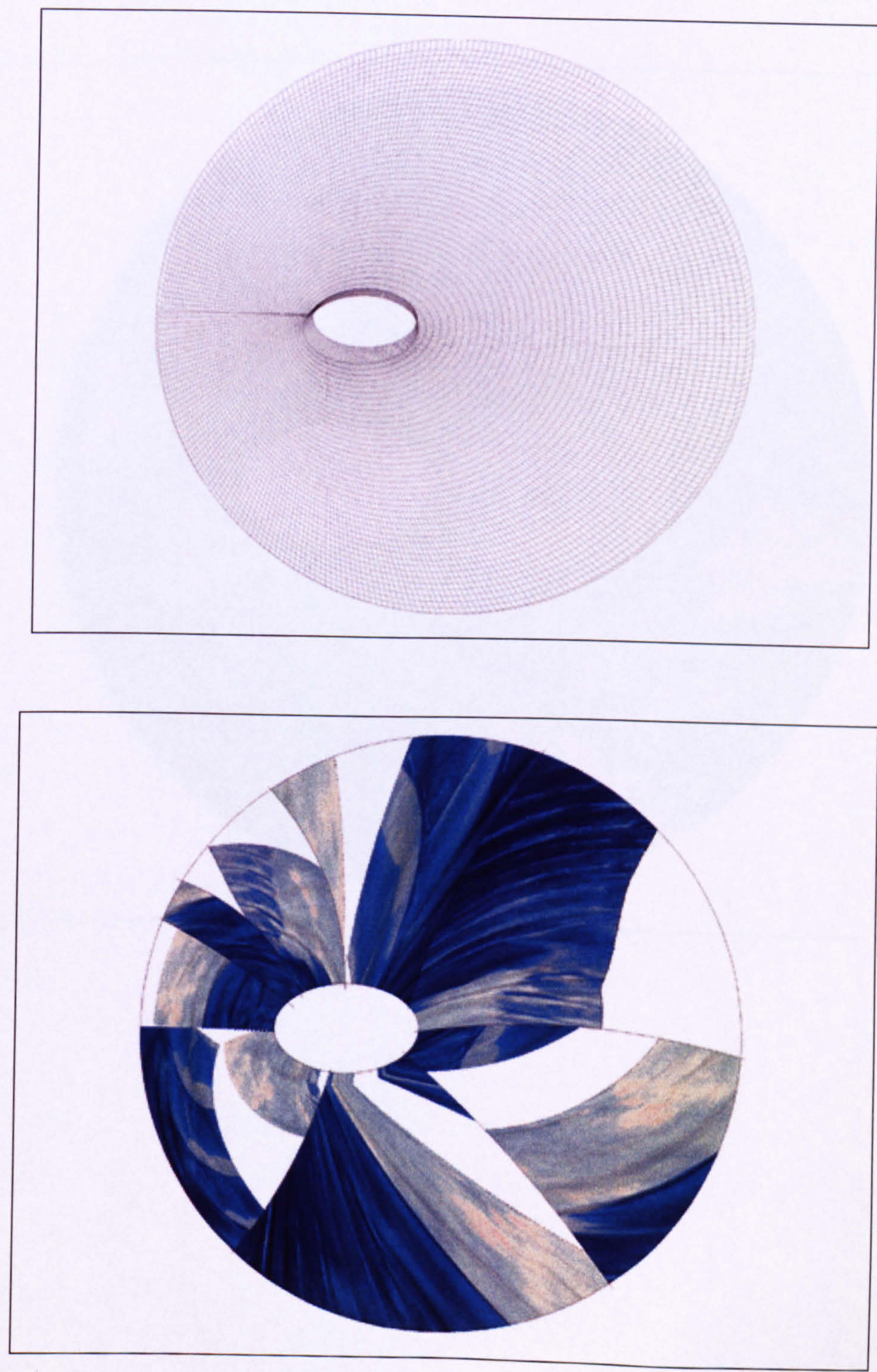

Figure 7-D Torus Grid

Figure 7-E Circle Pleats 5 


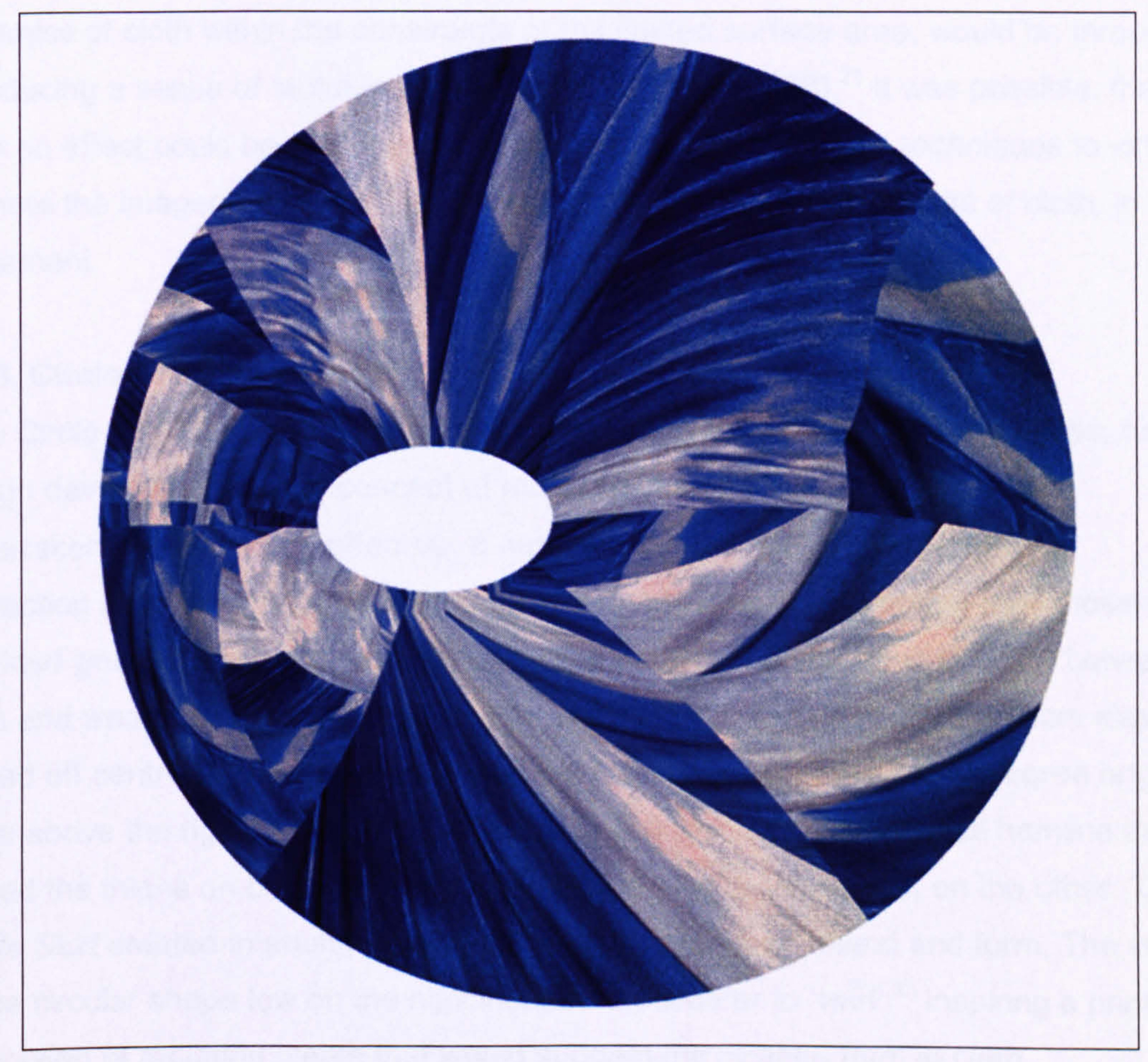

Figure 7-F Circle Pleats 6 


\subsubsection{Evaluation of Effects}

The dramatic effects on imagery, resulting from the application of a torus-shaped grid, provided possibilities for introducing a sense of 'movement' into the work. The predetermined $(144 \mathrm{~cm})$ dimensions of the Circle pattern provided considerable scope for image manipulation, but the shape was limited in terms of cloth volume and how this could be related to the form. ${ }^{20}$ I decided that the only way I could simulate the dynamics of cloth within the constraints of the limited surface area, would be through introducing a sense of 'autokinetic' illusion (Davies 1980: 28). ${ }^{21}$ It was possible, that such an effect could be achieved by employing 'double-mapping' techniques to virtually animate the imagery, through simulating the effect of a greater volume of cloth, in movement.

\subsubsection{Circle Skirt: Intentions}

With Circle Pleat 6 being considered the most innovative outcome of the series, further design development of the concept of multi-directional pleat placement was undertaken. For this to be effective, a new circular shape that interpreted the interaction between image, cloth and form was required. A skirt shape was chosen as it provided greater aesthetic possibilities for the illusion of confluence to occur between cloth and wearer. A new $144 \mathrm{~cm}$-diameter shape was cut in calico with a $40 \mathrm{~cm}$ slash placed off centre. ${ }^{22}$ The resulting, Circle Skirt (7-G) was placed at a 30 degree angle (from above the right hip to below the left), resulting in an asymmetrical hemline that skirted the thighs on one side and dipped beyond the lower calves, on the other. The Circle Skirt created interesting asymmetrical shapes on the stand and form. The styling of the circular shape low on the hips inspired the wearer to 'twirl', ${ }^{23}$ inspiring a print composed of radiating pleats that would suggest the rotating form in cloth.

\subsubsection{Circle Skirt: Process}

A circular pattern shape was created and converted into Contour $C 7$ by adding nine curved contours, which divided the shape into ten segments. The placement of the segments was based on observations of the physical configuration of the draped toile on both the stand and human form. Lines correlating with pivotal draping points were

\footnotetext{
${ }^{20}$ For example some of Christian Dior's printed skirts employed over 8 meters of cloth to achieve dramatic effects (3.3), whereas I had approximately $1.5 \mathrm{M}^{2}$ with which to transform the human shape.

${ }^{21}$ Davis discusses the two major types of illusion as: 'static', or not moving and 'autokinetic', or appearing to move.

${ }_{22}$ The width of the opening enabled the piece to be eased over the head and chest of a wearer/mannequin to rest on the hips.

${ }^{23} \mathrm{~A}$ full, gathered skirt can have this effect on the wearer; the volume of cloth inspiring a turning movement to appreciate the swish of the cloth.
} 

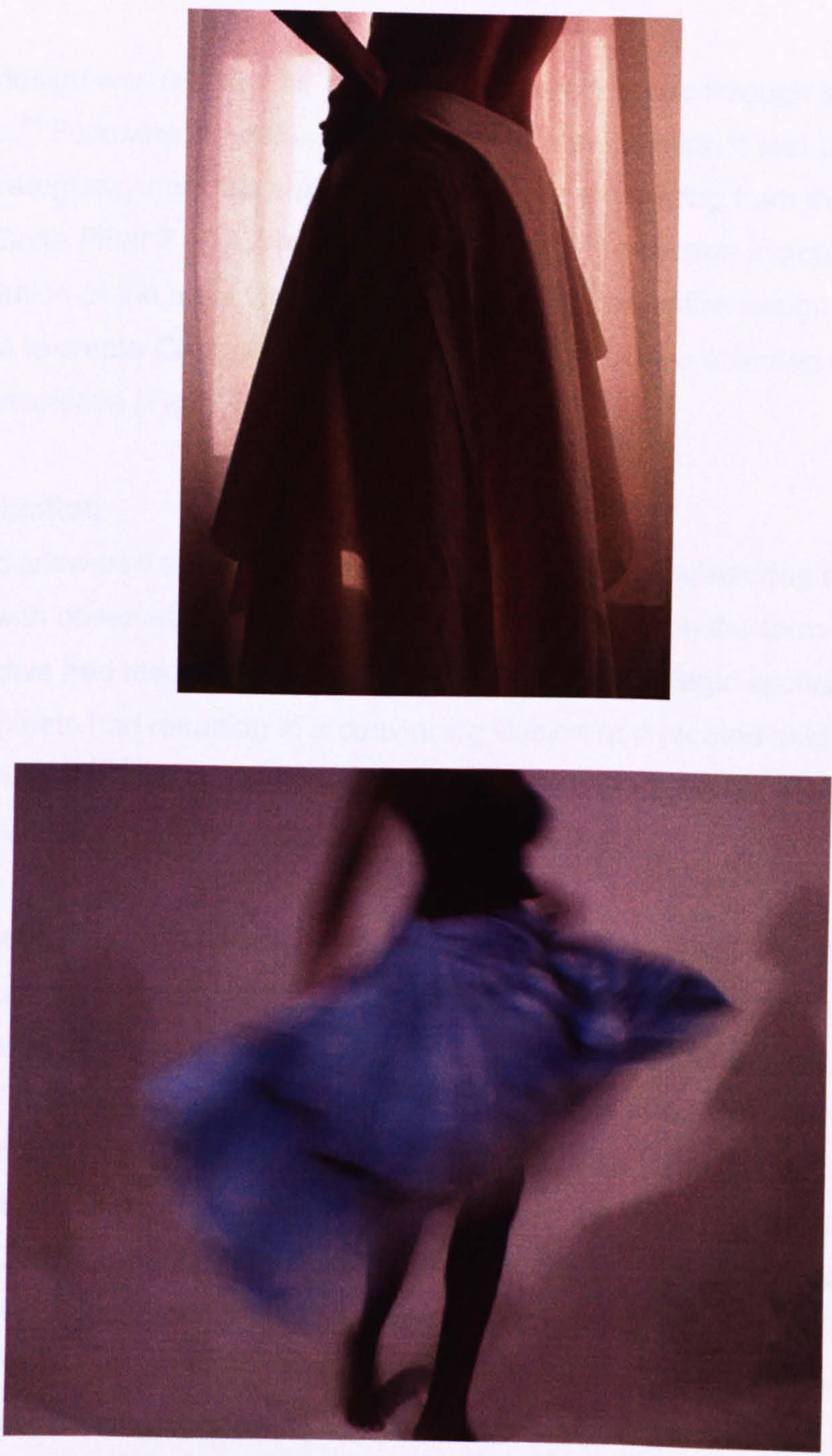

Figure 7-G Circle Skirt toile on the form

7-Gi Nautilus Skirt in movement on the model 
drawn directly onto the toile, allowing measurements to be taken, so that contours could be drawn accurately (in CAD) to correspond with strategic changes in the fall of the fabric around the form.

A new print design was created, by mediating a pleated image through a torus-shaped mapping grid. ${ }^{24}$ Following considerable attempts at manipulation it was possible to map the pleats strategically onto the shape as if they were emanating from the opening, resulting in Circle Pleat 7 (Fig.7-H). Paper print-outs of the design indicated that the original resolution of the motif was not high enough, so the entire design procedure was repeated to create Circle Pleats 8 using Pleat 4, an image scanned at a higher $(400 \mathrm{DPI})^{25}$ resolution (Fig. $\left.7-1\right)$.

\subsubsection{Evaluation}

Circle Pleat 8 answered the first of the design objectives of engineering the print in accordance with observations of the 3D draped, cloth shape on the form (7.1.5). The second objective had also been partially fulfilled, with the strategic application of trompe l'oiel pleats had resulting in a convincing illusion of a pleated skirt. The pleats radiated out from the hips in a vertical direction, ${ }^{26}$ which emphasised the shape of the skirt, but failed to evoke an expression of spiralling motion.

A 3D visualisation of Circle Pleats 8 integrated with the Circle Skirt toile, indicated that the printed illusion of woven, vertically pleated fabric was static and did not interact with the contours in a sculpturally, but in line with an architectural shape appeared to be 'emancipated' from it (3.3). The 'geometric illusion'27 conveyed by the trompe l'oiel pleats, was so convincing that it emphasised the architectural relationship that crisp, pleated cotton has with the body. Following a period of reflection, I concluded that the architectural nature of Circle Pleat 8 had been pre-determined by the original, calico toile. The woven calico had not only informed the shaping (2.3.1), but the directional weighting of the drapery had also inspired an architectural print. To test this analysis, I printed the design onto georgette, to assess whether a lighter quality would render the design more sympathetic to the form. The result was informative, as while the rigidity of the print was softened through its semi-transparent rendering, the geometric illusion

\footnotetext{
${ }^{24}$ Torus Grid 2 was created with a smaller central opening than Torus Grid 1, to accommodate the $40 \mathrm{~cm}$ slash of Contour C7.

${ }^{25}$ An intermediary motif, Pleat 3 was created by scanning the pleats at $300 \mathrm{DPI}$, was not considered to be of a high enough resolution.

${ }^{28}$ The design was redolent of the Goray pleated skirts of the 1950s while the trompe l'oeil pleats revisited the 1970 s concept of printed patchwork.

${ }_{27}$ Graphic illusion is also referred to as 'carpentered', which deals with 2D flat lines, angles, spaces and shapes that affect the visual perception of size, space and direction (Davis 1980: 29).
} 

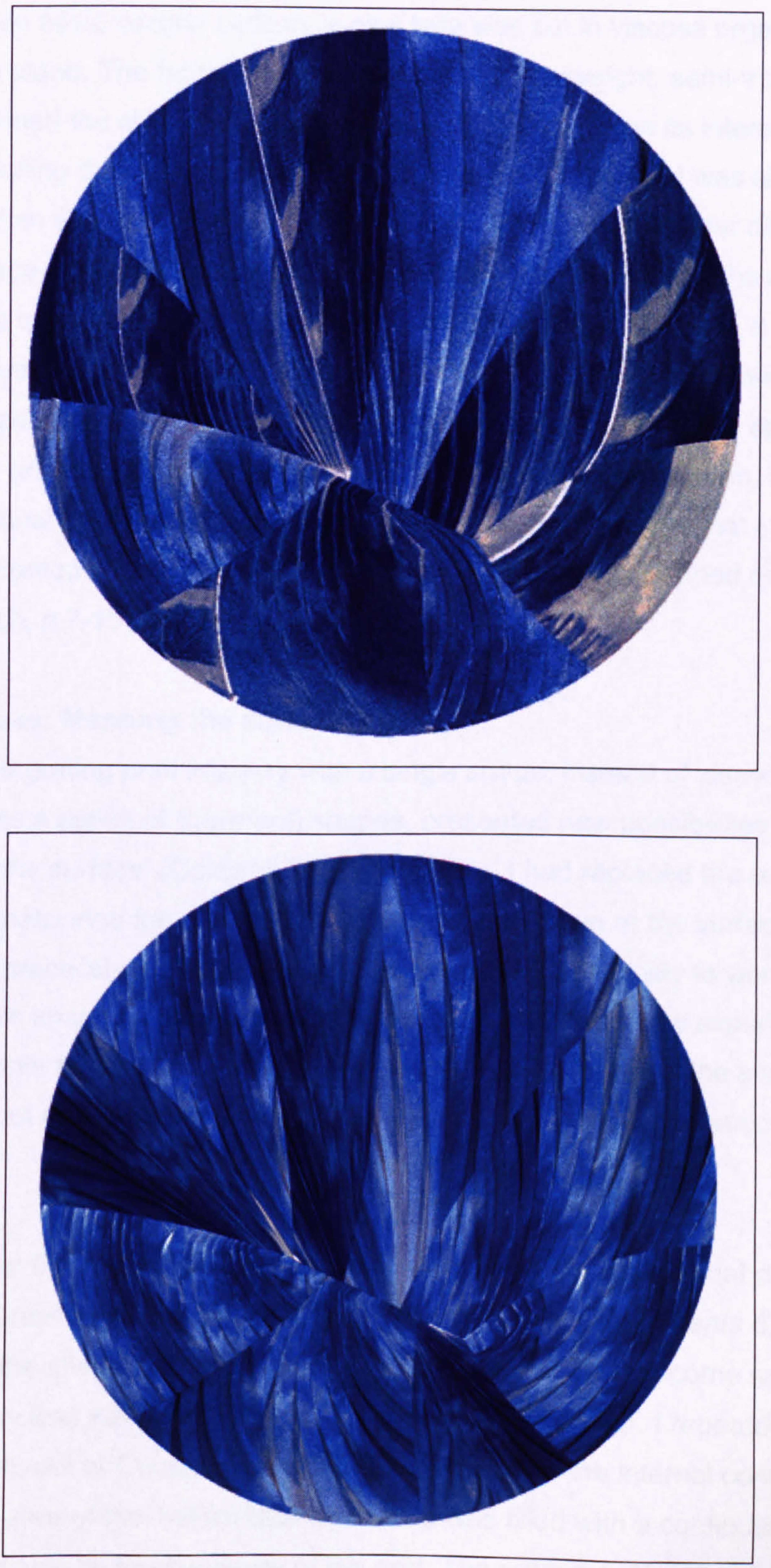

Figure 7-H Circle Pleats 7

Figure 7-I Circle Pleats 8 


\subsubsection{Nautilus: Intentions}

Using the same basic circular pattern, a new toile was cut in viscose organza and placed on the stand. The fabrication of the piece in a lightweight, semi-transparent cloth, transformed the shape into one that relied more readily on its interaction with the form. By modelling the organza shape on myself and on a model, I was able to observe the way the cloth shape circled the form through a $360^{\circ}$ turn, in greater detail. The combined image of cloth and form in spiralling motion was dramatic. The movements of the body were imparted to the skirt, but owing to the inertia of the cloth, it did not follow the bodily movements exactly, leading to some remarkable effects. These included the irregular curved shape, created by the edge of the piece as it rotated in space and the wrapping and unwrapping of the excess cloth as it collided with the form, slowed and halted. The visual impression inspired a new series of print designs that synoptically reflected the contours of the female form undertaking a choreographed movement in space (Fig.7-Gi, p.7-15).

\subsubsection{Process: Mapping the surface}

The task of integrating print imagery with a single shape, instead of weaving imagery together across a series of (garment) shapes, presented new possibilities for 'interrogating the surface' (Coldwell 2002). Ironically, I had replaced the constraints of seaming, by contouring the circle shape. This breaking down of the surface area was chiefly due to practical issues connected with the computer's ability to work effectively with large-scale images at high resolution. It was also related to my experience as a designer of prints for stretch garments; that were directly related to the scale of the form, but did not exceed its parameters. I resolved to take a more organic approach to the circle.

Taking Contour C6, I replaced the straight $40 \mathrm{~cm}$ slash with a curve that divided the circle in two. Drawing on the earlier successful outcome of Circle Pleats 6,1 filled the two halves of the shape with two arcs of simulated pleats. The outcome was striking, but the imagery was still curtailed by the single, internal contour. I repeated the mapping action, out of Contour Mode. ${ }^{28}$ In the absence of the internal contours, the entire surface area of the $144 \mathrm{~cm}$-diameter circle was filled with a continuous sweep of pleats directed only by the curvature of the grid. The outcome, Nautilus 1 presented a

\footnotetext{
${ }^{28}$ If this is not activated on the menu the application will attempt to 'fill' to the nearest outline, or in the absence of a boundary, the entire work surface, resulting in the system crashing.
} 


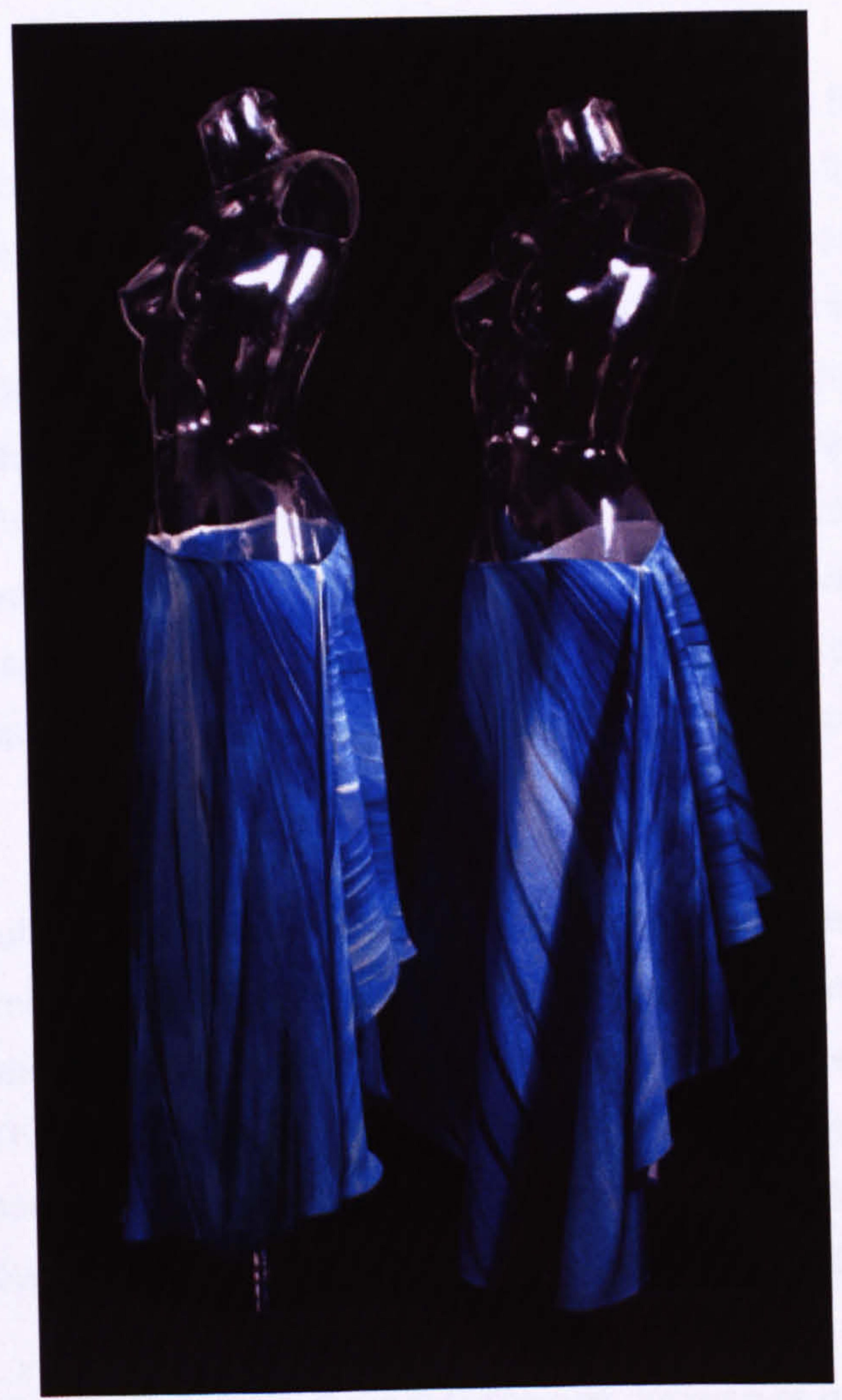

Figure 7-J Circle Pleat 8 on cotton drill and silk georgette, on stand 
spontaneous whorl of pleats evoking the appearance of the toile on the rotating form. The visual effect presented a possible design solution to the problem of integrating surface, shape and form, fluidly. The use of a nautilus-style image built on an earlier piece Ammonite Dress, where spiralling imagery was integrated across seams. A series of planned manipulations followed, using only the external contour of the circle. ${ }^{29}$ Figure 7-K shows an early and latter selection of the stages of design development.

\subsubsection{Analysis of Outcome}

Nautilus 16 was selected as the final design, which was printed on three qualities: cotton sateen, viscose javanaise and viscose georgette. ${ }^{30}$ Printing the same design onto three times provided a valuable opportunity to analyse the effect of similar mark making on different substrates. The cotton piece alluded to an architectural form through the weight of the cloth and the opacity of the print/cloth, which effectively masked the form. The javanaise version presented crossover characteristics through the lighter weight of the cloth and appearance of the print, which worked more closely with the form. The semi-transparent organza rendered the print and the form as indivisible, with the spiral markings accentuating the contours. Despite the influence of the different fabric qualities, in each piece, the illusory style of the print described the form sculpturally.

Nautilus was particularly evocative in the exhibition where its gentle rotation in space on the suspended mannequin replicated the movement that had originally inspired the design. The integration of print and cut appeared as a continuous spiral, without beginning or end. The ability to view the print through the transparency of the cloth and mannequin heightened the piece's visual fluidity and its ability to describe space, form and movement through pattern (Fig.7-L). As Penrose observes (1973: 261):

For a sculptor already working in three dimensions, instead of on a flat surface as in painting, the sense of space has a different significance. An inevitable contrast exists in sculpture between solid form and empty space, and the interaction between them can be made significant.

Ostensibly Nautilus was conceived as design that would describe the form by circumventing it, but the transparent nature of the mannequin led the print to perform as an encircling graphic structure, that also described space.

\footnotetext{
29 The circle was integrated with positive and negative versions of Pleat 4 in association with Torus Grid 3.

30 The printing substrates were supplied by the printers, except for the javanaise quality which was provided by Lectra Systems.
} 

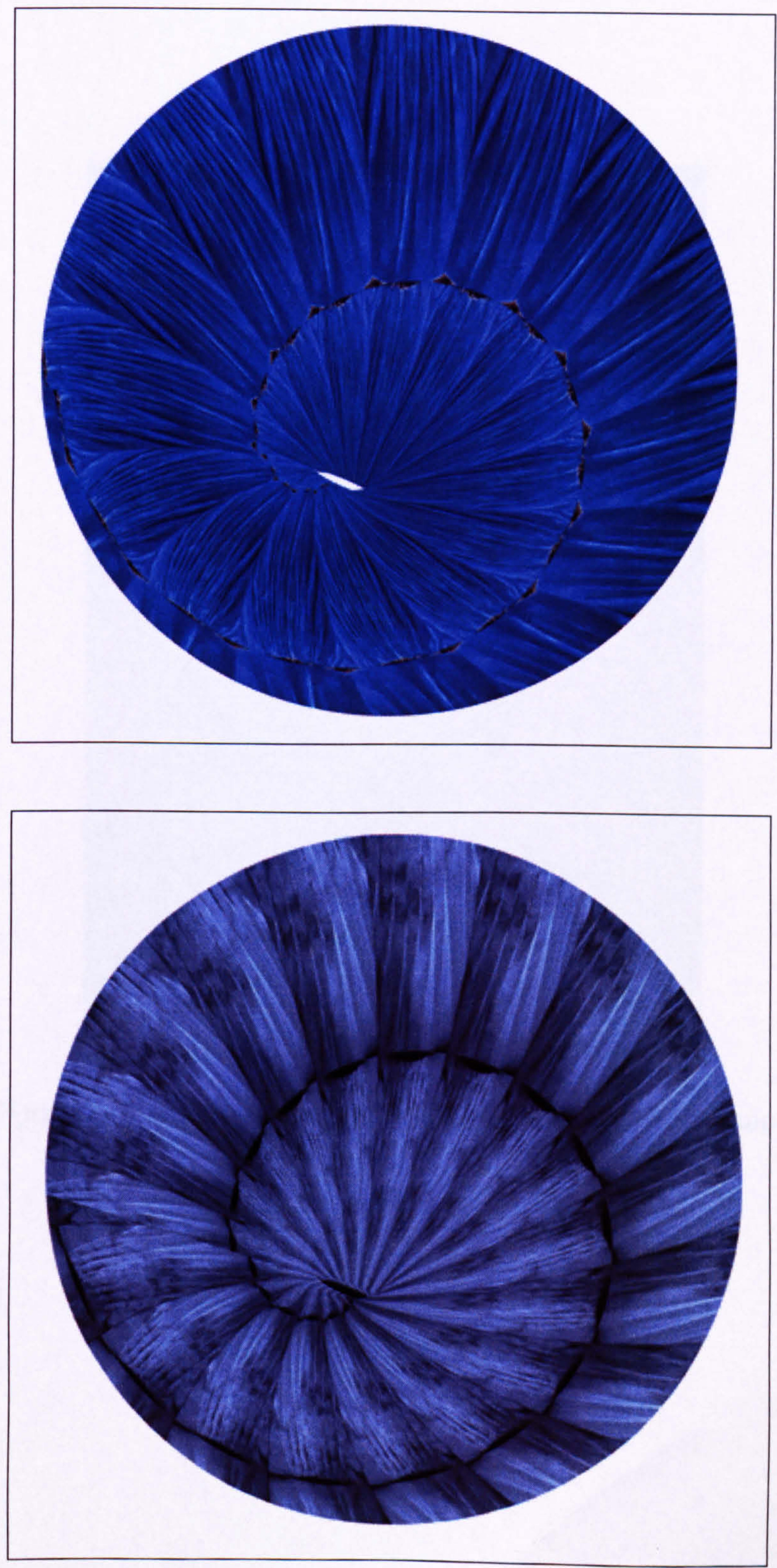

Figure 7-K Nautilus design development $(150 \mathrm{~cm}$ diameter) 


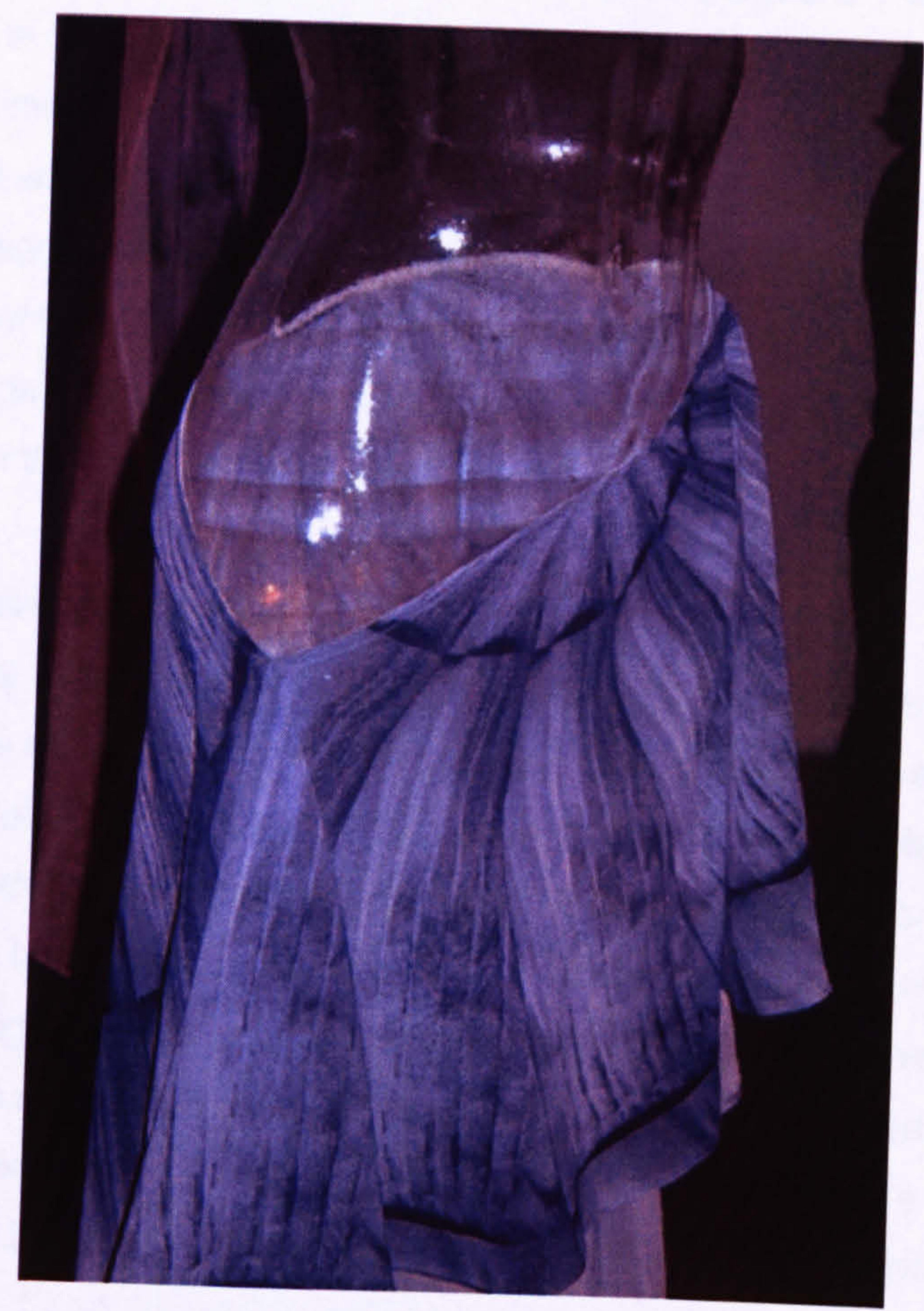

Figure 7-L Nautilus on the mannequin in Transforming Shape 


\subsection{SQUARE}

The Dress Square potentially presented a more regular, hard-edged shape to work than the circle. As with all the shape exploration, the final development of the print was ultimately more dependent on the fabric quality in which the shape was translated, and how this defined the 3D form, rather than the strict 2D geometry of the piece.

Prior to tackling the Dress Square, an alternative piece, Square 1 was investigated in muslin, resulting in the creation of a collection of cyanoforms that built on the earlier research into 3D modelled print. The final exhibition piece, Tide, was not related to these pieces, but was the result of rigorous experimentation with strategic print placement (in association with texture mapping), to create the illusion of the vertical flow and arrestment of water. The CAD manipulation undertaken in the creation of Tide demonstrated additional creative design possibilities for engineering prints within shapes, based on their relationship with the form.

\subsubsection{Initial Experimentation}

Initial observations were made of Square $1^{31}$ draped on the shoulders of the stand. The smoothness of the shape did not inspire pattern-making strategies, encouraging me to cut a new piece Square 2 in muslin. The muslin draped in a completely different way from the jersey, exhibiting crossover properties. Muslin performs more sculpturally when wet and has been used to sensuously articulate the female form by contemporary designers, such as John Galliano (1996) and Vivienne Westwood (1998) through the replication classical drapery (1.7). In order to create print designs based on this phenomenon, I used the cyanotype process to capture visual impressions of the $3 \mathrm{D}$ draping pattern of a series of $50 \times 50 \mathrm{~cm}$, muslin squares.

Six cyanoforms were created with the squares using a combination of draping and wrapping methods. The outcomes built on earlier outcomes such as Shadow Tunic 6 , by illustrating the patterning potential of the capturing the effect of light on cloth (6.3.4). The designs were not developed as final pieces due to the similarity of the fundamental structure of Square 2 to the Circle Skirt. ${ }^{32}$

The Dress Square was developed in calico by Sue Keen, providing a contrasting, more architectural shape to investigate through print (Fig.7-M). ${ }^{33}$ The strong vertical drape of

\footnotetext{
${ }^{31}$ Square 1 was developed by Rosemarie Goulding using 1 square meter of cotton jersey, with a central $30 \mathrm{~cm}$ slash as an opening..

${ }^{32}$ See images no. 6-10 in Chapter 5: Blueprints on the enclosed CD.

${ }^{33}$ In contrast with the Circle Skirt, the Dress Square was conceived as a wrapped, rather than a draped piece, measuring $100 \times 100 \mathrm{~cm}$ and styled on the form at 45 degrees as a diamond shape.
} 

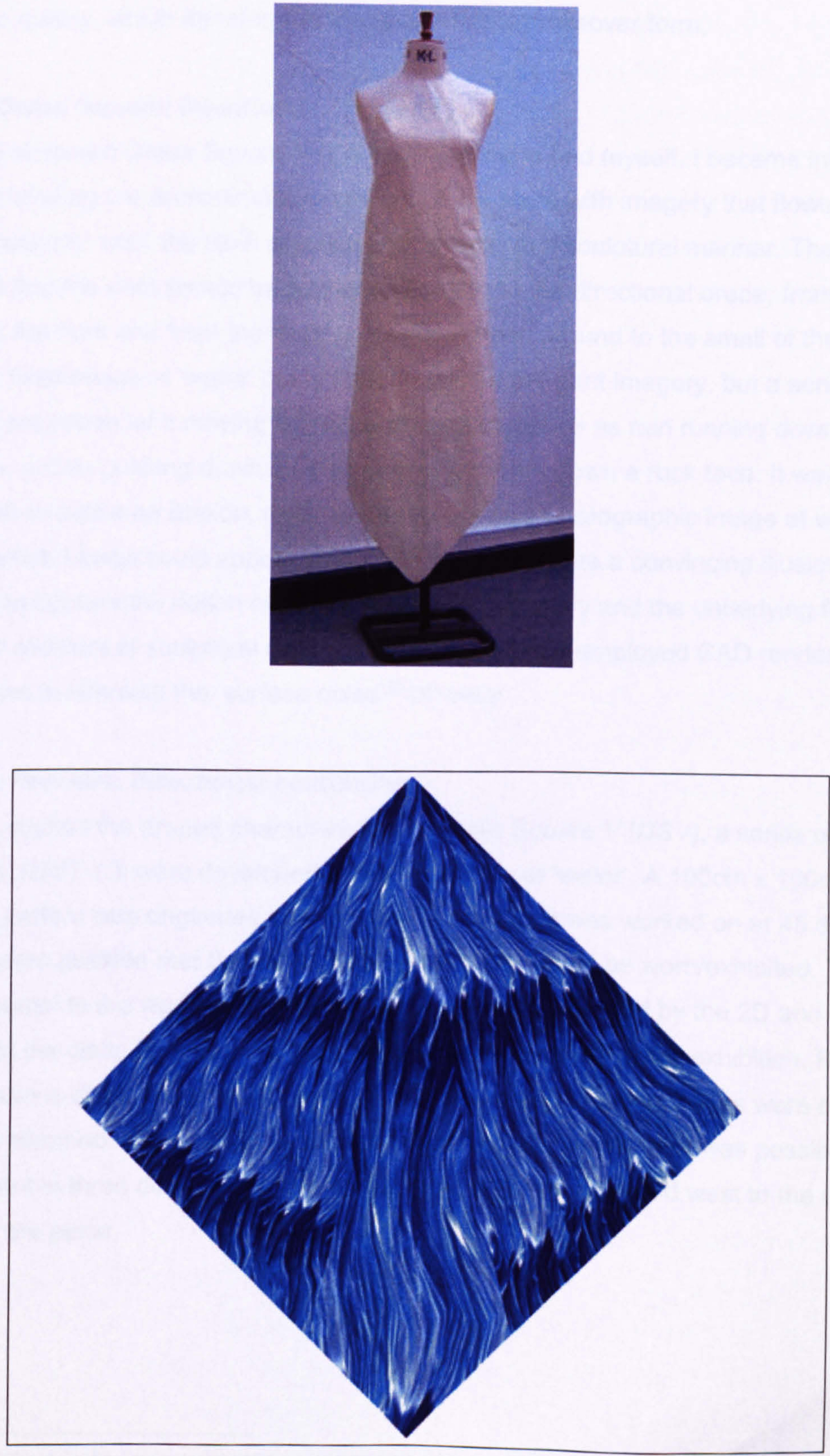

Figure 7-M Dress Square toile by Sue Keen

Figure 7-N Dress Square 1 (DS1) 
the centre-front of the modelled shape inspired the idea of the downward, directional, flow of liquid. The crisp quality of the calico impeded such a notion from being expressed through the cloth, leading to the re-sampling of the piece in a more fluid viscose quality, which transformed the shape into a crossover form.

\subsubsection{Dress Square: Intentions}

Having observed Dress Square V(DSV) on the stand and myself, I became interested in accentuating the dramatically simple cut of the piece with imagery that flowed empathetically 'with' the cloth and underlying form, in a sculptural manner. The shape implied that the print should be applied according to the directional drape; from the neck to the hem and from the neck across the chest, around to the small of the back. I had no fixed image of 'water' in my mind to inspire the print imagery, but a series of mental snapshots of it moving quickly and vertically, such as rain running down a window, a river gushing down a slope or lava coursing down a rock face. It was my intention to evoke an illusion, rather than reproduce a photographic image of water on cloth, which I knew could appear static. ${ }^{34}$ In order to create a convincing illusion, I sought to capture the notion of flux between liquid drapery and the underlying form, in a manner redolent of sculptural drapery. To achieve this, I employed CAD rendering strategies to simulate the 'surface noise ${ }^{, 35}$ of water.

\subsubsection{Process: Directional contouring}

Having studied the draped characteristics of Dress Square V(DSV), a series of designs, (DS1-10) were developed along the theme of 'water'. A $100 \mathrm{~cm} \times 100 \mathrm{~cm}$, square pattern was originated and the resulting contour was worked on at 45 degrees, in the same position that the shape was created and would be worn/exhibited. This was fundamental to the working context as the design was informed by the $2 D$ and $3 D$ shape of the cloth, in relation to the form and would be sited in the exhibition. Based on observations of the draping pattern of $D S V$, seven internal contour lines were drawn into the diamond. By dividing the surface area into eight sections, it was possible to apply print in three different directions; south to the hem, east and west to the centre back of the piece.

\footnotetext{
${ }^{34}$ In 2000 Paul Smith transposed photographic prints of the sea onto shirts, which were striking, but static, leading the wearer to be effectively dominated by the print.

${ }^{35} \mathrm{~A}$ term often used in graphics to denote surface texture. The artist John Pengelly (2002) used the term to describe his attempt to create the textural effects of woodblock prints using computer rendering techniques.
} 


\subsubsection{Integrating the Concept of 'Flow'}

As well as being used to describe the crafting process (6.1), 'flow' can be used to describe the elemental quality that I was intent on capturing through the design of the Dress Square. An existing print design, Water Pleat (Fig.5-T, p.5-33) was chosen for its visual appearance (which alluded to ripples) and its technical background. As a 'virtually pleated' design, the piece presented the opportunity for experimenting with 'multi-mapping'. Prior to integration, the design had to be stretched by $200 \%$ (lengthways) to correlate with the scale of the $1 \mathrm{M}^{2}$ shape more accurately, which immediately increased the fluid appearance of the motif. In DS1, the design was integrated on a flat-fill basis with the contoured sections of the diamond, resulting in an effect that was more evocative of feathers ${ }^{36}$ than water (Fig.7-N, p.7-24).

A mapping grid, Diamond Grid 1 (Fig.7-O), was created that echoed the shape and drape of $D S V$ with the intention of heightening the notion of vertical and horizontal tidal flow. DS2 (Fig.7-P) was the first integration using the grid, which indicated the innovative results that could be achieved through applying different grids to the same image, twice. DS2 appeared to have a greater sense of movement than DS1. By strategically, scaling and placing the motif, further designs were engineered to evoke the illusion of the ebb and flow of water, within the parameters of the diamond shape. In DS3, the flow was mainly directed beyond the lower hemline, but appears to lap at the corners of the centre back. In DS4 the illusion of flow was hastened, by enlarging the scale of the motif. Of the four initial studies, DS2 and DS3 were considered to evoke the effect of fast, flowing water most successfully, and provided the basis for the final design (DS10), Tide.

\subsubsection{Contrasting Approaches}

The Dress Square was the only piece tackled by each of the four surface designers. In order to contexualise my own design solution I feel that it is appropriate to visually analyse how the other members of the group integrated surface pattern with the diamond shape. Figure 7-Q (p.7-29) shows four working pieces modeled on the halfstand. Amanda Briggs-Goode's design focused on the placement of flowers to correspond with the draped form; through the strategic placement of the hyper-real elements, which appeared to float down and gather in the lower half of the piece, visually weighting the shape accordingly. Gillian Bunce explored the possibility of manipulating a basic check to correspond with the 3D shape of the square the distorted optical patterning was achieved by mediating the print through a mapping grid.

${ }^{36}$ The structuring of swan feathers had been studied briefly in the research as they presented a continuously patterned, seamless, 3D covering. The final design, DS10 was perceived of as feathers by independent observers. 


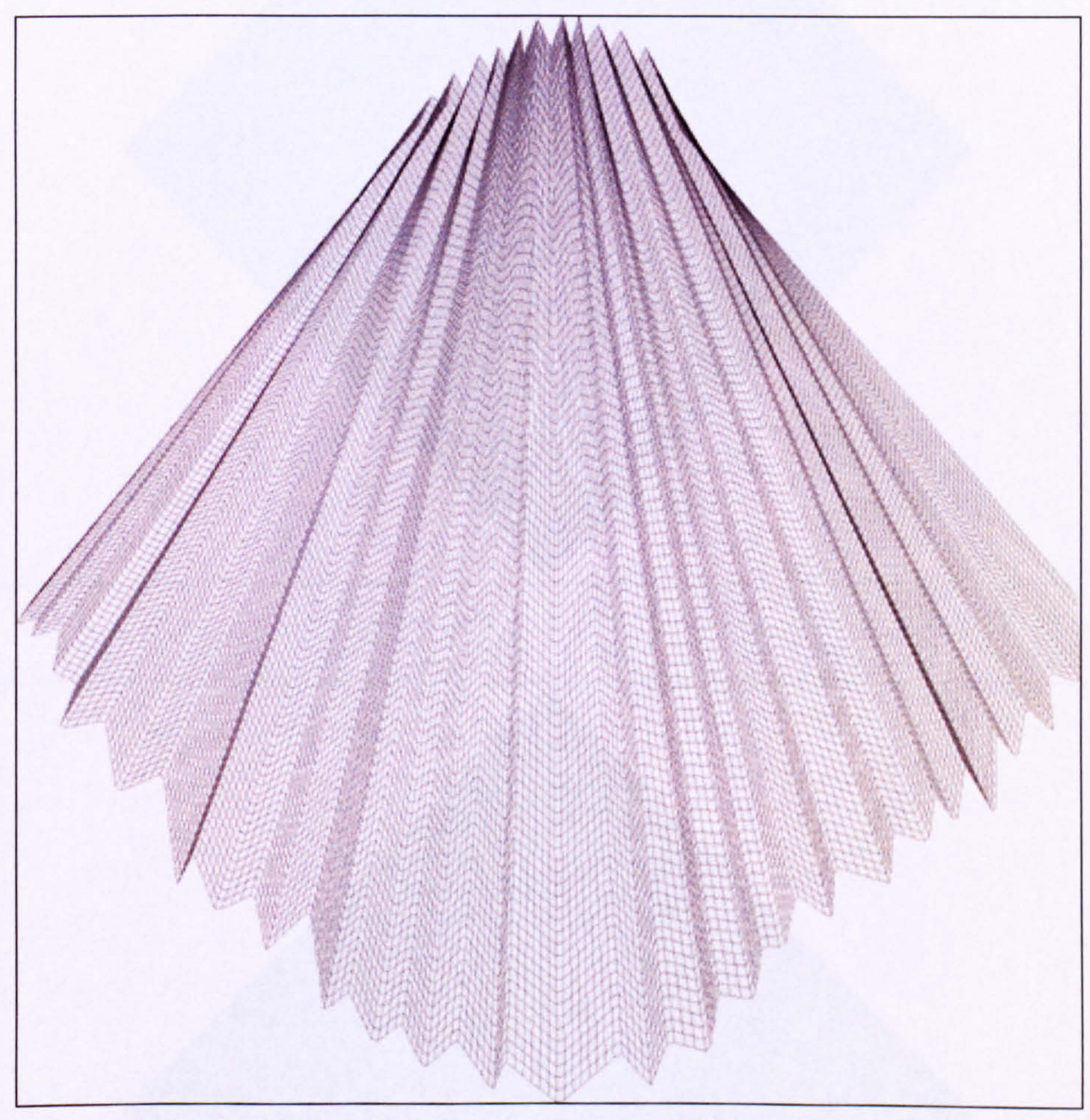

Figure 7-O Diamond draping grid 

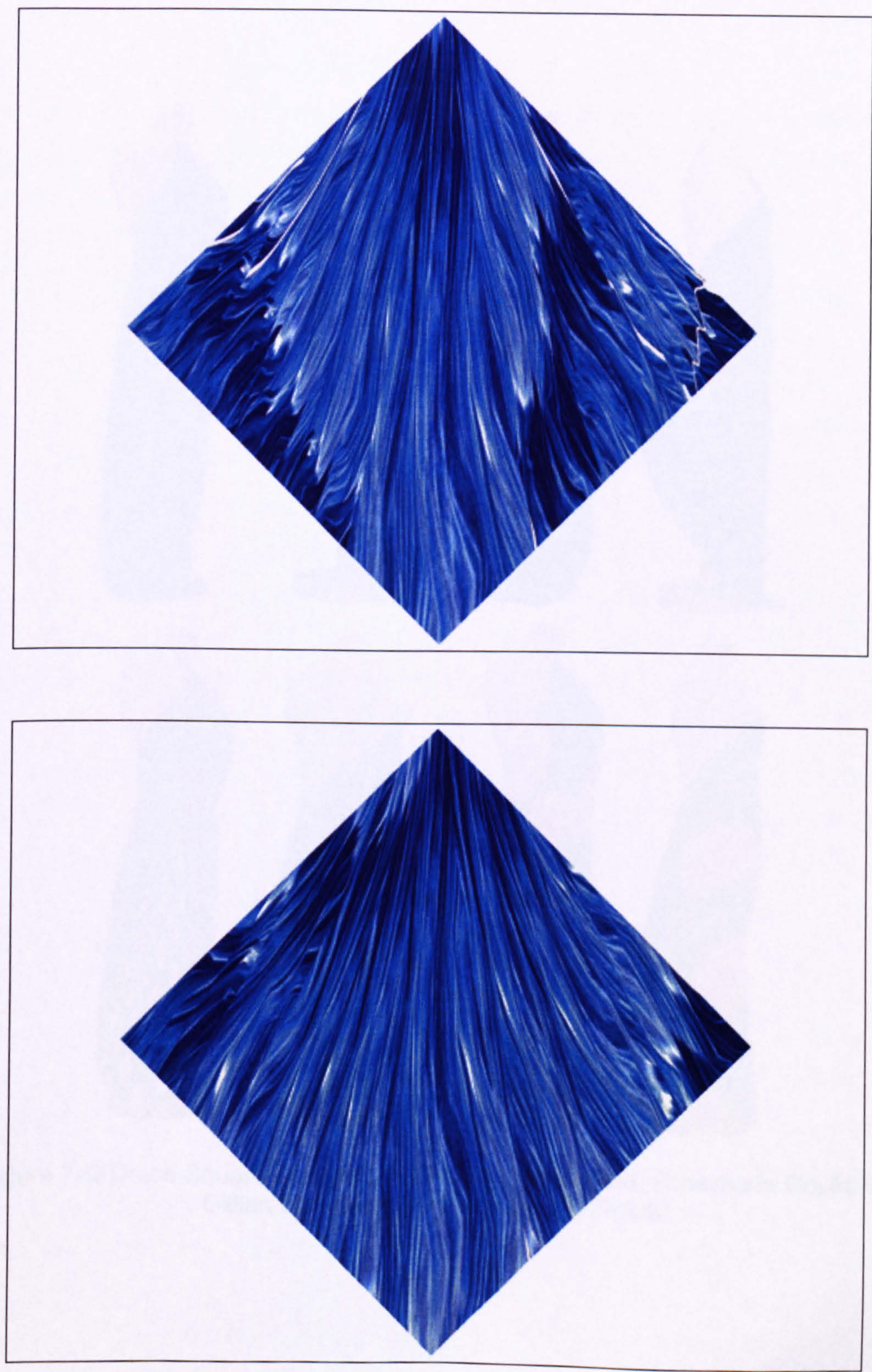

Figure 7-P Dress Square 2 (DS2) and Dress Square 6 (DS6) 

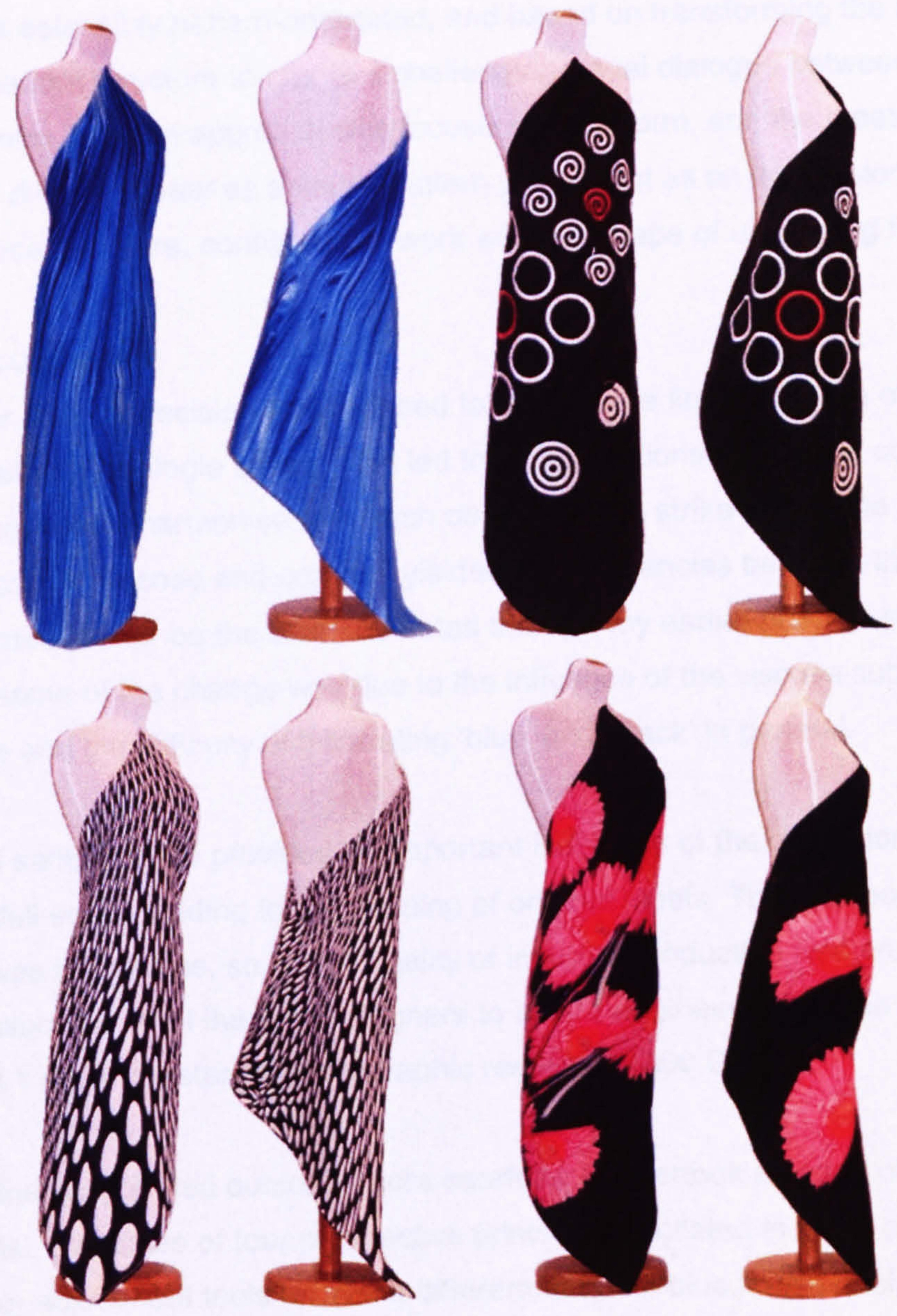

Figure 7-Q Dress Square designs by Katherine Townsend, Rosemarie Goulding, Gillian Bunce and Amanda Briggs-Goode 
Rosemarie Goulding's piece was centred on the dialogue between the geometry of the square contour and that of the internal circles, in relation to the form, which she developed further using transparent fabrics.

Gillian Bunce's optical approach was the most similar to my own, but her aesthetic objective was ostensibly pattern-orientated, and based on transforming the appearance of a simple pattern structure to create a challenging visual dialogue between $2 \mathrm{D}$ print and the 3D form. My own approach was focused on the form, and the creation of imagery that did not appear as a textile pattern per se, but as an impression of an elemental force of nature, configured to work with the shape of underlying form.

\subsubsection{Contour Colour}

In November 2001, a decision was reached to present the final collection of twelve designs together in a single space. This led to considerations of how the colours in the various pieces would harmonise with each other. Sample strike-offs of the Dress Square on cotton, viscose and organza yielded inconsistencies between the 'screen' and the 'printed' colour on the cloth, as noted through my earlier practice (5.5.1). I was aware that some of the change was due to the influence of the viscose substrate on the reactive dye and the difficulty of translating 'blue' and 'black' in general.

The printed samples also provided an important indication of the resolution of the designs at full-scale, leading to re-scanning of original motifs. The key focus of the exhibition was the textiles, so a high quality of image reproduction was crucial. It proved challenging to all the print designers to create engineered images in sizes upwards of 1 square meter, at photographic resolution (400 DPI).

To gauge the final printed outcome more carefully, I undertook a series of printed 'colour tests'. Swatches of four prospective prints were collated in strips and rendered using colour adjustment tools to create different tones of blue. ${ }^{37}$ The design was darkened, tinted and diffused in an effort to create a blue that would 'print' more closely to the original blueprinted cloth. Due to the tonal nature of the designs it was impossible to undertake conventional colour changing procedures using CAD (4.1.1). A spectrophotometer could have been useful here, but I wanted to attempt the task by 'eye', as this is how most independent designers would approach the issue. Following extensive, yet unacceptable 'blue' outcomes, I decided to convert the tonal images to 'grayscale'. ${ }^{38}$ This decision was difficult to make as cyan is a beautiful colour and

${ }^{37}$ See Colour Tests in Square on the CD.

${ }^{38}$ None of the shades of blue were considered to be particularly complimentary to the other colours in the exhibition, so a decision was reached to use a more neutral shade of grey. 
naturally symbolises water, the element I was seeking to replicate (5.2.3). But on reflection, colour was not my main concern, but rather the engineering of print as a means of defining the outline and contour of the form, which could be achieved with greater clarity using a non-colour. ${ }^{39}$

The contrasting tonal effects in my designs converted to grayscale without too much loss of detail. I was however, slightly concerned that the depth of illusion would be diminished through substituting cyan with grey. The re-coloration exercise involved more than a direct conversion to 'grayscale' and a considerable amount of further manipulation in CAD. Following further printing tests I finally selected an inverted version of the reconfigured design, which still resembled a fast flowing current in its positive form, DS11. An inverted version of the image appeared more textural; as molten lava or sculpted stone, resulting in its inclusion in the exhibition, as Tide (Fig.7R).

The colour changing exercise reinforced the value of CAD as a rendering tool, leading to alternative, innovative designs drawn from a single concept and the importance of digital print sampling prior to the printing of final pieces. A considerable amount of time was spent creating printed colour swatches on a range of substrates. I discovered that even slight alterations in the balance or saturation of a shade could alter the visual and resulting aesthetic quality of the cloth.

\subsubsection{Tide: Analysis of Outcome}

The printed square, Tide, interacted empathetically with both the model and the mannequin. The print imagery did not emphasise, but flowed with the form, as was my intention. Despite being engineered in different sections, the strong directional flow and repetitive rhythm of the linear markings worked visually as a moiré effect. In contrast with Nautilus which interacted with the notion of space and form, the wave-like markings of Tide worked optically to underpin the three-dimensional form of the model (Fig.7-S) and the mannequin (Fig.7-T). The design appeared textural from a distance; as a pleated Delphos, as feathers, as texture.

If the notion of text is expanded into any sign or context...the text of the order for CAM or the text of the order for CAD are in close textual proximity to the text of textiles per se, whose tactile quality is simulated in its material existence, and whose sensual properties are stored in the compressed chip-information unfolding into the fabric (Brink 1994: 90).

\footnotetext{
${ }^{39}$ In The Empty Body Part 2, Chris Townsend (2002: 76) discusses Judith Shea's shift from creating
} monochrome, coloured garment installations to exploring the clarity of form achieved through black. 


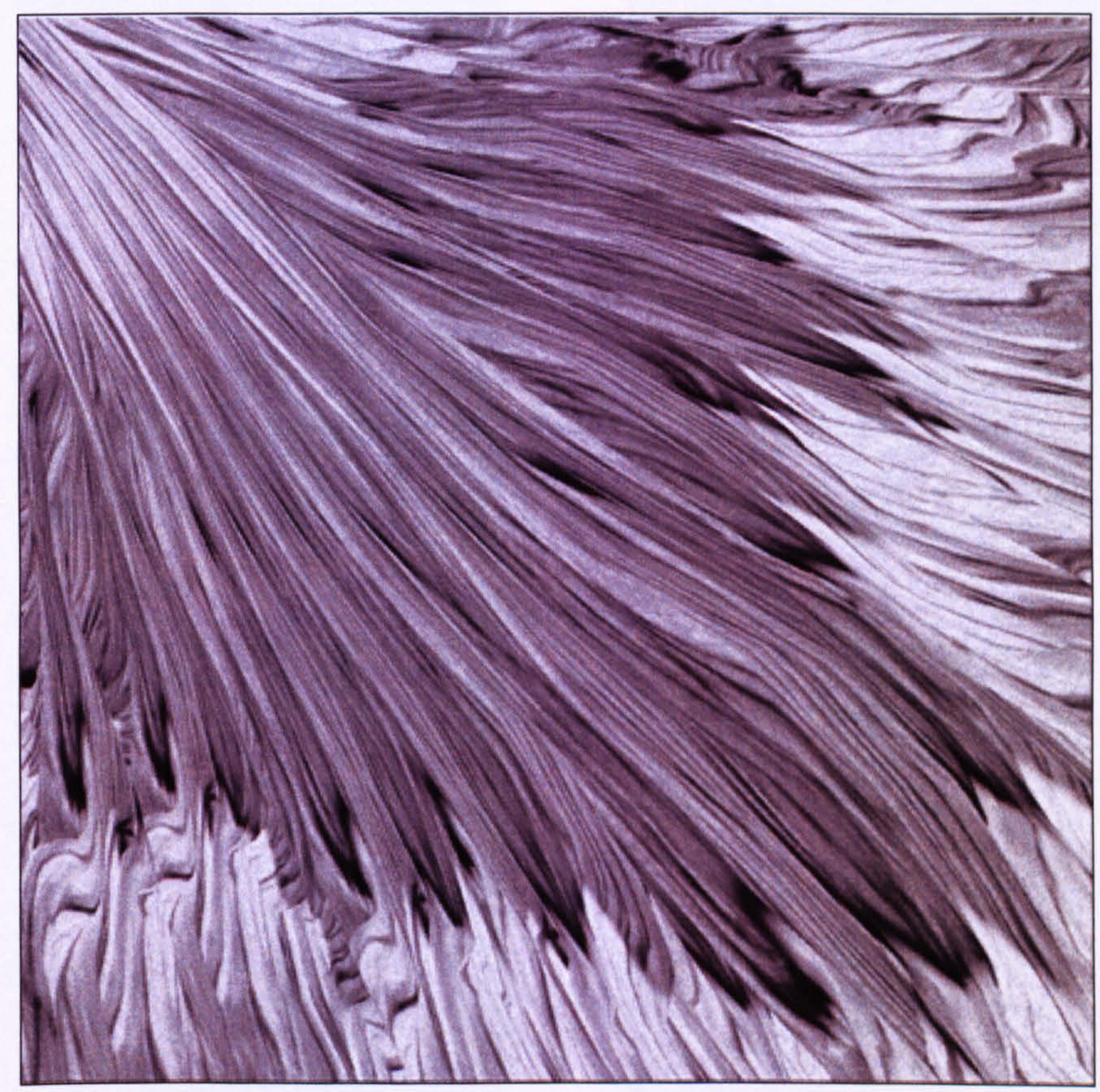

Figure $7-R$ Tide $(100 \times 100 \mathrm{~cm})$ 

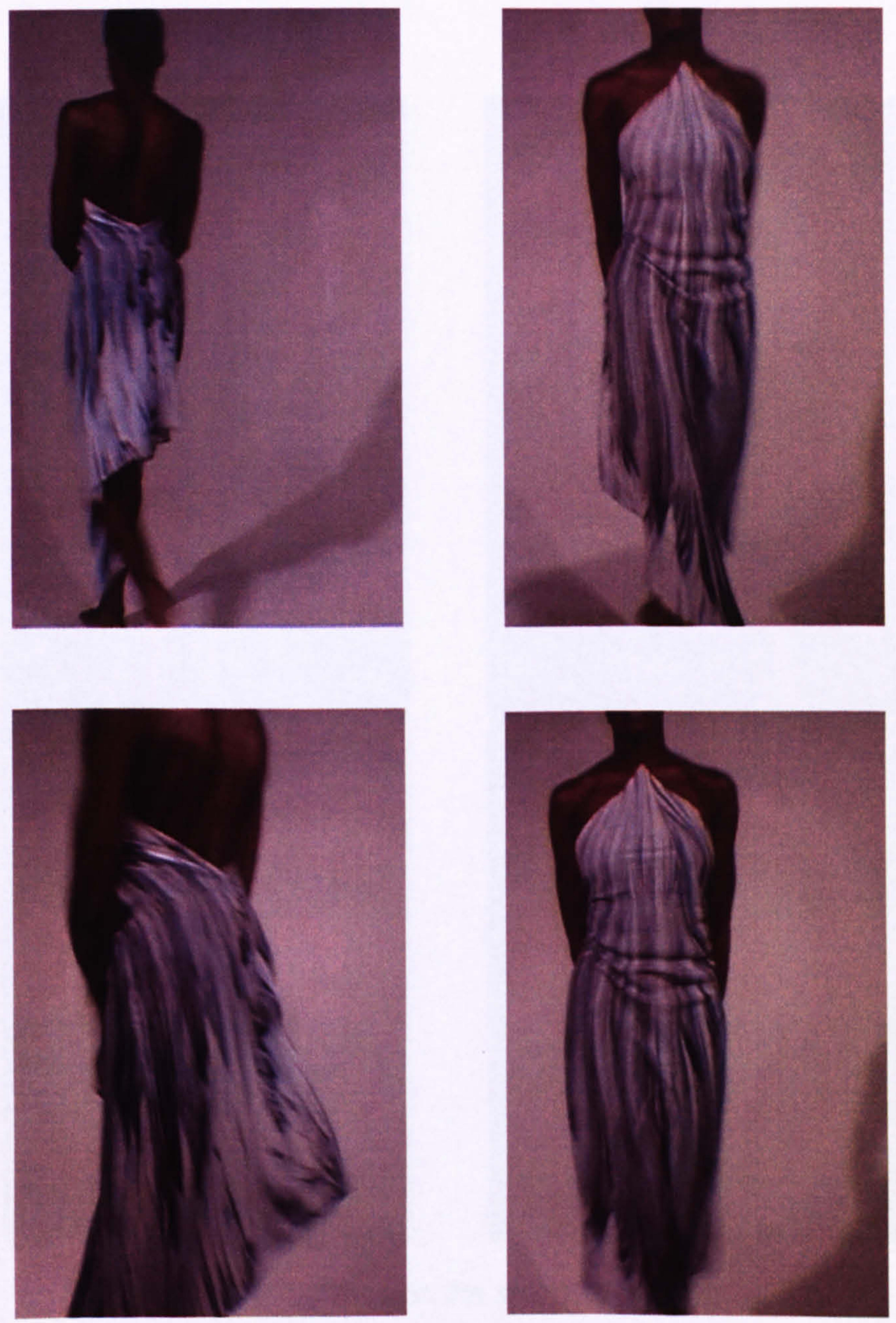

Figure 7-S Tide on the model, four views in movement 

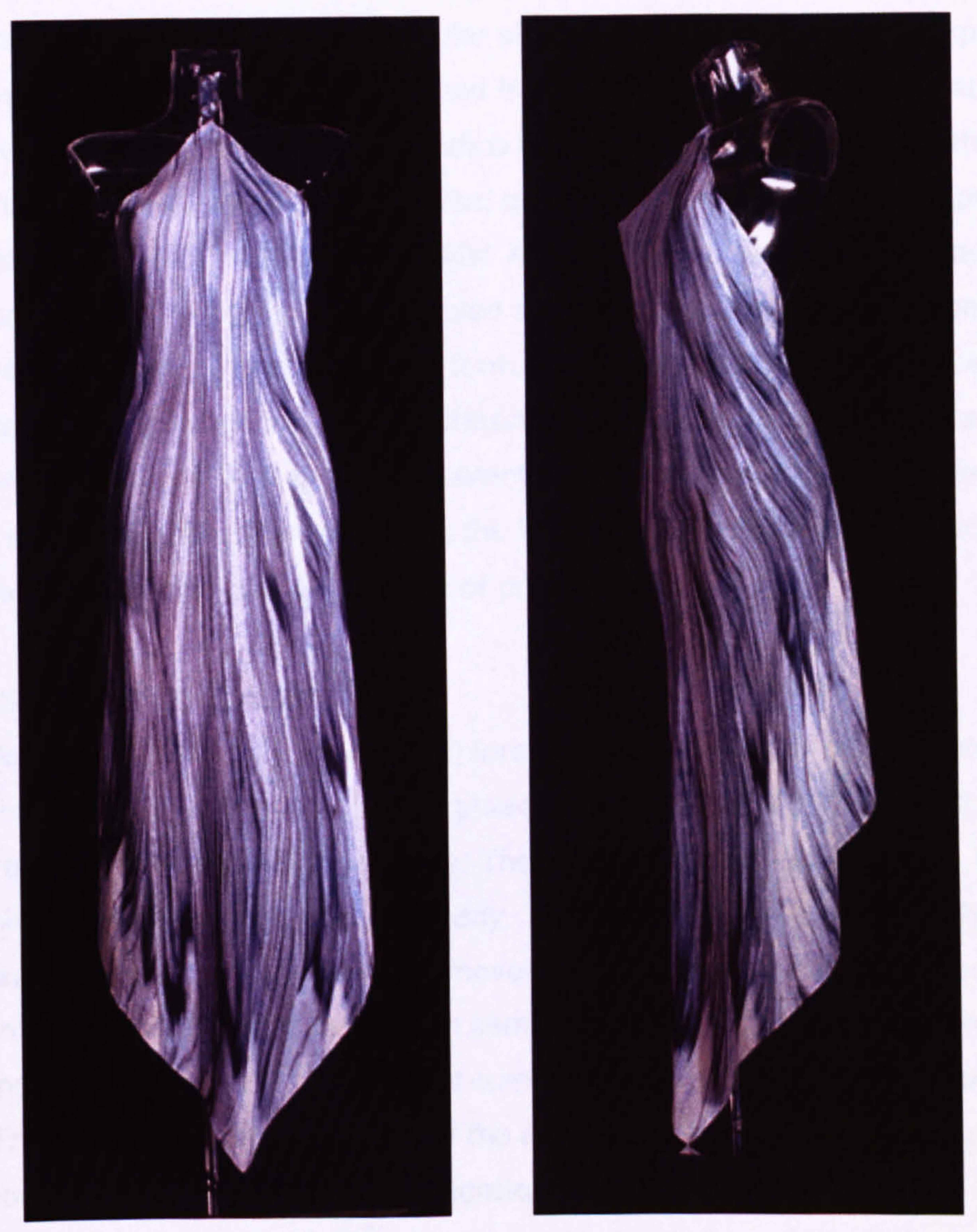

Figure 7-T Tide on the stand, two views 
Tide demonstrated the potential for using CAD in association with digital printing to translate illusionistic effects onto cloth that appeared to streamline the form. The piece illustrated the potential for altering the visual perception of the body shape through engineered print

\subsection{RECTANGLE}

I had already tackled a series of rectangular shapes through the Pin Wrap experiments (6.4.1). These pieces had been approached from an architectural design perspective that had relied on the characteristics of calico to be folded, wrapped and pleated. I was therefore initially drawn to the more ethereal qualities of some of the early experimental pieces; Rectangle Drift and Rectangle Twist. After exploring these pieces, I tackled the architectural Rectangle Wrap, which enabled me to explore the relationship between the scale of mark making and that of the form. Following the production of a range of digitally printed samples on a range of different substrates, a decision was made to present only transparent and semi-transparent fabrics for the exhibition. ${ }^{40}$ This led me to further investigate scale, by translating the final design: Wrap, into proportions that that challenged the accepted dimensions of printed textile imagery.

\subsubsection{Initial Experimentation}

The Rectangle Twist $(180 \times 90 \mathrm{~cm} /$ muslin) formed a twisted loop of cloth around the torso. The shape was fluid, yet complex, presenting the opportunity for showing the face and back of the cloth simultaneously. The Water Pleat was employed to convey the illusion of water swirling around the body. The use of this print was directly inspired by the combination of transparency and movement evoked by the twisted muslin shape on the form. By circumventing the form in semi-transparent cloth, the Twist presented a contrasting application of the Water Pleat compared with its strong vertical application in Tide. The semi-transparent qualities of the Rectangle Drift $(150 \times 80 \mathrm{~cm} / \mathrm{muslin})$ were also explored, resulting in a series of integrated CAD 'sketches'. While these experiments were highly relevant to my own research into the effect of integrating similar imagery with different fabric qualities and shapes, the designs did not present sufficient contrasts with Tide, to be included in the exhibition.

\subsubsection{Rectangle Wrap: Process}

The original Rectangle Wrap (Fig.7-U) developed by Sue Keen, formed an envelope of calico, folded in the centre, seamed, turned and draped asymmetrically on the hip to

${ }^{40}$ Cotton sateen, cotton jersey, linen, viscose georgette and viscose javanaise were sampled, but only the viscos qualities were considered to be of appropriate quality for the exhibition. The choice of light, semitransparent qualities was also considered to be sympathetic to the use of clear mannequins. 


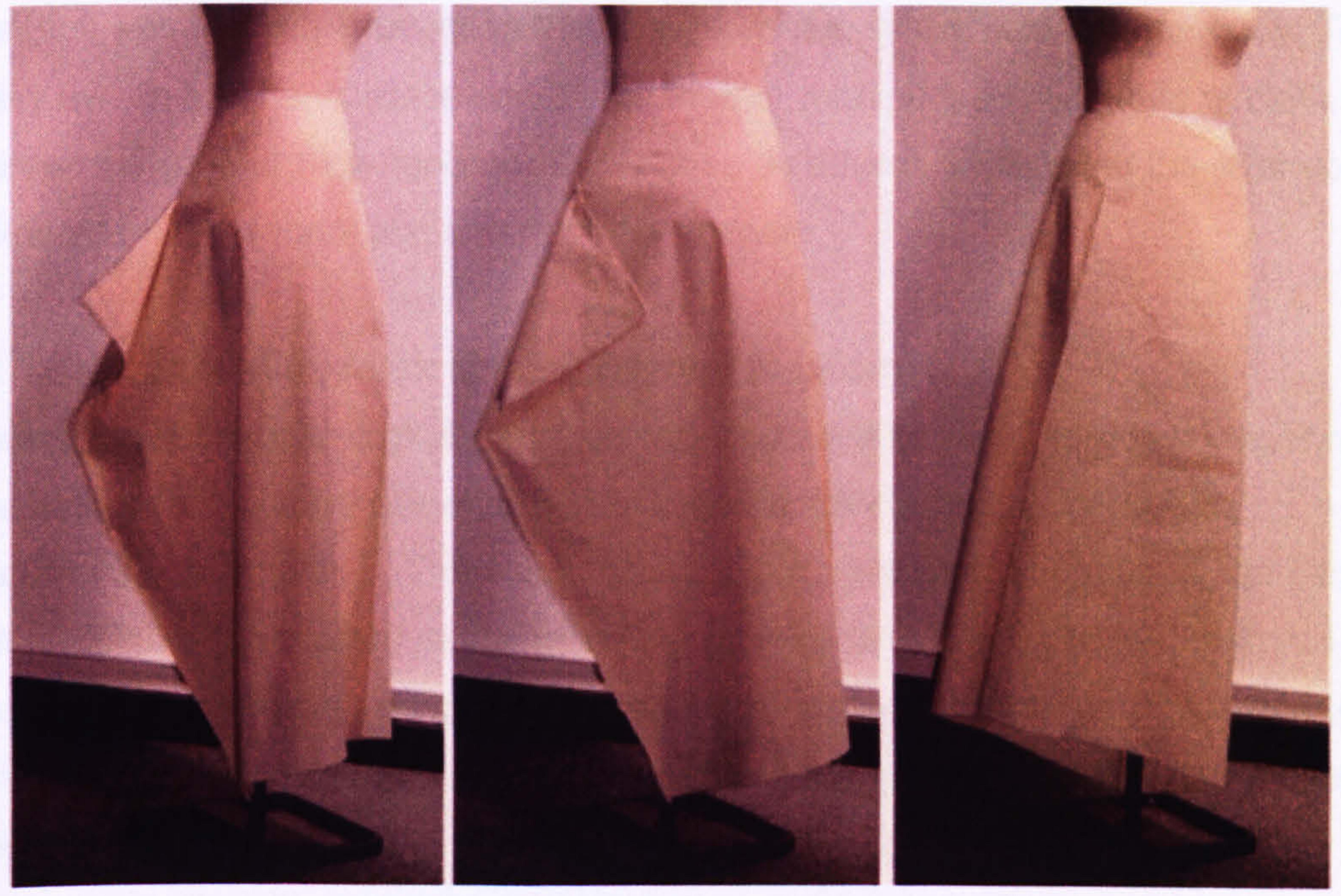

Figure 7-U Rectangle Wrap toile by Sue Keen 
form a skirt shape. I began by integrating imagery of the Pin Wrap 1 cyanoform $^{41}$ with, as a $3 D$ visualisation and a $2 D$, flat-filled pattern. The resulting print-filled pattern was printed out at half-scale onto paper to assess the relationship between the increased scale of the mark making and the form. Despite the absence of 'drape', the fabrication of the piece as a printed paper toile provided a valuable opportunity to visually analyse the piece. By observing and taking physical measurements of the installation I was able to make projections regarding the appearance of the piece at full-scale.

Rectangle Wrap1 presented architectural characteristics through both its enveloping structural shape and strong graphic detail (3.3). The support of the skirt-like structure by the hips was the only interaction that the geometric shape had with the body. The imagery, which had been conceived of via another manipulated rectangle of cloth, reinforced the garment's autonomous existence as a form, by drawing the attention of the viewer to the diagonal placement of the imagery.

\subsubsection{Wrap: Extending Mark Making beyond the Form}

Following the decision to digitally print on two viscose qualities, I could no longer rely on the architectural properties of cotton to execute the Rectangle Wrap1, so considered the alternatives. There was little point in attempting to replicate the same shape in viscose (javanaise) as the piece would flop, devoid of its former drama. I had already explored 'vertical and circular, directional', surface design strategies through the Tide and Nautilus pieces, so considered the Rectangle Wrap from a 'dimensional'42 perspective.

I contemplated the proposed Transforming Shape collection and noted that while each shape was related to the proportions of the human form, none of the pieces explored the space beyond its immediate physical boundary. I recalled the elongated dresses I had seen in exhibitions of art textiles by Beverly Semmes, Caroline Broadhead and Jane Baker (Jeffries 2001); how dramatic these pieces had appeared and that few had explored the concept of the 'digitally printed dress.'

I manipulated the original Pin Wrap1 motif, to create an elongated image on screen and paper. I considered how the design might appear as a 1, 2, or 3-meter length dress. There is a generally accepted range of motif sizes that are currently compatible

\footnotetext{
${ }^{41}$ Pin Wrap 1 had originally designed at half-scale at $60 \times 30 \mathrm{~cm}(6.6 .2)$. The design was re-scaled to fit the new dimensions $(140 \times 100 \mathrm{~cm})$ of the Rectangle Wrap.

${ }_{42}$ Flugel (1930: 29) states that: 'the purpose of Dimensional decoration is to increase the apparent size of the wearer, and it therefore has a general similarity to the Vertical form.'
} 
for use in clothing design which are traditionally understood to relate to the proportions of the human form (Campbell 2000). The idea of distorting a print beyond the accepted dimensions of a textile design or garment, built on issues raised in the earlier practice (6.6.2.3). I decided that although Transforming Shape was chiefly concerned with how surface pattern could be related to the form, that by exceeding average proportions 1 could make a valid visual statement regarding the role of the body as an informer of scale. The approach would also enable me to make a more lateral visual statement regarding the potential of integrated $C A D$ and digital printing technology.

The Wrap (dress) was finally designed at $100 \times 280 \mathrm{~cm}$, as this represented twice the ratio of the original Rectangle Wrap. The Pin Wrap1 image was scaled to fit these proportions then changed from its original 'blue' to 'grayscale'. I had already created two inverted grayscale designs in the Tide and Nautilus pieces, so opted for a positive version with a tint of colour ${ }^{43}$ to add warmth to the collection (Fig.7-V).

\subsubsection{Wrap: Analysis of Outcome}

On the model the Wrap was fashioned as a tube that pinned at the centre of the back. The length of the garment meant that the piece had to be ruched up at the back on the model (in the video). The styling of the imagery streamlined the body, so that from the front the form appeared as a vertical column (Fig.7-W). In the exhibition the Wrap 'dress' was suspended so that the hemline hovered above the ground. The longitudinal printed shape appeared as an ethereal column in the subdued lighting. The colour combination of dark grey with rose, and the trompe l'oeil effect of stretched pins, darts and stray threads, imbued the piece with an antique textile quality. The presentation of the piece on the mannequin suggested it was a 'garment', but its manifestation beyond the form emphasised the impractical, yet poetic qualities of cloth (Fig.7-X).

\subsection{IN PRAISE OF SHADOWS ${ }^{44}$}

The space that the pieces for Transforming Shape occupied, was central to their realisation, as Henry Moore observed: 'the structure is a space within which the eye can move, giving the form a spatial existence. ${ }^{, 45}$ The use of suspended mannequins in the exhibition allowed the textiles to be visually described in space as $3 \mathrm{D}$ constructs in their own right. The printed and embroidered viscose shapes presented qualities of sheen and semi-transparency. The combined translucence of the

\footnotetext{
${ }^{43}$ A shade of orange was chosen to harmonise with the other pieces in the exhibition and was based on the outcomes of the extensive colour tests (7.3.7).

${ }_{44}$ In, In Praise of Shadows, (first pub. in 1934), Junichiro Tanizaki discusses the pursuit of the shadow within Japanese culture as central to their aesthetic appreciation of space, and how Western cultures tend to drive shadows out in favour of brightly lit environments.

${ }_{45}$ Moore, H. (1937) 'The Sculptor Speaks' from the Listener 18/8/37, quoted in Millar (2001).
} 


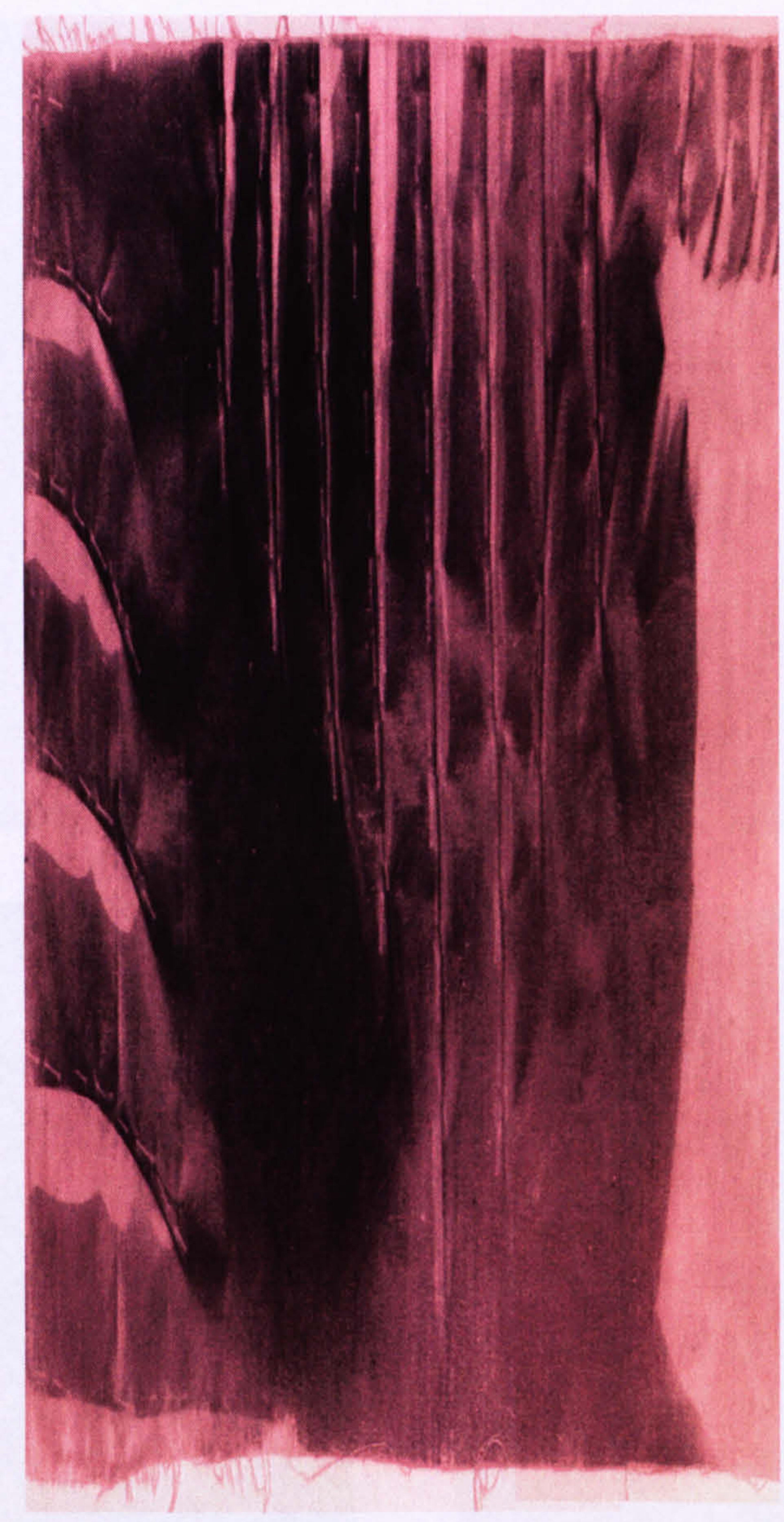

Figure 7-V Wrap $(100 \times 280 \mathrm{~cm})$ 

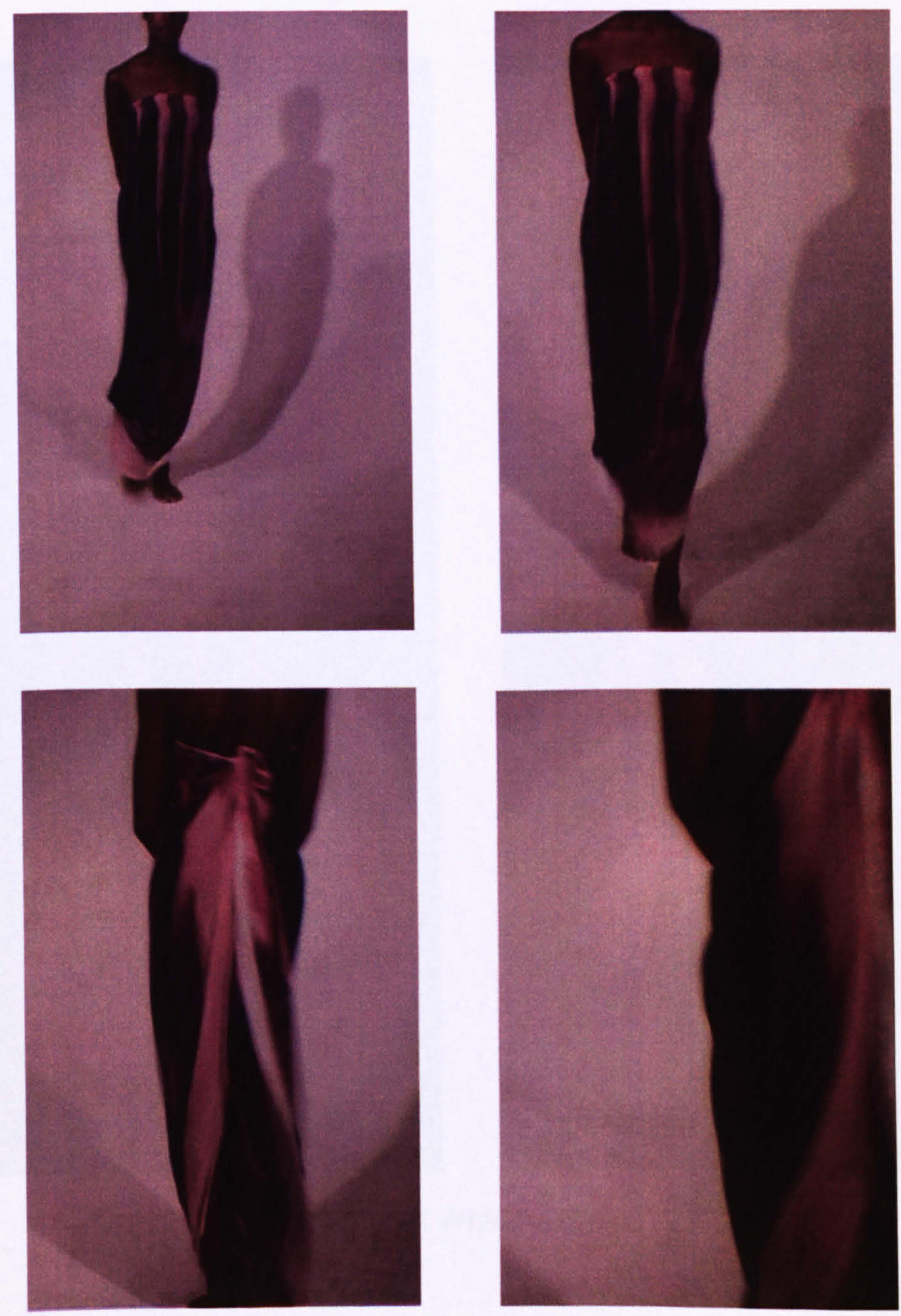

Figure 7-W Wrap on model, four views 

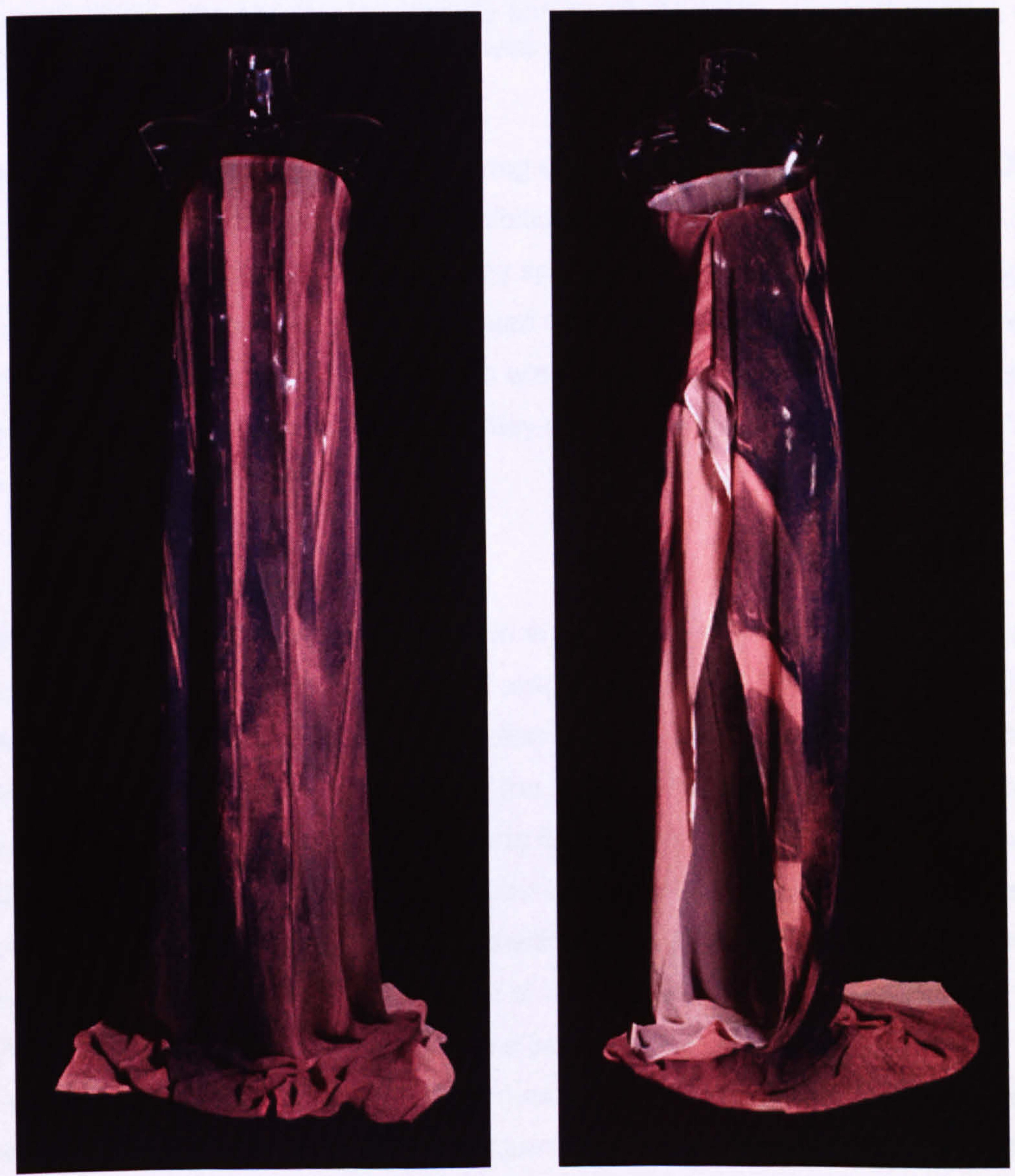

Figure 7-X Wrap on stand 
Fabric qualities and the torso-style mannequins presented the viewer with new dialogues between image, cloth and form. The ambient mood of the exhibition was further enhanced with a soundtrack entitled 'Moon' which was kindly supplied the Japanese composer, Akira Rebalais. ${ }^{46}$

The use of the shadow reverberates throughout the history of human representation...the shadow is culturally and psychologically, a potent symbol; a projection of the body, an area of darkness defined by surrounding light...(Johnson 1998: 27)

My own designs were based on the capturing of effect of light and shadow on cloth. The subdued lighting conditions of the exhibition emphasised the ethereal nature of the mark making, which was only illuminated by spot lighting. The shadows created by each of the twelve draped forms cast ghosted versions of the originals on the floor. The exhibition was very successful, attracting a wide audience who were intrigued by the textiles, and the original manner in which they were presented. Figure 7-Y shows two views of Transforming Shape.

\subsubsection{Personal Design Outcomes}

The group's consideration of surface design in relation to modelled cloth shapes was prompted by my earlier research. As I had already investigated this concept through a series of sculptural and architectural cyanoforms, I was anxious to use Transforming Shape to further the practice, by exploring the notion of 'sculpted print' at life scale. As discussed in the conclusion of Chapter 6 , the fundamental differences between my own and Delaunay's approach rested on the treatment of pictorial space within the design. Delaunay employed 'a vast range of compositional and chromatic variations' to enrich the garment that did not 'alter the structure of clothing, nor break it apart in order to transform it' (Celant 1996: 32). Similarly, my particular design approach did not challenge the principles of formal (garment) construction, but sought to interpret simple shapes using new design vocabulary. Delaunay's designs relied on the optical effects created by the synthesis of colour, form and movement (3.7). As Vreeland observed, she 'knit planes and colours together in such a way that colour became the garment' (Morano) 1986: 9). My designs were centred on a different type of optical illusion, based on the simulation of shadow and texture, to iterate the form of a wearer. My prints were (technically) composed of flat colour, but alluded to pictorial space, rather than the flattened picture plane. The manipulation of the image was the focus of the work, and how the notion of fluid-style patterning could be integrated to transform the appearance of both garment and form.

${ }^{46}$ Rebalais music was featured in Radical Fashion at the V\&A (2001). 

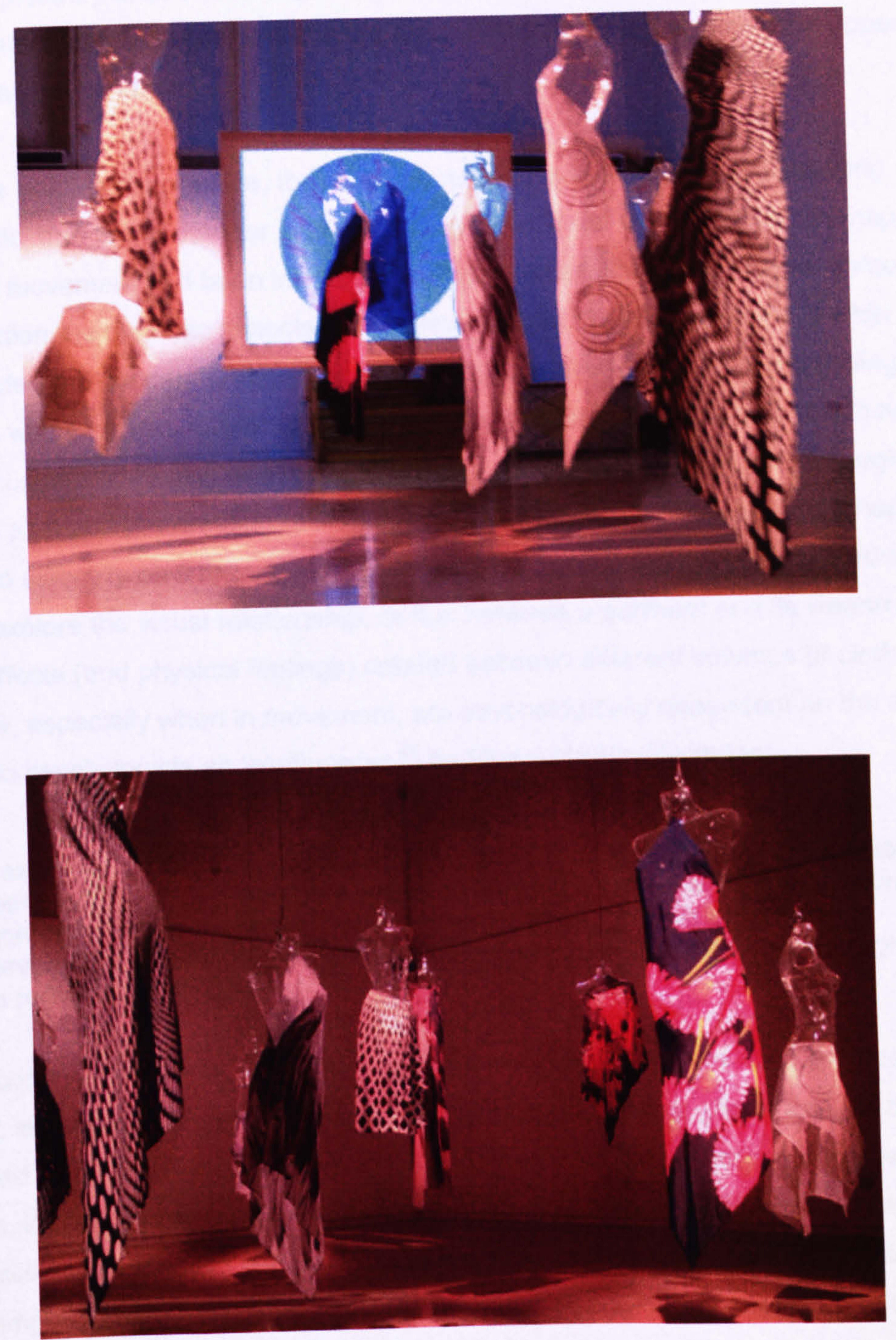

Figure 7-Y Transforming Shape December 2001 
1986: 9). My own designs were centred on a different type of optical illusion, based on the simulation of shadow and texture, to iterate the form of a wearer. My prints were (technically) composed of flat colour, but alluded to the pictorial, rather than the flattened picture plane. The manipulation of the image was the focus of the work, and how the notion of fluid-style patterning could be integrated to transform the appearance of both garment and form.

Up to this point in the practice, the design outcomes had been visually arresting, but fairly static, due to the manner in which they were crafted. In Transforming Shape a sense of movement had been introduced to the Nautilus and Tide designs, through an investigation the rhythmic aspects of the moving body in cloth. Wrap had further investigated the concept of the static form in cloth, with the final outcome raising parallels with a carved, Greek column. From the outset, the practical research had been focused on devising new ways of relating print imagery to the form through garment shapes. The creation of life-sized printed pieces for Transforming Shape, modelled statically on a mannequin, and dynamically on a model, had enabled me to further explore the visual relationship, or flux between a garment and its wearer. The visual effects (and physical feelings) created between different volumes of cloth and the body, especially when in movement, are psychologically dependent on the illusion known to psychologists as 'confluence'. ${ }^{47}$ As Flügel (1930: 35) states:

The extension of the total (human) figure, really due to clothes, is unconsciously attributed to the body that wears them, as being the more vital and interesting portion of the whole. However, certain laws governing the illusion must be observed. The chief is that the difference between the two shall not be so great as to prevent the confusion.

The recording of the effect of light on specific cloth shapes on the form had fuelled the project, leading to the creation of trompe l'oeil images of folds, pleats and pin tucks. CAD had been employed as a method of re-interpreting these images with new shapes, leading to the creation of new aesthetic dialogues with fabric. CAD had also been utilised to render visual elements in such a way that they appeared to interface more empathetically with the contours of the form. In both instances, the practice had relied on 'illusion' and how such a device could be aesthetically employed to enhance both textile and garment. As a research vehicle, Transforming Shape, had presented the opportunity to further explore the relationship between trompe l'oeil imagery and the human body, by using both the static and the moving form as inspiration. The

\footnotetext{
${ }^{47}$ Here the mind fails to distinguish between two things which are normally kept apart, and attributes to $A$ what really belongs to $B$, so that $A$ undergoes an increase.
} 
resulting outcomes had blurred the boundary between cloth and the underlying form as a means of visually 'transforming shape.'

\subsection{CONCLUSION OF CHAPTER}

Transforming Shape provided the opportunity to test the simultaneous design approach towards textile design, from a shared, group perspective. The project also enabled me to develop my practice with the objective of realising design outcomes for public exhibition.

The creation of the Circle piece, Nautilus, highlighted some key design issues. Circle Pleats 8 was designed by integrating architectural pleated imagery with contoured segments of the shape. The design was developed in two contrasting substrates, which revealed that although fabric quality could determine the spatial configuration of a garment shape and influence the visual appearance of a print, it could not render an architectural print, sculpturally. The strong directional and solid appearance of the trompe l'oeil pleats in Circle 8 were so convincing that they dominated the piece in cotton drill, which stood away from the form architecturally, and silk georgette which clung to it in a sculptural manner.

The Nautilus design was originated directly within the circular contour and reflected the spirit of a circular movement in space. Printing the piece onto a variety of substrates resulted in different spatial qualities, but the illusionistic effect of the spiralling imagery dominated the dialogue between print and cut, visually rendering the outcomes as sculptural pieces.

The development of the Square design raised issues regarding the matching and balancing of colour throughout the collection of pieces for the exhibition. The extensive sampling indicated that even a slight variation in tone or hue could alter the aesthetic appearance of a design. The Tide piece explored the notion of directional fluidity, by employing multi-mapping, a technique unique to the research. Tide embodied the aesthetic principles of a sculptural garment, with the trompe l'oeil illusion of the vertically directed, textural pleats providing surface interest that appeared to sculpt the form of the wearer.

The Rectangle investigated the concept of dimensional print by extending the scale of imagery beyond the standard measurements of body and garment. Darts were integrated with the Wrap Skirt as decorative detail, at $200 \%$ usual scale. The inverted version of the design heightened the $3 \mathrm{D}$ effect of the calico shape, making the darts 
appear as angular structural details that exaggerated the architectural shape. The shape was finally developed as a Wrap dress in a more fluid fabric. The stretching of the design to almost 3 meters illustrated the potential for engineering prints beyond average dimensions, and the capacity for digital printing technology to transpose nonrepeating, large engineered images that appeared as continuous patterns, onto cloth. Wrap illustrated the potential of CAD and digital printing to be harnessed for the creation of textile pieces that challenge existing notions of the relationship between cloth, print and form. 


\subsection{REFERENCES}

Binns, P. (2003) Exhibition Review of The Jerwood Applied Arts Prize Exhibition 2002: Textiles, in Textile: The Journal of Cloth and Culture, Vol. 1 Issue 1, pp 86-91

Brink, R. (1994) Tactile Texts, essay in Braddock, M. and O' Mahoney, M. (1994) Eds. 2010 Textiles and New Technology, London: Crafts Council

Campbell, J.R. and Stielglitz, M. (2001) Digital Connections in Imagery, Cloth and the Human Form, Robert Hillestad Textiles Gallery, University of Nebraska, Lincoln, NE, 8/1/01-2/2/01

Campbell, J.R. (2000) An Overview of Digital Textile Printing and How It Affects the Approach to Textile Design, presented at Ars Textrina Conference, Minnieapolis, Minnesota, USA

Celant, G. (1996) 'To Cut is to Think', essay in Looking at Fashion: Biennale di Firenze Coldwell, P. (2002) 'Interrogating the Surface', presented at Creativity and Embodied Mind in Digital Fine Art, AHRB seminar, Deluxe Gallery, Hoxton Square, 14/11/02 Davies, M. L. (1980) Visual Design in Dress, London: Prentice-Hall

Gale, C. and Kaur, J. (2002) The Textile Book, Oxford and New York: Berg Jeffries, J. (2001) Reinventing Textiles: Gender and Identity, Winchester: Telos Art Publishing

Johnson, P. (1998) Bodyscape: Caroline Broadhead, Nottingham: Angel Row Gallery Flügel, J. C. (1930) The Psychology of Clothes, London: Hogarth Press (Repr. 1971) Millar, L. (2002) Jerwood Applied Arts Prize 2002: Textiles, Catalogue essay, London: Crafts Council

Millar, L. (2001) Textural Space: contemporary Japanese textile art, Catalogue essay, Surrey: The Surrey Institute of Art and Design

Morano, E. (1986) Sonia Delaunay: Art into Fashion, New York: George Braziller Murdoch, W. (2003) Private conversation with Wallace Murdoch, Programme Leader for Textiles, Nottingham Trent University, 6/6/03

Pengelly, J. (2002) 2.5D Digital Print-Making, presented at Creativity and Embodied Mind in Digital Fine Art, AHRB seminar, Deluxe Gallery, Hoxton Square, 14/11/02 Penrose, R. (1973) In Praise of Illusion, in Gregory, R. L. and Gombrich, E. H., Art and Illusion, London: Gerald Duckworth and Co. Ltd

Tabatabai Asgbahgi, (1996) 'The Sculpted Dress', essay in Looking at Fashion: Biennale di Firenze

Tanizaki, J. (1977) In Praise of Shadows, Leete's Island Books

Townsend, C. (2002) The Empty Body Part 2, in Rapture: Art's Seduction by Fashion, London: Thames and Hudson

Transforming Shape (2001) Press release, The Nottingham Trent University 
Shioda, J. (2000) Making Things for the People, essay in Issey Miyake: Making Things, Museum of Contemporary Art, Tokyo, 29/4/00-20/8/00

Wilson, L. (2000) The Importance of Textiles to Donna Karan New York, in Textiles an Afterthought? Loughborough University School of Art and Design, p. 35 
Chapter 8. Conclusions

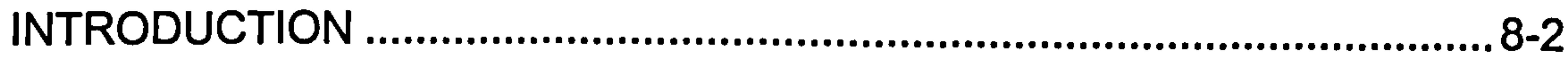

8.1. OVERALL CONCLUSIONS .............................................................. 8-2

8.2. CONTRIBUTIONS TO NEW KNOWLEDGE......................................... 8-5

8.3. FURTHER WORK 


\section{INTRODUCTION}

This, the final chapter begins by outlining the overall findings of the research, through reiterating the conclusions of the previous seven chapters. The following section, 8.2 describes the contributions to new knowledge that this research has made to the areas of printed textile and printed garment design, within practical, educational and research contexts. The final section, Further Work, discusses the future directions and possible applications of this design research.

\subsection{OVERALL CONCLUSIONS}

The parallels between the Cubist perspective and printed garment design, discussed in Chapter 2, have underpinned the simultaneous approach investigated through this research. When creating 2D pattern shapes, or integrating print with such shapes, it is advantageous for the designer to envisage how the 3D form will interact with, or be iterated through the combined design outcome. This research advocates a more creative design approach towards 2D-based printed textile design and rectangularbased garment shaping methods, by considering printed garment design from a 3D perspective.

The recent interest of the mass clothing industry in returning to the principles of madeto-measure garment design, as practised in haute couture, could lead to a more shape orientated approach to surface print. The use of a dress mannequin within this practice explores of the possibility of approaching printed garment design from a modelled perspective. By employing a mannequin, I have employed the same series of surfaces, as those used by a fashion designer. When a fashion designer uses cloth to model a garment toile on a mannequin, its weight and textural qualities are used to amplify the resonance of the human shape. The origination of print imagery in association with a 3D garment or draped piece of cloth has resulted in design outcomes that are empathetic to the shape of the form. My use of the mannequin illustrates the possibilities for enlisting the physical attributes of the female form in the designing process. As discussed in Chapters 6 and 7, such an approach could lead to new notions of textile design that are created in a '3D' rather than a '2D' designing context.

The combined use of CAD and digital printing presents considerable creative potential for integrating print with both the garment and the body contour. My past practice designing and printing stretch garments has inspired a design approach that seeks to iterate the form through woven fabric. The style of print imagery that I consider to be most effective for achieving this task works on the principle of optical illusion. The practical research, detailed in Chapters $5-7$, demonstrates that prints composed of 
linear patterns can be employed to suggest 3D effects, and trompe l'oeil imagery based on the effect of light and shade on cloth can be manipulated to enhance fabric and form aesthetically. The notion of defining or re-defining the natural female shape through print represents a new area of fashion and textile research. A more aesthetic approach to printed garment design is regarded by this research as a relevant method for enhancing contemporary garments and the body image of their wearers.

The identification of 'sculptural' and 'architectural' garments, and the formulation of a third 'crossover' category, enabled me to analyse the aesthetic relationships between different spatial forms and styles of surface pattern. When I began the research in 1998 I was naturally drawn towards sculptural shapes, where the often, complex interaction between cloth and form constitutes both garment and surface decoration. The idea of the 3D garment shape acting as the catalyst for mark making was explored through the practice by adopting a simultaneous design approach to body, cloth and print. The design collections created by applying this approach, detailed in Chapter 6, employ crossover shapes with a sculptural and architectural bias. The use of these templates ensured that the focus was placed on the Simultaneous Design Method (6.2), and how a novel 3D approach could transform simple garment shapes into integrated design outcomes that enhanced both garment and form.

Textile-led and garment-led styles reflect a focus on surface and structural design issues. While this research has been conducted from a textile designer's perspective, the simultaneous approach advocated through the practice, synthesises textile and garment-led design. The approach was inspired by the practice of Sonia Delaunay, who wrapped the equivalent of her painted canvases around women's bodies. The use of the mannequin to replicate the female form in this practice, and the original manner in which imagery was generated through the creation of cyanoforms (5.4) resulted in imagery that embraces a 'garment as canvas' approach by providing a photographic visual narrative of the print modelling process.

There is a tendency for users of CAD for textiles to rely on its ability to create colourways and rudimentary repeats, rather than explore it to produce challenging design styles and more complex repeats. This is particularly true of the mass clothing industry, where colour fidelity is of paramount importance and print integration is understandably enlisted as a means of decoration. This research has demonstrated that CAD for textiles can be used beyond its facility to generate colour ways and simple repeats, to originate and translate prints into a variety of structures that contribute to both the visual appearance of a garment and that of the wearer. By employing CAD as 
a tool and medium, for the creation of engineered images, simple garment shapes can be transformed into innovative outcomes that embody signifiers of exclusivity, generally associated with haute couture and designer collections. As well as visualising my designs as 3D garment forms, I have adopted textile draping for its design qualities. The integration of textured, shaded, and distorted effects has underpinned my 3D approach to printed garment design, resulting in original textile vocabulary.

The flexible approaches to CAD, identified through the hybrid practices of independent designers such as Hilary, Carlise, Laura Buadas and Helena Rosen indicate some of the benefits of combining manual and digital design media (4.5). Innovative design outcomes concerned with random patterned, engineered and customised print, indicate a strong focus on the end-use of the textile. CAD presents possibilities for developing innovative, yet functional printed styles that iterate the form, or can be customised by the wearer in new ways. In sympathy with these approaches, the creation of a range of contrasting printed garment designs based on a single tunic shape in Chapter 5 , demonstrated that simple garment shapes can be transformed through the integration of sophisticated or novel imagery, to appear more complex. The translation of materialbased concepts such as fabric structures, seaming, folding, pleating, as textile constructs, represents an original use of CAD. The incorporation of flaws, fraying and faded details explores the 'notion of wear' as a conceptual design issue.

The sculptural cyanoforms illustrated how imagery configured through wrapping and draping cloth, can be engineered to enhance the fluidity of garment and form, while architectural treatments such as anchoring and folding leads to geometric mark making related to the cloth shape. The collections showed contrasting styles of manipulation can render a similar shape very differently. The use of integrated CAD to realign deconstructed cyanoforms with accurate garment contours, the application of virtual shadow and the development of virtually pleated fabrics, presented original uses of textile draping. The use of digital printing to realise designs as material outcomes revealed notable differences between their appearance on screen, paper and cloth, which highlighted the importance of the print-sampling process. The production of garment shapes integrated with photographic-style imagery represented a creative use of digital printing, and which stretched the technology beyond its more familiar role for sampling. The research indicated possibilities for using CAD and digital printing for short-run, niche production, which remains unviable for the mass clothing industry but could be explored more effectively by independent designers. 
The experimentation into re-shaping a garment contour to accommodate print imagery (6.3.2) represents a reversal of commercial printed garment design, which is often necessarily garment-led (3.6). The role of print to provide a visual narrative of the surface designing procedure underpins my interest in deconstructed print design styles, which can be generated aesthetically in CAD. The Shadow Tunic (6.3.4) contributed to the conceptual element of the project by providing visual evidence of cloth's capacity to retain the memory of a previous manipulation, within its folds.

The pieces for Transforming Shape explored engineered prints from both directional and dimensional perspectives. The translation of a 360-degree movement of a cloth shape on the form into a circular design resulted in imagery that spiralled within the shape and circumvented the form. The notion of directional flow, first explored in the experimental Drip designs, was further developed through Tide, where a digitally enhanced torrent of pleats appeared to coarse down the length of a diamond-shape of cloth. The piece illustrated the capacity for print to contour a fabric shape and the underlying form. The rectangular Wrap continued with the vertical theme, by extending the print beyond the usual length of a garment, which questioned the aesthetic relationship that exists between pattern and the human form.

\subsection{CONTRIBUTIONS TO NEW KNOWLEDGE}

The findings of this research are considered to have broad design implications within design practice, design research and design education. The following theoretical issues have been raised by the research:

- The identification of 'sculptural' and 'architectural' garment archetypes

- The formulation of the 'crossover' garment archetype

- Analysis of the aesthetic relationship between sculptural, architectural and crossover garment spatiality and different styles of surface pattern

- The identification of 'textile-led' and 'garment-led' approaches to printed garment design

- The formulation of a 'garment as canvas' approach to printed garment design

- The development of a 3D-orientated 'simultaneous design method' that synthesises manual and CAD processes

The contributions to new knowledge raised by the practical element of the research are as follows: 
- An integrated approach to printed garment design that enhances both garment shape and the form of the wearer.

- The combined use of manual and CAD methods to create trompe l'oeil -style prints that can be employed to visually transform the natural female shape

- The formulation of a new creative design strategy for approaching rectangularbased shaping, that considers printed garment design from a 3D starting point

- The application of a 3D simultaneous approach to the body, cloth and print resulting new design styles that challenge existing $2 D$ practice

- The creation of the cyanoform, which provides a unique 3D record of the effect of light on a modelled cloth shape which can be translated in CAD as a printed garment prototype

- The combined use of CAD with digital printing technology to develop engineerprinted garment prototypes

- The testing of digital fabric printing on a range of substrates to assess the potential use of the technology as a niche production tool for independent designers

Many of the ideas regarding print integration in this thesis build on the aesthetic design principles practised within couture. As the clothing industry moves towards masscustomisation, such concepts could hold new relevance in the future. But for the present the aesthetic design issues raised through this practice are of greatest significance to the independent designer market. Independent designers continue to produce the some of the most challenging printed garments despite, often limited, access to the latest CAD technology. The increasing accessibility of integrated software platforms and digital printing technology through CAD bureaus and price reductions presents considerable design advantages for this area of the market.

As a design practitioner, I plan to develop some of the conceptual ideas raised through the practice, as commercial designs. My ultimate goal is to design and market a 'universal'-style of printed garment that embodies the principles of timeless pieces such as Fortuny's Delphos and Miyake's Pleats Please scarf. The design would be based on a printed geometric shape that could be wrapped around the body in a variety of different ways, resulting in the iteration of the print and form in a contrasting, contoured fashion.

\subsection{FURTHER WORK}

The increasing sophistication of software for the 3D design and animation of garments suggests that in the future there may be less of a requirement for manual designing 
and making skills. However, this creative enquiry has led me to conclude, that when designing for the 'real world', it is beneficial for the designer to have tacit knowledge of both virtual and physical design contexts, and the ability or facility to switch between the two. There is often considerable difference between how imagery manipulated in CAD can appear on screen and on fabric, resulting in print sampling being a crucial part of the digital designing process. Sometimes the disparities between screen-based designs and the final printed fabric can be visually arresting, leading to new print vocabulary. It is my intention to develop further work in collaboration with providers of digital printing technology, such as Stork, to promote the aesthetic design potential of this medium. While digital printing is becoming an accepted part of the garment sampling industry, its use as a creative production tool could benefit from further exposure. It is my intention to strengthen my contacts with Stork and Lectra, at the forthcoming ITMA 2003 exhibition, to be held in Birmingham in October. The companies have already expressed interest in using my designs to demonstrate the potential for translating 3D effects onto cloth, and plan to feature my design Crease as a digitally printed fabric on the Lectra stand.

Throughout this research I have made contacts with various research groups and bodies, which have focused on the relationship between theoretical and practical research. As practice-led research is a growing area, an important aspect of the further work will be to disseminate the new knowledge derived from this project to a wider audience, through conferences, design seminars, exhibitions and publications. I have already applied and had abstracts accepted by two conferences scheduled for 2003: Pixel Raiders 2, at Sheffield Hallam University, UK and Creativity: Designer Meets Technology at The University of Philadelphia, USA. I have chosen these two events as appropriate vehicles through which to disseminate my textile-based research, as both of the organisations are particularly pro-active in researching the effect of digital technology on established craft methods.

Textile design is currently experiencing increased exposure, which is leading to new perceptions of the term 'textile'. Manually and digitally originated textiles now co-exist within an art/textile context. This research provides a relevant account of how the integration of CAD technologies into craft-based practice is blurring of the boundary between manual and digital crafting techniques. I plan to investigate this concept through my future practice, with a view to exhibiting the outcomes. As well as aiming to exhibit pieces at the conferences detailed above, I have also had a the Tide design accepted by the organisers of the forthcoming Surface Design exhibition at Aarhus, Denmark in September/October 2003. 
The 3D, simultaneous designing principles explored through this research have a wide variety of possible applications within design education and design practice. I have lectured in printed textiles in a variety of posts since graduating in 1981. I am currently a senior lecturer at the Nottingham Trent University where I am aware of the increasing influence of textile and graphic software on the designing process. I am also conscious of the increasing role that visualisation tools such as textile draping, or 3D mapping plays within the design presentation process. Some students find it difficult to conceptualise their surface designs as products or garments, by switching between 2D and 3D modes of expression. The simultaneous design method presents students with an innovative way of approaching printed textile, printed garment and printed product design. It is therefore my intention to introduce this approach through a 'simultaneous design module' that would approach the area of surface print from a '3D', rather than a traditional 2D perspective.

I would like to do further research into the potential of body scanning as a design or director of print design placement. This technology is currently used for highly accurate body measuring for sizing data and for the fashion and health service. While some research has been undertaken in association with pattern cutting, I think there is potential for this technology to be used creatively and aesthetically for fashion and medical textiles. I have discussed this idea with Mike Karol from Blueprint, who make bespoke, origami-style dressings and he conceded that 'natural' coloured bandages are sometimes very unappealing and could be improved through the integration of prints that decorated and contoured the form. I have also discussed with the research group Size, Shape, Fit the possibilities for enlisting body scanning to raise point clouds relating to individual body profiles that could be integrated with printed garment designs, with a view to surfacing the form with a made-to-measure print (4.2.3).

The following ideas summarise the future direction of the research:

- The dissemination of the new knowledge through design journals, publications, seminars, conferences and design lectures

- The dissemination of the 3D simultaneous approach to printed garment and textile design through design education within undergraduate and post-graduate forums

- Further research within group projects into the aesthetic design potential of digital printing and body scanning as informers of a more shape-centred design approach 
- The further development of 'contoured print' as a commercial design concept for creating trompe l'oeil-style printed garments that visually enhance both garment and wearer

- The further development 'contoured print' in association with body scanning as a method for introducing made-to-measure digital print to garment design

This research considers 3D garment modelling software as the most significant influence on the future design of printed garments, as it reinforces the 3D manual/digital approach promoted through the practical investigation. New technologies require new design approaches, which is why I have employed CAD and digital fabric printing to develop garment prototypes that explore new styles of shapecentred imagery. Until more independent designers access this technology, it will continue to be a sampling medium, as opposed to a creative design and production alternative. 


\section{Appendix 1: Past Practice}

\section{3 - 1998 Freelance Textile Designer}

Printed Textile Designs sold through agent Suszi Corio, trade shows including Indigo (Premier Vision) and directly to stockists in North America (Henri Bendel), Canada, Japan (Joyce's)

\section{5 - 1993 Cocky's Shed, Nottingham/London}

Director/designer in company specialising in printed garment design

Regular exhibitor at The British Designer Collections (Olympia) and The London Show (Islington)

Wholesale: Sold to independents in UK, Europe, North America and Japan Diffusion ranges designed for Miss Selfridge (Cocky's Shed for Miss Selfridge), Pineapple, Top Shop and Top Man (Oxford Circus)

Retail: Cocky's Shed, Hyper Hyper, South Kensington, London

Press: Drapers Record, Fashion Weekly, The Independent, Company, Cosmopolitan, '19' Magazine, Clothes Show Magazine, Clothes Show (BBC)

\section{1 - 1985 Katsu, Nottingham}

Director/designer in printed textile company

Specialised in hand printed silks and cottons, including commission design/printing Designs sold to independents such as Academy, Kings Road and Soho, London 


\section{Appendix 2: Related Studies}

\section{Visits and Interviews}

2000 Mark Eley, private telephone conversation with the co-director of printed textile and garment designers Eley Kishimoto, London

2000 Shelly Fox, private interview with the fashion and textile designer, Nottingham Trent University 2000 Andy Frogson, private interview with the digital printing consultant and director of CV Apparel, Coates Vyella, Huthwaite, Notts 2000 Laura Mylius, private interview with the CAD textile software consultant at Lectra Systems' Research and Development Centre, Cestas, Bordeaux, France 2001 Alan Shaw, private interview with the digital printing consultant Alan Shaw during visit tothe $\mathrm{Ce}$ Centre for Advanced Textiles (CAT), Glasgow School of Art 2003 Vebeke Riisberg, private interview with the textile designer in Department of Textile Design at the Nottingham Trent University

\section{Conferences and Seminars}

1998-2000 The Nottingham Trent University, Research Colloquia, featuring guest speakers engaged in national and international art and design research 1998 Angel Row Gallery, 3D Body Scanning, Lecture by Professor Stephen Gray 1999 European Academy of Design (EAD), Third conference: Design Cultures, Sheffield Hallam University 1999 CANCADCAM?CADCAMCAN, FINS, International Clothing Centre 1999 Lectra/CDI User Group Seminar, International Clothing Centre, Nottingham 2001 CADE:Crossing the Border, 9-12 April, Glasgow School of Art, 9-12 April 2002 The Victoria and Albert Museum: Pixel Raiders, Art and Design Symposium, 2002 AHRB Seminar: Creativity and Embodied Mind in Digital Fine Art, Deluxe Gallery, Hoxton Square, London

2003 The Textile Institute, Seminar: Satisfying Consumer Demand, Leicester 2003 EMCAT Festival, Designing for the Future with Technical Textiles, Derby

\section{Presentations}

1999 Kuopio Academy of Craft and Design, Kuopio, Finland, Lecture and masterclass, 1999-2003 MA and BA Fashion and Textiles, Lectures on aspects of Integrated Design and $C A D$ and Digital Printing at the Nottingham Trent University 2000 Computers in Art and Design Education (CADE) Post Graduate Forum, Falmouth School of Art, Cornwall 
Collections and Exhibitions

1999 The Victoria and Albert Museum: One Women's Wardrobe

1998 Angel Row Gallery: Bodyscape: Caroline Broadhead, Angel Row Gallery,

Nottingham

1999: Hayward Gallery: Addressing the Century: 100 Years of Art and Fashion 1999 The Serpentine Gallery: Brigit Riley

1999 The Warrington Gallery: Ossie Clark 1942-1996: fashion Designer

2000 Royal Academy: Amazons of the Avant Barde

2000 Leicester City Gallery: Kei Ito: One Person Show

2000 The Museum of London: Vivienne Westwood

To be comp in finial draft 


\section{Appendix 3: Poem for Mme Delaunay}

\section{Simultaneous Dress}

On the dress she wears a body.

The woman's body has as many bumps as my skull

Glorious if you are incarnate

With wit

The tailors do a stupid job

Just like the phrenology

My eyes are kilos weighing down the sensuality of women.

Everything that bumps progresses into depth

The stars penetrate the sky

The colours disrobe in contrast.

'On the dress she has a body'

Beneath the heather's arms

Shade, halfmoons and pistils

When the water flows into the back with its blue-green shoulder blades

And the double conch of the breasts passing beneath the bridge of rainbows

Belly

Discs

And the perpendicular cries of the colours fall onto the thighs

Saint Micheal's sword

There are hands stretching out

In the train there is the beast, all the eyes, all the fanfares, all the customs of the Bal

Bullier

And on the hip

The signature of the poet 


\section{Appendix 4}

\section{Schiaparelli's Tear Dress: First hand observations}

The Tear Dress was viewed ${ }^{1}$ and photographed flat on a table, as hanging would have placed stress on the garment structure. This was disappointing, as I had hoped to assess the illusory qualities of the print in both two and three dimensions; the effect of the garment's drape on the print and the interplay between the print and underlying form. However, observing the dress at first hand revealed other information about how the print and cut had been designed and synthesised.

The print consisted of a three-colour design, in purple, pink and dark brown, which appeared to have been hand screen-printed onto silk crepe with reactive dyes. There was evidence of the dye bleeding in the purple ${ }^{2}$ areas and tiny splashes and misprints throughout the piece. The print repeat was in a half-drop structure. The colour separations appeared to have been hand-painted. The design appeared flat close-up but was convincing from a distance, where it conveyed the illusion of torn layers of cloth, as opposed to 'strips of torn flesh'.

The dress design was based on rectangle with a slash for the side zip. Two triangles had been sewn into the seamed side of the tube, to create a slashed train, which appears in photographs at the back of the dress, as shown in Figure $X$, but is actually an extension of the sided seam. Shaping for the bust was incorporated with three horizontal pleats at each side, which distorted the otherwise strong, vertical direction of the torn imagery, but avoided the use of darts. Another integrated use of the print was provided by the method in which the zip had been accommodated on the left-hand side of the dress, preventing the print from being cut and seamed unnecessarily. The flow of the print was not disrupted by the structure, due to the placement of the motifs. ${ }^{3}$ The sheen of the silk would have undoubtedly contributed to the drama of the piece on the body, as ascertained from earlier photographs. Today, the dress would fit a standard size 10. My overall impression of this historical piece was that Schiaparelli had been presented with a piece of cloth, which she used as creatively as possible to fashion a theatrical 'one-off'. The tubular shaping was of its time, but ultimately it was Dali's print she was displaying, with as few cuts as possible.

\footnotetext{
${ }^{1}$ The dress was viewed at the Department of Textiles and Dress, Victoria and Albert Museum, 22.5.02.

2 Rubine dye is used to create 'purples' and often bleeds during the steaming process.

3 The tears were placed at a distance to one another, leaving areas of the base cloth in between.
} 


\section{Appendix 5: Published Papers}

Integrated design: from Delaunay to digital

Exchange 2000: Facilitating research in art, design and media, conference at the University of West England, Bristol, 2-3 November

Exchange online: research papers in art, media and design, launched February 2001 www.media.uwe.ac.uk/exchange_online/exch2_toc.php3-12k

Surface, Shape, Structure: An investigation into digitally printed garment design

CADE 2001 Digital creativity: crossing the border, 9-112 April, Glasgow School of Art. Published in conference proceedings (ISBN 0-901904-82-1) pp.396-400 


\section{Surface, Shape, Structure: An investigation into digitally printed garment design}

\section{Katherine Townsend}

Digital Creativity: Crossing the Border CADE 2001, 9-11 April, Glasgow School of Art, published in conference proceedings (ISBN 0-901904-82-1) pp. 396-400

Abstract: Integrated CAD/CAM technology presents the Fashion and Textile industry with new possibilities for the creative design and manufacture of printed garments. However, due to limited exploration by designer-makers, the potential design benefits of this new integrated technology have revolved around the commercial sector of the clothing market. The recent merging of leading integrated CAD software providers, Lectra Systems and Stork Digital Imaging, represents an important step in the Industry's commitment to mass customisation. This paper discusses a creative research response to the Lectra/Stork alliance, from a textile designer's perspective.

\section{Introduction}

The fashion and textile industry is currently undergoing a period of transition in responding to the challenges presented by E-Commerce. CAD/CAM clothing technology is being further integrated in order to deliver garments on a bespoke basis to customers ordering virtual styles from e-catalogues. Body scanning, made-tomeasure pattern cutting, print matched lay planning, integrated CAD software and digital printing and cutting systems are all contributing to the new 'total clothing solution'. The development of mass customisation has important ramifications for designer-maker practice, particularly in the area of printed garment design. In response to this, a practice-led PhD has been established at Nottingham Trent University, entitled The Integration of Print Design and Garment Shape using Traditional and CAD/CAM Technology. The overall objective of the investigation is to research new methods of print/garment integration for designer-makers, by combining established craft, CAD software and digital printing technology.

A more aesthetic approach to print/garment integration using CAD significantly differs from the empirical stance taken by the majority of users working in this underresearched area of design practice. The 3D approach to the origination of both print and cut, central to this research, encompasses garment-modelling methods with contemporary $2 \mathrm{D}$ and $3 \mathrm{D} C A D$ processes. It is envisaged that in line with recent 
research the outcomes of this creative enquiry will provide valuable insights for other designers seeking to integrate CAD/CAM technology with established textile practice. ${ }^{1}$

\section{Integrated CAD/CAM technology employed in the research}

The main CAD software employed throughout the practice was Lectra Systems' Prostyle, which combines raster (image) and vector (line) based formats within a single interface. The integrated software enables full-scale garment shapes generated in pattern cutting programs, such as Modaris (Lectra), to be imported, combined with bitmapped imagery, manipulated and printed out with mathematical precision. Prostyle's rendering tools were used to manipulate textile designs in conjunction with Adobe Photoshop and PAD 3D Sample. Peripherals such as an A3 scanner, A0 digitiser and pattern plotter were used for converting analogue samples into digital formats. A Stork Amber inkjet, sample printer, was used to print designs developed in Prostyle onto a range of natural substrates.

\section{1:2 Garment shaping considerations}

In order to define the different printed garment structures recorded and created throughout the practice, the research has developed the notions of 'sculptural' and 'architectural' models, based on the Constuctivist artist, Luibov Popova's spatial garment conceptions. ${ }^{2}$ For the purposes of this research the term 'sculptural' is used to describe a garment style that incorporates draping and relies on the underlying contours of the wearer for its definition. In contrast, an 'architectural' model refers to a geometric garment shape that is supported by the wearer but does not rely on the form for it's silhouette. The aesthetic association of printed textile designs with these models has formed the basis of the practical research.

\subsection{Design approach}

Historical research into print/garment integration of the Twentieth Century resulted in the discovery of four general approaches: 'textile-led', 'garment-led', 'the garment as canvas' and 'simultaneous design'. ${ }^{3}$ Of these, the simultaneous design approach presented the method most empathetic with the core aim of the practice to integrate surface imagery with garment shape holistically.

A design method was developed based on the practice of the artist couturier Sonia Delaunay. ${ }^{4} \mathrm{Her}$ conception of designing both the print and garment shape simultaneously, then printing both onto suitable fabric, paralleled with the objectives of the research in conjunction with the use of current integrated CAD/CAM technology. The notion of 'simultaneous design' was advanced by the research through 
approaching the equation of print and cut from a three-dimensional perspective.

Drawing on Madeleine Vionnet's garment modelling methods, ${ }^{5}$ a design process was established whereby printed garment designs could be originated in-the-round, on the dress stand. The presence of the underlying form would be integral to both the shaping of the garment and orchestration of the print imagery, and represented a shifting of textile design into a new modelling paradigm.

\section{Modelling the surface}

Following various experiments with a range of analogue and digital media, blueprinting ${ }^{6}$ was employed to facilitate the capturing of print and cut, in situ on the stand. The direct printing process lent itself to the project, with the application of positive elements resulting in white images on a cyan background. Although the use of cyan as the major sampling colour presented a limited palette, the complexity of the tonal range (created when using cloth) provided considerable possibilities for further manipulation using CAD. The method called for exposure of sensitised material to sunlight, which facilitated toile rotation and the creation of serendipitous, analogue mark making.

\section{2:1 Experiment 1: Initial garment prototyping}

Having studied the interrelationships between print imagery (surface) and garment cut (shape) in three-dimensional form (structure), a method of garment prototyping was developed that sought to use CAD/CAM as a means of extending the craft tradition. By integrating the established principles of textile design and garment modelling, with current technological innovation, the practice sought to synthesise the use of traditional and digital technology for the purposes of innovative design.

The initial experiment was carried out using a bias cut, sculptural tunic, constructed from two pieces and modelled in muslin on the stand. The full-size toile was digitised and converted in Modaris (Lectra), as a full and half-scale pattern. A replacement halfscale toile was sensitised and blueprinted on the half-stand. Print imagery was generated by winding a length of length of fine ribbon around the 'dressed' stand, with the aim of creating mark making that traversed garment structuring and emphasised the inherent fluidity of the style.

The resulting processed tunic was imbued with (negative) white linear markings, where the ribbon had been in contact with the cloth, on a complex, blue tonal background. The outcome of the experiment was an engineer-printed garment that featured nonrepeating imagery, uninterrupted by side and shoulder seams. Once deconstructed, the 
blueprinted pieces were scanned into Prostyle and re-assimilated with the original garment outlines and a final design was created.

\section{2:2 Analysis of Experiment 1}

The outcome of the Experiment 1 yielded an aesthetically pleasing design and valuable insights into the inherent difficulties and creative possibilities of the process. The CAD development or transition stage of the process was more challenging than expected, caused by the instability of the muslin and resulting in difficulties in re-aligning the print with the garment shape. 3D modelling and rendering tools were used strategically to 'correct' and enhance the final design. The practical realisation of the 'simultaneous method' presented the research with a new set of design objectives based on the subversion of tools used primarily by Prostyle users for product line development.

\section{Aims of the continued investigation}

Having established a method of print/garment integration that encompassed the objectives of the practice, the 'simultaneous method' was applied to a series of sculptural and architectural garment shapes. The aims of the continued practical investigation were:

- To demonstrate the principle of a simultaneous design approach to print/garment integration through the combining of traditional craft and CAD/CAM technology.

- To explore and develop engineered, printed textile designs from a threedimensional perspective using the blueprinting process.

- To investigate the creative potential of integrated CAD software in conjunction with digital fabric printing in order to develop new garment prototyping strategies for designer-makers.

\section{3:1 Experiment 2: The sculptural model}

Using the sculptural garment pattern originated for Experiment 1, a second toile was cut in calico and a similar wrapping procedure was employed. The resulting blueprinted calico sample, Cord Tunic, varied distinctly from the muslin version. The change in substrate had resulted in a far more stable template to work with during the CAD stage, but this was at the expense of the mark making, which was more contrasting but less interesting, visually. The most original aspect of the mark making was augmented through the capturing of light on the manipulated folds of the cloth in the neck area of the shape. 
In order to compare methods of decoration, a third toile was cut in calico, treated and integrated with a continuous length of vine. The outcome, Vine Tunic, was more visually interesting than the previous images, due to the more complex modelling procedure. However, in parallel with Experiment 2, the most innovative mark making was centred on the ensuing effect of light on manipulated cloth where the nuance of tone was heightened. After further design exploration, a fourth sensitised toile was exposed without any masking materials being applied. The resulting piece was a record of mark making more in accord with the author's aesthetic development, which continued from this point to be dedicated to the capturing of the physicality of light on modelled cloth surfaces and garment forms. In addition to forming the basis of fullscale garment prototypes, this novel style of 3D-originated mark making was further developed using integrated $C A D$, to create new textile vocabulary.

\section{3:3 Experiment 5: The architectural model}

Cutting a rectangle of calico measuring $120 \times 60 \mathrm{~cm}$, a wrapped skirt was modelled on the dress stand. The shape was fashioned with the use of pins to gather the waist in with a series of darts. The shaping was copied at half-scale with a $60 \times 30 \mathrm{~cm}$ piece of sensitised cloth. The resulting blueprinted cloth was imbued with a series of darts, tucks and pin marks that not only formed a pattern but were also a record of the entire modelling process. The integrating of print and cut had become demonstrably synthesised - the surface detail was a direct outcome of the process of structuring the garment.

Dealing with a rectangle of cloth during the CAD development stage presented distinct advantages when realigning the print with the 'pattern' and a range of new possibilities for design distortion using stretching and inversion functions. In view of the aim to create a garment prototype, the blueprinted cloth was re-pinned onto the stand in its previous 3D form, then digitised into Modaris as a 2D shape to create a wrap-over skirt pattern. The pinned cloth was also scanned into Prostyle and aligned with the new outline to form a printed skirt prototype. The pleated effect, though slightly flattened through the scanning process proved an effective design element, and was developed into a series of alternative designs.

\section{Digital printing of garment prototypes}

The creative potential of digital fabric printing is the subject of much interest within the Fashion and Textile design industry and its application within this enquiry builds on current research in the area. ${ }^{7}$ The technology has been developed in response to the changing industry, and presents an ideal medium for producing one-off garment 
prototypes. The realisation of Experiments 1-5 into a range of concept garments was achieved using a Stork Amber printer. Reactive dyes were printed onto cotton poplin as this was the most similar printing substrate to the original blueprinted toiles. The individual garment designs were saved as printed lay plans, in Tiff file format to $C D$, then printed out in series using Stork printing software.

\section{4:1 Analysis of scale conversion}

The blueprinted half-scale garment pieces were originally scanned in at between 100 and $200 \mathrm{dpi}$. The appearance of the imagery scanned at $100 \mathrm{dpi}$ was considerably affected when converted from to full-scale garment proportions. In general scanning at 200 dpi proved successful, resulting in a full-size print outs at $100 \mathrm{dpi}$ - which were of acceptable quality when printed transposed onto cotton. However, following the initial print run, dpi was experimented with further, to produce intentionally pixelated and distorted effects. The increase in scale also had a considerable effect on the different types of mark making, for example a larger leaf retains its graphic integrity when doubled, whereas a dressmaking pin at $200 \%$ appears clumsy. This questioned the fundamental premise of the design method, which led to further experimentation into alternative ways of distorting the designs from half to full-scale garment proportions, using a range of CAD tools.

\section{4:2 Colour and visual qualities}

The colour of the finished, digitally printed cotton appeared heightened compared to that of the original designs, which is the reverse of conventional fabric printing which tends to be slightly darker than the artwork. It was decided that Tiff Lab file formats would be used in future, to calibrate screen and printing colour more accurately. The photographic quality, generic to the digital printing process provided some innovative design possibilities based on textural and trompe l'oiel effects, including the integration $3 D$ design constructs derived from the effects of light on pleated and draped cloth. The potential use of deconstructed-style elements captured through CAD was successfully explored through the process. The aim of the practice to experiment with structural detail as surface embellishment was realised through the digital printing stage of the design process.

\section{4:3 Conclusion}

The printed garment designs and prototypes presented in this paper demonstrate possible new approaches to print/garment integration. The experimental research has resulted in establishing a novel way of working that combines analogue and digital craft holistically. Integrated CAD software offers fashion and textile designers a new platform 
to work from that can be used as a creative tool in its own right and/or for final design development. When used in conjunction with digital fabric printing the combined technologies offer practitioners the opportunity to create individual garments on a made-to-order basis, in line with the creative objectives of the designer and the requirements of individual customers.

Clearly this CAD/CAM technology is not readily available to the majority of independent designers, but it is becoming increasingly available on a bureau basis, in order to service niche production. The key to innovative practice is in understanding the creative possibilities of this new technology, then tailoring it to one's individual needs as a designer.

\section{References}

${ }^{1}$ Briggs, A. Changing Perspectives: CAD and Printed Textile Design, Design Cultures, Third EAD Conference (30/3-1/4/99), Sheffield Hallam University.

2 Adaskina, N. Sarabionov, D. (1990) Popova, London: Thames and Hudson, p.303.

${ }^{3}$ Townsend, K. Integrated Design: From Delaunay to Digital, Exchange 2000 Conference, 2-3 November, UWE, Bristol, Exchange online: research papers in art, media and design (Feb. 2001).

${ }^{4}$ Buckberrough, S. (1980) Sonia Delaunay: A Retrospective, Buffalo: Albright Knox Gallery.

${ }^{5}$ Bryant, N. (1991) The Interrelationship between Decorative and Structural Design in Madeleine Vionnet's Work, Costume, No. 25, pp. 73-78.

${ }^{6}$ Sacilotto, D. (1982) Photographic Printing Techniques, New York: Watson Guptil, p.177

7 Bunce, G. The Impact of Digital Printing on Textile Design Research, Unpublished keynote address, DK Textile Conference, 27-28/10/00, Designskolen, Kolding, Denmark. 


\section{Bibliography}

Adaskina, N, \& Sarabianov, D. (1990) Liubov Popova, London: Thames \& Hudson Adaskina, N. (1999) Liubov Popova and Her Contemporaries, in J. E. Bowlt and M. Drutt (Eds), Amazons of the Avant-Garde, London: Royal Academy of Arts, pp. 185-190 Albeck, P. (1969) Printed Textiles, London: Oxford University Press

Aldrich, W. (2002) Private Interview, Nottingham Trent University, 23 August Aldrich, W. (2001) The Impact of Fashion on the Cutting Practices for the Woman's Tailored Jacket, University of Reading, Conference paper, A History of Clothing: the business of Fashion or the Fashion of Business, December 142001.

Aldrich, W. (1999) 'Fabric, Form and Flat Pattern Cutting', Lecture at The Kuopio Academy of Crafts and Design, 10 April

Aldrich, W. (1996) Fabric, Form and Flat Pattern Cutting, Oxford: Blackwell Science Aldrich, W. (1990) New Technology and Clothing Design, PhD thesis, Nottingham Trent University

Another Magazine (2003) Blow by Richard Bush, Issue no. 4

Atkins, A. (1985) Sun Gardens, New York: Aperture

Bannister, J. (2003) Private interview with Jane Bannister, director of Palm Studios, printed and woven textile designers, London, 14 April 2003

Barnard, M. (1996) Fashion as Communication, London and New York: Routledge Barnett, P. (1999) Folds, fragments, surfaces: towards a poetics of cloth, in Textures of Memory, The Poetics of Cloth, Nottingham: Angel Row Gallery

Barthes, R. (1983) The Fashion System, translated by M. Ward and R. Howard, New York: Hill and Wang

Bassey, M. (1995) Creating Education Through Research, Newark: Kirklington Moor Press

Beardon, C. (2000) Seminar hosted by Colin Beardon, editor of Digital Creativity, at CADE: Post-Graduate Forum, Falmouth College, Cornwall, July 2000

Bell, Q. (1974) On Human Finery, London: The Hogarth Press

Benaim, L. (1997) Issey Miyake, London: Thames and Hudson

Biennale di Firenze (1996) Looking at Fashion, Florence: Biennale di Firenze Binns, P. (2003) Review of The Jerwood Applied Arts Prize Exhibition 2002: Textiles, in Textile: The Journal of Cloth and Culture, Vol. 1 Issue 1, Spring 2003, pp 86-91 Blanchard, T. (1999) Design for Living, The Observer Magazine, 25 April Bohringer, A., Hilden, J., Yonenaga, A., and McClain, A. (2001) Printing: New Ways to Achieve Higher Quality and Efficiency, International Textile Bulletin, 4/2001, pp. 8-26 
Bowlt, J. and Drutt, M. Eds (1999) Amazons of the Avant-Garde, London: Royal Academy of Arts

Bowlt, J. (1976) Russian Art of the Avant Garde: Theory and Criticism 1902-1934, New York: Viking Press

Boydell, C. (2001)

Braddock, S. (2000) Textiles and Function within Fashion, Point, 9, 2000, pp.7-17

Braddock, S. and O'Mahony, M. (2002) SportsTech: revolutionary fabrics, fashion and design< London: Thames and Hudson

Braddock, S. and O'Mahony, M. (2000) Fabric of Fashion, London: Crafts Council Braddock, S. and O'Mahony, M. (1998) Techno Textiles, London: Thames and Hudson Braddock, S. and O'Mahony, M. (1994) 2010 Textiles and New Technoilogy, Great Britain: Crafts Council

Braddock, S. (1998) Technology and Diversity in Textiles, Proceedings of the Textile Symposium, Loughborough University, 20/2/98

Brandon, R. (1999) Surreal Lives, London: Macmillan

Briggs, A. (1997) A Study of Photographic Images, Processes and Computer Aided Textile Design, PhD thesis, The Nottingham Trent University

Briggs, A. and Bunce, G. (2001) Breaking the Rectangle: Innovative approaches to printed textile and garment design, CADE 2001, 9-12 April, Glasgow School of Art, published in conference proceedings (ISBN 0-901904-82-1) pp. 78-81

Briggs, A. and Bunce, G. (1995) Breaking the Rules: Innovatory Uses of CAD in Printed Textiles, Ars Textrina, Vol. 24, pp.185-283

Brink, R. (1994) Tactile Texts, essay in Braddock, M. and O' Mahoney, M. (1994) Eds. 2010 Textiles and New Technology, London: Crafts Council

British Elle (2001) Sophia Kokoslaki: My Inspiration, London: Hatchette-EMAP Magazines Ltd., June, p.191

Britt, D. Ed (1999) Modern Art: Impressionism to Post-Modernism, London: Thames and Hudson

Bruzzi, S. and Church Gibson, P. Eds (2000) Fashion Cultures: Theories, explorations, and analysis, London: Routledge, pp.49-60

Bryant, N. (1991) The Interrelationship between Decorative and Structural Design in Madeleine Vionnet's Work, Costume, No. 25, pp.73-78

Buckburrough, S. (1980) Sonia Delaunay: A Retrospective, Buffalo: Albright-Knox Gallery

Buckley, R. and Gundle, S. (2000) Flash Trash: Gianni Versace and the theory and practice of glamour, in Fashion Cultures, S. Bruzzi and P. church Gibson, (eds), London: 
Routeledge

Bullock, A. and Stallybrass, O. (Eds) (1979) The Fontana Dictionary of Modern Thought, London: Fontana Books

Bunce, G. (1999) CAD and the Role of the Printed Textile Designer, CADE 99, University of Teeside, 7-9/4/99, pp.59-65

Bunce, G. (1999) Textile Printing in The Age of CAD/CAM, To See, To Touch, To Feel Symposium, Kuopio Academy of Crafts and Design, Finland, 18-19 Feburary

Bunce, G. (1996) The Unexploited Potential of New Technology for Repeat Pattern Innovation in Printed Textile Design, Point, No. 2, pp.32-36

Bunce, G. (1993) An Investigation into the CAD/CAM Possibilities in the Printing of Textiles, PhD thesis, Nottingham Trent University

Bunnell, K. (1998) Re: Presenting Making, The Integration of New Technology into Ceramic Designer-Maker Practice, PhD Thesis, Grays School of Art, The Robert Gordon University

Butler, J. (1990) Gender Trouble: Feminism and the Subversion of Identity, London: Routledge

Campbell, J.R. (2000) An Overview of Digital Textile Printing and How It Affects the Approach to Textile Design, presented at Ars Textrina Conference, Minneapolis, Minnesota, USA

Campbell, J.R. (2000) An Overview of Digital Textile Printing and How It Affects the Approach to Textile Design, 11/6/2000

Carlisle, H. (2002) Towards a New Design Strategy: A visual and cultural analysis of small-scale pattern on clothing, PhD Thesis, The Nottingham Trent University

Carlisle, H. (2001) Need I Repeat Myself? Non-repeating computer-aided designs for printed textiles, Digital Creativity, Vol. 12, No. 2, pp.89-98

Casadio, M. (1997) Emilio Pucci, London: Thames and Hudson

Celant, G. (1996) To Cut is to Think, essay in Looking at Fashion: Biennale di Firenze Chen, J. (1998) An Investigation into 3-Dimensional Garment Pattern Design, PhD thesis, Nottingham Trent University

Chicago, J. \& Lucie-Smith, E. (1999) Women and Art: Contested Territory, London: Weidenfeld \& Nicolson

Clark, H. (1985) Textile Printing, Princes Risborough: Shire Publications

Clark, O. (1998) The Ossie Clark Diaries, London: Bloomsbury

Colchester, C. (1993) The New Textiles: Trends and Traditions, London: Thames and Hudson

Constantine, M and Reuter, L. (1997) The Whole Cloth, New York:The Monacelli Press 
Crawford, A. (2003) Satisfying Consumer Demand, Seminar, The Textile Institute, Leicester, 6/3/03

Cunningham, R. (1998) The Russian Women Artist/Designers of the Avant-Garde, TD \&T, Spring, pp.38-50

Damase, J. (1991) Sonia Delaunay: Fashions and Fabrics, London: Thames and Hudson Davies, M. L. (1980) Visual Design in Dress, London: Prentice-Hall

De La Haye, A. and Wilson, E. Eds. (1999) Defining Dress: dress as object, meaning and identity, Manchester; Manchester University Press

Deleuze, G. The Fold: Leibniz and the Baroque, translated by T. Conley, London: Athlone Denton, M. J. (1972) Fit, Stretch and Comfort, Textiles, Vol. 1, No. 1

De Givry (1998) Art and Mode: l'inspiration artistique des creators de mode, Paris:

Editions du Regard

Dormonex, J. (1991) Madeleine Vionnet, London: Thames and Hudson

Dudley, E. and Mealing, S. (2000) Becoming Designers: Education and Influence, Wiltshire: Cromwell Press

Durandaud, C. (1996) The Luxury Goods Industry in a High Tech Era, Lectra Magazine, September issue

Eley, M. (2000) Private telephone conversation with Mark Eley, Co-director of Eley Kishimoto 6/1/00

Entwistle, J. (2000) The Fashioned Body: Fashion, Dress and Modern Social Theory, Cambridge, USA: Polity Press

Entwistle, J. and Wilson, E. (1998) The Body Clothed, in Addressing the Century: 100 Years of Art and Fashion, London: Hayward Gallery

Evans, C. (1998) Martin Margiela: The Golden Dustman, Fashion Theory, Vol 2, Issue 1, pp. 73-94

Evans, C. and Thornton, M. (1989) Women and Fashion: A New Look, London: Quartet Books

Falkman, S. (2002) A Second Skin, Form, 1/02, pp.52-59, 83-84

Fer, B. (1998) The Pleasure of Cloth, in Liz Rideal: New Work, Exhibition catalogue, Angel Row Gallery, Nottingham, 30/5/98 - 4/7/98

Fernand, D. (2002) No More Frock Horror, The Sunday Times Magazine, 31/3/02, pp. 3237

Fletcher, S. B. (1937) Pattern Design For Printed Dress Fabrics: A practical guide for the industrial designer, London: Sir Isaac Pitman and sons.

Flügel, J. C. (1930) The Psychology of Clothes, London: Hogarth Press, Reprinted in 1971 
Fox, S. (2000) Private Interview, Nottingham Trent University, 5/4/2000

Frankel, S. (2003) Lang invests his modest urban angels with an ethereal glow of eroticism, The Independent, 8/3/03, p.11

Frank (1998) Mixed Metaphors, photographed by Steven Klein, Feburary issue, p.112 Frogson, A. (2000) Private interview with Andrew Frogson, Digital printing consultant, CV Apparel, Coates Vyella, Huthwaite, Nottinghamshire, 16/1/2000

Gamber, W. (1997) The Millinery and Dressmaking Trades, Illinois, Chicago: University of Illinois Press

Gan, S. (2000) Visionaire's Fashion 2001, London: Laurence King

Gan, S. (1999) Visionaire's Fashion 2000: Designers at the Turn of the Millenium, London: Laurence King

Gaten, M. (1996) Imaginary Bodies, Ethics, Power and Corporeality, London and New York: Routeledge

Giroud, F. (1997) Dior: Christian Dior 1905 -1957, London: Thames and Hudson Glanville, R. and Schiak, L. (2003) Designing reflections: Reflections on Design, in Durling, D. and Sugiyama, K. Proceedings of the Third Conference of Doctorial Education in Design, 14-17 October 2003, Japan: University of Tsurkuba, pp. 35-42

Golding, J. (1997) Cubism, in Stangos, N. (1997) Concepts of Modern Art: From Futurism to Postmodernism, London: Thames and Hudson, pp.50-78

Goldsworthy, A. (1996) Wood, Middlesex, UK: Viking

Gombrich, E. H. (1995) Shadows: The depiction of cast shadows in western art, London: National Gallery Publications

Grand, F. (1998) Commes des Garçons, London: Thames and Hudson Gregory, P. (2000) Colouring the Jet Set, Chemistry in Britain, August, pp.39-42

Gregory, R. L. and Gombrich, E. H. (1973) Art and Illusion, London: Gerald Duckworth \& Co. Ltd.

Guardian Weekend (2003) Shopping Life by Patricia Kwateng, photographed by lan Nolan, 26/6/06, p.51

Guillaume, V. (1998) Courreges, London: Thames and Hudson

Harpers and Queen (2003) Birdsong, styled by Alison Edmond, photographed by Ralph Mecke, pp. 100-108, June issue

Harrod, T. (2002) 'Otherwise Unobtainable: the applied arts and the politics and poetics of digital technology', Pixel Raiders: Applied artists and digital technologies, The Victoria and Albert Museum 19/3/02

Harrod, T. The Crafts in Britain in the $20^{\text {th }}$ Century, Harris, J. (2002) 'Beauty in the CG Beast', Pixel Raiders: Applied artists and digital 
technologies, The Victoria and Albert Museum 19/3/02

Harris, J. (2000) Surface Tension: The Aesthetic Fabrication of Digital Textiles (The design and construction of 3D computer graphic animation), PhD Thesis, The Royal College of Art

Hayward Gallery (1998) Addressing the Century: 100 Years of Art and Fashion, London: The Hayward Gallery

Hearle, J.W.S. (1994) computer-Aided Textile Design: The Problem of Three Cultures, World Review of Textile Design, XXXVII

Hepworth, B. (1966) Drawings From a Sculptors Landscape, London: Cory Adams \& Macay

Hirst, D. (1997) I want to spend the rest of my life everywhere, with everyone, one to one, always, forever, now, designed by Jonathan Barnbrook, London: Booth-Clibborn Holbrook, M. B. (1999) Higher than The Bottom Line: Reflections on some recent macromarketing literature, Journal of Macromarketing, 19 (1): 4-74.

Hollander, A. (1978) Seeing Through Clothes, New York: The Viking Press

Hollander, A. (1998) Sex and Suits: The Evolution of Modern Dress, Brinkworth: Claridge Press

Huckbody, J. (2003) Starship Trooper, The Independent Magazine, 8/3/03, pp. 38-41 Ings-Chambers, E. (2000) Over a Paper Moon, Financial Times Weekend, 5/2/2000 Jackson, L. (2002) $20^{\text {th }}$ Century Textile and Wallpaper Pioneers, London: Mitchell Beazley Jackson, L. (2002) Who's Afraid of Pattern Design, Crafts, No. 177, July/August, pp. 28. 31

Jeffries, J. (2001) Reinventing Textiles: Gender and Identity, Winchester: Telos Art Publishing

Jerrard, R. (1986) An Examination of Adaptive Behaviour in the Relationship Between Users and Computer Aided Design (CAD) Systems with Specific Reference to The Textile Industry, PhD Thesis, City of Birmingham Polytechnic

Jerrard, R. and Bell, S. (1998) The Fashion Designer in the Technological Workplace, Digital Creativity, Vol. 9, No. 2, 1998, pp.91-100

Johnson, P. (1998) Bodyscape: Caroline Broadhead, Exhibition catalogue, Nottingham: Angel Row Gallery

Karol, M. (2003) A Patient-Centred View of Designing Medical Textiles, Designing for the Future with Technical Textiles, EMCAT Festival, Pride Park, Derby, 16/5/03

King, C. (prod.) (1996) Painted Ladies: Nobility, Virtue and Morality, presented by Vivienne Westwood, Channel Four, Diverse

Kabat, J. (2002) A Pattern Emerges, Financial Times Weekend, 27/7/02 
Kim, Y.A. (2002) An Interview with Michelangelo Di Battista, Fashion Photographer, Apogee Photo Magazine, September 2002

King, C. (prod.) (1996) Painted Ladies: Nobility, Virtue and Morality, presented by Vivienne Westwood, Channel Four, Diverse

Kirk, W. and Ibrahim, S. M. (1965) Fundamental Relationships of Fabric Extensibility to Anthropometric Requirements and Garment Performance, Orlon Lycra Technical Division, Textile Research Laboratory, E.I du Pont de Nemours \& Co., Delaware

Knight, A. (1984) The Art of Zandra Rhodes, London: Jonathan Cape

Kuryluk, E. (1991) Veronica and Her Cloth: History, Symbolism, and Structure of a "True" Image, Oxford: Blackwell

Leak, A. (1998) A Practical Investigation of Colour and CAD in Printed Textile Design, PhD thesis, Nottingham Trent University

Leeds Art Galleries

Le Grice, M. (1988) The place of theory in practical art and design, in Bougourd, J. and Gronberg, T. (1988) The Matrix of Research in Art and Design Education, London: CNAA and the London Institute

Lehmann, U. (1998) Stripping Her Bare: The Mannequin in Surrealism in Hayward Gallery (1998) Addressing the Century: 100 Years of Art and Fashion, pp. 88-95

Lindsay, J. (1999) Private Interview, Nottingham Fashion Centre, 7 December

Lurie, A. (1981) The Language of Clothes, London: Heinemann

Maeda, J. (2000) Maeda Media, London: Thames and Hudson

Martin, R. (1998) Cubism and Fashion, New York: Metropolitan Museum of Modern Art Martin, R. (1988) Fashion and Surrealism, London: Thames and Hudson

Martin, R. (1997) Gianni Versace, New York: The Mueum of Modern Art

McCulloch, M. (1997) Abstracting Craft: The Practiced Digital Hand, London: MIT Press

McDowell, C. (2000) Jean Paul Gaultier, London: Cassell

McDowell, C. (1997) Galliano, London: Weidenfeld and Nicolson

McDowell, C. (1984) Mc Dowell's Directory of $20^{\text {th }}$ Century Fashion, London: Muller Mealing, S., Ed (2002) Computers and Art, Second Edition, Bristol: Intellect

Mendes, V. and De La Haye, A. (1999) 20TH Century Fashion, London: Thames and Hudson

Mendes, V. and Hinchcliffe, F. (1987) Zika and Lida Ascher: Fabric-Art-Fashion, London: Victoria and Albert Museum

Milbank, C. (1985) Couture: The Great Fashion Designers, London: Thames and Hudson Millar, L. (2002) Jerwood Applied Arts Prize 2002: Textiles, Catalogue essay, London: Crafts Council 
Millar, L. (2001) Textural Space, Exhibition catalogue, The Surrey Institute of Art and Design

Miyake, I. (1983) Issey Miyake Bodyworks, Edited by Shozo Tsurumoto, Tokyo:

Shogakukan Publishing

Moffit, P. and Claxton, W. (1991) The Rudi Gernreich Book, Koln and London: Taschen Morano, E. (1986) Sonia Delaunay: Art Into Fashion, New York: George Braziller Inc., Müller, F. (2000) Art \& Fashion, London: Thames \& Hudson Newbury, D. (1996) Knowledge and Research in Art and Design, Design Studies, Vol.7, no.2

North, M. Ed. (2000) Relativities: The $4^{\text {th }}$ British International Miniature Print Exhibition, Leicester: Loughborough University School of Art and Design

O'Hara Callan G. (1998) Dictionary of Fashion and Fashion Designers, London: Thames and Hudson

O'Neill, A. (2001) Imagining Fashion: Helmut Lang and Martin Margiela, in Wilcox, C. Ed. (2001) Radical Fashion, London: The Victoria and Albert Museum

Osma, G. de (1980) Fortuny, His Life and Work, London: Aurum Press

Palmer, A. (1997) New Directions: Fashion History Studies and Research in North America and England, in Fashion Theory, Vol. 1, Issue 3, pp. 297-312, UK: Berg Partington, A. (1996) Perfume, Pleasure, Packaging and Postmodernity, pp. 204-18 in The Gendered Object, ed. Pat Kirkham, Manchester: Manchester University Press Pengelly, J. (2002) 2.5D Digital Print-Making, presented at Creativity and Embodied Mind in Digital Fine Art, AHRB seminar, Deluxe Gallery, Hoxton Square, 14/11/02

Penrose, R. (1973) In Praise of Illusion, in Gregory, R. L. and Gombrich, E. H., Art and Illusion, London: Gerald Duckworth and Co. Ltd.

Phillips, P. and Bunce, G. (1993) Repeat Patterns, London: Thames and Hudson Polan, B. (2003) Custo Con Gusto, How To Spend It, FT Weekend

Pötz, T. (2002) Inkjet Printing: Present situation and prospects, International Textile Bulletin, No.5, October, pp. 80-83

Pirsig, R. M. (1974) Zen and The Art of Motorcycle Maintenance, Great Britain: The Bodley Head

Press, M. (2002) Pixel Raiders, Art and Design Symposium, Victoria and Albert Museum, London 19/3/02

Press, M. and Cusworth, A. (1997) A New Vision in The Making: exploring the value of craft education in the information age, European Academy of Design (EAD) Conference, Stockholm April 1997 
Primitive Streak (1997) Catalogue for international 1997-99 touring exhibition, designed by Helen and Kate Storey, sponsored by Phzer, New York and London

Quick, H. (2003) The Body Beautiful, Vogue, March, pp.328- 337

Ribeiro, A. (1999) 'Muses and Mythology: classical dress in British eighteenth-century portraiture' in De La Haye, A. and Wilson (1999) Defining Dress, Manchester and New York: Manchester University Press

Riisberg, V. (2003) Lecture, Department of Textile Design, Nottingham Trent University, $21 / 5 / 03$

Rosenthal et al (1997) Sensation: Young British Artists from the Saatchi Collection, London: Royal Academy

Rudge, G. (2001) A Piece of Cloth, Crafts, No. 173, Nov/Dec 2001, pp.22-25

Sacilotto, D. (1982) Photographic Printmaking Techniques, New York: Watson Guptil Publications

Sarabianov, D. (1999) Liubov Popova and Artistic Synthesis, in J. Bowlt and M. Drutt (eds), Amazons of the Avant Garde, London: Royal Academy of Arts

Schama, S. (1996) Landscape and Memory, London: Fontana Press

Shioda, J. (2000) Making Things for the People, essay in Issey Miyake: Making Things, Museum of Contemporary Art, Tokyo, 29/4/00-20/8/00

Schoeser, M. (2003) Distilling History, Crafts, No. 182, May/June, pp 40-43

Schouvaloff, A. (1991) Léon Bakst: The theatre art, London: Sotheby's Publications

Silberberg, L. and Shoben, M. (1992) The Art of Dress Modelling: Shape Within Shape, Oxford: Butterworth-Heineman

Stangos, N. Ed (2001) Concepts of Modern Art, London: Thames \& Hudson

Steele, V. (1998) 'A Museum of Fashion is More Than a Clothes-Bag', Fashion Theory, Vol. 2, Issue 4, pp.327-336, UK: Berg

Steele, V. (1997) Fifty Years of Fashion: New Look to Now, New Haven \& London: Yale University Press

Steele, V. (1985) Fashion and Eroticism, New York: Oxford University Press

Stylios, G. K., Wan, T. R., and Powell, N. J. (1996) Modelling The Dynamic Drape of Garments on Synthetic Humans in a Virtual Fashion Show, International Journal of Clothiong Science and Technology, Vol. 8, No. 3, pp.95-112

Surface (2002) Dreamweavers, photographed by Sean Ellis, Issue No. 39

Tabatabai Asgbahgi, P. (1996) Sculpted Dress, essay in Looking at Fashion: Biennale di Firenze

Tanizakl, J. (1977) In Praise of Shadows, Leete's Island Books

Taylor, L. (2002) Pattern Crazy, Exhibition catalogue, London: The Crafts Council 
Taylor, L. (1998) Doing the Laundry? A Reassessment of Object-based Dress History, Fashion Theory, Vol. 2, Issue 4, pp.337-358, UK: Berg

Taylor, P. (1990) Computers in the Fashion Industry, Oxford: Heinemannn Professional Publishing Ltd.

Thalman Mangenat, $\mathrm{N}$ and Volino, P. (1996) Interactive Computer Animation, Europe: Prentice Hall

The Independent (2003) Tales of the Unexpected, Living Review: Fashion, photographed by Jean Francois Carly, The Independent on Sunday, 2/3/2003, p. 38

The South Bank Show (1999) Ossie Clark, parts 1 and 2, LWT and ITV Thompson, F. (2003) Fordism, Post-Fordism and the Flexible System of Production, www.williamette.edu

Tilke, M. (1990) Costume, Patterns and Designs, London: Thames and Hudson Townsend, C. (2002) Rapture: Art's Seduction by Fashion, London: Thames and Hudson Tucker, A. (1999) Dries Van Noten: Shape, Print and Fabric, London: Thames and Hudson

Ujiie, H. (2001) The Effect if Digital Textile Printing Technology on Textile Design Styles, Centre for Excellence of Ink Jet for Textiles, Philadelphia Univesity, August 2001, accessed via Techexchange.com

Vanci-Perahim, M. (1999) Great Modern Masters: Man Ray, New York: Harry N. Abrams Vince, J. (1992) Computer Graphics, London: The Design Council

Völker, A. (1990) Textiles of the Wiener Werkstatte 1910-1932, London: Thames and Hudson

Wada, Y. Kellogg Rice, M. and Barton, J. (1983) Shibori: The Inventive Art of Japanese Shaped Resist Dyeing, Japan: Kodansha International Ltd

Watkins, P. (1999) The Appliance of Science, International Textiles, No. 806, Aug/Sept, pp.17-20

Watson, L. (1999) Ossie Clark: Fashion Designer 1942-1996, Warrington Museum and Art Gallery

Watts, A. (1976), Tao: The Watercourse Way, Great Britain: Jonathan Cape Weitemeier, H. (1995) Yves Klein (1928-1962) International Klein Blue, Koln: Taschen Wells, K. (1997) Fabric Dyeing and Printing, London: Conran Octopus Whife, A. A. (1959) Designing and Cutting Ladies' Garments, London: The Tailor and Cutter Ltd.

Wilcox, C. Ed (2001) Radical Fashion, London: V\&A Publications Williams, H. (2002) Pixel Raiders, [a-n] Magazine for Artists, May, pp.22-23 Wilson, A. (2001) 
Wilson, E (1992) Fashion and the meaning of life, The Guardian, 18 May, p. 34 Wilson, E. (1985) Adorned in Dreams: Fashion and Modernity, London: Virago

1 Wilson, L. (2000) The Importance of Textiles to Donna Karan New York, Textiles an Aferthought? Loughborough University School of Art and Design, p.35

Wolleh, P. (1998) Addressing the Century: 100 Years of Art and Fashion, London: Hayward Gallery

\section{Internet}

http://www.agetechnologies.com

http://www.belfordprints.co.uk

http://www.cat@gsa.ac.uk

http://www.datacolour.com

http://www.landsend.com

http://www.lectra.com

http//:www.managementartists.com

http://www.miralab.com

http://www.pixelraiders.org

http://www.storkdigitalimaging.com

http://www.eca.ac.uk/tacitus

http://www.eca.ac.uk/eurographics

http://www.smartlabcentre.com

$\mathrm{http}: / / q u a n t u m c l o t h i n g . c o m$

http://www.techexchange.com

http://www.tc2.com

http://www.tc2.com/RD/RDPrinting.htm 
THESIS

CONTAINS CD

ROM 